\title{
LANDSCAPES OF PILGRIMAGE IN MEDIEVAL BRITAIN
}

\author{
VOLUME 1: THESIS
}

\author{
Martin D. Locker
}

Thesis Submitted to University College London

for the Degree of Doctor of Philosophy

THE INSTITUTE OF ARCHAEOLOGY

UNIVERSITY COLLEGE LONDON

NOVEMBER 2012 


\title{
LANDSCAPES OF PILGRIMAGE IN MEDIEVAL BRITAIN
}

\author{
VOLUME 2: APPENDICES
}

\author{
Martin D. Locker \\ Thesis Submitted to University College London \\ for the Degree of Doctor of Philosophy
}

THE INSTITUTE OF ARCHAEOLOGY

UNIVERSITY COLLEGE LONDON

NOVEMBER 2012 


\section{Declaration}

I, Martin Locker, confirm that the work presented in this thesis is my own. Where information has been derived from other sources, I confirm that this has been indicated in the thesis.

Martin Locker 


\begin{abstract}
This thesis seeks to address the journeying context of pilgrimage within the landscapes of Medieval Britain. Using four case studies, an interdisciplinary methodology developed by the author is applied to a four different geographical and cultural areas of Britain (Norfolk, Wiltshire/Hampshire, Flintshire/Denbighshire and Cornwall), to investigate the practicalities of travel along the Medieval road network including the routes themselves, accommodation, the built environments and natural topographies encountered.
\end{abstract}

An introduction, assessment of current theory and scholarship is provided, followed by an explanation of the methodology used. The four case studies are then presented (Ely to Walsingham, Salisbury to Winchester, St Asaph to Holywell, and Camelford to Bodmin). Within each case study, both the selected starting point for the pilgrimage (typically either a locale confirmed in the historical record as linked to the pilgrim destination, or a settlement of some significance within the local area and thus well connected to the route network), and the site of the saint cult itself are analysed for their growth, reaction and accommodation to the pilgrim phenomenon. Also addressed are the route networks of the county as a whole, relationships to economic centres and their impact on travel possibilities, the topography, the distribution patterns for saint dedications in parish churches within the area, material culture and the ecclesiastical built environment (for example pilgrim badges, monasteries), and the physical landscapes through which the pilgrim travels. Here, the interaction between the pilgrim and the environments through which they move is addressed. Considerations include fatigue, exertion, panoramas and way-finding, route visibility, sight lines to monuments, folklore within the landscape, and the potential echoing of Christian scriptural motifs within certain landscape types/features (e.g. wilderness and sanctuary).

Within the final section of the thesis these themes are compared and expanded into the broader context of pilgrimage not only in Medieval Christendom, but within Buddhist, Hindu and Islamic religious traditions, in order to demonstrate the methodology's validity and flexibility in addressing pilgrimage holistically. Comparisons are made between the local and universal pilgrim routes in terms of material culture, landscape interaction and travel practicalities, and suggestions for future research and development of the pilgrim studies field are also provided. 


\section{Acknowledgements}

Without a doubt my primary debt of thanks is owed to my two supervisors: Dr Joe Flatman and Professor Andrew Reynolds. Their enthusiasm for this project, invaluable support and knowledge has often served not only to keep my research foccussed and engaged, but also reminded me during testing times of why I embarked on this path of research and how stimulating the archaeological discipline can be. I also owe thanks to the Schools Competition Act and Settlement Trust, whose generosity with an annual bursary over my three years of research served to ease the financial burden of fieldwork and tuition fees.

I have been fortunate enough to encounter many people who have lent me their time, support and experience, and I would like to thank the following in particular. Marion Marples of the Confraternity of St James was invaluable with her help in arranging and researching the initial trial fieldwork between Roncesvalles and Pamplona, and the Confraternity library in general was a haven of pilgrim learning. Whilst visiting Winchester, Dr John Crook was kind enough to give me a personal tour of the cathedral including areas which are typically off-limits to the public. He has been a great source of information about the St Swithun cult, and always generous with both his time and research. Dr Michael Lewis from the British Museum has also been consistently supportive with information and advice regarding pilgrim souvenirs, and to him I am extremely thankful.

Closer to home, my parents hold my strongest gratitude, as not only were they kind enough to help me financially throughout this doctoral process, but in poor recompense they had to endure me talking about it incessantly, yet always offered support. I should also like to thank Peter Sandberg for being such a stoic walking companion during the Ely to Walsingham pilgrimage, and for his good humour despite the awful weather and having to shelter in potato barns. Special thanks are also owed to the following friends and fellow researchers, who have made both the PhD process and university life so enjoyable: Eric Lacey, Michael Shapland, Victoria Symons, Michael Bintley, Tom Williams, Michelle Baugh and Tina Paphitis. Finally, I should like to thank Mónica Ruz Manzano, whose company and support has made the writing up of this thesis infinitely less gruelling than it may have been. 
Volume 1: Thesis

Declaration

Abstract

Acknowledgements

Chapter 1-The Purpose and the Pilgrim

$\begin{array}{lll}1.1 & \text { Research Aims } & 16\end{array}$

$\begin{array}{lll}1.2 & \text { Thesis Structure } & 17\end{array}$

$\begin{array}{lll}1.3 & \text { What is Pilgrimage? } & 19\end{array}$

1.4 Pilgrimage in the Medieval West 22

1.5 Travel in the Medieval West 29

Chapter 2 - The Pilgrim's Presence in Scholarship

2.1 Theorising Pilgrimage: The Current Dialogue 37

2.2 Medieval Pilgrimage in the Archaeological and Historical Record 43

2.3 Liminality, Movement and the Landscape 50

2.4 Methodology: The Need for a New Approach 56

\section{Chapter 3 - Case Study I: Ely to Walsingham}

$\begin{array}{lll}3.1 & \text { Introduction to the Case Study } & 67\end{array}$

3.2 The Landscape of Medieval Norfolk 68

$\begin{array}{lll}3.3 & \text { The Road Network of Medieval Norfolk } & 72\end{array}$ 
3.4 The Cult of Our Lady of Walsingham 81

3.5 The Distribution for Pilgrim Souvenirs 89

3.6 The Archaeological and Etymological Remnants of Pilgrimage 93

$\begin{array}{lll}\text { 3.7 Pre-Reformation churches in Norfolk } & 105\end{array}$

3.8 The Sensory Dialogue 111

$\begin{array}{lll}3.9 & \text { Conclusions } & 122\end{array}$

\section{Chapter 4 - Case Study II: Salisbury to Winchester}

$\begin{array}{lll}4.1 & \text { Introduction to the Case Study } & 124\end{array}$

4.2 The Landscapes of Medieval Wiltshire and Hampshire 125

4.3 The Road Network of Medieval Wiltshire and Hampshire 135

$\begin{array}{lll}\text { 4.4 The Cult of St Swithun } & 139\end{array}$

4.5 The Distribution for Pilgrim Souvenirs and Relics 150

4.6 The Archaeological and Etymological Remnants of Pilgrimage 154

4.7 Pre-Reformation churches in Wiltshire and Hampshire $\quad 164$

$\begin{array}{lll}4.8 & \text { The Sensory Dialogue } & 168\end{array}$

$\begin{array}{lll}4.9 & \text { Conclusions } & 181\end{array}$

\section{Chapter 5 - Case Study III: St Asaph to Holywell}

$\begin{array}{lll}5.1 & \text { Introduction to the Case Study } & 183\end{array}$

5.2 The Landscapes of Medieval Denbighshire and Flintshire $\quad 184$

$\begin{array}{lll}\text { 5.3 The Road Networks of Medieval North Wales } & 191\end{array}$

$\begin{array}{lll}5.4 & \text { The Cult of St Winefride } & 195\end{array}$

5.5 The Archaeological and Etymological Remnants of Pilgrimage 202

5.6 Pre-Reformation churches in Denbighshire and Flintshire 209

5.7 The Sensory Dialogue 213

$\begin{array}{llr}5.8 & \text { Conclusions } & 220\end{array}$ 


\section{Chapter 6 - Case Study IV: Camelford to Bodmin}

6.1 Introduction to the Case Study 221

6.2 The Landscapes of Medieval Cornwall 221

6.3 The Road Network of Medieval Cornwall 229

6.4 The Cult of St Petroc 233

6.5 The Distribution for Pilgrim Souvenirs and Relics 248

6.6 The Archaeological and Etymological Remnants of Pilgrimage 251

6.7 Pre-Reformation churches in Cornwall 260

6.8 The Sensory Dialogue 263

$\begin{array}{lll}6.9 & \text { Conclusions } & 275\end{array}$

Chapter 7 - Responses, the Pilgrim Experience and Cultural Comparisons

$\begin{array}{lll}7.1 & \text { Introduction } & 277\end{array}$

7.2 Response to Research Questions and Methodology 278

7.3 The Landscape \& the Monument 282

7.4 Possessions, the Personal Element \& Post-Pilgrimage 295

7.5 Beyond the Borders of Britain 301

7.6 Conclusions \& Routes for Further Research 306

$\begin{array}{ll}\text { Bibliography } & 312\end{array}$ 
Volume 2: Appendices

Declaration

Table of Contents

Appendix A Shortlist of Data Recorded for Each Case Study

Appendix B Detailed Maps of the Route Taken for Each Case Study

Appendix C Digitised Data Sheets Recorded for Each Site

Appendix D Surviving pre-Reformation Church Dedications

465

Appendix E Religious Houses Present in Each Case Study County

483

Appendix F Data from Portable Antiquities Scheme for Walsingham Ampullae

Appendix G Data from Portable Antiquities Scheme for Walsingham Badges

493 


\section{List of Figures:}

\section{Volume 1}

\section{Chapter 1}

Figure 1 'View of Delphi' by Claude Lorraine, 1672

Figure 2 Map of the main pilgrimage sites in Medieval Christendom by the $14^{\text {th }}$ century

Figure $3 \quad$ Pilgrims represented in stained glass at Canterbury Cathedral

Figure $4 \quad$ Map of the principal fairs and trade routes in western Medieval Europe

Figure 5 Strip map showing the route from London to Chamberry, from Matthew Paris' 'Book of Additions'.

Figure 6 The Mapped Itinerary of Edward I, showing the Road Network Used

Figure $7 \quad$ Illuminated manuscript displaying the four seasons from the $15^{\text {th }}$ century 'Les Tres Riches Heures', commissioned by the Duke of Berry

\section{Chapter 2}

Figure $8 \quad$ Examples of Medieval pilgrim badges and Ampulla (dedication unknown).

Figure $9 \quad$ Shrine of St Swithun, Winchester Cathedral

Figure 10 Map of Hampshire taken from William Camden's 'Britannia', 1607

Figure 11 'Christ in the Wilderness', by Moretto de Brescia (1498-1554)

Figure 12 Map displaying the case study sites in relation to the major towns/cities of Medieval England and Wales

\section{Chapter 3}

Figure 13 Map of the basic landscape character of Norfolk,

Figure 14 The distribution of the various religious houses and hospitals in Medieval Norfolk

Figure 15 The distribution of the 11 Hospitals in Medieval Norfolk founded to care for poor travellers and pilgrims 
Figure 16 A map of the routes used progressing from Ely to Walsingham (comprising of the Hereward Way, Palmer's Way, and Pilgrim Walk)

Figure $17 \quad$ Ground plan and sketch of Walsingham Priory

Figure 18 Map of Walsingham

Figure 19 Remains of the Friary, Slipper Chapel and Priory at Walsingham.

Figure 20 Distribution map for ampullae connected to Walsingham cult by iconography.

Figure 21 An ampulla bearing the crowned ' $W$ ' motif of Walsingham and scallop shell relief on the reverse.

Figure 22 Distribution map for pilgrim badges connected to Walsingham cult by iconography

Figure $23 \quad$ Plan of Ely showing relevant sites

Figure $24 \quad$ Plan of Ely Cathedral

Figure 25 Ely Cathedral, Pilgrim Cross at Hockwold cum Wilton (with St James Church behind), St Mary's Church at Cranwich, Castle Acre Priory ruins

Figure 26 The ruins of Castle Acre Priory

Figure 27 Table for saint dedication frequencies for surviving Norfolk pre-Reformation churches

Figure 28 Chart comparing frequency of saint dedications in surviving Norfolk pre-Reformation churches

Figure 29 Map displaying the scatter of surviving St Mary and St James pre-Reformation church dedications across Norfolk

Figure 30 Map of Ely showing Hereward Way and radius of transition between the Isle and the fenland

Figure 31 Map of Blackdyke, showing route along earthwork, radius of elevation, and sight line to St James' Church in Hockwold cum Wilton

Figure 32 The approach to Castle Acre showing the initial line of sight to the Priory and the River Nar creating a natural boundary between the 'wilderness' and 'sanctuary'

Figure 33 The Holy Mile of Walsingham showing the route coming down from Houghton St Giles to the Slipper Chapel leading to the town, including the sight line to the Friary

Figure $34 \quad$ Map showing the proposed sightline to the site of the Priory upon entering Walsingham, and the sacred area of the Priory grounds which housed the shrine to Our Lady 


\section{Chapter 4}

Figure 35 Map showing key landscape characters of Hampshire and Wiltshire; Salisbury Plain, Hampshire Downs, New Forest, Hampshire Basin and the Test Valley

Figure 36 The main production and market centres of Wiltshire textile industry

Figure 37 The distribution of Medieval religious houses throughout Wiltshire and Hampshire

Figure $38 \quad$ Map of route taken between Salisbury and Winchester along the Roman Road.

Figure $39 \quad$ Map of central Winchester with relevent sites located

Figure 40 Plan showing locations of the Old Minster, New Minster and the Norman Winchester Cathedral

Figure 41 Conjectural plan of the monastic complex of St Swithun's Priory

Figure 42 Table of curative records for St Swithun

Figure 43 Map of the known distribution of St Swithun's relics outside of Winchester

Figure $44 \quad$ The upper skull of St Swithun, relic of Evreux Cathedral

Figure $45 \quad$ Map of central Salisbury with relevent sites located

Figure 46 Late $19^{\text {th }}$ century postcard displaying the Old George Hotel, and photo of surviving $15^{\text {th }}$ century interior fabric

Figure $47 \quad$ All Saints Church, West Winterslow

Figure 48 Mottisfont Priory, Text Valley

Figure 491840 Ordnance Survey maps showing the Roman road entering Winchester, past 'Great Copse Road'

Figure $50 \quad$ Map of churches dedicated to St Swithun across England

Figure $51 \quad$ Map displaying the lands of the Bishop of Winchester in 1224. Several of these held churches or chapels dedicated to St Swithun

Figure 52 Surviving Pre-Reformation Church Dedications in Wiltshire

Figure 53 Surviving Pre-Reformation Church Dedications in Hampshire

Figure 54 'Salisbury Cathedral' by William Turner

Figure 55 Early $20^{\text {th }}$ century tinted postcard of Salisbury cathedral viewed from the south west

Figure 56 Radius from which the cathedral building is clearly visible from the east and the Roman road from Old Sarum to Winchester

Figure 57 The path of the Roman road accessed on the outskirts of Salisbury 
Figure 58 Cobhill Barrow in relation to the Roman road and the distance at which is visible from the western approach

Figure 59 Roman road running alongside Upper and Lower Noad's Copse, including detail of cobbled surface

Figure 60 The Roman Road in relation to the Test Valley and the River Test/flood plain

Figure 61 The West Gate in Winchester

Figure 62 The two basic zones of urbanism presented to the pilgrim during the western approach to Winchester: outer sprawl and the city centre via West Gate

Figure 63 Interior approach via the High Street to Winchester Cathedral, showing the outline of known St Swithun's Priory buildings, St Swithun's probable original burial shrine spot (circle near north transept), the Nunnaminster site, and St John's Hospital in the High Street

\section{Chapter 5}

Figure 64 Map of the Upland and Lowland landscapes of Medieval Wales in the $14^{\text {th }}$ century

Figure 65 Sight line for Moel Maenefa Hill-fort in relation to the Offa's Dyke and Clwyd Valley

Figure 66 Map displaying locations of major Silver and Lead mines in Medieval Britain including Wales

Figure 67 Birds-eye view of Pont Dafydd and potential drover trail near St Asaph

Figure $68 \quad$ Map of central Holywell with relevant sites marked

Figure $69 \quad$ Plan of St Winefride's Well

Figure $70 \quad$ The inner original basin at St Winefride's Well

Figure $71 \quad$ Plan of Basingwerk Abbey

Figure 72 St Asaph Cathedral (east facing)

Figure $73 \quad$ Map of central St Asaph with relevant sites marked

Figure 74 The view of the cathedral approaching Pont Elwy, and Pont Dafydd

Figure 75 View from the remains of Offa's Dyke abutting Mynydd y Cwm, facing west into the Clwyd Valley

Figure 76 The Maen Achwyfan Cross with the Garreg Tower visible

Figure 77 Seal of St Asaph Cathedral showing St Winefride with crozier and reliquary 
Figure $78 \quad$ Map displaying distribution of church, well and spring sites dedicated to St Winefride and her uncle St Beuno

Figure 79 Chart Showing Frequency of Universal Saint Dedications in Surviving Flintshire and Denbighshire pre-Reformation Churches

Figure 80 Chart Showing Frequency of Local Saint Dedications in SurvivingFlintshire and Denbighshire pre-Reformation Churches

Figure 81 Map showing location of bridges in relation to St Asaph, the visibility of St Asaph cathedral from the two bridges, and the distance one can see from the cathedral site

Figure 82 Radius of view from Offa's Dyke into the Clwyd valley with sight line to St Asaph cathedral

Figure 83 Map displaying visual interplay between sites around and including the Maen Achwyfan Cross and the Grange near Whitford, Flintshire, and the panoramic expanse offered by the Beacon Tower

Figure $84 \quad$ Map showing sites at Holywell, and visual interaction between sites and the western approach to the town

\section{Chapter 6}

Figure $85 \quad$ Map of Cornwall displaying the uplands, anciently enclosed land and recently enclosed land, according to the Cornwall \& Scilly Historic Environment Record

Figure $86 \quad$ Map of early mining sites in Cornwall

Figure $87 \quad$ Principal areas of farming and uncultivated ground in Medieval Cornwall

Figure 88 Distribution of post $11^{\text {th }}$ century Medieval religious houses in Cornwall

Figure 89 Distribution of Free and Villein Messuages in the Camelford Borough in the $14^{\text {th }}$ Century

Figure 90 Route taken from Camelford to Bodmin including key sites, plotted on the 1885 Report of the Boundary Commissioners for England and Wales.

Figure $91 \quad$ Map of central Bodmin with relevant sites marked

Figure 921881 OS Map of central Bodmin, highlighted are the sites of the Priory church and cloisters and St Petroc's Church

Figure 93 Fragments of sculpted masonry from the Bodmin Priory

Figure $9412^{\text {th }}$ century ivory casket which contained the relics of St Petroc, now in the Bodmin church of St Petroc

Figure 95 St Petroc's Well (centre) in Priory Park 
Figure $96 \quad$ Remains of the Chapel of St Thomas Becket

Figure 97 St Gurons Wellhouse

Figure $98 \quad$ Berry Tower

Figure 99 Distribution map of reputed St Petroc relics in England during the Medieval period

Figure $100 \quad$ Map of Camelford with relevant sites marked

Figure 101 St Juliot's Well, near Camelford and Lanteglos parish church

Figure 102 St Adwenna's church in circular graveyard within field system

Figure 103 Free Standing Wheel Cross near Advent Church

Figure 104 Arial image of Carwether DMV, and ground level appearance facing east towards Bodmin Moor

Figure $105 \quad$ Holy Well at St Brewards

Figure 106 Map of Dedications to St Petroc in Cornwall

Figure 107 Map of the route taken out of Camelford, following the Camel River

Figure 108 Map of Camel River valley floor with route and St Adwenna's church

Figure 109 Map of Adwenna's church in relation to the route, and the free standing cross.

Figure 110 Map of Carwether and Upland section, and view from uplands east to Bodmin Moor

Figure 111 The southern approach to St Breward, the church's visibility and the locations of the church and well sites.

Figure $112 \quad 19^{\text {th }}$ century sketch of the holy well in St Breward

Figure 113 The journey through the woodlands, and the exiting ascent into the uplands of Helland Parish

Figure $114 \quad$ The path through the woodlands in the Camel River valley floor during early February

Figure 115 The approach to Bodmin

\section{Chapter 7}

Figure 116 'Hunters in the Snow' by Pieter Breugel, 1565

Figure $117 \quad$ Ely Cathedral in fenland mists 
Figure 118 The July panel from the Très Riches Heures du Duc de Berry, 1489, showing the beginnings of the harvest.

Figure 119 Maen Achyfan Cross

Figure 120 Examples of flowers which bear relations to saints in plantlore, and may have been used in the context of 'found souvenirs'

Figure 121 Christian labyrinth motif used within Chartres Cathedral 


\section{Chapter 1 - The Purpose and the Pilgrim}

\subsection{Research Aims}

Amongst the various cultural and religious phenomena within Medieval Christendom, pilgrimage and the industry it spawned stands as an enduring testament to devotion. Stimulating growth in sacred art, music, literature and a steep rise in saint cults during the later Medieval period, the influence of pilgrimage is also felt in areas which are traditionally seen as secular in nature such as trade, communications networks and hospitality. Pilgrimage in Medieval Christendom has in the past been viewed and addressed in distinctly simplistic terms, focussing on the shrine and material culture generated from this site. This is an insufficient and unbalanced scope of study, considering the complex factors which made pilgrimage both desirable and practical for the laity. Principally, within British scholarship the shrine at the pilgrim's destination receives the large majority of attention, with little or no attention to how the pilgrim travelled, and their experiences in terms of journeying practicalities and movement through disparate landscapes en route.

In my research I seek to redress this imbalance, paying particular attention to the journeying aspect, examining through four British case studies the route-network and accommodation possibilities available to the pilgrim, the sites encountered along the journey, and potential for interaction with the landscape from a sensory perspective. This 'journey-centric' approach will be driven by an interdisciplinary methodology, primary data and body of secondary source material, showing the act of pilgrimage in its entire sense, and not merely the final approach to the shrine which so dominates current pilgrim studies. This interdisciplinary methodology is discussed in detail in Chapter 2.4. Therefore the urban context of pilgrimage, whilst discussed, will not form the bulk of research. My primary research aims which are expressed through the four case studies (discussed in Chapter 2) are as follows:

1. To develop a methodology which addresses the study of pilgrimage from an interdisciplinary perspective within the Medieval Western context, considering the processes motivating pilgrims, the practicalities of sacred travel, and the experiential aspects encountered en route.

2. To identify the surviving archaeological evidence for Medieval pilgrimage, and compare this record with that offered by the documentary data.

3. To differentiate between the pilgrims' experience and interaction with the landscape with that of 'secular/commercial travellers' (such as merchants).

4. To explore this sensory dialogue between pilgrim and landscape through theories of liminality and perception applied to topographical data. 


\subsection{Structure of Thesis}

This thesis is comprised of seven chapters, which aim to lead the reader from the specific sanctuaries already discussed by prior scholarship, out into the landscapes and topographies which form the majority of the pilgrim experience. Chapter 1 presents a background to the phenomenon of pilgrimage both as a world-wide practise and in the specific context of Medieval Christendom, introducing the means and motives of pilgrimage in relation to Christian dogma and the general route networks.

Chapter 2 expands on these themes in relation to current theoretical approaches employed by archaeologists, historians and anthropologists when addressing pilgrimage in the historical and contemporary record. Problems which can occur when addressing concepts such as spatial delineation are also highlighted, along with the current conceptualising of the ritual of pilgrimage from an anthropological standpoint. Archaeologically definable features of pilgrimage are also discussed, and aspects in the historical literature which inform on and confirm pilgrim activity at certain sites. This chapter ends with a detailed explanation of my method for fieldwork and the collection of primary data sets, including the categories of monument or site recorded. The justification for the selection of the four case study sites is supplied and reasons given for the exclusion of Canterbury as a case site.

Chapters 3, 4, 5, and 6 comprise the majority of this thesis, and these four chapters show the application of my method to the four case studies (see Chapter 2), involving both primary data collected from fieldwork, and desk based research into available scholarship on these sites. For consistency, these chapters follow the same structure, which addresses the topographical, economic and ecclesiastical environments of the broader area in which the study site is located; the Medieval route network available in the area; the development and fabric of the pilgrim site itself; the distribution of relics and pilgrim souvenirs relating to the cult; the archaeological/building evidence of pilgrimage between the origin site (a term explained in Chapter 2) and the pilgrim site; the distribution of church dedications in the local area; the experiential aspects of the landscapes between the origin site and the pilgrim site; and finally some brief conclusions drawn from the case study. Where possible I have included ground plans of the major ecclesiastical buildings in each case study, however with sites such as Bodmin Priory it has been impossible to locate any such data.

Chapter 7 draws on themes raised throughout the preceding four chapters, expanding on concepts which resonate with landscape theory and the comparisons of universality and locality in 
terms of the pilgrim experience. Further comparisons are drawn with universal continental pilgrim routes, trends relating to the souvenirs and the concept of 'pilgrim culture' are addressed, and elements linked to the landscapes of the case studies are compared and contrasted. These themes are then expanded further in relation to pilgrimage in cultures far removed from the Medieval West to support the application of my methodology to pilgrimages universally, when combined with specialised knowledge of the religious and social aspects of the culture in question. Finally, concluding remarks are offered, and followed by suggestions for future avenues of research in this field. 


\subsection{What is Pilgrimage?}

'Science walks on the earth. Poetry flies above the earth. Both are necessary for the progress of man; but his progress is his pilgrimage and his pilgrimage is his becoming.' (Macaro, 1973, 14)

The phenomenon of pilgrimage can be found in a wide range of belief systems throughout human history, either as a specific term or event, or as a manner of experiencing the landscape within daily routine. A precise definition of the term can and has presented problems to scholars, who have struggled to strip the term of the cultural baggage which accompanies the act within each cultural and historical context. In this thesis I use my own definition of pilgrimage, based upon my research, as 'the undertaking of a journey to a site which holds specific relevance to the pilgrim's system of belief'. All combinations and nuances of this religio-cultural process hold a distinct spiritual state as their goal, and demonstrate an effort to relinquish the normative state of being temporarily in a bid for divine contact (Turner and Turner, 1978, 3). Three fundamental tenents are required in order for pilgrimage to be considered a desirable and effective manifestation of spirituality:

1. One or more forces have the power to influence the course of our lives.

2. It is possible to engage with those forces and potentially influence their actions with regard to our own fate.

3. There are certain places where one can be 'closer' to these forces, where we are able to experience their power more fully and establish a relationship with them.

(Davidson and Gitlitz, 2002, xvii)

Thus pilgrimage can be considered both an act of devotion and personal gain, an exposure to the divine through some manner of hardship, solitude and a journey to a location or artefact which embodies the spirit of the divine, with the hope of obtaining lasting benefit from the experience. Certain locations become centres of pilgrimage typically through a perceived link with the divine, either through a miraculous event channelled through an earthly representative (or seemingly directly from the divinity itself), or via the remains of someone who was known to have been closely linked to these forces, a 'saint' or 'holy person'.

The universality of pilgrimage is represented in the wide and varied array of sites globally which draw visitors throughout the year, each hoping for a mystical contact with the divine. These numerous sites embrace varied, rich and complex religious, social and cultural histories, of which a few examples are given below from the 'main world religions'. Within the Islamic tradition, the attendance of the Hajj (pilgrimage to Mecca) at least once in every Muslim's lifetime forms one of the five pillars of the faith (Esposito, 2011). Within Hinduism there are a vast array of pilgrimage sites, include the Shivkhori (a cave site dedicated to Lord Shiva) in the Jammu and Kashmir region, 
the temple of Vaishno Devi (dedicated to Shakti, a manifestation of the 'Great Divine Mother') and the well-known city of Benares or 'Varanasi' in the Uttar Pradesh region, situated on the banks of the holy Ganges river, which in a simplistic sense can Benares be regarded as the spiritual hub of Hinduism and creation (Feldhaus, 2003; Eck, 1999). Within both the Buddhist and the broadly preBuddhist animist 'Bön' traditions of Tibet (as well as Hindu and Jain traditions), Mount Kailās is an important site of pilgrimage, at which an annual circumnavigation is performed by devotees, clockwise for Buddhist and Hindu pilgrims, counter-clockwise by Jains and Bön practitioners (Davidson and Gitlitz, 2002, 416 - 417). Judaic pilgrimage sites are predominantly geographically local to Israel and Palestine, this being the area of the majority of events in Jewish religious scripture. The city of Jerusalem is a point of convergence for some of the most sacred sites in Jewish (e.g. the Western Wall), Islamic (e.g. the Masjid Al-Aqsa mosque) and Christian (e.g. the church of the Holy Sepulchre) traditions, and the Dome of the Rock with its multi-layered history presents a hub of monotheist pilgrimage (Armstrong, 2011).

Within the Medieval Christian context, pilgrimage can be taken as a performed allegory for the movement through life towards 'Heavenly Jerusalem', the true 'home' of every Christian both in life and death. Earthly life is an exile from the heavenly state, and progress through it is a journey that culminates in reunion with God, reflected in the early $14^{\text {th }}$ century within Dante's extended metaphor 'the road of our lives' in 'The Divine Comedy' (Alighieri, 1998, 45). It is also present throughout Bunyon's late $17^{\text {th }}$ century work 'Pilgrim's Progress', in which the character 'Christian' travels from the 'City of Destruction' (i.e. the earthly profane realm) to the 'Celestial City' (i.e. paradise (Bunyan, 2008)). Whilst the Canterbury Tales would seem like an obvious inclusion in this series of allegorical tales, its purpose is much more profane in that it sought to satirise a variety of the social types one would find performing pilgrimages (Webb, 2000, xii). It does not provide much in the way of the underpinning ideology surrounding pilgrimage, but instead remarks upon the sometimes mercenary motives of undertaking a pilgrimage, such as those of the pardoner who wishes to sell his indulgences at the shrine of Thomas Becket.

The theme of movement from the profane to the sacred environment is recurrent within theological scripture, and two aspects become immediately important with regard to scholarship: the landscape through which one moves, and also the manner in which one moves through the landscape (Webb, 2002). In order to fully realise and investigate the pilgrim experience of the Medieval laity, these two aspects must be dealt with equally (Webb, 1999, 237). On the primary level there is the practical and earthly matter of navigating through the various topographies, the physicality of travel over hills, through valleys, in sheltered or exposed stretches of terrain. On a subtler level there is the mental aspect of movement to consider; the qualities imbued to the mind through personal memory, religious scriptural reverberations, experiences of sight, and the alternating penitent and meditative experiences which can be triggered by travelling by foot through familiar and unfamiliar landscapes. This environmental influence upon the pilgrim has been addressed in the modern anthropological field, and one of the many studies of Hindu pilgrimage culture which deals specifically with this link between topography, spirituality and perception is Feldhaus' 'Connected Places: Region, Pilgrimage and Geographical Imagination in India' (2003), 
which concentrates on the Maharashtra region. With special attention to the role of the river (most notably the Ganges) in Hindu spirituality, Feldhaus writes that 'people in Maharashtra have created religious texts, abstract concepts, and concrete images through which they bring various places along a river together in their minds and imaginations...they do this by moving their bodies from place to place: by travelling on pilgrimages.' (Feldhaus, 2003, 18). This embodies a concept which has yet to be applied properly to pilgrimage in the historical and archaeological record, and forms an important aspect of my approach. Landscapes are comprised of landmarks, sensory dialogues, reference points for the traveller which link individual sites, collective local/personal memories, and folk/religious lore, which when approached from a spiritual perspective (as adopted by the pilgrim) transform the journey from that encountered in the daily profane cycle, and make it part of a process of transformation. This is further discussed in Chapter 2, in relation to theoretical approaches utilised in anthropology. 


\subsection{Pilgrimage in the Medieval West}

As can be seen above, pilgrimage is by no means exclusive to Christianity. Pilgrimage had been practised in the West at cult sites long before Christianity reached the continent, one brief example of which would be the site of Delphi in Ancient Greece (see Figure 1 below (Webb, 2000, xi)). Situated on Mount Parnassus, this pan-Hellenic sanctuary of Apollo was famed for its connection to the Pythian Games, and its oracle, receiving visitors from around the Hellenic world who wanted to present sacrifices and votive offerings to Apolo or hear the oracle's predictions (Burket, 1985, 172).

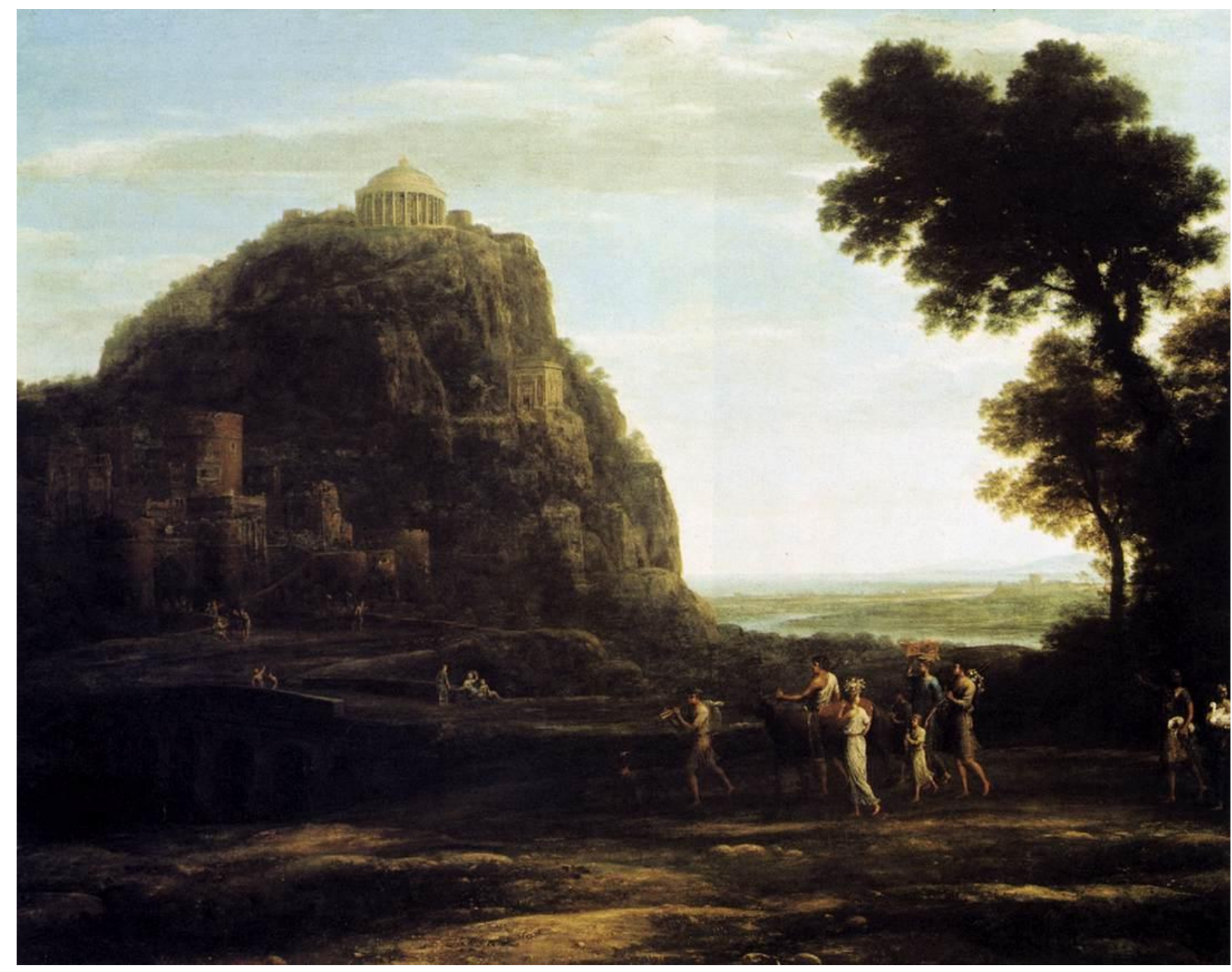

Figure 1. 'View of Delphi' by Claude Lorraine, 1672. Reproduced from http://www.claudelorrain.org/View-of-

Delphi-1672.html

Turning to pilgrimage's rise within the Christian framework on an institutional level, this being the broad state of pilgrimage within the later Medieval period, Christian pilgrimage in the Medieval West can be said to have evolved from monastic and ascetic practises in the $4^{\text {th }}$ century Syrian church (Vöörbus, 1958; Olson, 1989). The culture of movement and wandering for certain members of monastic communities was initially condemned by church fathers, who feared that this 
exposure to the profane world outside of the precinct walls would corrupt the monks (Brock, 1973, 4). However the possibilities for ascetic development and revelation beyond the typical confines of religious houses, and the opportunities this practise offered for seeing new places and extending their influence became visible and eventually garnered a tacit support in the church (Brock, 1973, 5). As the power and administrative centre of Christianity spread west into Europe, this desire for seeing and accessing sites which echoed events recorded in scripture or the vitae ('lives' or biographies) of saints found a willing and receptive audience. Within pre-Christian contexts there were those who made their own travels to sites of sacred significance to undertake rituals or receive imparted wisdom from priests, and Christian pilgrimage (prior to becoming more formalised and a commercial advantage to local settlements) followed similar patterns of motivation, mainly curiosity and reverence (Webb, 1999, iv).

The most celebrated pilgrimage site in Medieval Christendom was Jerusalem, which held within its walls a rich catalogue of sites that either hosted or played a role within the scriptures; most significantly those which featured in the Passion. Eusebius of Caesarea (a prominent Roman historian between the $3^{\text {rd }}$ and $4^{\text {th }}$ centuries $A D$ ) records visitors or 'pilgrims' routinely being shown biblical sites, suggesting that the practise was already established by this point (Stopford, 1999). The two other sites which formed the upper echelon of Christian pilgrimage destinations during the Medieval period were the cities of Rome, and Santiago de Compostela in Galicia, Spain. Within Britain, we can see references to Rome luring several noble and royal figures of the English kingdoms on pilgrimages during the late $6^{\text {th }}$ century in Bede's 'History of the English Church and People', and this sacral movement between Britain and Rome became increasingly common during the $7^{\text {th }}$ century, including for 'layfolk' (Webb, 2001, 11). By the $9^{\text {th }}$ century, Rome had become such a popular location for pilgrims throughout Europe that four main groups were to be found constantly within the city's walls; English, Frankish, Frisians and Lombards (Webb, 2001, 12). Santiago de Compostela was the third principle pilgrimage site in Christendom, and home to the hugely popular cult of St James the Apostle. St James not only became the patron saint of pilgrimage, but came to embody the practise through being identified with the Scallop shell, a piece of iconography which originated at the Santiago cult site and whose emblem has been found on numerous pilgrim souvenirs distributed around Christendom (Webb, 2002, 4). 


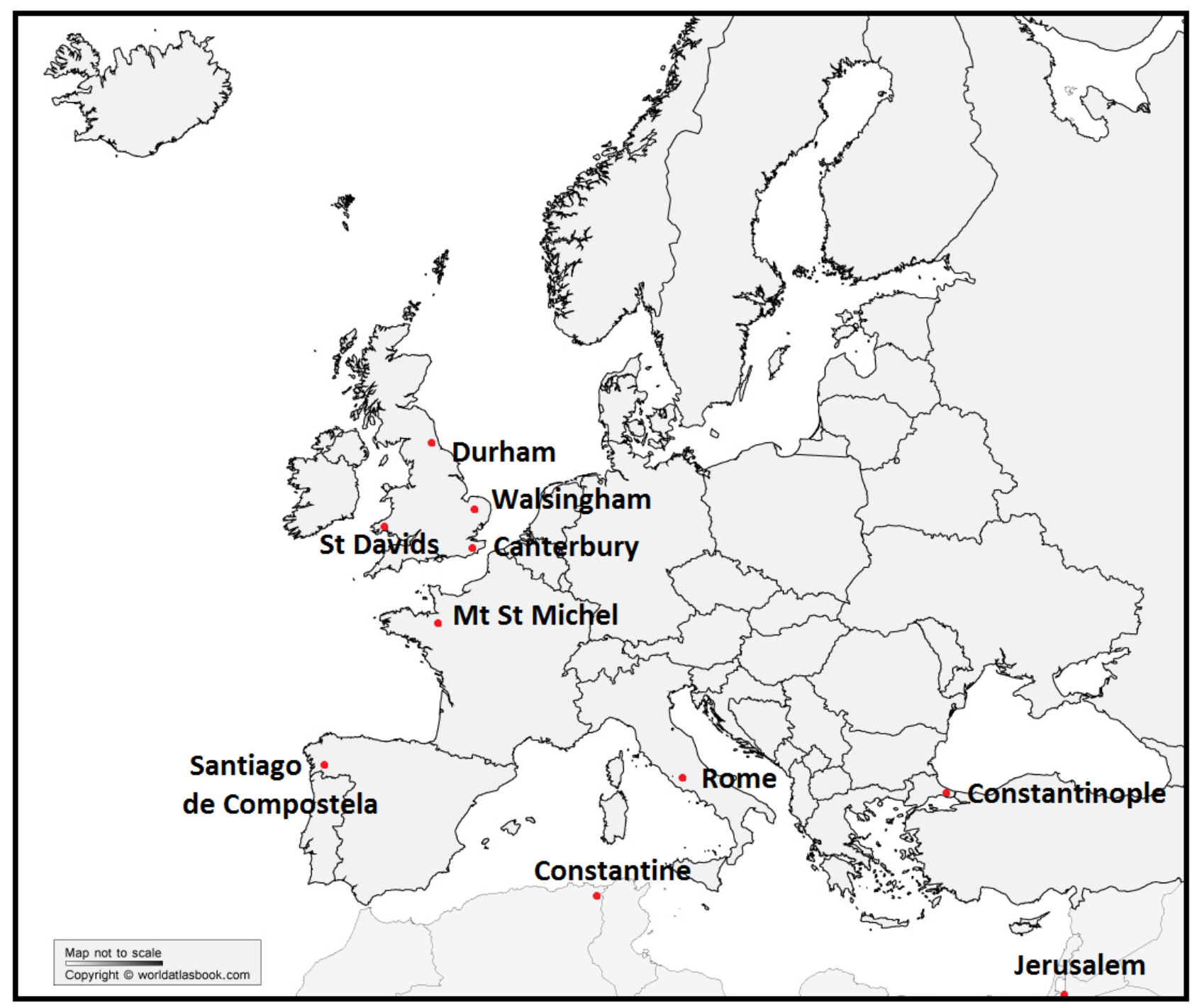

Figure 2. Map displaying some of the key pilgrimage sites in Medieval Christendom by the $14^{\text {th }}$ century. Redrawn from the original map outline: www. worldatlasbook.com

With the turn of the millennium, pilgrimage started both to become more formalised, with the Libri Poenitentiales ('Book of Penances') listing pilgrimage in varieties of length and hardship as components of punishment for crimes, and specific pilgrim hospitals and guest halls being established to cater for this burgeoning travel industry (McNeil \& Gamer, 1990). It also began to gain detractors within the Roman church, particularly towards two groups of pilgrims: women, and monks. Women it was felt were unsafe and liable to distract the attentions of other pilgrims, and similarly to the objections of the Early church fathers, some figures in the Roman church (especially St Bernard) felt that monks required 'stability' above all else to contemplate God, not to be undertaking journeys to shrines, and that 'everyone shall remain where he has been placed, and where he has taken his vows, there shall he fulfil them before God.' (Webb, 2001, 13) Towards the end of the $11^{\text {th }}$ century, a range of saint cults had been established throughout Europe and into Turkey, modern Israel and North Africa (see Figure 1 above), developed as sites of pilgrimage offering relics, miracles, sacred souvenirs, and accommodation, with varying degrees of veneration 
and curiosity (Adair, 1978, 9). By the $12^{\text {th }}$ century the shrines of lesser saints and martyrs had sprung up 'like mushrooms after rain' across Christendom, and England was no exception (Adair, 1978, 10). Figure 1 above shows the key pilgrim sites, but there were numerous other popular shrines such as Limoge (St Martial), Tolouse (St Sernin), Florence (the cult of the 'Holy Shroud'), Salzsburg (Our Lady of Maria Plain) and many more (Webb, 1999).

Along the roads and pathways which led to these various pilgrim shrines, different classes of pilgrim could be encountered, embodied in the characters described in the Canterbury Tales who were a mixture of professional ecclesiastical figures, tradesmen, aristocracy and soldiers (see Chapter 1.3). The layfolk were driven by a mixture of piety and touristic impulse, eager to see and venerate at the shrine but also keen to see outside the normal confines of their environment (Webb, $1999,4)$. Personal motivations for pilgrimage amongst the laity were as varied as the individual pilgrims themselves, but can be broadly placed within two categories; the wish to implore for divine aid at a shrine on behalf of oneself or a relative, and the opportunity such an act offered in terms of travel and temporary escape from 'the daily and domestic setting' (Webb, 2002, 45). So overt was the second motivation that, for some, pilgrimage appeared to be an excuse to shirk discipline and duty by a variety of social classes and professions, from vagabonds and fugitive serfs to monks and nuns (Webb, 2002, 45). Monastic figures would travel to ecclesiastical destinations for a variety of reasons, possibly with a desire to pay devotions to a particular cult centre, but also predominantly with administrative business, diplomacy or communications to impart to another institution on behalf of the head of their order (Russell, 1944). This also enabled the travelling monks to be mobile and visit shrines despite some orders and figures declaiming pilgrimage as a distracting activity. Due to this disapproval the official motives for these journeys were frequently commercial, administrative or diplomatic, with Gerald of Wales accompanying the Archbishop of Canterbury (Baldwin of Forde) around Wales on a recruitment campaign for the Third Crusade in 1188 (Kightly, 1988). Amongst the itinerary on this mission of propaganda were Holywell and St Davids, both relatively major features of the British pilgrim landscape. However, these visits were not the primary reason for the journey, although they undeniably involved an aspect of pilgrimage: yet to what degree can we call these figures 'pilgrims' (Kightly, 1988, 68)? This mixture of sacred and profane stimuli can also be seen in the corresponding rise in the production of pilgrim badges and souvenirs at pilgrimage sites, produced under strict license by the monks who cared for the shrine, and those who were caught producing 'black market' badges were dealt with severely (Spencer, 2010, 7). These souvenirs fulfilled the role of spiritual talismans, but also as 'status' symbols, verifying the bearer as someone who had completed a pilgrimage, and also generated significant revenue for the shrine sites (Spencer, 2010).

The foremost pilgrimage sites in England were at Canterbury (St Thomas the Martyr - see Figure 3 below), Durham (St Cuthbert), Ely (St Ethelreda), Walsingham (Our Lady of Walsingham), Rochester (St William of Perth), Winchester (St Swithun) and Worcester (St Wulfstan and St Oswald); all of whom boasted impressive cults and shrines dedicated to their respective patron saints. In an architectural development which echoed their counterparts in Europe, these shrines were typically 
set up in a Saint's chapel which 'normally occupied the bay immediately behind the High Altar, and was enclosed by screens usually of timber.' (Cook, 1957, 34) The presence of pilgrims at cathedral churches was so common during the Medieval period that 'one of the main reasons that prompted the elongation of the choir-arm in many cathedrals during the thirteenth century was the provision of a Saint's chapel with an ambulatory for the easy circulation of pilgrims.' (Cook, 1957, 34) Typically, pilgrims would be guided on a specific route around the cathedral, visiting different stations and culminating in the Saint's shrine or reliquary where devotions would be made.

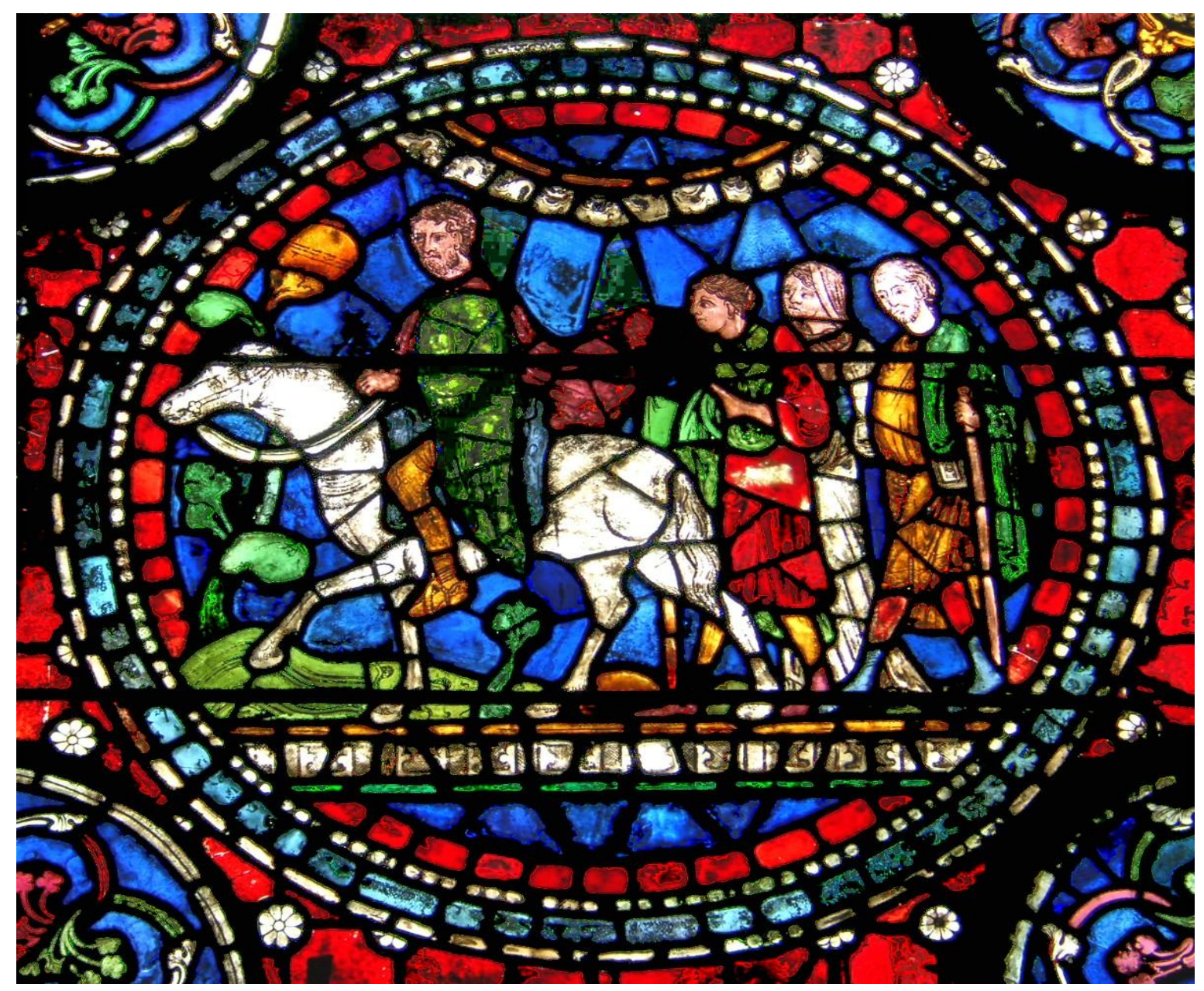

Figure 3. Pilgrims represented in stained glass at Canterbury Cathedral. Reproduced from http://www.transromanica.com

These shrines were distinct from their previous 'tomb' incarnation being lavish and permitting interaction with the devout: 'The relics were housed in the most sumptuous reliquaries, for only by show could they testify to their powers and invite commensurate gifts.' (James, 1987, 38) Some incorporated port-holes and niches where the penitent could touch and implore the relics for aid, and others apparently exuded 'holy oil' from disguised valves in the masonry, said to cure diverse ailments and bottled in ampullae for sale. However, evidently the desire to get close to the divine drove some of the laity to extreme measures, as Benedict reports that at the tomb of St Thomas Beckett 'an insane man, AElward of Selling, actually contrived to climb into the tomb and lie 
on top of the coffin, much to the consternation of the monks, who feared that the monument might have to be destroyed in order to set him free.' (Crook, 2000, 260) These cases seem to have been rare yet demonstrate the power that relics held in Medieval Europe, a power which at times shifted from veneration into chaos, as exemplified in this record by Abbot Suger in 'De Consecratione S. Dionysii': 'As the numbers of the faithful increased, the crowds at Saint Denis grew larger and larger until the old church began to burst at the seams. On feast days it was always full to overflowing, and the mass of struggling pilgrims spilled out of every door. As they fought their way towards the holy relics to kiss and worship them, they were so densely packed that none of them could so much as stir a foot...In the cloister outside, wounded pilgrims lay gasping out their last breath. As for the monks who were in charge of the reliquaries, they were often obliged to escape with the relics through the window.' (James, 1987, 39) In Britain however, the formalised nature of pilgrimage and its commercial offshoots was gathering criticism towards the end of the $15^{\text {th }}$ century, and there had long been a history of theologians disapproving of pilgrimage which they felt effectively culminated in a form of idolatry, with Thomas a Kempis in his text 'The Imitation of Christ' criticising the 'localization of the holy in sacred places' (Duffy, 2005, 190). Combined with a general downward trend in pilgrimage's popularity in Britain during the late $15^{\text {th }}$ century, events such as the Dissolution and Reformation in the mid-16 $6^{\text {th }}$ century, which declared pilgrimage papist in nature and illegal, served to outlaw and interrupt pilgrim activity in Britain. During the post-Reformation period, it is likely that British pilgrims crossed to Europe to perform pilgrimages, being prevented in doing so in Britain. This placed the pilgrim in a very literal state of self-imposed 'exile', a concept further discussed in Chapter 2.1, however the scope of this thesis does not extend beyond the borders of Britain and the Reformation, and consequently this Early Modern element will not be further mentioned here.

The main point of comparison between British and Continental pilgrimages involving Britain as an origin point concern scale, and the possible motives surrounding choosing a longer or shorter distance. The concept of universality versus localism in terms of a saint cult's value to its laity and pilgrim visitors is discussed at length in Chapter 7, and demonstrated throughout the case studies, which increase in localized appeal throughout the thesis ranging from a Marian shrine (Walsingham) to that of St Petroc whose appeal was restricted mainly to Cornwall and Dorset. The interpretative aspects of landscape, familiarity and pilgrim theory are left to this final chapter, but I will outline here the differing practical motivations between long distance overseas and local pilgrimages within Britain's borders. As mentioned below in Chapter 1.5, seasonality dictated both the climatic conditions of the journey, and also the possibility of being granted time away from one's agricultural obligations on feudal estates, especially during the lambing and harvesting seasons (Ohler, 1989). One's physical state also played a role in planning the journey, as those travelling to a shrine to beg for cures may not have been in a fit state to undertake long distance journeys. Margery Kempe records going on a pilgrimage to a church of St Michael the Archangel, a mere two miles from her home, and explicitly records it as a pilgrimage, indicating that the meanest journey could be considered a pilgrimage (Windeatt, 2000, 62). One of the most interesting factors, and an excellent indicator of how pilgrimage became more hierachal and formalised in nature during the later Medieval period, was the purpose of the pilgrimage. A pilgrimage overseas was a monumental undertaking whose cost in terms of time and risk was repaid in prestige, but was an exceptional 
event for most, and likely to be resorted to for major displays of devotion, pleas of cures for severe conditions or similarly dramatic situations. Instead for the more 'mundane' requests local or at least national shrines were used, and a Lollard preacher is recorded as complaining that a $14^{\text {th }}$ century housekeeper 'would not have gone to Jersualem in the hope of finding her keys, but she might spend more than her keys were worth on a little journey to an English shrine of the 'servant saint' Zita of Lucca.' (Webb, 2000, xiii) An unofficial cult, but a popular one, St Zita or 'Sitha' (Anglicised) was depicted in many churches across southern England, and the church of St Benet Sherehog in London contained a chapel dedicated to this domestic saint. 


\subsection{Travel in the Medieval West}

Movement on any scale, but especially the volume seen during the medieval period, depended on a comprehensive route network. In what has come to be regarded as one of the defining books on travel in the Medieval period, Ohler writes that religion, trade and communication were the primary driving forces in developing and refining the system of roads which covered (to varying degrees) Christendom, and that 'the influence pilgrimages had on travel in the Middle Ages cannot be overstressed' (Ohler, 1989, 57).

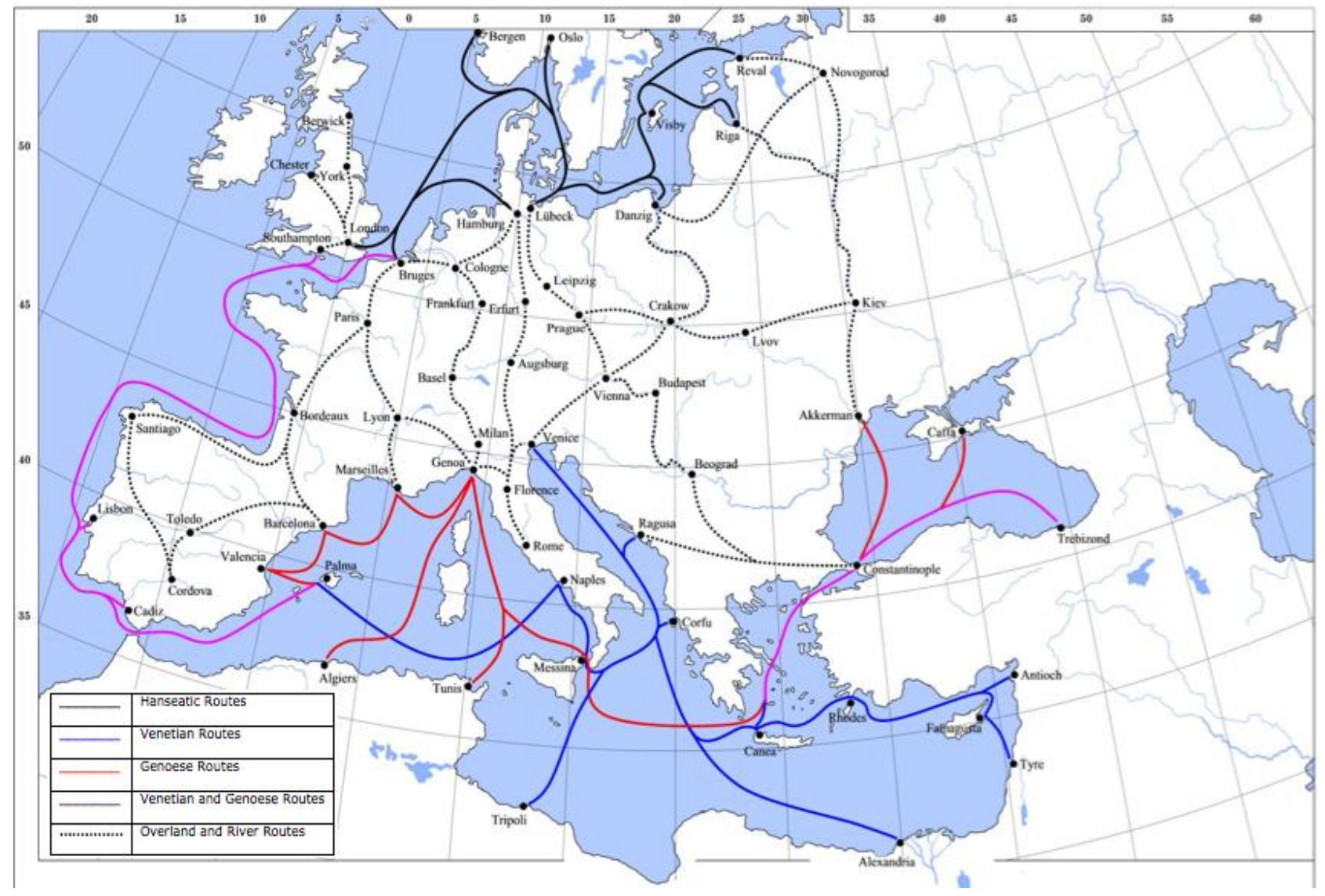

Figure 4. Map of the principal fairs and trade routes in western Medieval Europe. Reproduced from http://www2.warwick.ac.uk/fac/arts/history/undergraduate/modules/hi127/programme/western/late_medie val_trade_routes.jpg.

On the roads of Medieval Christendom, pilgrims were not by any means the sole travellers undertaking long-distance journeys, as merchants had for centuries made use of and built upon the route networks laid down by the shifting cultures inhabiting the continent (Webb, 2002, 114). However, pilgrims were responsible for bringing some settlements and sites into greater relevance and contact with major roads. Whilst previously these locations had not offered an economic motive for incorporation within the larger surrounding route networks, possession of a spiritual commodity both demanded and necessitated easy access to the laity. This was by no means a more important 
factor than trade in influencing and expanding the Medieval road system, and Figure 4 above shows some of the larger trade routes and market centres which existed in Western Christendom. Not shown in this map but of huge importance to those travelling towards Jerusalem was the Silk Road trading network, which connected Western Europe with China through a series of overland and maritime routes. For pilgrims this route network could be exploited by boarding trading boats in Venice heading towards the Holy Land, which docked (amongst other places) at Constantinople and Antioch, both of which offered overland access to Jerusalem (Foltz, 2000).

The maritime trading network of Medieval Europe is shown above in Figure 4, and was also used by pilgrims travelling to Santiago de Compostela, Rome and the Holy Land (Mackay \& Ditchburn, 1996). A favoured route from British pilgrims during the $14^{\text {th }}$ century who shrank from walking the length of France and Spain to St James' shrine involved boarding trading ships from Southampton to Corũna, only forty miles from Santiago, and was known as the 'English Route' (Storrs, 1995, 9). Many pilgrim badges bearing iconography relating to St James have been recovered from the Thames foreshore. Together with Southampton dock, this would have been a frequently used point to board ships heading for Santiago (Childs, 1999, 123). Many pilgrims would visit the church of St James Garlickhythe for a prayer of safe passage, or thanks for a safe return, before boarding these 'pilgrim ships', as these voyages were not without their dangers (Childs, 1999, 128). Aside from the array of natural disasters there was the danger from pirates; in 1473 'The Mary' from London was seized off Waterford on its return to Ireland with 400 pilgrims (Childs, 1999, 125). In Britain the Marian cult centre of Walsingham (examined in detail in Chapter 3) received several pilgrims who arrived explicitly to give thanks for safe travel on the seas. In the $15^{\text {th }}$ century Nicholas Palmer travelled from Hull to Walsingham as soon as his ship docked from Iceland, and 'in 1457 the York Mercers recorded payments for journeys to Walsingham which had been promised in the face of danger to the Katherine of York.' (Childs, 1999, 126) Pilgrims travelling to Jerusalem typically took a sea voyage from the ports of Venice or Bari, to Jaffa, then made their way onward to Jerusalem by land (Childs, 1999, 123). Until the $14^{\text {th }}$ century we see the pilgrim and crusader being interchangeable in the Medieval imagination, with some crusaders being termed 'peregrini' (a Latin term for pilgrims, expanded upon in Chapter 2.1), and until the $13^{\text {th }}$ century the Holy Land crusade was known a 'peregrinatio' (Webb, 2000, xii). However, unlike the crusaders who undertook the voyage to Jerusalem for the purposes of reclaiming the city, pilgrims were driven by a combination of curiosity and piety (see Chapter 1.3), and the crowds of pilgrims which flowed towards Jerusalem in the Medieval period mingled with traders, merchants, and countless varied social classes (Chareyron, 2005)

Meeting the needs of those visiting these pilgrimage centres we can see from the $12^{\text {th }}$ century the emergence of literature explicitly aimed at the wealthier literate class of pilgrim, who wanted to know how to get there and what to see; in essence, guide books. These were not unknown before the Medieval period, with Egeria the Pilgrim writing her account of a pilgrimage to 


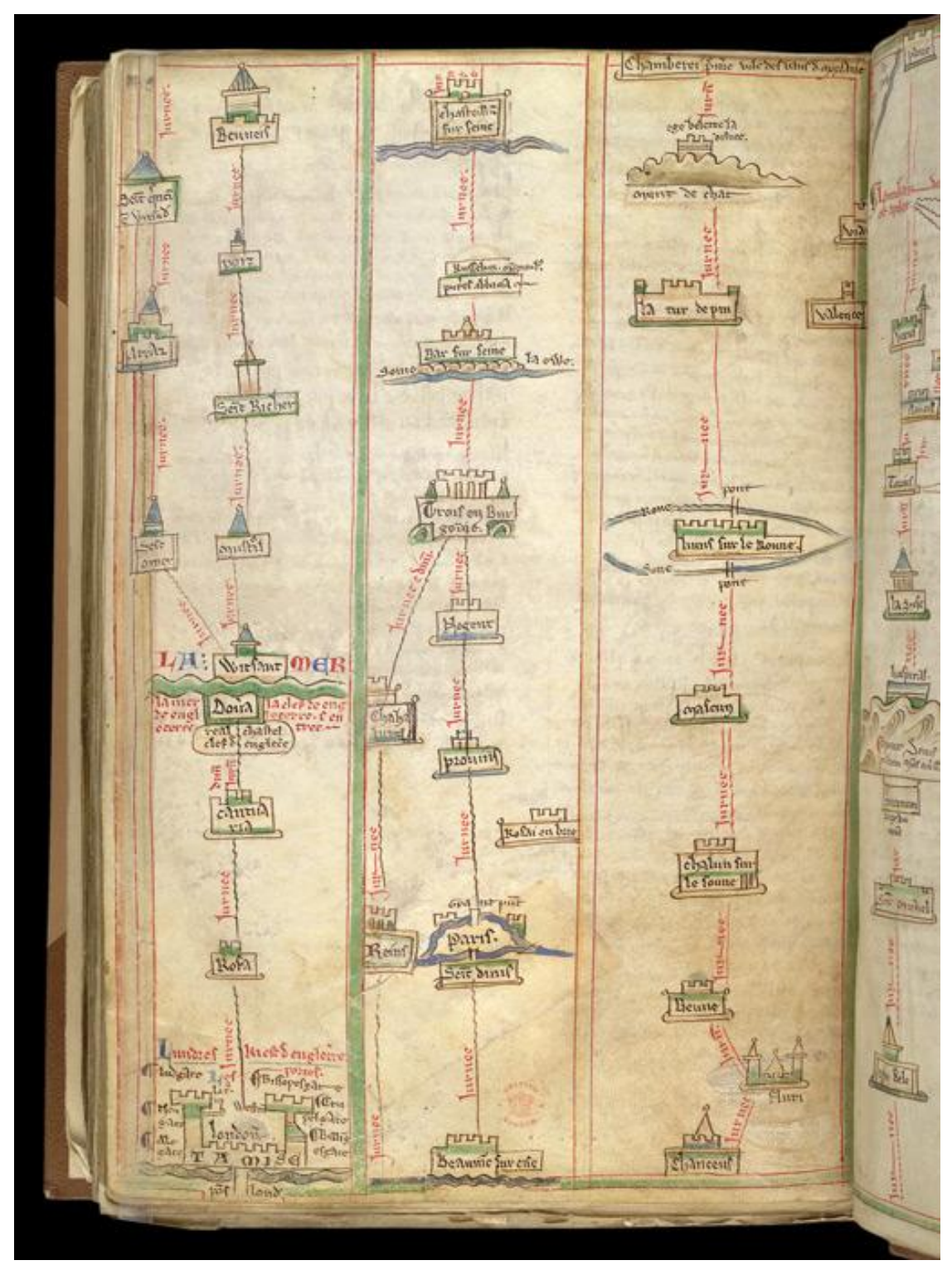

Figure 5. Strip map showing the route from London to Chamberry, from Matthew Paris' 'Book of Additions'. Reproduced from http://www.bl.uk/onlinegallery/onlineex/illmanus/cottmanucoll/i/ largeimage $75385 . h t m l$

the Holy Land in the late $4^{\text {th }}$ century (the 'Itinerarium Egeriae'), which records the liturgical seasons and practices of the region, a report on the historical and sacred places of Jerusalem, and a general travelogue (Wilkinson, 2006). It was at during the later Medieval period however that these informative and practical guides became more widespread in connection with pilgrimage. Matthew Paris wrote an itinerary or guide to the route from London to Rome in 1250, Adam of Usk published his route itinerary for the same journey between 1402 and 1406, and the itinerary of William Wey details the roads linking Calais, Rome and Venice in 1458. The Bruges Itinerary is a $15^{\text {th }}$ century road inventory for Western Europe, and for the French traveller, Charles Estienne's 1552 'La Guide des Chemins de France' would have proved invaluable. Upon arrival in Rome, the affluent pilgrim could turn to their copy Leon Battista Alberti's 'Descriptio Urbis Romae' (c.1433) or William Brewyn's 'A XVth Century Guidebook to the Principle Churches of Rome' (c.1470), which includes details of the 
route from Calais. For those travelling along the Camino de Santiago de Compostela, the $12^{\text {th }}$ century 'guide book' (the Codex Calixtus) for pilgrims travelling the Camino de Compostela de Santiago offers a variety of practical information including mileage stages, key towns and religious sites along the route, descriptions of the peoples and regions of Spain encountered along the Camino, and detailed notes on the churches and cathedral of Santiago itself (Stones et al., 1998). Discussed in Chapter 2.2 are the key British travel guides and surveys which contribute towards the research in this thesis.

Accommodation opportunities for these travellers (aside from informal lodging with family or friends) came in three forms. The inn or guesthouse has been a commercial service offered throughout history, and was the most commonly used option by merchants and traders, who tended to have more ready cash than other non-commercial wayfarers or pilgrims. An option generally for high status guests and pilgrims involved lodging at a monastery; the degree of luxury depended on the status of the guest. Priors were often obliged to house visiting nobles and members of the aristocracy (and at the larger and more celebrated monastic sites, royalty). The Benedictine rule of hospitality made shelter available to pilgrims, although in less opulent surroundings than the Prior's guest chambers, typically bedding down in rooms such as a Great Hall or guest dormitory (Webb, 2002 , 82). British examples are given in the studies presented in chapters 3 through to 6 . The final option for poor travellers and pilgrims were the various hospital institutions. Deriving from hospitium, which originally denoted a manner of 'house, billet, shelter, hospital, [or] rented room', by the $12^{\text {th }}$ century a reference to a hospitium had come to mean a guesthouse which offered travellers board and lodging, as well as almshouses which offered more permanent accommodation to those who were sick, destitute or elderly (Webb, 2002, 86). These institutions were funded through donation, land tenure and the income derived from their estates, and thus could offer free temporary shelter for pilgrims and wayfarers as part of their charitable obligation.

The religious landscapes in Britain through which the pilgrim travelled were highly populated by religious houses, particularly Augustinian. Linking these institutions with the route networks and parish churches were 'a dense network of sacred sites', creating 'a landscape defined by ritual movement which linked the more eminent centres of pilgrimage and monastic houses with a host of minor sites' (Whyte, 2009, 21). An example of how monastic institutions impacted upon the formation and economic infrastructure of the surrounding area is provided in Chapter 4, examining the role of Beaulieu Abbey in the New Forest, Hampshire. These institutions helped to develop the route networks, as they needed to be well connected to local centres of commerce in order to sell the produce of their estate; typically wool, timber and flour (Massachaele, 1997). They also competed to attract pilgrims, to whom they were obliged to offer hospitality, but these visitors represented a potential bonus to the Priory account book through revenue from the sale of religious souvenirs and shrine donations. 
The research by Stenton (1936) and Hindle (1976) underpins most modern investigations into the road network of Medieval Britain. Drawing on a range of source material including contemporary cartographic evidence, royal itineraries and travel literature (such as John Leland's 'Itinerary'), these two scholars suggest that the route network in Medieval Britain was fairly comprehensive, involving four major 'King's Roads' (i.e. Watling Street, Ermine Street, the Fosse Way, and the Icknield Way) which formed the basis for smaller routes connecting the various settlements across the county. Stenton concludes that the 'tracks and paths for communication among villages, hamlets and individual homesteads had clearly been established over the centuries, and the reasonably ubiquitous via regis, or 'king's road', indicated that a series of prioritized roads

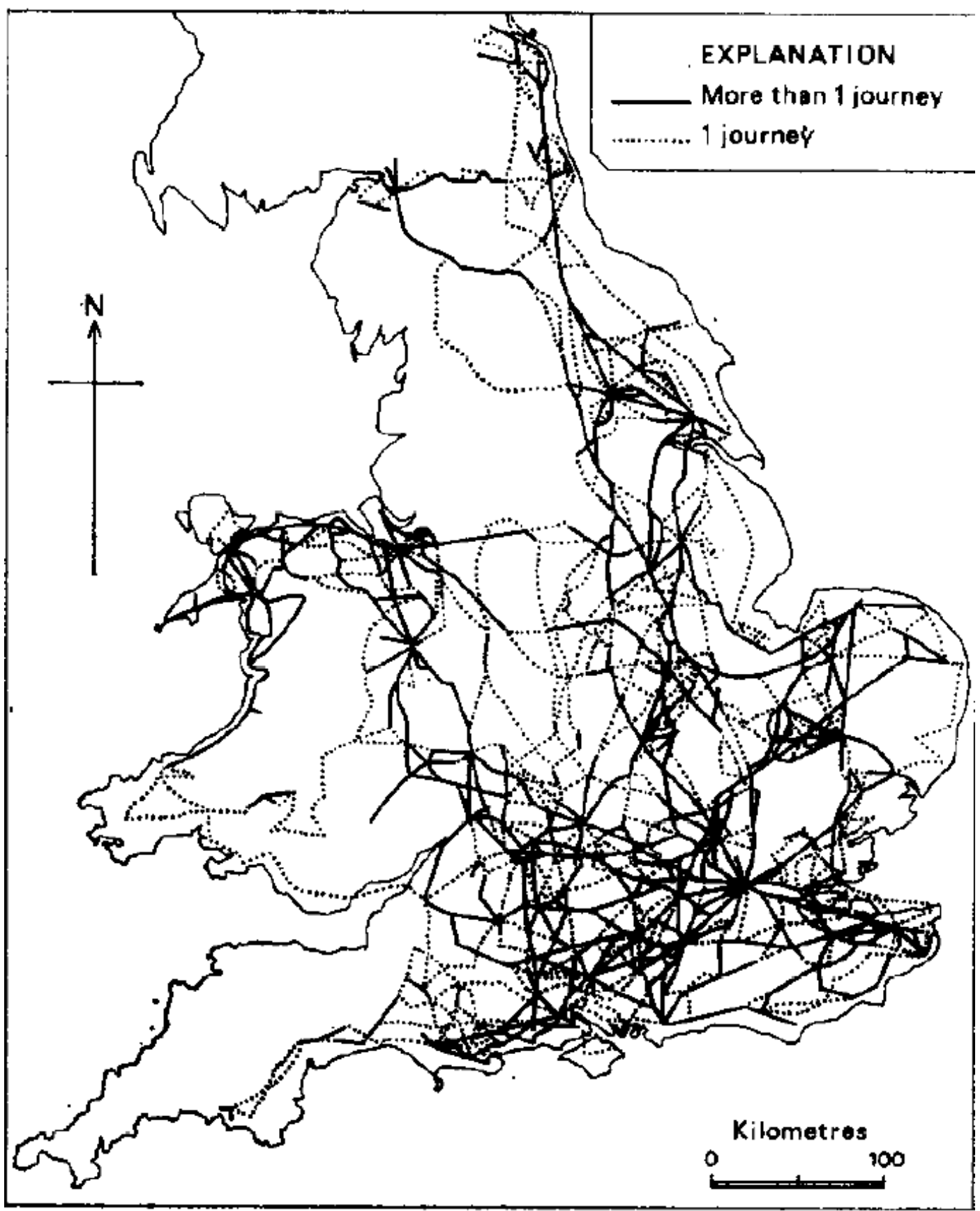

Figure 6. The Mapped Itinerary of Edward I, showing the Road Network Used. Reproduced from Hindle, 1976, 
did exist as medieval ' $A$ ' routes, linking major hubs', which existed alongside the 'lesser' informal tracks and paths which ran across rural areas linking villages, farming communities and religious institutions (Stenton, 1936, 3). This presents in most cases at least an overlapping series of single paths which converge on each-other from point $A$ to point $B$, and with larger distances which cover numerous regions we can see use made of long distance trade routes and communication networks (Hindle, 1976). A detailed analysis of the Medieval road networks in Norfolk, Wiltshire and Hampshire, Denbighshire and Flintshire and Cornwall are presented in my case studies (chapters 3 through to 6). Above is an example of the routes used by Edward I during his movements around Britain, collated and mapped by Hindle (1976). These form part of the basis for my investigations into each case study's route network, and whilst not being an exceptionally clear map it does give an appreciation for just how extensive the Medieval road network of Britain was. It is also worth bearing in mind that these also represent merely the major routes which were thought to be serviceable for the king's travels, and a larger, more informal network of tracks, paths, trails and roads were present within the rural areas which were largely available to the pilgrim.

The time of year could influence the quality of the journey as much as the routes taken, with seasons being a popular feature of illuminated manuscripts (see Figure 7 below). For many, winter represented the very worst season in which to travel, especially in the wetter lands of northern Europe. Roads were frozen or mired in mud, rain lashed down, and seas were prone to heavy storms (Ohler, 1989, 11). In Britain winter was in all probability the most unpopular season for travel, given the weather and the attraction of the hearth, with 'fear of famine, fear of sickness, fear of bonechilling cold; fear of death.' (Henisch, 1999, 30). However, some pilgrimages must have been made during this season due to necessity (such as imploring for a sick relative). Calendar manuscripts show predominantly interior activities such as the baking of bread, the maintenance of hearth fires, and emptying the larder of food stores during winter (Henisch, 1999, 30). This does not mean that spiritual activity was confined to indoors, for whilst a less popular season for feast days, winter did hold several key celebrations, not least the birth of Jesus.

Summer was the season of choice for undertaking travel. The conditions were drier, days were longer, and for pilgrims the months of June, July and August offered a universal range of feast days including the Nativity of John the Baptist/Midsummer Day (24 ${ }^{\text {th }}$ June), the Apostles Peter and Paul ( $29^{\text {th }}$ June), the translation of St Thomas of Canterbury ( $7^{\text {th }}$ July), St Mary Magdalene (22 ${ }^{\text {nd }}$ July), St James ( $15^{\text {th }}$ August), the Assumption ( $15^{\text {th }}$ August), St Bartholomew ( $24^{\text {th }}$ August), and the nativity of the Virgin $\left(8^{\text {th }}\right.$ September (Reeves, 1995, 167)). Relics were common in churches and cathedrals through Britain, attracting interest from local communities and beyond. The feast of St Thomas Becket's translation was associated with the general feast of relics on the following Sunday, 'an occasion for pilgrimage and the granting of indulgences in many churches with notable relics' (Duffy, 2005 , 47). Medieval calendar manuscripts typically show sheep shearing over the month of June, and at markets and fairs held during the mid to late summer both wool and wool merchants would have been common sights to the pilgrim among the traffic on the road (Henisch, 1999, 91). However, this may have increased the risk of thieves or outlaws, who viewed these seasonal visitors as easy 
and profitable prey. For example, Matthew Paris records two Flemish merchants being attacked by thieves on the roads leading into Winchester during Lent in 1249 (Vaughan, 1993, 93).

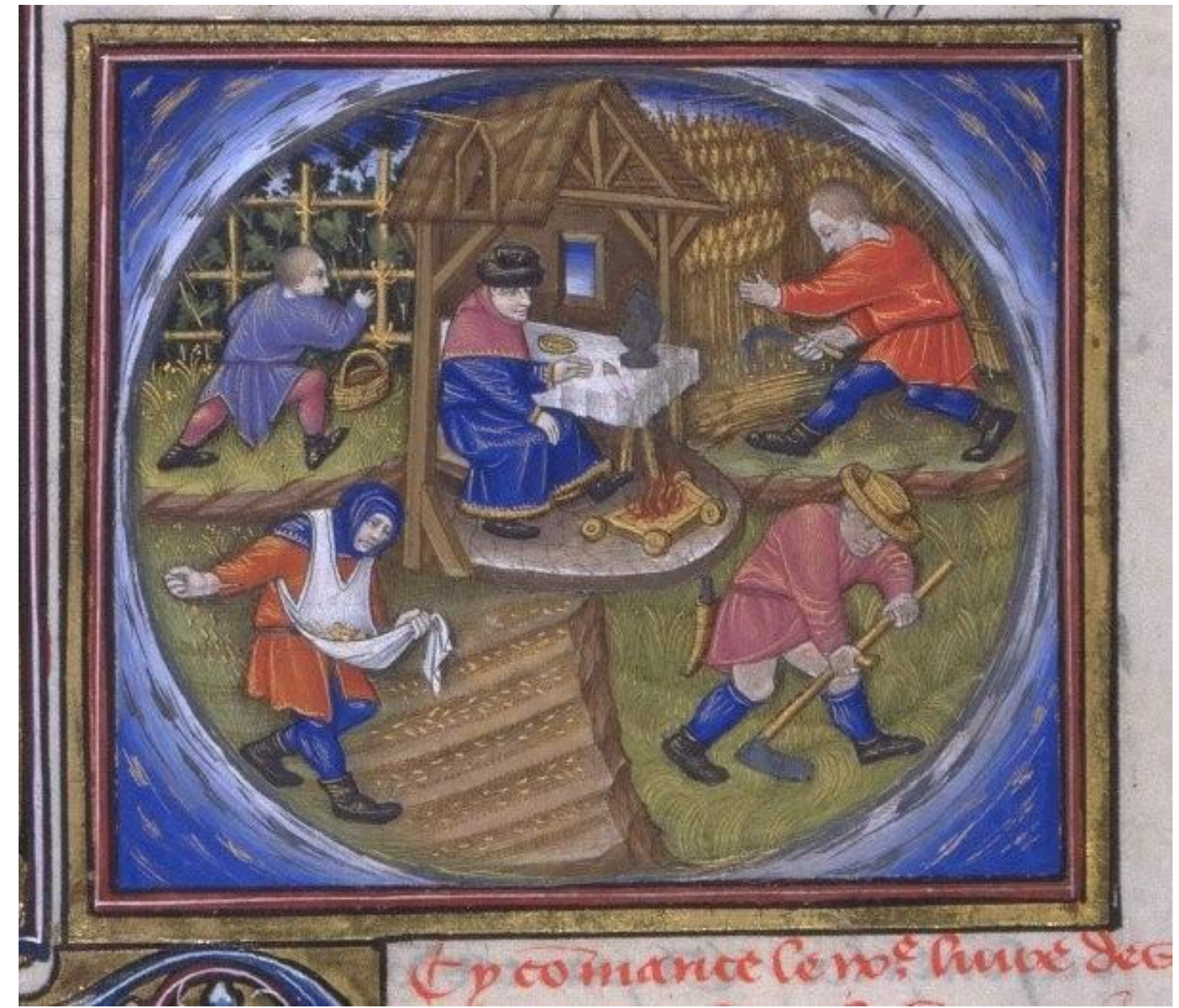

Figure 7. Illuminated manuscript displaying the four seasons from the $15^{\text {th }}$ century 'Les Tres Riches Heures', commissioned by the Duke of Berry. Reproduced from Longman and Meiss, 1995, 11.

Chaucer uses March and April in his 'Canterbury Tales' as the setting for the company's journey to Becket's shrine, suggesting that, within Britain at least, it was not uncommon for pilgrimage to resume in spring after the thawing of winter, and with spring's progression the sun shone higher and more consistently, leading towards the prime season for travel; summer (Saunders, 2001, 189; Ohler, 1989, 6). The lengthening of the days in this season, combined with better weather allowed for nights spent outside, and in the case of Alpine travel the opening up of mountain passes made summer a popular choice for travel down into Italy over the Tyrol region (Ohler, 1989, 8). For pilgrims there was another element which encouraged their movements during late spring and summer. Throughout the year there were countless feast days, at least 200 of which served as foci for pilgrimage (Nolan and Nolan, 1992, 56). However, during the later spring and summer months there were some of the most important feasts of the liturgical calendar, including Easter, Ascension and Pentecost (all changeable in date), the Virgin Mary's Visitation (July $2^{\text {nd }}$ ), 
Assumption (August $15^{\text {th }}$ ) and her Nativity (September $8^{\text {th }}$ (Nolan and Nolan, 1992, 56)). Autumn was advantageous for travel in the hotter, southern territories, as temperatures dropped, though roads were dry, nights warm and snow yet to fall. However, the annual harvest falls in this season, limiting the time of many people for long journeys, rural populations being typically engaged in reaping and gathering their crops (Ohler, 1989, 9). 


\section{Chapter 2 - The Pilgrim's Presence in Scholarship}

\subsection{Theorising Pilgrimage - The Current Dialogue}

'For the majority pilgrimage was the great liminal experience of religious life. If mysticism is an interior pilgrimage, pilgrimage is exteriorized mysticism.' (Turner, 1978, 7)

Reaching a universal definition for the term 'pilgrimage' has presented difficulties for scholars. As has been described in Chapter 1.3, the motivations for undertaking such a journey are complex and culturally nuanced, and whilst being broadly applicable to undertaking a journey with devotional overtones, cultural and practical variations in pilgrimage throughout the world have rendered it difficult to address the core motivations underpinning 'sacred travel'. As mentioned in Chapter 1.5, historically the term 'pilgrim' has been in use for centuries developing from the Classical Latin term 'peregrinus', but Gillian Clark points out that this term 'peregrinus' originally had quite different connotations from the term 'pilgrim' as we now understand it (Clark, 2004, 78). In her examination of Augustine's 'De Civitate Dei' Clark suggests that 'peregrinus' originally meant becoming a stranger, or a foreigner in one's own country (Clark, 2004, 78). This emphasises the monastic desire during these travels to adopt the ascetic qualities of the hermitic tradition ascribed by the Anchorites and the Desert Fathers; namely solitude, hardship and an unwavering devotion to God, undiluted by worldly distractions (see Chapter 1.4). By becoming a pilgrim or peregrinus one would cast off familial society, and assume the marginal role of a traveller and, before the concept of pilgrimage became so popular amongst the Medieval Christian laity, the early Christian peregrinus would perhaps become almost psychologically hermit-like for the duration of the journey, shunning company as a distraction from their veneration and devotions (Clark, 2004, 83). Declaring oneself a 'stranger' echoes the words of the Hebrews in the Old Testament who 'confessed themselves no more than strangers and passing travellers on earth.' (Brock, 1973, 10).

Prior to the creation and spread of the Benedictine rule, monastic practise in Christendom varied greatly from region to region, and many monks were involved in a culture of movement. In his text 'Pilgrimage: An Image of Medieval Religion' Sumption writes that 'the monastic ideal remained for many years inseparable from contemporary notions of pilgrimage', which whilst waning to some degree in the seventh century, blossomed again with the monastic revival of the eighth century (Sumption, 1975, 95). Despite being condemned by sections of the religious elite, this phenomenon of travelling to visit holy men, women, shrines and other places of 'divine inspiration' proved extremely popular, and Sumption asserts that the roots of this early form of the pilgrimage 'industry', which we encounter in pre-Reformation Britain during the Middle Ages, can be traced back to the attitudes and ideals of the 'Desert Fathers' with their Anchorite and Coenobite orders. Therefore, with regard to the origins of a rigorously ascetic vision of Christian life which so informed 
the development of proto-pilgrimage, the genesis of this ideal can be traced back to monastic communities in the Syrian Orient during the $4^{\text {th }}$ century (Brock, 1973, 1). A defining study of this evolution and practise of pilgrimage in the early Syrian church is provided in Vöörbus' 'A History of Asceticism in the Orient' (1958). The early pilgrim monks between the $4^{\text {th }}$ and $8^{\text {th }}$ centuries had many motives which spurred them to travel, such as the urge to commune with the holy Anchorite hermits, to pray at the burial sites of saints, and to escape the daily routine of the community - as well as the simple yet powerful spur of curiosity (Vöörbus, 1958, 8). Many of the sometimes commercial or tourist aspects of pilgrimage during the Middle Ages stemmed from this early monastic tradition of wandering, originally tied with the observance of poverty amongst early Christian monks in Syria. Poverty and piety were key components of the lifestyle practised by wandering monks, and were adopted features of life on the road for a Medieval pilgrim, although a slightly more forced attribute for some of the laity than their monastic forebears (Vööbus, 1958, 10). This may be the most direct continuation of the Christian ideal as conceived and practised by the Syrian ascetics, who lived in 'in the desert or the mountains like a wild animal, totally untouched by any of the appurtenances of civilisation, which is regarded as the work of Satan.' (Brock, 1973, 12).

Anthropological approaches have expanded our understanding of pilgrimage in both contemporary and historical contexts. The principle example of this is 'Image and Pilgrimage in Christian Culture' by Victor and Edith Turner, which claimed to reach a universally applicable definition of pilgrimage sites: 'Places where miracles once happened, still happen, and may happen again' (Turner and Turner, 1978, 6). This study states that 'pilgrimage as an institutional form does not attain real prominence until the emergence of the major historical religions - Hinduism, Buddhism, Judaism, Christianity and Islam', and this emphasis on the link between pilgrim culture and institutionalised spirituality is revealing about the mindset of the scholars in the then emerging field of pilgrim studies (Turner and Turner, 1978, 1). Pilgrim activity in 'animist' cultures (such as the Huichol, the Saami, and the 'pre-Buddhist' Bón tradition of Tibet) has historically been perceived as incomparable with what emerged in the highly institutionalised Medieval Christian west, leading to an urban-centric study of pilgrim routes with an emphasis on the site of the saint cult (Negrín, 1979; Mulk, 1994; Belleza, 2002). However all pilgrimage functions as 'a kinetic ritual' and a 'limnoid phenomenon', so it is surprising that more work has not been carried out on the actual journeying experience of the pilgrim, as the interaction between person and place during a pilgrimage is a universal phenomenon (Turner and Turner, 1978, xxiv). Movement is inseperable from the act of pilgrimage, and the focus of current scholarship on the shrine and material culture of pilgrimage gives this phenomenon an unnaturally and falsely static impression.

The landscapes through which the pilgrim moves contain that ethereal concept of 'spirit of place', which whilst not being a scientific or indeed rational element does hold a place in the discussion of how an environment affects those passing through it, as 'the land is a repository of memory' (Pearson, 2006, 6). The concept of 'spirit of place' often finds itself manifested through folk 
lore in the idea that a certain landscape holds 'significance' (Pearson, 2006, 7). Although successive generations might not fully understand why, these attitudes are replicated through a superstitious view of certain locations. In the context of the early $20^{\text {th }}$ century, authors such as Vernon Lee devoted multiple volumes to their concepts and experiences whilst travelling which revolved around encounters with the 'spirit' of a landscape or particular region (Lee, 1924). This echoed an interaction with the land found in the scriptural and hagiographical records, which saw the landscape as populated with unseen supernatural forces and the weight of history- 'The scenery then is never separate from the history of the place, from the feeling for the lives that have been lived there.' (Williams, 1993, 72). Returning to the Medieval context, in relation to local pilgrimages or those within familiar environments, aspects of 'performative memory' can be seen where the physical action of travelling through a local landscape allows the pilgrim to access their memories which are attached to certain well known features or monuments. These might be personal, or belong to the wider community in the form of folk lore or saint lore (Connerton, 1989).

Liminality is a concept and state which plays a large role in the exploration of the pilgrim experience, and here I will briefly summarise its definition and application within this thesis; it is more fully discussed in Chapter 2.3. Liminality is broadly defined as 'of or pertaining to the threshold or initial stage of a process' (Oxford English Dictionary, second edition). To be in a 'liminal state' is to be involved a 'transition of potentiality' (a change in not only what is going to be, but also what might be), and thus can be broadly applied to a wide range of experiences (Turner and Turner, 1978, 3). To maintain focus in my analysis, it will be used in conjunction with the following phenomena in my thesis:

i. Physical geography: one can be moving from one topographic environment to another, crossing a natural feature such as a river which acts as a boundary, or within an environment which is classically regarded as being home or a conduit for 'otherworld' phenomena. Forests are very commonly mentioned in this category, and further explored with regard to Thetford Forest in Chapter 3, and Upper Noad Copse in Chapter 4.

ii. The 'Pilgrim' label: as a self-elected 'outsider' from society (see the peregrinus concept discussed above), temporarily 'exiled' from daily life and moving through primarily rural or uninhabited environments, the role of a pilgrim by definition places him or her on the margins of the social landscape.

iii. Spatial boundaries: These can involve physical frontiers of territory, or (for example) zones of habitation, such as entering a town through suburbs to the city centre, or degrees of 'sacred space' radiating out from a monument such as a cathedral, church or shrine. The encounters with these spaces as the pilgrim moves towards or away from the hub provide transitional, and therefore liminal, experiences. 
In 'Sacred Journeys: The Anthropology of Pilgrimage' (1992), Morinis argues that due to the heterodox nature of pilgrimage (i.e. operating outside of social parallels), its study has been avoided by many anthropologists as it does not form around habitual social realms. This creates problems for any researcher, as it involves questions about creating artificial boundaries between what is understood as 'normal' and 'abnormal' perceptions of sacred and mundane environments in historical societies (Morinis, 1992, 2). However, the duality of sacred and profane elements in the landscape has long been a subject occupying scholars investigating disparate cultures, and in the context of the Medieval Western laity, with religious ideals and activity being fundamentally interwoven into the fabric of their lives, this duality was exemplified by the pilgrim. Consequently with the rise of 'pilgrim studies', this reluctance to address a subject which did not obey the same cultural and social norms as that of everyday life has started to be addressed, and the question of how a landscape can exist in a liminal sense as both sacred and also profane has produced some remarkable works. In the text 'Defining the Holy' (2004), the authors suggest that 'for many people the mundane landscape was, and is, interwoven with sacred sites.' (Hamilton and Spicer, 2005, 4). In this approach the laity acted out both the rituals of everyday existence, and also engaged in devotions which utilised sacred sites, all within a landscape which allowed the co-existent simultaneous presence of sacred and profane space. Amongst the more celebrated urban pilgrim sites it would not be unusual to see merchants and pedlars within the church knave itself, jostling for position amongst the clerics and pilgrims. Members of the laity were known to celebrate feasts by coming into church and singing obscene songs, bringing the profane world into direct contact with sacred space (Webb, 1999; Hamilton and Spicer, 2005). Eliade reconciles these simultaneous attributes of these landscapes with the supposition that the religious person views the whole world as 'the work of the gods' and consequently sacral at all times, which brings these layers of interaction into union (Eliade, 1959, 64). The manner in which this can be applied to a dualist dogma such as Medieval Catholicism is debatable, but Insoll provides a similar yet more nuanced suggestion that 'the same landscape can mean different things to different people, and can be one and the same, and thus lack any arbitrary division.' (Insoll, 2007, 88)

Arnold van Gennep defined the rites of passage in pilgrimage as being composed of three principle phases which are summarised by Turner and Turner as states of 'separation', 'liminality' or marginality, and 'aggregation', and I will briefly outline these phases below (Gennep, 2004, 184; Turner and Turner, 1978, 2):

i. Separation: This arises from the behaviours of the pilgrim which separate him from his fellow laymen and initiate his journey - this could be attending a special 'pilgrim mass' such as that performed at Roncesvalles in Spain (on the first Spanish stage of the Camino de Santiago de Compostela), at which numerous blessings are bestowed upon the pilgrim in readiness for their journey.

ii. Liminality: This phase comes about through the process of travel; the motion and detachment from the rest of society initiates the becoming of a peregrinus or a 'stranger', acting outside the normal machinations of society in a variety of social and 
personal contexts (interaction with fellow travellers of different social standing, and the meditative quality of walking long distances. In this state the pilgrim experiences time in a different manner, as the overriding rhythm of the day is that of the footstep - this is very noticeable today where walking is no longer the primary means of travel. This experience is related by Frey when describing his experiences on the Camino de Santiago de Compostela when he suggests that the pilgrims are aiming to temporarily transcend the fast-paced and mechanical modern world by moving through the landscape in a manner which actually deliberately slows their progress, rather than utilising the most efficient and fastest method (Frey, 1998, 34). This rejectionism is far from being a recent concept; in the fourth century St Jerome wrote of 'forsaking the bustling cities of Antioch and Constantinople', showing disdain for the manner in which (then) modern urban life interfered with spiritual development and renewal (Sumption, 1975, 95).

iii. Aggregation: This final phase sees the subject 'consummate' the process of pilgrimage by arriving at the final site and performing appropriate devotions and supplications, and return to normal life and society.

These interior 'transformations' involve the pilgrim subsuming himself into a radically different mode of life for a time, and movements assume a devotional aspect which render the pilgrim unique from the rest of the laity (Turner and Turner, 1978, 2). By completing the pilgrimage the laity may 'enhance their mundane status through having made the journey'; the initiation and subsequent ritual of pilgrimage would offer a release from the normal social responsibilities, which undoubtedly made the prospect of such a journey attractive across the public spectrum (Turner and Turner, 1978, 9). Here we see one of the core precepts of Turners' text, that the process of pilgrimage actually facilitated inter-hierarchal interaction on a social level which would have been rare outside of the highly specialised environment of sacral travel. This also creates a liminal state of temporary social mobility. The Turners adap van Gennep's depiction of life as a series of transitions into a pilgrim context, which is an appropriate and cyclic analogy, as pilgrimage was seen as a metaphor for the journey of life.

Another consideration for examining interaction between landscape and pilgrim is that of the sensory delineation of space. An example of the audible element is given in the pealing of bells across parish lands. According to the $13^{\text {th }}$ century canonist Henry of Susa, the definition of a parish was 'a place with well-defined frontiers whose inhabitants belong to a single church.' (Sumption, $1975,11)$, and it is suggested that the ringing of bells could denote the "lordship and domination of a particular house over its territory' (Hamilton and Spicer, 2005, 7). Here we see how the overlapping fields of meaning (dominion, sanctity, hierarchy) meet in a novel interpretation of experiencing church bells as a parishioner or pilgrim, and their effect in endowing status to a parish based on their quality (French, 2000). Another area for consideration is that of smell, and Atchley address the use of incense inside a church and its role in marking a space as sacral by flooding the senses with sweet odours (1909). St Thomas Aquinas stated that incense 'set the divine apart from the smells of the 
world', imbuing church interiors with an actual odour of sanctity (Aquinas, 2007, 12). Whilst one can agree with Insoll (2005) that sites were all things to all men and debunk the relevance of arbitrarily demarking certain sites as sacred as opposed to profane, claiming that the two terms were nebulous in their application, there can be no doubt that these sensory trappings helped to instil a feeling of truly being in 'God's house' in which devotion became the primary focus.

The importance given to protecting the senses against devilish influence, receiving the symbology of Christianity, and directing the senses of the laity towards God during the Medieval period, makes consideration of sensory impetus desirable within an interdisciplinary examination of pilgrimage, and ties into phenomenological themes rased later in this chapter. Sensory interaction in the ecclesiastical setting was governed by rules during the Medieval period, which could dictate proximity to either the laity, monastic bodies or the relics and tombs of saints. The touch of a saint or their relics was 'widely recognised as conveying virtue', and many pilgrim shrines became scenes of frenzy as overly zealous visitors pushed and jostled eachother to reach the openings in tombs which allowed greater access to the saint's remains (Woolgar, 2006, 42). Similarly the Host, containers of holy water and sacraments were all seen as able to impart goodliness and sanctity on a person via proximity, leading to more chaotic scenes within churches and processions. Here again we see what are traditionally thought of as boundaries between spatial regions appropriate for sacred/profane behaviour as being blurred and overlapping within the Medieval mind (Woolgar, 2006, 42). Milner writes that 'It is clear that [pre-Reformation] English churchgoers [and by logical extension pilgrims] participated in a religious culture deeply affected by its views on sensation, a constant tension between its exploitation and acknowledgement of its limitations, all under the rubric of governance.' (Milner, 2011, 53). This tension between the manipulation of senses to render the laity suitably devotional and the frequent cross over into over-zealous anarchy is illustrated in the behaviour recorded by Margary Kempe, detailed in Chapter 3.4, where at Walsingham she weeps uncontrollably in a hysterical manner (Windeatt, 2004, 398). The senses were often represented as a battle ground between desirable and undesirable urges, the influence of God and the Devil, with the laity representing the field across which these two forces grappled for supremacy. No less so with the pilgrim, whose multi-faceted appreciation of space within the church provoked the possibility of both profane and devotional behaviour, and also within the open spaces of the pilgrim journey, a theme expanded upon in the case study chapters and also Chapter 7, but briefly touched upon here. Pythinian-Adams suggests the existence of 'topographies of superstition' in the Early Modern period, and with the wealth of religious-lore and folklore being present in the Medieval landscape it seems logical to suggest this could also be a feature impacting upon the Medieval pilgrim's senses (Pythinian-Adams, 2000, 134 - 142). Nicholas Corcos expands upon this theme with relation to the Shapwick and Moorwick parishes of Somerset (Corcos, 2001). He suggests that the use of boundaries, siting of churches in the landscape, meaning of place-names and corresponding natural topographies all provoked profound sensory reactions within the laity, thereby championing a tentatively phenomenological approach to the Medieval landscape to arrive at a greater understanding of the Medieval laities daily and religious experience (Corcos, 2001). 


\subsection{Medieval Pilgrimage in the Archaeological and Historical Record}

Pilgrim studies in both the anthropological or archaeological sphere have tended to avoid examining the great Christian routes in the West, favouring studies either of The Hajj, or the practise of pilgrimage within the urban environment of Jerusalem (Peterson, 1994; Elad, 1995). In 'Some Approaches to the Archaeology of Christian Pilgrimage', Stopford outlines several key areas of focus when attempting 'pilgrim archaeology' if we are to redress this imbalance in study. These are summed up as 'the assemblage of pilgrimage in its entirety, with routes, buildings, monuments, landscapes and artefacts all relevant to the theme.' (Stopford, 1994, 69). She argues that in order to provide relevant interpretations of the data along pilgrim routes, one must avoid analysing sites in isolation and always consider the site within the context of a fluid population of pilgrims and neighbouring settlements. Notable exceptions, and perhaps influenced by Stopford's critique, are by Candy in Spain $(2005 ; 2007)$ which is discussed below in 2.4 and also O'Sullivan and O Carragain, (2008) in 'Inishmurray: Monks and Pilgrims in an Atlantic Landscape'. This latter work focuses not only on the shrine of St Molaise, but also explores how the satellite monuments on the island (principally leachta, dry-stone structures) and cemeteries interacted with the pilgrim, in preparation for the eventual arrival at the shrine through recorded ritual behaviour. Studies were also made of probable landing points for pilgrims by boat, of processional liturgies which would have been appropriate to the island's exposed geography, and of Inishmurray's role within the larger tradition of Medieval Irish pilgrimage. These seemingly disparate strands are brought together to provide a integrated picture of pilgrim activity on Inishmurray, and fulfil Stopford's call to consider the wider context, and avoid purely isolationist studies of each site.

Archaeologically, the class of pilgrim material culture which is most visible in the material record are badges, ampullae (small metal vials or flasks for containing holy water), pocket altars, mounted relic fragments and other souvenirs sold at the shrine sites (see Figure 8 below). Brian Spencer pioneered the detailed study of these artefacts, and his text 'Pilgrim Souvenirs and Secular Badges' (1998) displays the variety of souvenirs found in London. Spencer states that prior to the rise of the souvenir trade, pilgrims used to steal objects, pieces of masonry, nails or indeed anything which was attached to a shrine as a talisman, and this dubious practise is confirmed by de Villard's monograph 'Liber Peregrinationes de Jacopo da Verona' (1950), in which a story is recounted of a pilgrim 'assaulting' the Golden Gate in Jerusalem to prise loose a nail as a keepsake (Villard, 1950, 44). The response to this problem was to 'devise, manufacture and sell cheap souvenirs' such as ampullae and badges, with iconography on each badge being unique to the saint(s) or relic venerated at the place of sale (Spencer, 1998, 3). Spencer reproduces and cites several contemporary paintings which display the pilgrim badges being worn customarily on the layman's headgear with such detail that they can be matched to surviving souvenirs (Spencer, 1998, 3). In 'Beyond Pilgrim Souvenirs and Secular Badges: Essays in Honour of Brian Spencer' (Blick, 2007) a series of papers draw and expand upon the work of Spencer, analysing the presence and evolution of these souvenirs in relation to saints and cult centres, including an essay on late Medieval English 
amulets by Peter Murray Jones (1984) which addresses the medical applications of some pilgrim souvenirs. This volume rigorously re-examines these souvenir artefacts within specific cultural contexts and points to a promising future in this area of pilgrim studies. These examples are analysed not as isolated objects or as merely links within an artistic or stylistic progression, but instead with the aim of informing us on the evolution of pilgrimage's trends and industrial growth within Western Medieval Europe. A comparison between pilgrim badge iconography and that of secular and obscene badges of the late Medieval period has been made by Ostkamp, demonstrating the applications of both types of badge amongst the laity (2009).

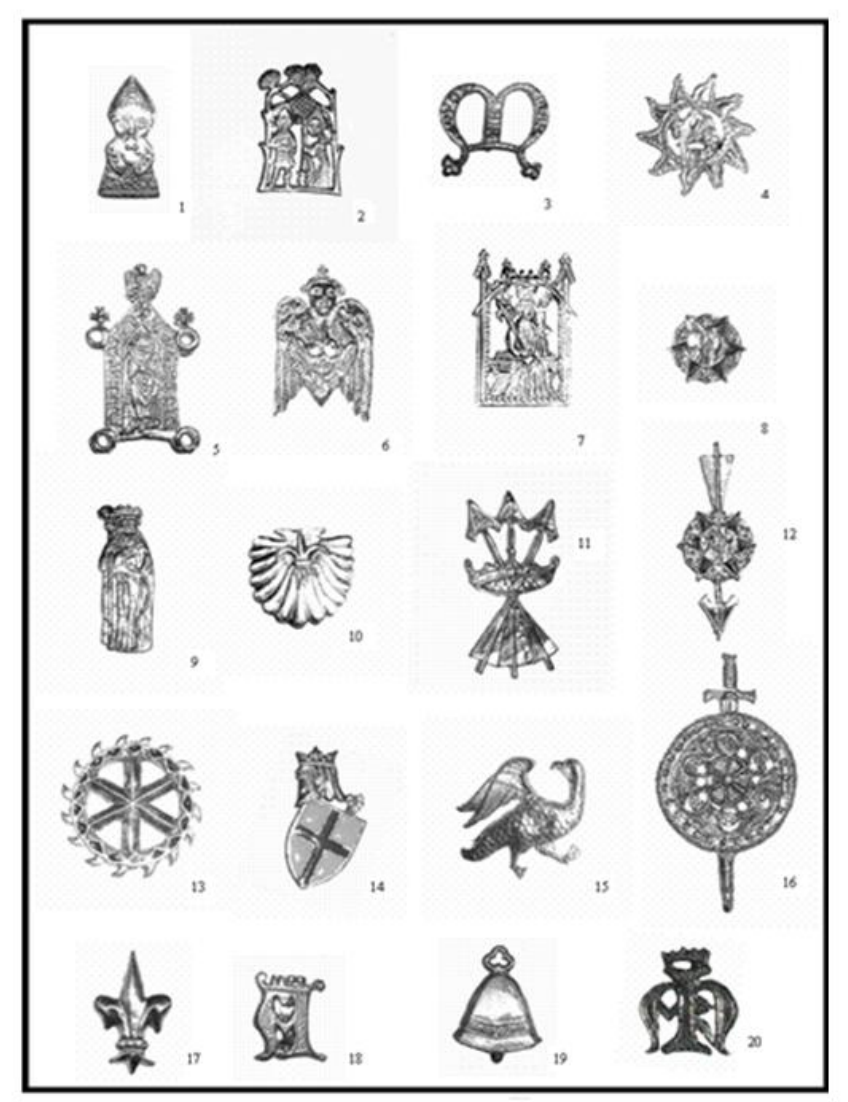

Examples of Pilgrim Badges

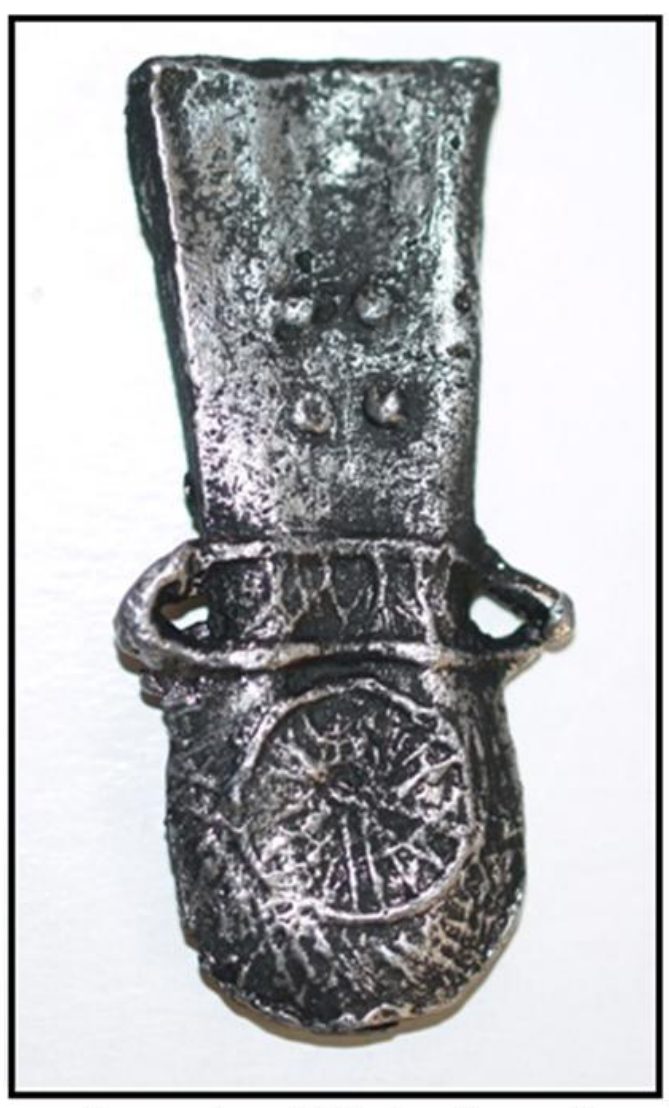

Example of Pilgrim Ampulla

Figure 8. Examples of Medieval pilgrim badges and Ampulla (dedication unknown). Reproduced from www.castsfromthepast.co.uk

Cross-textual research is crucial to forming an interdisciplinary approach to pilgrimage, and in the case of Medieval Britain the literature available on the hospitals and religious houses is wide ranging, cataloguing in detail the locations, accounts and histories of many religious houses. These texts are vital when considering both the development of route networks, the possibilities of en route accommodation, and sites which housed relics belonging to saint cults. The most complete example of this category of literature is 'The Medieval Religious Houses in England and Wales' by Knowles and Hadcock (1953), and there are two additional volumes concerning Scotland and Ireland. 
This catalogue contains a wealth of information regarding monastic orders, dedications, dependencies and hospital admittance records for every religious house in Britain. This text makes extensive use of the Victoria County History series and of Rotha Clay's 'Medieval Hospitals of England' (1909), which was the first extensive survey and catalogue of its kind. Hadcock also published an Ordnance Survey map entitled 'Monastic Britain' (1950), which is invaluable for examining distribution patterns and clusters of monastic activity in rural areas. The distribution of these monasteries also gives clues as to possible shelter for pilgrims, as the monks would have been under charitable obligation to take in bona fide travellers for a night. Another catalogue source for the larger ecclesiastical institutions which offered sanctuary to travellers is the text 'The Sanctuaries and Sanctuary Seekers of Medieval England' (1911) by James Cox. This focuses on detailing the different laws regarding offers of sanctuary (not just to those who were fleeing the law), and relates the histories and anecdotes of religious houses including Durham cathedral, Beverley minster, Beaulieu Abbey, Battle Abbey, St Buryan's and Padstow.

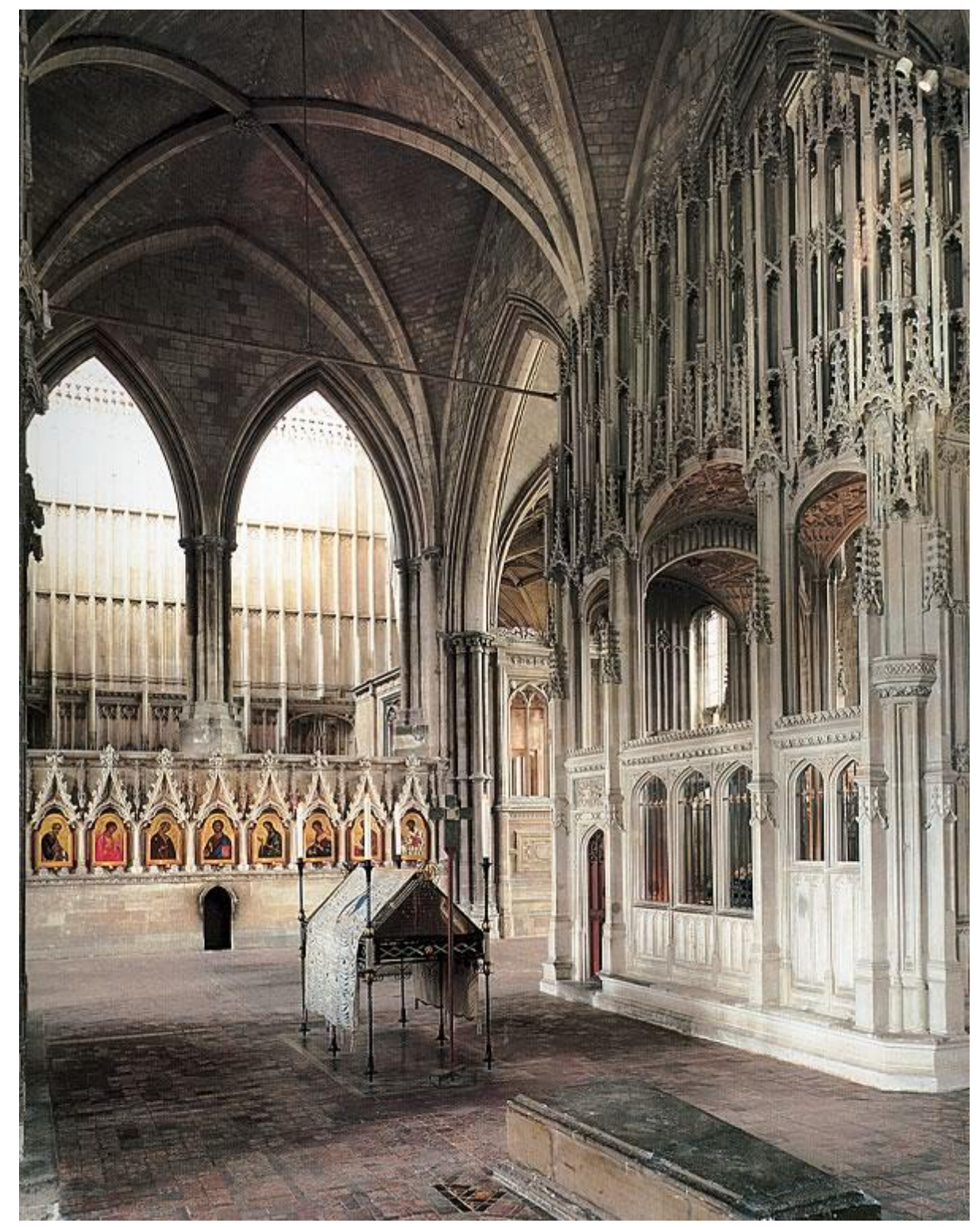

Figure 9. Shrine of St Swithun, Winchester Cathedral. Reproduced from www.britannia.com 
This thesis does not focus on the shrine sites in general, as there is already a substantial body of literature dealing with the architectural development of these edifices and the emphasis here is on the journeying context. The published studies of shrine sites are too numerous to cite here (and are addressed with regard to individual sites in the case studies), but Dr John Crook's work on the modifications at the shrine of St Swithun (see Figure 9 above and Chapter 4 ) is of particular note for its discussion of relic translation and display for pilgrims, as is his recent work on English Medieval shrines, which covers the evolution of these monuments from the Anglo-Saxon saint tombs to Reformation period pilgrim shrines (Crook, 1993; 2000; 2011). Prior to the steep rise in the popularity of pilgrimage, relics were typically displayed adjacent to the High Altar and so access to these artefacts were denied to the layman - 'These relics were probably not accessible to the layman, and any cults associated with the relics were relatively small 'private' affairs', and sanctuary areas were 'very small, and very simply constructed, either in an apsidal form or as a small square structure to house the principal altar.' (Tatton-Brown and Crook, 2002, 90) Contemporary sources give detailed accounts of these remains being transferred to more prominent positions in ecclesiastical institutions across Europe and Britain from the beginning of the seventh century, and relics would have been moved around churches for decades in response to the human need to touch and feel that which was close to divine. Newly converted Anglo-Saxon England was no exception: 'From the seventh century many of the changes in the physical setting of the cult of saints evident on the Continent also occurred in Anglo-Saxon England.' (Crook, 2000, 161)

Antiquarian accounts of holy wells in Britain include the meticulously catalogued 'Ancient and Holy Wells of Cornwall' by M and L Quiller-Couch (1894), and Robert Hope's 1893 'The Legendary Lore of the Holy Wells of England'. Juxtaposed to these folkloric and romantic texts is the work of James Rattue. In 'Living Streams: Holy Wells in Historical Context' (1995) he rejects many of the pre-Christian associations which his Victorian predecessors thought linked with Christian well sites, and calls into question the very concept of 'continuity of use', in terms of the laity approaching wells and springs with underlying pre-Christian sentiments. Stating that 'The folklorists tended to universalise their discoveries, regarding the 'survivals' of ancient custom as the untainted relics of pure antiquity', he suggests that the very issue of continuity is difficult to prove categorically (Rattue, $1995,3)$. In order to prove that pre-Christian style worship and customs took place at these spring and well sites there must be conclusive evidence to suggest that the laity had expressly nonChristian concepts and ideals in their minds when worshipping at the well; evidence which is not conclusive in the archaeological record.

In terms of contemporary pilgrimage accounts, manuscripts which document such journeys in Britain are few; however a primary document which does explicitly record several British pilgrimages undertaken by a member of the laity is 'The Book of Margery Kempe' (Windeatt, 2000). Although studies have proven her accounts to be exceptional (even hysterical), and so cannot be considered the 'normal' behaviour of the laity, the descriptions of the shrines and manner in which she arrived at these sites is of interest and her emotional responses to the shrines do provide an 
impression of their devotional impact. The international travel literature listed in Chapter 1.5 is also of use in identifying key sites of relevance to the pilgrim (such as the itineraries of Matthew Paris and Adam of Usk, the guides to Rome and the Camino de Compostela de Santiago), and in addressing the route networks used to travel across the landscapes of Christendom, however there is no need to repeat their examples here. I will now briefly turn to travel literature in the British context, in which five reliable works emerge as key and are quoted from in this thesis; the works of William Worcester in the mid-15 $5^{\text {th }}$ century (Worcester, 1969), John Leland, early $16^{\text {th }}$ century (Chandler, 1998), Desiderius Erasmus, also early $16^{\text {th }}$ century (Nichols, 1849), William Camden in the late $16^{\text {th }}$ century (see Figure 10 below (Tymms, 1842)), and Richard Carew from the early $17^{\text {th }}$ century (Carew, 2000). All of these writers, with the exception of Erasmus, were commissioned to produce extensive reports on the towns, villages, topography and histories of the regions of England in an attempt to produce 'scientific' and accurate accounts of the realm, and so contain brief but precise information on pilgrim centres in their respective counties. William Worcester also provides paced dimensions for several of the churches and shrines, including Walsingham and Bodmin Priories.

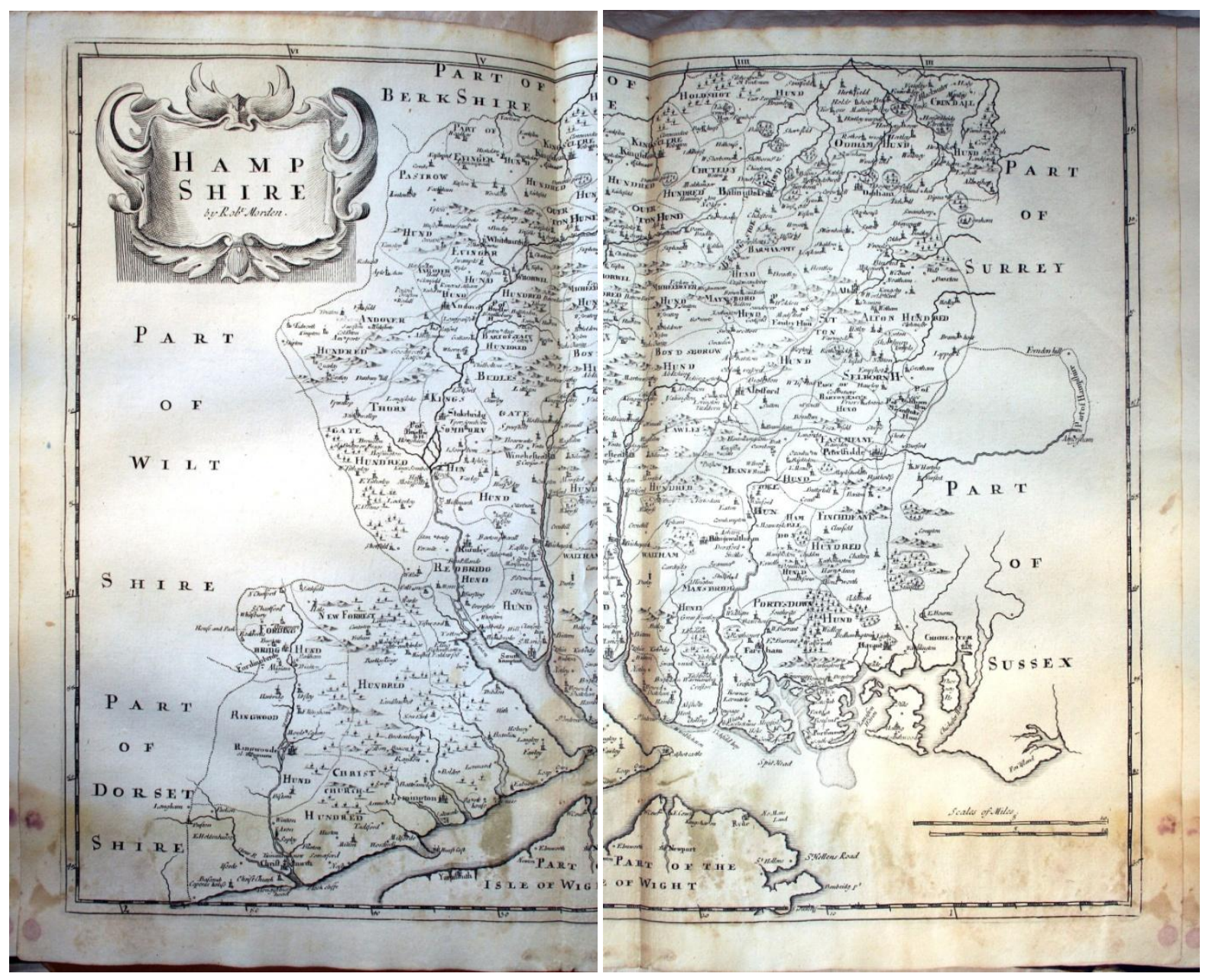

Figure 10. Map of Hampshire taken from William Camden's 'Britannia', 1607. Reproduced from http://ebooks.adelaide.edu.au/c/camden/william/britannia-gibson-1722/part41.html 
Other categories of writings which can reveal details about pilgrimage within Britain are the hagiographies (vitae) or miracle accounts (miraculae) of saints, and epic prose such as Langland's 'Piers Plowman'. I am deliberately leaving aside Chaucer's 'The Canterbury Tales' from detailed discussion for three reasons; Canterbury does not feature within my case studies (the reasons for which are stated below in Chapter 2.4), there is already a significant body of scholarship by literary experts dealing with this text in detail, and as explained in Chapter 1.3 Chaucer does not aim to enlighten about the pilgrim process of motivation but instead make character studies of the social classes involved in pilgrimage. This is useful in that it demonstrates the wide range of backgrounds and places in the social hierachy pilgrims occupied, and supports the Turner's assertion that pilgrimage temporarily removes social distinctions allowing for greater interaction and mobility; however it fails to provide information about the general behaviours and journeying experiences en route to Canterbury along Watling Street (Turner \& Turner, 1978). Miracle manuscripts, such as those by Lantfred written in the $11^{\text {th }}$ century regarding St Swithun (Lapidge, 2003), frequently reveal the primary category of ailment the saint's powers are famed for curing, the nature in which they are beseeched by the sufferer, and the donation offered after successful cure. William Langland mentions Walsingham in 'Piers Plowman' (c.1330 - 1386), where he describes the touristic aspect of pilgrimage represented by 'false' and immoral pilgrims or holy men, who 'Wenten to Walsyngham, and their wenches after.' (Langland, 2009, 183) The relevant details from these various miracluae, vitae, pipe/account rolls and other primary sources are provided in chapters 3 through to 6 in relation to the saint whose cult was the subject of the pilgrimage discussed.

It is worth briefly highlighting the transmission of biblical motifs and religious tales to the laity, which was largely achieved from the $13^{\text {th }}$ century via church sermons and mission preachers (Jolly, 1997, 431). This transmission on a regular basis further coloured the manner in which the general laity perceived the world i.e. as a spiritual battleground between benevolent and malign forces. Tales which involved the lives and miracles of saints (both local and universal), scriptural metaphors and stories, and moral instruction based on examples set by pious figures in church history were presented to the laity in church services. Some of these are preserved in the writings of Jacques de Vitry, a priest, bishop, cardinal and patriarch in the early $13^{\text {th }}$ century (Crane, 2004), Étienne de Bourbon, a $13^{\text {th }}$ century Dominican monk (Jolly, 1997), and Ceaser of Heisterbach, a $13^{\text {th }}$ century prior at Heisterbach monastery (Jolly, 1997). Within the sermons of parish churches, the motifs or scriptural elements which filtered down to the laity were not directly taken from the dense theologies of for example; Augustine, Gregory the Great or Thomas Aquinas. Rather, 'in order to become 'prevailing ideas', the ideas of the elite had to be translated into a language comprehensible to all. For the most part, this was done by preachers who were in direct contact with their flock.'(Gurevich, 1992, 2) Specific genres of Christian literature were created for this transmission of doctrine, moral instruction and heavily simplified theology, such as sermons, admonitions, miracle stories, saint lives, catechisms and penitentials (Gurevich, 1992, 2). These concepts and stories would have required framing in a manner which resonated with the local population and could be achieved by including aspects of local folklore or popular 'history', and include references to relics, saints, biblical folklore, morality plays, the Virgin and the Devil, and many other such 'popular' subjects (Jolly, 1997, $431-435$ ). It is these concepts and aspects of Christian perception that are 
discussed in the context of sensory interaction during the penultimate section of each case study chapter. There are many other areas of artistry which either utilise pilgrimage as a theme, study, influence or motif, such as religious paintings, choral pieces, literature or illuminated manuscripts; however there is neither the space nor the scope in this thesis to delve into these areas in detail. The influence of pilgrimage upon the arts was broad and its reach long, and those that would wish to explore this area of research further are recommended to turn to the text 'Art and Architecture of Late Medieval Pilgrimage in Northern Europe and the British Isles' (Blick \& Tekippe, 2005). 


\subsection{Liminality, Movement and the Landscape}

When addressing pilgrimage, one area which has long been overlooked yet is vital to our understanding of the pilgrim experience is the movement and interaction with the landscapes and different, often simultaneous classes of 'space' within these environments. These multiple perceptions of space or 'multivocal spaces' engender different responses depending upon the origin, background, role and mental state of the person inhabiting or passing through them. In 'Experiencing Landscapes' (2003), Karin Altenberg discusses how archaeologists have 'traditionally used a quantitative approach to space', but she argues that 'social space must not, or indeed cannot, be formally quantified' (Altenberg, 2003, 1). Neither, it appears, it is possible to concretely define spheres of Medieval 'space' through purely archaeological approaches. There is not the space within this thesis to fully explore all the nuances of the relationship between the Medieval mind and nature, but outlined below is the basic underpinning dichotomy of this area from which I approach my research.

The Medieval attitude to the 'natural' and 'wild' places was deeply tied to Christian doctrine, and at times contradictory. We are presented with a dualism within the personal response to nature; it represented both a locus amoenus ('lovely place', typically a bucolic pastoral landscape) and the locus horribilis ('terrible place', wild and barren in character (Howe, 2002, 210 - 212)). The concept of locus amoenus was inherited from Greek and Roman pastoral literary traditions (such as Theocritus' 'Idylls' and Virgil's 'Pastorals'), containing all that was beautiful, pure, and representative of a paradisiacal state devoid of distractions from spiritual contemplation (thus ideally suited to hermits and religious retreat), although this landscape was not thought of as being beyond improving by man's efforts (Howe, 2002, 210). The 'wilderness' is the setting in many biblical tales for interaction with the spiritual world (such as Jesus' temptation, Moses' receipt of manna, John the Baptist's dwelling place) although this interaction was not always benevolent, and forms a separate realm from that which is encountered in the daily rhythm of the majority laity. This view of the 'wild' landscape is inherited from the Hebraic literary heritage which runs through the scriptures, and it was just these 'broken' environments to which hermits and monastic communities were originally drawn in the East, which may have started the transformative process from horribilis to amoenus simply through their Christian presence (Howe, 2002, 213; White, 1972, 6). This Hebraic 'wilderness' is the locus horribillis, a bleak and blighted landscape which frequently found its way into hagiographies during the $11^{\text {th }}$ and $12^{\text {th }}$ century (Howe, 2002, 212). It is this concept of wilderness, that of the benighted topography and uninhabitable lands that was most likely within the minds of the Medieval laity, due to the Hebraic sermon material they experienced within the parish church and its scriptural content. Within Britain, moorland would fit the mould of a locus horribillis, which may explain the array of stone crosses surrounding Bodmin Moor, aiming to protect the transitional landscape between the settled fertile valleys and the moorland at the centre (Chapter 6). 


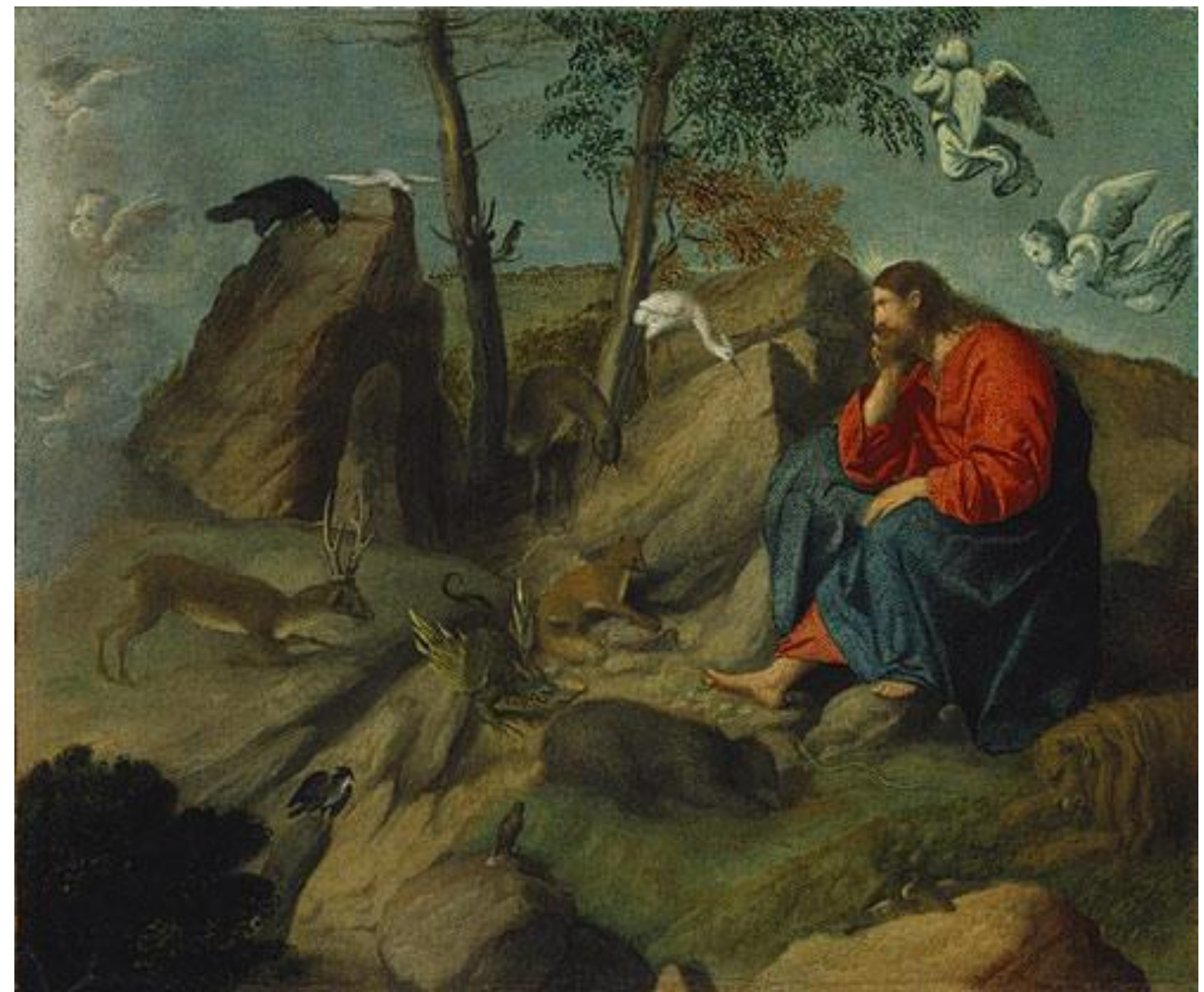

Figure 11. 'Christ in the Wilderness', by Moretto de Brescia $(1498$-1554). Here the Hebraic desert wilderness has been placed in a western context and made to resemble a forest clearing, echoing the view of the forest an effective parallel for 'wilderness' and setting for supernatural/divine encounters. Reproduced from http://www.metmuseum.org/toah/works-of-art/11.53

Other wilderness landscapes within the British Isles included the coastlines and moorlands of Scotland and Northern England, demonstrated by the monastic presence established by St Columba on Iona, as related by Adomnán (Sharpe, 1995) and also by the ill-fated Holy Island of Lindisfarne off the coast of Northumbria. However the most commonly encountered landscape within Britain (and within the case studies of this thesis) which took on the role of the scriptural desert's Western equivalent was the forest. This presents another example of dualism, in that the forest represents both a foreboding place, filled with spiritual and physical danger, but also represents a paradisial shelter in several chivalrous Romances, providing encounters with 'wise men', sages and hermits (Le Goff, 1988, 56). The forest also was seen as the setting for liminal encounters, blurring the real and supernatural, and we can see this in representations of Christ in wooded 'wilderness' ', preparing to encounter Satan (see Figure 11 above). This idea of encounters from 'otherworldly' forces within the forest is a popular aspect of folklore throughout Britain and Europe, and is expanded upon within the sensory sections of the case studies. In this way the idea of 'the desert' has always been composed of juxtaposing material and spiritual realities, and the persistant interplay of symbolism and geography (Le Goff, 1988, 52). Visibility was a crucial factor in 
this melding of roles, in that the tree cover provided a screen which both hid others from your view, and in turn hid you from others. Paths typically lead through cleared spaces, and the surrounding vegetation can be impenetrable both physically and visibly. Thus the forest was typically seen as 'opaque', able to contain great and useful reserves of game, honey, timber and grazing land, and also filled with those at the social and literal fringes of society such as 'hunters, charcoal-burners, blacksmiths, honey and wax gatherers, ashmen...and bark pullers.' (Bloch, 1951, 6) These environments represented a serviceable 'wilderness' for monastic communities seeking solitude, and who were placing themselves in the margins of society in order to escape its profanity. Like the pilgrim, monks (and to more extreme degree ascetics, anchorites and hermits) were imposing an exiled status on themselves within these marginal landscapes. The 1065 cartulary of Sainte-Foy of Conques records that a cell of monks had settled where 'there was no human habitation except for the brigands in the forests'; as far as ecclesiastical institutions were concerned the forest represented the desert (Le Goff, 1988, 54). Woodlands could however be 'tamed' by human enclosure, and in some cases formed into 'hunting forests' which seek to allow nature to flourish in a controlled manner and specifically for the enjoyment of high status society, or made use of as sources of timber (Cummins, 2002, 33 -56). It is important to note however that encountering true 'wildwood' (i.e. primeval woodland) would be rare in Medieval Britain, as nearly all the wooded environments of Britain had by this point been altered since the Mesolithic, however this may not have altered its perception of being 'wild' in character (Rackham, 2002,14). This dualistic view of the landscape represents the product of a mixed heritage of Eastern and Classical Western literature which created the Western Medieval Christian identity, and were united through the concept that, that wherever possible, truly unpopulated and 'wild' landscapes should be made useful in terms of crops, livestock and industry, and be tamed through Christian presence (Fumagilli, 1994, 14).

Other elements of the natural environment are linked in scripture with spiritual experiences in the biblical landscape. Water was associated with regeneration and healing, and rivers act as natural boundaries across which a transition from one area to another (geographically and spiritually) can be made. Trees were linked with the Cross, and the mountains and fissures of Israel had been created 'by God's own hand', representing God's intimate involvement with the formation of the world - the tectonic processes not being known to the contemporary laity. These motifs would have echoed down to the laity through sermons, as 'neither the concept of a hallowed place nor the assumption that nature was responsive to human conduct was alien to biblical thought.' (Walsham, 2011, 39) This may also have affected the manner in which the laity experienced the landscape on a daily basis, many of which were occupied in primarily agricultural work that put them in consistent contact with the local environment, thus allowing them to develop a perceived 'relationship' with the landscapes they encountered.

Whilst not occupying a central position within this thesis, phenomenology and its theoretical underpinnings do contribute to the interdisciplinary approach developed within my research. Consequently I will briefly outline how this field has the potential to add a deeper layer of understanding to the pilgrim journey, aspects of liminality and monument interaction within the Medieval landscape, and discuss key elements of current phenomenological scholarship. As 
mentioned by Corcos (2001), whilst traditionally applied to prehistoric landscapes, phenomenology has begun tentatively to be addressed in regard to the Medieval environment, and has the added advantage of being used in conjunction with both Medieval archaeological and historical data sources (many of which are unavailable to the prehistorian) in order to complement interpretative analysis. The modern notion of landscape 'rejects the spatial science of the 1960's, opting instead to concentrate on culture and social relations, power and politics, identity and experience', and thus the appreciation of a landscape must include the realisation that 'it' has the potential to fulfil multiple and simultaneous meanings to different individuals, meanings which at times overlap and/or exist in polarity (Thomas, 2012, 168). Ingold asserts that the landscape is just as much a part of us as we are part of it (Ingold, 1993, 156), and this raises an interesting point in the application of this suggestion to a culturally Christian landscape; with a monotheistic God as both responsible for the creation of these environments and omnipresent within them, can we assert that the Medieval laity truly felt this 'oneness' with the environment, or were they (through the rejection of 'earthly' aspects, especially under the guise of 'exile' taken on by pilgrims) eager to differentiate themselves from it? Certainly a familiarity with a landscape would engender a rooted sensation with an area's topography, yet religious ideology may have encouraged the laity to concentrate in their hearts on heavenly landscapes. Sadly this is an area of inquiry which cannot be solved. However what is clear is that whilst through modern cartography we are used to travelling over landscapes, for millennia travellers have moved through the various environments of the planet, using monuments and natural features as reference points for orientation. Phenomenological theory asserts that it is therefore essential to recognise the importance of being within a landscape not as an observer but an active participant in its appreciation through interaction.

Christian scripture details numerous events of sacred significance to the laity, nearly all of which take place within and populate the Holy Land with a litany of human and natural sites that feature within this record. This achieves a temporality which defies chronology and links the past with the present for the visitor through interaction with the sites and their history, mythology or reputation (Ingold, 1993, 157 - 160). Similarly the vast range of miracle sites and Christian monuments spread across the British landscape endowed it with a network of spiritual locales, through which the pilgrim progessed. Human understanding of these landscapes is informed by social, cultural and topographical influences, which combine to form the 'experience' of a landscape mediated through the body (Brück, 2005, 47). Ingold argues against a division of the 'inner' and 'outer' appreciation of one's surroundings, in which information is internalised and then re-built in order to construct a mental impression of one's environment (Ingold, 1007, 28). He instead suggests a cohesive overlap and blending of one's place within the landscape, and also appreciation of spatial non-divisions within these environments (Ingold, 2007, 28). This approach to landscape within a phenomenological framework fits very well with current scholarship of Medieval perceptions of space as being multi-vocal (e.g. sacred and profane) as demonstrated by Hamilton \& Spicer (2005), and with the immersion in environments which are redolent of mythological or supernatural motifs yet remain physically rooted in reality, as described by Le Goff (1988) and discussed earlier in this chapter. 
The difficulty remains, when applying aspects of phenomological investigation to an historical landscape, in whether it is really possible to appreciate the environment with the eyes of the past. Tilley explores the rationale in attempting this manner of analysis concisely in his 2008 paper 'Phenomenological Approaches to Landscape Archaeology', in which he stresses the importance of physically walking landscapes in order to begin to comprehend their qualities and temporality (Tilley, 2008b, 272). Physical limitations of body and landscape (as long as that landscape retains its historic character) are asserted to produce commonalities between past and present experience - 'we and the people of the past share carnal bodies', and these commonalities 'provide an entry point into people's interpretations of that landscape in the past' (Brück, 2005, 54). Study of a landscape is ultimately limited by one's own body (and to a degree I would argue by one's imagination), and whilst Tilley describes a distinction between 'outer' and 'inner' experiences within a landscape, I believe that using such a distinction is more appropriate to prehistoric study. This is because within the Medieval record we possess numerous theological documents which give us greater insight as to potential aspects of landscape which combine immediate outer and more profound inner experiences, such as the symbolism offered by rivers etc., which is detailed above. Most crucially however Tilley argues repeatedly for an appreciation of natural and human features within the landscape, a suggestion which Medieval landscape archaeology (so preoccupied generally with monuments) is beginning to take up, and this is echoed within my thesis (see Chapter 2.4 below). Hamilton \& Whitehouse argue convincingly that, despite phenomenology being open to attack of being contrary to the post-processualist rejection of 'universal experience' through its assumption that we can find commonalities of 'being' within landscapes, monuments were logically located within their environs for sensory effect (visual, audial etc) which possessed universal appeal, and this is an aspect which must be engaged with (Hamilton \& Whitehouse et al., 2006, 34). Using three case study sites lying between the Tavoliere plain and the Gargano Promontory in Puglia, southern Italy, they outline a methodology for phenomenological research which collects and analyses phenomenological data in a methodical and scientific fashion, adding an invaluable layer of interpretation to the Neolithic history of the area. There exists in the phenomological approach an undeniable level of subjective experience from the researcher, however the post-processual temptation to critique its use due to a 'hyper interpretive' nature that ascribes commonality of experience (Flemming, 2006, 270) renders the landscapes of history dead, and is surely alien to the interdisciplinary and inquisitive nature of archaeology. A Ingold states, the environment is 'pregnant with the past' (Ingold, 1993, 153). Better to offer an array of potential interaction points for the historical person within this environment, with which the individual may or may not have engaged with depending on them, than to ignore such aspects entirely. Given that the subject of study in this research is pilgrimage, a process which is innately tied to stretches of movement amidst natural surroundings, the investigation of bodily and personal reactions to the environment is appropriate for inclusion within the study, when coupled with varied archaeological and historical data sets which can frame interpretive phenomenological suggestions.

In the study of travellers' interaction with landscapes, a key aspect of this thesis lies in discerning how the pilgrim experience of these routes differed from that of (e.g.) the merchant or secular wayfarer. Elements from the fields of cognitive psychology (with regard to differing perceptions of landscape) and 'landscape studies' can offer concepts which add to our understanding of this experiential aspect. When examining a religio-cultural phenomenon such as 
pilgrimage which utilises commonly accessible landscapes, route networks, buildings and objects, it is crucial to consider the theme of 'multivocality', the multi-purpose use of and interaction with the environment, building or artefact in question. In the case of pilgrimage, these routes, churches and monuments would have been utilised and perceived differently by the varying social groups who encountered them, be they pilgrims, merchants, wayfarers, peasants or princes. Certain lines of site, panoramas, natural features or built monuments may (for instance) reflect Christian motifs from scripture either physically or allegorically to the pilgrim mind, or the carved shafts of wayside crosses could inspire contemplation for the spiritual traveller (Walsham, 2011, 61).

'Legibility' is another term which will be used in this thesis, and refers here to the manner in which an environment is visible to the traveller. Environments are examined by travellers for a 'cohesive structure', a series of easily mappable or recognisable features (Lynch, 1960). This is so that the journey can be contextualised in terms of distance, direction, topography and landmarks to help the traveller situated himself/herself spatially in the landscape in relation to the journey length. Therefore a legible environment is one where the spatial structure and arrangement is relatively obvious (Lynch, 1960). With regard to the processes involved with monuments both natural and human-made in the landscape (such as elevated topography, or wayside crosses), I will address these on a case by case basis in my study chapters, and the relevant theoretical information is provided within these chapters in relation to the appropriate monument or landmark. When addressing the practise of 'wayfinding' and 'mental mapping' of landscapes, 'landscapes usually act as anchor points for organising other spatial information into a layout', marking stages in a journey or the location and direction of routes taken thereby counting off the miles (Golledge, 1999, 17). These can also form part of a set of instructions passed on orally to the traveller revealing how to move from point A to point B (Golledge, 1999, 17). To someone who intimately knew the land they were travelling across (a feature of 'local' pilgrimage), these monuments or natural landmarks may be bound to recollections relating to personal experiences, or collective 'memories' of the area preserved in folklore in 'association with current use, past social actions or actions of a mythological character' (Tilley, 1994, 24). 


\subsection{Methodology; The Need for a New Approach:}

The far ranging nature of the theories and data sources discussed above necessitates a comprehensive collaboration in order to create a fuller picture of Medieval pilgrimage and its experiential role than previously attempted. One of the first to realise that a broader view must be taken to assess pilgrimage's impact in the landscape was Stopford (1994), who wrote 'However, a massive physical infrastructure was required to enable the pilgrims to get to these shrines, including roads, boats, bridges, hostels, hospitals, cemeteries and defences. Pilgrims also required many goods and services on the way, including food, drink, souvenirs, clothes, shoes and protection. Supplying the needs of such large numbers must have involved access to, and the exploitation of, a huge hinterland.' (Stopford, 1994, 59) Stopford does not provide an actual methodology, mainly suggesting types of archaeological and documentary evidence which could expand our understanding of the pilgrim process. Despite this for many years theoretical approaches have failed to be applied in analyses of historical pilgrimages, and Julie Candy's 2005 paper, part of her 2007 $\mathrm{PhD}$ thesis 'Landscape and Perception: the Medieval Pilgrimage to Santiago de Compostela from an Archaeological Perspective', is one of the first to address the experience of the pilgrim moving through the various environments of this famous route. Corroborating themes are raised in Coleman and Eade's (primarily) anthropological study 'Reframing Pilgrimage' (2004). Candy believes that pilgrimage research projects need to be engaging more in addressing entire landscapes, and using interdisciplinary methods and landscape theory to arrive at a more complete understanding of the pilgrim experience in the Medieval West.

However, Candy's method cannot be described as universally applicable, as it relies on the fact that 'the trajectory followed by Medieval pilgrims should be both well-defined historically, and clearly identifiable today, and....that the route traverses a range of diverse landscape features.' (Candy, 2005, 5) This method is tailored explicitly to the Camino de Compostela de Santiago, huge in scale and topographic variations, and a well preserved and maintained 'camino' which hosts primarily pilgrim traffic. This does not transmit so eloquently to pilgrim activity utilising the multipurpose road network of the British Isles, either not defined by hosting primarily pilgrim traffic, or highly local pilgrimages undertaken across single or dual landscape characters. It is this experience of interaction with the landscape at a cognitive and archaeological level in multi-vocal environments which is the focus of my research, and addressing the 'pilgrim landscape' filled with topographical nuance and symbolism. My method, outlined below, aims to be applicable primarily to localised environments (i.e. cross-county), yet flexible enough in approach and comprehensive enough in terms of varied data sources, to be expanded to larger trans-frontier routes. Through the examination of the archaeological record (categories of evidence are supplied below), documentary evidence (ranging from Medieval sources and Antiquarian texts to the latest scholarship and site reports), topographical data and aspects of iconography in the architectural record, I will provide an interdisciplinary understanding of the pilgrim phenomenon in Britain, its subtlety in the archaeological and topographical record, its potential cultural distinctiveness (in comparison to other countries in Medieval Christendom), and the comparison of 'local' and 'universal' pilgrimage. 
By cataloguing the available dedications for surviving pre-Reformation churches in the counties of my case studies (see Appendix D), and the data processed in the case study chapters, my thesis also presents a record of the predominance of particular saint cults within specific areas, allowing for a greater understanding of the role played by these subjects of pilgrimage in relation to the laity who venerated them.

In order to develop a first-hand understanding of the most visible archaeological record associated with pilgrimage and an awareness for the sensory play between pilgrim and environment, I initially examined a short section of the Camino de Santiago de Compostela, a $60 \mathrm{~km}$ stretch between Roncesvalles and Pamplona. The Camino is a clearly marked and recorded route, on which I trialled my method before engaging with the formal case studies I have chosen in Britain. Both celebrated and conserved, its features are 'loud' in the landscape, with a high frequency of roadside churches, a designated and maintained route, and a large volume of documentary sources. Consequently for a preliminary study designed for familiarisation with the in situ archaeological and documentary record, the Camino is ideal. This exploratory piece of fieldwork has not been listed as an official case study, as it represents both a testing ground for my initial method, an example of how my method evolved from its theoretical inception to a practically applicable recording system used for my four primary case studies. This method was then refined during the first British case study, Ely to Walsingham (Chapter 3 ), which bridged the ground between a highly maintained pilgrimage route and one which now no longer fulfils that role (such as the Roman road linking Salisbury and Winchester, detailed in Chapter 4). The shrine at Walsingham suffered destruction during the Reformation, but together with Canterbury is one of the most celebrated Medieval cult centres in Britain, and so merits inclusion for this reason alone. The subsequent case studies include Salisbury to Winchester (the site of the major saint cult of St Swithun), St Asaph to Holywell in Wales (site of St Winefride's Well and one of the oldest surviving pilgrim centres in Britain), and finally Camelford to Bodmin in Cornwall (the site of St Petroc's cult and principle shrine, which was destroyed during the Reformation). The principle parameters used to select these case studies are:

i. Their geographic dispersal across the landscapes of Britain, which allows investigation into regional variations in pilgrim 'culture' and the differences in interaction with these varied topographical environments.

ii. Their cults being proven centres of pilgrimage in either the archaeological or written record, with the cults representing a range of 'locality', from a universal Marian cult (Our Lady of Walsingham) to a comparatively highly localised cult (St Petroc in Bodmin). This allows my analysis to cover an effective cross section of the saint cult types available to Medieval pilgrims in Britain (and their potential relevance to certain sections of society or occupation). 
iii. Their cults showing as a series a range in scale, from the universally celebrated cult who was popular throughout Christendom with a journey involving several days travel from the origin site (represented by the Marian cult of Walsingham, from Ely), to a highly localised cult whose fame was restricted to its surrounding landscapes (St Petroc of Bodmin from Camelford).

iv. That the distribution of the case studies reflected the range of cultural contexts across Britain, from East Anglia and Wessex to the Cornish and 'Celtic Christian' contexts.

From these various parameters, the chosen pilgrimage sites with their selected points of origin for the journey are listed below and mapped in Figure 12. Each case study (chapters $3-6$ ) provides a detailed analysis of the environments and topographies encountered, and thus these data are not listed here.

1. Walsingham (Our Lady of Walsingham) from Ely

(73 miles)

Walsingham in Norfolk was one of the most popular pilgrim destinations in Britain, receiving visitors from across Christendom, and thus well connected with the route network and documented in the historical and archaeological record. Ely was a major ecclesiastical centre in the nearby fenlands, and a logical stop for those approaching Walsingham from the west. This case study is the largest and most celebrated, representing the 'universal cult' of Mary within Britain with a significant archaeological, historical and material culture record, and is described in Chapter 3.

\section{Winchester (St Swithun) from Salisbury (22 miles)}

Winchester's cathedral in Hampshire was home to the well recorded cult of St Swithun, and as a settlement a powerful and influential centre of administration and commerce in the south east. As a site with Roman origins, it was linked via a significant Roman road to Salisbury, which was a significant market town (with its own saint cult of St Osmund), and gateway for those moving towards Canterbury via Winchester from the West Country. This case study represents the nonuniversal but still broadly popular cult that attracted a large scale following, and was linked via the road network to a larger still cult, that of Thomas Becket in Canterbury.

\section{Holywell (St Winifred) from St Asaph (14 miles)}

Holywell in Flintshire is one of the oldest sites of pilgrimage in Britain, and the only one to see contiuous use across and beyond the Reformation to the present day. With a written historical record of royal visitors and benefactors and connection to nearby Basingwerk Abbey, it was included in Gerald of Wales' $12^{\text {th }}$ century itinerary which led Archbishop Baldwin to its waters (the well of St Winefride) via St Asaph in neighboring Denbighshire. This case study presents what has been termed 'Celtic Christian' context of Britain, explored in detail in Chapter 5. 
The last and most localised pilgrim experience, Bodmin Priory hosted the cult of St Petroc, whose appeal was broadly limited to Cornwall and neighboring Devon. The town is linked to the small market village of Camelford 14 miles to the north by the river Camel and its valley, with networks of small agricultural tracks. This case study presents a uniquely Cornish landscape identity with the presence of nearby Bodmin Moor and the intensely local saint dedications of the parish churches encountered en route. With a presence in the scholarly record which is incomplete, it is an ideal choice for the final case study as it allows my methodology to be tested to the utmost on an archaeological and historical record which has not been fully exploited, this being done in Chapter 6 .

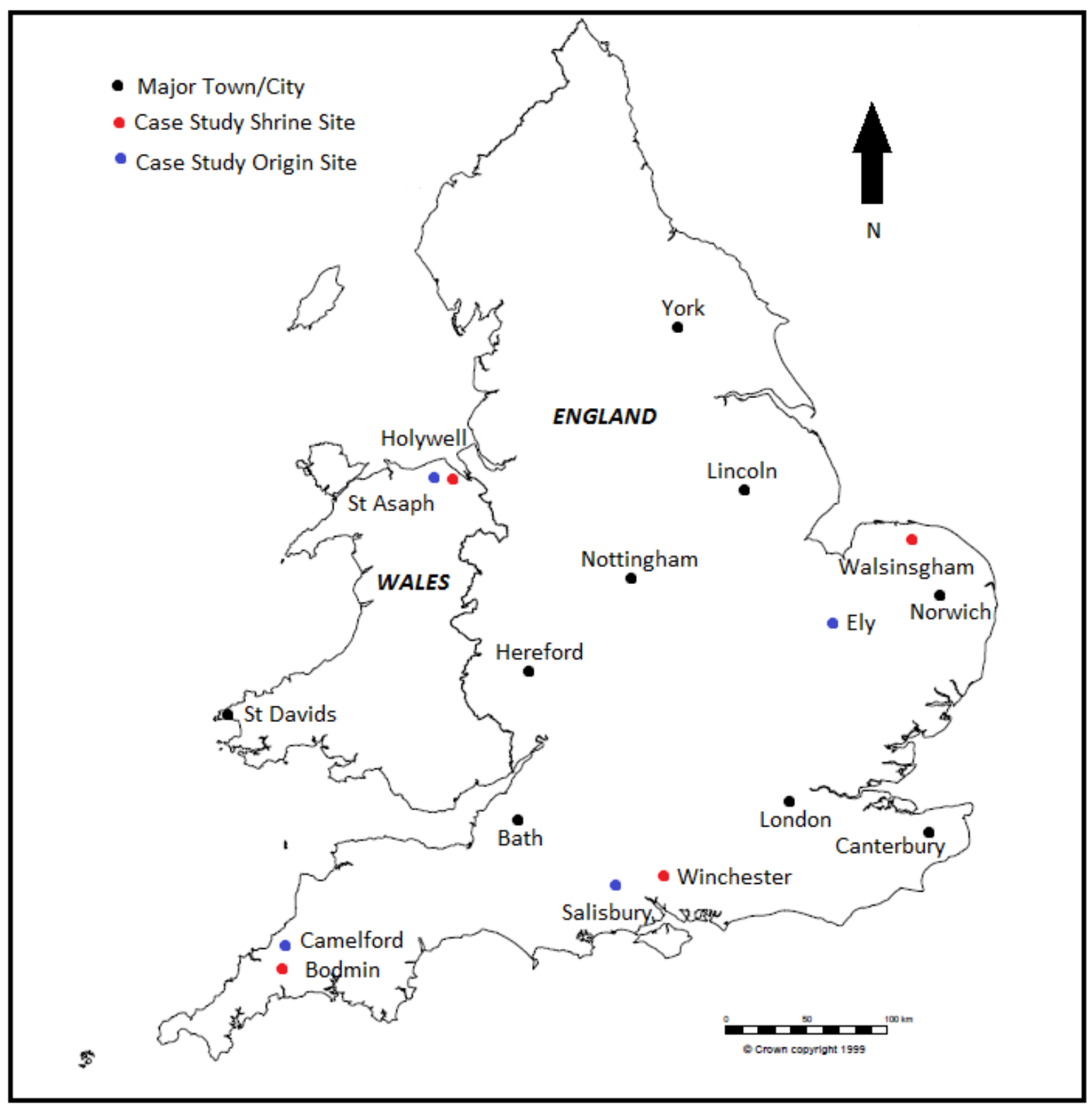

Figure 12. Map displaying the case study sites in relation to the major towns/cities of Medieval England and Wales. Redrawn after the map of Norfolk parishes published by the Norfolk Record Office. 
As has been stated in Chapter 1, Medieval pilgrimage was not typically a formalised affair. Some pilgrim sites did have specific routes which were developed to enhance the spiritual aspect of the journey - often passing sites which related to the life of a saint or martyr. However, the vast majority of pilgrim travel would have taken place on roads and tracks used by a variety of travellers and were not exclusive to pilgrim activity. As mentioned previously in this chapter, appreciating multivocality is essential to forming an approach for addressing the mechanics of pilgrim travel. The Medieval road network contained a range of Roman roads (e.g. the Fosse Way), pre-Roman trackways spanning great lengths of the country (e.g. the Icknield Way) and Medieval drover roads and trading roads. Evidence of this road network has been gathered from the examination of royal itineraries, cartographic evidence, and the works of Stenton and Hindle (Stenton 1936; Hindle 1976). It is suggested by Stenton that many modern roads broadly follow their Roman forebears, thus it is not unreasonable to suggest that medieval routes did the same, as there would be little foreseeable advantage in not utilising the existing Roman road network. This view is corroborated by Diana Webb, who writes that 'pilgrims were most likely to follow roads which were - literally - viable for broader economic reasons, rather than to create roads, which existed for no other purpose.' (Webb, 2000, 219)

For each site of pilgrimage analysed within the case studies, there must be a corresponding stipulated point of origin, in order for the journey to be assessed in terms of archaeological remnants, available route networks and interactions with the landscapes encountered. Where there is no recorded prescribed route for pilgrims to follow in the archaeological or historical record, I have chosen the nearest ecclesiastical centre, or the nearest market town mentioned in the 'Gazetteer of Markets and Fairs in England and Wales to 1516' (Letters, 2005), as the Medieval route network typically afforded a high level of access to and from these commercial sites. These 'origin sites' have been chosen primarily either for their mention and position along an established route used by (amongst others) pilgrims to the cult centre, and the integrity of the surviving Medieval landscape is also considered. If this information is not available in the historical or archaeological record, then their accessibility to the pilgrim site via the Medieval route network in general is taken into account (as in the case of Camelford to Bodmin, in Cornwall). The evidence which has led to the choosing of the specific origin site in relation to the individual cult centre is provided in detail in each case study chapter. By designating a point of origin, this makes each route a finite entity and therefore makes the case study a manageable subject for analysis within the context (and limitations of space) of this thesis. These pilgrimage sites themselves are recorded in text sources as pilgrim centres (again these are examined in depth in the case study chapters below), and so their credentials as sites which would have attracted visitors from nearby settlements are strong.

My fieldwork involved travelling between the point of origin and the pilgrim site utilising the surviving Medieval transport network of Roman roads, trackways and trade roads, recording landscape features and archaeological evidence relating to pilgrimage. To clarify this approach, I 
have compiled a catalogue of the key topographical and monumental features which a pilgrim may have encountered on the way which is reproduced below. The natural features have been selected on the basis of of their relevance to the pilgrim, as explored earlier in this chapter, as a degree of selection is necessary to avoid the data sets becoming bloated and unmanageable. The majority of these are not designed specifically for pilgrim interaction, however the theme of multivocality again demands they be addressed within the pilgrim perspective, in order to answer my third research aim: 'To differentiate between the pilgrims' experience and interaction with the landscape with that of 'secular/commercial travellers' '. The environmental features are particularly crucial to my fieldwork, as it is on these features that I shall build theories of sensory and cognitive interaction and experience between the pilgrims and the landscape through which they travelled.

Conspicuously, Canterbury has not been selected as a case study. The reasons for not including this most famous of British pilgrim centres are linked mainly to the current state of the route between London and Canterbury. Urban sprawl has covered what is now Greater London and much of Kent with commuter towns. Watling Street which traditionally was one of the four principal 'king's roads' in Medieval England and linked London to Canterbury, has evolved into a linked series of $A$ roads and motorways stretching between brown-belt commuter towns, which include the traditional stopping points of Dartford, Rochester and Ospringe. This renders travel by foot along them both dangerous and futile (and illegal in the case of the motorway). The volume of traffic, noise pollution and aggressive clearance of the landscape has destroyed any meaningful way to engage with the landscape in a manner which might reveal more about the pilgrim experience. Canterbury itself does preserve a great deal of its Medieval fabric, however there is already a large body of scholarship on this city and its pilgrim element, either wholly or utilising it as a case study (e.g. Saunders, 2001; Holloway, 1992; Morris et al, 2002), and my thesis concentrates primarily on the non-urban journeying aspect of pilgrimage. It is for these reasons that I have excluded a case study which focuses explicitly on Canterbury and its cult of St Thomas Becket.

My fieldwork was conducted through walking from the origin settlement to the pilgrimage centre, using either a prescribed route which has its origins in Medieval use for this purpose, or using a road network which would have been contemporary with Medieval pilgrims as described above. Between the origin site and the pilgrimage site the various features outlined below were recorded. In terms of features which are not strictly 'en route' but aside from it (e.g. a chapel in a nearby village bearing relics), their inclusion and recording will be decided on a case by case basis, as whilst a pilgrim may deviate across fen and field to reach a particularly sacred site this would most likely be the exception rather than rule. Otherwise this practise would add significantly to each journey. Whilst walking the routes I recorded the natural and built features described below on a standardised set of data sheets used for all four case studies (digitised versions of which are supplied in their entirety in Appendix C). The mental and cognitive aspects (outlined below) were recorded through the same method, noting what can be seen, how clearly, zones of extraordinary interaction 
between pilgrim and environment, concepts of liminality and spatial arrangements. The data gathered during each piece of fieldwork is presented in the relevant case study chapter and appendices via distribution maps, tables, charts, and map-based representations of sensory interaction (i.e. sight lines, radius' of view, zones of transition) all of which are accompanied by photographs where appropriate.

With reference to the manner in which these map-based representations of sensory interaction are presented in this thesis, some qualification on my choice to use a more informal presentation via Google Earth (C) and Adobe Photoshop CS6 (C) is necessary. In order not to allow the image to overshadow the textual accompaniment and explanation, whose form is designed as a narrative to give the reader a sense of the journeying process, the avoidance of using GIS software was purposefully undertaken. The illustrations of radiuses of sight, for example, are utilised for impressionist purposes, corresponding to the descriptive passages provided in the accompanying text. I believe that in some cases, this being one, GIS can detract from the narrative and lend a potentially overly scientific gloss to a description of potential interaction points along the journey. It is for these reasons that I have chosen to use more informal illustrative software, in order to highlight the speculative (yet thoroughly researched) narrative text which forms the bulk of each case study's 'Sensory Interaction' penultimate section. As Brück writes, 'the detached and analytical character of GIS runs counter to the spirit of phenomenological approaches', and whilst I would not label this thesis a phenomenological one, it is within the penultimate sensory section of each case study where this field of inquiry is most prominent, and the use of more impressionist data displays are I believe appropriate to these sections (Brück, 2005, 54).

Below are listed the physical landscape elements which were considered when choosing and performing fieldwork on my four case studies, and references to key works which informed my methodological and theoretical approach to each category:

\section{i. Distance and Orientation}

The length of the journey is fundamental to how it is experienced, with aspects such as pace, frequency of overnight stops and seasonality all playing roles in the manner in which the pilgrim interacted with the landscape on both a physical and sensory level. Ohler's examination of the physical nature of travel in Medieval Europe (1989) provides an excellent basis for these investigations.

\section{ii. Place names}

The etymology of topographical features and settlements can reveal information about the presence of pilgrimage or local saint preferences (e.g. 'St James' wood' may indicate 
a tradition of religious folklore attributed to the saint or a pilgrim presence in the forest). The work by Margaret Gelling (1984) offers an effective reference point for engaging with etymological studies.

\section{iii. Topographical features}

The topography of the route plays a role in both enlivening and debilitating the pilgrim. Fatigue is not the only aspect considered in relation to topography, as the concept of legibility (discussed above) is also intricately linked to aspects of elevation and tree cover (as is shelter and exposure). Notable features in the landscape such as steep rises, viewpoints, bodies of woodland along the route and other such sites are recorded during the fieldwork. As stated above, Golledge's work is highly influential in this field (1999; 2003).

\section{iv. Historical changes within the landscape}

Linked to factor iii above, to avoid making erroneous statements about a Medieval landscape which may have differed substantially from its modern counterpart, the changes in its de/re-forestation, draining, agricultural make-up and enclosure are also considered. The work of countryside historians Rackham $(1986 ; 1996)$ and Darby (1962; 1967; 1974), particularly their work in conjunction with the Domesday records, are of primary use in this context.

\section{v. Roads and Tracks}

One of the prime factors to consider when selecting a pilgrim site for study, developing a method for and subsequently undertaking the fieldwork is that of its links with the Medieval road network, and that of the county in general. The process of selecting the routes by which my fieldwork was performed involved multiple varied sources. The $1^{\text {st }}$ edition Ordnance Survey maps from the early $19^{\text {th }}$ century were invaluable in revealing droving roads and other routes which now, thanks to being discarded or tarmaced, have lost their original character and so would not now reveal their role within a Medieval route network. The royal itineraries of travelling kings, such as Edward I and Edward II, are also strong sources of information for the general road network of Medieval England (Gough, 1900; Safford, 1974). Numerous other sources which provide detailed information for each of the four studies are presented in their corresponding chapter. 
Of equal importance to the natural monuments and environments encountered during pilgrimage were those constructions which reflected the power and permanence of Christianity within the landscape. The categories which were recorded during fieldwork are listed below:

vi. Churches, cathedrals and chapels:

These houses of worship were centres of communion with God, Jesus and the saints, and as such commanded both respect and power within their local parish landscape, and in the case of cathedrals over far larger territories. There is not the space to analyse the role of the church building for the Medieval laity, and there exists a body of work on this from the parish perspective (French, 2000). As such, the specific role of each recorded site within the fieldwork is explained in detail within the individual case study chapters.

vii. Free-Standing Crosses:

Crosses located outside of a churchyard or settlement performed multiple functions as way-markers, monuments to a particular site or religious event (real or mythical), preaching posts or as boundary markers in the landscape. Their placing within the landscape is also significant as to their visual impact, and interpretive suggestions for these monuments are found in Turner (2006a; 2006b) and Orme (2007b).

viii. Religious Houses

Up until the Reformation the British landscape was rich in priories, abbeys, monasteries and friaries, and these were frequent features of the visible landscape. Offering spiritual sanctuary, refuge, and contact with the divine (through prayer, blessings and notably relics), they would have been a fundamental part of the pilgrim's experience as sites in their own right and also landmarks within both the rural and urban context. As stated above the catalogue by Knowles and Hadcock (1953) is a primary reference for locating and examining these sites and their denomination, dependencies, wealth, and accommodation possibilities.

ix. Inns

Predominantly found in the urban context, inns form a small subset of recorded sites in my fieldwork, due to their role in offering accommodation to those pilgrims who could not or would not rely on the charity of hospitals. Their names (wherever possible traced back to the original Medieval form) in some cases reflect links to the pilgrim trade. Literature is sparse on this subject, however local records for guilds can provide some information (Haskins, 1912). 


\section{x. Holy Wells}

Holy wells (and occasionally springs) frequently featured in folklore which attributes them a miraculous origin, and as such some of these were reputed as curative wells. Functioning in some instances as sites of pilgrimage in their own right, they an important category of localised sacral sites in the south-west of Britain which were often linked to a parish church or chapel (Rattue, 1995).

The final category of data relate to the diverse opportunities for visual and mental interaction between the pilgrim and both specific sites and the surrounding environment in general.

\section{xi. Sight lines}

Linked primarily with aspects of elevation, certain monuments connected either geographically or religiously with the route become visible at distinct points during the journey from the origin site to the pilgrimage site. Again, utilising work by Golledge (1999; 2003), Hamilton and Spicer (2005) and Jones (2007) amongst others, it is possible to offer interpretations of the impact that the sight of (e.g.) church towers or free standing crosses had upon a traveller whose primary goal was spiritual.

xii. Folklore

Mostly applicable to those pilgrims who had an intimate knowledge of the environment they were traversing, the presence of both sites and events within the landscape associated with miraculous events, malign spirits (such as barrows (Semple, 1998)), or locally known tales may have coloured certain sections of the journey. This in turn would have created a parallel level of interaction with the landscape, not just as a topographically difficult terrain but supernaturally dangerous, one an example of which is provided in the initial Spanish stage of the Camino de Compostella de Santiago by the Bosque de Sorginaritzaga ('Wood of the Witches') outside of Roncesvalles. Here, local folklore maintains that local witch covens met up until the $17^{\text {th }}$ century. With regard to British folklore, works by Alexander (2005), Monger (1997) and Wilson (1985) are of particular relevance.

xiii. Liminal zones and Audible zones

Finally, as has been discussed above, whilst making allowances for the subjective nature of these interactions certain environments provide greater potential for transition and liminal experience, such as territory boundaries, the crossing of natural features from one environment type to another, and approaches to settlements or monuments. These 
instances are recorded and addressed in the penultimate section of each case study, represented through map-based and photographic methods. Other transitions which are briefly considered in specific cases are the changes in audible environments, such as the movement from the predominantly rural and natural sounds encountered in the rural context, and the encroachment of urban and human-made noise encountered when approaching settlements.

By combining these diverse data sets and sources, both primary and secondary, I aim to bring a new methodology to the field of pilgrimage studies. It considers a broader collection of influences which dictated the manner in which the laity encountered pilgrimage as a journey in both a practical and psychological sense, and the manner in which the landscape became sculpted in their own minds by reflecting religious motifs such as 'wilderness', the locus amoenus, and the recurrent motif of pilgrimage representing a lifelong pursuit of becoming closer to God. The rich variety in local and universal saint cult lore attributed to certain sites encountered en route offers an insight as to the highly localised aspect of some pilgrimages, as do my analyses of the distribution and frequency of saint dedications in the counties relevant to my case studies.

The multivocal nature of many of these sites or categories means that they come to mean most when considered in relation to each other and the route network, not as individual sites examined in isolation. It is this isolationist approach which has been used frequently with regard to the eventual shrine site, and which has divorced the travelling aspect of pilgrimage from discussion. An interdisciplinary method which utilises diverse source material (primary, secondary and that recorded from direct personal experience) must consider all these elements in relation to the grander 'whole' of the journey and the religio-cultural context in which they are placed; in this case the theology and ideology of the Medieval Christian West. Thus the methodology forms a 'core' data set which investigates a diverse variety of monuments, natural features, written and archaeological records. Around these data we can apply knowledge related to the cultural context in which the pilgrimage takes place, subtly modifying the categories as necessary to include specific elements unique to that environment, whilst leaving their essential range and diversity intact. This will then be a methodology that can truly be called interdisciplinary and capable of intergrating the practical and sensory narrative of pilgrimage not only in the Medieval Christian West, but potentially elsewhere. It remains flexible enough with a broad scope of data sources to allow for ommissions of certain categories where they are not represented in the landscape. 


\section{Chapter 3: Ely to Walsingham}

\subsection{Introduction to the case study}

In this study I will be examining the archaeological, documentary and travel evidence for pilgrimage between the Isle of Ely (eastern Cambridgeshire) and the Marian cult centre of Our Lady of Walsingham (northern Norfolk). Firstly I will provide a brief overview of the physical, ecclesiastical and economic landscape in Medieval Norfolk from which the road networks serving trade and communications around the county can begin to be put into a context of agricultural growth in a favoured region for founding religious houses. The road network which facilitated this growth and expansion, as well as the movement of pilgrims around the county, in particular between Ely and Walsingham, will be discussed and analysed in the second section, in order to place pilgrimage within the pre-existing travel infrastructure of Medieval Norfolk. I will then discuss the origins and development of the cult, including the built environment which the pilgrim would have encountered at the height of the cult's fame prior to the Reformation. Following this will be a presentation of the archaeological evidence recorded by my fieldwork in this area, dedications, road names and track origins for the route used, and analyses of the data sets including material culture left behind by pilgrim activity in the form of pilgrim badges and ampullae. The penultimate section will deal with the sensory narrative of the journey, and the interaction between the pilgrim and the landscape including appropriate theological aspects behind the act of pilgrimage and potential areas of liminality, sight lines and the mental engagement of entering Walsingham with regard to these issues. A summarising section will complete the case study, offering conclusions drawn from the analyses and addressing the holistic study of the journeying experience for a Medieval pilgrim in Norfolk. 


\subsection{The Landscape of Medieval Norfolk: Environmental, Economic and Ecclesiastical}

\section{Environmental:}

In essence the Medieval topography of Norfolk was broadly similar to that of today. Prior to the industrial drainage of the fens during the 18th and 19th centuries (reclaimed for agriculture), the fens had covered the majority of the coastal lands surrounding the Wash, and extended inland, resulting in a network of dikes, causeways and bridges which spanned the areas of Lincolnshire, Norfolk, Suffolk and Cambridgeshire. The chalk based 'Uplands' in this Medieval landscape formed a boundary stretching through Lincoln, Peterborough, Huntingdon, Cambridge, Brandon and Kings Lynn (Darby, 1974, 5). However 'Uplands' is a relative term; Norfolk is and was generally flat, with little in the way of gradient or incline. The fenlands were traversable using a series of causeways and bridges, but a traveller could still stray into the marshes and have difficulty in rejoining the path. A

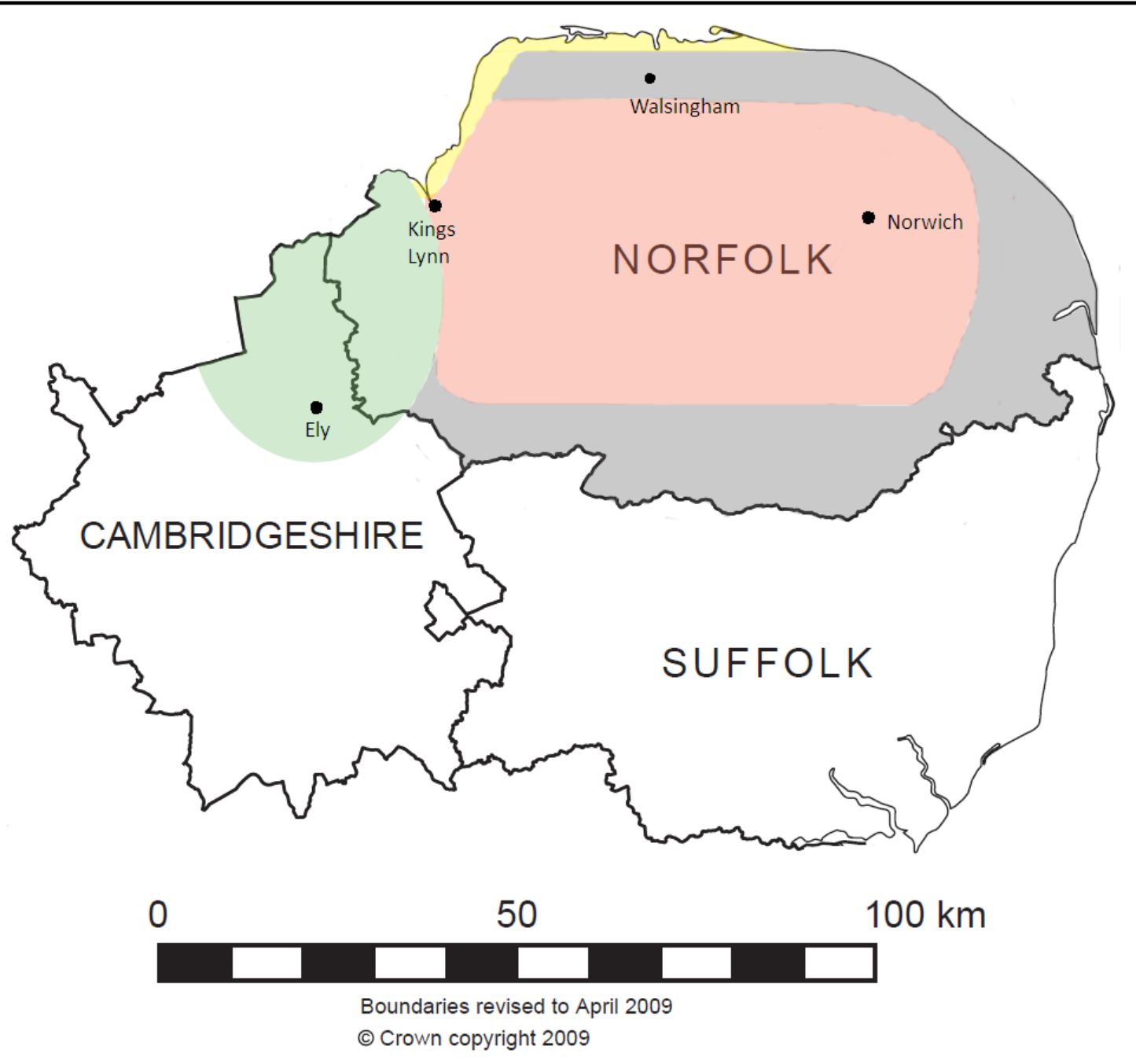

Figure 13. Map of the basic landscape character of Norfolk, with the extent of the Medieval fenland (green), the coastal sands (yellow), uplands (pink) and the lowlands (grey). Redrawn from the Ordnance Survey GB Coastline and Administrative Boundaries Map. 
tradition of folklore arose, revolving around the 'Black Shuck'; a 'devil hound' whose first appearance was recorded around the time of the first Viking invasions (Westwood and Simpson, $2005,500)$. Within the fens were small 'islands' which became favoured settling places being both dry and prominent in the landscape - Ely is a prime example (Darby, 1974, 18). The majority of land outside the fens was used for agriculture. The Domesday Survey provides some information as to the presence of woodland in the county, though much seems to have been ploughed out (WadeMartins, 1994, 46). South Norfolk is recorded as having a sizeable portion of woodland, however the other northern, eastern and western areas appear to be relatively treeless through Medieval forest clearance for more fields. Deer Parks are evident though, primarily in the middle vertical strip of the county, which may indicate the presence of preserved or enclosed forest (Wade-Martins, 1994, 48).

\section{Economic:}

Prior to the Norman Conquest, Norfolk possessed only three boroughs - recorded in the Domesday Survey as Norwich, Thetford and Yarmouth. However, the coronation of William the Conqueror marked the turning point for Norfolk's fortunes, and swiftly churches, religious houses and market towns began to be developed under Norman rule. The gradual expansion of population and economy which was generally seen across England reached its peak around 1300, and consequently 'The premium which this placed upon agricultural land in general, and arable land in particular, was considerable, and nowhere more so than in the closely settled and intensively exploited countryside of Norfolk.' (Wade-Martins, 1994, 48). Due to this comparatively intense agricultural activity, the spatial arrangement and relationship between settlements in Norfolk differed from the Medieval norm. The majority of English peasantry by the $\mathrm{C} 13^{\text {th }}$ lived in a fairly standard form of nucleated villages, farming open fields of regular form. However, in East Anglia there was a greater variety of agrarian arrangements which reflected the varied landscapes of the region (Williamson, 2005, 11). The structure and administration of lordship was unusually complex, and 'one source of the region's socio-economic distinctiveness and dynamism of specific localities within it', resulting in dense and sometimes tangled manorial dependencies encapsulated in a $14^{\text {th }}$ century manuscript called the 'Nomina Villarum' which lists the all the townships in each hundred and their lords (Wade-Martins, 1994, 52). Records indicate that at its peak, Norfolk had around 140 Medieval markets, the highest density in Britain, approximately one market per every five or six parishes (Wade-Martins, 1994, 76). This gives some sense of the scale of trade and economic activity in Norfolk, and the micronetwork of tracks and drover trails leading from village or hamlet to the parish market, though 'informal' compared to long distance roads such as the Peddar's Way or the Great Road (described below), may have been an option for a pilgrim with local geographical knowledge when travelling to a shrine in the area.

The demand for fine English wool by European merchants and weavers was crucial in the economy of Norfolk. Records from the 'Little Domesday' (the Domesday volume which covers Norfolk, Suffolk and Essex) indicate that between the four Eastern Counties (Norfolk, Suffolk, Essex and Cambridgeshire), and the four Western counties (Cornwall, Devon, Somerset and Dorset) and 
the Abbey at Ely, some 292,000 sheep were present, giving some idea of the portion of fleeces sheared and sent to various markets and ports around East Anglia (Power, 1941, 21). The Domesday Survey proper records Ely Abbey as having some 13,400 sheep on its estates spread among six counties, which demonstrates not just the ecclesiastical position but also the level of economic power held by Ely (Power, 1941, 21). Ports such as Kings Lynn and Great Yarmouth were crucial in exporting primarily cloth, wool and corn to the European mainland, and merchants would have been a common sight on the roads around the county. Medieval Norfolk was a key region in England's economic activity, and with many religious houses of varying orders and functions it's ecclesiastical profile was also high. In order to facilitate trade, agriculture, communications and the general infrastructure which kept Medieval Norfolk profitable, an adequate road network linking ports, market towns, monasteries and villages was fundamentally necessary. It was this road network which allowed pilgrims to visit shrines and miracle sites across the region, and is examined in detail below.

\section{Ecclesiastical:}

According to construction records, Medieval Norfolk boasted 921 parish churches by the beginning of the $16^{\text {th }}$ century, a figure which exceeds by quite some distance the number possessed by other counties at the time (Wade-Martins, 1994, 60). However, Norfolk and the bordering fenlands of Lincolnshire, Suffolk and Cambridgeshire contained a number of religious houses which formed ecclesiastical power bases and promoted saint cults for pilgrimage. Over seventy monasteries, priories, friaries, hospitals and abbeys are recorded in Knowles and Hadock's catalogue of religious houses, and eleven of those hospitals were explicitly founded to care for poor travellers and pilgrims (Knowles and Hadcock, 1953). Of these the most famous included the cathedral and priory at Norwich, and the Augustinian priory of Our Lady of Walsingham. This saint cult was only eclipsed by Canterbury in terms of pilgrim importance in Medieval Britain, and was sparked by a vision in 1061. The Virgin Mary allegedly appeared to the wealthy widow Richelde de Faverches, instructing her to build a wooden replica of her Annunciation house (Adair, 1978, 114). This was initially housed in a small stone church which subsequently became a shrine for the laity, and her son's chaplain Edwy founded the first religious house there that grew into the Augustinian Priory - the remains of which are still visible in Walsingham in the form of a free-standing arched window (Adair, 1978, 114). The shrine attracted devotees from far and wide and serves as the goal site for this case study. However Walsingham was not the only ecclesiastical powerbase in the county; Benedictine foundations included most notably the abbey of St Benet at Holme in the Norfolk broads. Cluniac orders also prospered in Norfolk, with foundations including Castle Acre and the celebrated Bromholm Priory which became a site of pilgrimage as it housed a crucifix fashioned from pieces of the 'True Cross' (Page, 1906, 315). Other celebrated ecclesiastical sites (and pilgrim destinations) in the area were the aforementioned Norwich cathedral (St Julian and St William), Crowland Abbey (St Guthlac), Ipswich (with a Marian shrine to Our Lady of Grace), and Bury St Edmunds (St Edmund), all of which received handsome donations from royal patrons and peasants alike (Darby, 1974, 31). 
The Isle of Ely lies in the fenlands of eastern Cambridgeshire, and for the purpose of my research serves as the starting point for the hypothetical pilgrim. Ely was an ecclesiastical powerbase in the fens for the Benedictine order, and according to surveys of Medieval Ely the town was still relatively rural during the mid-13 $3^{\text {th }}$ century - however by the survey of 1416 the settlement was broadly similar to the town as it is today. The site was founded as a small monastic community by St Ethelreda in $673 \mathrm{AD}$, reputably a mile north of the 'lost' Anglo-Saxon village of Cratendune (Page, $1906,183)$. The monastery was looted and destroyed by raiding Danish forces in $870 A D$, and the site was left empty for a hundred years before two bishops (St Dunstan and St Ethelwold) refounded the Abbey in the $10^{\text {th }}$ century, shaping the building into a cathedral by the late $11^{\text {th }}$ century. The abbey and subsequent cathedral hosted the cult of their founder St Ethelreda, whose fame drew an average annual turnover of $£ 40$ at her altar, compared to just $£ 25$ taken at the High Altar (D.J Stewart, 1868, 130). During the Medieval period, acquiring relics was an essential part in establishing the fame and reputation of a religious house, and at Ely cathedral the monks certainly pursued this aim with dogged tenacity and in at least one case, dubious tactics- 'The bodies of the sainted abbesses Etheldreda, Sexburg, and Ermenild were soon joined by that of Etheldreda's sister St. Withburg, which the monks, by a combination of trickery and force, stole from Dereham, where she was buried.' (Salzman, 1948, 202) This relic enhanced the status of both the cathedral and the whole settlement, marking it as a place worthy of pilgrimage and donations. 


\subsection{The Road Network of Medieval Norfolk}

'Traffic included merchandise carried both on horseback and by cart as well as various officials, both secular and ecclesiastical, pilgrims, justices and tax collectors; medieval men often travelled beyond their village or town and mobility increased throughout the period.' (Hindle, 1982, 193)

\section{Norfolk in General:}

The Medieval road network encompassed Roman roads (e.g. the Fosse Way), pre-Roman trackways across the country (e.g. the Icknield Way), medieval drover roads and trading roads. As stated previously, evidence of this network has been gathered from the examination of royal itineraries, cartographic evidence, and the works of Sir Frank Stenton and Brian Hindle (Stenton 1936, Hindle 1976). Hindle goes as far as saying that 'there was virtually no road building in the Medieval period', which would suggest an even heavier reliance on habit-formed tracks and the basic layout of the pre-existing road network (Hindle, 1976, 208). The Gough Map drawn up roughly in 1360 displays 2,940 miles of roads which span the length and breadth of England, $40 \%$ of which follow the line of earlier Roman roads (Hindle, 1982, 196). As previously mentioned Norfolk's economic and agricultural status would have necessitated a relatively comprehensive and well maintained road network, facilitating travel by merchants, tradesmen and drovers for business in market towns and ports as well as pilgrims to saint cult centres such as Walsingham. As well as roads and tracks, bridges and raised walkways were required to cross the fenlands which comprised the Wash linking settlements for travellers and locals alike. The steady growth in the fortunes and population of $14^{\text {th }}$ century Norfolk sustained the need for trackways and paths at local level to allow movements between village, town and city, as well as to and from the growing number of religious houses founded in the region.

Fenlands are often thought of as immutable and impassable obstacles, and the Medieval fens of East Anglia are often portrayed as 'untraversable by unaided man' (Belloc, 1924, 14). However, the fens served as commercial avenues which spanned the length of the region, and were passable via bridges and causeways: 'a few new roads were built - perhaps most notable were the causeways built across the fenlands' (Hindle, 1982, 195). Ely, the largest of the fen isles, was often described by visiting chroniclers such as Thomas of Ely and Richard of Devizes as inaccessible in the main part, however there were three points at which the fens narrowed sufficiently for causeways to be established; the eastern and western ends of the southern approach, and the eastern approach which provided access to Stuntney and then Soham (Darby, 1974, 107). These causeways allowed the monks to access their grange at Stuntney, and also to maintain communications and relations with the world outside (Darby, 1974, 109). However, as with all public highways, maintenance was a constant issue. If the causeways, bridges and tracks which spanned the fens were not maintained they became unusable, effectively cutting off access. The Hundred Rolls for Cambridgeshire reveal a bishop of Ely during the $13^{\text {th }}$ century left the bridge and causeway in a state of disrepair for sixteen years, establishing a ferry service for which he charged a toll until the locals complained to parliament - the resulting inquiry forced the bishop to make the necessary repairs 
(Darby, 1974, 111). The responsibility of maintaining these causeways and bridges was a constant source of friction between parishes, but generally they were kept up, allowing travel and trade around the fenland communities - both secular and monastic. Thus the five major religious houses in the fenlands (Ely Cathedral Priory, Thorney Abbey, Crowland Abbey, Ramsey Abbey and Peterborough Abbey) were all accessible for visitors and pilgrims either travelling from or through the marshes, and 'despite their many deficiencies and their frequent lack of repair, these causeways often did provide, both for merchants and for pilgrims, a dry, as well as a safe, crossing over many a difficult stretch of country' (Darby, 1974, 118).

The distribution of Roman roads in East Anglia shows there was an existing network of roads connecting the major settlements within Norfolk and also a series of roads, which led from London, Colchester, Cambridge and further afield, into the county via recognisable routes such as the Icknield Way and the 'Great Road' (both leading through London). Whilst not all of these would have survived into the Medieval period, falling into disuse along with settlements, or through poor maintenance, the larger roads were still in use at the time of the Reformation (Margary, 1967, 245). An example of the continuity of Roman roads into the Medieval period in East Anglia is the 'Peddars Way', connecting Holme Next Sea (located on the northern Norfolk coast) down to Knettishell Heath (Suffolk) - essentially spanning the county from north to south. Castle Acre is located along this road, which intersected with Roman roads reaching into the middle and east of Norfolk, and these are likely to have been integrated into the Medieval route network, linking towns such as Threxton, Caistor St Edmund (shown prominently on the Antonine Itinerary), and Brampton (Margary, 1967, 269). With regard to this case study (Ely to Walsingham), the trackways known collectively as the Hereward Way are of great importance, and will be addressed in relation to the archaeological evidence for pilgrimage in the fourth section. An $11^{\text {th }}$ century local leader 'Hereward the Exile' or 'Hereward the Wake' used these while rebutting the Norman conquest of the fens. These linking tracks pass through towns such as Stamford, Peterborough, Ely and Brandon, joining the route taken by pilgrims from London travelling to Walsingham via Newmarket, Brandon, and Fakenham (Hindley, 2006, 343). A study of masons marks around the county by Richard Fawcett (Wade-Martins, 1994, 58) provides evidence of ease of movement in the region. The distribution of 10 mason marks attributed to individuals working between the $14^{\text {th }}$ and $15^{\text {th }}$ century show that these craftsmen were able within a number of years to work on and complete separate projects all around Norfolk, presumably sourcing materials which also required transporting from quarries and forests on carts, which require maintained roads. Another option for pilgrims travelling in Norfolk would have been by river or sea - however this does not form part of my thesis research as I am focusing strictly on land based travel by foot, and making detailed studies between a set town of departure (Ely) and an established pilgrim centre (Walsingham), both being important and influential Medieval towns.

Documentary evidence for travel within a comprehensive road network in Norfolk is compelling. The primary sources for routes often used by high status travellers (though not exclusively) is supplied by royal and ecclesiastical itineraries, and records of overnight guests in religious houses, again, typically high status. Details of less illustrious travellers were not generally noted. During the late $13^{\text {th }}$ century king Edward I undertook an extensive pilgrimage to the shrines of 
well-known saints around Britain, calling at (amongst other destinations) Walsingham, Castle Acre and Swaffham. When the locations around Norfolk listed in the itinerary were mapped against the known roads of Medieval and Roman origin the task of reaching at least the larger settlements was revealed to have been facilitated by using the major routes (Taylor, 1979, 113). In Norfolk the king's movements seem to suggest a bias towards sites visited in the north of the county, or a better maintained road network in this part of the region - necessitated by the trading of goods along the ports on the northern coast such as Kings Lynn, Stiffkey and Blakeney, and also the ports of Great Yarmouth and Caister in the east, as well as the administrative centre for the county, Norwich. A map of the dispersal of religious houses in Norfolk also shows bias towards the north, with the majority forming a crescent which leaves the south east corner of Norfolk comparatively bare (see Figure 6). This may be linked to the power exerted by Norwich in the south east of the county, whose religious houses and saint cult of St Julian formed a religious monopoly on lands surrounding the city, yet this does not explain the trend in the south for hospitals over other institutions. Eleven of these hospitals (listed in Appendix E) are described by Knowles and Hadcock (1953) as being founded primarily for the purpose of caring for travellers and pilgrims, seven of which were dependents on the priories, abbeys and friaries of the various orders in the county. Augustinian priories were the dominant religious house in Norfolk, particularly in the north west of the county (including Walsingham, King's Lynn and Thetford - although not Norwich, emphasising their links to the west of Norfolk). Whether this concentration of settlement and ecclesiastical activity in the west follows the Roman pattern of activity in the county remains to be seen, but when traced through to Saxon and finally high Medieval occupation patterns there is a strong case of continuity for a preference of settlement in this region of Norfolk (Wade-Martins, 1994, 34).

The distribution of these traveller-orientated hospitals is sparse, but there is a correlation with three of the overnight stops typically taken by pilgrims approaching Walsingham from the south when compared to the roads used by Edward I in his itinerary shown in Figure 6 (Chapter 1), as well as the route from London which leads through Thetford, Swaffham, Fakenham and finally Walsingham. We can see that three hospitals along this route were commissioned specifically to care for pilgrims. Norwich also houses a hospital for the same purpose, which is unsurprising given that it is home to the cult of the celebrated English mystic St Julian. So whilst the number of hospitals do not form spatial patterns or statistically firm distribution sets, they do corroborate the route commonly used to reach the shrine of Our Lady of Walsingham from southern counties. The religious houses along the route (see Figure 14) would have offered accommodation for pilgrims as part of their monastic duties (especially Benedictines given their patron's founding rule of hospitality), and the listed hospitals are those which were explicitly founded to attend to this charity and most would have offered this service.

There is an inherent bias from ecclesiastical records towards the royal or 'well-to-do' travellers, but these individuals were the high profile 'tip of the iceberg' of human traffic circulating around Norfolk. The hagiographies and miracle stories (especially in the case of Walsingham) describe many cures of peasants, and whilst such sources must be read with caution due to their 


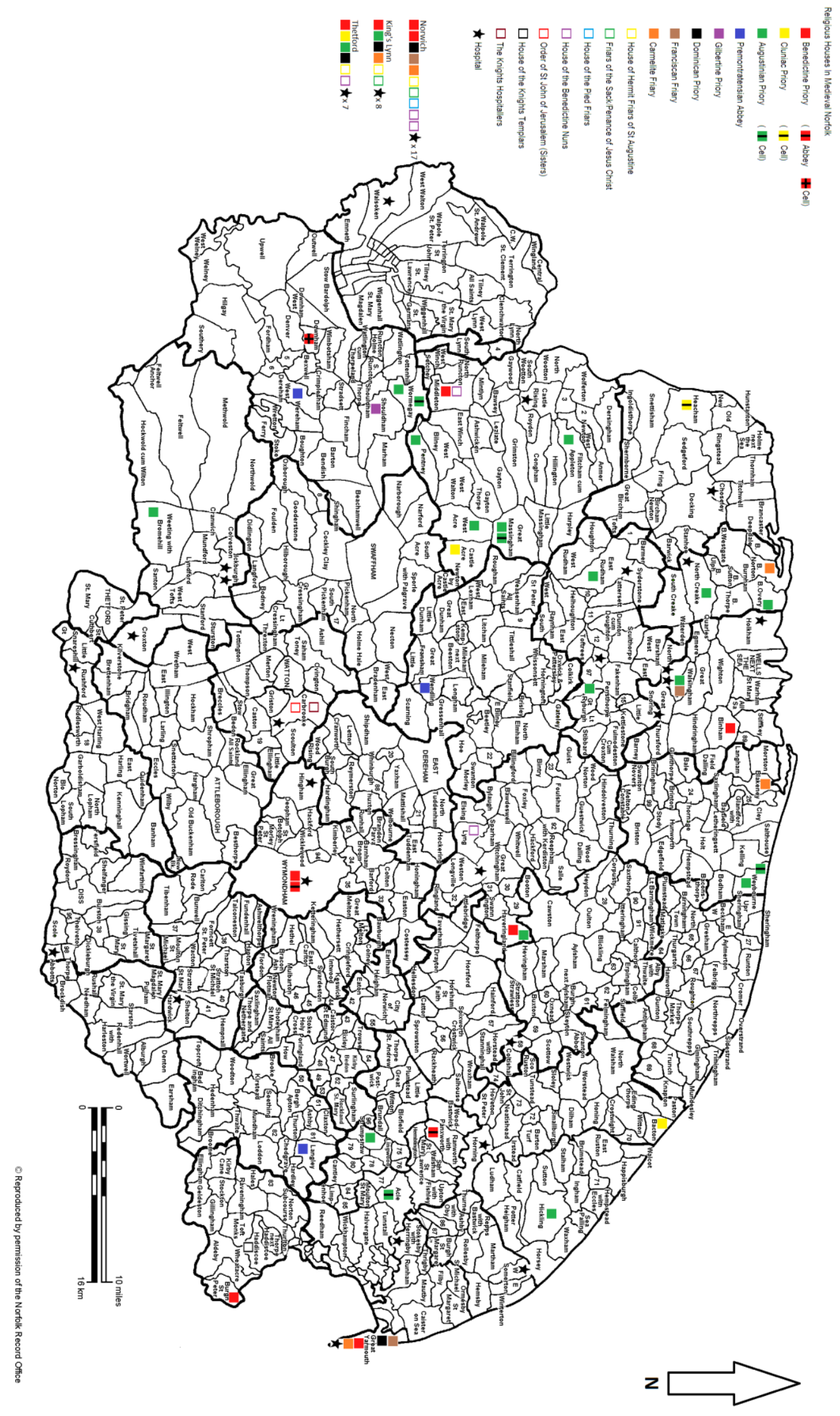

Figure 14. The distribution of the various religious houses and hospitals in Medieval Norfolk. These are supplied in Appendix C. Redrawn after the map of Norfolk parishes published by the Norfolk Record Office. 


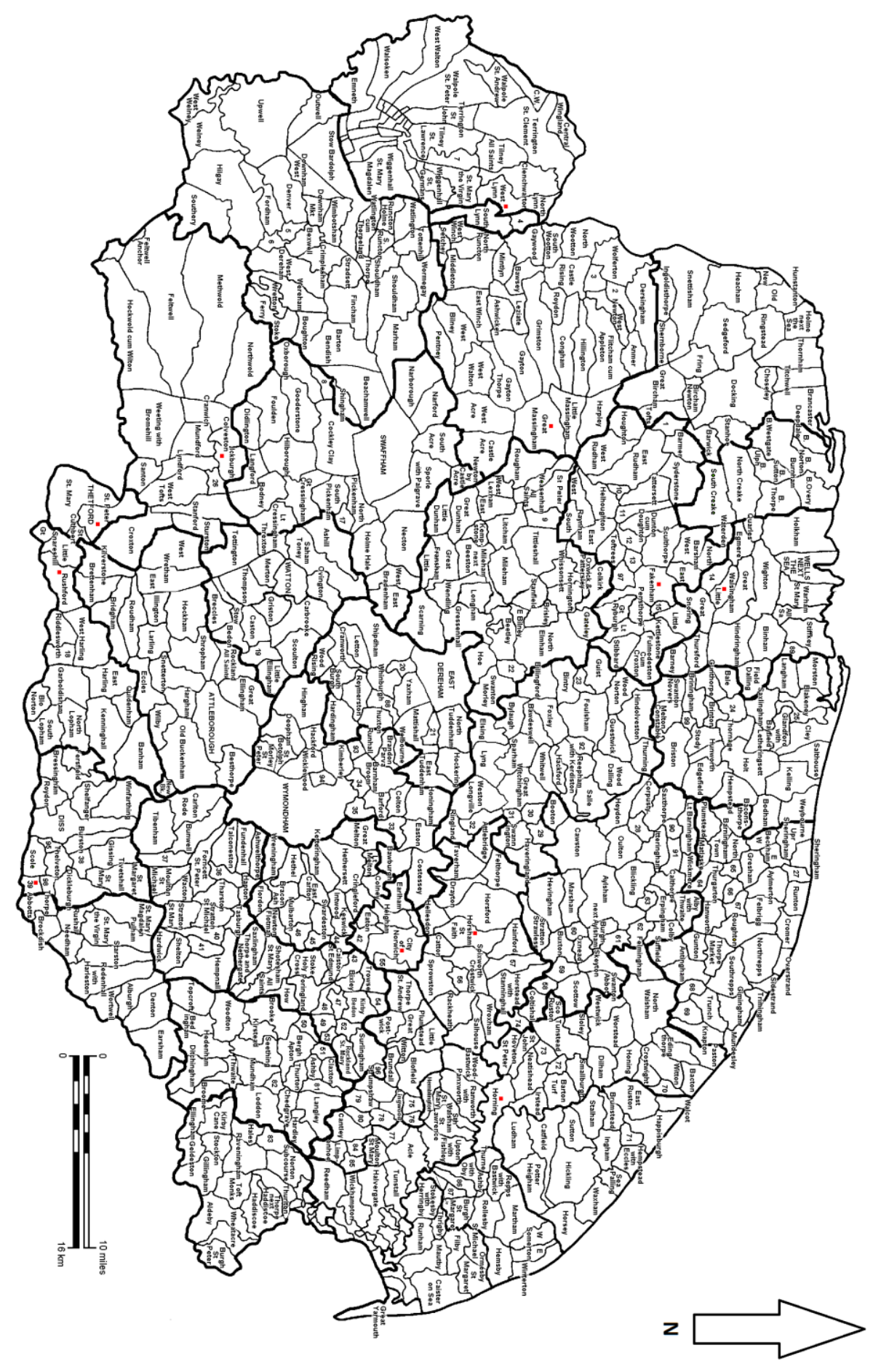

Figure 15. The distribution of the eleven hospitals in Medieval Norfolk founded to care for poor travellers and pilgrims. Detailed table in Appendix D. Redrawn after the map of Norfolk parishes published by the Norfolk Record Office. 
faith driven content and essentially 'brand promotion' purpose, they do give an indication the numbers of people who flocked to these shrines.

Other later itineraries by travellers such as Celia Fiennes and John Leland describe commonly used roads amongst the fens and uplands. Fiennes' description of the route into Ely, and the less than generous account of the town itself, is a rare snapshot of the area prior to drainage in the $18^{\text {th }}$ century. She mentions crossing 'a bridge over water which enters into the Isleand of Ely', and that the city is surrounded by dykes and raised track ways. Fiennes also records that the streets were ' $a$ harbour to breed and nest vermin in', her guestroom was plagued with frogs and slow-worms and the city in general 'cannot but be infested with all such things being altogether a Moorish and fenny ground which lyes low... a cage or nest of unclean creatures.' (Morris, 1982, 141) These descriptions, whilst anecdotal, do provide further information on access to these fenland isles from causeways, and their integration into the route network of the area as a whole. Fiennes' mention of a bridge correlates with the case of the aforementioned immoral Bishop in the Cambridgeshire Hundred Rolls leaving the eastern entrance (being a bridged causeway to Stutney and Soham) to fall into ruin.

\section{The Walsingham Way:}

Walsingham was such a revered place of pilgrimage in Medieval Christendom that local folklore explains the Milky Way as existing to light the way to the Priory (Rye, 1885, 173). The principal road to Walsingham followed a south/north course through Newmarket, Brandon, Swaffham and Fakenham, and this route is still known as 'The Palmers' Way' - the term 'palmer' denoting a pilgrim in Medieval slang. Those arriving from the north passed via Kings' Lynn, where there still stands a pilgrims' chapel, and subsequently by the priories of Flitcham and Coxford before arriving at Walsingham (Nichol, 1849, 199). It is also recorded that there were pilgrim chapels set up along these routes at South Acre, West Acre, Hillborough, Prior's Thorns, Stanhoe, Caston and numerous other locations for wayside devotions (Page, 1906, 399). The little that survives of these chapels will be addressed later on in this chapter. Following on the from the general road network of Medieval Norfolk, the principal route taken from the south approach to Walsingham will be examined in connection with the Hereward Way track series which links Ely to Brandon, and thus with the 'Palmers' Way' (Figure 16 below). During my fieldwork I travelled from Ely to Walsingham by foot via the following route (in this list $(t)$ denotes a town and $(v)$ denotes a village at the time of my fieldwork, this list being provided solely in this case study due to the amount of settlements encountered):

Ely $(t)$ - Hockwold cum Wilton $(v)$ - Brandon $(t)$ - Weeting $(v)$ - Cranwich $(v)$ - Cockley Cley $(v)-$ Swaffham $(t)$ - Castle Acre $(v)$ - Rougham $(v)$ - Weasenham All Saints $(v)$ - Helhoughton $(v)$-North Barsham $(v)$ - Walsingham $(t)$

These settlements and the principal roads and tracks used are illustrated in Figure 16 below. All of the major settlements are Medieval in origin as evidenced by their standing buildings, religious houses, and/or recorded presence as market towns in Medieval charters, church records and royal itineraries. By examining the parish churches and their records in the smaller settlements, it also 
became clear that the majority of the villages also flourished at least during the Late Medieval period. Both Ely and Hockwold cum Wilton lie on the Hereward Way, however the remaining towns are all traversed by the 'Palmers' Way', with many of the villages lying only a mile in distance from the road. The archaeological evidence in terms of standing buildings, town entrances and monastic or castle ruins are covered in the fourth section of this case study, but below I will briefly discuss the roads taken from Ely to Walsingham and their relevance to pilgrimage.

The Hereward Way as has been mentioned previously is a series of linking tracks which connect Stamford to Brandon, allegedly for the purpose of the $11^{\text {th }}$ century rebel Hereward the Wake to maintain a campaign of resistance against the Normans - ultimately unsuccessfully. The route runs along the fenlands, brushing the Great River Ouse outside Ely, and it is here that it becomes of interest for this case study - representing now what would have been a series of causeways traversing the fens prior to their draining. The route runs in a straight fashion into Prickwillow, and is then briefly transformed into a B road and then joins the A1101 (a likely continuation of a major fenland causeway which still suffers from flooding). The Sedge Fen track branches off from this road, leading the traveller across agricultural land and then onto the Black Dyke (thought to be a Roman conduit across the area for garrison movements - Allcroft, 1908, 497) which runs parallel to the Little River Ouse into Hockwold cum Wilton. This effectively marks the end of the fenland environment for the pilgrim, and 3 miles east along 'Main Street' is the market town of Brandon, an important stopover point for pilgrims approaching from the south along the 'London Road' (see Figure 16). Here the Hereward Way intersects what effectively became the primary access route for pilgrims to Walsingham - the 'Palmer's Way'. A wayside cross amongst the undergrowth of Thetford forest, along 'Pilgrims' Walk' on the parallel but 'cross country' route I took on fieldwork between Brandon and Swaffham, indicates a pilgrim presence along this route, as does the pilgrim cross at Hockwold cum Wilton, however the archaeological record is discussed later in this chapter. Leading into Swaffham are several roads which converge in the market place in the town centre, next to the $15^{\text {th }}$ century church of SS Peter and Paul. The main road from the south which formed part of the Palmer's Way - is 'Brandon road'. From this point the Roman Peddar's Way (which became absorbed into the 'Palmer's Way' route) can be used in part to reach Castle Acre. A section of this approach is named 'Procession Lane' which suggests a possible sacral connection, and Castle Acre owned a popular relic, the arm of St Philip, and would have constituted a convenient stopover point and site of pilgrimage in its own right (Baker, 1990,4). Records indicate that 'The offerings at the arm of St. Philip, their most important relic, averaged at that time 10s. a year', and was known to receive Royal visitors (as well as the general laity who rested in the guest hall), some of whom were recorded as being on their way to Walsingham (Page, 1906, 357). The Close Rolls of Edward I record him resting at Castle Acre on the $29^{\text {th }}$ January, 1297 , and subsequently staying in Walsingham from the $3^{\text {rd }}$ to the $6^{\text {th }}$ - returning to Castle Acre on the $8^{\text {th }}$, and then Ely on the $12^{\text {th }}$ (Maxwell-Lyte, 1906, 11). Proximity to both Swaffham, and the monastic houses of West Acre and Great Massingham (the latter having a hospital for travellers and pilgrims) imply that access to this area was not problematic. From this parish one could use either the main trading road (now the A1065) or drover trails to Fakenham; a market town and a popular stopping point with both merchants and pilgrims (Adair, 1978, 115). In order to reach Walsingham from Fakenham, the pilgrim would have used a series of tracks (now lanes) which weave north for roughly five miles to 

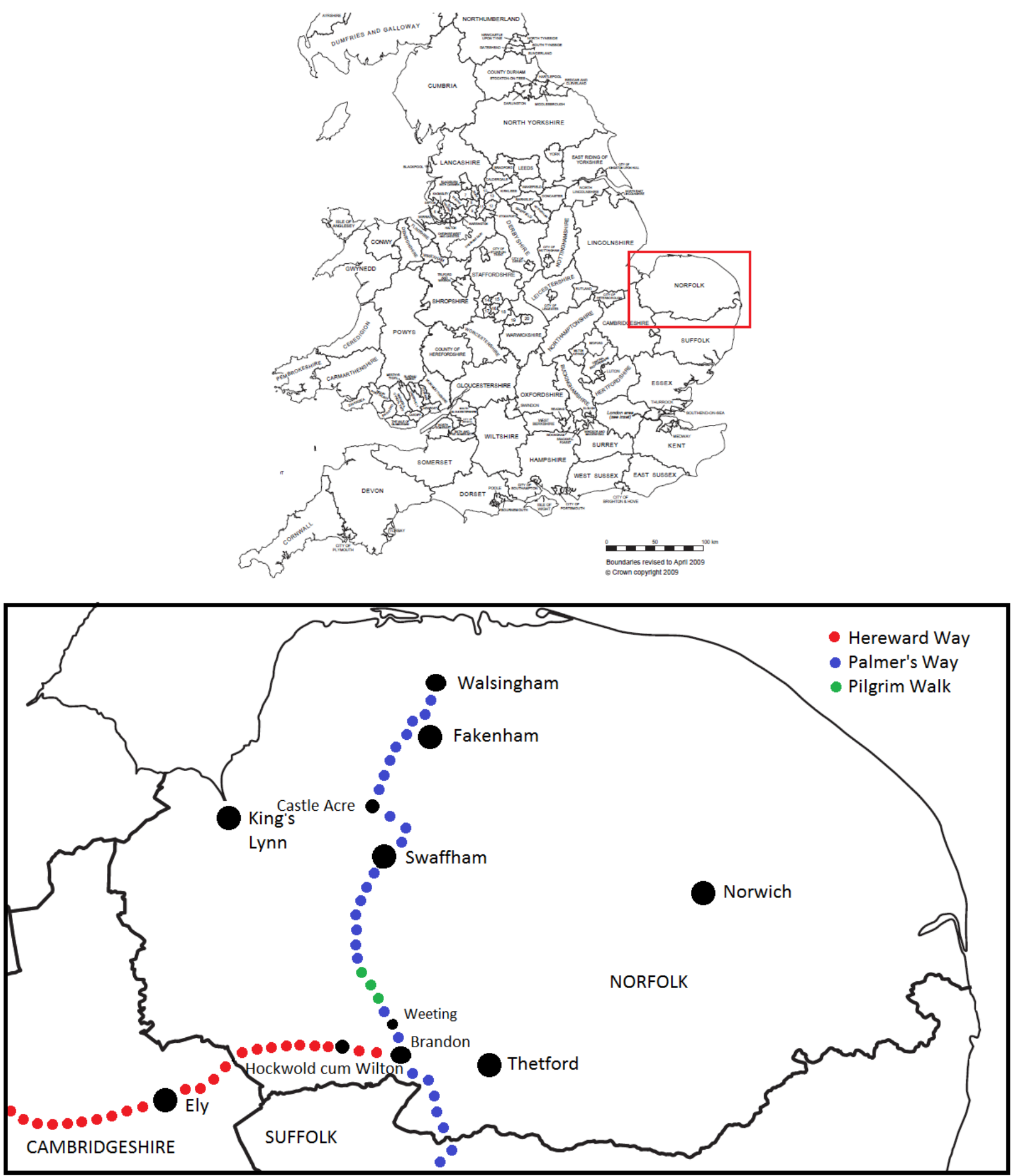

Figure 16. A map of the routes used progressing from Ely to Walsingham (comprising of the Hereward Way, Palmer's Way, and Pilgrim Walk). A detailed map is presented in Appendix B. Redrawn from the 2000 Ordnance Survey map of the UK. A Detailed Route is Supplied in Appendix B. 
reach the Slipper Chapel via North Barsham. An interesting question at this point is how the pilgrim would have set about approaching Walsingham without the aid of a major route or a map. Fakenham was frequently used as a resting spot by pilgrims - with a traveller/pilgrim hospital in nearby Horsham - so it would seem likely that they followed oral directions and other pilgrim traffic towards Walsingham (Knowles and Hadcock, 1953, 276).

In effect the road network of Medieval Norfolk allowed for relatively straightforward access to Walsingham from every direction, although primarily from the south and west. Pilgrims were a familiar sight on the roads (although not so frequent as merchants or drovers) and Walsingham received the majority of their attention, being famed across Britain and in Europe. In the next section I will deal with the growth of the cult and the corresponding evolution of the settlement from a rustic hamlet into a thriving pilgrim centre, solely reliant on the revenue brought by its visitors. 


\subsection{The Cult of Our Lady of Walsingham; Origins, Growth and The Shrine}

The miracle of Walsingham has been related above and the cult of Our Lady was born here in the late $11^{\text {th }}$ century. The cartulary of Walsingham Priory (now in the British Museum) includes a list of priors, which records the priory being founded in 1153. Before this religious house was established, the Pynson ballad (a $15^{\text {th }}$ century text recording the origin of the cult) records a chapel built by Lady Richeldis (the recipient of the Marian vision) which subsequently became incorporated into the priory by her son Geoffrey - this is also corroborated by Geoffrey's founding charter (Dickinson, $1956,4)$. However, what by the Reformation was an internationally revered cult centre 'began as nothing more than a place of private devotion erected by the great lady of the parish probably in the second quarter of the twelfth century. It was not intended as a centre of public worship, the parishioners' spiritual needs being very adequately met at this time by the three churches, All Saints', Little Walsingham, and St Peter's and All Saints', of Great Walsingham' (Dickinson, 1953, 9). What is striking is that the form of this chapel was left more or less intact until the Reformation. As a rule, the Medieval view towards preserving previous buildings was cavalier, and the prevailing attitude was one of rebuilding on a grander and more opulent scale where possible. It therefore suggests that this chapel was held in such high esteem by the laity that, unusually, the thought of modifying it (beyond practical measures for easing pilgrim circulation) was rejected despite the Priory's wealth.

\section{Walsingham Priory}

The scale of the Augustinian Priory's wealth and influence generated by the cult is testified by its taxation record in 1291. By this point, the Priory had possessions in eighty six separate Norfolk parishes, and generated an annual income of $£ 79$ 2s. 6 33/4d (Page, 1906, 395). The replica House of Annunciation which promoted the cult initially rapidly became eclipsed in favour of the accompanying statue of Our Lady of Walsingham - so much so that chapel became viewed primarily as a means of displaying this statue (Dickinson, 1953, 9). Although merely a single east window from the chancel survives, we have precise information on the layout of the Priory thanks to William of Worcester's notes on the building. His observations on the Friary layout in Walsingham proved to be exceptionally accurate when the building was excavated in the late 1930s. In his 'Itineraries' William writes of the Priory 'The length of the new building of Walsyngham consists of 16 yards, its width below the platform of 10 yards. The length of the chapel of blessed Mary consists of 7 yards 30 inches, its width of 4 yards two inches. The length of the whole church of Walsingham as far as the beginning of the chancel consists of 136 paces, its breadth of 36 paces. The length of the nave from the west door as far as the belfry in the middle of the church consists of 70 paces. The crossing or belfry area consists of 16 paces each way. The width of the nave of the church alone without the two aisles is 16 paces. The length of the cloister, which is completely square, 54 paces. The length of the Chapterhouse alone consists of 20 paces and its breadth 10 paces, but the length of the portico of the Chapterhouse from the cloister consists of 10 paces, thus totalling 30 paces.' (Harvey, 1969, 67) 

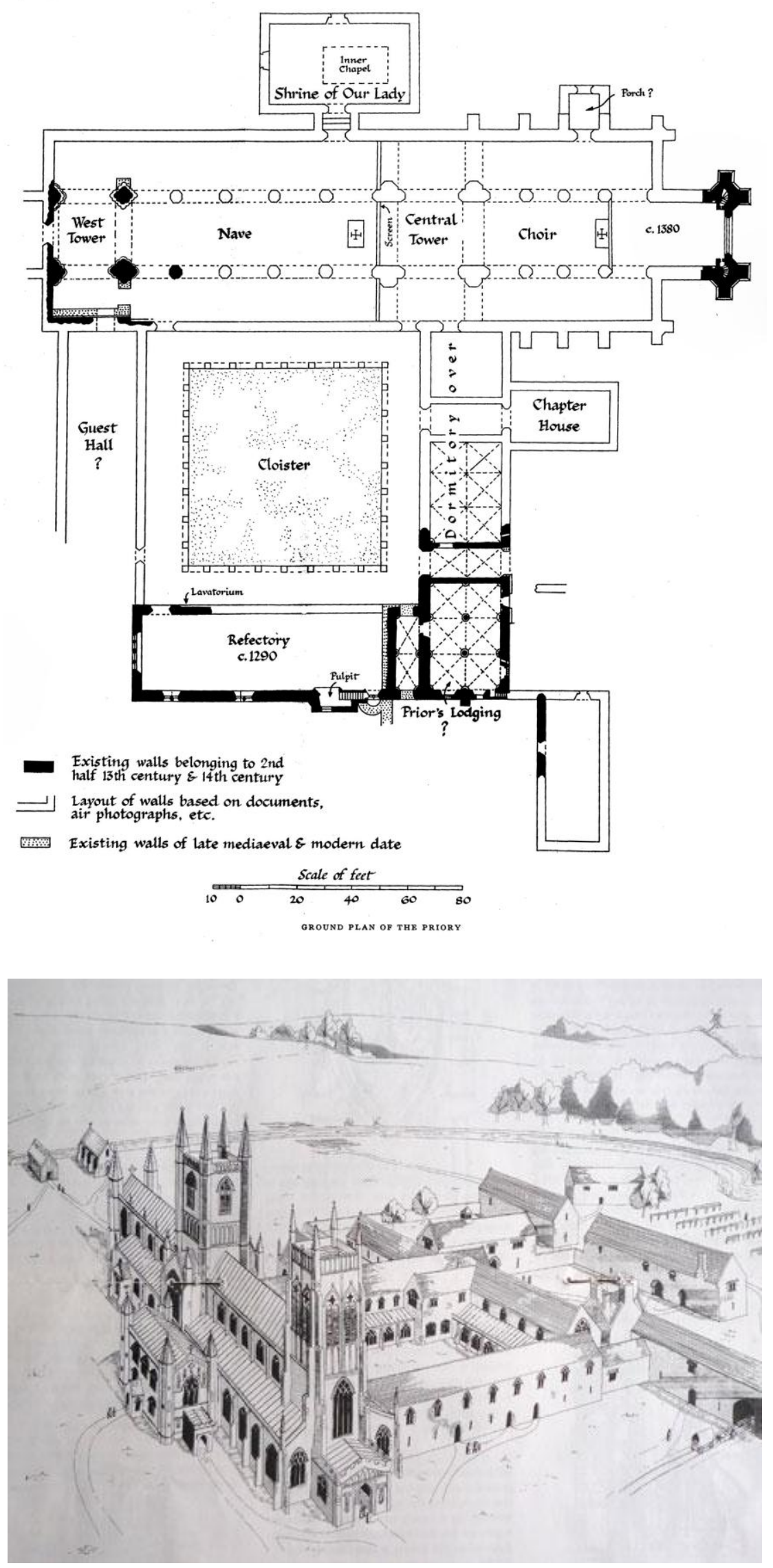

Figure 17. Ground Plan and sketch of Walsingham Priory. Reproduced from Dickinson, 1956, 144. 


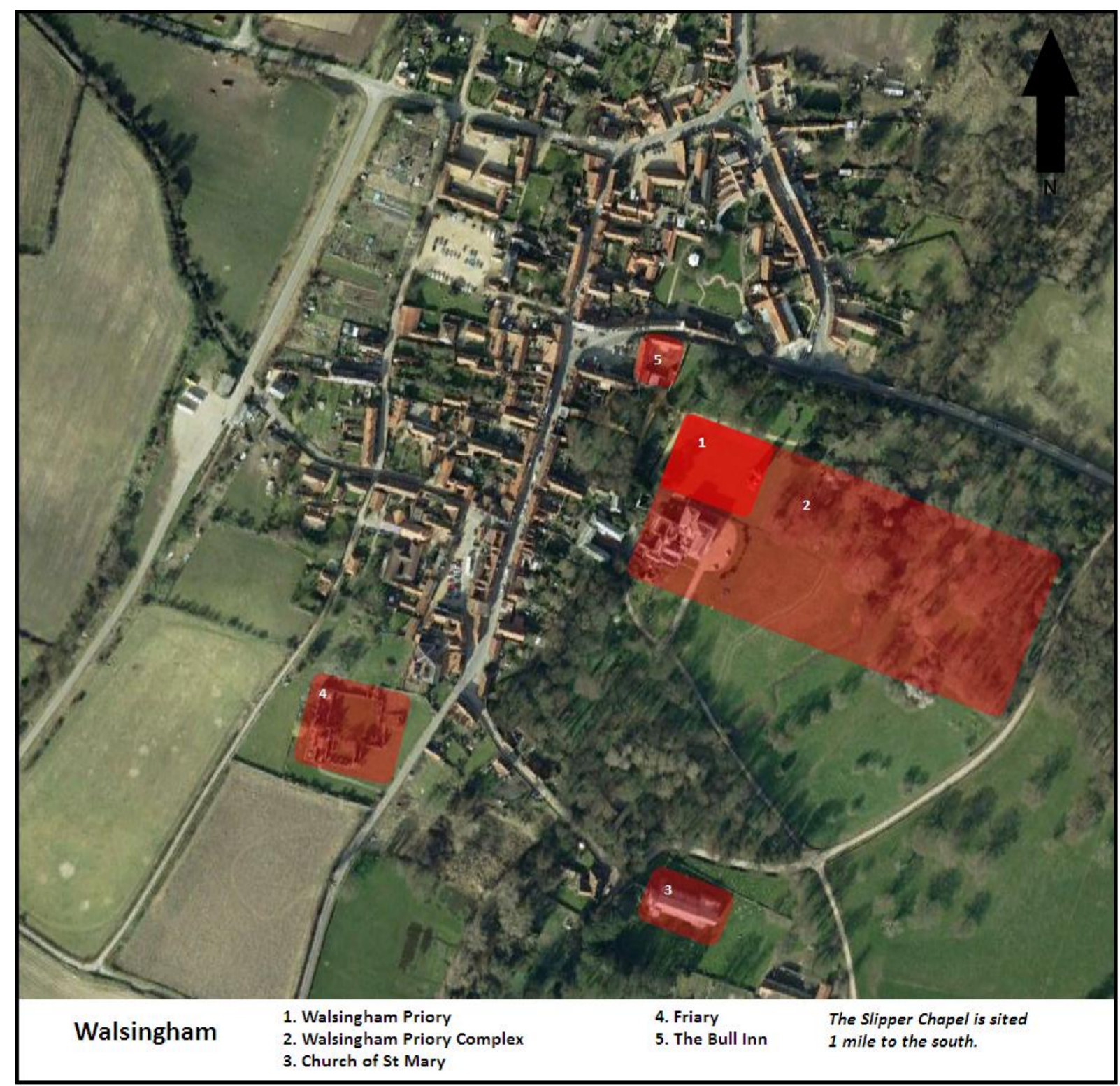

Figure 18. Map of Walsingham. Original satellite image reproduced from (C) 2011 Google.

The town of Walsingham was a planned settlement, laid out by the monks of the Priory to facilitate pilgrim movement (Dennis, 2006), and similarly the Priory itself was built to careful specifications to ease the flow of devotees and ensure that the laity did not inconvenience the regular canons (Dickinson, 1953, 91). In his $16^{\text {th }}$ century text 'Pilgrimages to Saint Mary of Walsingham and St Thomas of Canterbury', Desiderius Erasmus describes the approved process of manoeuvring around the Priory church and shrine (Nichols, 1849). Entering the gatehouse situated on the High Street, the pilgrim first proceeded through a narrow wicket, where one was 'obliged first to subject his limbs to attack, and must then stoop his head.' (Nichols, 1849, 17) The origin for this wicket is given as relating to a miracle, where a knight fleeing his attackers was transported by the Virgin through the locked gates into the safety of the precinct. However, practically it would have 
been a method of controlling the inflow of pilgrims, so that the grounds were not overcrowded with visitors; a bottleneck which restricted the numbers entering the precinct at one time. To the immediate east of this wicket was a small chapel, in which rested a relic of St Peter's finger joint, and adjacently a shed with a holy well which 'burst from the earth at the command of the Virgin' whose waters were 'wonderfully cold, and efficacious in curing the pains of the head and the stomach.' (Nichols, 1849, 20) The Prior Richard Vowell in the $15^{\text {th }}$ century issued a book of instructions to the guardians of the well, which wisely insisted that no sick pilgrim immersed himself without permission (Adair, 1978, 118). It is from these wells that the ampullae (covered later in this chapter) were filled; often bearing a stamped letter ' $W$ ' on their lead forms (Adair, 1978, 118). This chapel of St Laurence with the accompanying wells can be argued through examination of the Pynson ballad to have been sited on the original shrine site, which was moved and attached to the Priory church when the votive offerings began to overcrowd the shrine itself:

\author{
'A chapel of saynt Laurence standeth nowe there \\ Faste by tweyne wells, experience doth thus lere [teach], \\ There she thought to have set this chapel \\ Which was begonne by Our Ladyes counsel.'
}

(Dickinson, 1953, 127)

The pilgrim would then proceed to the Priory church where an important relic was stored - a crystal vial allegedly containing the Virgin's own milk (powdered), located at the High Altar next to the hand of a statue of Christ (Nichols, 1849, 22). After this the pilgrim was taken to 'a little house' which held the shrine with the replicated House of the Annunciation which 'literally blazed with silver, gold and jewels' and the statues of Mary and Christ fashioned from gold and silver gilt (Nichols, 1849, 26). This little house (which can be seen on the plan above labelled as the 'Shrine of Our Lady') was within the church, 'a small chapel made of wainscot, and admitting the devotees on each side by a narrow door' (Nichols, 1849, 14). This use of a narrow door would have both controlled the flow of pilgrims into the shrine room, and also kept the contents hidden from view until admittance, possibly in order to produce a 'revelatory' effect when the pilgrim finally made their way through the small opening into a room practically glowing with jewels and precious metals. In his description of these proceedings, Erasmus mentions being taken to these places; monks often escorted the more illustrious visitors (while herding the general laity) around pilgrim shrines so that a suitable order was followed and the pilgrims did not wander around the precinct and interrupt the monastic duties and schedule of the brothers. As to the behaviour of pilgrims at this shrine, we must take our cue from that recorded at other sites such as Compostela and Canterbury (Webb, $2001,86)$. Typically pilgrims offered prayers, gave offerings in the form of coin, jewels, or votive waxen statues and candles representing some aspect of the reason for their pilgrimage (such as cure of a certain affliction or body part, safe travels on the seas). Other more unusual gifts at Walsingham included a banner from the Battle of Stoke in 1487 offered by the victorious King Henry VII (Page, 1906, 396). Unlike other examples in Christendom, the shrine of Our Lady of Walsingham did not 
possess any niches or portals through which the eager pilgrim could get even closer to the divine, and instead worship effectively took the form of legal idolatry. This pilgrim practise was cited as a theological reason for the events of the Reformation which effectively outlawed pilgrimage in Medieval England after the mid-15 $5^{\text {th }}$ century. The emotional Margey Kempe visited Walsingham in the $16^{\text {th }}$ century where 'sche had hir meditacyon and hir devocyon wyth wepyng and sobbying as wel as yf sche had ben at hom.' (Windeatt, 2004, 398) Whilst this was recognised even then as an extreme and 'uninhibited' reaction (and indeed she often had priests blanching at her theatrical displays of piety), it does give a flavour of the sort of devotions which occurred at shrines in the late Medieval period.

\section{Franciscan Friary}

The Franciscan Friary of Walsingham lies at the south of Little Walsingham, at the side of the road which leads from the Slipper Chapel and Houghton-St-Giles. The house was granted license by Edward III in 1347, despite the objections of the Augustinian canons from the Priory. This is presumed to be linked to the matter of pilgrim accommodation, which could be had by the poorer devotees for a small donation at the Priory's guest hall, but would be offered gratis by the Friary (Page, 1906, 435). Another cause for concern from the Priory's perspective was that 'the site proposed by the Countess [Elizabeth de Burgh, Countess of Clare] for her new foundation was at the very entrance to Walsingham, so that the vast majority of the pilgrims coming to visit the shrine would be likely to be intercepted by the Friars, and there was fear of not only losing the gifts and offerings they had intended for the Holy House [Priory], but also in the case of the better-to-do, their patronage and favour.' (Patten, 1948, 2). Little of the chancel survives, but behind the remaining wall are the finest domestic ruins in Norfolk - now a private residence. The Friary building contained the Chapter House, the Friars' Cloister, the Preaching Cloister, the Kitchen, and a large Guest House that provided accommodation for poor and sick pilgrims (Page, 1906, 435). The church was dedicated to St Anthony, originally a Franciscan monk himself, and the Priory's fears seemed to have been well founded as in 1514 a Robert Grey of Walsingham gave two silver censers to the Friars, objects which would more generally have gone to the Canons or the parish church (Pattern, 1948, 2).

Inns

The main entrance for pilgrims would likely have been from the market place (now known as 'Friday Market Place'), near which was an anchorite's cell (Pattern, 1948, 3). The Friary church went much the same way as the Priory during the Reformation, and was demolished in 1539, with the Guild of Blessed Mary at Walsingham recorded as paying 40s for the bell of the Friar's Minor - this now hangs (recast) in the parish church of St Mary. The Friary does not receive the same attention in the documentary record as the Priory, and this is understandable given that the focus of Walsingham rested on the shrine in the Priory precinct. However it played an undeniable part in the accommodation of pilgrims, along with the numerous inns in Walsingham, and would have been the first religious house encountered by pilgrims approaching from the Slipper Chapel and consequently formed an initial impression for these travellers with the daily procession of the Grey Friar(s) to the Holy House (Pattern, 1948, 2). 

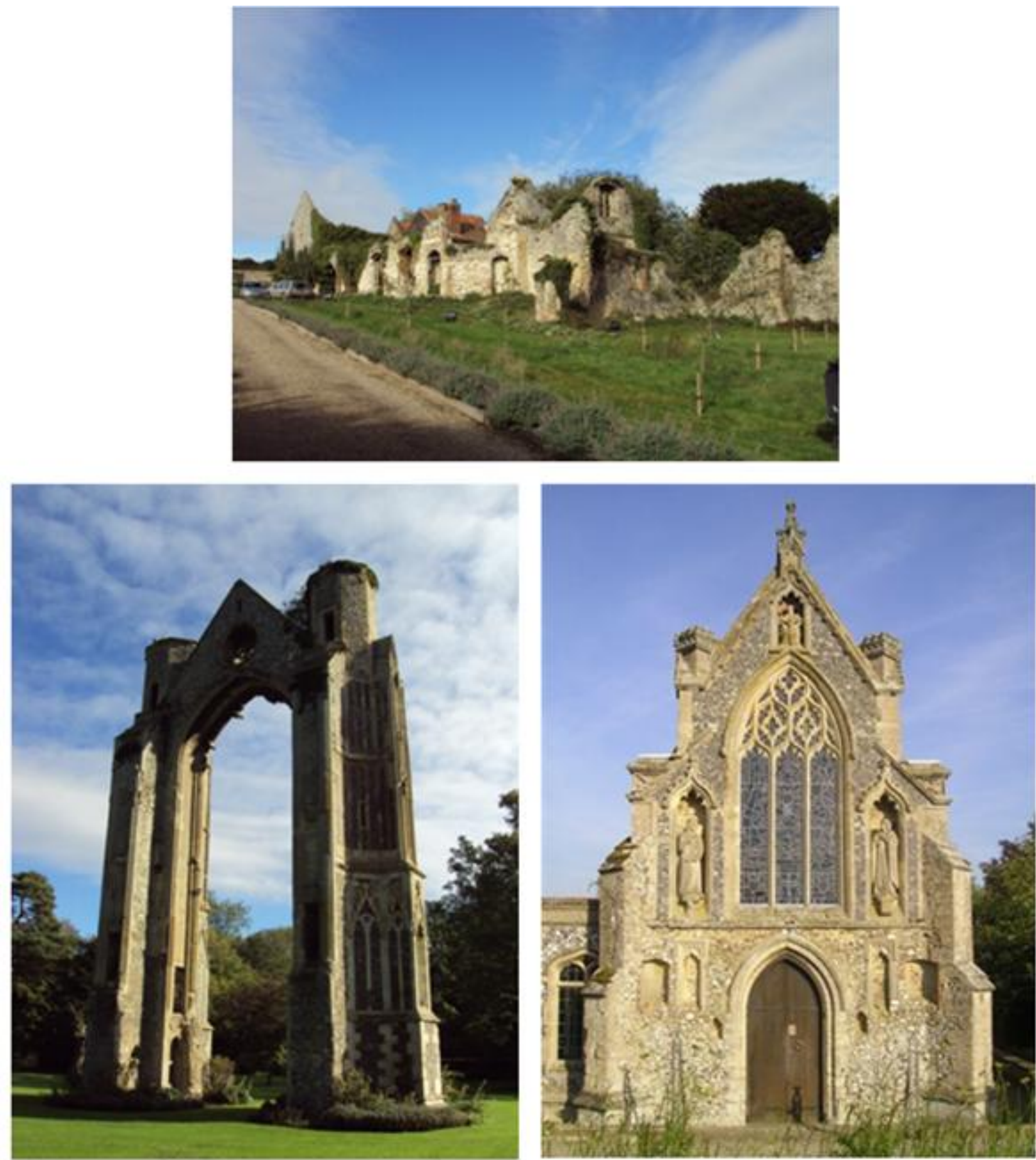

Figure 19. Clockwise: Remains of the Friary, Slipper Chapel and Priory at Walsingham. Photographs taken by author.

Other venues for accommodation were inns and a Shire Hall. The Norfolk Historical Environment Record (NHER) suggests that the structure of this hall indicates that the main room was used to house travellers and pilgrims, with kitchens and services provided beneath on a basement level (NHER no. 15129). This hall now forms part of the Priory museum, and is of a scale which could 
have slept up to a hundred pilgrims. There are also records of the foundations of a Medieval inn or almonry which existed on the site of the modern Anglican shrine (NHER no. 2035). Foundations for a well are also found on this site, with a mould for making white hart badges being located at the well floor. When compared to the records for the Priory, it is mentioned that a man was set here by the Cluniac Prior in charge of giving out alms to the poor and pilgrims, and that his house was next to a well, which makes a convincing case for this being the site of such an almonry (Bond, 1961, 19). A great number of taverns and inns took advantage of the steady influx of pilgrims as is neatly summarised in the following quote - 'No less than seventeen inns catered for the needs of the pilgrims. On entering Walsingham from the south, near the Priory stood an inn, 'le Beere', once called Ie Dowe'. In the Friday Market [near the Friary's main entrance] were 'The Crowned Lion', the 'White Horse'; nearby the 'Moone and Sterr', and the 'Sarassyn's Head', both mindful of adventures in the East. There were also the 'Swan and Bull', the 'Ram', and the 'Angel now Wasted', which was absorbed later in the 'Swan and Bull'. In Stonegate were the 'Chekker', and the 'Boult and Tonn'. In the North Town-end, the 'White Hart', and the 'Bell'. In Church Street was 'The Crane', and near the churchyard was the 'George'. Of these only four now remain.' (Walsingham; England's Nazareth, $1969,18)$. Since the publication of the above text, the contending inn on the list is thought to be 'The Bull', which may be a corruption of the 'Swan and Bull' name, the road leading to it being called 'Swan Entry' which may refer to the lost 'Swan' element of the inn's name.

\section{Church of St Mary and All Saints}

The parish church of St Mary and All Saints is situated on the site of the original Saxon village of Walsingham Parva, roughly 300 yards east of the Friary over a small bridge crossing the River Stiffkey. The tower dates to 1320 , with the body of the church being a $16^{\text {th }}$ century re-build. It does not seem to have played a specific part in the actual pilgrim activity of Walsingham in terms of being part of an ascribed route to the shrine, however to the local community it would have been of great importance as the parish church. Its dedication to St Mary echoes the patron benefactor of the town, and whilst there is no mention of 'Our Lady' in the dedication name, it is reasonable to suggest that it was to their Mary that prayers were said in the liturgies here.

\section{The Slipper Chapel}

For most pilgrims, the so called 'Slipper Chapel' would have been their first tangible link to the Walsingham cult. Situated outside of Houghton-St-Giles on the banks of the river Stiffkey, almost exactly a mile from the Priory, this chapel was originally just one of the many wayside chapels which led to Walsingham, and the penultimate stop along the route. The chapel is $14^{\text {th }}$ century in origin, and plain in design. Its primary function was to serve hourly masses for the pilgrims arriving to Walsingham, and possibly act as boundary marker to signify the start of the 'holy mile' between it and the town (Webb, 2000, 86). The etymological origin of the term 'Slipper Chapel' might be, as is commonly thought, from the connection with the practise of removing ones shoes for the final 'holy mile' to Walsingham's gates, or from the term 'slip' or 'slype', meaning in architectural terms a covered passage or, in liminal terms, the passage from one area to another; from the profane to the 
sacred. This aspect of the journey will be addressed in more detail in the penultimate section of this chapter. 


\subsection{The Distribution of Pilgrim Souvenirs Relating to the Walsingham Cult}

Ampullae ( lead containers for holy water ) and pilgrim badges were the most commonly produced type of pilgrim souvenir during the Medieval period - others included flasks, medals and even minor relics, as well as the illicit practise of 'acquiring' a souvenir from a shrine or site via a surreptitious chisel (Webb, 2001, 124). During the $12^{\text {th }}$ century, ampullae were the most popular form of souvenir, although these decline in the record during the $14^{\text {th }}$ century when the pilgrim badge becomes the souvenir of choice. However ampullae enjoyed a renaissance in the $15^{\text {th }}$ to $16^{\text {th }}$ centuries (Anderson, 2010, 183). Ampullae were developed to hold a small quantity of water from a

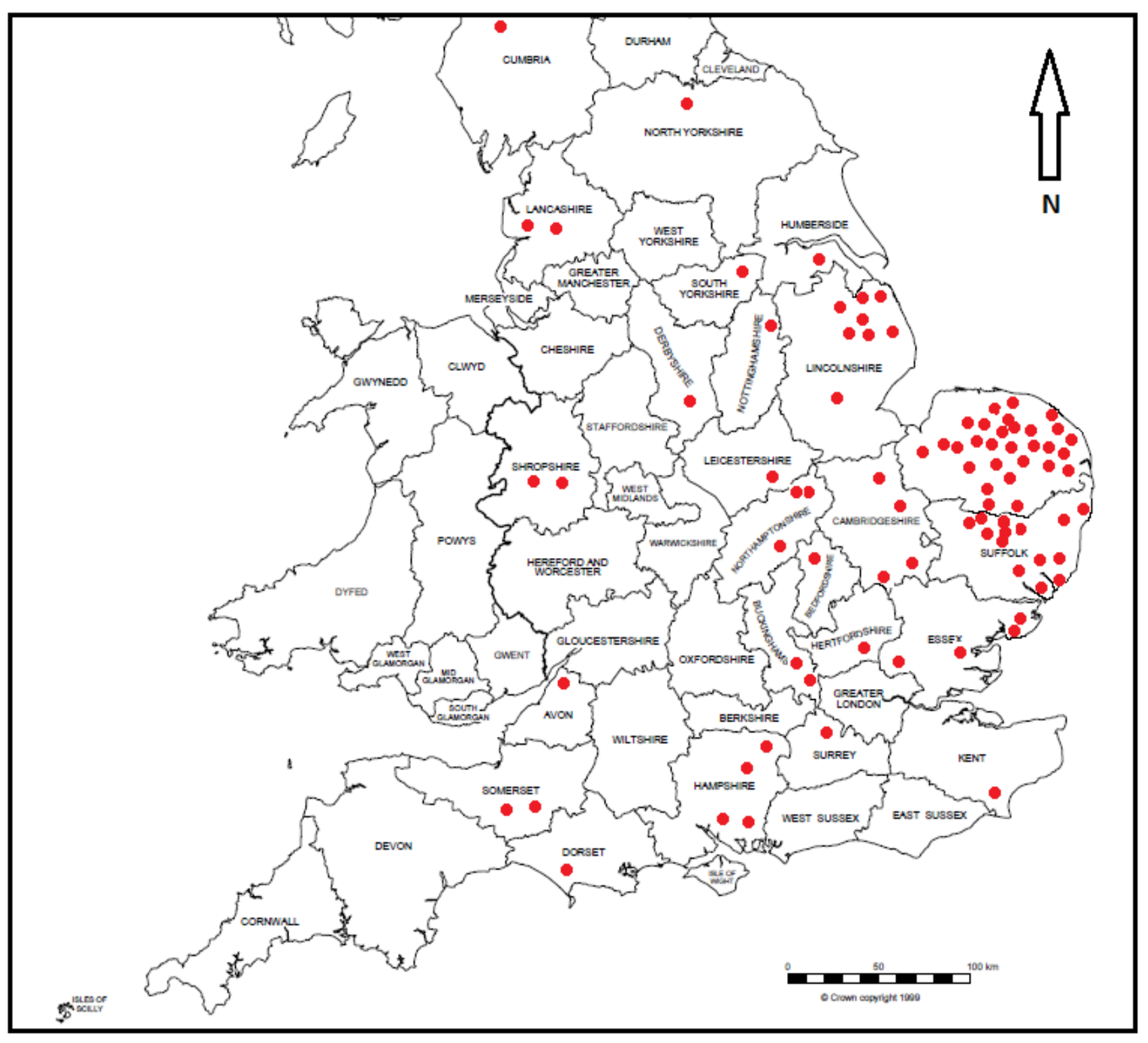

Figure 20. Distribution Map for Ampullae Connected to Walsingham Cult by Iconography. Redrawn from Ordnance Survey 1995 County Boundary Mapping. 
holy source attached to a pilgrim shrine, and could have a number of uses for pilgrims; talismanic, curative or votive. Their popularity endured because 'while a badge had only been in contact with the place of pilgrimage, an ampulla actually contained tangible material from the holy place' (Boertjes, 2005, 451). Souvenirs such as these were cheaply and mass produced from casts, and so offer an insight into the economic status of individuals as well as their origin.
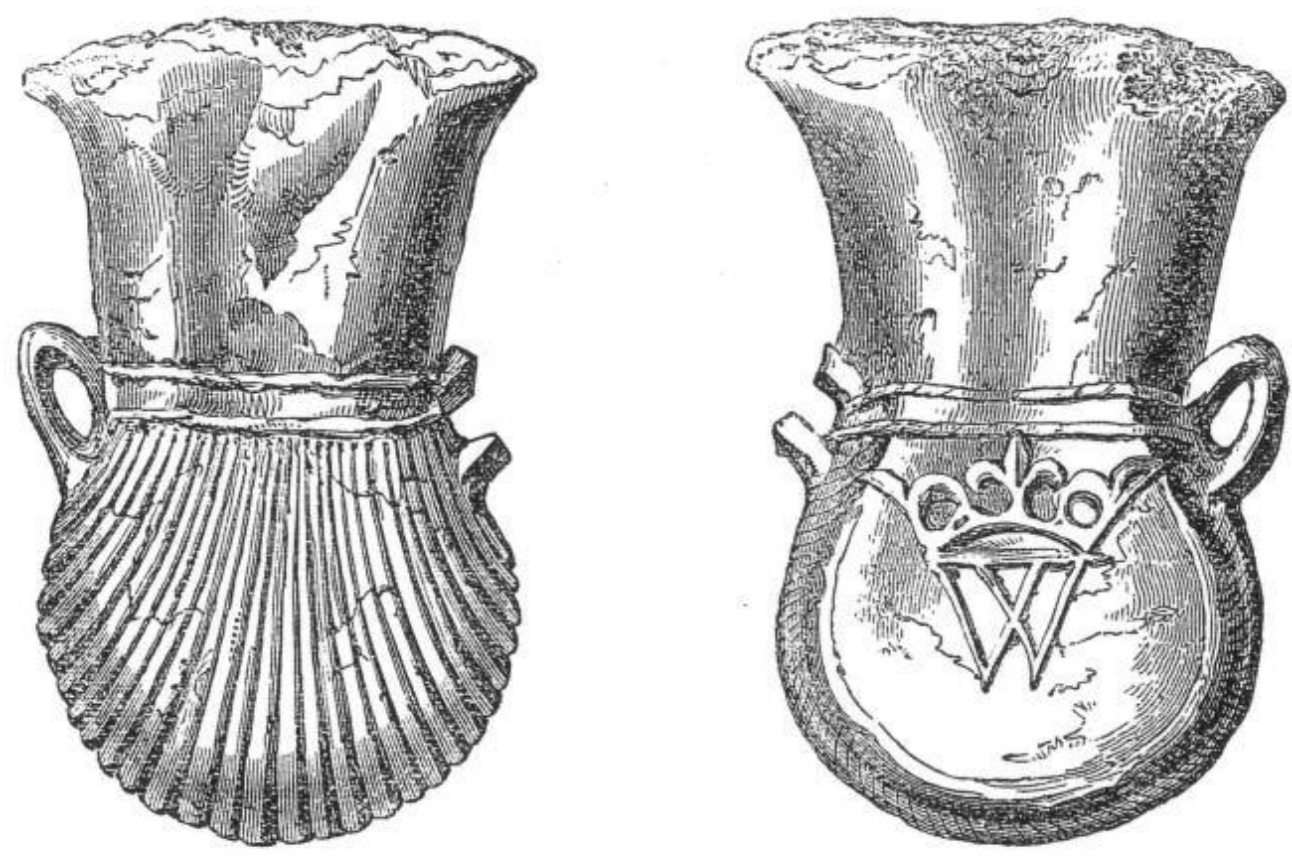

WALSINGHAM BADGE.

Figure 21. An Ampulla Bearing the Crowned 'W' Motif of Walsingham and Scallop Shell Relief on the Reverse.

Reproduced from Hart, 1864.

The data from the Portable Antiquities Scheme record over some 100 ampullae possibly connected with the Walsingham cult (this data is recorded in Appendix F); this connection is achieved primarily through the iconography on the body of the object. Motifs such as a lily or lily pot, moon, ' $W$ ' beneath a crown (see Figure 21 above), ' $R$ ' taken to indicate 'Lady Richeldis' the founder of the shrine, or a downward facing arrow are usually accompanied by a scallop shell relief on the reverse side, and have been linked to the Virgin Mary when combined also with their location (frequently near the Marian cult at Walsingham) by the founder of pilgrim souvenir studies, the late $\mathrm{Dr}$ Brian Spencer (1990). Anderson points out that there is a tendency to attach all pilgrim artefacts bearing Marian insignia to the Walsingham cult, and that prudence is needed when addressing origin as the cult of Mary was universally important across Britain and Christendom at large, not restricted to the north of Norfolk (Anderson, 2010, 190). Whilst this is a timely call for caution, Walsingham was the premium Marian cult in Britain, and so it is reasonable to suggest that the majority of these artefacts (especially when engraved with a crowned ' $W$ ', a motif which makes up $14 \%$ of the entire 
ampullae record for Britain) are highly likely to relate to Walsingham. This is given further weight from their distribution pattern, which is heavily slanted towards the east of England; more specifically towards rural Norfolk and Suffolk. Lincolnshire, Suffolk and Norfolk bear the highest tally of ampullae bearing iconography which relates to the Walsingham cult. This significant presence of ampullae in the eastern regions correlates broadly with the national figures for ampullae distribution; Lincolnshire 95, Norfolk 57, Yorkshire 50 and Suffolk 45 (Anderson, 2010, 194). A note of caution must be applied to this data, in that these counties also have the longest histories of metal detectoring, and so this may present some bias in the data. Also these items are amongst the sturdiest of pilgrim's souvenirs and therefore survive in the plough-soil, unlike badges which tend to be more delicate. However, if the locations given in the PAS archives do represent genuine patterns of Medieval deposition, then they fall highest in three counties which were centres of agriculture during the height of the cult's popularity with pilgrims, thus tying the ampullae of Walsingham into the theory of 'field blessing' with the waters taken from the Priory's wells (described earlier in this section). Recent research has indicated that there is a strong connection statistically and behaviourally between the find spots for ampullae, rural communities and agricultural regions (Anderson, 2010, 184). These objects are frequently found purposefully broken open or 'torn' in an agricultural context, but given their spiritual value for their owners, it is unlikely that such items were casually discarded or broken in such a fashion. Instead it is suggested that their function was more towards some sort of votive behaviour such as sprinkling holy water amongst a field and crops to ensure a good harvest, and this is supported by the fact that 'several bear signs of deliberate damage, including crimping, fissures and tooth marks, and where the owners have broken the seal to release the vessels' contents' (Anderson, 2010, 184).

In terms of what this distribution pattern can tell us about the origins of Walsingham pilgrims, $36.6 \%$ of the ampullae bear a Norfolk locale. If we posit that most pilgrims purchased a popular form of souvenir at the shrine of Walsingham (which took the form principally of ampullae and badges) and consider the rural/agricultural application of these artefacts, then the northern, central and eastern parishes of the county could have supplied a substantial portion of pilgrim traffic towards Walsingham - along the surviving Roman roads and trade routes which crossed to the east of Norfolk via centres such as Billingford, Brampton, Crownthorpe, Norwich and Great Yarmouth (Gurney, 1995, 34). The cluster of ampullae finds in northern Suffolk are located very close to Thetford and the route which typically led pilgrims from London to Walsingham - the Palmer's Way (detailed in the second section of this chapter), by which they travelled to and from the shrine, prior to scattering their ampulla's contents upon their fields.

Brian Spencer records 14 pilgrim souvenirs found in waterfront excavations on the Thames (1998). These depict the statue of the Virgin at Walsingham, the Holy House, the Annunciation which has a 'highly individual frame' - and an image of the legendary knight who miraculously fled through the gates of the Priory precinct in flight from his attackers (Spencer, 1998, 146). Some badges typically show the crowned Virgin with sceptre and holding the Christ child and occasionally she is seated within an embattled canop, however, since these badges of Virgin and child usually have no inscription it is impossible to be certain whether or not they were made for the Norfolk cult, as opposed a Marian cult elsewhere. Their location in waterfront deposits is puzzling, as whilst 
pilgrims were known to arrive at Walsingham via the nearby port of Blakeney, this was not typically the manner in which pilgrims from London travelled to the shrine (Spencer, 1998, 154). The only conclusion which I can draw from this is that they may have been lost when being worn boarding ships to other pilgrimages overseas such as that of Santiago de Compostela, the souvenirs declaring other pilgrimages taken. There would be no perceptible advantage in depositing these badges deliberately in the waters (other than perhaps in a votive context for a safe crossing), so it would appear that they were recovered at waterfront sites more by accident than design. Also, it is apparent that many intricate badge types survive best in the waterlogged conditions of the Thames mud, rather than on arable farmland where most detecting takes place. Outside of London, 11 pilgrim badges have been found with scenes which can be linked to Our Lady of Walsingham and the Pieta. Below (Figure 22) is the distribution scatter for these surviving recorded pilgrim badges according to the Portable Antiquities Scheme archives (recorded in Appendix G).

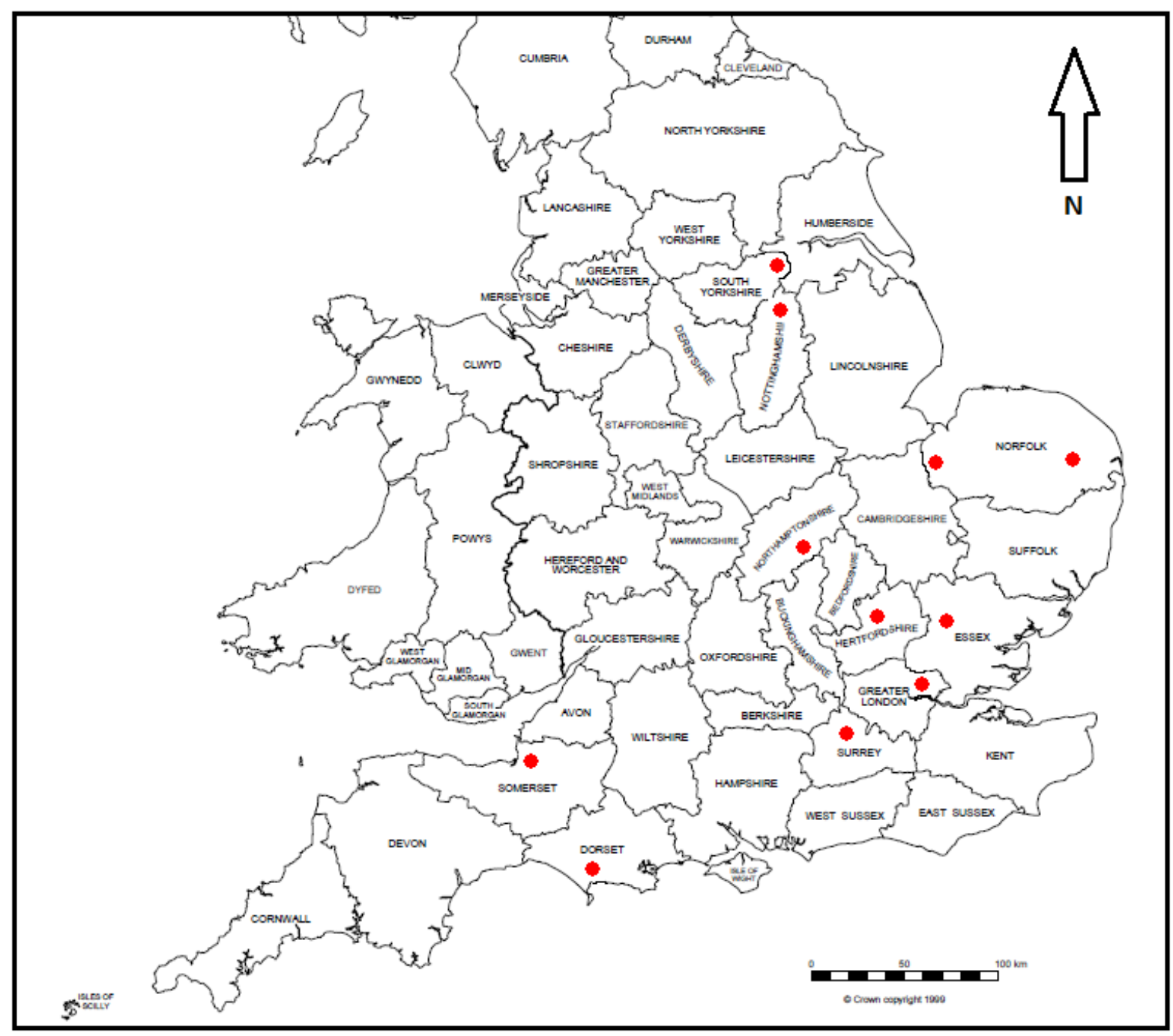

Figure 22. Distribution Map for Pilgrim Badges Connected to Walsingham Cult by Iconography. Redrawn from Ordnance Survey 1995 County Boundary Mapping. 
The pilgrim badges bearing iconographic relations to the Walsingham cult do in several cases broadly match the distribution patterns for some of the ampullae; namely in South Yorkshire, Nottinghamshire, Northamptonshire, Norfolk, Surrey and Dorset. This may have been the result of returning pilgrims influencing others in neighbouring parishes who follow the same route. Supporting the concept of ampullae being predominantly found in rural contexts, whilst there are several Walsingham pilgrim badges recorded by Brian Spencer along the Thames waterfront, London is almost devoid of ampullae aside from three instances which Spencer states are 'stylistically manifestly earlier than corresponding figures on Walsingham's badges', which throws their relation to the cult into some doubt (Spencer, 1998, 145). These London finds have not been plotted in Figure 22 above due to the restrictions of space within the scale of the map. The scatter in general is thin, but does indicate (similarly to the ampullae) a bias towards the central east of England. This may be due to rival saint cults in other areas of the country (such as Beckett in Kent, St Swithun in Hampshire, St Cuthbert in Durham and the many 'Celtic' saints in Cornwall) which had their local followers who were unlikely to travel across to Norfolk, when a more localised 'Our Lady of' shrine was nearer at hand. There are competing factors to consider when thinking about which shrine a pilgrim would favour; i.e. the local versus the universal. The universal cult centres could offer greater spiritual rewards and display a greater degree of piety. However, a local cult in the diocese or parish would be easy to get to (not taking time away from agriculture or necessarily requiring a lord's permission), and the pilgrim would be familiar with the workings of the saint and his/her connection with the local landscape

The paucity of pilgrim badges in the archaeological and PAS record (aside from London) compared to the number of ampullae may relate towards their functions. Ampullae may be better represented because they were deliberately discarded in pre-designated locations for specific purposes. Aside from being kept for curative or talismanic purposes they were also widely used in a votive sense as discussed above. Pilgrim badges were less likely to be discarded, given their role as emblems of piety, status symbols of pilgrim travel and amulets, and so are less likely to be found in numbers, perhaps being kept by family members after the original owner's death - archaeology is often the study of objects people chose not to keep but discard. They were also in many cases intricate and, in the case of the better crafted badges, very fine in design, and so with their integral character being less sturdy may have been more likely to be twisted, broken and snapped beyond recognition or identification as a sacred emblem. Evidence for the stone moulds used to create these badges at Walsingham have been discovered, and point towards a thriving trade in these artefacts, as do surviving records of minor transactions of badges to (often) high status pilgrims - in one instance an Elizabeth Newhouse writes to her wayward son in the 16 century, stating 'Look wisely to yourself, I send you a Walsynggham brooch' (Spencer, 1998, 145). However despite these sources, and the comparisons drawn from other major saint cult centres such as the shrines of Beckett, St James and the Holy Land which all point towards an industrious production of these badges, their presence in the archaeological record is slight when compared to the more robust ampullae. 


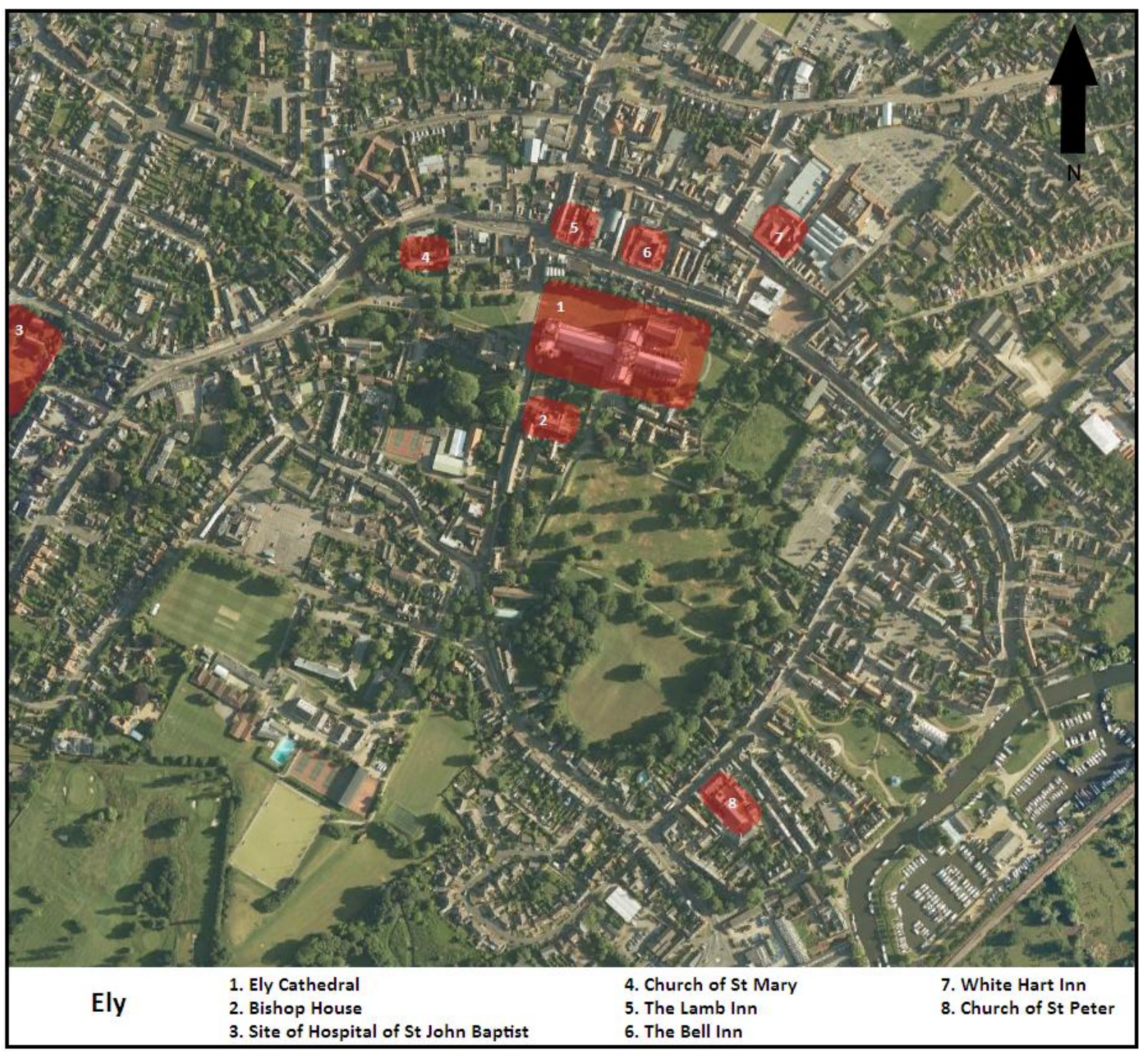

Figure 23. Plan of Ely showing relevant sites. Original satellite image reproduced from (C) 2011 Google.

As has been discussed above, travel for the pilgrim between Ely and Walsingham was facilitated by a relatively comprehensive sequence of raised tracks, earthworks and roads of varying historical date. In this section I will analyse the data recorded during my fieldwork, examining the pilgrim presence in the archaeological and etymological record of the Norfolk landscape between these two cult centres along the route network contemporary with Medieval pilgrimage. There were a number of relevant sites along the route which my fieldwork uses (the Hereward Way and paths relating to the Palmer's Way), and these are provided in a table in Appendix A. The analysis of the archaeological and etymological material will follow the chronological path of the fieldwork, working from Ely east into Norfolk to Brandon, then through the landscapes and settlements northwards to Swaffham, Castle Acre and finally Walsingham. The aspect of sensory dialogue with Ely as a landmark in the 
environment (and the route to Walsingham from the origin point in general) is not covered here, instead being supplied as a narrative whole in the penultimate section of this case study (a structure followed by the three subsequent case studies). Already discussed above are the archaeological traces of pilgrimage in Walsingham (the Slipper Chapel, the Church of St Mary, the Friary, and the Priory precinct) and contemporary sources of accommodation, and so will not be repeated here.

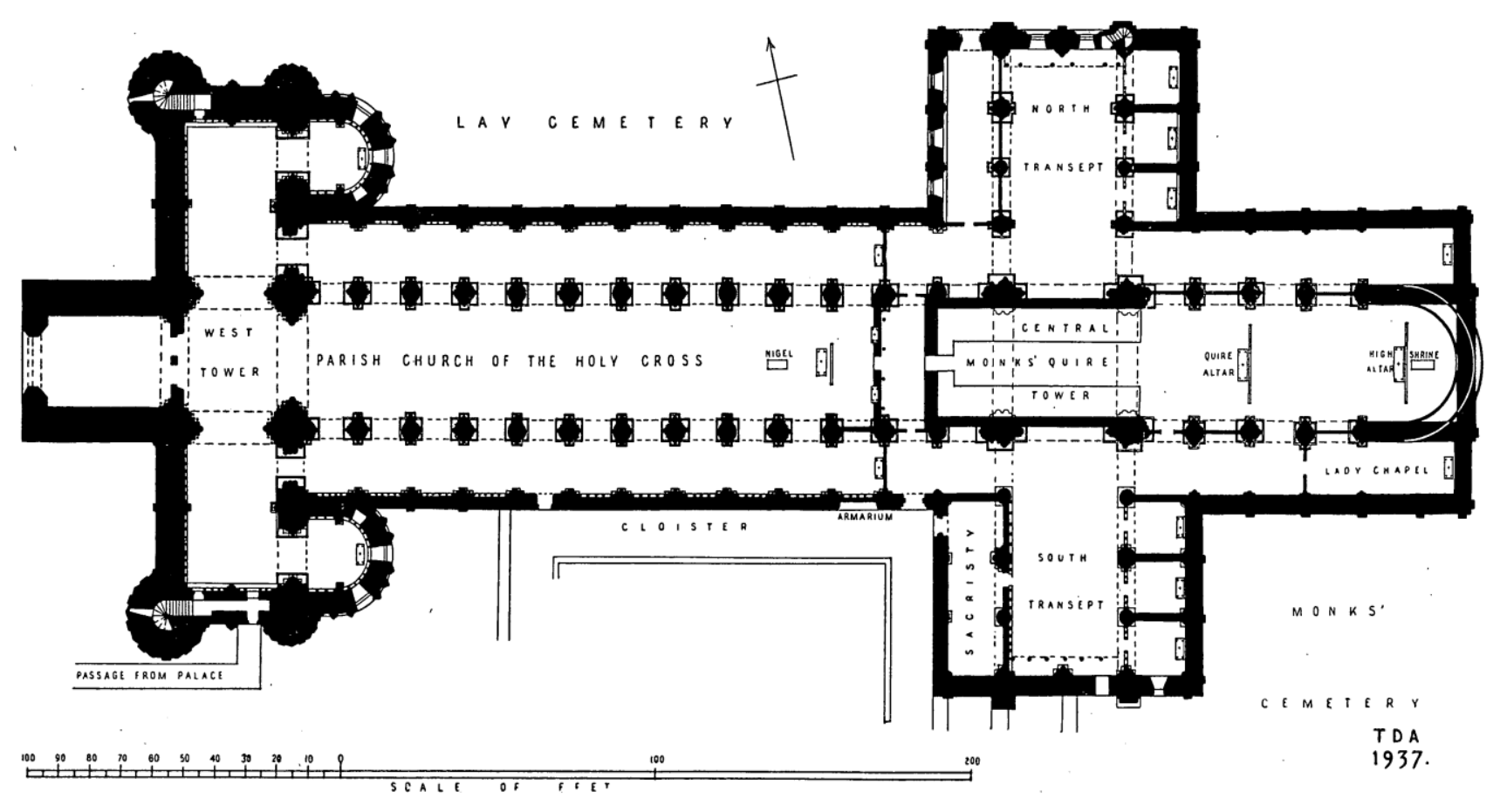

Figure 24. Plan of Ely Cathedral. Reproduced from Pugh, 2002, 60.

The Isle of Ely possesses one of the most prominent Christian monuments in the region. Ely cathedral with its delicate cupola or 'lantern tower' is a landmark amidst the fens, and has drawn devotees to the shrine of St Ethelreda since its construction in the early $12^{\text {th }}$ century. Dedicated to the Holy and Undivided Trinity, it evolved from an earlier monastic institution founded by St Ethelreda in $673 \mathrm{AD}$, transforming completely into a Benedictine monastic complex and cathedral in 1081 during Hereward the Wake's campaign of rebellion against Norman rule. Ely, aside from being an economic hub and prosperous was also a centre for pilgrims in Cambridgeshire (Pugh, 2002, 55). Donation records shown earlier in this chapter demonstrate that St Ethelreda's shrine in the extreme east of the cathedral (see Figure 24 above) received a sizeable portion of the building's annual revenue, primarily from pilgrims - no doubt this was due to the jealously guarded cache of relics relating to Ethelreda in her shrine reliquary (Pugh, 2002, 56 and Adair, 1978, 56). The octagonal 'Lantern Tower' which caused the cathedral to become known as 'one of the wonders of the Medieval world' was constructed in the $12^{\text {th }}$ century, but this architectural feat was completed in the late $14^{\text {th }}$ century after the initial tower collapsed in 1322 due to an earthquake (Maddison, 2000, 34). The Lady Chapel at the north of the cathedral was one of the largest of its kind, and above the doorway were inscriptions of all the benefactors to the chapel 'without which it would make small 
appeal to pilgrims who would pass it at the beginning of their progress' (Pugh, 2002, 68). The cloisters, Prior's Range and Old Bishop's Palace all date from the $12^{\text {th }}$ century, and an outer guest hall dating from roughly the same period was used to provide accommodation for travellers and pilgrims visiting the cathedral (Knowles and Hadcock, 1953, 65). The Cambridge HER records also show that at the western edge of the precinct lay inner guest quarters, built in 1301. Given their situation within the precinct boundary they may have been reserved for visiting monks or the wellto-do visitors of the cathedral, with the outer guest hall satisfying the needs of the general laity. At the south west end of the complex are remnants of this accommodation, with a small lane bearing the names 'Firmary Lane' in which is a private house called 'The Black Hostelry'. At the west end of the cathedral green the hospital of St Mary was built in 1171 to provide relief to the poor and to visiting pilgrims. The leper hospital of St John the Baptist was also constructed in the $12^{\text {th }}$ century and was united with St Mary's in 1254. Prior to and after this union, both hospitals were dependent on the cathedral priory (Knowles and Hadcock, 1953, 270).

With Ely being a regional economic and ecclesiastical hub, several inns developed to accommodate visiting merchants and pilgrims. Despite the scant documentary record for these sites and their surviving Medieval features, they deserve to be briefly mentioned here as part of the commercial infrastructure relevant to the Medieval pilgrim. Of the remaining inns with Medieval origins and fabric, one in particular is singled out for mention by Bishop Fordham in his 1416 survey of Ely - what is now 'The Lamb Hotel' at the western end of the High Street (see Figure 23). 'The White Hart Inn' on the north side of the market place is also of $15^{\text {th }}$ century origin, and 'The Bell' in the middle of the High Street is the last surviving inn to be of interest to us prior to the Reformation, dating from the early $16^{\text {th }}$ century (Pugh, 2002, 31). Whilst there are no documentary sources which recount specific pilgrim stays in these inns, they must have been used by devotees arriving at Ely to visit St Etheldreda's shrine and those continuing on towards Walsingham. Combined with the ecclesiastical options for travellers, pilgrims were well catered for in terms of accommodation and alms in Ely, and the Isle truly lived up to its reputation as a Christian haven amidst the fens.

\section{Hockwold cum Wilton}

The next settlement which the pilgrim would reach after traversing the Hereward Way eastwards across Norfolk's borders and along the Black Dyke would be the village of Hockwold-cum-Wilton (these tracks and earthwork are covered in the 'Medieval Route Network' section of this case study). As Wilton village it was ruled by the same lords during the reign of Edward the Confessor as Hockwold, and soon after became merged (in administrative terms) with nearby Hockwold or Hocuuella (Blomefield, 1805, 174). The village stands only a few hundred metres from the Black Dyke's end, at the border of the fenlands as they segue into the uplands of western Norfolk. Despite being only a matter of miles from the pilgrim stopover of Brandon on the Palmer's Way, evidence for the pilgrim presence here is limited but compelling. Two monuments in the centre of the village have strong dedicatory ties to the phenomenon, and seem to support the use of the Hereward Way and Black Dyke by pilgrims arriving from Ely. The first, the parish church $\left(14^{\text {th }}\right.$ century) is dedicated to St James, the patron saint of all things pilgrim related and celebrated by the universally known Camino de Santiago de Compostela (otherwise called the St James Way or 'Jakobsweg') leading to 
Santiago and St James' shrine, which was one of the three principal pilgrimages in Medieval Christendom (the other two being Rome and Jerusalem). This church possessed a fine set of wooden panels which, whilst now lost to time, are worth recounting from Blomefield's early $19^{\text {th }}$ century history of Norfolk:

'Behind the [communion] table is an old wainscot partition which runs the breadth of the chancel; on a panel of this wainscot are represented two priests kneeling at an altar, with their books before them; on another panel the figure of St. John the Evangelist, with a cup, and a dragon issuing out of it, and on a label In principio erat Verbum [In the beginning was the Word], under him the portrait of a man kneeling, and this label, Ora pro nobis beate Jacobe [Pray for us St. James]; on a third pannel, the figure of St. John Baptist with a lamb, andc. and a label Ecce Agnus Dei [Behold the Lamb of God]; under him the portraiture of a woman bidding her beads [rosary], and this label Omnes Sancti Apostoli orate pro nobis [May all the Holy Apostles pray for us]. On the panels by St. John the Evangelist, are the arms of lords Scales, Poinings, Arundel, earl Warren, and St. George.' (Blomefield, $1805,174)$.

The depiction of rosaries and saintly intercessions point towards a Catholic, pre-Reformation origin for these panels, which may have been prayed to by both locals and passing pilgrims. The phrase 'Ora pro nobis beate Jacobe [Pray for us St. James]' is particularly noteworthy, as it appears on several inscriptions (churches, wayside crosses and chapels) along the Camino de Santiago and also in the $14^{\text {th }}$ century Codex Calixtinus, a contemporary pilgrims' guide to Santiago de Compostela, which potentially links the church further to the pilgrim aspect of St James' cult and dedication (Gerson, Stones and Krochalis, 1998, 352). The second ecclesiastical monument in the centre of Hockwold-cum-Wilton is an unremarkably decorated early $14^{\text {th }}$ century cross known locally as 'The Pilgrim Cross'. Little is known about this cross. The reasons for erecting crosses in a landscape are varied, and it might be considered a statement of Christian presence in the landscape, 'In the wider medieval countryside, crosses had other roles, as waymarkers, boundary points and preaching crosses.' (Turner, 2006a, 34). In this case, being in the centre of the settlement it could have functioned primarily as a village cross, a preaching post or point for outdoor worship, but it is telling that it is commonly referred to by locals and subsequently guide books as 'The Pilgrim Cross', which (if not a corrupted name) may suggests a past function as a prayer spot for pilgrims on their way to Brandon and the Palmer's Way.

\section{Brandon}

Brandon is located roughly 4 miles east of Hockwold cum Wilton, on the border between Suffolk and Norfolk. The road which arrives at the town from the south ('Bury Road') forms part of the Palmer's Way and links Brandon with Bury St Edmunds - an important ecclesiastical hub in Medieval England and home to the cult of St Edmund, one of the first English martyrs. Brandon has its origins as a market town, firstly renowned for its production of rabbit fur, and later as a supplier of gun flints. Flint is a key commodity in the history of the region, with the Neolithic flint mines of Grimes Graves 
being nearby. Its situation on the banks of the Little Ouse river and at the convergence of both Thetford road, London road and Bury road made it ideally suited for hosting trade for merchants and accommodation for travellers, and it is referenced in Eramus' colloquies on pilgrimage as a key town for overnight stops (Nichol, 1849, 199). Brandon was also tied to Ely (part of its diocese) during the Medieval period, and the Bishops of Ely collected the revenue generated by tolls at the bridge entering the town from the north via their own personal bailiff. In the register of Bishop Grey (1454 - 1479) we find reference to 'a mandate from the Bishop to the Bailiff of Brandon requiring him, whereas Thomas Passhelaw, lately the occupant of nostrum super pontem de Brandon, was dead, to admit John Herryman to be hermit there for his life 'si bene se gesserit,' the said hermit to keep the buildings of the hermitage in due repair, i.e., out of the offerings received from those who should cross the bridge.' (Gibbons, 1891, 195). This bridge also hosted (along with a toll collector) a small chapel dedicated to St Mary, and as is suggested by the text above, a small hermitage - whose occupant carried out duties in the chapel. The western approach to Brandon was made via the wooden 'fengate', which as its name suggests brought the traveller from the fenland borders into the town. This fell into a state of disrepair and was replaced by firstly a ferry which linked The Ram Inn with Ferry Street (now the High Street), but this too fell into disrepair and was replaced in 1497 by a bridge and linking causeway. The tolls from this 'service' went to Ely.

Brandon's church of St Peter is located on the London Road which leads out from the south west of the town. It is descended from a lone Saxon nave church, but was extensively rebuilt in the $14^{\text {th }}$ century. As a parish church it served the needs of locals in the usual cycle of liturgical celebrations and masses, and for pilgrims one can speculate that it may have provided a place of prayer and 'pilgrim blessing' (in a similar manner to the collegiate church at Roncesvalles, the first Spanish town along the Camino de Compostela) for those continuing to Walsingham. The documentary and archaeological record for potential pilgrim accommodation in Brandon is sparse, with only cursory references to 'by late medieval times inns for travellers were well established in the present High Street area' as quoted on the Brandon town council website (http://www.brandon.suffolk.gov.uk/Brandon_History.html). However, the one notable exception is The Ram Inn, where the ferry and subsequent causeway linked the road from the west to Brandon High Street (or 'Ferry Street' as it was known), which dates back to 1349 and would have sheltered pilgrims and travellers alike. This information is taken again from the town council website's section on historic buildings (http://www.brandon.suffolk.gov.uk/buildings.html). There was also a small Augustinian Priory at Bromehill, a mile north of Brandon near Weeting. This priory was dedicated jointly to St Thomas the martyr and the Blessed Virgin, with only seven canons presiding here (Page, 1906,375 ). By all accounts (mainly complaints by visiting nobility about the quality of the food, beds and lamps) the premises was rather shabby, but it would have provided a potential resting spot for some pilgrims, given the rule of charitable hospitality observed (however grudgingly at times) by monks (Page, 1906, 376). 


\section{Weeting}

Approximately a mile north of Brandon along the Palmer's Way is the small village of Weeting, on the edge of what is now Thetford Forest (a post-war plantation). Here there is an $11^{\text {th }}$ century church with another Marian dedication. Whilst being almost entirely rebuilt in the $19^{\text {th }}$ century, there are vestiges of $11^{\text {th }}$ century vertical stones in the north wall and quoins which betray its earlier origin, and its location close to the site of Weeting Castle suggests that it evolved from a manorial chapel attached to the castle. The site of the Medieval church of All Saints (now demolished) is located near All Saints road, and may have acted as the parish church for Weeting. Little information is present on this church, it being demolished in the mid- $18^{\text {th }}$ century, but its situation on the main road leading through the village and the fact that this road is named after its dedication suggests that it held a level of significance for the locals (although there is no evidence for relics), and perhaps for pilgrims passing through to receive a blessing before embarking on the 'Pilgrims' Walk' track through what is now Thetford Forest.
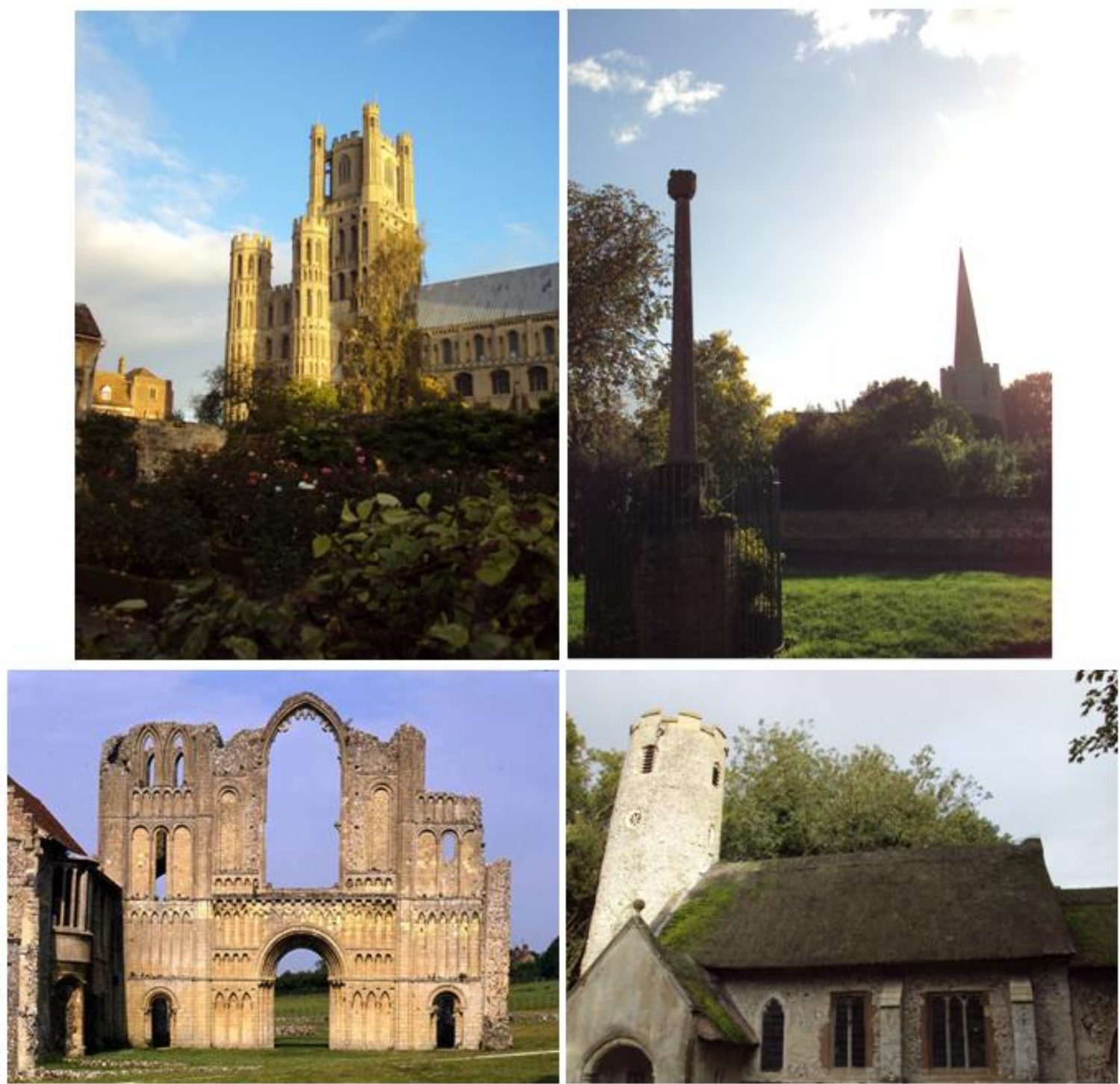

Figure 25. Clockwise: Ely Cathedral, Pilgrim Cross at Hockwold cum Wilton (with St James Church behind), St Mary's Church at Cranwich, Castle Acre Priory ruins. Photographs taken by author. 
The 'Pilgrims' Walk' is a straight flat-topped earthwork, which takes the traveller along a north/south axis for a kilometre to the outskirts of Cranwich village. This trackway is $80 \mathrm{~cm}$ high and $6 \mathrm{~m}$ wide, and encounters a 'stump cross' midway along its edge. Francis Blomefield was strongly convinced that this was used by Walsingham pilgrims as part of the Palmer's Way - 'In the fields of Weting north of the town is a green-way called 'Wolsingham-way', used (as it is said) by pilgrims on their way to the Lady of Walsingham' (Blomefield, 1805, 173). The orientation and elevation of this track leading out from Weeting northwards towards Walsingham, combined with the presence of the stump cross, makes this a case to be considered seriously. The stump cross stands in a clearing in Mount Ephraim plantation, an area which during the Medieval period would have been open grassland, which was likely (given Turner's interpretation of the role of the cross in the landscape) fulfilling a function as a wayside prayer point and directional aid for the pilgrim (Turner, 2006b, 34). It lacks any real ornament, crafted from Barnack stone, which was typically used to construct the Abbeys of Peterborough, Crowland, Ramsay, Sawtry and Bury St Edmunds, and was usually transported by barge along the fenland waterways via the river Welland, thereby linking this monument to a broader local tradition of ecclesiastical masonry (Ashurst and Dimes, 1998, 103).

\section{Cranwich}

Cranwich parish, into which the Pilgrims' Walk leads, possesses one of the oldest thatched roof round towers in the country dating back to the $11^{\text {th }}$ century and standing in a circular Saxon graveyard (Stanford, 2007, 32). The Medieval village that it served as a parish church (Cranwich) was all but deserted in the late Medieval period, with just a handful of modern houses now comprising the settlement. Surrounding the bell are knotwork-traced 'sound holes'. These would have amplified the range of the bells, which would have extended not just to the parish but also to those traversing the Pilgrims' Walk. Bells and their accompanying sound were important features of parish life; aside from marking out liturgical hours and prayer times, they 'drove away the devils present during a thunderstorm...came to symbolize individual parishes... and a traveller might hear the church bells before seeing the tower' (French, 2001, 146). Bells were often distinctive, and local parishioners took pride in the quality of their sound. This makes the case for adding sound holes in the Cranwich church all the more interesting and relevant to pilgrims and travellers from afar, as wayfarers may have formed a primary impression of Cranwich against their native parish based on these booming bells, amplified from the church tower through the sound holes (French, 2001, 147).

\section{Ickburgh}

Ickburgh lies one and a half miles north east from Cranwich, and here there was a pilgrim hospital attended by Austin Friars (Knowles and Hadcock, 1953, 280). Dedicated to St Mary and St Laurence it offered accommodation and care for poor travellers and pilgrims, the majority of which would be passing north towards Walsingham. One option from Cranwich to reach Swaffham would have been to use Brandon Road, which is commonly suggested to have been the primary route of Walsingham pilgrims. Little lies between these two settlements, apart from the small parish of Hilborough (or Hilburgh) - recorded in the Domesday Survey as 'Hildeburhwella'. Here there is a parish church of All Saints dating from the $13^{\text {th }}$ century, although nothing at this church suggests any particular 
relevance for pilgrims aside from an opportunity for prayer and brief rest. However, across the road is a small plantation of trees covering a series of small earthworks which once constituted the foundations of St Margaret's Chapel; a free chapel which became one of the many pilgrim wayside chapels en route to Walsingham (Bryant. 1910, 79). Here pilgrims would have stopped for prayer and blessings from the chaplain before continuing on to their next overnight stop in the market town of Swaffham (Blomefield, 1807, 114). Now all that remains of this chapel is a small tree covered grassy mound next to the A1065, a victim of the Reformation.

\section{Swaffham}

Highly valued in the Domesday Survey, Medieval Swaffham was 'in no sense a backwater...control over the town was exercised and contested by a number of wealthy aristocrats, 'courtiers' and government officials' (Heslop, 2005, 270). This town was central to the trading network for sheep and wool in Medieval Norfolk, and consequently was well linked in to the existing road network and easy to access (Wade-Martins, 1994, 76). It was also well-placed to offer accommodation and prayer for pilgrims travelling north towards Walsingham, and one surviving example of this is The Greyhound Inn. The building retains the bridging beams and wall plates which indicate a construction date of around 1520, and the inn is situated on the eastern edge of the market place next to the church (NHER 34721). Another potential respite for pilgrims may have been the monastic hospital at Friars Farm, but this site is speculative as no archaeological evidence has been sought or found (Knowles and Hadcock, 1953, 311). It is known though from documentary records that the hospital was dependent on Sawtry Abbey (Cambridgeshire) and may have offered shelter for poorer pilgrims unable to pay at one of the town's inns, suggested by the role of other recorded hospitals along the route (Knowles and Hadcock, 1953, 311).

The church of SS Peter and Paul at Swaffham has two features which distinguish it from the typical parish churches in Norfolk; stone carved shields, crossed keys and crossed swords motifs around the exterior base (including flying quadrofoils), and an 'angel roof'. The sword and key motifs are representative of St Peter and St Paul respectively (St Peters' keys to heaven and St Paul's swords representing his martyrdom), and the shields are blank, however it is likely that these would have been painted, possibly with the heraldries of donors and noblemen of the town. The earliest surviving phase of the interior is $14^{\text {th }}$ century, with later repairs and extensions, but the most striking aspect of the church is the late Medieval 'angel roof'. Here pilgrims would have prayed beneath 28 angels and 26 cherubim carved from chestnut, wings poised, each one individual and unique and probably gilded to enhance their divine quality (Heslop, 2005, 268). There have been several theories put forward as to the purpose of an angelic host on the vaulted ceilings of churches in Medieval East Anglia, with the most logical being to provide 'devotional inspiration with the angels exercising a benevolent and comforting guardianship over isolated groups of worshippers scattered across a harsh and lonely landscape.' (Bentley-Cranch and Marshall, 2005, 4). To a tired pilgrim the sight of these carvings high above their heads would have been awe-inspiring, and whilst not carved specifically for the pilgrim there can be no doubt that it would have constituted a memorable experience on the road to Walsingham. 


\section{Castle Acre}

A mile east of Swaffham, the Peddar's Way takes the traveller to Castle Acre, passing by two sites of interest; a small part of the route is known as 'Procession Lane'. The name may be connected with pilgrims processing towards Castle Acre, which became a pilgrim centre in its own right in the $15^{\text {th }}$ century housing the arm of St Philip, or a similar ecclesiastical reference. The second feature is the Deserted Medieval Village (DMV) of Great Palgrave.

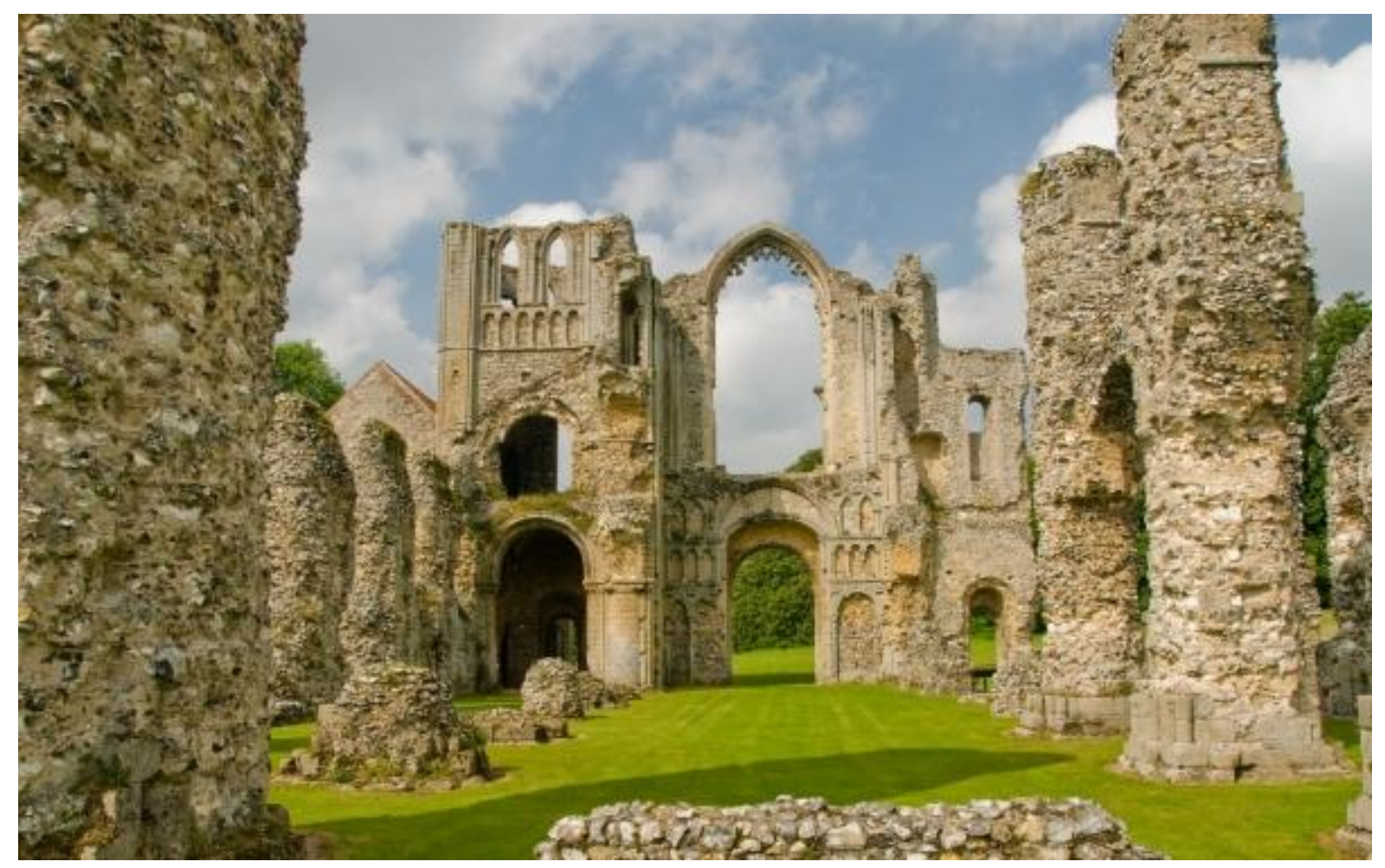

Figure 26. The ruins of Castle Acre Priory. Reproduced from http://www.castleacre.net/

Castle Acre was a prosperous market town by the Late Saxon period and given over to Norman rule by William the Conqueror as a gift to one of his most loyal lords after the conquest. The entrance to the settlement of Castle Acre is accessed via the Peddar's Way crossing the River Nar and proceeding uphill along Bailey St, through the $13^{\text {th }}$ century Bailey Gate. Built during the fortification of Castle Acre and contemporary with the castle after which the village is named, the gate led the pilgrim into the High Street. A hundred feet to the west along Priory road is Castle Acre Priory, founded in the $11^{\text {th }}$ century by the Cluniac order and dissolved in 1537, during the Reformation (see Figure 26 above). A guest hall is recorded on the first floor overlooking the cloisters which would have accommodated visitors and pilgrims, although given the size of the hall and its proximity to the Prior's own lodgings these were likely to have been high status i.e. ecclesiastical or aristocratic/royal (Coad and Coppack, 1998, 6). Examples of these high status visitors include the Prior of Wynlock, the equerry of the Abbot of Cluni, the Priors of Mt Didier and Lenton, and kings Henry III and Edward I (and queen Eleanor). They all stayed at Castle Acre Priory while on pilgrimage to the shrine at Walsingham (Page, 1906, 357). The church 'wherein are divers 
relics of saints' would have been an important feature for those pilgrims passing through Castle Acre, possibly their main reason for stopping here, and the Valor document of 1535 shows that reliquary of the priory church (containing the arm of St Philip) was receiving on average 10s in donations per year (Page, 1906, 357).

Two other noteworthy buildings in the village are the parish church and castle. The church is dedicated to St James (another link to pilgrimage), dating mainly from the $14^{\text {th }}$ century. The pulpit is painted with panels of a popular devotional theme, the four Latin doctors of the church (St Augustine, St Gregory, St Jerome and St Ambrose), and the roodscreen features a painting of St James, mutilated during the Reformation due to his patron status of pilgrimage (Nairn, 2000, 34). The church is unusually large, suggesting large congregations, and a busy town prior to the Reformation. Castle Acre castle was a motte and bailey castle and initially constructed in the late $11^{\text {th }}$ century. It continued to be an administrative centre until it became derelict in 1397 (Coad and Streeten, 1982, 18). The keep was built as a residence for the Warenne family and strengthened into a castle in the $12^{\text {th }}$ century, holding an imposing position in the local landscape.

\section{Weasenham All Saints \& East Barsham}

Leaving Castle Acre along the northern road, the pilgrim reached Weasenham All Saints, however little survives of the $14^{\text {th }}$ century church's original perpendicular style, being largely rebuilt in the $19^{\text {th }}$ century. From this point they followed the Swaffham road (part of the Palmer's Way) north towards Fakenham, where they might stop overnight. Fakenham was granted a charter to become a market town in 1250 , possessing a $13^{\text {th }}$ century parish church dedicated to SS Peter and Paul. The town has a reputation as a favoured spot for pilgrims to rest. However it is at Hempton (just before crossing the River Wensum and entering Fakenham), that there was an Augustinian Priory dedicated to St Stephen which cared for pilgrims (Knowles and Hadcock, 1953, 138). The Priory was 'situated at the end of a dam or causeway between the towns of Fakenham and Hemton, and hence was sometimes known as Demnesende', being founded originally as a hospital in c.1135 before becoming a priory at the start of the $13^{\text {th }}$ century and subsequently dissolved during the Reformation (Page, 1906, 381). In the second year of King John, the archbishop of Worcester gave permission 'for a fair to be held yearly on Tuesday in Whitsunday week, for the profit and use of the brethren of the hospital of St. Stephen, (as then called,) by the causey of Fakenham' which pilgrims would have encountered on their way into or past Fakenham (Blomefield, 1805, 100). The earliest architecture of Fakenham church is $13^{\text {th }}$ century in origin, however the reused masonry in its walls indicates that an older building once stood on this site, possibly a Saxon church which served the needs of its parishioners and in later periods that of pilgrims (Blomefield, 1805, 100).

Whether passing by, or staying, to leave Fankenham and head closer towards Walsingham the pilgrim needed to proceed along Fakenham road (now the B1105) to East Barsham. Less than a mile north are the remains of the shaft and base of a Medieval 'preaching post', and the field in which they lay is shown as 'Preaching Cross Fields' in the early $19^{\text {th }}$ century tithe maps of Norfolk 
(Kain and Prince, 2000, 71; NHER 15477). One interpretation is that it may have been a place in which priests linked to Walsingham preached to the pilgrims preparing them for their final leg of the pilgrimage. However, this is my own speculation, as the wealth of parish churches (and at that time wayside chapels) would have provided plenty of venues for services and sermons which suggests that it could have been for Walsingham pilgrim related activity. After this the pilgrim would have an uninterrupted journey to East Barsham, with its $14^{\text {th }}$ century church of All Saints. This church effectively lies at the edge of the valley through which the River Stiffkey flows to Walsingham Priory, and so occupies an important position in the procession towards Walsingham. The church was under the care of the monks at Castle Acre, and next to the church stood a chapel dedicated to Our Lady (possibly linked to the Walsingham cult), and Blomefield suggest that pilgrims took mass here before progressing down along Fakenham road towards the Slipper Chapel and subsequently along the 'Holy Mile' towards and into Walsingham itself (Blomefield, 1805, 61). 

pilgrims

For the pilgrim, parish churches (much like wayside shrines and crosses) offer both spiritual and physical shelter within (at times) arduous landscapes. Whilst not offering as much to travellers and pilgrims as religious houses (which could offer bed, board and blessings), the parish church was both a comfort and source of spiritual renewal on the road. Many churches possessed minor relics, attached holy wells and sites of miraculous events, and therefore constituted an important and frequent built element of the pilgrim journey. It is, therefore, worth briefly exploring what the parish church meant as an institution and part of the social and spiritual fabric to both locals and also visitors, whom would be able to relate to the church based on their own experiences of parish life at home.

A parish is the smallest administrative community unit within a diocese. For the laity of a parish, the church functioned as both the spiritual and social hub for the community, effectively embodying the community, and 'the laity expressed and acted upon their understanding of community through their involvement in parish activities... they worked collectively to build and keep a worthy home for the host.' (French, 2001, 23). As has been mentioned in the previous section, details such as the quality of the church's bells were a source of personal pride for parishioners, and for those whose parish was too poor or rural to afford a church, chapels of ease were erected to service the laity - some of which became pilgrim destinations at a local level (Webb, 2001, 79: French, 2001, 24). The concept of non-local visitors to the church was not unfamiliar in the parish; as a rule, the presiding bishop was obliged to hold a visitation once every three years - although this was admittedly an optimistic obligation (French, 2001, 32). The laity were intimately involved in the care, fundraising and liturgical cycle of their church, although the Eucharist for parishioners was held typically only once a year. All of these duties were rooted in the belief that they were serving God, as 'fixing the church made the building a worthy home for the host...[and] making contributions to meet the parish's financial needs became a local expression of religious faith rather than simply a response to the demands of church doctrine or polity' (French, 2001, 100). They were generally proud of their parish and church, viewing both as inseparable and tangible demonstrations of both their devotion to God and their local identity. Local saint cults heightened this sense of geographic and a spiritual localism within the parish which parishioners were keen to impress upon visitors (Jones, 2007, 35). The liturgical cycle and structure was essentially the same across English parishes, however "local details [folklore, saint cults] infused the processional route, locations of the celebration, and lay participation with additional significance.' (French, 2001, 186) This mention of processional routes recalls the 'Procession Lane' outside of Swaffham en route to Castle Acre, which may have played a part in liturgical celebrations centring around one of these two parishes. 


$\begin{array}{lrrrr}\text { Saint(s) } & \text { No. } & \text { \% } & \text { National Rank } & \text { Norfolk Rank } \\ \text { St Mary } & & 21.4 & 1 & 1 \\ \text { All Saints } & 151 & 19.1 & 2 & 2 \\ \text { St Andrew } & 128 & 11.3 & 5 & 3 \\ \text { St Peter } & 73 & 7.8 & 3 & 4 \\ \text { St Margaret } & 52 & 6.9 & 11 & 5 \\ \text { St Michael } & 49 & 4.4 & 4 & \text { N/A } \\ \text { SS Peter and Paul } & 31 & 3.4 & 7 & 8 \\ \text { St Nicholas } & 24 & 3.2 & \text { N/A } \\ \text { St Botolph } & 23 & 2.5 & & \\ \text { Others (41) } & 18 & 20 & & \\ & 150 & & & \end{array}$

Figure 27. Table for Saint Dedication Frequencies for Surviving Norfolk Pre-Reformation Churches

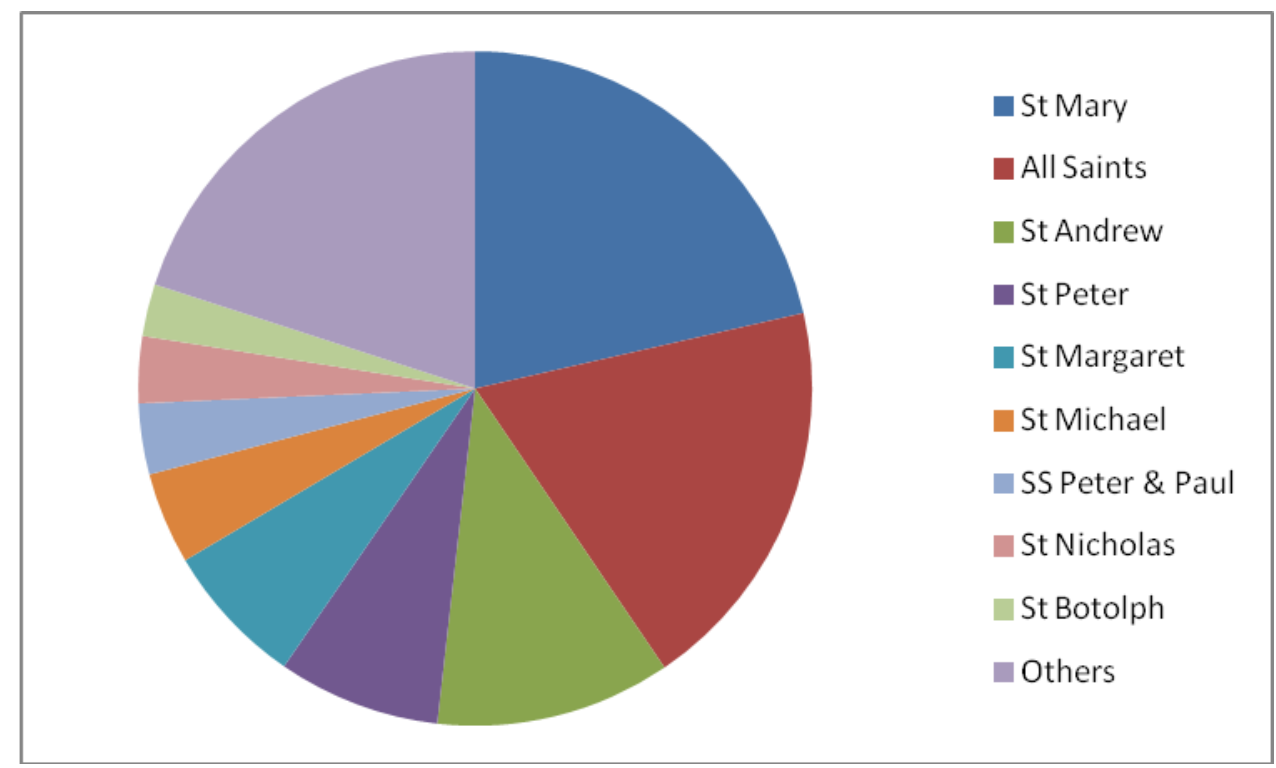

Figure 28. Chart Comparing Frequency of Saint Dedications in Surviving Norfolk Pre-Reformation Churches

Medieval Norfolk could claim one of the highest tallies for parish churches within England prior to the Reformation, as well as religious houses. Of the 921 churches built between the $11^{\text {th }}$ and $16^{\text {th }}$ centuries, 704 survive (over 610 of which are still in active use), and these are presented individually in Appendix E (Wade-Martins, 1994, 60). I have chosen to record only those surviving, as the location and dedications of the remaining 217 are comparatively unsubstantiated, often surviving as passing references in various charters or ecclesiastical documents, and no mention of their patron saint. It is therefore more profitable to work from a solid and existing dataset, which can be corroborated through cross-referencing both primary and secondary sources, and this 
practise is followed in the subsequent case studies. Dedications to St Mary emerge as the most popular, which concurs with the findings of Linnell (1962) at both a national and county level. Marian dedications across Western Christendom blossomed during and after the $12^{\text {th }}$ century, when St Bernard of Clairveux (1090 - 1153) and Pope Innocent the Third (1198 - 1216) propagated her cult (Bond, 1914, 31). Prior to this, Bede records only three dedications to Mary, as opposed to SS Paul and Peter, whose dedications outweighed all others (Bond, 1914, 31). This is an unsurprising trend, given the importance of Mary in the Christian divine hierarchy as both Mother and Protector, and 'having borne God, it was thought, she was uniquely placed to ask her son for his mercy to those who gave her their allegiance' (Jones, 2007, 67). The numerical hierarchy of saint dedications in later Medieval England can be listed as follows:

St Mary/Blessed Virgin - 2,335

All Saints/All Hallows - 1,217

St Peter $-1,129$

St Michael - 687

St Andrew - 637

St John the Baptist - 500

St Nicholas - 437

St James the Elder (patron of pilgrimage) - 414

St Paul - 326

(Jones, 2007, 34)

Mary's popularity as manifested through dedications was highest in the central east of England (Suffolk, Cambridgeshire, Norfolk, Essex, Hertfordshire and Bedfordshire). The 'All Saints' dedication has been thought of being Saxon in origin, thereby possibly corresponding to Saxon settlement patterns, and there is a discernable correlation between their distribution and the Danelaw boundary; i.e. they are more frequent within this region where Danish law held sway over Saxon custom (Jones, 2007, 129). Another interesting connection is with regard to dedication frequency, this time between St Edmund and Norfolk; 17 churches bear his name here, the highest number in England, despite it not being his native county and his shrine being in Suffolk. 


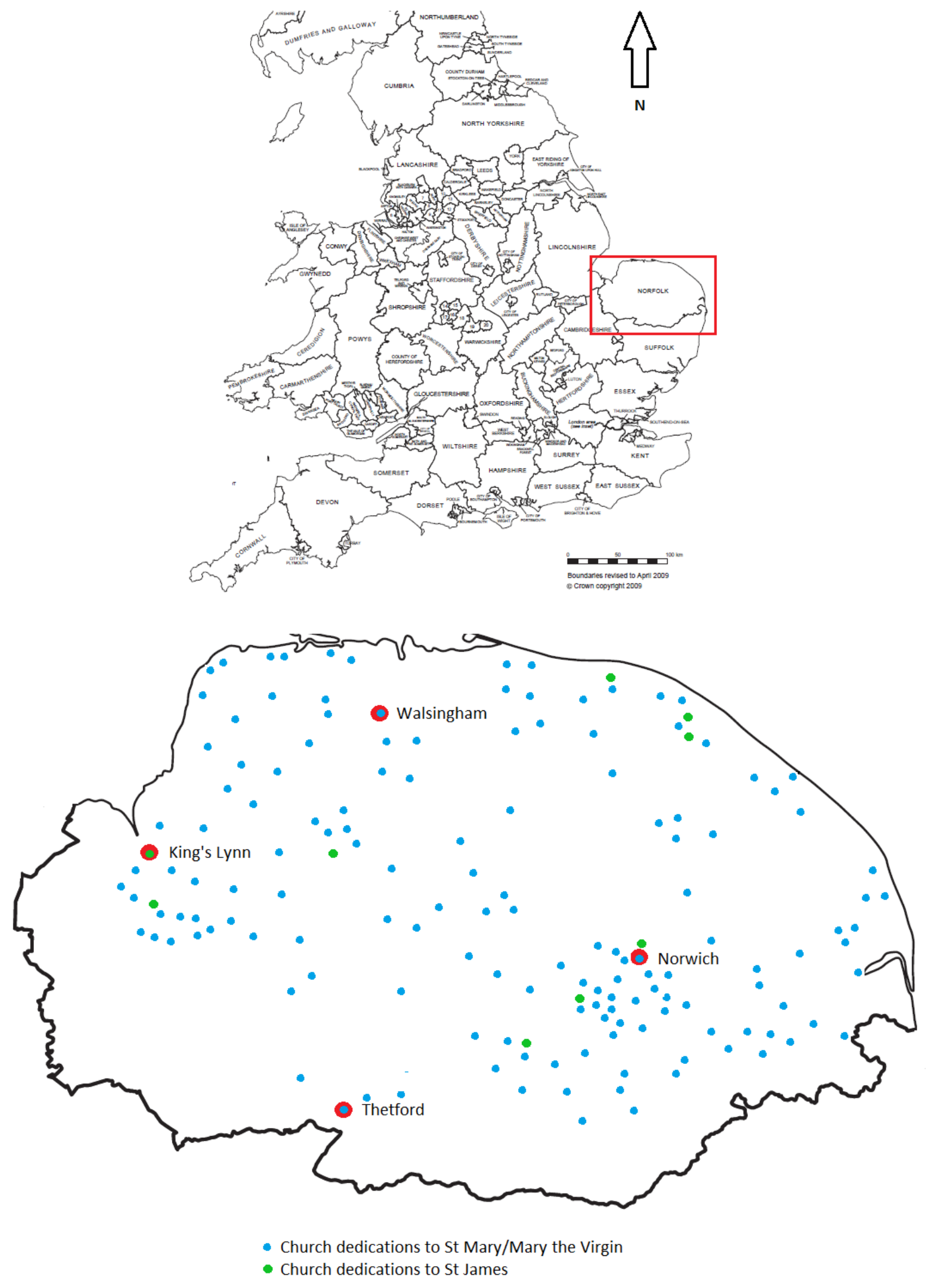

Figure 29. Map Displaying the Scatter of Surviving St Mary and St James pre-Reformation Church Dedications Across Norfolk. Redrawn after the 2000 Ordnance Survey GB Coastline and Administrative Boundary Map. 
From the table above we can see that Mary retains her position as the most highly favoured recipient of devotions (albeit in different guises as 'Our Lady of...', 'Blessed Virgin', 'St Mary of...'), and although not counted in the figures above she also features heavily in parish names, such as 'Thwaite St Mary'. Her distribution in the Norfolk landscape (see Figure 29 above) does not at first glance seem to align with any influence of the Walsingham cult, in terms of commonly used routes of access from the south, east or west. One possible cause for this may be the destruction of the many alleged wayside chapels which lined the road(s) leading to Walsingham, of which only 2 remain; Red Mount Chapel (1485) in Kings Lynn, and the Slipper chapel at Houghton St Giles. The whereabouts of the majority of the others remains unrecorded or the documents relating to their location undiscovered. There are identifiable Marian dedication clusters around the two of the major urban centres of Medieval Norfolk - Kings Lynn and Norwich (also two of the seven planned towns in Norfolk) - and also along the northern coastline. In the ninth century, the Belgian monk Paschasius Radbertus wrote 'De Nativitae Sanctae Mariae', which attributed the Virgin Mary with links to the sea, suggesting that the origin of the name Mary was 'Stella Maris' or 'Stilla Maris' ('Star of the Sea' or 'Drop of the Sea'), which as a dedication would have been an appropriate patron saint for parish churches whose congregation were involved with the sea as sailors or fishermen (Stouck, $1998,109)$. This also ties into the local folkloric concept of the Milky Way being a celestial or starry 'Walsingham Way', guiding people to Walsingham and Mary's shrine.

Mary's popularity in Norfolk also has roots in her links to agriculture. Her feast day of the Assumption (15 ${ }^{\text {th }}$ August) was known as 'Mary in Harvest', and the Nativity feast ( $8^{\text {th }}$ September) was known as 'Little Mary in Harvest'. The elements of renewal surrounding both these feasts, as well as the coinciding of the Assumption feast with the harvest, helped to cement Mary's place in the hearts of the rural and agricultural communities (Jones, 2007, 179). It is likely that this played a role in the seasonality of local pilgrimage to Walsingham, with the Norfolk laity (and others further afield) giving pre and post-harvest thanks, and purchasing ampullae to increase the next year's yield.

Other saints which held in high renown in Norfolk included St Andrew (for fishermen), St Peter (fishermen, harvesters, sailors, bakers), St Margaret (who performed many pilgrimages, and was related to St Thomas of Canterbury), St Michael (healing and baptism), St Nicholas (mariners), and St Botolph (farmers), (Jones, 2007, 35)). It is evident that patron saints of agricultural and maritime practises were the most popular, and given Norfolk's status as a county of grain, wool and fish exports this is hardly surprising. If the St Margaret dedications referred to the 'English' saint, rather than the lady and martyr of Antioch, then we come across a significant statistic. St Margaret (English) is an interesting $12^{\text {th }}$ century figure, as her sainthood was effectively gained mainly from piety and undertaking numerous pilgrimages (during her journey to Jerusalem she lived a life of penance in Bethlehem), so she may have had link to the practise in the eyes of the laity. This could link her frequency in dedications to a heightened awareness, appreciation or presence of pilgrimage among the laity of Norfolk, and may explain the comparatively infrequent level of dedications to that traditional patron of pilgrimage, St James the Greater. However if the dedications refer to St Margaret of Antioch then this too is of interest in the pilgrim context, as she was the patron saint of nurses which may link the church location to a hospital (which could offer shelter to pilgrims), and 
this is in fact the case at Hardwick and King's Lynn where they were attached to these buildings (Page, 1906, 439 - 442). An alternative explanation for her popularity would involve Margaret of Antioch's alleged patronage of sheep and shepherds, which also ties into Norfolk's prime industry of wool production and explain her popularity in the region.

St James the Greater possesses only ten dedications, which given presence of such a prestigious pilgrim site in Norfolk is surprising. His churches are plotted (along with those of St Mary) in Figure 29 (above) due to his long standing association with pilgrimage, but it makes for puzzling analysis. Their locations do not readily correlate with those of the pilgrim hospitals, nor the routes which are traditionally thought of as leading into Walsingham from the south, west and east. Thus we must conclude that, at the moment, there is no discernible distribution pattern linking the few (surviving) St James dedications in Norfolk and the Walsingham cult. However, they are of interest: at Kings Lynn, there is a St James dedication, as well as a pilgrim chapel (reputably one of the finest of the Walsingham wayside shrines), and the main parish church at Castle Acre is also dedicated to him. Norwich too, although the town has such a number of churches and religious houses that the significance of this specific dedication is rather diminished. This does not mean however that the few St James churches which were sited along the Walsingham way or other routes to the shrine were not viewed as beneficial to the pilgrim. In this context, the church of St James at Castle Acre may have held pilgrim specific services of blessing as they made their way onward towards Walsingham, in a similar manner to the St James chapel in Roncesvalles at the Spanish start of the Camino de Compostela (Dunn and Davidson, 1996, 48). 


\subsection{The Sensory Dialogue Between the Pilgrim and the Landscape from Ely to Walsingham}

Having covered the physical landscape, the historical and archaeological remnants of pilgrimage and their interpretation, it is now time to analyse these data sets in regard to areas of liminality, and lines of sight between pilgrim and monument; the sensory aspect of travel through unfamiliar landscapes with regard to Christian theology and popular motifs. As discussed in Chapter 2, a liminal zone is one where there is transition, be it between topographic types (e.g. entering a forest, crossing a river or natural boundary), or spatial distinctions (e.g. leaving an unpopulated area and entering the outskirts if a settlement). Both of these physical liminal types also produce mental transitions which, in the case of Medieval pilgrimage, tie into theological and scriptural concepts of wilderness, sanctuary, profane and sacred spaces. This encounter and search for these areas of interaction and transition between human and the divine lie at the heart of pilgrimage, so that 'by its very nature, pilgrimage challenges the traditional line between physical and spiritual, between heaven and earth, and most significantly, between man and God.' (Weber, 2005, 27) Despite the mainly flat terrain between Ely and Walsingham, there are many instances where natural features, built monuments and sight lines combine to form these transitional zones, often bordering and leading from one 'area' along the route to another. I will now examine four individual areas along the route; leaving Ely, travelling along the Blackdyke earthwork leading to Hockwold cum Wilton, entering Castle Acre, and finally entering Walsingham.

Ely:

Beginning with the Isle of Ely, we can see many different types of liminal zones which revolve around the cathedral and geography of the Isle itself, topographical and spiritual, combined with aspects of sanctuary, monument sightlines and settlement density. Physically, and at the most basic level, as an 'island' in the Medieval landscape we have the fens surrounding Ely providing a distinctive boundary between upland and lowland. Ely's height compared with the surrounding topography creates a clear transition for the traveller descending to the causeways or Hereward's Way, from a stable drier land type to the wetland (see Figure 30 below). Leaving Ely also sees a transition in the built landscape, from the highly populated Isle to the sparsely inhabited fens, with Ely cathedral standing high above the immediate fenlands and visible for several miles along the Hereward Way. Where now surburban housing lies on land reclaimed from drained fens in, Medieval times Ely would have appeared as a sharply defined boundary between that which was high, dry and settled, and that which was wet and untamed.

However, transition boundaries are not restricted to the physical realm. In a more intangible sense, the dialogue between Ely, the pilgrim, and the surrounding fenland produces some interesting liminal interactions. One example is the movement from a sacred to a profane space, that of Ely with its cathedral, monastic history and reputation as a holy island amongst the fens, to the dangerous marshes and swamps surrounding the isle. The symbolism of 'wilderness' and 'sanctuary' is well documented in the Christian tradition, and rests at the core at some of the most 
celebrated biblical tales such as Jesus' temptation by the devil in the desert, and underpins the activities of several prophets and the original desert fathers (Brock, 1973, 5). These biblical tales would likely have been known to the majority of the laity, with the 'wilderness and sanctuary' polarity holding a special resonance for those to whom the harsh fenland landscape was a novelty. In the case of the Isle of Ely, there was a transition from what was effectively a highly visible and prominent Christian sanctuary, into the often mist drenched boggy surroundings below - a hazardous landscape compounded by local folklore (Westwood and Simpson, 2005, 500). This spiritual frontier would have undoubtedly played to the superstitions of the medieval mind, especially when accompanied by the eerie glow of the cathedral's copula as described by Defoe:

'As these fenns appear cover'd with water, so I observ'd too, that they generally at this latter part of the year appear also cover'd with foggs, so that when the Downs and higher grounds of the adjacent country were gilded by the beams of the sun, the Isle of Ely look'd as if wrapp'd up in blankets, and nothing to be seen, but now and then, the lanthorn or cupola of Ely Minster.' (Defoe, 1724, 79)

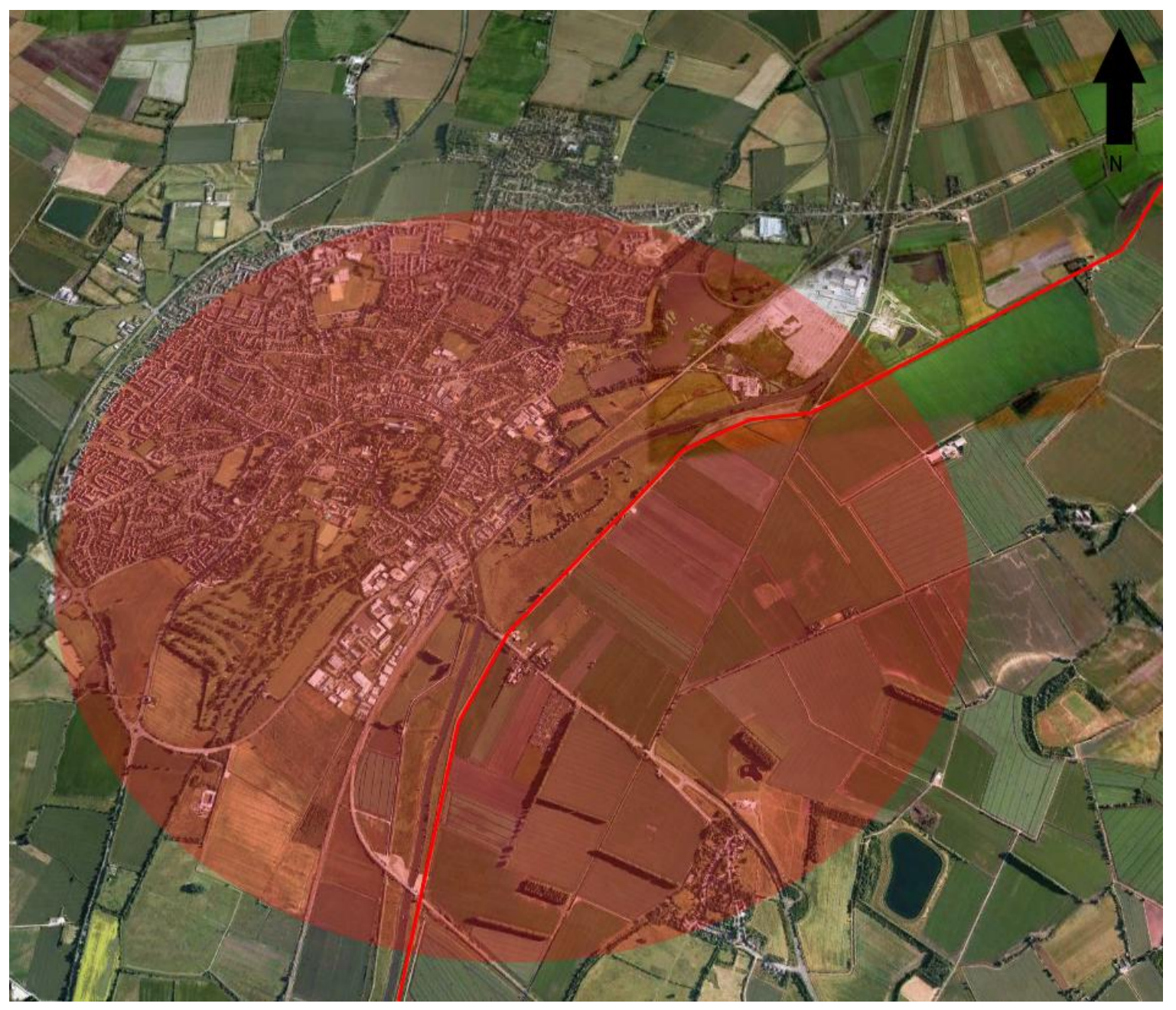

Figure 30. Map of Ely showing Hereward Way (red) and radius of transition between the Isle and the fenland (red shade). Original satellite image reproduced from (c) 2011 Google. 
Coupled with this realm of 'spiritual' visibility, was that of actual visibility. From the elevated ground on which Ely cathedral rests, there is an extensive panorama of the 'fen-scape' which is effectively uninterrupted for several miles when fog is not lying heavily over the wetlands. This majestic view and the subsequent transition down into the fens, where visibility is severely limited by weather conditions, obstacles in the form of trees and gentle undulations in the flat topography, may have given rise to the process of reading the landscape. Lynch defines 'legibility of a landscape' by the following statement: 'Environments are examined for a cohesive structure, so a legible environment is one where the spatial structure and arrangement is relatively obvious.' (Lynch, 1960, 3) Weisman has expanded upon Lynch's statement by adding that the landscape would have different levels of significance to varying social groups, with whom pilgrims can be included, with their heightened focus on spirituality in themselves and the landscape through which they were travelling (Rockman and Steele, 2003, 24). Following these assertions, the most effective method of examining a landscape's structure is clearly from an elevated point; an opportunity that Ely provides. On a clear day the course of the River Ouse is highly visible along a south-west/north-east axis, which meets the Isle of Ely and leads the pilgrim onto the Hereward's Way. Also visible would have been a network of small causeways and raised tracks covering the wetlands (Darby, 1974, 36). In a time when maps were scarce and effectively unavailable to the laity, directions and routes would have been passed on by word of mouth, corroborated by waystones, inscribed crosses and distinctive physical landmarks (Verdon, 2003, 68). Even the maps which were inscribed such as the Gough map, whilst showing certain major road networks and towns in a previously unseen level of detail, would have been effectively useless for navigating at a local detailed level (Ohler, 1989, 117). Consequently the act of 'reading' the landscape one is about to traverse, looking out for mentioned natural features which mark the way, would have been a useful orienteering exercise for any traveller.

Another 'boundary' which has already been mentioned previously (with regard to Cranwich's church tower and its amplifying 'holes') is that of sound. The prominence of the cathedral tower, coupled with the remarkably flat landscape would no doubt have given the Ely bells an impressive audial range. When combined with the noise in general created by Ely (as with any large settlement), the pilgrim would have remained within earshot of the Isle for several miles. From a pilgrim's perspective the clanging bells would have signalled one of a variety of scheduled times for devotion - a notable example being the Angelus hours of 6am, noon and $6 \mathrm{pm}$ - and may also have delineated a range of sanctity, in that a particular church's Christian influence covered the land in which the bells were heard (French, 2000, 47).

In this case all of these liminal zones owe their existence to a great degree to the built environment of Ely, especially the imposing figure of the cathedral. However the next area along the Walsingham Way to be examined involves a different emphasis - the interaction between the pilgrim and largely natural features when traversing the Blackdyke. In the earliest monastic times in Britain, nature and the wilderness were tools through which one could experience revelation and dialogue with the divine, with the celebrated peregrines in Scotland retreating to small islands for contemplation (Rees, 2001, 12). Nature and wilderness enjoyed a dualistic presence in Christian 
theology, popularly representing both godlessness and also purity, and in pilgrimage crossing harsh terrain both symbolised and increased the traveller's piety (Webb, 1999, 31).

\section{The Blackdyke:}

The Blackdyke stretches for three miles alongside the Little Ouse River through marshland and flood plains filled with grazing cows (see Figure 31 below). This section involves the pilgrim on several levels, including sight lines, reading the landscape or mental mapping, elevated travel, wilderness to sanctuary and landscape transition. It is also worth considering the local folklore aspect involving the ghosts of nuns and horses wandering the river banks - however whilst this would have been known to locals, 'foreigners' may only have a brief awareness of this danger from those who gave directions to Walsingham (Westwood and Simpson, 2005, 493). Fortunately a large part of the area through which the dike passes is now a nature reserve, and consequently the bulrushes, reeds and willows

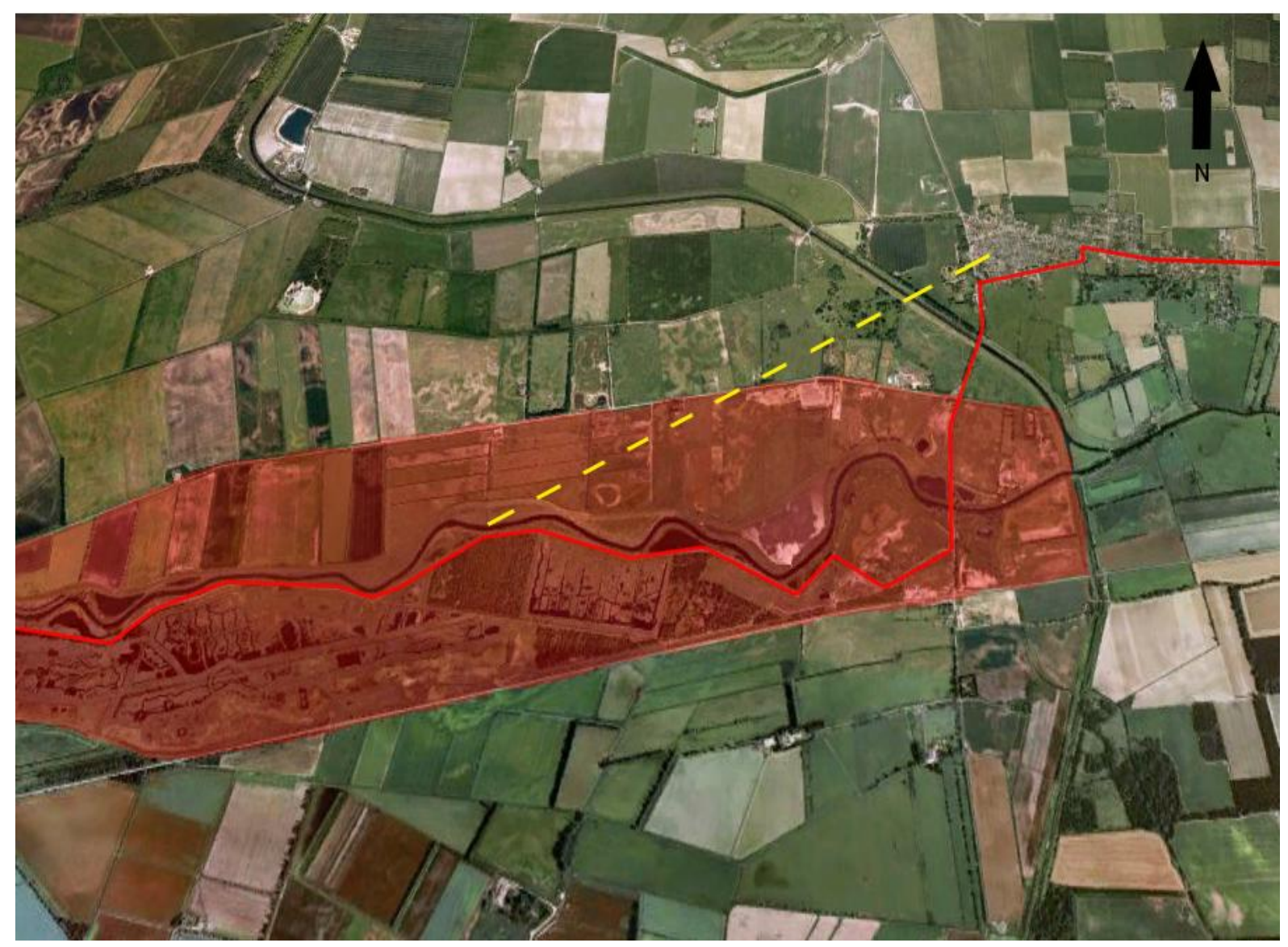

Figure 31. Map of Blackdyke, showing route along earthwork, radius of elevation, and sight line to St James' Church in Hockwold cum Wilton. Original satellite image reproduced from (C) 2011 Google. 
grow freely creating as close a fenland environment as possible to that experienced by the Medieval pilgrim prior to the drainage. This is the environment through which the pilgrim would have been travelling for several miles, hemmed in by vegetation and thus unable to relate themselves spatially to the landscape. However, the elevation afforded by the dyke combined with the typically flat Norfolk landscape allows the traveller to place themselves within the landscape, view the route and its landmarks and also rise above the majority of the environment. As we have seen with the case of Ely, legibility of a landscape goes hand in hand with elevation, and whilst the rise in ground on the dyke is significantly less than the Isle of Ely, it still becomes an effective vantage point by which one can identify the next settlement, direction of travel and other travellers (Rockman and Steele, 2003, 24). A sight line to the spire of St James' church in Hockwold cum Wilton from the Blackdyke reveals itself when atop the earthwork (as recorded in yellow in Figure 31 above). As has been discussed above, the link between St James and the pilgrim is well established in Christian hagiographic and iconographic tradition. However to the non-local pilgrim this would not have been a readily apparent dedication from the distance of the Blackdyke. It was more likely that the highly visible church tower fulfilled the roles of both an identifiable landmark (to which prior received directions made reference), drawing the pilgrim towards Hockwold cum Wilton, and also perhaps as a Christian boundary marker against the edge of the fens - signifying 'sanctuary' at the border of the fenland 'wilderness'.

The elevation of the earthwork (shown in translucent red in Figure 31 above) also has sensory ramifications beyond the 'legibility' issue. Travelling above and not merely through a landscape brought one literally closer to the heavens, albeit marginally, but also the simple process of rising above an environment produces a sense of detachment. This allows one to both survey 'God's creation', and also shift oneself away from the earthly and produce a more contemplative mood, which is the real aim of pilgrimage - to be an exile from daily thought and worldly cares, concentrating instead on the divine. The concept of deliberate removal from one's environment is well recorded in the Blickling Homilies in which we find the following prose: 'We are in the country of exile of this world; we are exiles, and always have been since the first parent of humankind broke God's commands; and so in sin we were sent on this miserable pilgrimage and now ever after we have to look for another homeland.' (Morris, 2000, 12)

\section{Castle Acre:}

As has been mentioned earlier in this chapter, on a practical level Castle Acre offered shelter, sustenance and sanctuary for the pilgrim and received its fair share of high status guests (sometimes on their way to Walsingham). However as one of the most notorious and impressive sites encountered along the pilgrim's route to Walsingham, Castle Acre would have engaged the traveller on a number of levels from near and afar, generating a dialogue with the pilgrim's senses, and these will be addressed in accordance with the pilgrim's approach from Swaffham, passing the DMV of Great Palgrave. Castle Acre lies on the valley side of the river Nar, with its priory sitting at the foot of the river (see Figure 32 below). It is possible to delineate three areas with regard to this aspect: 
1. The preliminary encounter from afar.

2. Arriving at the valley floor where the Priory lies and crossing the River Nar.

3. The walk up through the Bailey Gate into the heart of Castle Acre, and subsequently the priory.

When cresting the top of the hill, before the road leads the pilgrim down into the valley, the first sightline is that of the church tower of St James. In terms of the effect this sight would have had on a pilgrim, it would reinforce the concept of the landscape being under the protection of both the fortified town and God himself, with the church as a demonstration of the Christian influence upon the land. If the pilgrim knew of the dedication then there may have been an added level of symbolism in this sight, with the church acting as a guiding and reassuring presence in the name of the patron of pilgrims. Also apparent from this point (prior to the Reformation) would have been the noise generated not only by the town but also by the Priory (in terms of liturgy and bells). This initial contact with the resting place of St Philip's arm, a wealthy and influential priory, could have formed initial impressions in the mind of the traveller, much in the same way that one

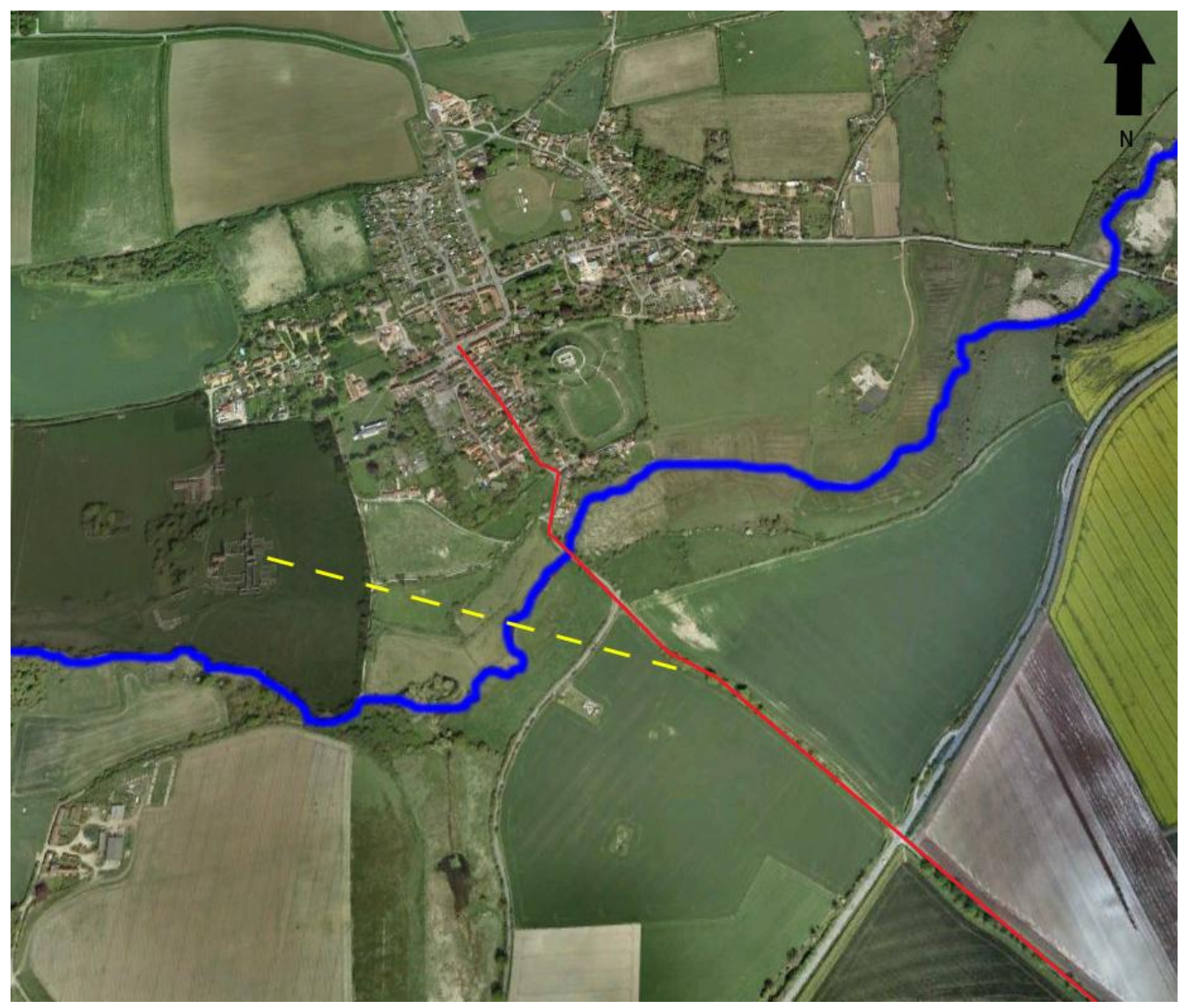

Figure 32. The approach to Castle Acre (red), showing the initial line of sight (yellow) to the Priory (black shade) and the River Nar (blue) creating a natural boundary between the 'wilderness' and 'sanctuary'. Original satellite image reproduced from (C) 2011 Google. 
may be impressed by the scale of an object or building prior to seeing it, simply judging by the amount and type of noise it produces.

The descent into the valley floor involves crossing a natural boundary between the priory and West Acre: the River Nar. Rivers feature heavily in Christian theology, particularly in a baptismal and miracle capacity, and feature frequently in pilgrim tales. They also serve as locations in numerous written sources for bandits, toll-gatherers, murders, accidents, and so would be firmly rooted as places of 'action' in the Medieval imagination (Candy, 2007, 77). A possible impression would be that of a liminal area which shifted the traveller from the profane world into the territory of the Cluniac monks, with the river acting as a symbolic frontier between the inner monastic world and the outer profane spaces. Other sensory aspects such as scent might also come into consideration, with the usual variety of smells produced by a busy market town, and perhaps those of worship at the monastery through incense, thereby gradually increasing the sensory engagement with the priory on behalf of the traveller. The priory would at this point be fully visible, dominating the field of view, and its size and decoration would have been impressive to the pilgrim. This building would have broadcasted a message of power, influence, wealth and sanctuary for all who visited Castle Acre, as did the presence of the castle earthworks at the east of the town and the fortifications which survive in the form of the Bailey Gate at the southern entrance.

The final approach up Bailey street (part of the Peddar's Way) towards the gate led the pilgrim past the priory, whose complex was set slightly apart from the rest of the town. The transition from the rural surroundings between Swaffham and Castle Acre into the town itself could be seen as an active metaphor for moving between spaces of wilderness and sanctuary. It is important to note that, as opposed to its present status as a village, Castle Acre wielded a powerful influence in the region as an ecclesiastical and economic centre, vying with Swaffham for market reputation (Coad and Coppack, 1998, 5). To the more rural devotee, it would have been one of the more impressive settlements visited with its trading and monastic activity, with the arm of St Phillip as an additional attraction.

\section{Walsingham :}

As the culmination of the pilgrimage, and similarly to Castle Acre, the Walsingham area can be loosely divided into the following regions (see Figure 33 below) and will be addressed chronologically below:

1. Exterior: The approach to the Slipper Chapel.

2. Interior I: 'The Holy Mile' from the Slipper Chapel to Walsingham. 


\section{Interior II: The settlement of Walsingham.}

4. Interior III: The Priory precinct and church.

Exterior: The approach to the Slipper Chapel:

The topography of the Walsingham area is quite different to that of Ely. Having left the wetlands, mists and causeways of the fens, the pilgrim is now in the uplands of Norfolk, whose surroundings are primarily agricultural and pastoral. Walsingham is situated in a shallow dell and bordered by farmland, which adds to its seclusion and sense of being set apart from the rest of the area. The landscape complements the feeling of sanctuary attached to 'England's Nazareth' through the fertility of the soil, the streams and meadows surrounding the town, all of which add to a sense of relief as one approaches Walsingham. Although the topography is undulating, the elevations in this final stage are slight, and so there is no way to read the landscape beyond the fields and stream which border the path. In consequence, as the route weaves in towards the Slipper Chapel and through Houghton St Giles the sight of Walsingham Priory looming a mile ahead would have been sudden, only forecast by the sounds of the monks in worship, and the clamour of the bells from the Priory and Slipper Chapel. Therefore the dialogue with the landscape is subtler than at Ely. There are no sweeping panoramas with which to survey the prospective route, and no forbidding wetlands. Instead, the lane curves through the fields to Walsingham, and the features of the landscape including Walsingham's built environment - are gradually revealed as the route progresses. Walsingham's status; set apart and a more intensely spiritual place than most, is enhanced by this approach as this slow unfolding of the location provides a sense of travelling from the normal and profane world into that of the secret and hyper-sacred, with the Slipper Chapel as the frontier or liminal marker.

\section{Interior I: 'The Holy Mile' from the Slipper Chapel to Walsingham:}

The 'Holy Mile' designates the final highly charged approach to the Nazareth of Norfolk, where processions with sacraments and relics would have taken place, and penitents walked barefoot to the town (Page, 1906, 395). The reputation of being 'England's Nazareth' would in the imagination of the laity have linked Walsingham directly with the Holy Land, suggesting that a topography aligned with biblical scripture was present in this Norfolk settlement. Complimenting this, aside from 'Nazareth', the area was also known colloquially as 'The Holy Land of Walsingham'. The Slipper Chapel was the last in the series of Walsingham-linked wayside pilgrim chapels. Its purpose (aside from masses for pilgrims) may have also been to represent a spiritual border post or frontier between the profane English landscape and that of this surrogate 'Holy Land'. Having crossed the 'threshold' at the Slipper Chapel, to the pilgrim the landscape in this approach to Walsingham from the Slipper Chapel would have a sacral quality, since it was in this small valley that the Virgin Mary appeared and blessed the area with instructions for a replica of her annunciation house. They would literally have been walking in a region which was believed to have been favoured by the 'mother' of Jesus and the church. Therefore this link with biblical lands, the Virgin cult and the Christian mythos was surely not lost on the majority of the laity. 


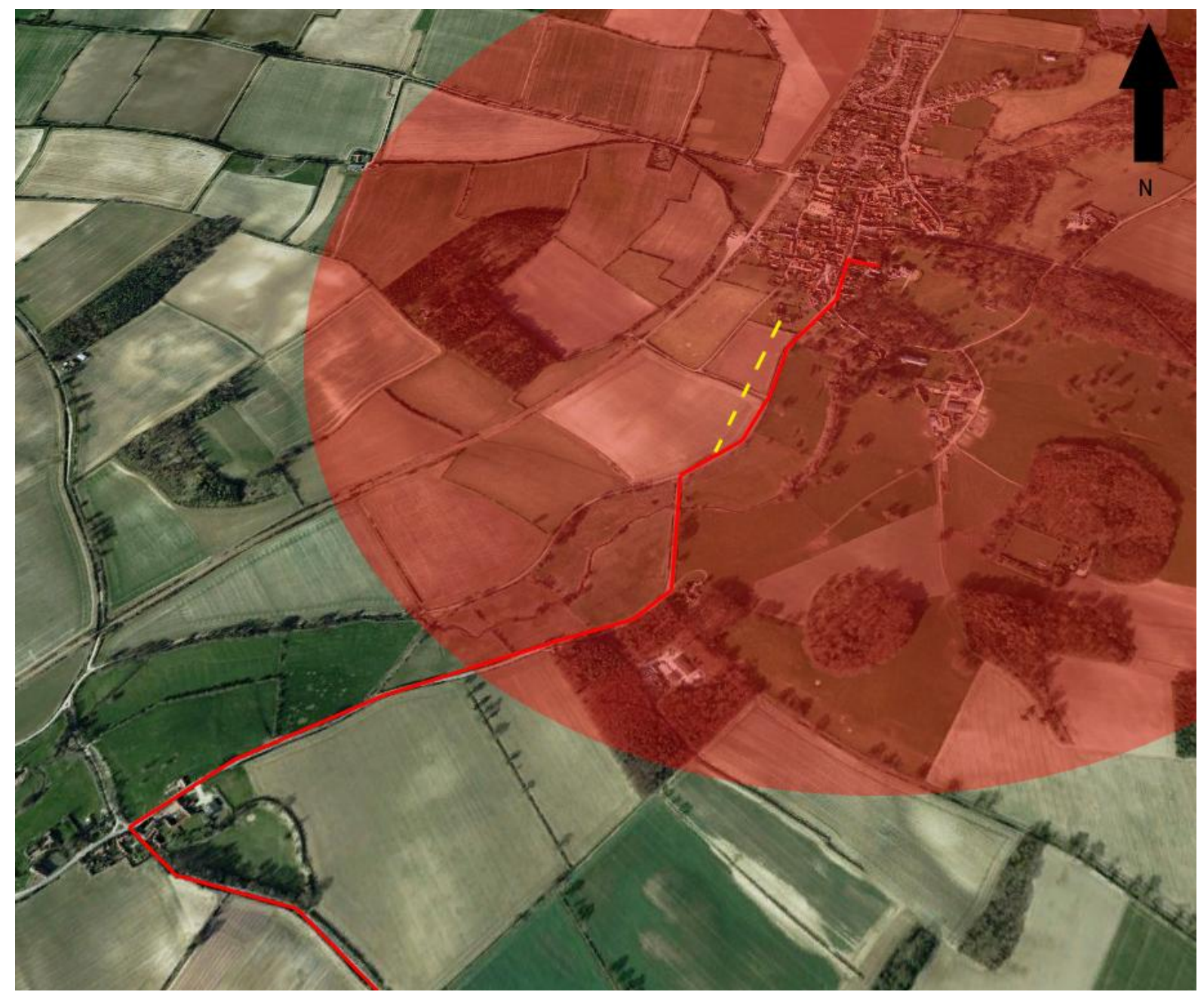

Figure 33. The Holy Mile of Walsingham (red shade), showing the route coming down from Houghton St Giles to the Slipper Chapel leading to the town, including the sight line to the Friary (yellow). Original satellite image reproduced from (C) 2011 Google.

Interior II: The settlement of Walsingham:

Upon entering Walsingham during the $14^{\text {th }}$ century the first monument to be encountered was the Friary, which signified the second interior or stage; that of the holy town, scene of the Marian vision which prompted the building of the shrine. Visually, the Friary occupied a small complex in comparison to the Priory, however it was also the foremost ecclesiastical sight (shown above and below in yellow) which occupied a prominent position at the south entrance to Walsingham, and the Friary church (whilst not being particularly high as indicated from its ruins) would have been the initial view for pilgrims approaching the town. The sensory impact of the Friary's monastic activity increased the 'sense of place', providing yet another tangible reference to the sanctity of the Walsingham. Processions of the monks to and from the shrine site, accompanied by chants would also have heightened the experience for the pilgrim. What would have been most noticeable to the pilgrim however, after the relative quiet during the many miles of travel amongst fields and fenland 
(alone or with travelling companions), was the noise emanating from this pilgrim centre. Providing another example of how the spheres of the sacred and profane often overlapped, the pilgrim's ears would have been assaulted by bells, liturgical hymns,

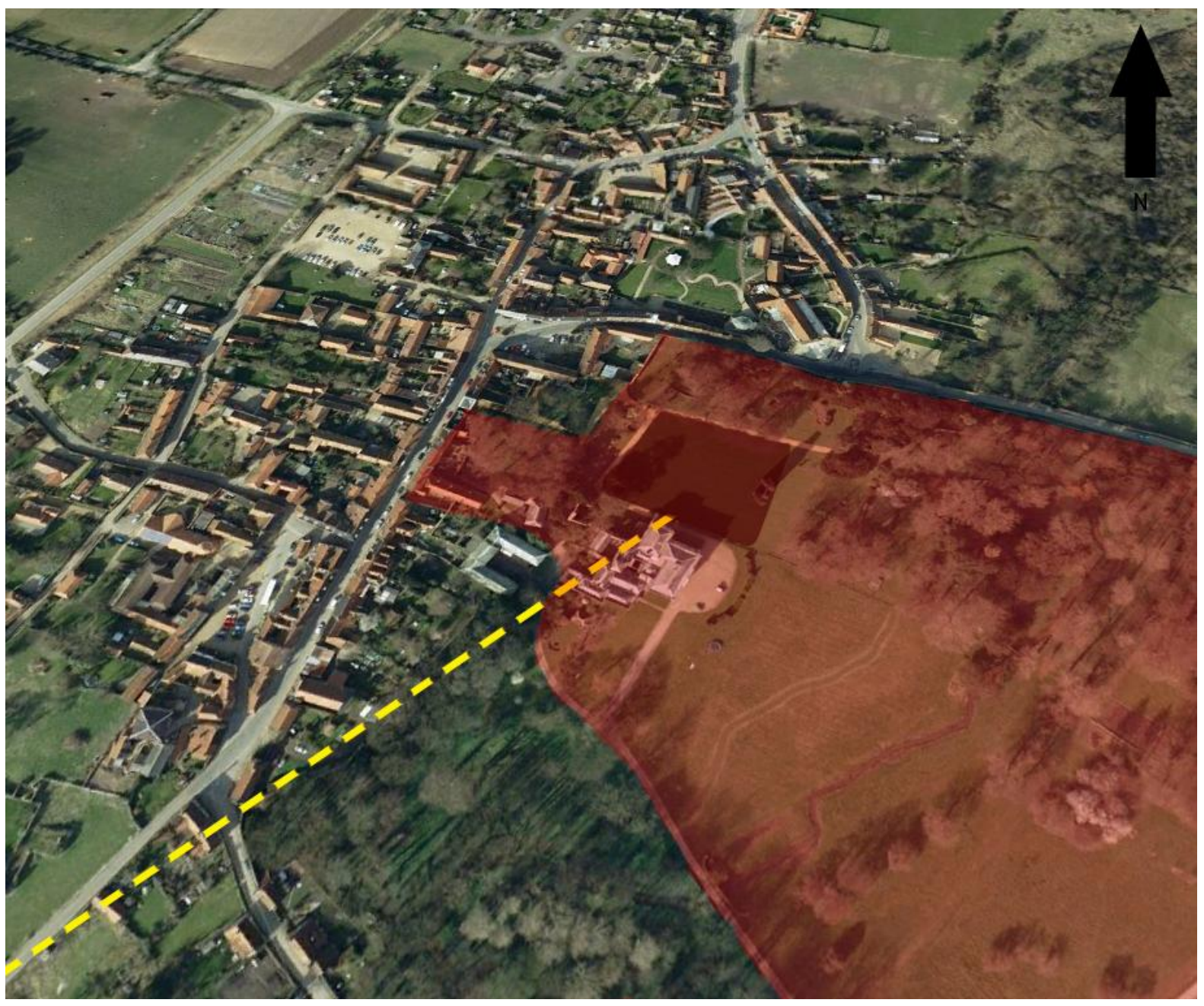

Figure 34. Map showing the proposed sightline (yellow) to the site of the Priory (footprint) upon entering Walsingham, and the sacred area of the Priory grounds which housed the shrine to Our Lady. Original satellite image reproduced from (c) 2011 Google.

itinerant preachers, souvenir merchants peddling their wares, inn keepers competing for guests, and the general sounds of the market place next to the Friary. The church of St Mary to the east would have contributed to this mixture of sound with its bell tower, and the flow of people to and from the site, however it is likely that as a parish church it did not provide as much of pilgrim impact as the two religious houses, especially when compared to the Nazareth connections produced by the Priory area (shown in Figure 34 above in red). 
Interior III: The Priory precinct and church:

In the section on the archaeology of Walsingham, the manner in which pilgrims processed through the Priory precinct has been described in relation to Erasmus' descriptions, and consequently leaves little to add here. Aside from these descriptions and the remains of the foundations in the archaeological record (showing the general layout of the building), few visible traces of the Priory remain to give us clues about potential dialogue between it and the pilgrim. However there are several aspects of sensory interaction in the precinct and church which can be discussed, taking cues from other cult centres, William of Worcester's measurements and Erasmus' caustic commentary. Size is undoubtedly one of the most immediate visual aspects which struck the visitor stepping through the wicket gate into the Priory precinct, and Worcester provides a detailed description:

'The crossing or belfry area consists of 16 paces each way. The width of the nave of the church alone without the two aisles is 16 paces. The length of the cloister, which is completely square, 54 paces. The length of the Chapterhouse alone consists of 20 paces and its breadth 10 paces, but the length of the portico of the Chapterhouse from the cloister consists of 10 paces, thus totalling 30 paces.' (Harvey, 1969, 67)

This scale seems to roughly equate with that of Castle Acre, and based on the foundation plans which corroborate Worcester's measurements and the surviving window arch, the height of the Priory seems roughly similar as well. Not only would the Priory have dominated the skyline when entering Walsingham, once inside the precinct it would have filled the view of the pilgrim and been a hive of activity. The clamouring of other pilgrims, combined with the proscribed route taken around the precinct accompanied by a guiding monk would also have created a sense of anticipation, building as one proceeds site by site towards the pinnacle of the journey - the shrine room itself. Within the church, the chatter of the laity awaiting entrance to the shrine, combined with the pilgrim's own sense of excitement and awe (enhanced by the sensory overload of relics, incense, ornament and candles) would have created an intense experience.

It is not the aim of this thesis to deconstruct the pilgrim experience within the church, however, a very brief examination of the pilgrim's interaction with the shrine will be included. Within the shrine room was the replica of the House of the Annunciation, dictated by divine decree, and the statues of the Virgin Mary and Jesus Christ; as well as an opulent display of jewels, precious metals, and other 'votive' offerings from high status visitors (Nichols, 1849, 26). This was an intensely emotional experience for the pilgrim, in the presence of what was perceived as a detached enclave of the Holy Land, surrounded by a material richness which would rarely have been encountered. Erasmus relates more practical aspects of the shrine, indignantly recording that 'the place is very draughty on all sides; the windows are open, and the doors are open, and not far off is the ocean, the father of winds' (Nichols, 1849, 18). No doubt this bracing atmosphere combined with monks' encouragement, would have kept circulation in the shrine swift. Maintaining an efficient flow of pilgrims around the shrine and out the door, would have been beneficial in terms of donation turnover and keeping the laity from interfering too much with the activities of the monks at the Priory, and this appears to be generally the case in most pilgrim centres (Crook, 2000, 117). 


\subsection{Conclusions}

As a pilgrim destination, Walsingham vied with Canterbury as England's favoured shrine and the established route network both enabled and reflected this, sometimes adapting to the needs of the pilgrims and in their naming such as the 'Palmer's Way'. Being situated in Norfolk, one of Medieval England's most profitable, ecclesiastically powerful and agriculturally successful regions, access to the shrine was aided by the road networks bolstered through trade, ports and market towns (owing much to Norman investment). There can be little doubt that during the height of Walsingham's popularity in the $15^{\text {th }}$ and $16^{\text {th }}$ centuries the sight of pilgrims and merchants travelling along the same route would have been a common one, and the duties of care for these roads frequently fell to religious houses or parish communities and church funds. Religious houses of the Augustinians were the most common order, spread across central and north west of Norfolk, and dominate the abbeys and priories along the Palmer's Way - they would also have played a role in the upkeep of the route. Of the eleven hospitals which were dedicated to pilgrim care, there is a higher density of Augustinian-dependents surrounding the Walsingham area, suggesting an ideological and and economic link between this order and the major pilgrim centres in Norfolk (and they follow a similar pattern across the south-east and central-east of England). The pattern of large urban settlements combined with royal intineraries and the distribution of these hospitals and religious houses (which offered pilgrim accomodation) displays a clear preference for stopovers at Brandon, Swaffham, Castle Acre, and for those wishing to be fully refreshed before arriving at Walsingham, there was the priory at Hempton or Fakenham's inns. NHER records from Walsingham show several inns which corroborate the impression given by Erasmus that Walsingham subsisted economically solely from its pilgrim industry, as well as from guest halls at the Friary and Augustinian Priory of Our Lady.

A significant socio-religious connection provided by studying the church dedications in Norfolk is of that between St Mary's popularity in relation to areas heavily reliant or involved in agriculture. This is also reflected in the distribution patterns for recorded ampullae displaying Walsingham motifs frequently turning up in rural parishes, and may be in connection with the practise of 'blessing the fields' with their holy water. The role of Marian-dedicated churches in the pilgrim landscape of Norfolk therefore appears to relate to rural activity, and it is clear that the number of Walsingham related ampullae in Norfolk far outweighs any other county, suggesting a high level of reverence for the Virgin Mary. This is unsuprising given her position in the Christian 'pantheon', but conveys a particularly intimate relationship with the Norfolk laity as a 'local universal saint', whose primary English shrine was within their borders and directly linked their region conceptually with the Holy Land. It is in this respect that the Walsingham cult differs from the other major saint cults in England. Not only did the shrine offer a touchstone with the divine, but also a tangible connection with Nazareth and a location which most devotees would have hoped (but not expected) to visit. This ability to represent the Holy Land within an accessible locale enhanced Walsingham's status, and the corresponding flow of human traffic towards the Slipper Chapel. 
Travel to Walsingham utilised a collection of roads and tracks which constituted the Palmer's Way, and this movement generated a series of liminal interactions. The journey culminated in the entrance to a series of increasingly sacred 'zones' via the penultimate wayside 'Slipper' chapel, but prior to this the pilgrim from Ely had crossed over two very different environments and through open countryside and urban/ecclesiastical centres. These also produced a variety of encounters on a theological and sensory level which added and identified with the basic concepts of pilgrimage; i.e. piety, sanctuary, wilderness and temporary exile from common existance. The road network combined with these changing natural environments, church dedications and positioning of religious houses in the landscape, all conspired to produce this sensory aspect to sacred travel. Lines of sight towards certain monuments, aspects of known local folklore (both in terms of supernatural beasts and saintly miracles) made the journey along the Palmer's Way an unique experience, compounded by this alleged spiritual link between Walsingham and the Holy Land. The transition from the fenlands surrounding the Isle of Ely to Norfolk's uplands via established trackways, subsequently joining a flow of pilgrims arriving from the south using the Palmer's Way can only be mirrored in England in terms of human traffic by the route along Watling Street towards Canterbury. This formed a fluid community of travellers who frequently grouped together for security. However this would not have precluded the more intimate encounters with the landscape described above, due to the meditative nature of long distance walking. This 'kinetic ritual' across a region which itself (through the construction of churches, abbeys, priories and hospitals) had been steadily transformed into a Christian ritual landscape, represented a microcosm of the ulimate form of pilgrimage - that which every layman undertook throughout life towards the heavenly (and for some the physical) city of Jerusalem and the Holy Land, which became linked to Walsingham (Turner and Turner, 1978, xxiv). 


\section{Chapter 4: Salisbury to Winchester}

\subsection{Introduction to the case study}

Medieval Winchester was an influential ecclesiastical and economic centre, with a highly renowned saint cult, that of St Swithun. Its cathedral was a celebrated landmark and institution, whose shrine to St Swithun received a large volume of pilgrims each year. Salisbury too was home to a cult, and the shrine of St Oswald in Salisbury Cathedral was also a popular pilgrim destination. Between these two cathedral cities there were the remains of a Roman road, which was very much in use during the Medieval period, being a primary and efficient route across the Wiltshire and Hampshire landscapes (Adair, 1978, 50). Pilgrims travelling to Canterbury from the West Country would have passed through Salisbury and then through Winchester via this Roman road (which was constructed to connect Old Sarum (the Roman settlement north of Medieval Salisbury) with Venta Bulgarum (Winchester), stopping in both towns overnight, the distance being around 24 miles, which takes between roughly 7 and 9 hours to walk (Adair, 1978, 50).

This chapter will explore the movement of pilgrims from Salisbury to Winchester along this Roman road with two types of journey in mind: that of a specific pilgrimage to Winchester to worship St Swithun, and also as part of a longer journey originating in the West Country and continuing beyond Winchester towards Canterbury and the shrine of St Thomas Becket. When discussing the broader territory of Wessex as a land unit or historical kingdom then the term Wessex will be used, and when referring to a specific county within that region then the appropriate county name will be referred to. 


\subsection{The Landscape of Medieval Wiltshire and Hampshire: Environmental, Economic and Ecclesiastical}

\section{Environmental:}

The counties of Hampshire and Wiltshire were the heartland of the historic kingdom of Wessex. The following major landscapes define these two counties: the Hampshire Downs, the Hampshire Basin, the New Forest, and the Salisbury Plain, shown below in Figure 35 (Melville and Freshney, 1982, 79). I do not intend to describe in detail the geology of Hampshire and Wiltshire, but only outline briefly the 'Landscape Character Assessments' of these regions including data from the most recently available surveys by the Wiltshire and Hampshire County Council records (2010) in order to give topographic detail which will feature in my route and provide background to the general development of Hampshire and Wiltshire's road networks.

The Hampshire Downs are dominated primarily by chalk formations, being part of a larger geological band of chalkland (the 'Southern England Chalk Formation') which cuts across southern England in a north easterly direction from the Dorset downlands, through Salisbury Plain into Hampshire (Hampshire County Council, 2010). These chalklands formed 'a distinctive core to the landscape of Hampshire and Wiltshire' (Hare, 1994, 159). The northern and eastern boundaries of the Hampshire downs are bordered by the Alton Hills and the Vale of Kingsclere, while the interior contains a network of valleys (Melville and Freshney, 1982, 79). A distinctive 'rolling' topography is present, much of which comprises a mixture of ancient woodland and regular fields enclosed by hedgerows (Melville and Freshney, 1982, 79). Within the Hampshire Downs, a distinctive field pattern developed which can be found throughout the Southern England Chalk Formation. Open fields were created adjacent to settlements, with much of the downland being used as pasture for sheep, and the meadow areas along valley floors used for grazing cattle (Edwards, 2006, 2). In terms of settlement patterns in this area, 'the broad distribution of rural settlement in the county during the Middle Ages consisted in general of nucleated villages on the central chalklands (Hughes, 1994, 203).

The Hampshire Basin encompasses the coastal region of Hampshire, and the eastern coastal area of Dorset, reaching its limit against the chalky South Downs. In northern Hampshire there is a major watershed on which Basingstoke is sited; rivers running north of this flow into the Thames and those which flow south run down to the Hampshire Basin, enabling a river transport network (Sumbler, 1996). Major Medieval settlements in this area include Wareham, Poole, Southampton and Portsmouth, the latter two becoming renowned ports and trading centres not only within Hampshire but nationally (Melville and Freshney, 1982, 80). The historical categories of land use which occurred in the Hampshire Basin are primarily agricultural, with arable fields. The Domesday Survey indicates that the many river valleys along both the Basin and the Downs were where, by the Norman Conquest, the majority of agricultural wealth in Hampshire was generated (Short, 2006, 48). 


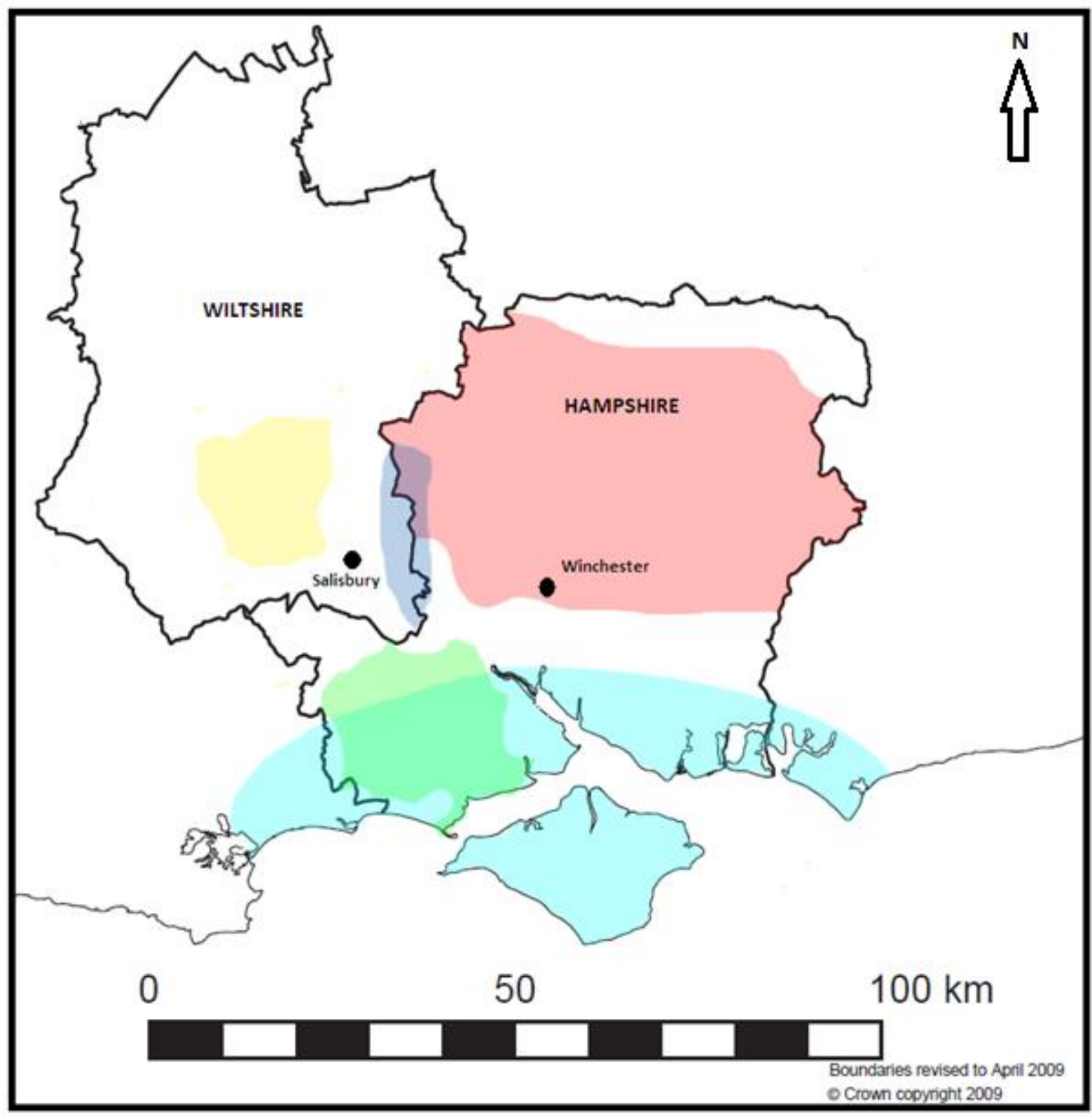

Figure 35. Map showing key landscape characters of Hampshire and Wiltshire; Salisbury Plain (yellow), Hampshire Downs (red), New Forest (green), Hampshire Basin (light blue) and the Test Valley (dark blue). Redrawn from the Ordnance Survey GB Coastline and Administrative Boundaries Map.

The New Forest lies within the Hampshire Basin, and is comprised of a mixture of woodland and heathland (Hampshire County Council, 2010). There is evidence that both ecosystems have been exploited by the surrounding populations since the Iron Age; tree clearances occurred in areas during the Bronze Age with the aim of cultivation, however the poor soils did not allow for arable activity and so these turned to heathland which supported grazing (Tubbs, 2001, 59). The 2010 Character Assessment for the New Forest indicates that these land resources were initially controlled by hill forts such as Danebury (Hampshire County Council, 2010). In 1087 the Anglo Saxon Chronicle records King William as making many 'large forests for deer', including the New Forest which was declared under Forest Law in 1086 (Swanton, 2000, 168). The traditionally held view of 
large-scale eviction of settlements from the New Forest during this appropriation is called into question when one considers the poor quality of soil, which could not support any agricultural community to a self-sufficient degree (Short, 2006, 50). The distribution of villages within the hundred of the New Forest remained unchanged from the $14^{\text {th }}$ to $17^{\text {th }}$ centuries (Page, 1911, 615).

Salisbury Plain lies to the north of the New Forest, and forms another section of the Southern England Chalk Formation. There exists a large body of scholarship on the history and archaeology of this ritual landscape, and so here I only intend to outline the key features of this environment in brief as relevant to my research. The overall landscape character is one of a chalk plateau, with shallow river valleys and scattered woodlands (Countryside Commission, 1995). Neolithic monuments in the form of barrows (such as West Kennet longbarrow) standing stones and ritualised complexes (such as the Stonehenge and Avebury complexes) are especially prevalent in the area, as are Iron Age hillforts and Roman roads (Lawson, 2007). The settlement pattern of the Plain is one of nucleated villages occupying the peripheral spaces of valley floodplains, and at the border of escarpments (Countryside Commission, 1995). Like the Hampshire downs, whilst there was a degree of arable farming, the majority of the landscape was given over to pasture for sheep, much of their wool being sold through the cathedral town of Salisbury's market to the south (Bradley, 1994, 113).

These four principal landscapes types which define the Wiltshire and Hampshire topography effectively surround the Test Valley within the North Wessex Downs, over which the Roman road runs from Old Sarum to Winchester and this is the route which is used in relation to this case study. The Test Valley is an area of fertile arable fields, radiating from the flood plain of the river Test, and is characterised by a rolling agricultural landscape, bounded by hedgerows, with traces of ancient woodland and a high frequency of coppices (Hampshire County Council, 2011). Settlement forms in this area are dominated by nucleated villages and hamlets, and reflect the historical manorial structure in their distribution (Edwards, 2006, 2 and Hughes, 1994, 203).

Economic:

Exports of woollen goods from England rose from an average of 6,413 cloths in 1350 to 40,291 in 1390, and a major source of wool lay in Wiltshire (Bridbury, 1982, 116). Evidence for wool textile production in the broader region dating back to the Iron Age has been discovered in excavations at Danebury Hillfort (Hampshire), which indicate the husbandry of large flocks of sheep and goats that were 'maintained essentially for wool production' (Cunliffe, 1991, 149). The wool textile industry in Medieval Wiltshire found its chief production and market centres in two areas of Wiltshire: Salisbury and its surrounding valleys (i.e. the Ebble and Wylye), and the west of Wiltshire, bordering the Salisbury Plain and Marlborough Downs (Hare, 2012, 177), where a particular type of coarse woollen 


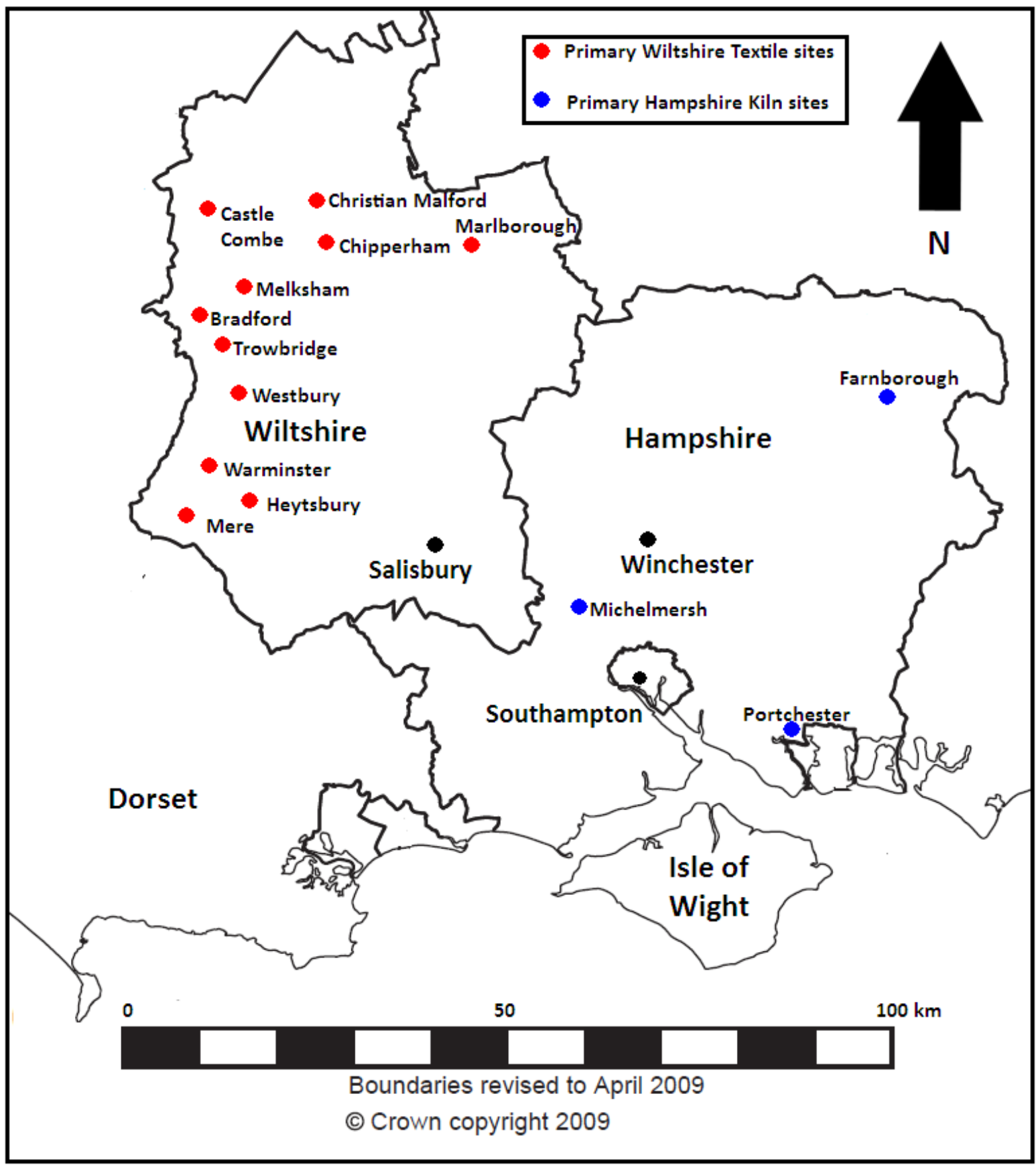

Figure 36. Map displaying the primary sites of the Medieval Wiltshire textile industry (red) and Hampshire ceramic production (blue) as referenced below in the text. Redrawn from the Ordnance Survey GB Coastline and Administrative Boundaries Map.

cloth known as 'Burel' was produced (Crittall, 1959, 116). The flocks which supplied the wool trade were chiefly put to pasture on Wiltshire's chalky downlands (i.e. Salisbury Plain and the Marlborough Downs), and necessitated both droving routes and general roads for the transport of fleeces from their source to the market centres mentioned above (Ramsay, 1965, 6). In Hampshire, Winchester emerges as another important processing site for the wool industry, with guild accounts indicating that the city was responsible for producing $76 \%$ of the county's sealed cloth in 1395 , and its 
'domination of the Hampshire industry remained supreme' (Keene, 1983, 317). Routeways from both Winchester and Salisbury to Southampton serviced a strong export trade in woollen goods from this important Medieval port. The 1444 Southampton Brokerage Book indicates that quantities of woad dye were carted from the port to both settlements (Coleman, 1960). The largest sales centre for woollen cloth during the $14^{\text {th }}$ and $15^{\text {th }}$ centuries was the Salisbury market, which the 1398 Aulnage Accounts (which record the taxes imposed on the sales of cloth) detail as selling 19,000 cloths from 159 merchants (Keene, 1983, 316). This intense economic activity points towards Salisbury's highly accessible location within the Medieval English road network, its links to Southampton and other market centres, which are further detailed in the next section of this chapter.

Other industries were present in the Wiltshire/Hampshire landscapes, which helped to promote wealth and communication routes within the counties. I will now outline selected sites representing the principal industries which contributed both economically and to the development of road networks required for the trade and transfer of goods from their processing sites to the main marketplaces. The 'Surrey/Hampshire Border Ware' kilns at Farnborough were discovered in the 1976 excavations at Ship Lane, Highgate Lane and Farnborough Street (Pearce 1992), and indicate a sizeable industry whose wares were frequently sold (and found in excavations) in London (Pearce, 1992, 47). Locally produced Portchester Ware has been found at excavations at Michelmersh (Addyman et al, 1972), Portchester (Cunliffe, 1970), Winchester, which also had its own distinctive ware (Biddle and Barclay, 1974), and Wickham Glebe (McCarthy and Brooks, 1988), all indicating a strong tradition of trade in local ceramics in Hampshire. In Wiltshire the pottery industry was less developed, although Laverstock Ware has however been found across Southern England, especially in Salisbury and London (Saunders, 1990). The tile industry also relied on the extensive regional clay deposits. The manufacture of clay roofing tiles in Wiltshire developed from the $14^{\text {th }} \mathrm{C}$ in the southeast exemplified by a kiln site in Alderbury; by 1354 this site was supplying the palace at Clarendon Palace (James and Robinson, 1988 and Hare, 2012, 168). Poll tax figures for 1379 show a large scale concentration of tile production here with 17 tilers (Carr, 2001, 137). However, these documents also claim tile kiln production and distribution in Wiltshire was far outweighed by that of Hampshire (Hare, 1991). Hampshire's tile kiln sites are too numerous to address here and are detailed in full within the county HER. As an example I will briefly describe the output of a kiln on the Bishop of Winchester's estate in Highclere (Dunlop, 1940). First mentioned in 1290, by 1307 the kilns were producing 28,200 tiles from locally sourced clay, and by 1340 with the rebuilding of Highclere castle and demand from the local area increasing, this production figure had effectively doubled (Langdon et al, 2003, 143). This well documented site was effectively a local production centre, and similar examples of kilns producing roof tiles for nearby construction projects are found around the county (Hare, 1991).

Long valued as a preservative, salt production was also important in coastal areas. Salt was transported inland utilising the road networks where it could not be moved by coastal or river craft. Some of the most productive saltern sites in Hampshire were around the Beaulieu river (Hampshire County Council, 2010, 7). Accounts from nearby Beaulieu Abbey show a large scale consumption of the small grained salt-type which was characteristic of England's salt industry (Hockey, 1975, 188). 
The distribution of the small grained salt from these salterns would have included fishing ports (mainly for herring salting), and estates within the Hampshire and Wiltshire region for domestic use (Hampshire County Council, 2010, 7). Portsmouth also held a large salt industry, utilising the coastal and interior road network to markets such as Winchester and even London. Along the Solent (Hampshire) were as many as 18 salterns, all utilising an extensive trade and route network for their distribution (Murphy, 2009, 40).

These industries were an important source of profit for Hampshire and Wiltshire and cemented their role as key suppliers of wool, salt and other commodities to several economic centres throughout Northern Europe (Hughes, 1981, 66). Their traffic also utilised and expanded the legacy of roads, tracks and drover trails which led from pastures or production centres to market towns and ports. Markets and fairs were common in both counties, with 62 being established in Hampshire prior to 1516, and 83 in Wiltshire (Letters, 2005). Of the trading events of the $12^{\text {th }}$ and $13^{\text {th }}$ century, St Giles' Fair held on St Giles' Hill in Winchester was one of the most celebrated, attracting merchants from overseas to buy bales of the renowned local wool (Hughes, 1981, 66). Salisbury too saw itself as the pre-eminent market economy in Wiltshire (Bridbury, 1982). Both of these towns were well linked into the route networks of their counties and beyond due in part to the strength of these industries, from livestock to textiles, salt and ceramics, which demanded access to and from markets, processing sites and ports. Another crucial aspect of these two counties was a strong ecclesiastical presence, which also required a strong transport network for both the supply and demand for goods produced and required by their communities.

\section{Ecclesiastical:}

So extensive was the ecclesiastical presence and their profit within Hampshire and Wiltshire, that space in this chapter does not afford a complete examination. Consequently I will focus on an abbreviated description of some of the major ecclesiastical estates in these areas.

According to Knowles and Hadcock's catalogue of religious houses in England and Wales (from which the data for Hampshire and Wiltshire has been mapped in Figure 37 below), prior to the Reformation Wiltshire possessed 39 religious houses (including abbeys, priories, hospitals and friaries), and Hampshire 35, the majority of which lay in Winchester (Knowles and Hadcock, 1953). Evolving from the Roman settlement 'Venta Bulgarum', this city with its cathedral and saint cult (St Swithun) had a lengthy history as a power centre. At the height of Winchester's power and size before the twelfth century, within the city walls were roughly fifty parish churches, three hospitals, and five separate order houses; two Benedictine sites are recorded, the Abbey and the Cathedral Priory (Keene, 1983). The suburbs are recorded as stretching for half a mile beyond the city walls, and 65 parish churches existed in the Winchester district in the $16^{\text {th }}$ century (Hughes, 1994, 197 and Keene, 1985,24$)$. By the $14^{\text {th }}$ century, the Bishop of Winchester's estates encompassed the majority of Hampshire (27 estates in total), with other estates in Somerset, Wiltshire, Oxford, Buckinghamshire, Berkshire and Surrey, and one of the wealthiest bishops in England (Britnell, 2003, 
3). Many of these estates supported large flocks of sheep, contributing to the wool trade and requiring a network of communication routes between the estates and the primary markets of Hampshire, Winchester in particular (Page, 2002).

Religious Houses in Medieval Hampshire \& Wiltshire

Benedictine Priory (I Abbey 4 Cell)

Cluniac Priory ( I Cell)

Augustinian Priory (I Cell)

Premontratensian Abbey $\square$ House of Trinitarians

Gilbertine Priory $\square$ House of Hermit Friars of St Augustine

Dominican Priory $\quad \square$ Friars of the Sack/Penance of Jesus Chris t

Franciscan Friary $\square$ House of the Pied Friars

Carmelite Friary $\square$ House of the Benedictine Nuns

Cistercian $\square$ Order of St John of Jerusalem (Sisters)

Bonshommes $\square$ House of the Knights Templars

Hospital $\square$ The Knights Hospitallers

* Winchester

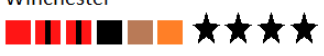

Salisbury

$\mathbf{\square} \star \star \star$

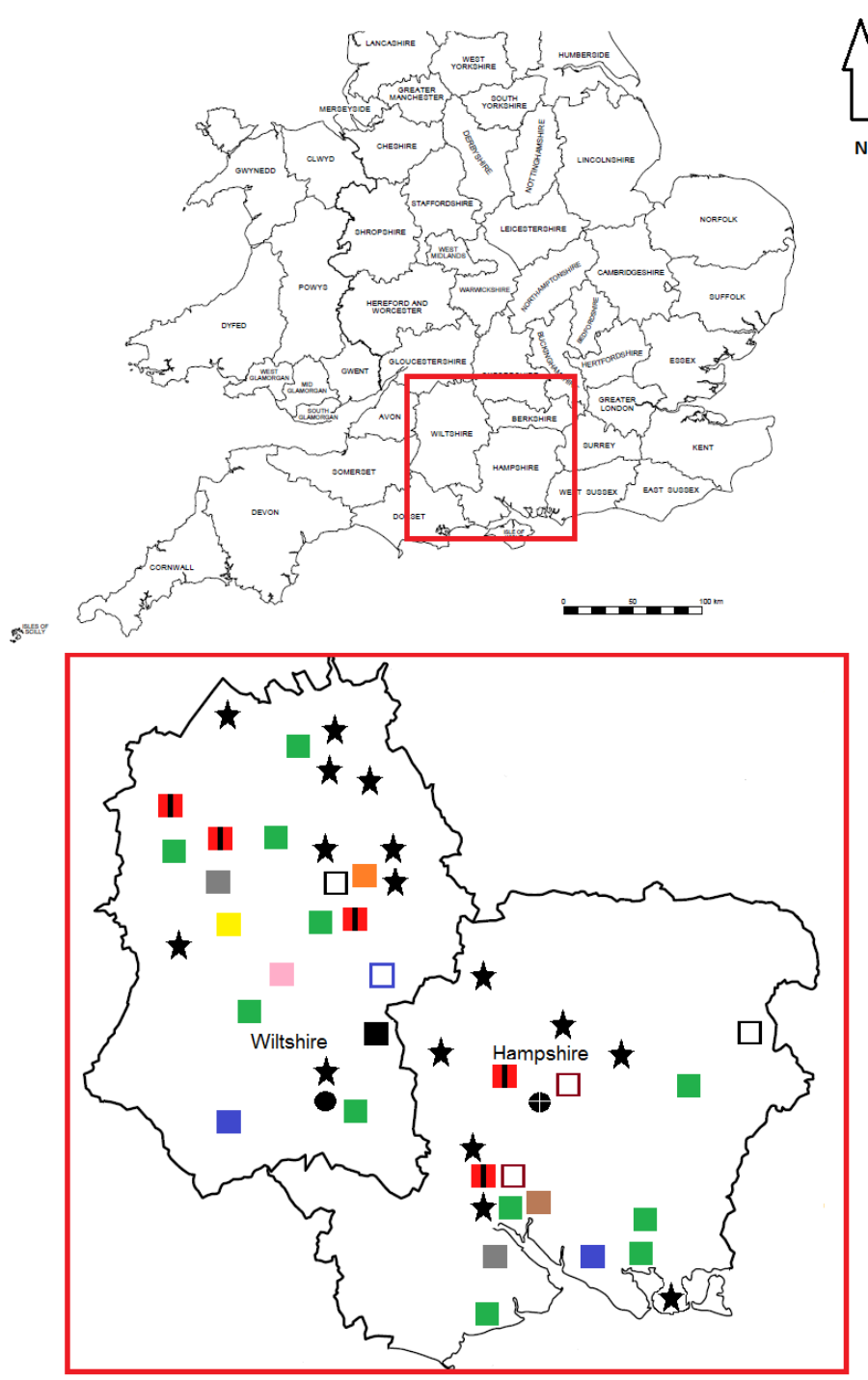

Figure 37. The Distribution of Medieval Religious Houses throughout Wiltshire and Hampshire (data provided in Appendix (). Redrawn After the Outline Map of the UK Published by the Ordnance Survey.

Hampshire has a high density of religious houses within its county borders, representing a variety of orders (see Figure 37 above). Outside of Winchester there were Benedictine abbeys at Romsey and Wherwell; Cistercian houses at Beaulieu, Netley and Quarr (on the Isle of Wight); Augustinian priories at Twyneham, Southampton, Portchester, Breamore, Mottisfont and Selborne; a Premonstration Abbey at Titchfield; a Friary in Southampton and numerous hospitals across the county (Doubleday, 1973, 104). From Figure 37 above it becomes apparent that the Augustinian 
order held the most influence across the two counties, a theme reflected across the data for southern England prior to the Reformation (Knowles and Hadcock, 1953).

Beaulieu Abbey, situated in the New Forest, emerges in the written record as one of the most prosperous and landed of the Hampshire houses which were not attached to the Bishop of Winchester. A brief description of the Abbey's influence will be provided here as a single demonstration of the extent of ecclesiastical influence on the economic and communication networks in Hampshire; more detail can be found in the Abbey counts (Hockey, 1975) or the Victoria County History of Hampshire (Doubleday, 1973, 140 - 146). The Abbey controlled a significant portion of the New Forest; coppicing and exploitation of these woodlands provided a basic income for the monks, combined with income from their granges, as well as from their estates at Faringdon in Oxfordshire (Hockey, 1975, 198 - 201). The community owned an extensive area around the Abbey, with the outlying granges providing processed goods, including wool, which necessitated transport by cartage across the New Forest area. A monastic hospicium was also present at Beaulieu, which in the abbey accounts is described as giving shelter to visiting monks, carters, travellers and pilgrims (Hockey, 1975, 33 - 34). The accounts reveal that the abbey was a hive of economic as well as sacral activity, with its own mill, brewery, stables, forge, coppices, and other outlying outhouses as distant as Yarmouth where a herring depot brought in revenue of over $f 66$ per year (Hockey, 1975,190 ). The abbey also controlled a (surviving) large wool warehouse in Southampton in the late $14^{\text {th }}$ century, exercising power over the export of wool grown and processed on their estates (Doubleday, 1973, 143). The relevance of including Beaulieu Abbey here is to illustrate the degree of control these institutions and estates typically exercised over the landscape, owning great tracts of productive land which required links to the rest of the county's (and national) markets and ecclesiastical centres. Religious houses were also responsible for the maintenance of these lands, including their roads, although as has been seen in the previous chapter on the Ely causeways, these were not always repaired efficiently (Doubleday, 1973, 104).

Other sites of importance in Hampshire's ecclesiastical landscape show some concentration along the county's coastline, with Southampton and Portsmouth supporting hospitals and a number of Augustinian priories (Doubleday, 1973, 104). It is likely that this high density of hospitals was linked to the overland route taken by pilgrims undertaking the pilgrimage to Canterbury from the docks of Southampton (Storrs, 1995, 38). Two large scale routes were available to these pilgrims, travelling straight to Canterbury along the southern coastline, or via Winchester and London, which proved popular due to the quality of the roads and security amongst other travellers, as well as the opportunity to visit other shrines such as that of St Swithun (Adair, 1975, 36).

Medieval Wiltshire also possessed a high degree of Augustinian sites, principally at Bradenstoke, Ivychurch, Maiden Bradley and Longleat; three high status Benedictine Abbeys at Malmesbury, Wilton and Amesbury; and eighteen hospitals, many of which provided care for travellers. The estates of these sites followed a similar level of economic activity seen above in the accounts of Beaulieu Abbey in Hampshire (Knowles and Hadcock, 1953). The county's spiritual 
centre however was Salisbury, the principle ecclesiastical sites of which are detailed later in the text. The original cathedral in Old Sarum was re-located in the newly founded Salisbury less than a mile to the south in 1280 (Crittal, 1962, 70). This was in part thanks to deteriorating relations between the clergy and the military, both vying for space in an increasingly crowded settlement, and the general population pressure on the site (Pugh and Critall, 1956, 157). The Salisbury Diocese grew out of the combined diocese of Sherborne and Ramsbury (to which Bishop Osmund - later St Osmund of Salisbury Cathedral - was appointed Bishop), the official centre of which was moved to Salisbury castle in Old Sarum in the $11^{\text {th }}$ century, and then subsequently to the newly founded Salisbury in 1220 AD (Crittal, 1962, 70). Its territory stretched diagonally from 'the neighbourhood of London on the northeast to the English Channel on the southwest and incorporated the counties of Berkshire, Wiltshire, and Dorset.' (Brown, 1995, 17) Below I briefly outline the lives of the patron saints of both Salisbury and Winchester, given their status in of both Medieval British pilgrimage and also this case study in particular.

\section{St Osmund (Salisbury):}

Born to aristocratic parents in Normandy, Osmund followed his blood relation William the Conqueror to England in 1066 and subsequently became the Royal Chaplain to the Norman court (Greenway, 1991, 2). In 1078 he succeeded Herman as Bishop of Salisbury (the unification of Sherborne see and Ramsbury see) and created a new centre at Old Sarum, overseeing the construction of the cathedral there (Pugh and Critall, 1956, 157). Much loved for his purity and learning (he was often portrayed with a book in his hand), he became a popular figure, approving the cult of Aldhelm (an Anglo-Saxon Abbot of Malmsbury) and working many miracles in his lifetime (and later posthumously (Greenway, 1991, 2)). His death in December 1099 was widely mourned and he was interred in a tomb in the cathedral at Old Sarum, and then relocated to a tomb in the new cathedral at Salisbury in 1226 (Pugh and Critall, 1956, 157). Despite initial enquiries being made into his possible canonisation by Pope Gregory IX in 1228, it was not until 1457 that Pope Calistus III declared him to be a saint, upon which Salisbury experienced a surge in popularity with pilgrims wishing to visit his shrine (Greenway, 1991, 2).

\section{St Swithun (Winchester):}

Prior to his death and rise to sainthood, little in the way of hard fact is known about the life of Swithun. A bishop of Winchester from 852 to 862, his death is recorded in the Anglo Saxon Chronicle in 862 , and it is not until the monks Lantfred and Wulfstan's hagiographies ( $11^{\text {th }}$ and $12^{\text {th }}$ centuries) that an attempt is made to flesh out details from the Bishop's life - albeit without biographical fact, emphasising a reputation for zeal and piety (Butler, 1866, VII, 2). These accounts describe St Swithun during his tenure as bishop as an 'accomplished model of all virtues', and relates how the saint after his death appeared to a 'certain trustworthy smith' and instructed him to ask Eadsige (an expelled $10^{\text {th }}$ century canon) to tell Bishop Ethelwold to exhume his remains (Lapidge, 2003, 14). In 
Lantfred's testimony (based apparently on contemporary accounts) a series of miracles at Swithun's tomb demonstrating his veracity as a saint followed; including the curing of a hunchback, and a paralysed man (chased by, rather bizarrely, three 'naked and terrifying Ethiopian women'), which persuaded the monks of the Old Minster to translate his relics into an inner shrine site (Lapidge, $2003,15)$. The shrine's evolving location and style are detailed later in this chapter. He is particularly linked to Winchester, Hampshire and the weather (Lapidge, 2003, 13). 


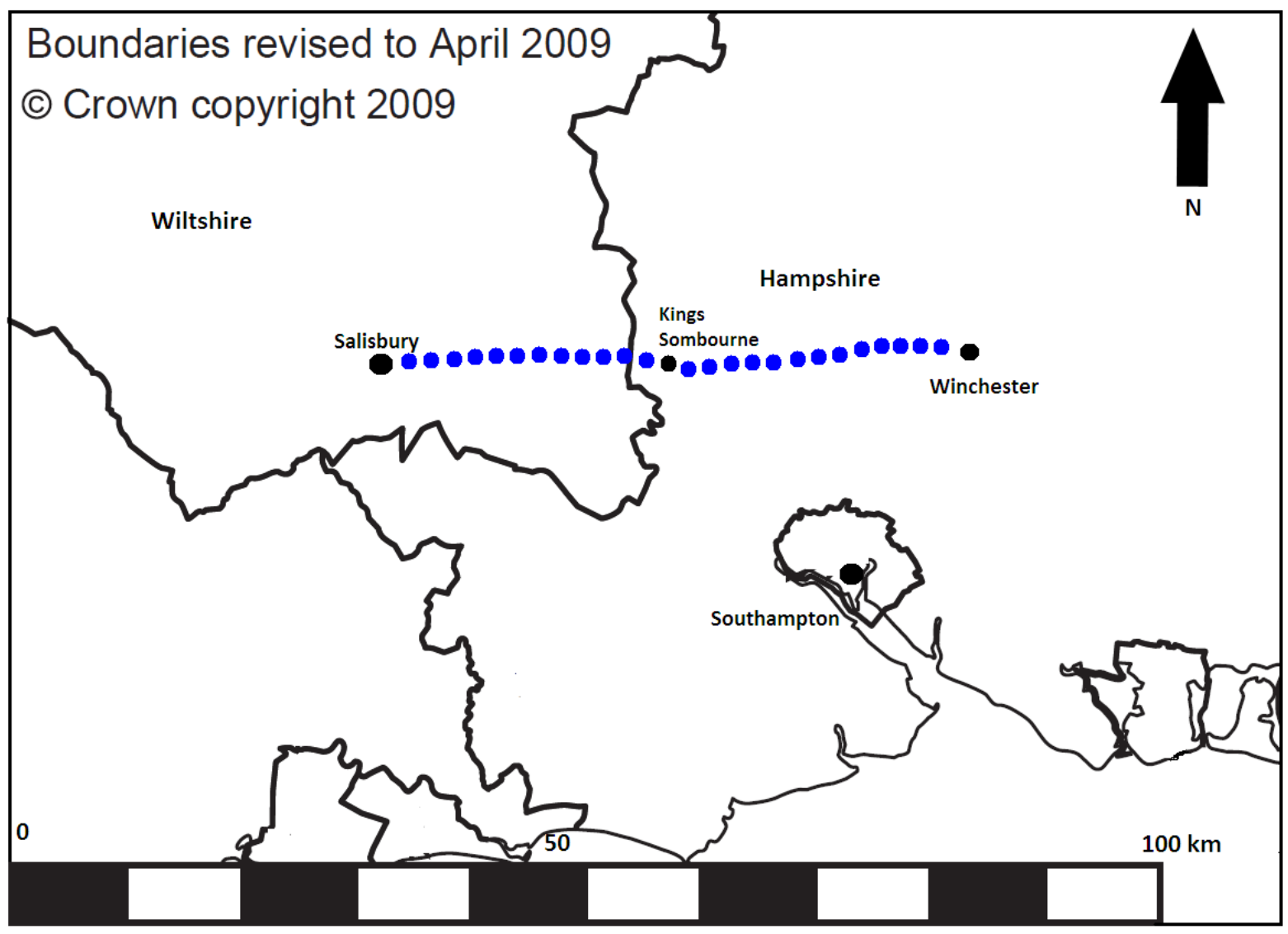

Figure 38. Map of route taken between Salisbury and Winchester along the Roman Road. A detailed map is presented in Appendix B. Redrawn After the Outline Map of the UK Published by the Ordnance Survey.

\section{Prehistoric:}

The landscapes of Hampshire and Wiltshire retain a strong Iron Age character, displaying field boundaries, trackways and drover roads which were subsequently utilised by later inhabitants and are still visible today (Aston and Lewis, 1994, 2). There has been much scholarship in this field and so I will now only present, in brief, the key elements to help construct an impression of the Prehistoric road network in Hampshire and Wiltshire. The high frequency of prehistoric monuments spread throughout these regions (Salisbury Plain being a notable example), are indicative of the high level of activity and settlement in these counties prior to its 'Romanisation' (Cantor, 1982, 15). These widely distributed settlements (such as Danebury, Buckland Rings and St Catherine's Hill in Hampshire, and Barbury Castle, Membury Camp and Old Sarum in Wiltshire) indicate that a comprehensive series of trackways and communication/trade routes existed allowing exchange between them (Thorpe, 1964). The array of funerary monuments which form a large portion of this 'ritual landscape' indicate a freedom of movement around the diverse topographies, allowing for their construction 
and incorporation into either daily or intermittent experience of the landscape (Aston and Lewis, 1994, 3). Great ridge-ways also spanned the region, and Timperley and Brill's 'Ancient Trackways of Wessex' clearly show a series of tracks radiating out from both Salisbury and Winchester, suggesting that both settlements were of great significance, situated on or near routes leading to various ports and estuaries along the North Sea and Channel coastlines (Timperley and Brill, 2005, 18). As has been described above, the use of the downlands in Wiltshire and Hampshire as pasture for sheep and goats also points towards an ease of movement from source, to processing site, and finally to distribution (Cunliffe, 1991).

Roman:

Hampshire and Wiltshire also benefited from the more formalised communication network established during the Roman occupation. These roads characteristically covered great distances in as straight a line as possible, and constituted 'a considerable expansion in the rural economy, with an increase in the number and size of both rural and urban settlements', ranging from farmsteads to villas, planned towns and nucleated settlements (Aston and Lewis, 1994, 4). This expansion in settlement density and economy required a route network to match, and roads were constructed to link these new sites such as Old Sarum (Wiltshire), Silchester (Hampshire) and Fishbourne (west Sussex) with expanded settlements such as Winchester and Southampton, as well as other sites around the country such as London (Margary, 1973).

As described above, these large-scale and formal roads were not the only routes which were used in the Roman period. Earlier trackways continued to be in daily use linking sites and settlements which had survived into the Roman period and, like Roman roads and town planning, in the Medieval period these prehistoric tracks continued to provide a vital series of travel networks around Wessex (Yorke, 1995, 6). Johnston surmises that 'the [Roman] road network may have been far more intricate than we suppose, comprising minor roads and tracks for particular purposes, such as moving flocks and produce to market, bricks and tiles to sites, and pottery to market or to the nearest waterways.' (Johnston, 1981, 47) In terms of this case study, the two settlements we are principally concerned here with are Winchester and Salisbury/Old Sarum. Winchester grew to be the fifth largest town in Roman Britain, and became the administrative capital of the region (Johnston, 1981, 47). Sited some 25 miles south west of Silchester, it lay at the centre of a convergence of major roads which set a precedent for its position in the route network of Britain for the future. Old Sarum (until its abandonment in the $11^{\text {th }}$ century when Salisbury was founded less than a mile to the south) was also a settlement of renown, primarily serving a military function, and was similarly sited on a road convergence 24 miles west of Winchester.

\section{Medieval:}

As has been discussed previously, the Early Medieval kingdom of Wessex inherited the communication networks laid down during Iron Age, British and Roman periods. It is important not to see these stages of 'occupation' as static, but as fluid streams of cultural groups using and 
enhancing remnants of the past - an appropriate example being the Wessex road network. The Roman road system performed both a practical function in spanning the Wessex territories, and it has been suggested they also played a significant role within the landscape in terms of being topographical features within their own right, as 'any de novo creation of boundaries in the Roman period or later would surely have made use of such obvious landscape features as Roman roads' (Bonney, 1972, 169). The growth of trade and fortified settlements in the region also had a profound impact on the developing route network. The $10^{\text {th }}$ century 'Burghal Hideage' cites around 30 fortified sites (or burhs) in Wessex (Rumble, 1996, 14 - 36), and the Domesday Survey lists a significant number of mints in marginal Wessex towns, which are indicative of a high and prosperous trading culture in the region (Yorke, 1995, 311). Barbara Yorke has argued that this broadly follows the Roman distribution for major trading sites (Yorke, 1995). This continuity was likely aided by the surviving roads linking them to both each-other and administrative centres, as Yorke states 'under the Roman Empire the best places for the location of towns had already been utilized and roads to link important centres had been built. Naturally the Anglo-Saxons made use of these aspects of their Roman inheritance.' (Yorke, 1995, 327)

As is shown in detail within the St Asaph to Holywell case study chapter (following), trade along with military activity are the two driving forces of route network development. After the Norman Conquest Wessex ceased to exist as a political unit, and (at least in an administrative sense) it divided roughly into the county boundaries we can see today. The settlement pattern currently visible in Hampshire and Wiltshire was largely established by the end of the Medieval period following the Dissolution, and 'enclosure of downland and the creation of turnpikes in the postMedieval period would have resulted in the alteration or replacement of some earlier routes but in the clay areas the road pattern has probable been little altered since the Medieval period.' (Edwards, 2006,13 ) The administrative hub of Hampshire (and during the $12^{\text {th }}$ and $13^{\text {th }}$ centuries, of England in general) was Winchester, and this is reflected not only in the ecclesiastical, itinerary and bureaucratic records, but also in the convergence of the local route network at the site which 'had excellent communications with the other regions through a network of Roman roads' (Yorke,1995, 327).

The $14^{\text {th }}$ century itinerary of Edward I records his staying at Winchester several times, usually after taking a day's journey from Lyndhurst and subsequently moving on towards Westminster (Safford, 1974). King John's $13^{\text {th }}$ century itinerary includes several stays in the city which had a total of six routes converging at its gates (Gough, 1900, 83; Hardy, 1835, 4). Strong links from Hampshire to London were maintained thanks to its growing status, not only within a material context but also in its position as an important location on the pilgrimage to Canterbury (Adair, 1978, 63). Lantfred mentions in his history of St Swithun that news of posthumous miracle workings at his tomb had spread to the ears of laity, notable in Canterbury, Rochester, London, Bedfordshire and Somerset (Lapidge, 2003, 23). Thus, the use of the Roman road between Salisbury and Winchester by pilgrims visiting Winchester and St Swithun's shrine and on to Canterbury is very likely, the route being described as the gateway out of the West Country (Adair, 1978, 70). 
Wiltshire was also well covered by roads and tracks, and this is evidenced in part by the high volumes of cattle driven across the county during the Medieval period from Wales towards London (Crowley, 1980, 5). Saxon charters indicate that out of the 79 roads recorded in Wiltshire, only 38 were Saxon in origin, the rest being Roman or earlier in date (Lavelle, 2003). The Saxon influence is evident in the contemporarily new concept of placing roads along river valleys, particularly along the rivers Nadder, Avon and Wylye, and by the $12^{\text {th }}$ century two of the great 'Medieval highways' ran through Wiltshire: the Fosse Way and Ermine Street, both of Roman origin (Crittal, 1959, 255). Whilst references in the historical record to particular roads in Wiltshire are rare, it is possible by looking at research on trade and itinerary manuscripts to argue that 'the road from Winchester to Old Salisbury, for example, must have been used very frequently by Henry II, and in the late 13th century the woollen merchants who dealt in the export of raw wool must have needed a good packhorse road between Salisbury and Southampton' (Crittal, 1959, 256). Salisbury, whilst being a relatively 'new' settlement (after relocating the ecclesiastical and settlement sites from Old Sarum in the $13^{\text {th }}$ century) managed to rapidly establish itself as both a spiritual and commercial centre of Wiltshire (Crittal, 1962, 126). This relocation placed the town in a similar location as Winchester; i.e. at the centre of a great route convergence, being linked 'not only with the south of England, but also with the continent of Europe' via connections with Southampton (Crittal, 1962, 129). It is worth noting that both main roads which lead south east and east out of the town are known respectively as Southampton Road and London Road, which are likely references to their primary destination functions during the Medieval period (Crittal, 1962, 126). 


\subsection{The Cult of St Swithun; Origins, Growth and the Shrine}

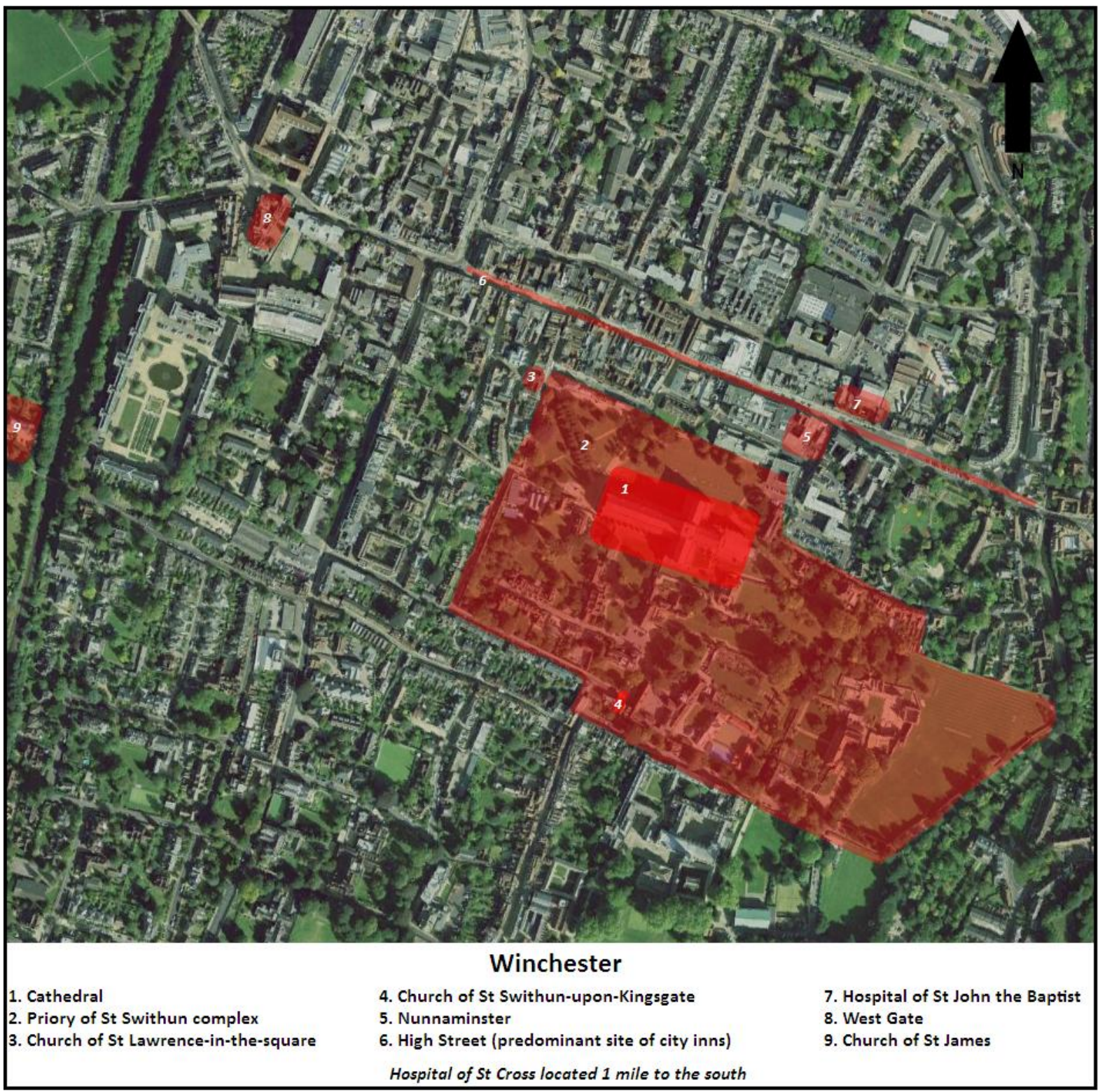

Figure 39. Map of central Winchester with relevent sites located. Original satellite image reproduced from (C) 2011 Google.

Winchester Cathedral and the Shrine of St Swithun:

The birth of the St Swithun cult can be traced to a definitive moment in Winchester's history; the translation of his relics by Bishop Æthelwold $(963$ - 984) from a stone sarcophagus lying outside the Old Minster's west door, and into the Old Minster itself on the $15^{\text {th }}$ July 971 (Lapidge, 2003, 9). This ceremony was recorded in two contemporary accounts, of Wulfstan (Narratio metrica de S.Swithuno) and Lantfred (Translatio et Miracula S. Swithuni). Both describe an impressive ceremony 
supported by King Edgar (this was a translation on a scale of which had not been seen previously in England), who shortly afterwards commissioned a lavish reliquary crafted from gold and silver to house these relics (Lapidge, 2003, 9). The accounts of Lantfred and Wulfstan, particularly Lantfred who composed his Translatio a matter of years after the event (thus containing a contemporary view lacking in later accounts), are the two principal documents used in discovering more about St Swithun and his works.

Prior to discussing the cult of St Swithun, a brief architectural history of Winchester Cathedral places the shrine(s) of St Swithun into context. The Old Minster, constructed in 660 AD and extended into its final building phase in 994 AD, served as the Anglo Saxon cathedral for Wessex and its footprint lies partially overlapping and extending north from the current building (KjølbyeBiddle, 1993, 13). St Swithun, Bishop of Winchester from 852 to 862, was interred in a sarcophagus outside the west door of the Old Minster and was not known for miracle working until roughly a century later, when Bishop Athelwold translated his relics into a temporary shrine inside the Old Minster. However King Edgar soon sponsored a lavish reliquary for these relics. It is not known exactly how long this reliquary took to build as it is not recorded by Lantfred. However, Wulfstan's account describes its commissioning, construction and ceremony of placement upon the high altar. Edgar made available 'three hundred pounds of silver, ruby gems and gold', and ordered that it be engraved with scenes from Christ's Passion, Resurrection and Ascension (Lapidge, 2003, 18). This was however melted down in the mid- $15^{\text {th }}$ century to provide metal for the new shrine of St Swithun (Lapidge, 2003, 19). The expansion of the Old Minster was undertaken to make the reliquary the focal point of worship and accommodate the visiting faithful, a practise that can be seen in many Continental examples from which Bishop Æthelwold probably took his cue (Crook, 1993, 59). The original tomb of St Swithun also continued to provide miraculous cures, and consequently AEthelwold chose a westwards extension of the Old Minster in order to accommodate this tomb (as well as the reliquary at the high altar) into the building (Crook,1993, 59). Thus there were two shrine sites to St Swithun (the tomb at the west and the reliquary at the high altar), amidst the shrines of other saints and venerations of the Virgin Mary.

The New Minster was built adjacent to the Old Minster in c.901, founded by Edward the Elder, and reputedly held a relic of St James the Apostle, however this is unverified (Crook, 1993, 20). Diana Webb asserts that the New Minster held the relics of St Josse in 903, which raises the question as to whether in this case the two saints have become confused in New Minster's historical record by later scholars; however both relics would have attracted some degree of interest from the laity (Webb, 2000, 81). What is certain is that these two churches co-existed for over a century, with each choir drowning out the other (Crook, 1993, 16). Archbishop Lanfranc's Council of London in 1073 encouraged the building or re-building of cathedrals, and this combined with Winchester's rising economic and ecclesiastical prosperity during the $11^{\text {th }}$ century spurred founding of Winchester Cathedral (Crook, 1993, 21). It was logical that this new cathedral should occupy the same site as the Old and New Minsters, both being part of the larger ecclesiastical complex of Winchester (including the Royal Palace, St Swithun's Priory, Nunnaminster and Wolvsey Palace), and the site of St Swithun cult, and work began in the late 1070's to develop a site which was adjacent (south-east) to the Old 
Minster and that partially overlapped it (see Figure 40 below (Crook, 1993, 21)). By 1093 the cathedral was ready to hold services, and the Old Minster was demolished in the same year, with St Swithun's relics being transferred to a feretory behind the cathedral's High Altar (Doubleday, 1973, 118). The Gothic fabric which can be seen today (generally hiding the original $11^{\text {th }}$ century Romanesque fabric rather than replacing it) is of $14^{\text {th }}$ and $15^{\text {th }}$ century origin, the remodelling of the cathedral by William Wykeham being complete by 1490, and is shown in its final phase in Figure 40 below (Crook, 1993, 34). The footprint of the Old Minster can be seen today directly outside the Cathedral outlined in stone at ground level. With the building of the cathedral New Minster lost its primary role as a church for the community, and Henry I ordered its relocation to the northern

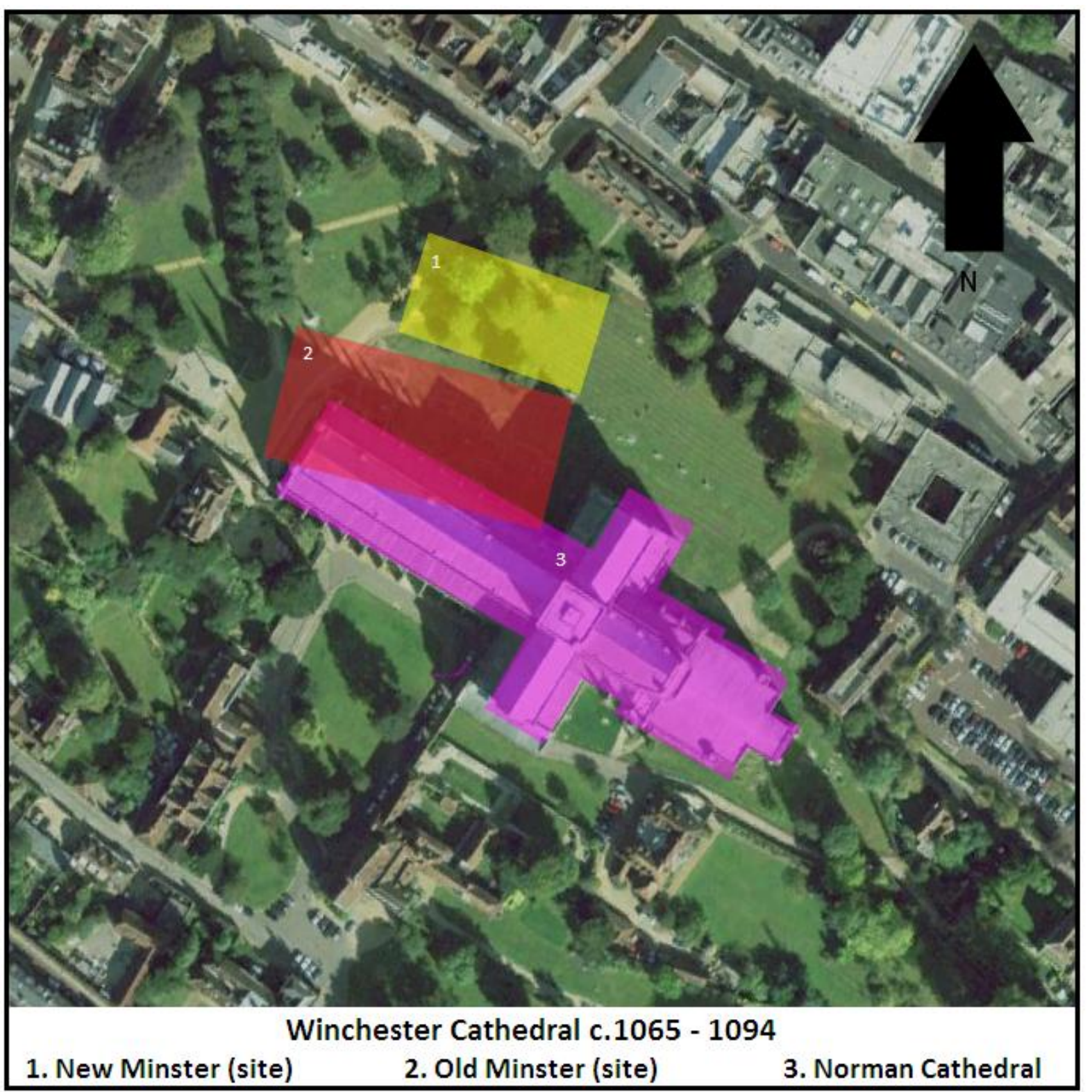

Figure 40. Plan showing locations of the Old Minster, New Minster and the Norman Winchester Cathedral. Redrawn from Crook,1993, 14. 
suburb of Winchester known as Hyde Meade in 1109, where it formed the basis for the founding of the Benedictine Hyde Abbey church, which was consecrated in 1110 and subsequently dissolved in 1538 (Crook, 1993, 22). The relic collection from New Minster was transferred here, and the Liber Vitae of Hyde Abbey lists a fragment of the true cross, the relics of St Judoc or Josse, and the remains of King Alfred (de Gray Birch, 1898).

The Reliquary in Winchester Cathedral was the focal point for pilgrims venerating St Swithun; therein lay his remains and the dispensation of miracles. After its transferral from the Old Minster into the Cathedral, it was placed behind the High Altar in a feretory which was remodelled in the mid-12 $2^{\text {th }}$ century: 'A platform was constructed within the apex of the Romanesque apse, surrounded by a retaining wall, in which the four cylindrical piers of the apse arcade were perhaps half embedded.' (Crook, 1993, 59). This new construction allowed a more efficient circulation of pilgrims, and included a 'holy hole' - a commonly used architectural device whereby pilgrims could crawl underneath the very remains of the saint to offer prayers and supplications. The feretory also included several other relics of St Birinus and other lesser Anglo Saxon saints, and this was common practise as not only would the spread of relics increase the prestige of the institution but the proximity of the lesser relics to those of the patron saint would increase their sanctity. Mortuary chests also lined the arcades, with the remains of several kings of Wessex and England such as Ethelwulf, Alfred the Great and Edward the Elder (Lapidge, 2003, 28).

The final site of the shrine was in the retrochoir, a few metres east of the feretory. This final shrine was constructed in the early $14^{\text {th }}$ century due to the building of the 'Great Screen', which blocked the view of the reliquary and feretory from the choir (Crook, 1993, 64). It took the form of 'a great marble tomb...upon which a silver and gilt reliquary had previously been placed' (Crook, 1993, 64). The archiepiscopal register of Cardinal Morton records a detailed description of the translation ceremony: 'Those of the clergy who were capable of doing so climbed up a ladder which had been erected from the ground to the reliquary on the east side, and on top of the monument the bishop of Winchester and the prior inserted the coffer containing the glorious relics into the reliquary through a certain hatch that had been made for this purpose on the east side of the reliquary. Then the bishop of Winchester got into the reliquary and, having kissed [the relics] with great devotion came out again, as did all the other prelates.' (Harper-Bill, 1991, 52-53).

The height of pilgrim activity In Winchester Cathedral would have been during the second shrine phase, in accordance with Winchester's peak in status. During its construction the flow of pilgrims and general logistics of interaction and circulation would have been considerations, with space in the retrochoir being needed to house large crowds and allow them to move around the dazzling shrine in the feretory, some stopping to crawl underneath the relics. With regard to the evolution of the shrine's location and form, 'There is, however, no unequivocal evidence that the shrine of St Swithun was placed in the retrochoir before the $15^{\text {th }}$ century...it [the retrochoir] would have provided space for a considerable number of pilgrims to congregate when visiting the shrines.' (Draper and Morris, 1993, 178) Pilgrims are known to have been admitted through a doorway in the 
north transept and guided past the reliquary by monks of St Swithun's Priory (Crook, 1993, 62). Access to certain areas of the cathedral would have been restricted, especially the interior of the shrine (i.e. the interior of the feretory), which was locked and guarded by a monk: 'Into the south transept, nave, or choir, no pilgrim could be allowed to pass' (Kitchin, 1892, 44). This northern doorway is still known as 'St Swithun's door', and also opened towards St Swithun's original exterior grave site, itself a sacred space (Nilson, 1998, 93). Wulfstan's account of a miracle involving a slave girl tells us that she was unusually transported inside the innermost sanctuary of his shrine, indicating that it was usually inaccessible for most, and Eadsige the shrine's custodian marvels at how she was locked within the 'holy enclosure' and accuses her of breaking in (Lapidge, 2003, 168). Thus the Eadsige character is an example of how these shrines were physically guarded, and St Swithun's relics were secured inside a private sanctum.

The reliquary was not the sole destination of interest for pilgrims. St Swithun's original grave site (an open air site adjacent to the cathedral) was excavated throughout the 1960's, and was discovered to have been surrounded by a 'memorial court' structure, and other tombs nearby are thought to have 'contained the mortal remains of pre-Conquest kings and bishops who had been buried ad sanctum - near to the saint.' (Biddle, 1967, 270). Fragments of masonry dating to the $13^{\text {th }}$ century show that the tomb structure possessed apertures through which the pilgrim could insert their head and shoulders in order to have physical contact with the grave site (Biddle, 1967, 271; Crook, 1993, 59). The location of the reliquary for the majority of its existence was in the feretory behind the high altar, which restricted direct access to the shrine from the laity; only the monks were permitted within this sanctum (Crook, 1993, 59). The grave site therefore provided a greatly more accessible site for pilgrims to interact with the saint, and many miracles took place there, many of which are related in the accounts of Lantfred and Wulfstan (Lapidge, 2003).

\section{St Swithun's Priory:}

The cathedral was part of a wider ecclesiastical complex, including St Swithun's Priory (see Figure 41 below). Established by Bishop Æthelwold in AD 964 and destroyed during the Reformation, this Benedictine institution became the model for eight other cathedral monasteries in Britain only half a century after the Norman Conquest (Greatrex, 1993, 139). The monks were involved in the care of the cathedral, the daily round of services, and maintaining the physical and spiritual fabric of the cathedral, which under the Benedictine rule of hospitality would have included the caring for the sick, poor, and to a degree, pilgrims (McCann, 1976, 15). Part of the complex was the guest house, now known as the 'Pilgrims' Hall', and this aspect of the Benedictine obedientaries was overseen by the almoner and the guest-master (or 'hostiller') who were also in charge of Sustrans Spital immediately outside the southern gate of the complex on St Swithun street (Greatrex, 1993, 151). 


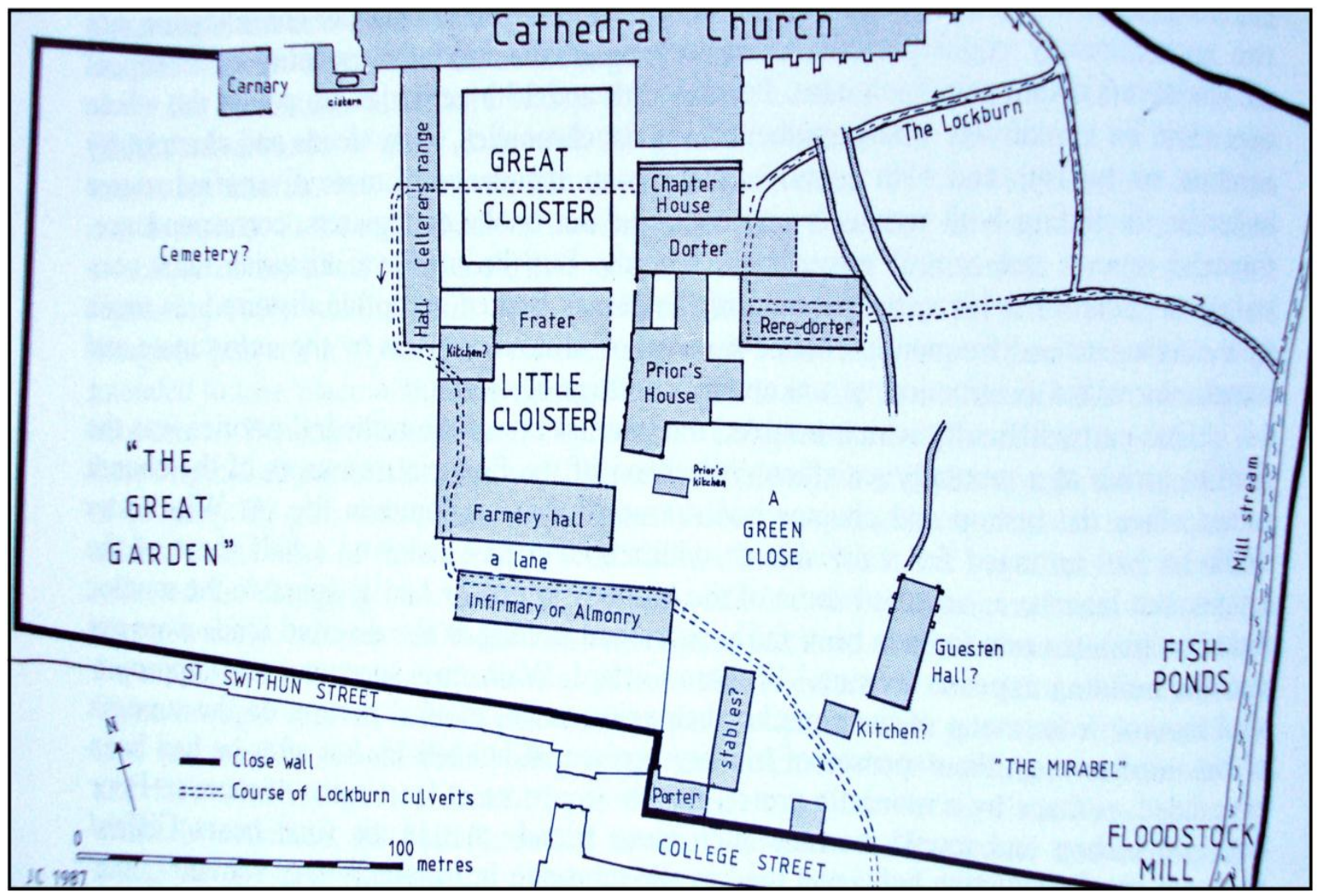

Figure 41. Conjectural plan of the monastic complex of St Swithun's Priory. Reproduced from Greatrex, 1993, 142, drawn by J.Crook.

For those who had come ashore at Southampton or Portsmouth heading towards London, St Swithun's was the first hostelry along their road. 'Others, and these were far more numerous, were the pilgrims toiling onwards, from south or west, towards their ultimate goal at the shrine of St Thomas of Canterbury. To these the earlier sanctity of St Swithun was an attraction and a comfort. The Pilgrims' Hall in which they were lodged, a structure built in the thirteenth or early fourteenth century, still stands on the side of Mirabel Close; and the rafters and massive principals of the roof shew [sic] clear traces of the smoke which curled up day by day from the fire kindled on the hearth in the middle of the building. Here the pilgrims with such rough food as charity or the Convent kitchen provided, rested and slept after their weary journey along the line of one or another of the Roman roads which converge of Winchester. Hence they came forth to worship at St Swithun's shrine, and, it may be, in hopes of cure to spend a night of vigil in the silent Church.' (Kitchin, 1892, 11) The hospitality provided by the monks at St Swithun's Priory was crucial for pilgrims. Sleeping within the shadow of the cathedral in an institution dedicated to the patron saint of the city, combined with the charitable provision of food, the Priory offered both physical and spiritual nourishment which many of the poorer travellers would have been unable to afford at the inns and guesthouses along the city high street. 
Church of St Swithun-over-Kingsgate:

At the entrance to the Close and the site of the Priory was Kingsgate (King's Gate), one of the ancient gates in the walls of the city of Winchester. The small church of St Swithun directly above the gateway is first mentioned in records in 1264 when it was also destroyed by fire at the hands of the people (Page, 1912, 73). Local people became alarmed at the prospect of rebel Simon de Montfort entering the city at the behest of the monks (the city being supportive of Henry III, whilst the monks preferred de Montfort), and as a consequence the inhabitants rose up against the Priory of St Swithun (Page, 1912, 73). It was subsequently rebuilt and has been much restored over the centuries. Little is present in the written record regarding this church aside from the usual baptismal register and administrative documents regarding upkeep. However, its situation on the outer boundary between the city and the St Swithun complex makes it worthy of mention in regard to pilgrimage. Being very literally in a physical gateway to this sacred space, the church also stands in a liminal area between the priory grounds and the general city, bustling with commerce. In its capacity as a St Swithun dedicated monument it becomes a border marker between these two worlds, in a very real sense watching over those who pass into the Close.

The Church of St James the Apostle:

This church was first recorded in 1114, and occupied 'a prominent site on the brow of the hill to the W. of the city in the angle between the modern Romsey Road and St James' Lane' (Keene, 1983, 1036). The fact that the church was dedicated to St James the Apostle makes this site worthy of brief inclusion, given the role St James had assumed as the patron saint of pilgrimage. Combined with the alleged relic held briefly by the New Minster (see above) this dedication further cements Winchester as a destination intricately tied into the pilgrim landscape and network.

The Hospital and Alms-house of St Cross:

One of the most recognisable and distinctive buildings in Winchester's surviving Medieval fabric, the Hospital of St Cross stands on the Roman road ('St Cross road') leading into the city. Founded in 1136 by Bishop Henry de Blois, the hospital was endowed to clothe and entertain 'thirteen poor impotent men, so reduced in strength as rarely or never to be able to raise themselves without the assistance of another', and to provide a daily dinner for 'one hundred poor men of good conduct' (Doubleday and Page, 1973, 193). There is no record that indicates specific providing for travellers or pilgrims, however in a tradition still continued to this day, a traveller may receive the 'wayfarer's dole' at the gate, consisting of a piece of bread and a cup of small beer (Hopewell, 1995, 12).

The situation of the hospital at the southern entrance to Winchester, suggests it is very likely to have offered help or at least the 'wayfarer's dole' to those travellers in the large volume of human traffic which flowed up from Southampton during the $13^{\text {th }}$ and $14^{\text {th }}$ centuries, prior to the city's 
decline (Hopewell, 1995, 45). A category of traveller whose presence would not have receded with Winchester's economic fortunes was the pilgrim, often travelling to Canterbury either from Southampton via the Roman roads linking Winchester with London and Watling Street, or from Salisbury and the West Country via the Roman road or the tracks of the river valleys (Adair, 1978, 68).

\section{Hospital of St John:}

The Hospital of St John the Baptist at the easternmost end of the High Street, near Nunnaminster, was founded for 'the sole relief of sick and lame soldiers, poor pilgrims, and necessitated wayfaring men, to have their lodging and diet gratis there, for one night or longer, as their inability to travel might require.' (Doubleday, 1973, 200). The history of the hospital is the matter of some dispute, with John Leland's initial observation that the institution was founded in 935 by St Brinston (Birinus), Bishop of Winchester, based on his image being present inside the hospital, initially accepted by many scholars and historians (Leland, 1907, Vol II, 163). However, it is suggested by more recent scholars that the history of the hospital truly begins with its re-founding in 1275 by John le Devenish, an alderman of Winchester (Keene, 1985, 82). What can be confidently asserted however is, that for over two centuries prior to the reformation, at least some of the many pilgrims who either passed through Winchester en route to Canterbury or came specifically to St Swithun's shrine would have been welcome to stay for a short period at the hospital if they were too poor for lodgings elsewhere, according to the rule laid down by Devenishe.

\section{Hospital of St Mary Magdalene}

Predominantly a leper hospital with an attached chapel, this institution (refounded in the $12^{\text {th }}$ century a mile east of the city) has little connection with the pilgrim aspect of Winchester, except for in one exceptional circumstance. Recent excavations in the leper cemetery have revealed a healthy adult male skeleton buried with a scallop shell, deliberately pierced by a drill in two instances suggesting an intention to attatch the shell to the person's clothing or possibly a bag (Roffey and Marter, 2012, 17). The scallop shell is an emblem predominantly of pilgrimage to the shrine of St James at Santiago de Compostela, which indicates that the individual had completed this journey and returned to the hospital, although his apparent good health suggests not as a patient (Roffey and Marter, 2012, 17). The rarity of finding an intact pilgrim scallop shell in a burial context, let alone in a leper cemetery, cannot be overstated. It is also possible to make a conceptual link between the pilgrim and the leper, in that both are considered 'outside' society, and although the circumstances and reception of these two categories are vastly different they do share an aspect of removal from the daily world which bonded them to communities of fellow sufferers or travellers. Both, in effect, were exiles. Although at a preliminary stage of interpretation, DNA and isotope analysis, this discovery demonstrates that inhabitants of Winchester were engaging with long distance pilgrimages and that such individuals did choose at times to be buried with their pilgrim souvenirs. 
Inns:

As interest in St Swithun's cult grew and his shrine became a focus for pilgrimage, the high volume of visitors needed beds, and whilst being the most economical option for the pilgrim, ecclesiastical charity was not the only source of accommodation in the city. The High Street in Medieval Winchester offered a series of inns and hospitable merchant houses, as shown in the $12^{\text {th }}$ and $13^{\text {th }}$ century Winchester court rolls (Keene, 1985, 167). Originally the hospitia of twelfth-century Winchester seem unusually to have been the town houses of important men which were perhaps let on terms which enabled them to lodge there whenever they wished', whose buildings in the coming centuries were often transformed into and indistinguishable from the commercial inns (Keene, 1985, 167). Prior to the $15^{\text {th }}$ century, these inns are not clearly defined in Winchester's property records; however 'it is clear from the regular presentations of innkeepers (hostillarii) in the city court, which had begun by 1361, and from other occasional references, that inns had long been a feature of the city.' (Keene, 1985, 167). From $15^{\text {th }}$ century records it is possible to draw together a common series of characteristics which these inns had in common; for example, aside from one exception all the inns lay in the central area of the High Street on its north side, and all had broad frontages (Keene, $1985,168)$. It has been suggested that the decline of St Giles' Fair and the subsequent growth of the city's cloth-finishing industry resulted in an increase in the number of inns in Winchester during the $14^{\text {th }}$ century (Keene, 1985, 168). The names of individual inns can often be found in the records of the city court when inn keepers were brought up on charges, mainly relating to selling short measures or some form of cheating or theft. Examples include The Bull (known to be in existence as an inn during the $16^{\text {th }}$ century), and deeds from the $14^{\text {th }}$ century mention both The Tabard and The Chequer, the latter absorbing the former by the $17^{\text {th }}$ century (Keene, 1985, 168). Typically a feature of the city centre, these inns continued to increase in number well into the $17^{\text {th }}$ century, however whether during this period they all continued to offer accommodation as the term 'inn' denotes is questionable, because 'inn' became used more broadly and encompassed those establishments which were in reality taverns or 'ale-houses' (Keene, 1985, 169). However during the period of St Swithun's shrine, an 'inn' offered overnight accommodation to the traveller, and by all accounts The Chequer was one of the largest inns in England after absorbing the neighbouring Tabard Inn (Keene, $1985,168)$.

Publicity/Cure Accounts and Reputation of St Swithun:

The success of a saint cult ultimately rested on its successful reputation for miracles; in some cases underperforming saints were systematically being relegated to less prestigious parts of the church in order to chastise them and encourage a better 'performance' (Nilson, 1998, 97). The wider the circle of a saint's posthumous influence, then the larger the possibility for their appeal, and St Swithun's hagiographers present a catalogue of his curative record, reproduced below in table form (Figure 42) based on information collated from Lantfred's $10^{\text {th }}$ century Translatio manuscript: 


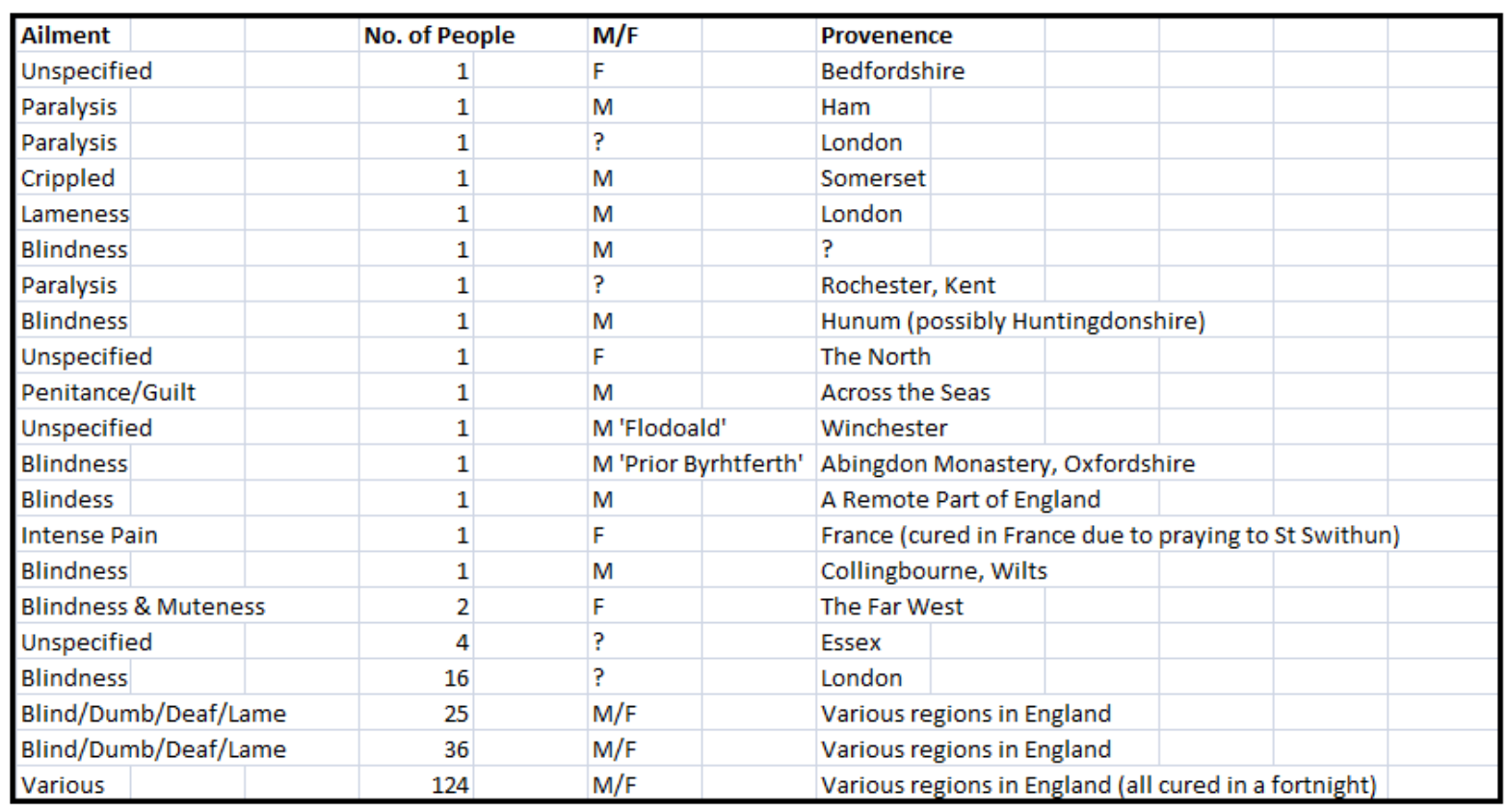

Figure 42. Table of the curative records for St Swithun

What is immediately apparent is the geographical spread of these successful pilgrims' provenances, and reflect the wide spread route network across Medieval Britain and beyond. One example given records a woman in France being cured of blindness by the saint not by journeying to his shrine but by praying to him, and Lantfred frequently stresses that people had often 'heard' about the saint's prowess, indicating that the fame of the saint was transmitted primarily by word of mouth (Lapidge, 2003,321 ). The specific mention of the name 'Flodoald' helps to cement the impression of Winchester as a trading centre of note not only within England but also in international circles during the $12^{\text {th }}-14^{\text {th }}$ century. The name 'Flodoald' is of Norman or Picard origin, and in his analysis of the manuscript Lapidge suggests that this name 'provides good evidence for commercial contact between Winchester and Normandy in this period.' (Lapidge, 2031, 308). Wulfstan's account of this miracle mentions that this merchant was living and well known in Winchester at the time, a trend of post-trading settlement which is noted by Ohler: 'After making such perilous journeys, traders wanted to rest in peaceful surroundings, and they often built houses of their own in the important foreign trading centres.' (Ohler, 1989, 60). The use of the term 'The Far West' in reference to the provenance of two female pilgrims indicates both a highly provincial origin in the West Country, and also the ability of travellers to move across southern England with relative ease.

Whilst not being hagiographically known as 'specialising' in curative miracles relating to eyes (unlike other saint cult centres, such as St Candida's shrine in Whitchurch Canonicorum, Wiltshire), eight out of the nineteen recorded cure miracles relate to blindness - with one instance being a group of sixteen blind pilgrims from London, and another being a mixed group of blind, deaf, dumb and lame pilgrims from various counties. This possible predisposition towards both blindness and paralysis (also well represented in Lantfred's manuscript) is corroborated by Aelfric's 'Lives of Three English Saints', which mentions that during its existence the Old Minster was 'hung around with 
crutches and stools of crippled from one end to the other on either wall', and Barbara Yorke writes in the 'Oxford Dictionary of National Biography' that 'the blind and paralysed were particularly likely to be cured' (Aelfric, 1966, 79 and Yorke, 2004, 859).

The feast days of St Swithun are provided below, taken from Lantfred's chronicle of the Saint's life and legacy:

\author{
2 July: Deposition of St Swithun \\ 9 July: Octave of the Deposition \\ 15 July: Transmission of St Swithun \\ 21 July: Octave of the Translation \\ 30 October: Ordination of St Swithun
}

Four out of the five official feast days of St Swithun fall within July. This alone would make the month the strongest candidate for an increase in pilgrim numbers, however when one examines the rhythm of the agricultural year in relation to those who worked the fields it becomes even more likely that July saw a marked increase in sacral travel not only to Winchester, but generally around the county (Ohler, 1989, 8). Aside from the weather being fairer and thus more conducive to travel, July was known as the 'hungry month', when the stores of grain were at their lowest prior to the gathering of the harvest in August (Ohler, 1989, 8). This then would have been an apt time to make a pilgrimage, with a period of comparative calm before the harvesting of crops, and also temporarily reducing the amount of mouths to feed within the family. Part of the St Swithun mythos has survived in popular British folklore, in that if it rains on St Swithun's day (1 $15^{\text {th }} \mathrm{July}$ ), it will continue to do so for forty days (Westwood and Simpson, 2006, 381). There is a theory that this corresponds to the saint's initial posthumous displeasure at being moved from his burial plot outside the church (chosen by him out of humility) into the shrine in the Old Minster, although this is at odds with the hagiographic records which attribute the move to the saint's wishes communicated through a vision. It may instead bear some numerical significance within the tradition of forty days and nights of Christ's wilderness experience, however this is speculation. 


\subsection{The Distribution for Pilgrim Souvenirs and Relics Relating to the Swithun Cult}

Despite being a major saint cult, and one of the most celebrated of the Anglo-Saxon saints, there are neither surviving records nor artefacts which point towards an industry in pilgrim souvenirs which bear specifically discernable motifs attached to St Swithun. This distinction is important, as if one follows the general trend at significant pilgrim centres (at least for Roman and post-Conquest saints) then it is customary to see either badges or ampullae whose iconography indicates at which shrine the item was purchased (for example St Thomas of Canterbury, Our Lady of Walsingham, the scallop shell of Compostela). However, this lack of material bearing artistic references to St Swithun does not mean that such an assemblage does not exist. Several possibilities present themselves;

1. Those bearing the St Swithun iconography are, as yet, undiscovered - the iconography which might have been appropriate for St Swithun souvenirs can be found in the manuscripts and wall paintings depicting his miracles in Winchester cathedral (Lapidge, 2003, 189) - or such material has not been recognised as being connected with St Swithun.

2. Similarly to some other Anglo Saxon saint cults such a style of souvenir was either plainer in design than those attached to Roman or post-Conquest cults, and has therefore not been defined as a pilgrim souvenir due to it's not being compatible with current classifications of souvenir artefact or decoration.

3. More problematic in terms of proof, but worthy of consideration, is the hypothesis that in terms of souvenir material culture the Anglo Saxon saint cults bore more in common with their Welsh and south-western British neighbours. For example, and as will be discussed in Chapter 5, St Winefride's Well in north Wales was (and still is) a major pilgrimage centre. However, no pilgrim souvenirs have been found in connection with the site. Instead it is recorded by contemporary accounts and historiographers alike that the faithful used to take stones from the well site and subsequent river bed, and put them in vessels of water at home, thereby creating their own miniature 'Winefride Wells' complete with 'blessed' water. This theme is expanded in Chapter 7. However, with Winchester being such an urban site, particularly the site of the shrine, it is hard to imagine what natural keepsake the pilgrim might have appropriated in relation to St Swithun.

It is thus problematic at this stage in our knowledge to examine the distribution for St Swithun's souvenirs. However, we are able to both map and examine the wide distribution of the saint's corporeal remains in the form of relics (which typically of the time were separated from the saint's corpse after his canonisation), and these are not restricted to Britain, as shown below in Figure 43. Whilst these three examples are not statistically impressive, they do display a wide and suprising distribution for the relics of an Anglo-Saxon bishop saint, extending beyond Britain's borders. 


\section{Peterborough Abbey}

After its destruction by raiding Danes in the late $9^{\text {th }}$ century, Peterborough Abbey (see Figure 43 below) was gradually rebuilt and repopulated with monks under the supervision of Winchester's own Bishop Athelwold, beginning in 963 (Friis-Jensen and Willoughby, 2001, 3). This however was not the only link that the institution shared with Winchester, as it was also reputed to possess amongst its collection of relics the arm of St Swithun, possibly acquired through its connections with Bishop Athelwold during the time when the saint's remains were portioned out to disparate institutions, or from the fact that 'John de Caux, prior of St. Swithin's, Winchester, was elected abbot [of Peterborough] in 1251, and ruled the monastery with success for twelve years' (Serjeantson and Adkins, 1906, 89). Records also indicate that the monks held an arm of St Oswald, however during the Danish raids many relics were carried off, and during the dissolution of the Abbey in 1539 all their relics were lost, and surviving architectural records are insufficiently complete to show the manner (and hierarchy) in which these various relics were displayed (Yorke, 2007, 857).

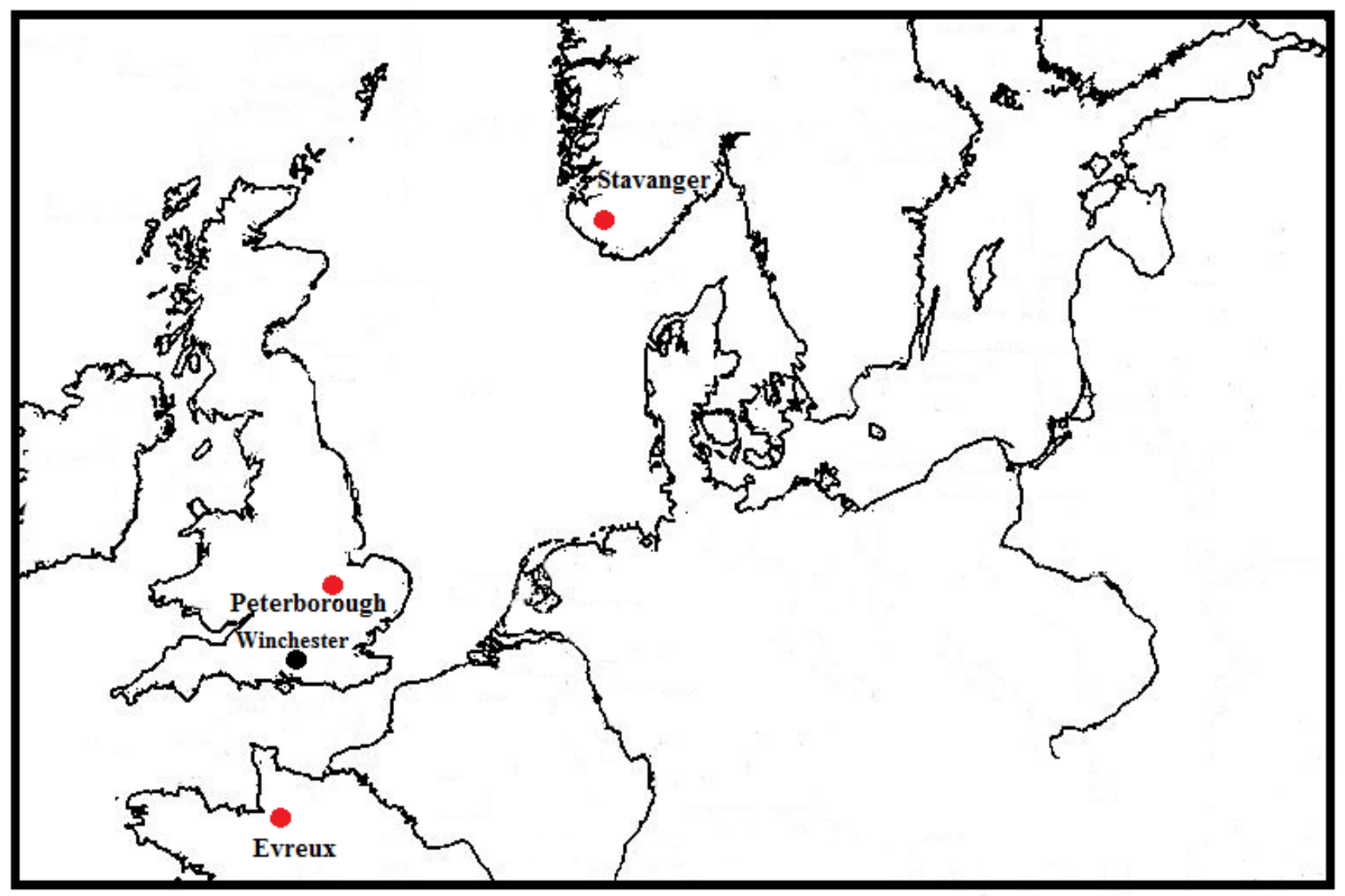

Figure 43. Map of the known distribution of St Swithun's relics outside of Winchester. Original map reproduced from Ordnance Survey Coastal Outline of Europe Map. 


\section{Evreux Cathedral, France}

In 1005 Elfeah, then Bishop of Winchester, took the skull of St Swithun with him when he was appointed to the See of Canterbury, presumably in order to propagate the cult of the saint whom had been his patron during his time at Winchester (Lapidge, 2003, 61). However, after his death his successors took little interest in the relic and the St Swithun cult, and the skull was relocated to Evreux Cathedral in northern France, shown above in Figure 43 (Lapidge, 2003, 62). One possible explanation as to how this important relic ended up in France, is that the skull was given to Giles, Bishop of Evreux, as a diplomatic gift during the coronation of Henry II's younger son ('Henry the Young King') as co-ruler of England, as Giles who, according to some sources, placed the crown on the boy's head (Lapidge, 2003, 63). The relic would thus have been a gift in lieu of the Bishop's service, and a way for those at Canterbury to pass on a relic which they may have thought (in terms of status) as 'out of date' - however Michael Lapidge has rejected this theory as chronologically unsound (Lapidge, 2003, 65). This relic still survives unlike the arm once at Peterborough Abbey.

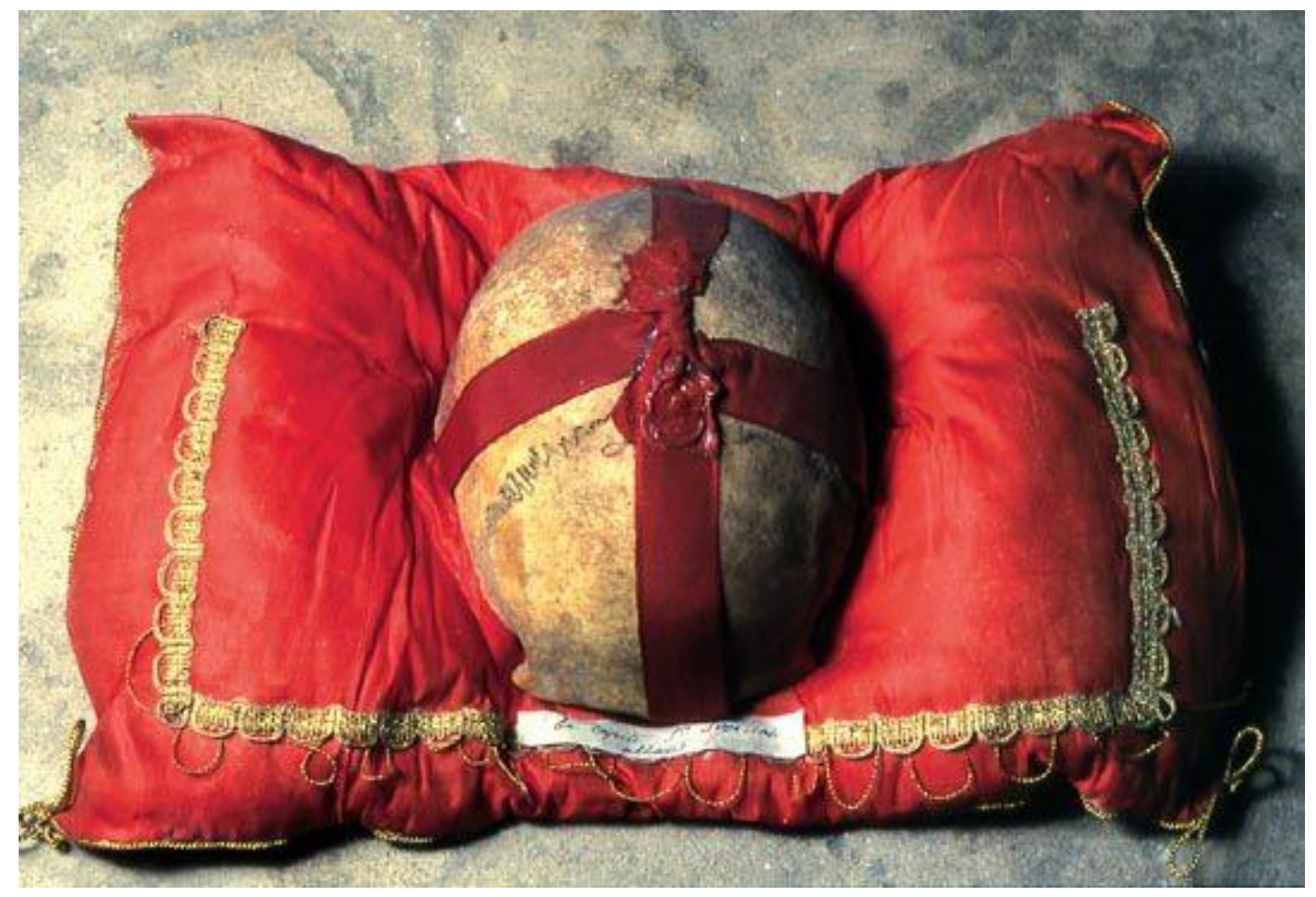

Figure 44. The upper skull of St Swithun, relic of Evreux Cathedral. Reproduced from www.gutenberg.org.

Consisting of the upper part of the skull (including the frontal and parietal bones), it currently sits on an upbraided cushion (see Figure 44 above), its earlier more ornate reliquary being stolen in 1792 although the skull was left behind (Lapidge, 2003, 65). The authenticity of such a relic is naturally questionable under initial examination of the facts; i.e. that the skull (considered the highest status part of a saint's skeleton) of an Anglo Saxon saint would end up in Normandy in the 
$14^{\text {th }}$ century. However Lapidge argues that 'the most powerful argument in favour of the authenticity of the relic in at least the fourteenth century is the tradition itself. The cult of St Swithun was not widespread in Normandy, and there is no obvious link between Winchester and Evreux. The fact that Evreux venerated a relic of what for the clergy of that cathedral would have been an obscure AngloSaxon saint is perhaps the strongest argument in favour of its authenticity.' (Lapidge, 2003, 65). The cathedral had so little to gain in terms of status and reputation from the ownership of the relic of a foreign and (in that locale) relatively unknown saint, it is difficult to discern a motive for being disingenuous regarding the validity of the artefact and its provenance.

\section{Stavanger, Norway}

Perhaps the most surprising destination for the relic of an Anglo Saxon saint is Stavanger Cathedral in Norway (see Figure 43 above). In 1192 Bishop Reinald or Reginald (a Benedictine monk from Winchester) was engaged as an Anglo Saxon missionary to Scandinavia, and asked to supervise the building of the Domkirke, or Cathedral, in Stavanger, so that the Norwegian king would have somewhere suitable in which to be married (Gjerset, 1969, 323). Corresponding stylistically to its founder, the cathedral was built in the Anglo-Norman style, and it is also dedicated to St Swithun (Gjerset, 1969, 323). A local tradition has it that Bishop Reinald took some relics, including an arm of St Swithun (presumably the companion to the one in Peterborough Abbey), to Stavanger, and this is corroborated in the cathedral inventory of 1547 (Jørgensen, 1874, Vol II, 861). However during the $16^{\text {th }}$ century the then Danish king plundered the church and removed the relic and its accompanying shrine, altars, pictures of saints and the cathedral bells. Packed onto a ship bound for Copenhagen (where much of the metalwork would be melted down), the vessel sank off Hastein with its sacred cargo still inside, and for this reason the location is known as 'Klokkeskjær' or 'Bell Skerries' (Gjerset, 1969, 323). It has not been recovered.

Section 4.7 of this chapter addresses the distribution of churches bearing St Swithun dedications within Britain, and it is likely (although manuscript evidence is scarce) that at least a small proportion of these claimed to possess relics of the saint, although they were probably smaller (such as finger bones) than the limbs reputed to have been in Peterborough and Stavanger, and the skull in Evreux, otherwise we would expect to find greater reference to them. St Swithun was a favoured saint by royalty, partly thanks to his alleged predilection towards scholarship and learning and his closeness to King Egbert of Wessex and his son Athelwulf, who was responsible for his appointment as Bishop of Winchester (Lapidge, 2003, 6). St Swithun remained principally Anglo Saxon in popularity, and these two foreign venerations of his relics were rare anomalies in terms of his presence in the church landscape, and we have no surviving records of miracles attributed to these 'foreign' remains. It is interesting to note, however, that the two portions of the saint to travel abroad would be typically categorised as 'major' relics, and perhaps owed their longevity and veneration to scale rather than the reputation of St Swithun outside of Britain (the $2^{\text {nd }}$ of July is still known as the 'Feast of St Swithun' in Norway). 


\subsection{The Archaeological and Etymological Remnants of Pilgrimage between Salisbury and Winchester}

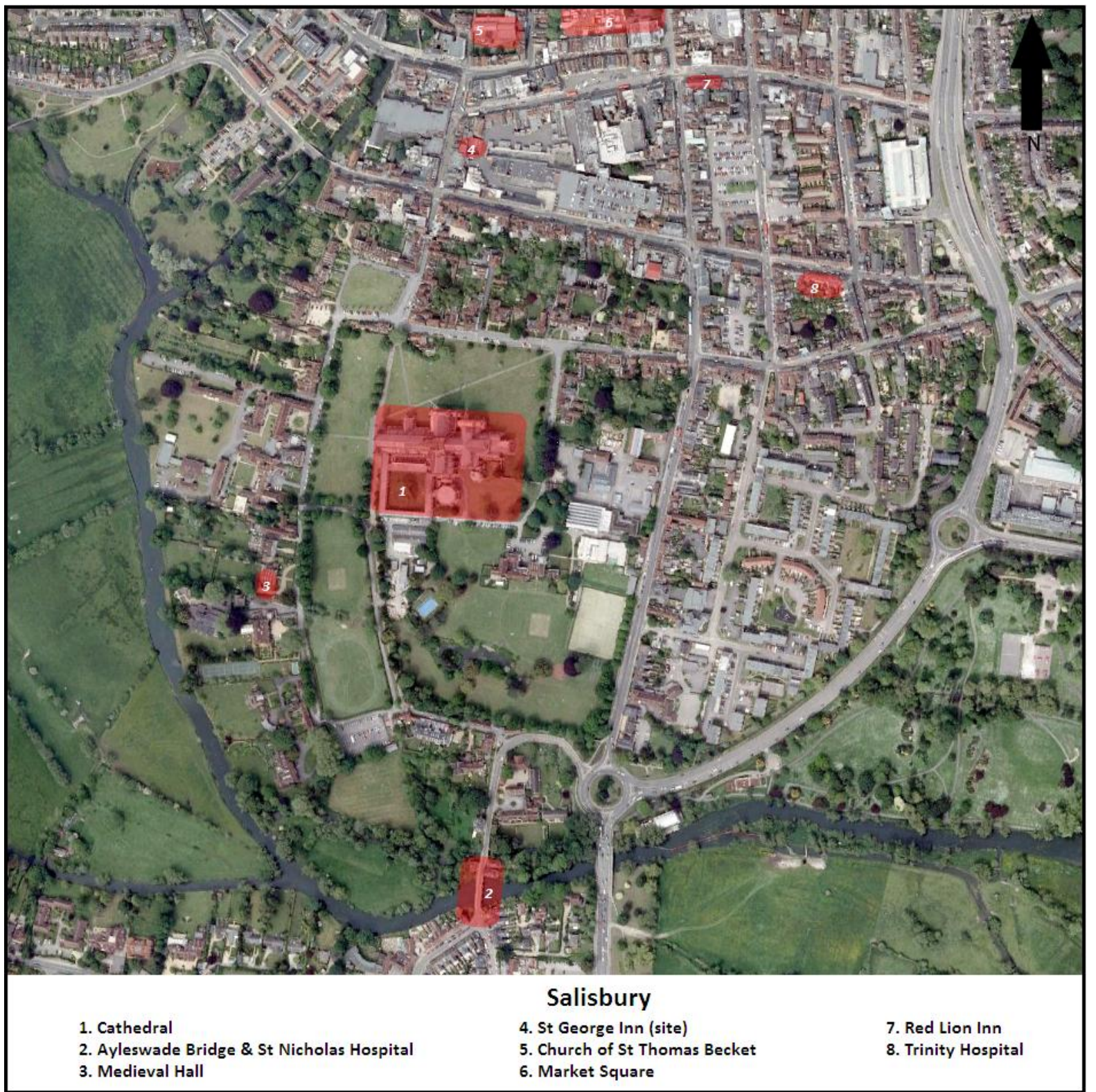

Figure 45. Map of central Salisbury with relevent sites located. Original satellite image reproduced from (C) 2011 Google.

Travel between Salisbury and Winchester was a frequent activity for many levels of society. Aside from the physical remnants of these routes in the landscape, this movement is also highlighted by more ephemeral evidence such as road names (London road, Old Sarum road, Winchester street), and was driven not only by access to the fairs and markets of these two cities, but also by the lure of Canterbury. Much like Winchester, the town's location on the road network saw it emerge on a confluence of roads (both Medieval, Roman and of even greater antiquity), and in particular with 
those roads which both reached into the far west of England, running through urban centres such as Exeter, and led travellers from the west into central southern England. Salisbury in effect became a 'gateway town', with its own patron saint in the form of St Osmund (whose life is briefly covered above). The majority of non-local pilgrims who came to Salisbury were bound for Canterbury via Winchester and London, but many would wish to also make devotions to St Osmund's shrine and play their part in developing the pilgrim industry of Salisbury in both the spiritual and secular areas.

\section{Salisbury Cathedral}

Much like Winchester, Salisbury was both a site of pilgrimage and an influential settlement whose location was situated on a major thoroughfare for human traffic progressing towards easterly English pilgrimage centres (Adair, 1978, 68). The most prominent landmark in Salisbury was also its defining monument; the cathedral, home to the shrine of St Osmund who was canonised in the $15^{\text {th }}$ century. Prior to its current location, the cathedral and associated settlement had lain at the original Roman site of Old Sarum, a mile to the north of current day Salisbury, surrounded by fortifications, where Bishop Osmund had been in charge of ecclesiastical duties (Pugh and Critall, 1956, 157). The original cathedral burnt down to be replaced by a larger construction in 1120 . However, pressures of an expanding settlement within the narrow confines of the fortified hill combined with rapidly deteriorating relations between the clergy and military at Old Sarum (both vying for control over the settlement and space), led to a re-siting near the fertile water-meadows to the south in 1220 where a new cathedral was constructed within thirty eight years. The cloisters, chapter house and $123 \mathrm{~m}$ tower were added in the $14^{\text {th }}$ century (Pugh and Critall, 1956, 157). It is the 'new' cathedral which concerns us in relation this case study, with its attraction for pilgrims and subsequent development of the hospitality and ecclesiastical aspects of Medieval Salisbury.

As has been briefly surmised earlier in this chapter, the cult of St Osmund was not given official status by the Roman church until the mid-fifteenth century. However after St Oswald's canonisation by Pope Calistus III in 1457, the town received a surge in pilgrim numbers almost overnight (Greenway, 1991, 2). In his more devotional pre-Reformation years Henry VIII is recorded as visiting St Osmund's shrine. In the 'Kings Book of Payments for Henry VIII' there is a record dating to the $7^{\text {th }}$ September 1516 for 'Offerings at Salisbury church and St. Osmund's shrine, 13s. 4d.' (Brewer, 1864, 1472) The new cathedral was notable for its considerable number of altars, although aside from the High Altar, the altar and shrine which commanded the most attention post 1456 is very likely to have been that of St Osmund (Wordsworth, 1901, 277). After being translated to the new cathedral in 1226, Osmund's remains were placed to the 'south syde of our Lady [the Lady Chapel] while the [pre-canonised] Shrine was in the makyng' (Leland, 1744, iii. 79). We can see from Chambers' 'Divine Worship in the $13^{\text {th }}$ and $14^{\text {th }}$ Centuries' (1877) that after his tomb was completed, it was situated in the centre of the Lady Chapel, and after Osmund's 1457 canonisation a new and 
opulent shrine was constructed directly in front of the altar of the Lady Chapel (Wordsworth, 1901, 281).

When St Osmund was translated from his tomb in 1457 'he was installed in a temporary shrine. Fifteen years later Edward Bowden, Goldsmith of London, appeared with a proposal drawn on paper for a new shrine which the Bishop of Salisbury, who was present, took away. The next day all concerned went to the treasury to view the jewels, precious metals and other valuables collected and offered to St Oswald since his translation.' (Nilson, 1998, 22) The recorded accumulation of precious offerings donated in 1472 by the laity are indicative of the rapid ascent the saint's reputation had made since being canonised a mere fifteen years earlier (Nilson, 1998, 22). The records indicate that even before the permanent shrine was erected, the long awaited canonisation of Osmund made a significant difference to the level of interest that Salisbury attracted, with increasing numbers of pilgrims eager to open both their hearts and their purses to the saint's relics. The canons charged with looking after the offerings were described as 'the keepers of the offerings and jewels and things pertaining to the shrine of St Osmund'. Two notices of 1456 show that offerings were being made to the shrine and money borrowed from it even before the next year's translation of St Osmund's relics. Another note from 1456 mentions money in both a cista (chest) and a saccula (little sack) of St Osmund. Finally, the Salisbury fabric accounts of the sixteenth century record two instances of pyx [a small container for the consecrated host] offerings in 1538: 15s. on $17^{\text {th }}$ February, and $f 611 \mathrm{~s}$. $6 \mathrm{~d}$. on 11 July.' (Nilson, 1998, 166 and Malden, 1901, 93 - 222) However the cathedral coffers were not the only sources of wealth which contributed towards the building of his permanent shrine. Over the next twenty five years there are records of notable ecclesiastical figures and local nobility leaving sizeable sums to the completion of St Osmund's shrine, and for these donations they were as a group immortalised in a special prayer engraved on the interior of the processional, referring 'in especial for ye soules of theym whiche have given or gyve any parte of theyr godes to the performing of the shrine of seynt Osmunde.' (Wordsworth, 1901, 32) These accounts indicate that the donations made to the shrine and cathedral by devotees of St Osmund's cult were both significant and in some cases extravagant, demonstrating his importance in the ecclesiastical landscape until 1539, when '2 men were employed for 9 days, 4 men for 1 day, and 2 men for a further 15 days on the destruction of St. Osmund's shrine, the long period of demolition suggesting that the jewels were carefully removed.' (Crittall and Pugh, 1956, 193)

Unusually, St Osmund's feast day falls on the $4^{\text {th }}$ December. Typically, when a saint is canonised during a winter month, the translation will wait until the following spring or even summer, so as to make his feast day fall in a time when the maximum of people will be able and want to travel to the cathedral to celebrate it (Jones, 2007, 139). However this is not the case in Salisbury, where his canonisation and translation (into his final opulent shrine in front of the Lady Chapel altar) are both celebrated by feast days as winter events. Processions possibly with a form of mobile reliquary and sacrament would have flowed around the town (Frost, 2009, 6). Frost's study of Medieval Salisbury's layout suggests that the first of the four annual Rogations would have broadly circumvented the Cathedral Close, with the other three varying in the number of circumnavigations around the cathedral and the extent to which they followed the city limits (Frost, 
$2009,6)$. These acts followed a symbolic representation of key Christian events such as the "birth and transfiguration of Christ' (engendering a triple tour around the cathedral), and also acted as a reconsecrating of the city boundaries (Frost, 2009, 6). Thus there is reason to believe that St Osmund's feast day would also have followed a route laden with gesture and symbolism, no doubt flanked by pilgrims and culminating in a lavish service in the cathedral itself. As is also typical with feast day celebrations of translation, a fair would have been held in Salisbury, most likely in the market place at the end of the High Street and directly in visible line with the cathedral (Nilson, 1998, 93).

Surviving records indicate that there were three hospitals in Medieval Salisbury, however one (St John the Baptist and St Anthony) was primarily engaged in working with lepers, and so does not concern us at this point (Knowles and Hadcock, 195, 303). The two below, Trinity and St Nicholas', are both recorded by Knowles and Hadcock as caring to varying degrees not only for the sick but also providing for poor travellers and pilgrims, and so are relevant and appropriate for inclusion in this analysis of Salisbury's urban pilgrim landscape (Knowles and Hadcock, 195, 303).

\section{Trinity Hospital:}

The earliest certain evidence for this institution comes from a patent letter in 1394 which granted a John Chandler permission for its foundation, however the more current Wiltshire HER credits its date to nearer 1379, drawing on a document of indulgence from the Archbishop of Canterbury (Pugh and Crittall, 1956, 357; Cal. Pat., 1391 - 1399, 383). The hospital could provide for 12 permanent poor and 18 temporary; the latter were given up to three days board unless they were sick, in which case this was extended (Pugh and Crittall, 1956, 357). The extensive surviving records include an inventory from 1418, which details 28 beds, 25 coverlets, 13 quilts, and 23 pairs of sheets, and suggests that that those staying in the hospital enjoyed a varied diet: 'Mutton, pork, or beef was served on Sunday, Monday, Tuesday, and Thursday; fresh or salted fish on the other three days. Eggs, milk, oatmeal, cheese, bread, ale, peas, salt, and wheaten flour also formed part of their regular fare.'(Pugh and Crittall, 1956, 357; Wordsworth, 1902, 72) The present $18^{\text {th }}$ century hospital building still occupies its original Medieval site on New Street, near the Close, and also parallel to the site of the Old George Inn (detailed below), and is built allegedly on the site of a former brothel (Pugh and Crittall, 1956, 357). It escaped the persecution of the Reformation remaining unsuppressed, and is currently an almshouse.

\section{St Nicholas Hospital:}

It is alleged that this hospital has $12^{\text {th }}$ century origins, however what can said in certainty is that the institution is mentioned in charters belonging to Ela, Countess of Salisbury, and Bishop Richard Poore, both dating to 1227, and both indicating that the hospital was under the Bishop's patronage with 'a steward, endowments, a chapel, and the obligations of a chantry and of caring for the poor, sick, and travellers.' (Pugh and Crittall, 1956, 359) In 1229 the new Bishop of Salisbury (Robert Bingham) commissioned substantial additions to the hospital building, most crucially connecting it 
with a new and large stone bridge crossing the Avon and the chapel of St John the Baptist atop the bridge. This bridge (Ayleswade Bridge), also commissioned by Bingham, enhanced access to Salisbury by replacing a ford which frequently flooded preventing regular access from the south (Pugh and Crittall, 1956, 359). The hospital also functioned as an almshouse, and early in the $16^{\text {th }}$ century the entrants to the hospital began to be recorded in a register of admissions, although this was for longer term residents not temporary travellers (Pugh and Crittall, 1956, 364). In Wordsworth's 'Fifteenth Century Cartulary of St Nicholas' Hospital, Salisbury, with Other Records', the author states that the hospital was 'conveniently placed for pilgrims making for the great shrines of Winchester, Canterbury, Chichester, andc.', and St Nicholas' functioned as the major hospital and almshouse in Salisbury throughout the Medieval period, (Wordsworth, 1902, 72). This building was consequently an important feature of both the urban and ecclesiastical landscape in Salisbury, and for many travellers arriving via the Ayleswade Bridge, it would have been the first major building to greet them as they entered the city limits. The hospital still fulfils its function as an almshouse today.

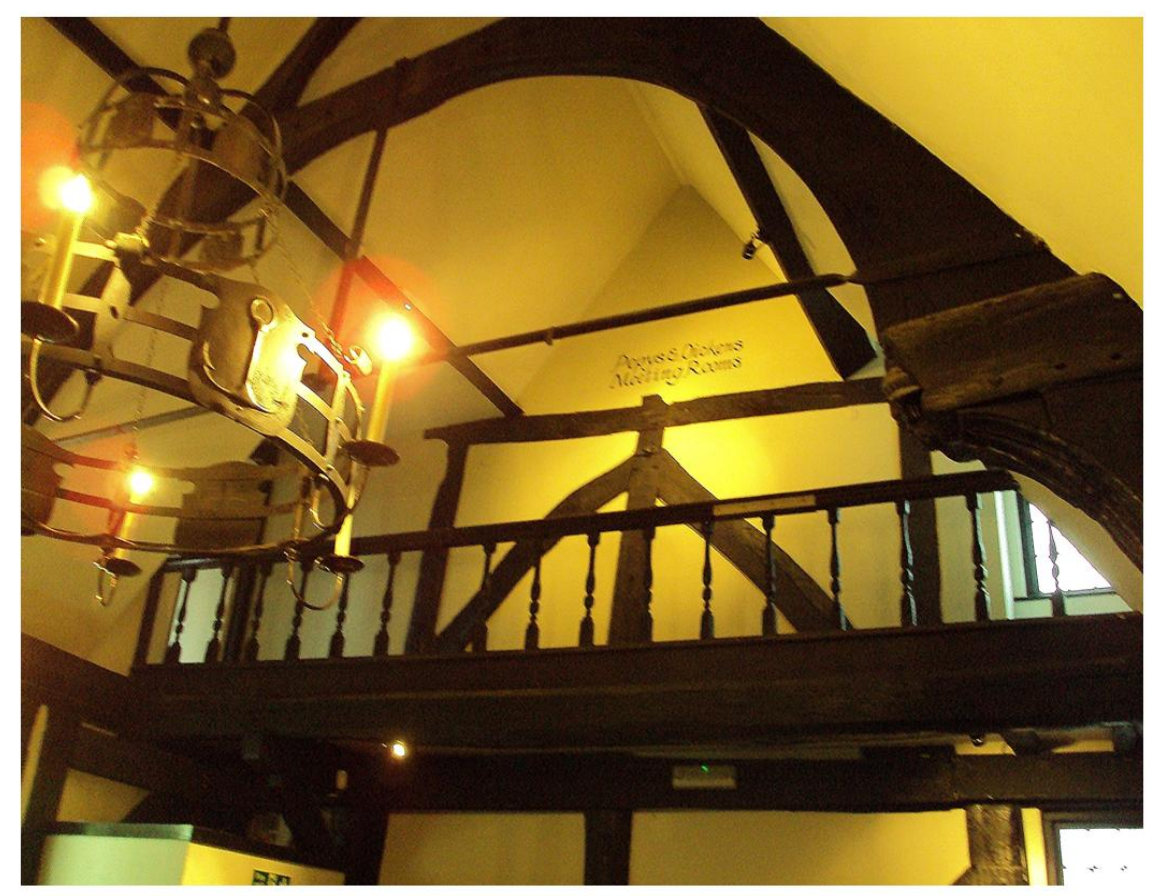

Figure 46. Late $19^{\text {th }}$ century postcard displaying the Old George Hotel (left), detail of surviving $15^{\text {th }}$ century interior fabric (right). Postcard reproduced from http://www.oldstratforduponavon.com/salisbury.html.

Photograph taken by author.

However, for those pilgrims and travellers not reliant on Salisbury's hospitals the High Street offered a series of inns in a similar manner to Winchester. The High Street runs north from the cathedral and Close to the market place, and was the heart of Medieval Salisbury's economy. The most celebrated and important of these inns was the 'Old George Hotel' or 'Georges Ynn' as it was originally named, and dates from the $14^{\text {th }}$ century (see Figure 46 above). The inn held thirteen guest chambers, some of these rooms being of such a size that a free school operated in one of them for 
several decades in the early $17^{\text {th }}$ century, and play rehearsals took place there (Crittall, 1962, 81). William Shakespeare, Samuel Pepys, Oliver Cromwell and Charles Dickens are all reputed to be among the inn's more illustrious guests. Other inns along the High Street included 'Pinnock's Inn' (this became 'The Helm', and was then demolished in 1491), 'Countewelle's Inn' (mentioned in a document dating from 1335), and 'Tarent's Inn', which changed its name to 'The Angel' in 1455 and was reduced to a timber yard in 1761 due to bankruptcy (Haskins, 1912, $310-$, 330). Just south of the High Street, across the river Avon near the hospital of St Nicholas is The Crown Hotel, which stands on the site of a $15^{\text {th }}$ century inn called 'The Rose', then 'The Rose and Crown' in the $17^{\text {th }}$ century (Haskins, 1912, 310 -, 330). Finally, the 'Red Lion Hotel' on Mitford Street (100m east of the High Street) dates in part to 1230, when it was known as the White Bear Inn (Haskins, 1912, 310 -, 330). Built initially to accommodate those working on the new cathedral, it continued to offer guest rooms to those visiting the cathedral throughout the Medieval period, and developed into a coaching inn during the $17^{\text {th }}$ century, when its name was changed to the Red Lion and it ran a postal service to London (Haskins, 1912, $310-330$ ).

There have been a number of pilgrim badges found in Salisbury (Spencer, 1990). Of the ten badges presented, three are from the shrine of St James in Santiago de Compostela, four are from the shrine of St Thomas Becket in Canterbury, and the remaining three are from the Salisbury's own shrine of St Osmund (Spencer, 1990, 10). Most of these have been found in watercourses, preserved by the anaerobic conditions of the river mud (Spencer, 1990, 3). Their distribution fits a pattern demonstrated by the majority of pilgrim badges found throughout Britain i.e. they are deposited at river-crossings or riversides, and in the case of Salisbury in the river Avon (Spencer, 1998, 24). Spencer suggests that these badges were thrown into rivers by returning pilgrims as thankful offerings a safe return, and also may have been part of the ritual for a person reverting to their 'nonpilgrim' state by casting off the classic pilgrim accessory (Spencer, 1990,11). It is not the aim of this thesis or chapter to discuss the meaning behind such actions or the role of the pilgrim badge in the spiritual landscape, but such a series of deposited pilgrim badges does inform us of two crucial facts about Salisbury. There was a local production of pilgrim souvenirs, presumably controlled by the cathedral in order to benefit the shrine of St Osmund, and there were pilgrims from Salisbury (depositing their souvenirs as they arrived back home) who had been, among other places, to Canterbury via the common route of Winchester, London, Dartford, Rochester and Ospringe. As such, given the directness of the route it makes it highly probable that the Roman road between Old Sarum and Winchester was habitually used for this journey, no doubt joining other pilgrims and travellers coming out of the far west of England.

The 'London Road' leads the traveller out from Salisbury, and connects the town with the Roman road which runs from the site of Old Sarum to the western approach into Winchester. Whilst the general area between Salisbury and Winchester is well populated with villages and hamlets, there are few settlements of consequence which fall either on or near the Roman road, aside from East/West/Middle Winterslow and Kings Somborne. 


\section{West Winterslow}

Collectively known in the Domesday Survey as 'Wintreslei', West, Middle and East Winterslow are three settlements which derive from three separate manors, a mile north east of Salisbury along the Roman road, historically supported through a combination of arable (wheat, barley and oats) and sheep farming (Short, 2006, 89). 100 metres south west from the Roman road is West Winterslow, whose parish church dates from the late $11^{\text {th }}$ century, dedicated to All Saints (see Figure 47 below). According to church historian Rev. Clive Cohen, All Saints was richly decorated prior to the Reformation, when the interior was whitewashed (Cohen, 1996, 27). One of the wall paintings to be lost was a $15^{\text {th }}$ century 'Doom painting' above the chancel arch, temporarily unearthed during alterations in the $19^{\text {th }}$ century but lost again during the rebuild (Cohen, 1996, 28). The potential role of this church for those pilgrims travelling to Winchester is uncertain. It is sufficiently close to the road to be easily visited, however it is not visible to the eye from the Roman road, and so would rely on being already known to the pilgrim. However for those who were aware of the All Saints church (and we must here presume that this would be a category mainly composed of locals), it may be that the Doom painting acted as a draw, for as can be seen in the surviving example in St Thomas' church in Salisbury itself, such paintings were of great symbolism to the Medieval mind, laden with references to the consequences of moral and immoral behaviour, penance, and the ultimate fate that awaited mankind (Gill, 2007, 66).

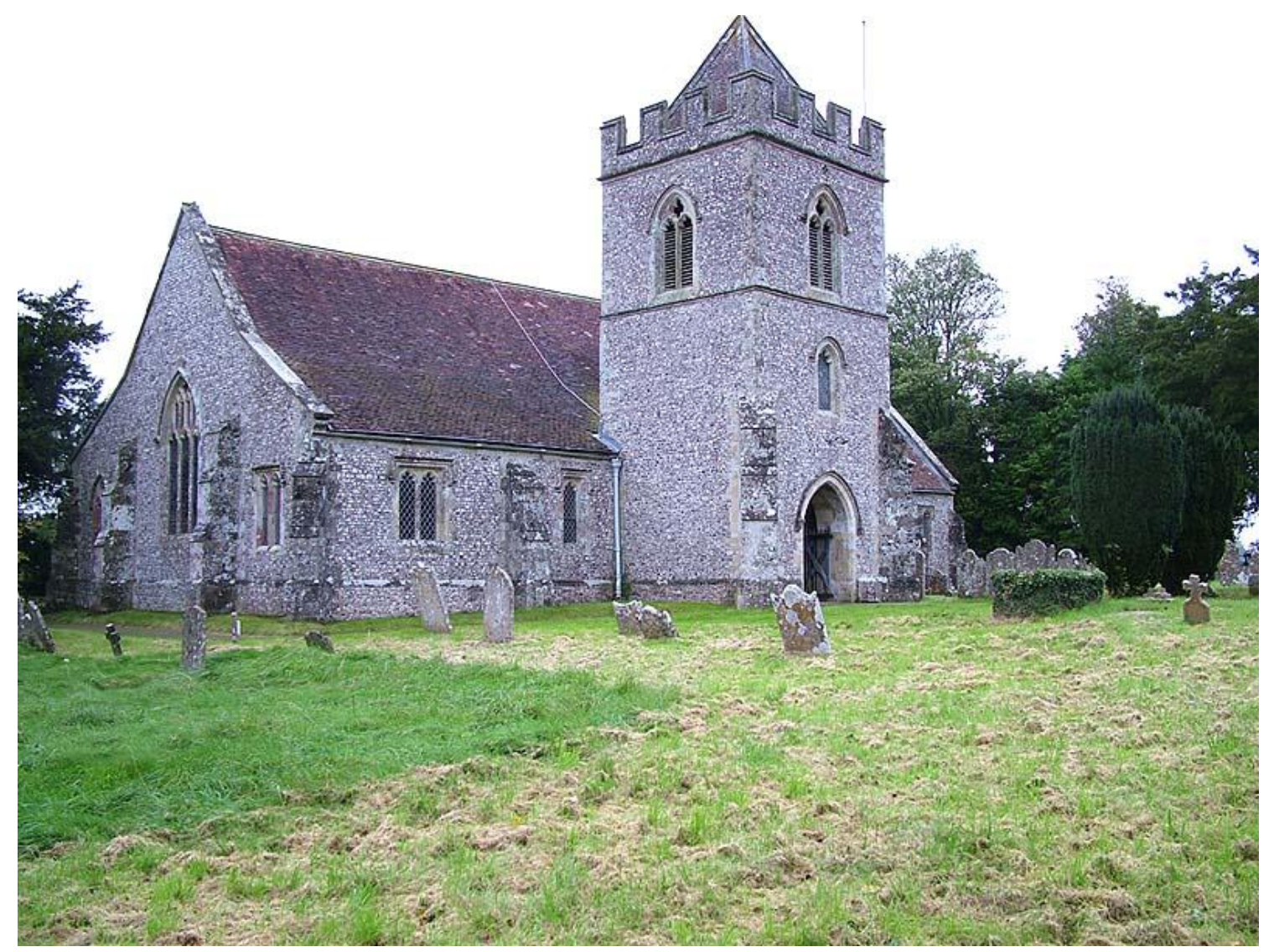

Figure 47. All Saints Church, West Winterslow. Reproduced from http://history.wiltshire.gov.uk. 


\section{Mottisfont Abbey}

Between Romsey and Stockbridge, on the western bank of the river Test and just over 2 miles south of the Roman road en route to Kings Somborne lies Mottifont Priory (see Figure 48 below). This Augustinian Priory, dedicated to the Holy Trinity, was founded in the early $13^{\text {th }}$ century by William Briwere (Moore et al, 2006, 1). A relatively wealthy institution, it had been gifted the use of the church at nearby Kings Somborne, forty acres of land and a mill at Stockbridge, lands and buildings within and outside of Winchester's walls and numerous other small parcels of land throughout the county of Hampshire (Moore et al, 2006, 3). What differentiates this Priory from others of its kind throughout Hampshire and Wiltshire (and also makes it relevant in this discussion in relation to pilgrims) was its association with miracle working. The roll of the Mottisfont canons makes it clear that they observed the anniversary of Peter de Rivallis (brother to the original founder), whom for an unexplained reason was known as 'The Holy Man in the Wall', and numerous miracles were worked through him (Doubleday and Page, 1973, 172). This would have been an important factor in attracting attention and donations from passing travellers and locals. However an even more prestigious relic was present in the Priory, an alleged finger bone from John the Baptist. As a relic this lay in the upper echelons of saint hierarchy, it attracted considerable attention not only from the laity but from the ecclesiastical authorities themselves; in 1457 the Priory was granted the authority to offer indulgences to the laity on Trinity Sundays, owing to the multitude of pilgrims enticed through its doors (Heale, 2007, 425). Crucially mention is also made that the canons 'welcomed pilgrims en route to Winchester, who came to worship Mottisfont's relic', the majority of whom were likely to be travelling towards Canterbury (Doubleday and Page, 1973, 172).

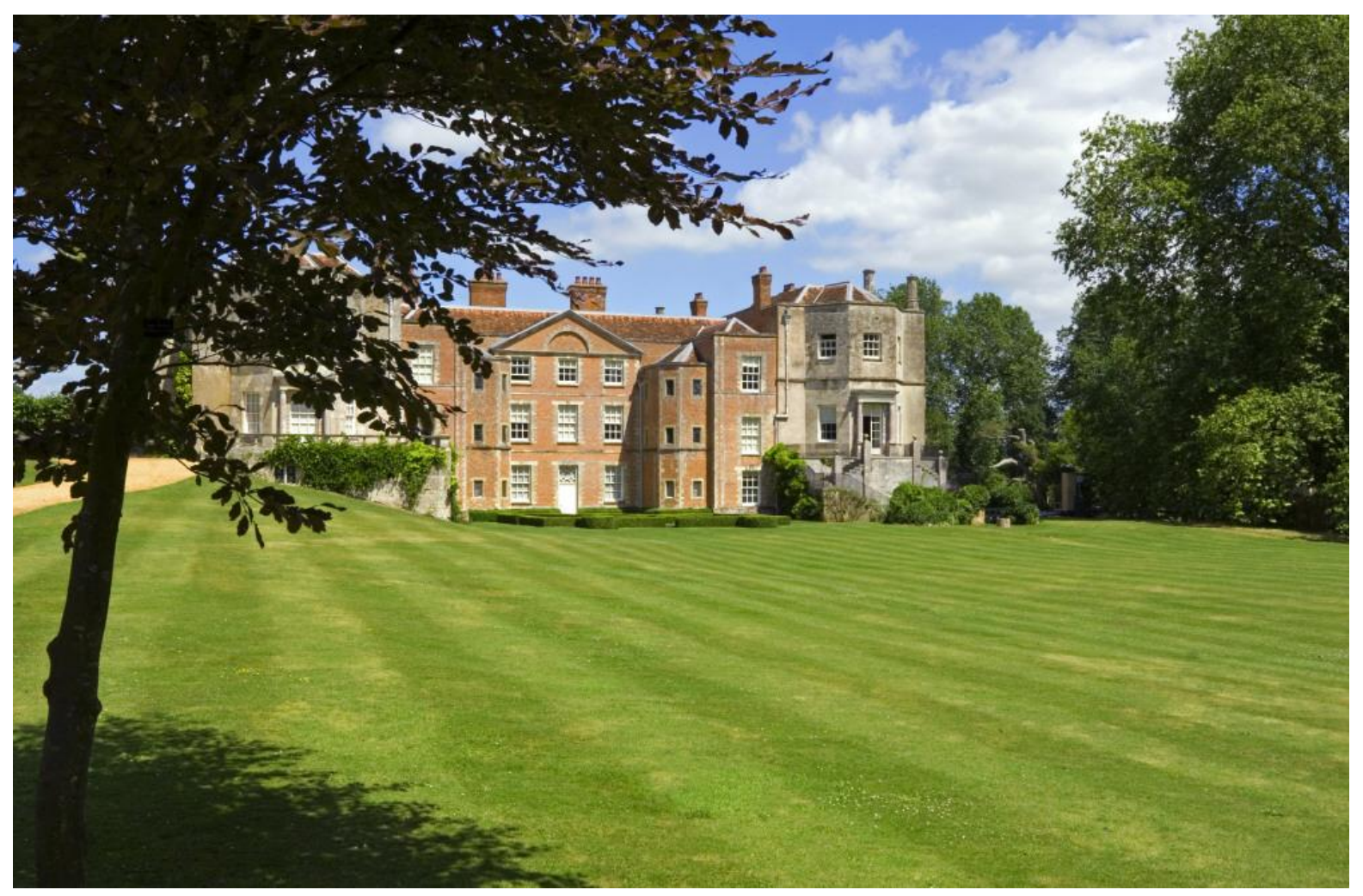

Figure 48. Mottisfont Priory, now a National Trust Estate. Reproduced from http://www.nationaltrust.org.uk. 
In 1536 the Priory was dissolved, but the relic which had proved so effective in attracting the hearts and purses of visiting pilgrims is unaccounted for (Doubleday and Page, 1973, 174). The position of Mottisfont in relation to the typical flow of pedestrian traffic from Salisbury to Winchester via the Roman road is sufficiently near (four miles return) to warrant a deviation from the route by an eager pilgrim, given the high status nature of the relic and its reputation.

\section{Kings Somborne}

Kings Somborne had little to offer the traveller other than possibly an inn or beer house, however its proximity to the route and the link between its church and Mottisfont Priory (mentioned above) make it worthy of a brief mention in this discussion. Several houses in the village retain their $15^{\text {th }}$ century fabric, as does The Crown Inn - however this establishment's continuity as an inn since that period is unknown (Capper, 1813, 259). The church, dedicated to St Peter and St Paul, has discernible $12^{\text {th }}$ century origins, with additions and rebuilds occurring throughout the $13^{\text {th }}$ and $14^{\text {th }}$ century, no doubt supported financially by Mottisfont Priory (Page, 1911, 175). The Domesday Survey records that Kings Somborne belonged to the king (hence the name), as it had never been 'hidated' or assessed in value, which would have given the church the status as a minster, despite being gifted to Mottisfont Priory in 1203 (Capper, 1829, 498).

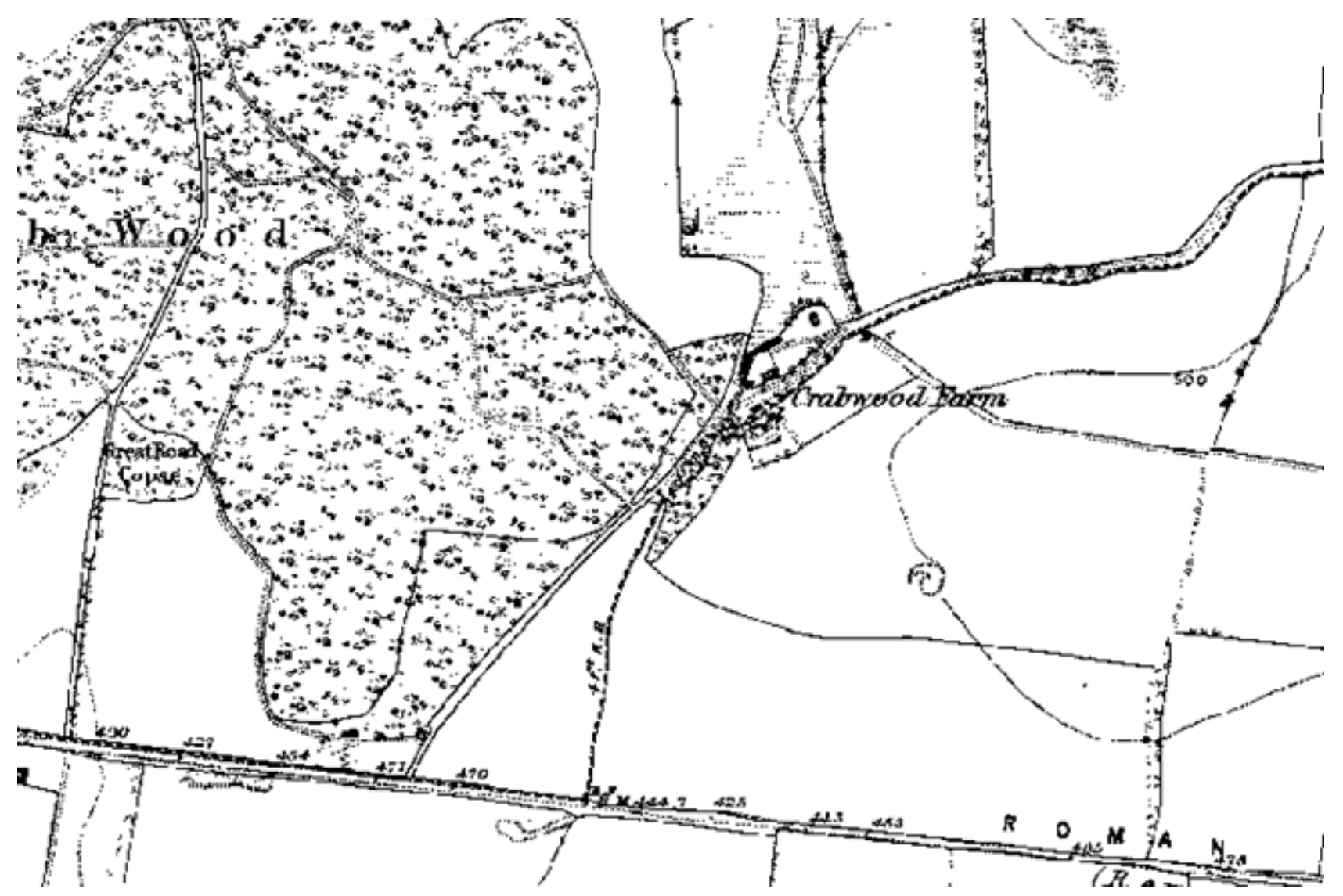

Figure 49. 1840 Ordnance Survey maps showing the Roman road entering Winchester, past 'Great Copse Road (middle left). Reproduced from http://www.british-history.ac.uk. 
Little else surviving between Salisbury and Winchester along the Roman road can be said to have been of direct relevance to pilgrims undertaking the day long journey between these two cult centres. On a final note, it is possible that this Roman road entering Winchester from the west could be said to be reflected in names of two place names; these are found in the road itself as it enters Winchester, it being known as 'Old Sarum Road', and the final copse which the road runs along before entering Winchester's outskirts, which is called 'Great Road Copse' (see Figure 49 above). That this is not a modern name is suggested by being shown in the 1840 Ordnance Survey map of the area under the same name, indicating a lasting impression in local memory of the scale of the road and its volume of traffic. 


\subsection{Pre-Reformation churches in Wiltshire and Hampshire: Their Dedications, Role in the Parish, and Relevance to Pilgrims}

Following the pattern across much of England, St Mary the Virgin dominates the ecclesiastical landscape, accounting for $26 \%$ of surviving pre-Reformation church dedications in Hampshire, and $18 \%$ in Wiltshire, closely followed by All Saints (14\% and $13 \%$ respectively). Figure 50 below shows the distribution for churches bearing St Swithun dedications across England. Many of these dedications are taken from the Valor ecclesiasticus, a survey of church properties drawn up in 1536 by Henry VIII's commissioners, and therefore may be dedications dating/surviving towards the later Medieval period (Lapidge, 2003, 43).

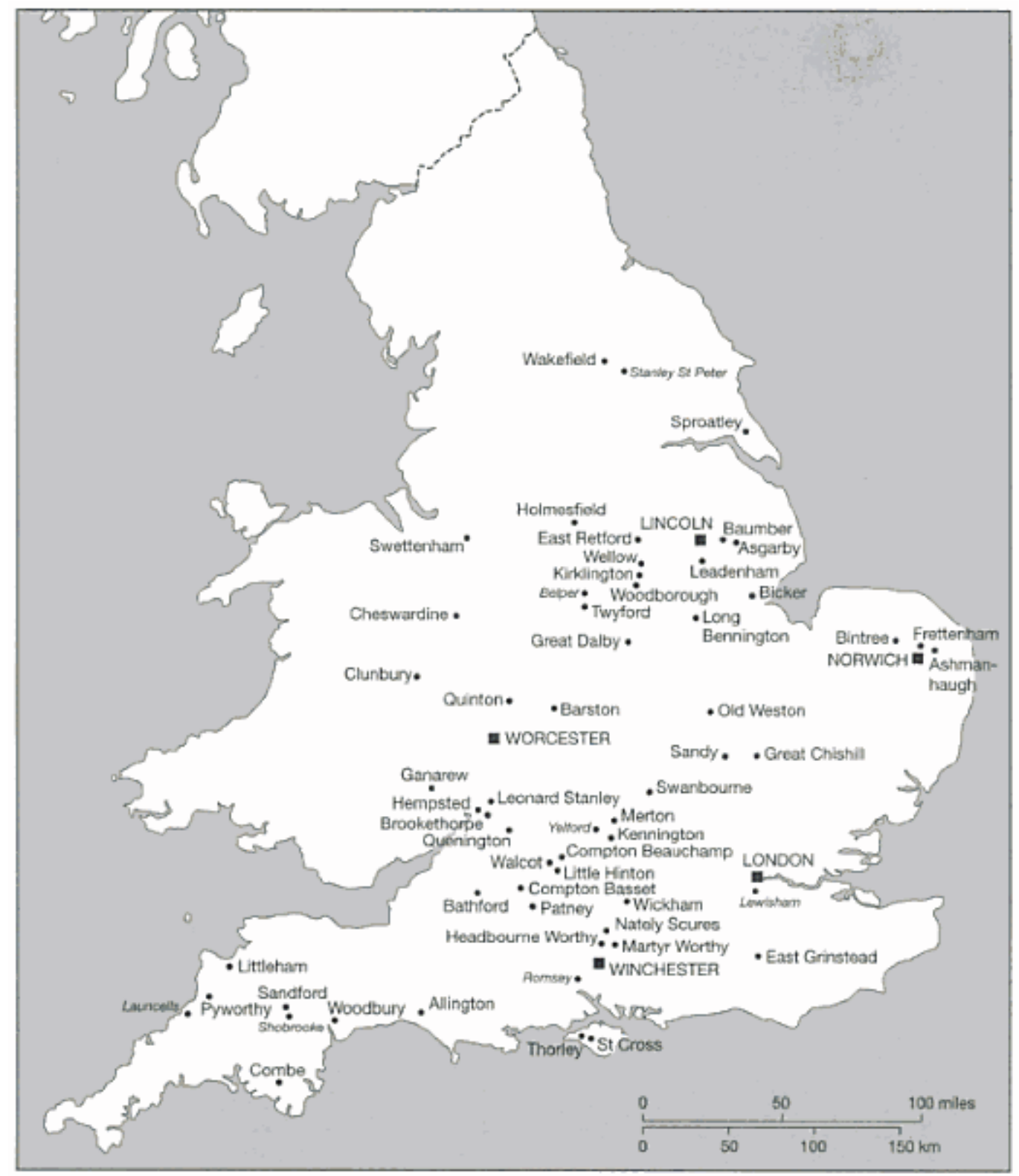

Figure 50. Churches dedicated to St Swithun across England. Reproduced from Lapridge, 2003, 45. 
I would argue that it is likely that many of these church dedications (especially those in and around the Hampshire region) have significantly earlier origins, given the saint's attested popularity within this region, and may have flourished within the golden age of Winchester (i.e. between the $11^{\text {th }}$ and $14^{\text {th }}$ centuries) thanks to the rising fortunes of the church and the circulation of that wealth. This would have allowed those ecclesiastical figures owning estates greater economic freedom to build churches and chapels on their land (examples of which are shown in Figure 51 below) which, typically, carried the dedication of their diocese's patron saint i.e. St Swithun; indeed 'the earliest attested dedications [outside Winchester's city walls] are from churches which either had historical links with Winchester, or were in its diocese, or were situated on estates owned by Winchester.' (Lapidge, 2003, 43) The Norman elite were not inclined towards supplanting native Anglo Saxon saint cults with Roman ones (perhaps to avoid unnecessary antagonism towards the local population) which allowed the continued veneration of St Swithun (and others), and would have allowed these dedications to remain relevant for the laity (Lapidge, 2003, 44).

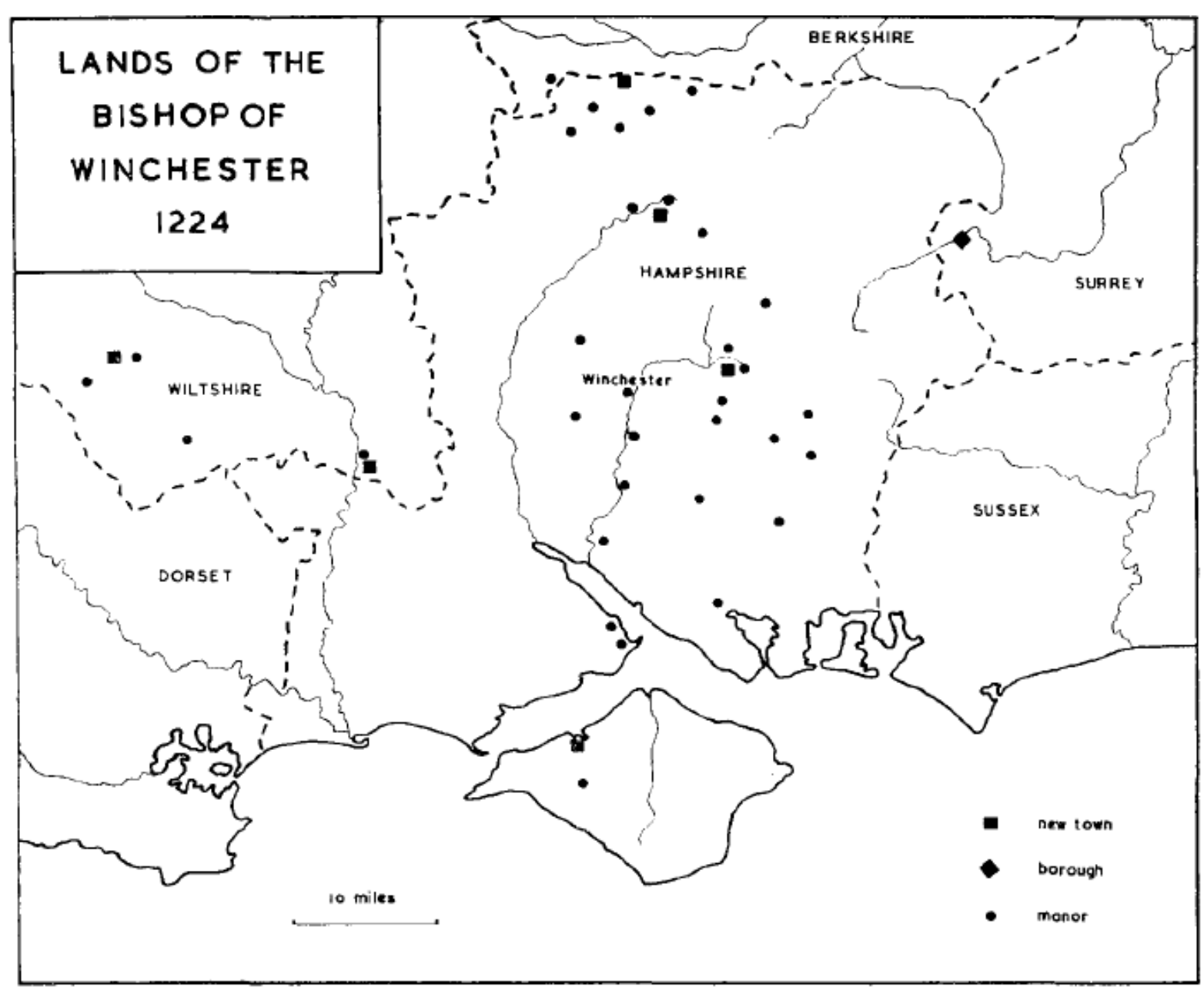

Figure 51. Map displaying the lands of the Bishop of Winchester in 1224. Several of these held churches or chapels dedicated to St Swithun. Reproduced from Beresford, 1959, 189. 


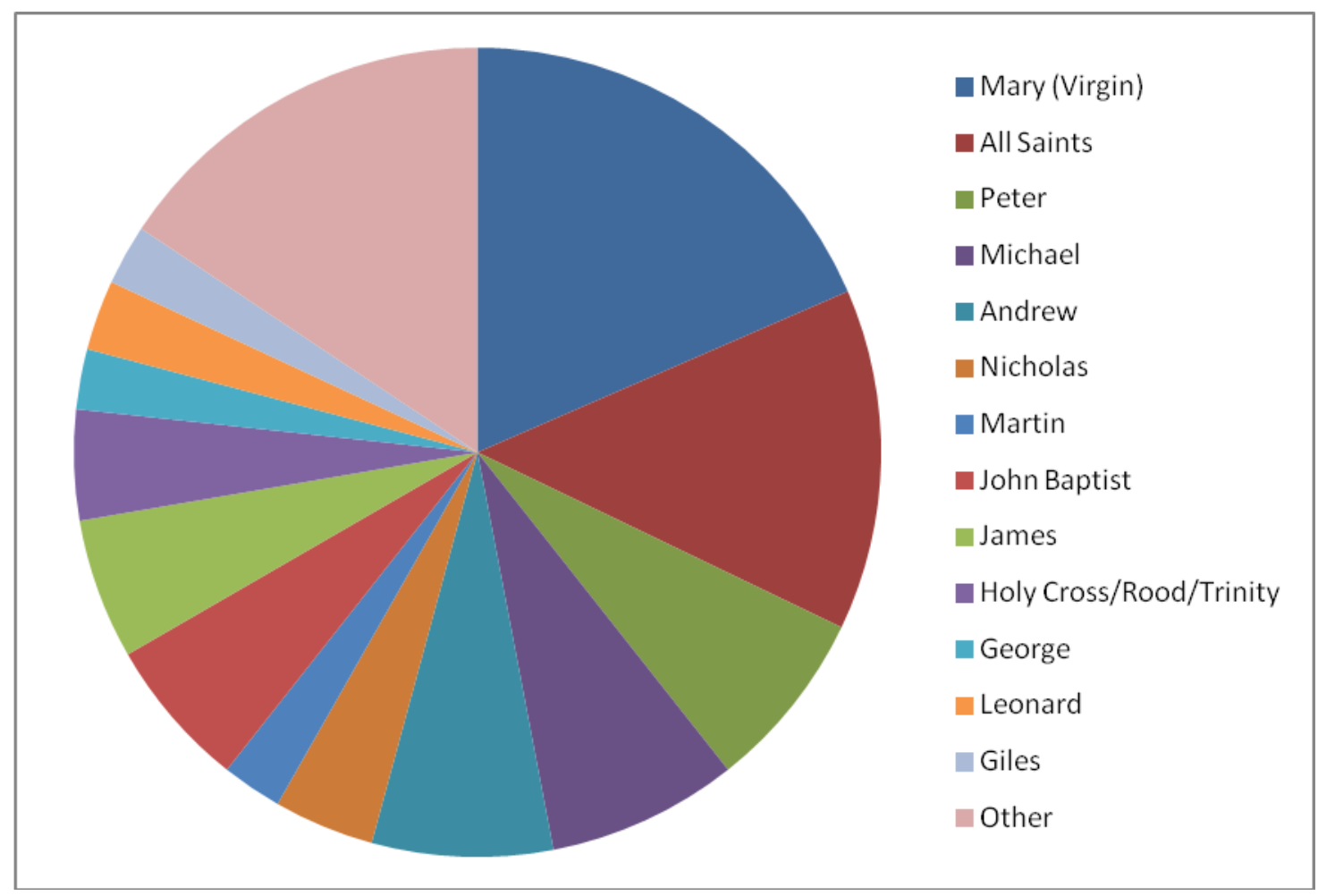

Figure 52. Surviving Pre-Reformation Church Dedications in Wiltshire

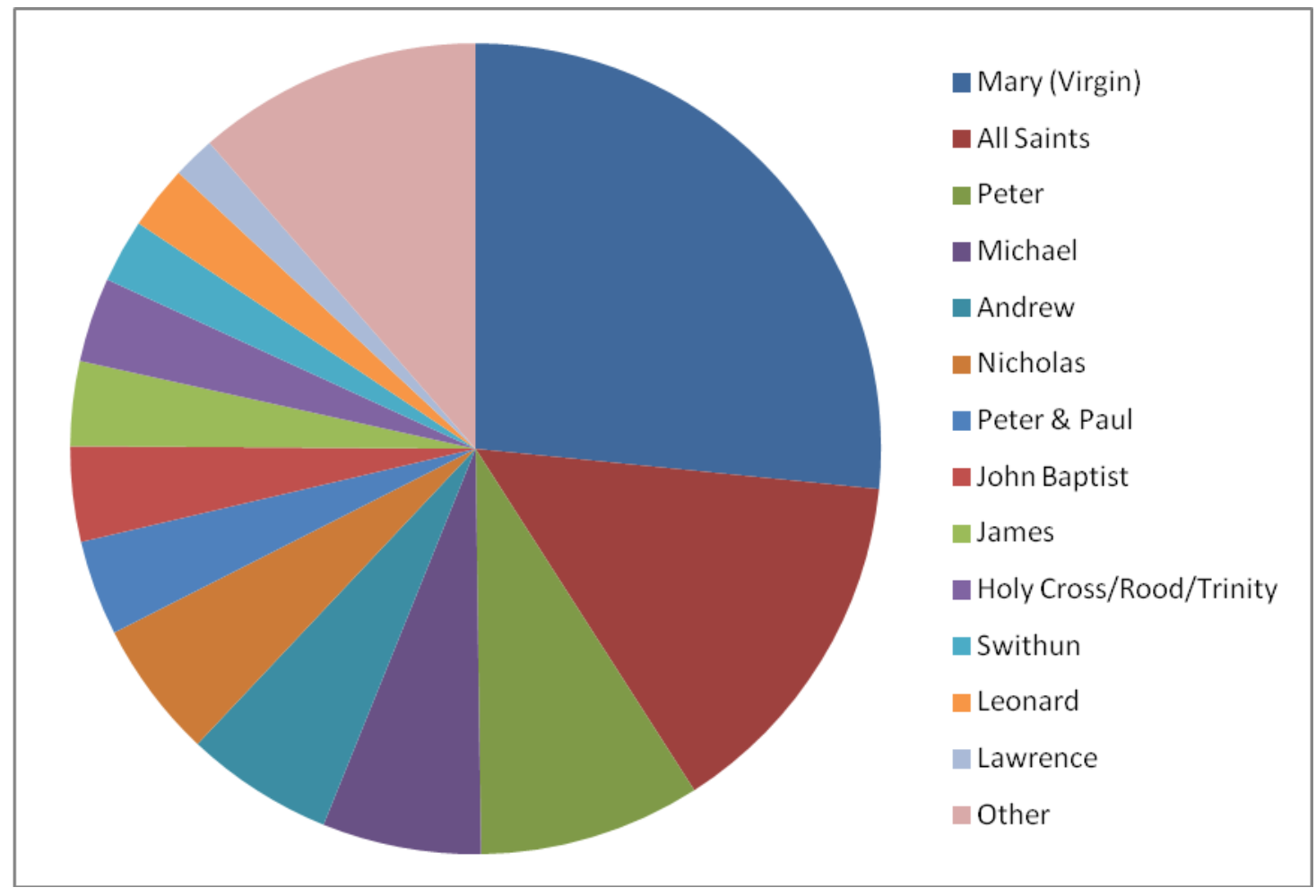

Figure 53. Surviving Pre-Reformation Church Dedications in Hampshire 
The figures for St Swithun dedications in England, which fall between 55 and 68 depending on which collated survey is used, compare favourably to other Anglo-Saxon saints such as St Cuthbert, St Oswald and St Botulf. This reflects, perhaps more than the adoration of the laity (although in the regions surrounding Winchester this was undoubtedly a factor) the high status held by Winchester in terms of ecclesiastical power, influence and land across England. When compared with the figures for pre-Reformation church dedications in Hampshire (Figure 53 above, data provided in Appendix D), St Swithun appears to command a low number of dedications in his native county. However, the saints which appear to have the most dedications in Hampshire and Wiltshire are in the very highest ranks of the Christian 'saint pantheon' (i.e. Mary, John the Baptist, Paul, Peter). St Swithun is the only example of an Anglo Saxon saint cult to receive more than a single mention ( 6 in total), with possibly many more whose dedication may have changed or the church was destroyed as parishes split (i.e. into 'Upper' and 'Lower') or joined together. Hagiographic records from Lantfred indicate that in excess of 220 individuals claim to have been cured either in groups or as solitary cases by St Swithun (Lapidge, 2003, $252-333$ ). Whether they were genuinely the recipients of divine grace or not, the numbers of pilgrims journeying to St Swithun's shrine in search of help indicates the strong faith in the saint. In Wiltshire, despite being the patron of Salisbury, St Osmund does not appear in any surviving church founded before the Reformation (see Figure 52 above). There may have been a small number of churches dedicated to him in the area which whose dedications have changed, but changes in dedication would indicate a falling out of either fashion or favour in the area in which much of his life was spent, and any miracles reputed to have occurred in the local landscape do not appear to have yielded dedications. From the data presented above in Figure 53, the same cannot be said about St Swithun. 


\subsection{The Sensory Dialogue Between the Pilgrim and the Landscape from Salisbury to Winchester}

\section{Leaving Salisbury:}

Salisbury lies in a depression in the Wiltshire landscape, the ground thereabout being described by Leland during the $16^{\text {th }}$ century as 'playen and low', bordered by water-meadows and the river Avon, with the terrain rising gradually to the east (Leland, 1907, 259). The relative subtlety of the topography allows the cathedral to be seen from a considerable distance on all sides, and this is helped by urban developments in Salisbury not rising in height particularly more than their Medieval predecessors. The presence of Salisbury or 'New Sarum' in the landscape is also worth briefly examining from a theological standpoint, as how it might appear in the mind's eye to those who are approaching or leaving the town with sacred intent. By uprooting the settlement from its cramped conditions in Old Sarum and placing it within the lush water-meadows of the lower lands nearby, fed by the river Avon, it has been suggested that this act fulfilled not only a practical need for space but also a spiritual yearning for a new urban archetype, 'the search for some form of representation of order within the world - the intentio, which would have been transformed by the creation of the city into - distentio or affectio, the yearning for, and the realisation of, the distance from the true urban archetype, Heavenly Jerusalem' (Frost, 2009, 11). The cycle of rogations, boundary rituals and the impressive presence of the swiftly constructed cathedral within this lowland settlement would have accentuated this concept of a new and sacred space, established with an emphasis on ecclesiastical and not military activity, the latter being the basis for Old Sarum's existence. The ruling hand of the Chapter over the new city 'enabled the church to picture a future where they reigned supreme over the urban landscape, and beyond.' (Frost, 2009, 10) The most striking feature of the 'new settlement' is the cathedral's immense Gothic tower, 123 metres tall, and visible from the point where the traveller embarks on the Roman road on its approach to Middle Winterslow. The symbolism of such a monument's silhouette on a pilgrim leaving Salisbury would have been profound, acting as a focal point or axis from which the land immediately east and west of Salisbury radiates and drawing the eye back to the resting place of St Osmund. The scale of the cathedral as a whole dwarfs the surrounding urban landscape, and is an imposing (and possibly reassuring) spiritual protectorate, a towering touchstone with the divine and the town within its shadow falls into the spatial (and biblical) category of 'sanctuary'.

In leaving Salisbury one makes the transition from the sheltered lowland, an area where this new urban environment was founded around ecclesiology and the memory of St Osmund (and later his legitimate cult), to a routeway which will lead the traveller over exposed ground and through perhaps unfamiliar territory to another site of sanctuary, Winchester. Classic accounts of contemporary travellers visiting Salisbury prior to the Reformation (such as John Leland) lack detail on both the shrine of St Osmund and the visibility aspect of the cathedral in the landscape (although the High Street and Castle Street are mentioned as particularly fine by Leland (Smith, 1907, 258)), There are later visual records which, while subject to artistic license, can at least give a sense of the dominance the cathedral and its tower held over the surrounding area. I refer to the early $19^{\text {th }}$ century Salisbury series by the artist William Turner, in particular to the 1816 painting below (Figure 54). While a certain amount of 'framing' of the picture fulfils the aesthetic desire of the artist, Turner 
set great store by studying nature, and the relationship between the landscape its visual perception by people in both a realist and fantastical sense (Walker, 1989, 7). Consequently whilst it could be

Figure 54. 'Salisbury Cathedral' by William Turner. Reproduced from www.william-turner.org.

considered unorthodox to use such a source as a reference point for discussing the impact of Salisbury cathedral upon the mind of a Medieval pilgrim, I believe it is appropriate. The painting represents the physical nature of the cathedral within the pre-industrialised landscape and in contrast with the town beneath it. Whether it does so entirely realistically is not the question. More importantly here it acts as a demonstration of the monument's deeper impact on both the eye and the mind, i.e. how the cathedral is encountered in a holistic context, a towering tribute to God, visible to all and an anomaly in the primarily pastoral landscape of Wiltshire. Another archival view of the cathedral prior to the modern motorway and ring-roads can be seen in Figure 55 below, from an early $20^{\text {th }}$ century postcard which also demonstrates the axis-like role of the cathedral tower. The range of visibility for the traveller leaving Salisbury joining the Roman road is also provided by an aerial view (see Figure 56 below). 
Figure 55. Early $20^{\text {th }}$ century tinted postcard of Salisbury cathedral viewed from the south west. Reproduced from http://www.oldstratforduponavon.com/salisbury.html

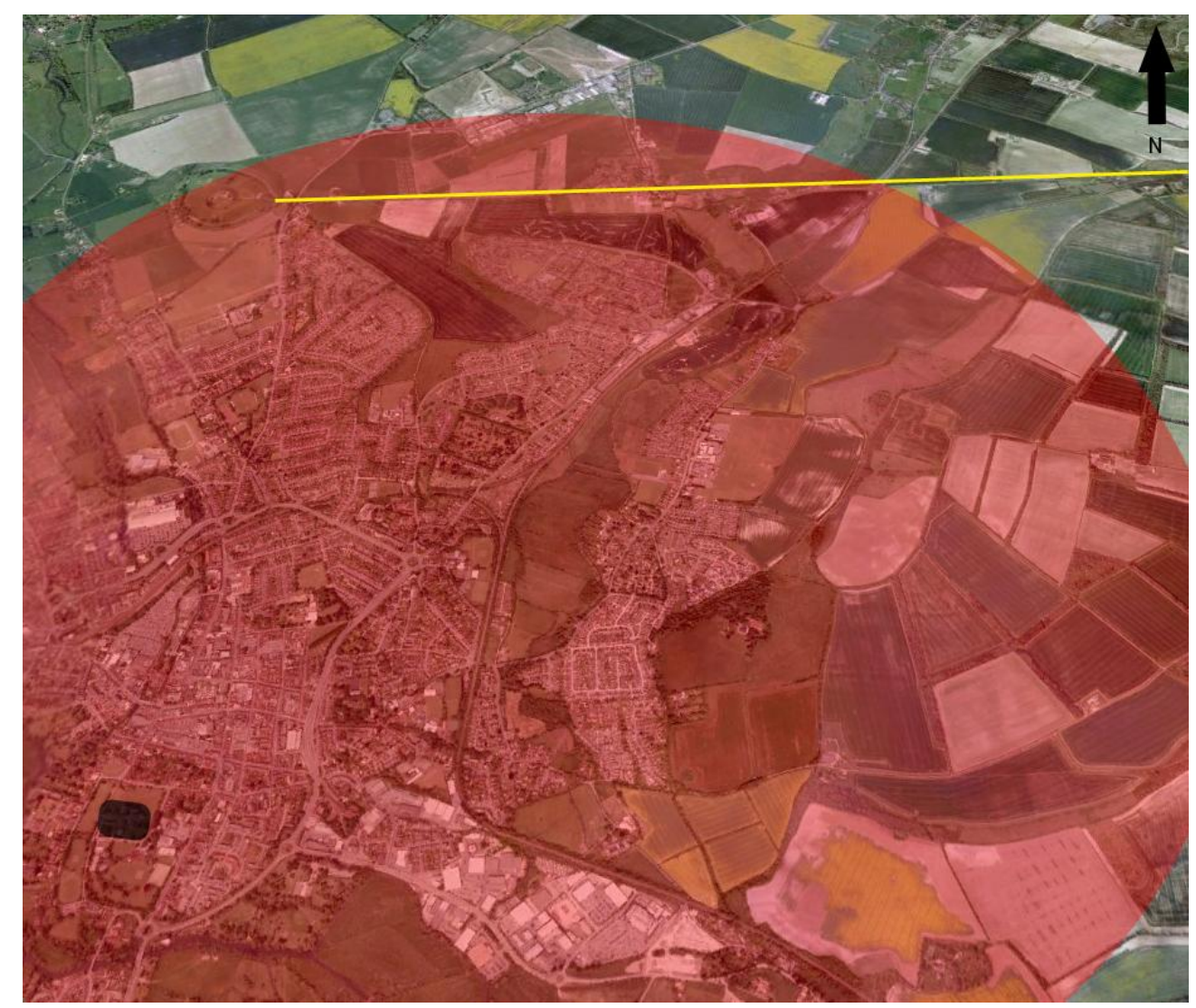

Figure 56. Radius (red shading) from which the cathedral building (black) is clearly visible from the east and the Roman road (yellow) from Old Sarum to Winchester. Original satellite image reproduced from (C) 2011 Google. 


\section{Arrival and start of Roman Road}

Having joined the Roman road (Figure 57 below), the pilgrim would become part of the volume of human traffic, which fluctuated depending on factors including seasonality, feast days and weather, and would be exposed to stimuli such as noise, comfort, interest and, assuredly in the case of some Medieval travellers, smell. The role of large roads in biblical tales is multi-faceted, such as that of St Paul on the road to Damascus, the 'Good Samaritan', and the theme of the road to 'Heavenly Jerusalem', which was commonly used as an allegory for the journey through life (and in representing life itself as a pilgrimage, a state of yearning to return from earthly exile to that celestial paradise (Clark, 2004, p78)). The road being a part of a larger collection of routes along southern England towards Canterbury, possibly the most famous British pilgrimage shrine, it is highly likely that in the warmer months and during holy years other pilgrims would have been commonly encountered either riding or on foot (Adair, 1978, 50). To those whose journey started in Salisbury, moving away from the familiar and to a degree 'urban' into the hamleted and, at times, purely agricultural landscapes of eastern Wiltshire, the Test Valley and western Hampshire (often through wooded or exposed uplands) would have presented representations of the 'wilderness' referred to in parish sermons.

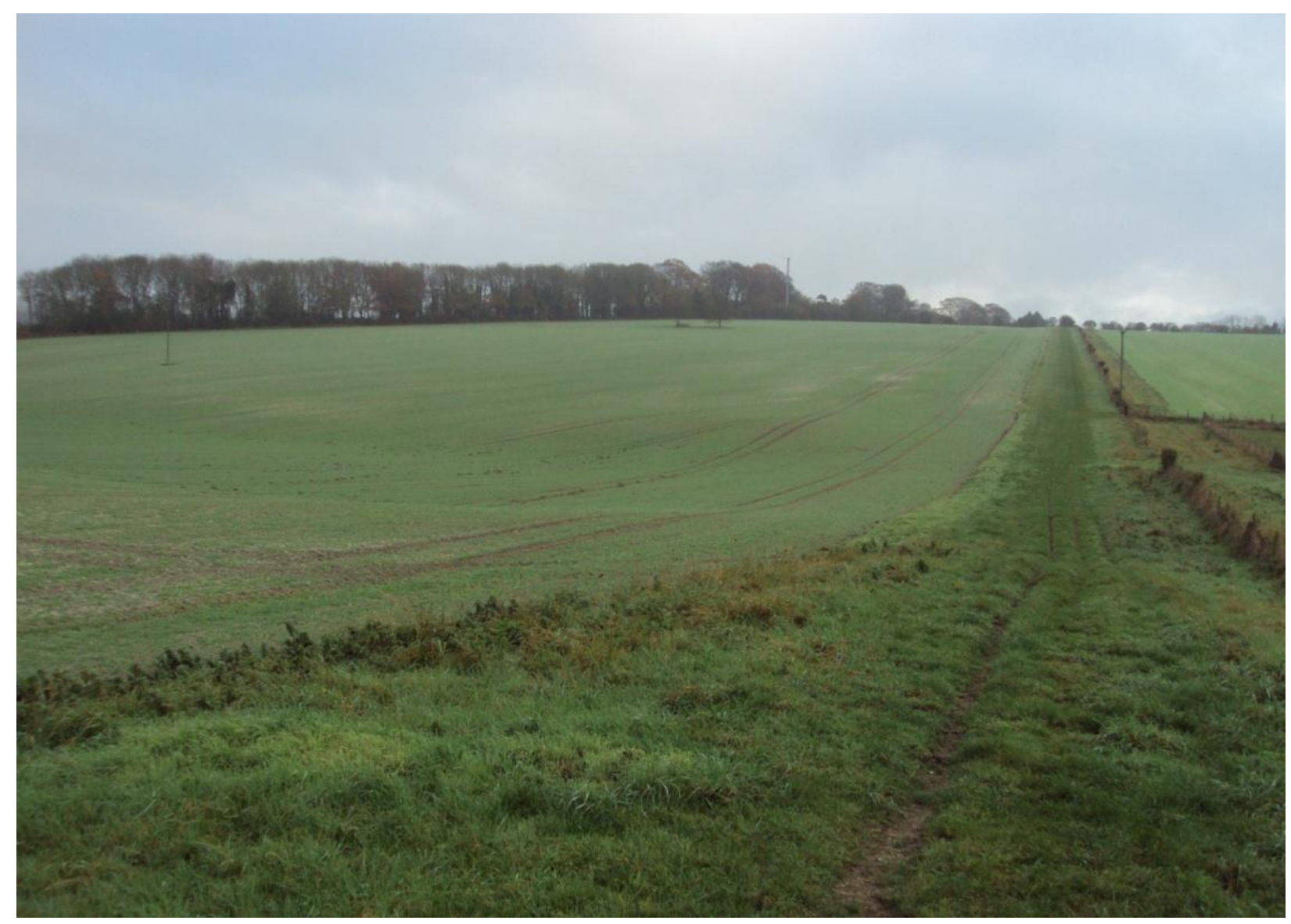

Figure 57. The path of the Roman road accessed on the outskirts of Salisbury. Photograph taken by author. 
It is also worth briefly considering what, if any, relevance the antiquity of the road held to its travellers. Other than the histories of Gildas ( $6^{\text {th }}$ Century) and Bede ( $7^{\text {th }}$ century), which the general laity were unlikely to be well acquainted with, there are few references to the Roman presence in Britain in Medieval literature, and the laity's main literary encounter with the Roman occupation would have been found in taught scripture, saint martyrdoms and hagiographies. For those who lived within towns which still displayed their Roman fabric, there may have been a greater awareness, however when considering roads it is highly likely that they were viewed as simply very antique long-distance tracks, and having been there as far down the generational memory as could be recalled.

\section{Cobhill Barrow}

The Cobhill Barrow lies just west of Middle Winterslow, along the route of the Roman road as it approaches the settlement, and is a Bronze Age 'bowl barrow' earthwork (now covered with trees) which must be scaled before arriving in Middle Winterslow. Such an ascent would, if it were not for a copse, afford a viewpoint over part of the ground covered since skirting the modern village of Firs; ground which still retains its agricultural and open character. It has been suggested that the deliberate inclusion of such a monument along the Roman road was so that the barrow could be used 'as a sighting point', and that it both marks and possibly formed a convenient re-orientation for the road towards Winchester (Grinsell, 1958, 263). Barrows are not an uncommon sight in Wiltshire, indeed much of the region can be said to be a far-reaching network of ritualised pre-historic landscapes. The folklore of barrows is a subject which has commanded a fair volume of scholarship (especially in the Anglo-Saxon context), and there is neither the space nor intent here to go into area of research in great detail. However it is relevant to mention some of the major themes which such research has identified as being tied to these pre-historic earthworks, in relation to how they might be perceived by travellers and specifically pilgrims encountering the Cobhill Barrow whilst travelling to Winchester. The issues of liminality with such a site are legion and complex, but can be broken down into three main areas:

1. A transect of time, where a monument from a distant and culturally different past meets the present. This is reflected in such earthworks being referred to as 'evil' due to their previous heathen origins, frequently in many of the Anglo-Saxon literary works (Semple, 1998, 123). The conception of pre-history for the laity would doubtless have been much informed by clerical rhetoric and malign folklore, and as such whatever concept of 'Britain's past' they held would surely have tended towards the negative.

2. The perceived presence and interaction between supernatural denizens that were thought to dwell in the barrow, sometimes guarding great treasures, with the laity. Closely related to the first category, the majority of folklore linked to barrows has at least some small element of malign spirits either attached or dwelling within the earthwork itself. Linked to their being remnants of a non-Christian past, these barrows would present a spiritual risk, and possibly carried a real (in the contemporary mind) physical risk of harm from their inhabitants. There is a local folkloric tradition of a 'golden coffin buried in the vicinity, which contains two of the 
largest barrows in the county (excluding Silbury).'(Grinsell, 1967, 32). However there are many barrows in the area (including the 'Bell Barrows' near the Pheasant Inn $100 \mathrm{~m} \mathrm{~N}$ off the A30) and so this specific folk tale cannot be assumed to apply exclusively to Cobhill Barrow.

3. The sharing of space and interaction between the living and the dead. This is a theme which is pervasive throughout the Wiltshire landscape, with its succession of barrows and burial sites, in that both areas and monuments which are specifically set aside for death (in effect realms of the dead), share landscapes which throughout the later centuries were settled. This would seem obvious given the shift in territorial boundaries, migrant cultural groups down the ages, and an expansion in population and settlement. However a crucial element to this is the Christian doctrine of the posthumous soul and its removal from this 'veil of tears' to another realm (Paradise, Limbo or Hell): 'The Christian spirit was far removed from the living world after death. The places where the dead spirits were accessible would be those burial places reserved for the damned-suicides, criminals and the unbaptized, those in a Christian world who were heathen and whose resting place was sometimes the barrow.' (Semple, 1998, 113). This argument is applied to the converted Anglo-Saxon mind, and the extent to which this early Medieval belief continued into the later period is unknown, but it could be argued that, in theological and folk belief terms and considering the records of similar folk beliefs in the early modern period, one cannot assume a drastic rationalist shift in perception of such monuments during the later Medieval period.

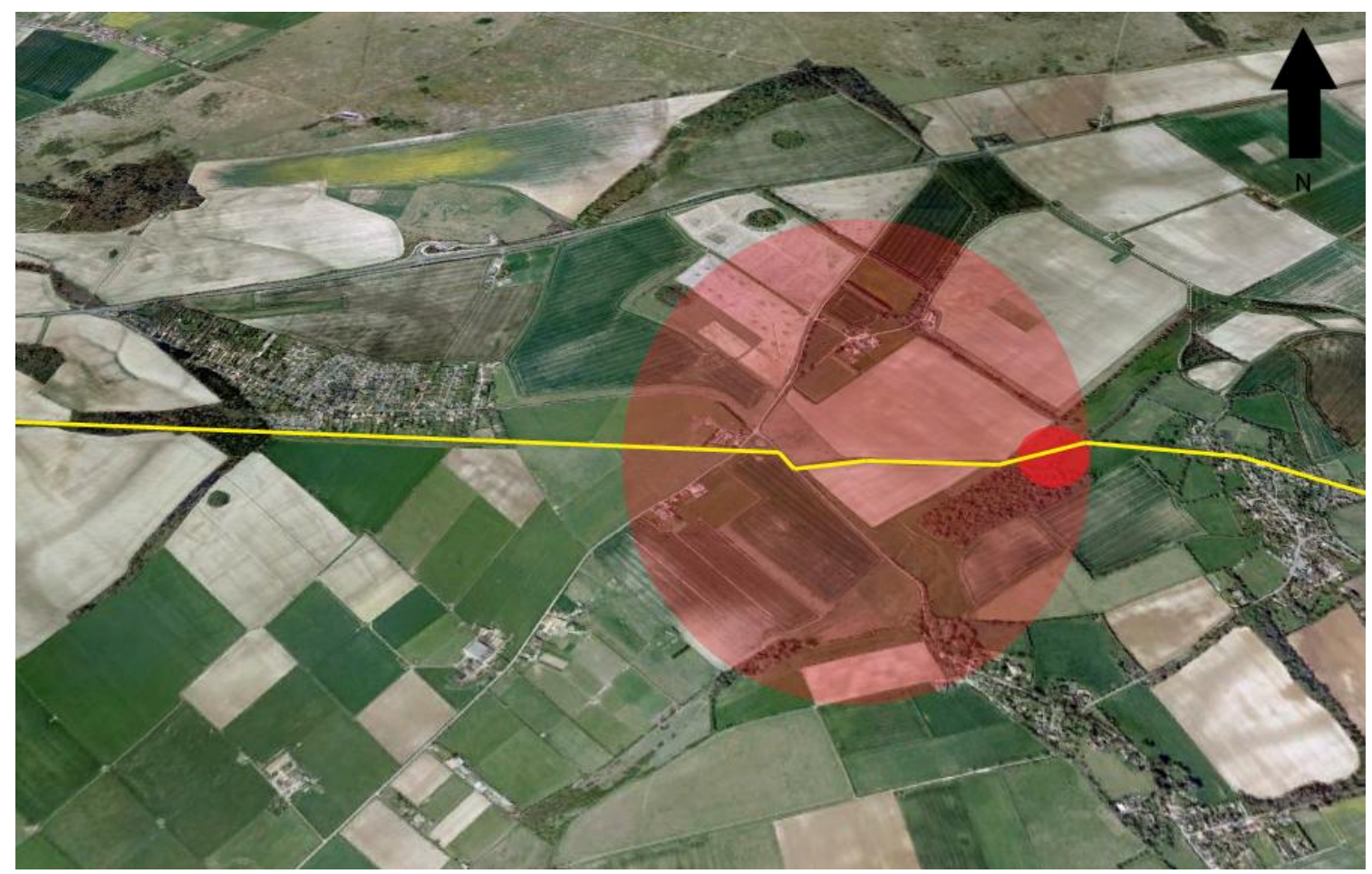

Figure 58. Cobhill Barrow (denser red) in relation to the Roman road (yellow) and the distance at which is visible from the western approach (red shading). Today visibility from the barrow is impossible due to dense tree cover. Original satellite image reproduced from (c) 2011 Google. 

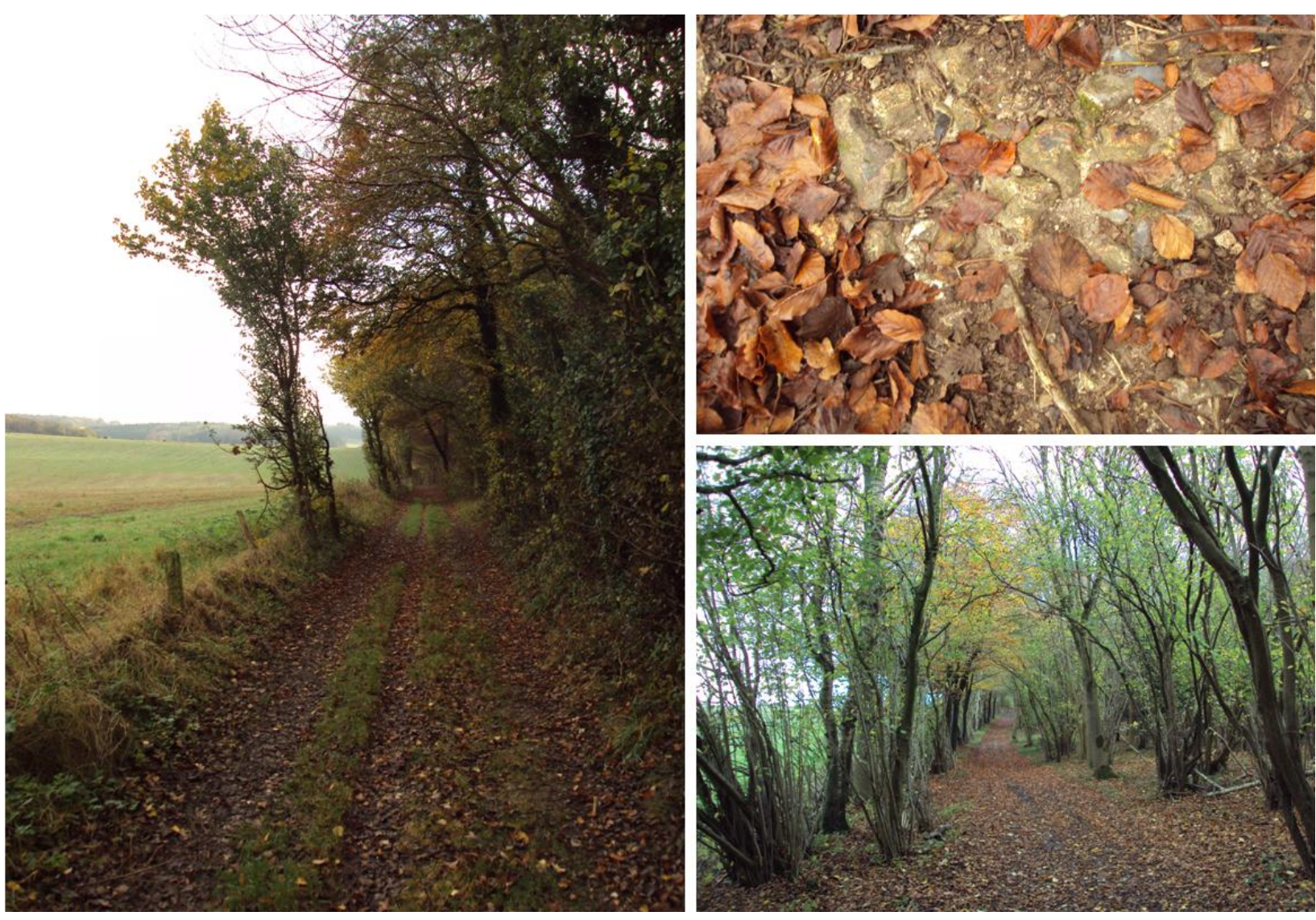

Figure 59. Roman road running alongside Upper and Lower Noad's Copse, including detail of cobbled surface (top right). Photographs taken by author.

One of the best surviving examples of the Roman road from Salisbury to Winchester, which remains in use as a long distance path, exits Winterslow and runs alongside both Upper and Lower Noad's Copse before becoming re-integrated into the local road network (see Figure 59 above). The 1883 Ordnance Survey map shows these copses being in same position, and enclosing slightly more of the path than currently, and it is entirely possible that these copse distributions reflect an earlier, more heavily forested local landscape which fluctuated depending on forest laws and the royal or aristocratic need for timber. A constant feature however is the straight course of the Roman road, which extends before the traveller into the visible distance, an unerring and reliable guide towards Winchester. Woodlands have long held vivid positions in human imagination; the theme of a 'path through the forest' is a common feature of folk tales in general, often featuring encounters of a supernatural, criminal, spiritual or revelatory nature (Porteous, 1928). The defining quality of these encounters is that they are of an extraordinary character in a liminal space, inhabiting a realm outside of one's daily experience (Porteous, 1928). For the pilgrim, this stretch of the journey may have raised some of these themes in the mind, vestiges of connected local folklore might be remembered, and physically a real danger of thieves or outlaws. Hagiographies often feature miracles occurring in forests such as those of St Giles, St Hubert, St Eustace and St Leonard, as well 
as near rivers (another prevalent and symbolic feature of biblical scripture), and the concept of wilderness and retreat from the world is heavily linked with woodlands (Howe, 2002, 213; Jones, $2007,192)$. The reduced visibility is a powerful tool in augmenting one's concept of space within a forest. As a consequence another possibility in terms of experience is that the enclosing aspect of the tree cover produces what is essentially a funnelling effect, removing the outside world from both vision and mind and giving an intense focus to the act of moving along the path. To the spiritually charged pilgrim, this almost meditative quality of movement through the trees may have produced some sort of heightened sense of what the pilgrimage is said to theologicaly represent, i.e. not just to entreat a divine favour but to transform oneself through movement. I would argue that this dualist sense of spirituality and danger can be applied in a more general sense to pilgrims involved in woodland travel across Britain and further afield, particularly when combined with research into local folklore involving the forest.

\section{Crossing the Test Valley}

The Test Valley is a shallow affair, gently descending to the River Test before rising eastwards to Kings Somborne and beyond. Although just within Hampshire's official boundary, it forms both a topographical and instinctive borderland between Wiltshire and Hampshire, with the Test broadly acting as both a linear and liminal marker of this territorial divide (see Figure 60 below). A river marks a boundary in one sense or another (i.e. natural, territorial) and also a threshold. The act

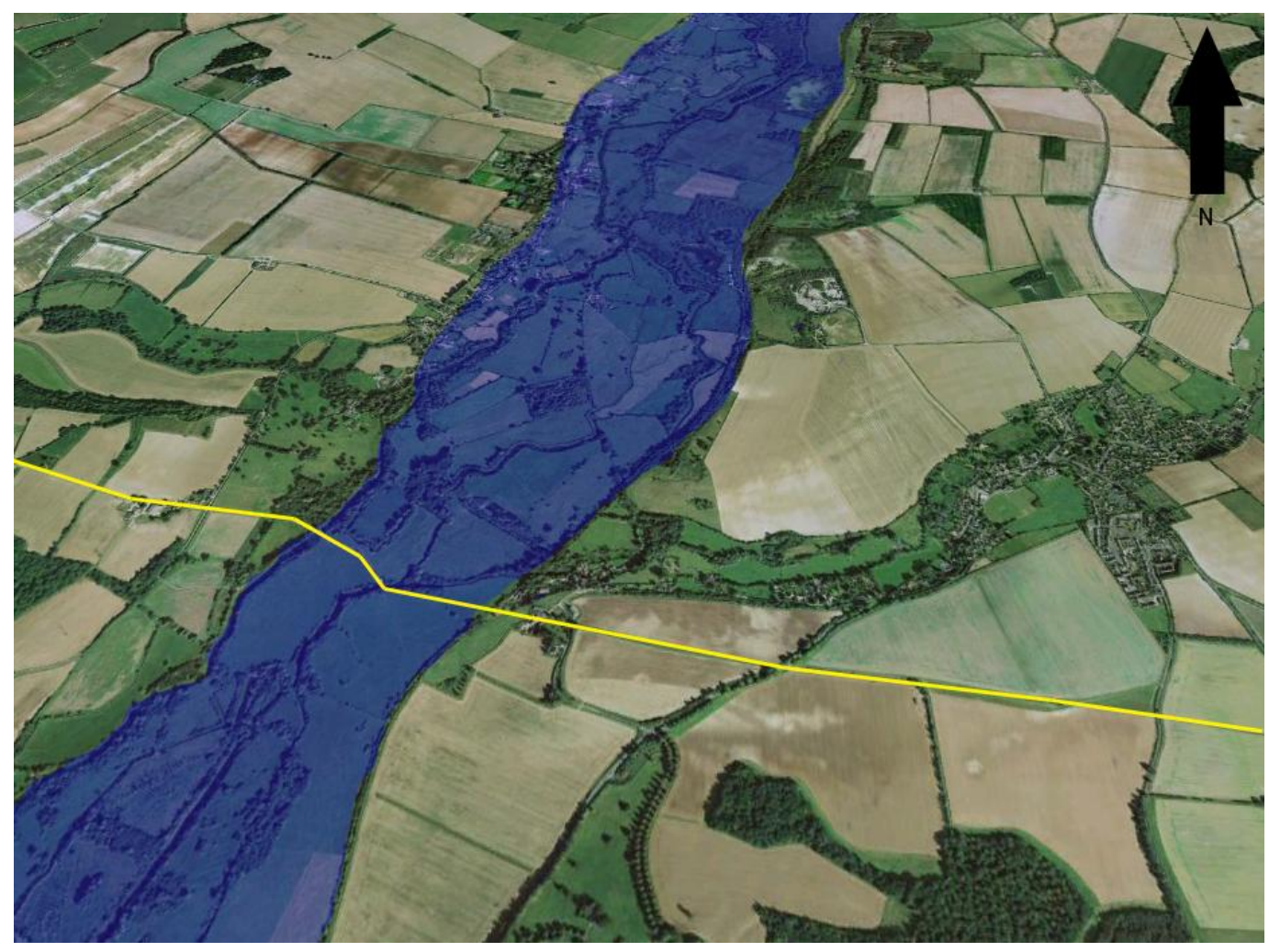

Figure 60. The Roman Road (yellow) in relation to the Test Valley, and the River Test/flood plain (blue shaded). Original satellite image reproduced from (C) 2011 Google. 
of crossing the river is a decisive one, for in a microcosmic sense the pilgrim is leaving one shore for another. As has been mentioned above, rivers play an important role in Christian symbolism and myth, with the River Jordan being the preeminent example. Rivers are also found to figure strongly in hagiographic miracle accounts (such as those of St Christopher and St Julian), and 'the frequency with which they appear in written sources, and their alliance with bandits, toll-gatherers, murderers, disastrous accidents and drownings, or, on occasion, miraculous events, leads to the hypothesis that they, along with fording points, ferry-men and bridges, occupied a special place in medieval imaginations and that various fears and associations were attached to such locales.' (Candy, 2007, 77) While not a major water course, the Test at this point is not inconsiderable in size and as such fording it could be a difficult depending on the river level, rainfall and season, which suggests that (as now) there were a series of bridges allowing passage. An example of this is found in the name of the village Horsebridge, adjacent to where the Roman road would have made its way across the Test to join its surviving course outside Kings Somborne. Whether or not these crossing points actually featured characters such as listed above (especially toll gatherers) is unknown, but due to their prevalence in pilgrim and folk tales they would have been part of the mental landscape for a traveller undertaking river crossings.

\section{The Approach to Winchester}

Upon emerging from the copses and connected woodlands (which can be seen on the extreme left of Figure 62 below), the pilgrim joins what is now called 'Old Sarum Road' as it leads uphill to Winchester's outskirts and then down into the heart of the city itself via the West Gate (Figure 61) which marks the entrance to the city proper, the High Street and finally the cathedral complex. This arrival introduced the city in degrees as the pilgrim drew in closer, and down into the Itchen Valley which cradles the city centre (Keene, 1985, 42). Moving from the rural to the urban context today, one encounters the western outskirts which extend roughly $1 \frac{1}{2}$ miles outside the West Gate and city walls. These peripheral settlements fluctuated throughout the Medieval period in relation to Winchester's prosperity. Evidence points to a stable and expanded population throughout the $12^{\text {th }}$ to $14^{\text {th }}$ centuries, with several parish churches and occupation extending up to half a mile outside the city walls (Keene, 1985,94 ). The plague of the mid-14 ${ }^{\text {th }}$ century, combined with Winchester's gradual decline as a commercial and political centre resulted in a reduction in population, and in density of structures, and after the western suburb was 'marked by fire', by the end of the $14^{\text {th }}$ century 'the suburb contained no more than a small group of houses immediately outside the West Gate.' (Keene, 1985, 143 - 144) This shift in population and the distribution of occupation in and around Winchester not only affected the extent of urban sprawl outside the city, it also resulted in changing property boundaries within Winchester's heart. So much so in fact, that 'At the beginning of the fifteenth century, Winchester was a city with more open space that it had had a hundred years before and possibly more than it had had since the eleventh century.'(Keene, 1985, 143) With regard to the pilgrim approaching Winchester from the west, this city's shifting patterns of settlement would have dictated both the traveller's primary impressions and sensory experience of arriving. These would be profoundly different depending upon in which century one made the western approach, ranging from a dense population to plague-ridden one, empty or derelict dwellings rather than expanding communities. 


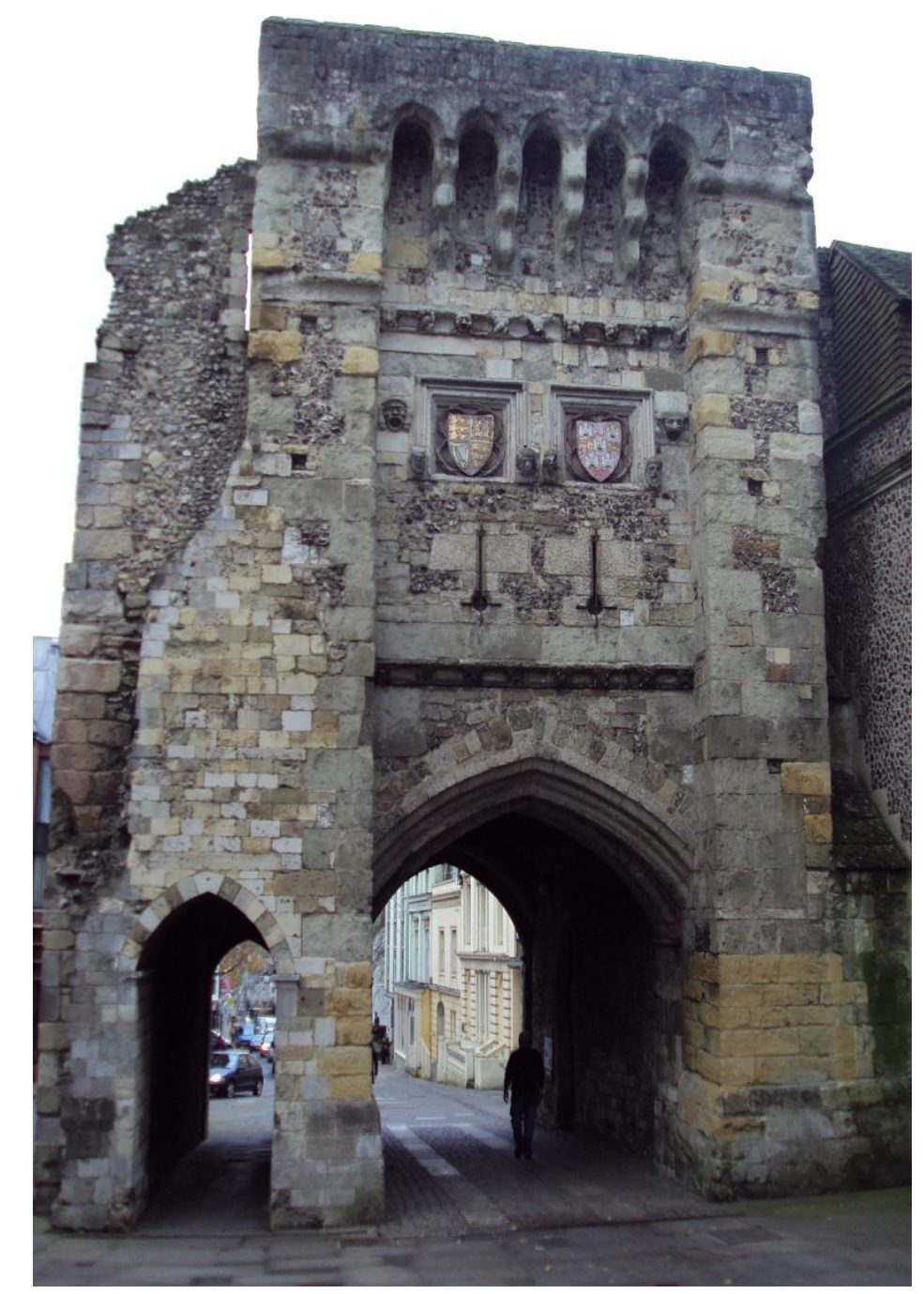

Figure 61. The West Gate in Winchester. Photograph taken by author.

Taking the $15^{\text {th }}$ century as a departure point (thus allowing for the development of St Osmund's cult in Salisbury and the steady rise in numbers of those travelling across England to Canterbury), Winchester was suffering economically due to competition in the cloth industry from neighbouring regions. The decline in its status was due to London's rising importance as a centre of royal and administrative activity, and the population had sharply declined following the ravages of the plague (Page, 1912, 6). The extended sprawl which characterised a booming $12^{\text {th }}$ and $13^{\text {th }}$ century in Winchester's fortunes was now largely destroyed or derelict in this western area, and may have given off a distinct impression of a city in decay or decline. The descent down to the West Gate passes the Royal Palace complex (built at the request of William the Conqueror), and takes the pilgrim to the boundary of the city proper. This transition from rural to pre-urban to city centre in a short space of time (roughly an hour of walking), perhaps through abandoned indicators of Winchester's high status past can be compared with the concept of Salisbury's inherent freshness and purpose-built design (discussed above). Winchester, which by the later Medieval period had already been well established as a high status and influential settlement since the Roman invasion, (but in decline by the $15^{\text {th }}$ century), can be seen as a (comparatively) ancient space, laden with 
history and a legacy of its own Anglo Saxon saint cult which predated St Osmund's canonisation by four and a half centuries. Moving from the comparative solitude of rural landscapes into that of Winchester's highly urbanised environment would also be a noticeable transition, shifting the pilgrim from the meditative movement of long distance walking to mindfulness of being in the vicinity of St Swithun's landscape of miracles. Added to this would be a change in the pilgrim's audible environment, from the subtle catalogue of rural sounds primarily produced by weather and fauna and parish church bells, to a brasher landscape filled with the noises of tradesmen, merchants, fellow pilgrims and the general bustle which forms the urban soundscape.

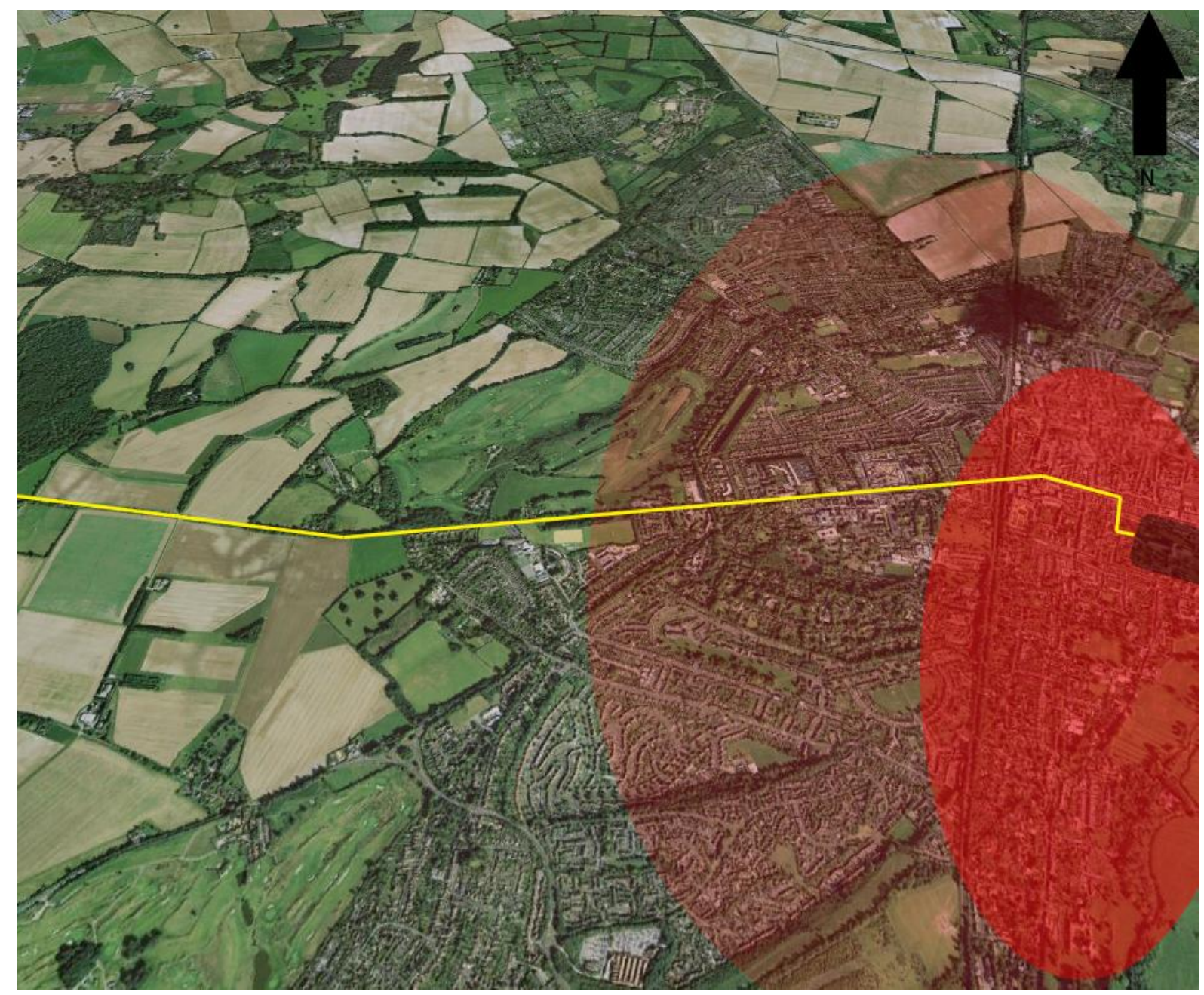

Figure 62. The two basic zones of urbanism presented to the pilgrim during the western approach to Winchester (yellow): outer sprawl (lighter red shading) and the city centre via West Gate (heavier red shading). The cathedral complex is shaded in black. Original satellite image reproduced from (c) 2011 Google.

The second 'zone' of transition occurs when turning from the High Street in the Cathedral precinct (shown in Figure 63 below in yellow). Up to this point, the approach from the west has rendered the cathedral all but invisible due to the elevation and presence of other aspects of the built environment masking the cathedral profile, save for its potential aural presence via the tolling of its bells. One is funnelled down the broad High Street, hemmed in on either side by shop fronts 
and public houses, which could at a price accommodate the weary pilgrim. However, leaving the High Street at the $15^{\text {th }}$ century Buttercross and entering the precinct and cathedral green, the enormity of the cathedral and its craftsmanship are suddenly revealed, and the pilgrim has moved

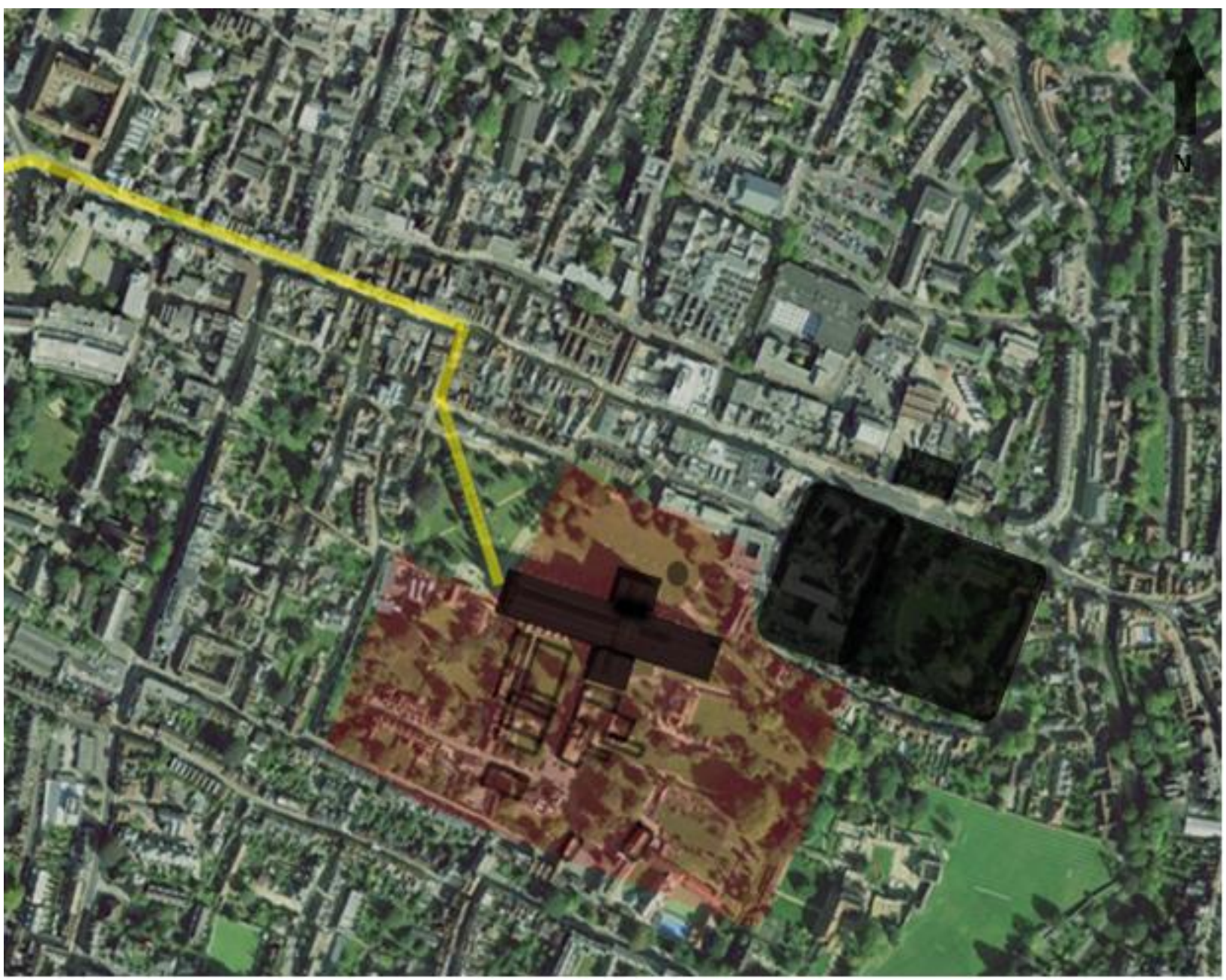

Figure 63. Interior approach via the High Street to Winchester Cathedral, showing the outline of known St Swithun's Priory buildings, St Swithun's probable original burial shrine spot (circle near north transept), the Nunnaminster site, and St John's Hospital in the High Street, based on the work by John Crook (1993). The entire site of the monastic complex is shaded in red. Original satellite image reproduced from (c) 2011 Google.

from a profane space (High Street) to a sacred one in few steps. It is an extraordinary feat of spatial use, that this impressive ecclesiastical institution manages to present itself as a peaceful enclave or sanctuary, when encountered after the High Street. This is the sacral heart of Winchester, around which the cult of St Swithun developed into one of the greatest of the Anglo Saxon saints. The initial impression would surely have involved one of activity, the daily movements of the monks performing liturgies, peddlers selling souvenirs and snacks; the distinct impression that this was the centre of sacred and secular activity in the region. While not related to St Swithun in a strict sense, being dedicated to St Mary and St Edburga, the church of Nunnaminster was rebuilt on a lavish scale following damage by fire in 1141 , and despite Nunnaminster suffering greatly following the Black 
Death by the $15^{\text {th }}$ century the church still commanded an impressive place in Winchester's skyline (Doubleday and Page, 1973, 124). Further south along the High Street were most of the inns offering accommodation, and at the High Street's end was the 'fair hospital of S. John', discussed earlier in this chapter (Leland, 1901, Vol. III, 149). Crossing the cathedral green the scale of the building becomes apparent, and depending upon the time of year (i.e. feast days), would have been populated by varying numbers of pilgrims filing into the cathedral and around its interior, filling the air with noise of peddlers, devotions of variable intensity, producing an overwhelming experience for the arriving pilgrim when combined with the fatigue ensuing from the journey. Upon being allowed to enter the cathedral (likely via the north transept door, with the main front doors being allocated for more august visitors), pausing perhaps to visit the outdoor tomb shrine which grew up around St Swithun's original burial site (a shaded grey circle directly north-east of the cathedral's eastern transect in Figure 63 above), the pilgrim would be led around the feretory by a monk of the priory, and stood before the shrine to make their devotions, which by the $15^{\text {th }}$ century was on prominent display in the retrochoir (Crook, 2000, 84 and Crook, 1993, 57). Judging from contemporary accounts of pilgrim activity in various shrines, especially that of Margery Kempe, it is very likely that there was a mixture of clamouring pilgrims vying for the saint's attentions, beseeching, murmuring prayers and prostrating themselves before the raised reliquary shrine in the retrochoir, combined with the customary heady incense smells and sacral sounds (bells, chants) and more general awe at the sheer scale of the enclosed ornamented space (Crook, 2000, 117). For those who had arrived in Winchester en route to the shrine of St Thomas Becket in Canterbury, this sensory overload would surely act as a tantalising and intoxicating taste of the experience which awaited them further along the road in Kent. 


\subsection{Conclusions}

There can be little doubt that as a pilgrim destination, Winchester owed as much to its geographical and infrastructural location as to the fame and efficacy of St Swithun's miraculous powers. News of miracles and saintly cures travels quickly by word of mouth, yet this reputation relies on being situated within a network of communications which can permeate into the lives of the laity through religious centres, trade, industry, and also into the corridors of royal power. The layers of successive occupation which make up the Wessex region's history have endowed it with a comprehensive road network, allowing verbal news to reach the laity locally, across the country and at times even further afield. Of special significance was Winchester's initial Medieval role as the seat of royal power, and its connection to the commonly used route to the shrine of St Thomas Becket in Canterbury. Salisbury too owed much to its situation within the regional infrastructure, and whilst not occupying quite such a prestigious status as Winchester, its cathedral and the tomb of St Osmund therein received significant numbers of pilgrims, many of which would then travel east towards Winchester and finally Canterbury. This positioning within local trade and travel allowed both towns to develop a flourishing hospitality trade, catering for both pilgrims and secular travel alike with numerous inns. However it is to their saint cults and pilgrim devotees that the development of charitable hospitality sites such as St John's Hospital in Winchester and St Nicholas' Hospital in Salisbury can be attributed.

For the pilgrim moving through the landscapes of eastern Wiltshire and western Hampshire towards Winchester we can see the rural spaces encountered as allegories of 'wilderness', that class of land which, through the dangers posed by forest travel, border lands and pre-Christian monuments in the landscape, offered physical and spiritual peril to the Medieval mind. Yet the rural context may also have offered something entirely beneficial to the pilgrim, the opportunity for meditative and hard travel, a penitential act which symbolised sacrifice and humility before arriving at the shrine site, and also an opportunity for contemplation in rhythm with one's steady tread along the road. This journey is interrupted by only two parish churches and the symbolically charged landscape of the Test Valley, which combines the presence of Mottisfont Priory (with its relic of St John the Baptist acting as an effective draw for pilgrims), and the crossing of the Test river - an act which resonated with the Medieval imagination, with rivers featuring heavily as places of danger and liminal environments for supernatural experience (Candy, 2007, 77). The distance between Salisbury and Winchester (both environments which can be placed within the 'sanctuary' spatial class) is roughly 24 miles, which whilst manageable in one day is taxing, and the descent into the Itchen Valley would have been a gratifying one.

The fact that Winchester retained in its fabric the trappings of royal and ecclesiastical favour, despite its ailing finances, combined with the sheer volume of ecclesiastical properties in the city would have impressed upon the pilgrim the sanctity of the city. Were they familiar with the hagiographic accounts (which doubtless leaked into local folklore), then the immediately surrounding landscape would also have been imbued with sites of divine aid or intervention. One need only look at the works by Wulfstan and Lantfred to see that Swithun was a saint whose cult, 
whilst being almost as celebrated a pilgrim destination (in its heyday) as Canterbury or Walsingham, retained a local aspect - it was rooted within the Hampshire landscape in terms of the miracles which led and introduced his canonisation, and also in terms of his Anglo-Saxon Wessex origins. However, it is worth considering that Winchester played a role in promoting and housing not only the cult of St Swithun, but also four other Anglo Saxon saints (Birinus, AEthelwold, Atthelthryth and Hæddi). All five saints were included in the small section dedicated to Anglo-Saxon saints in the 1586 Martyrdom Romanum, indicating that in the eyes of the wider context of Christendom Winchester was a true well-spring of Anglo Saxon sanctity, and that St Swithun was considered 'a universal saint' (Lappidge, 2003, 61). What seems most surprising in the distribution of St Swithun's otherwise Anglo-centric presence in terms of dedications and relics is his physical presence in both the Norwegian and northern French sacral landscape in the form of an articulated arm and a skull. Diffusion of information about high-ecclesiastical matters amongst the laity is not a hallmark of the Medieval period. However, St Swithun's reputation would have been well known to the general population and it can be argued that it would be in the interest of the monks keeping St Swithun's shrine to make sure that he also appeared as universal as possible. This would raise his profile in the saintly pantheon and secure larger donations (especially later when Winchester's fortunes were declining), and so promoting knowledge of these other shrines could have taken place during the pilgrims' tours of the shrine. What can be said with certainty however is that the pilgrimage to Winchester Cathedral either as a single event or, integrated into a larger pilgrimage tour (such as to Canterbury, or to Southampton to board ships bound for the north of Spain and Santiago de Compostela) would have been a significant addition to any pilgrim itinerary. The successful promotion of his cult made St Swithun's shrine a key figure in the British pilgrim itinerary. 


\section{Chapter 5: St Asaph to Holywell}

\subsection{Introduction to the case study}

St Winefride's Well in Holywell is a rare example in Britain of a site which has attracted a relatively uninterrupted stream of pilgrims since its founding in the late $7^{\text {th }}$ century. St Winefride's Well was spared from the worst excesses of the Reformation and lies on the North Welsh coast in the Greenfield Valley, near Chester and the Cistercian Basingwerk Priory. Several royal pilgrims have visited, despite its origins as a local saint cult. St Asaph was the ecclesiastical centre of the region, with its own saint cult of St Asaph as well as a cathedral and a record of monastic activity stretching back to the $6^{\text {th }}$ century under St Kentigern. St Asaph was also a diocese and an ecclesiastical powerbase for the region. My route between St Asaph and Holywell runs for 15 miles, and utilises Offa's Dyke, before descending to a series of tracks and fields, passing the Maen Achwyfan cross, through Whitford parish, and further down towards the coast and Holywell. This follows the direction of the Roman road between these two settlements, which would have seen much human traffic. However, I have used a route which parallels this road whilst not using it directly due to its evolution into the A55. The modern A road is inappropriate for the landscape interaction element of my research and does not take into account other sites which I believe to be of interest to the pilgrim in the Denbighshire/Flintshire landscape, and are close enough for pilgrims to incorporate into the journey from St Asaph to St Winefride's Well in Holywell - both reasons and sites will become apparent in the chapter below. No pilgrim souvenirs have been recovered which reflect either motifs linked to St Winefride or the pilgrimage activity at Holywell, consequently the section dealing with these artefacts in the other case study chapters has been intentionally left out due to a lack of evidence. Whether this is the case with other Welsh saint cults reflecting a cultural difference between English and Welsh pilgrim material culture is an area for future research, although it is very difficult to believe that the Winefride shrine was not commercially exploited and that souvenirs may yet be discovered. 


\subsection{The Landscape of Medieval Denbighshire and Flintshire: Environmental, Economic and Ecclesiastical}

\section{Environmental:}

Wales has a varied topography including mountains (Snowdonia being the most prominent and well known) and high moorland. However the landscapes of North-East Wales are predominantly agricultural and low lying. Compared to the rest of the country, the region has less in the way of peaks but includes hills (the Clwydian Range) and valleys (the Vale of Clwyd) which offer challenges to the traveller. The counties of Denbighshire and Flintshire both meet in these hills, and then fall away into the Vale of Clwyd and Flintshire Plateau, where St Asaph and Holywell respectively lie. The Clywd Landscape Character Assessment (Denbighshire County Council, 2000) cites nine different landscape types for the region, including 'high moorland ridges', 'hill-slopes', 'plateaus', 'farmland'

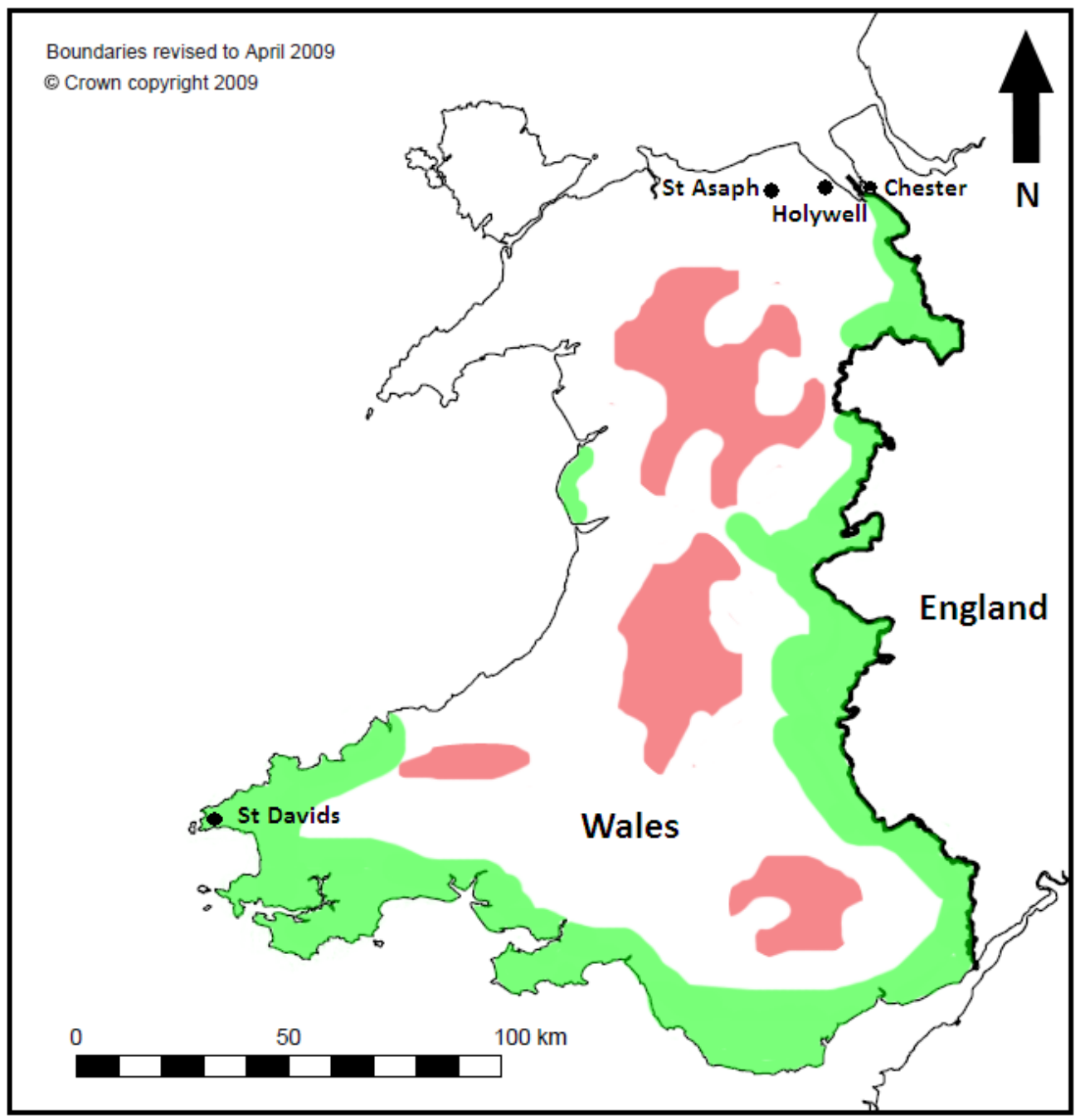

Figure 64. Map of the Upland (red) and Lowland (green) landscapes of Medieval Wales in the $14^{\text {th }}$ century. Redrawn after the Outline Map of the UK published by the Ordnance Survey. 
and 'valleys'. The Medieval landscape would be broadly similar to today's (although less forested), a result of continuity of land-use in the area, with the Clwydian range reaching $264 \mathrm{~m}$ in the northern areas near St Asaph, ridged by the Clwydian range and Offa's Dyke (Brown, 2004, 8). The small woodlands which are found throughout these two regions hide numerous natural springs, and 'period woodland declined, possibly as a result of increased grazing pressure', with the climate supporting optimum agricultural conditions around the $11^{\text {th }}$ century (Brown, 2004, 97). The majority of the landscape was gradually given over to sheep grazing in the upland areas, with small pockets of arable land and cattle pastures which contributed to the development of the drover trails which cross the region (Burnham, 1995, 3). Other features of the local landscape which are of note are the imposing hill forts scattered along the hilltops: 'The most visible and impressive of all the archaeological sites in the Clwydian Range are the Iron Age hillforts that adorn the tops of the hills along virtually all its length.' (Brown, 2004, 68) One in particular relating to this pilgrim case study between St Asaph and Holywell is the hill fort of 'Moel Maenefa', which is visible after Rhualt from Offa's Dyke and remains a statement of power within the landscape (see Figure 65 below). The Dee Estuary which flows into Liverpool Bay supports a salt marsh, now drastically reduced as a result of urbanisation, but which would have been more extensive during the Medieval period, and is still an important fishery (Jones and Silvester, 1996, 12). It also functioned as a major trading route to and from Chester, as well as providing shelter for ships which could wait in the estuary for favourable winds.

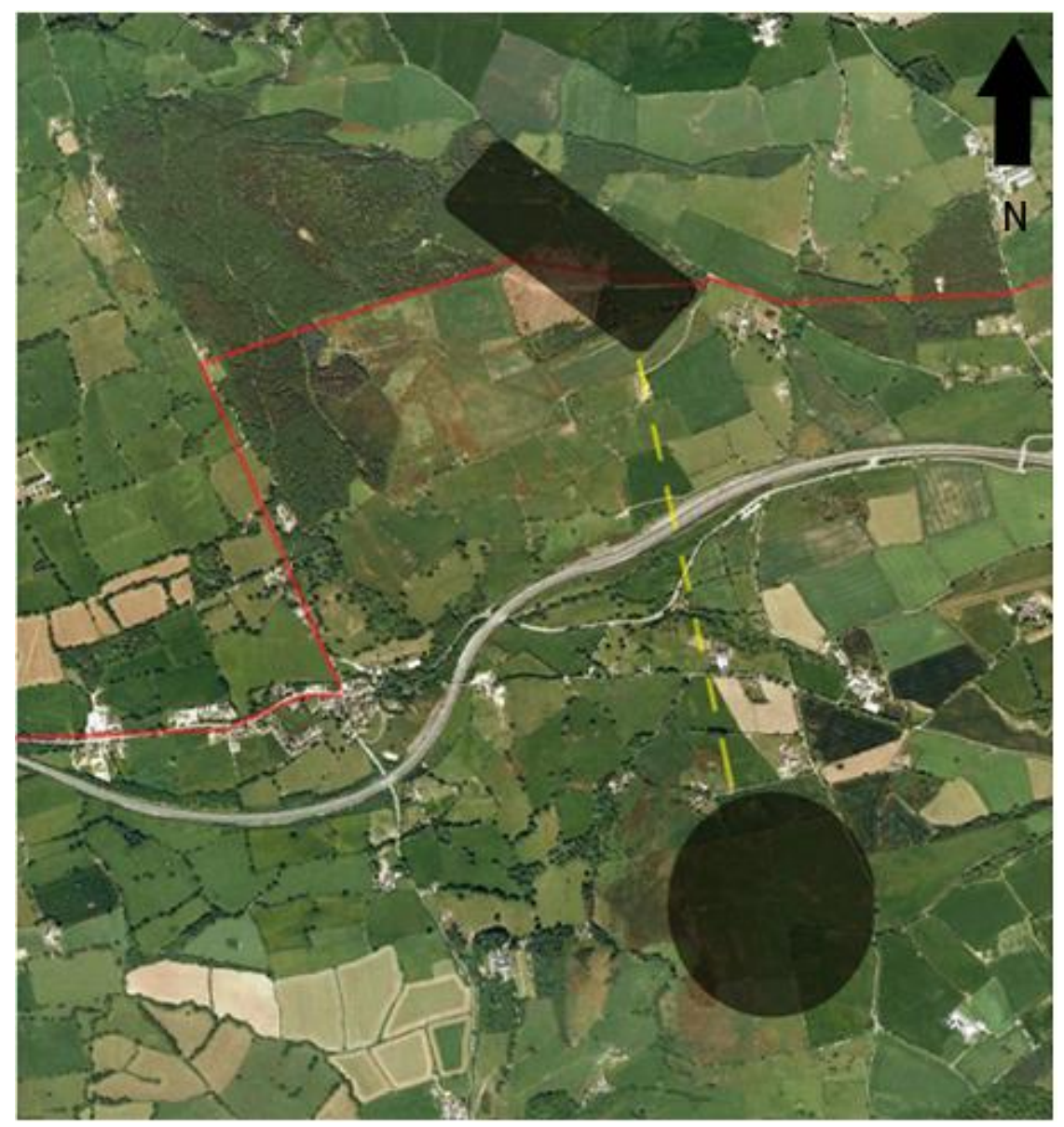

Figure 65. Sight line (yellow) for Moel Maenefa Hill-fort (black shaded circle) in relation to the Offa's Dyke (shaded black lozenge) and Clwyd Valley. Original satellite image reproduced from (c) 2011 Google. 


\section{Economic:}

The two prime industries of Medieval Wales lay in agriculture and mining (primarily for lead, copper and silver), with pastoral lands occupying much of the interior, and mines located largely in the northern areas of the country. The impression of the early Medieval Welsh economy is one of an intricate network of small close-knit farming communities, defining the Welsh as 'primarily a pastoral people - a nation of dairy farmers grouped together in self-sufficing hamlets.' (Lewis, 1903, 127). This impacted negatively on the development of trade centres which did not start to become common until around the $12^{\text {th }}$ century: 'Trading activity, with its fixed centres and market privileges, was not known to the Wales of the tenth century. Giraldus Cambrensis confirms this view two centuries later. 'The Welsh,' he says, ' have no towns, villages, or castles. They pay no attention to commerce, shipping, or manufactures. They anxiously study the defence of their country.' The building of castles, the erection of monasteries, and the walling of towns-all this, done by the Norman, marks a new stage in the development of the mineral resources of Wales.' (Lewis, 1903, 128). However during the Medieval and early modern period mining became an important factor in the local economy (Blanchard, 1981, 77). The majority of the Welsh landscape is sparsely populated, leaving much land available to the peasantry for arable or pastoral use. The few places populated by more than 50 people per square mile are linked to large urban centre s such as Cardiff, Swansea and nearby Chester, and these areas are typically surrounded by areas of relatively high population density of $30-49$ people per square mile. Flintshire and Denbighshire fall into both of these categories. Flintshire abutts Chester, and Denbighshire contains a similar population density which benefited from the mining activity in the area, as well as its agricultural and religious heritage. In terms of population, the five border counties which include Flintshire and Denbighshire made up roughly $35.5 \%$ of the Welsh total, with Flintshire one of the most populous regions (Thirsk, 1967, 145). This will have affected the development of road networks connecting villages and towns, or earlier routeways serving the region, most probably a combination.

Flintshire and Denbighshire possessed one of the few major post $13^{\text {th }}$ century lead mines in Wales (see Figure 66 below) exploiting the ore-rich Clwyd landscape, as well as smelting and processing sites. Edward I's campaign of castle building increased the demand for lead in the north of the country, as roofing material: 'The massive programme of castle building undertaken by the first three Edwards after the conquest of North Wales provided a direct stimulus to the development of an indigenous industry within the principality...from 1354-1420 the southern section of the Flintshire field once more established the county as the premier Welsh production area' (Blanchard, 1981, 82 - 83). Documentary sources in particular mention a substantial lead mine at Llanymynech, as well as at Holywell (the nearby Halkyn Mountain was one of the main sources of lead and zinc ore in Medieval Wales), however recent exploitation in these mines has obliterated their Medieval workings (Kirkham, 1968, 18). These mines are mentioned by Gerald of Wales in his itinerary of the Archbishop Baldwin, where he states that 'we continued our journey through a country [Flintshire] rich in minerals of silver, where money is sought in the bowels of the earth' (Giraldus, 1978, 24). This industry was profitable in many ways; records for the privileges of the miners at Englefield state that they were given lands spacious enough for a house and garden, they were 'free men', allowed to sell 


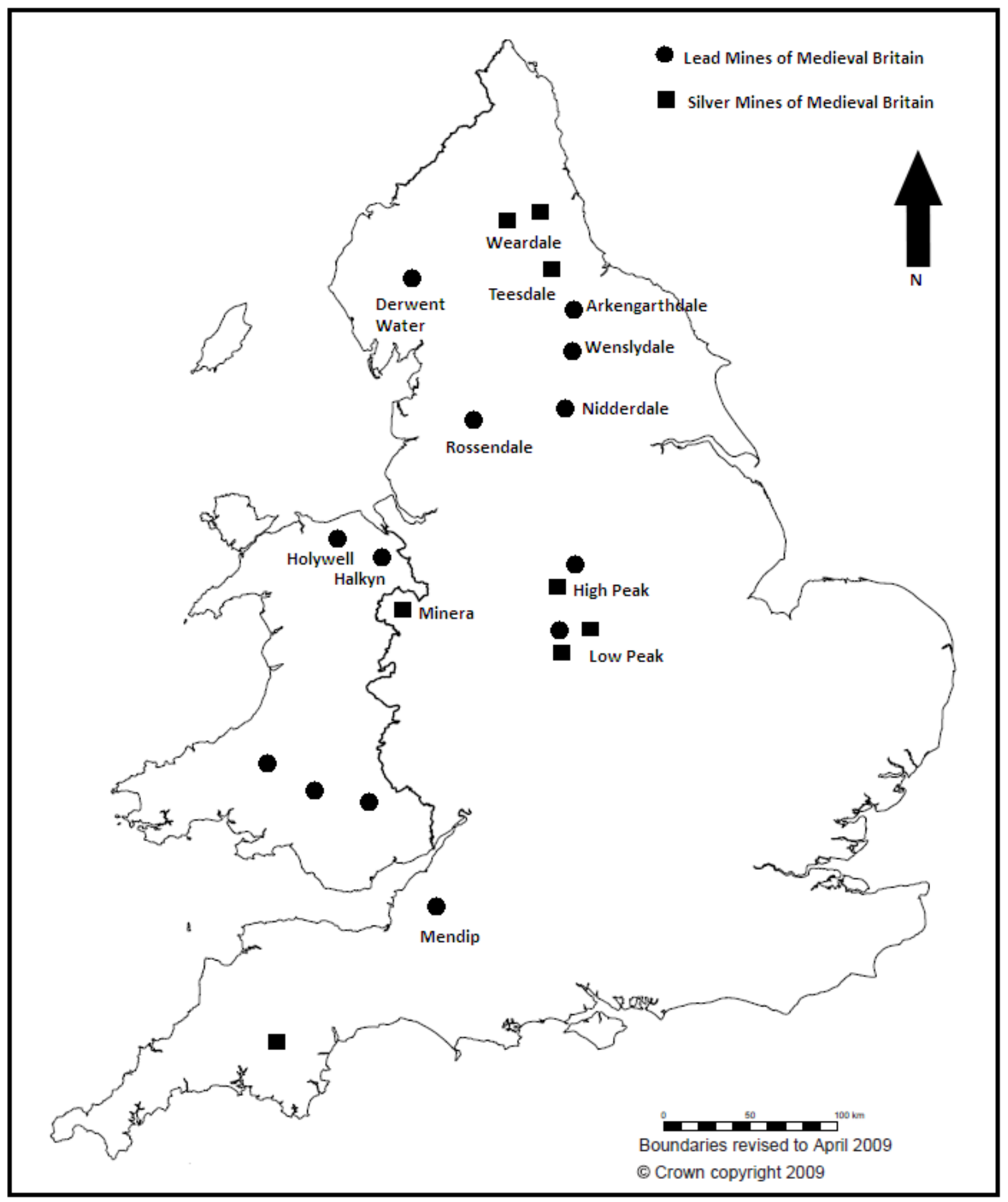

Figure 66. Map displaying locations of major Silver and Lead mines in Medieval Britain including Wales, redrawn from Blanchard, 1981, 73. Redrawn after the Outline Map of the UK published by the Ordnance Survey.

their ore on the free market providing they paid their Lord his dues, and were permitted to graze their animals on common land (Frost, 1994, 45). Agriculture land use in the Clwyd region was mainly restricted to grazing for sheep, and so whilst underpinning the primary occupation and dispersal of settlements in the north east of the country, it was neither as profitable in income or privilege as the mining industry. Lead was also in demand from the churches which were so prevalent in the Welsh landscape, and the Clwyd Denbighshire/Flintshire region was no exception. 


\section{Ecclesiastical:}

The majority of northern Wales during the Medieval Period fell within the Kingdom of Gwynedd, which had grown out of the petty states and tribal law which followed the Roman withdrawal. Between the $6^{\text {th }}$ and $8^{\text {th }}$ centuries there was a sharp rise in the establishment of monastic settlements by aristocratic and religious figures such as Saint David and St Teilo, and examples of these monastic sites in north Wales can be found in the Cistercian Aberconwy House, Penmon Priory, Bangor Cathedral, and the $6^{\text {th }}$ century monastery founded by St Kentigern at St Asaph. The so-called 'celtic' Christianity of Wales was the spiritual landscape that greeted the Normans in the $12^{\text {th }}$ century, for whom this distinctive brand of Christianity did not sit well, either spiritually or politically. In order to assert a more 'Roman' influence they actively encouraged monasticism and the first to settle in Wales were the Benedictines who by 1150 had already set up 17 priories and cells throughout the Welsh principalities, Cistercian houses were founded at Basingwerk, Aberconway, Strata Marcella and Valle Crucis. There was a Dominican house at Rhuddlan and a Cistercian nunnery at Llanllugan - many of these were dependent on larger English or French monasteries (Herbermann, 1913, 79; Knowles and Hadcock, 1958, 228). As in Cornwall, North East Wales hosted a range of pilgrim destinations, with Rhuddlan, Yr Wyddgrug and Tremeirchion all possessing famous Roods. St Asaph had a cathedral and St Asaph's relics, while Holywell was home to the miraculous St Winefride's Well. Chester, just 14 miles south east of Holywell, had a cathedral (including a shrine to St Werburgh) and St John's Church (Charles-Edwards, 1962, 12).

The diocese of St Asaph encompassed a large portion of north eastern Wales comprising at the time of the Reformation of one hundred and twenty-one parishes, including Holywell. Established by St Kentigern in the sixth century (along with the foundation of the monastic settlement of Lanelwy - an archaic name for St Asaph meaning 'church by the Elwy'), the diocese initially correlated broadly with the borders of the Powys region, however these territories were gradually reduced by what is described as a 'Mercian encroachment marked by Watt's dyke and again by the construction of Offa's dyke, soon after 798.' (Herbermann, 1913, 45) Within the diocese the primary shrines were; St Winefred's Well, St Garmon in Yale, St Dervel Gadarn in Edeirnion, St Monacella at Pennant, and the Holy Cross in Strata Marcella. However St Winefride's Well at Holywell remained its most celebrated cult centre up to and following the Reformation (Herbermann, 1913, 47).

Wales has traditionally been viewed as a 'land of saints', with sanctity being 'written into the human landscape' (Gray, 2000, 34). This tradition of local saint cults was more prevalent than in England, and devotionally the majority of these saints were firmly rooted in the communities in which they had lived out their lives, with the two exceptions in terms of dedication dispersal being St David and, to a lesser extent, St Winefride. St David is undoubtedly Wales' most celebrated saint and a national figure, the son of a royal house with a birth foretold by angels, and his dedications are spread across the Welsh landscape (Adair, 1978, 170). St Winefride however falls within the remit of a 'local saint', though her area of 'locality' seems significantly larger than those of her compatriots (Cartwright, 2003, 79). Both the range and distribution pattern of church dedications in her name are discussed later in this chapter. This type of 'spiritual localism' resulted in some rather specific 
rites which were typical of certain parishes or geographical areas in the Welsh landscape. Ian Brown records that 'In the Clwydian Range certain ancient rituals accompanied the dead. Bells, officiated by the sexton, were rung to announce a death, whilst the parish clerk preceded a funeral procession from house to churchyard with a handbell.' (Brown, 2004, 117)

Before discussing the ecclesiastical landscape in relation to the specific pilgrim site of Holywell, I will briefly summarise below the life and reputation of both saints (Winefride and Asaph) whose influence so strongly pervaded the region.

\section{St Winefride (Holywell)}

Winefride was a $7^{\text {th }}$ century welsh noblewoman who was martyred (briefly) after refusing the advances of her suitor, the king's son Caradog. He decapitated her in a fury and her head rolled downhill; where it came to rest a healing spring bubbled forth and became St Winefride's Well (Adair, 1978, 162). After her head was miraculously rejoined to her body by St Beuno, 'Saint Winefride lived for another fifteen years. When Saint Beuno went to Clynnog, she went first to Saint Deifr at Bodfari, and then to Saint Sadwrn at Henllan. She was directed by the latter to Saint Eleri at Gwytherin, in a remote valley in the mountains, where she became a nun.' (Charles-Edwards, 1962, 3) During the $15^{\text {th }}$ century a chapel was built which housed a pool fed by the spring, where devotees bathed in the holy waters (Adair, 1978, 162). Her uncle was the renowned Welsh saint Beuno, who had his own monastery at Clynnod Fawr in Gwynedd (north-west Wales). The 'Vitae St Wenefrede' records some of the miraculous tales of healing which after pilgrims had prayed to the saint or taken the waters, including those afflicted with agues or fevers, cripples, and sickly children. Practises at the well are recorded in this text, including (mentioned in Chapter 4 ) that of removing a stone from the well and placing it in a body of spring water at home, thereby sacralising those waters for future cures (Fleetwood, 1713, 85).

This story of pursuit, decapitation and miraculous healing has been thought by some to be an elegant metaphor for perhaps a very real incident where Winefride was in fact raped by Caradog, and the legendary resurrection of her body by St Beuno represents her uncle caring and restoring her to physical and mental health after the ordeal - however this intriguing interpretation seems only to be found on the website for the well itself (http://www.saintwinefrideswell.com/meaning.htm). Whether the death of Caradog in the story is meant to signify the destruction of his reputation is an additional interpretation of events. It seems unlikely that the death or murder of a king's son would go unnoticed or unpunished; no matter what crime he committed 
The early years of this saint's life are unrecorded, but from Jocelyn of Furness' 'Life of St Kentigern' we know that the boy Asaph came into Kentigern's monastic community at (what is now called) St Asaph in the mid- $6^{\text {th }}$ century. So impressed was Kentigern by Asaph's piety and sanctity that he made the boy his successor, and thus Asaph became bishop of the community and the region. Prior to his death in $A D 601$ he gathered a reputation for miraculous healing which attracted many followers to his monastic community, and his veneration continued the church which evolved into a (very) small cathedral (Attwater and John, 1993, 27). He is seen as the spiritual protector of the Clwyd valley. 


\subsection{The Road Network of Medieval North Wales}

When modern scholarship on Welsh saints (Cartwright, 2003; Evans and Wooding, 2007; Henken, 1991) is combined with the mid-twentieth century work on religious houses and the development of the Welsh historical landscape (Hadcock, 1950; Rees, 1951) one can begin to build a picture of the religious and communication networks in the North East of Medieval Wales. Through further crossreference with the work carried out by Hindle on Medieval road networks (Hindle, 1976), and by Margary on Roman roads in Britain (1973), one can begin to investigate how pilgrims travelled between settlements and sites. Of particular relevence in this case study is the role of Offa's Dyke, as a conduit or a frontier between the vale of Clwyd in which St Asaph lay and the region of Flintshire the heart of the Winefride cult.

\section{Roman foundations:}

The Welsh road network does not favourably compare to its English neighbour in terms of range and breadth (Hindle, 1976, 210). From Hindle's work (Figure 6, Chapter 1) there would appear to be a road system which connected the exterior of the country at least to the rest of Britain, which may echo some of the patterns of Roman infrastructure, which in Wales revolved mainly around forts and a handful of large urban administrative centres such as Moridunum (Carmathen) and Isca (Caerleon (Hindle, 1976, 212)). Many of these forts/towns were located in the southern portion of Wales, serviced by Roman roads across this region and along the Welsh border (Davies, 2002, 45). The central and northern interior of Wales also benefited from Roman road-building linking a scattering of forts and the profitable lead and copper mining industry (the extraction of Welsh silver occurred primarily during the Medieval period) and some connecting routes between settlements, but nothing on the same scale as in the south of the country (Allen, 2005, 3). This impacted on the Medieval route network, which so often followed and utilised the blueprint of the Roman road system, resulting in the majority of direct and major routes being found in the south of Wales, whereas the centre and north relied primarily on more agricultural based tracks (such as drover trails). This also correlated with the agrarian livelihoods of the locals in the interior, where moorlands and valleys were filled with grazing sheep and cultivated fields (Allen, 2005, 3).

\section{Drover trails, trading routes and local paths:}

The history of cattle grazing in Wales is long, reaching its climax in the $18^{\text {th }}$ and $19^{\text {th }}$ centuries (Anne Wilson, 1973, 79). As a consequence there existed during the Medieval period and up until the late $19^{\text {th }}$ century a comprehensive series of droving trails around Wales, typically leading from grazing areas and regions of transhumance to the market towns and trading centres nearby, or fresh pastures. Drover trails were of particular use to the traveller (and by extension the pilgrim), as they 
offered a relatively direct route through rural areas towards one of the 137 market fairs in Wales during the Medieval period (Toulson, 1978, 24 and Letters, 2005, 1). These trails are usually recognisable being deeply eroded in the land with high earthen banks, and occasionally make a 'dogleg turn' (a sharp bend) in order to provide shelter for the animals and their drovers during severe weather (Moore-Colyer, 1976, 34). The typical droving road varied in width from $10 \mathrm{~m}$ to $20 \mathrm{~m}$ with grazing verges either side, called the 'long acre', which as the animals wore down the road surface would sink deeper into the landscape with the verges remaining on their original level (Ryder 1997, 220). Within the context of my fieldwork between St Asaph and Holywell, Moore-Colyer states that the cattle in this region were highly productive (mainly Anglesey and Llŷn breeds), and large quantities of butter and cheese were taken to market at Holywell by cart (Moore-Colyer, 1976, 36). There is a possible drover road with a dogleg at Pont Dafyyd which moves east towards Rhuallt (see Figure 67 below) and fits the description laid down by Moore-Colyer, with high earthen banks, and farming tracks which lead over field strips. Many of the lanes which link these small farming settlements may, similarly to Cornwall, reflect an earlier Medieval route network across rural areas, and so travel across the Flintshire/Denbighshire region would utilise a combination of these tracks, drover routes, and surviving Roman roads. The large number of monastic houses and mother churches around Wales (e.g. St Asaph), would also require a comprehensive travel network, even at an informal level on local paths. For the larger institutions, roads would be needed for high status visitors to arrive by, and the condition of these roads would generally be the responsibility of the religious house and/or parish community.

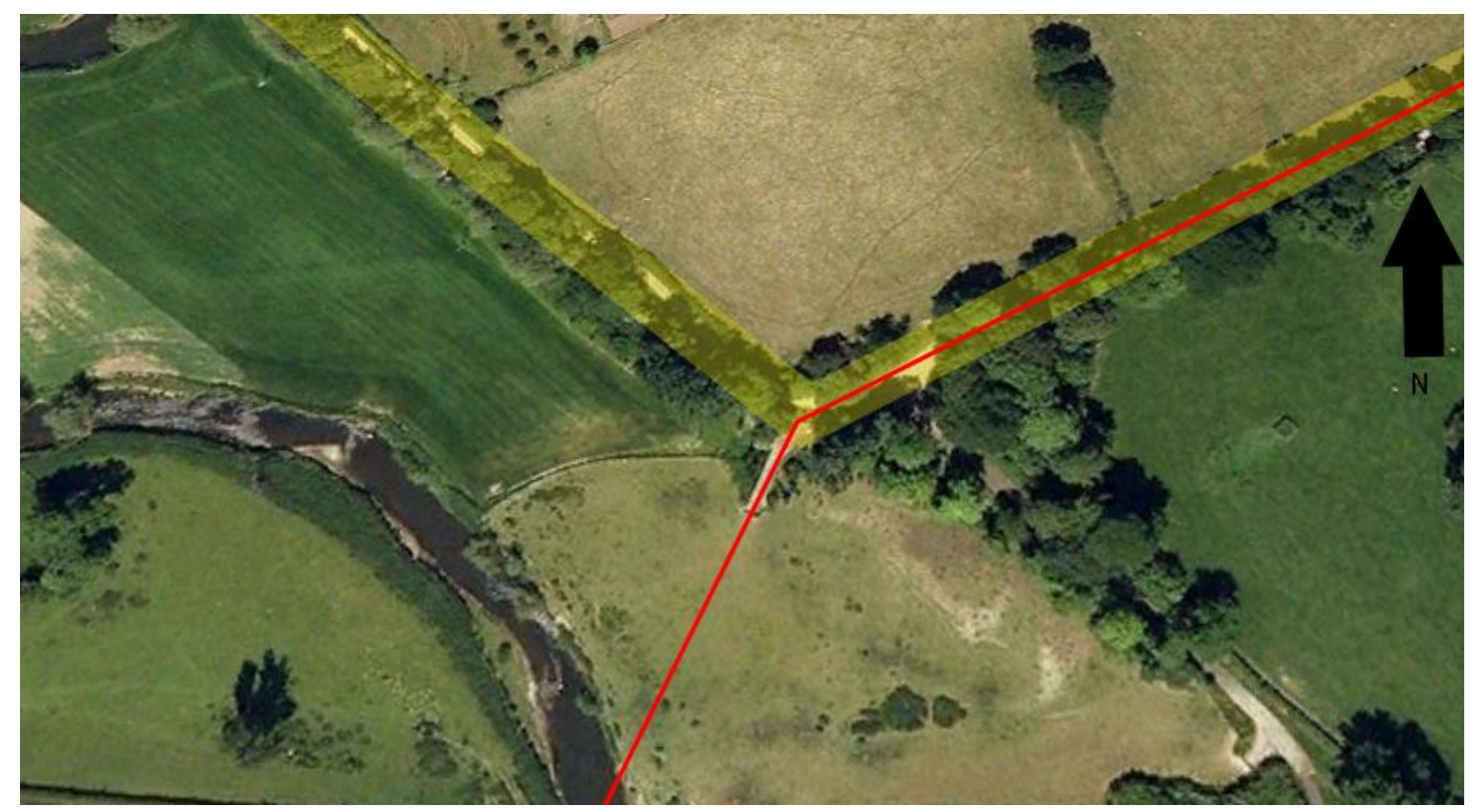

Figure 67. Birds-eye view of Pont Dafydd and potential drover trail (yellow) near St Asaph. Original satellite image reproduced from (c) 2011 Google. 


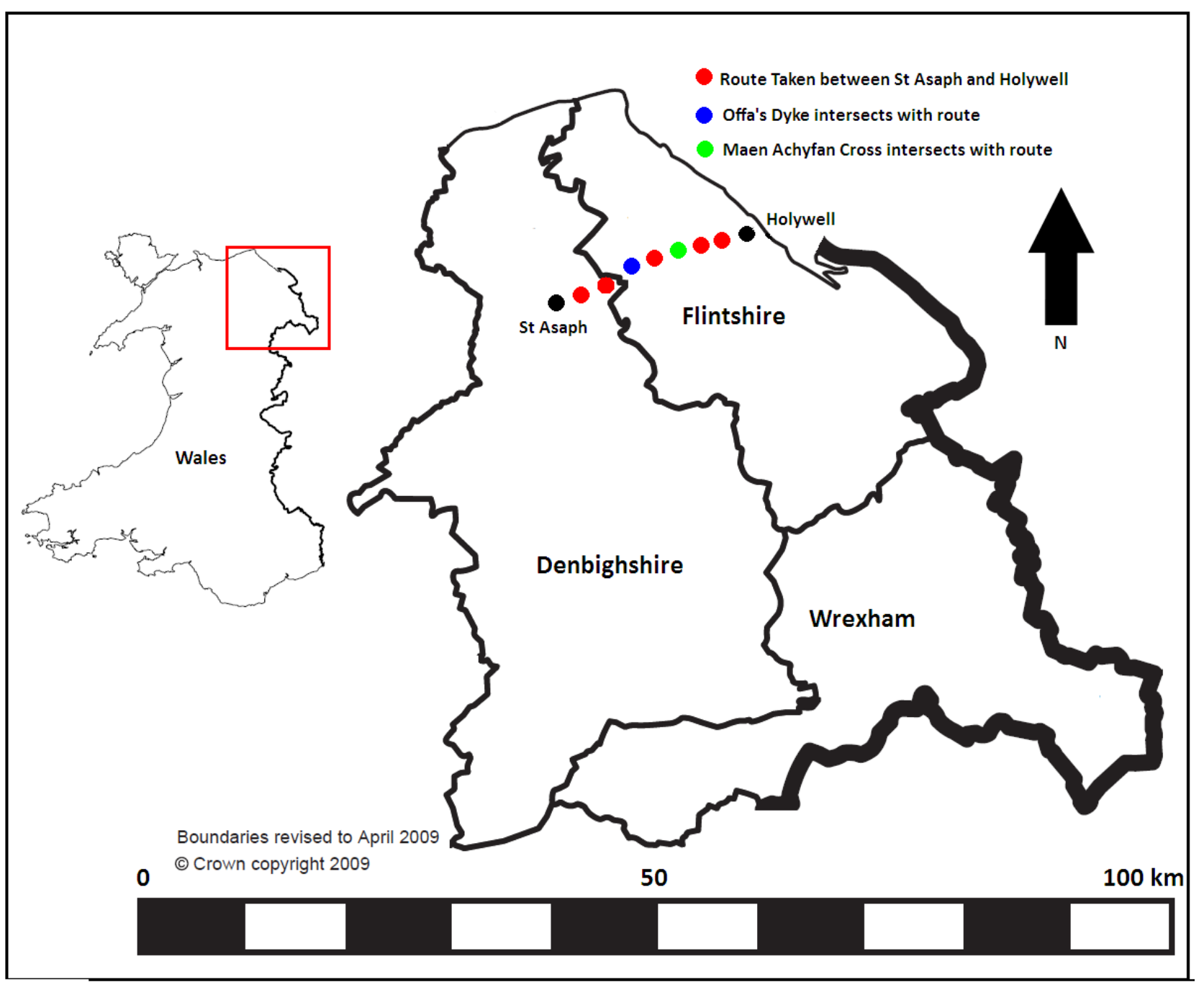

Figure 68. Route taken between St Asaph and Holywell. A detailed map is presented in Appendix B. Reproduced at source from the Ordnance Survey GB Coastline and Administrative Boundaries Map, additions made by author.

During the reign of Edward I in the $13^{\text {th }}$ century, many new towns were constructed in north Wales (mainly on the coast) including Aberystwyth, Beaumaris, Caernarfon, Caerwys, Conwy, Cricieth, Flint, Harlech, Holt, Newborough, Overton, Rhuddlan and Winchelsea. These fortified towns were not designed to be isolated from the rest of Wales, and would have been integrated into the Welsh road network in order to capitalise on, for example, coastal trading positions. In the case of Flintshire and Denbighshire, the itinerary of Edward I indicates several days spent at or near to Basingwerk Abbey followed by a day long journey to St Asaph (roughly 16 miles), which preceded another day's journey to Rhuddlan - all of which took place between the $18^{\text {th }}$ and $25^{\text {th }}$ August, 1277 (Gough, 1906, 74). There is also a large degree of movement by the king between Chester, Denbigh and Rhuddlan (especially between June 1282 and February 1283), indicating a competent road network in the area (Gough, 1906, 95). The itinerary records the king travelling from Chester to Rhuddlan (a distance of 24 miles) in a day, which given the normal retinue accompanying a travelling monarch further supports the idea of a serviceable route or series of routes between these two towns (Gough, 1906, 95). The itinerary of Gerald of Wales and his travels with Archbishop Baldwin 
reveal that travel between St Asaph and Basingwerk (and thereby Holywell) were certainly possible, and given that such an august visitor made the journey then it might be far from unusual. Gerald makes the following entry in his 'Itinerarium Cambriae':

'Many persons in the morning having been persuaded to dedicate themselves to the service of Christ, we proceeded from Ruthlan to the small cathedral church of Lanelwy [St Asaph]; from whence (the archbishop having celebrated mass) we continued our journey through a country rich in minerals of silver, where money is sought in the bowels of the earth, to the little cell of Basingwerk, where we passed the night.' (Thorpe, 1978, 139)

This also emphasises the abundance of ore and associated industry in Denbighshire and Flinsthire, as well as the accommodation possibilities for high status guests at Basingwerk; a theme addressed later within this chapter.

Another factor which supports the necessity of a comprehensive route network along the borderlands extending up into the broad Chester/Flintshire region are the unstable military and political conditions in the Marchlands. Hindle mentions that 'the continual Welsh political troubles ensured good roads throughout the Marches' (Hindle, 1976, 207-208). This is corroborated by several royal itineraries which indicate visits to towns along the Marchlands, as well as the Gough map showing a major route from Bristol leading up to Chester. Around the Welsh interior, Rees' 'An Historical Atlas of Wales' (1951) maps the turnpike roads, which although rather later than the period examined here, do tend to follow established tracks and roads. In the case of St Asaph and Holywell the turnpike road closely echoes the course of the modern A55, displaying in combination with the Roman road recorded here, a history of travel between or onwards from these two settlements. This is particularly important as St Winefride's influence was largely confined to the North East and Marchlands of Wales, and would have primarily received pilgrims from these areas who would have utilised these routeways between St Asaph and Holywell - a direction which my own route closely mirrors without sacrificing the landscape interaction which the A road has destroyed. 


\subsection{The Cult of St Winefride; Origins, Growth and the Shrine}

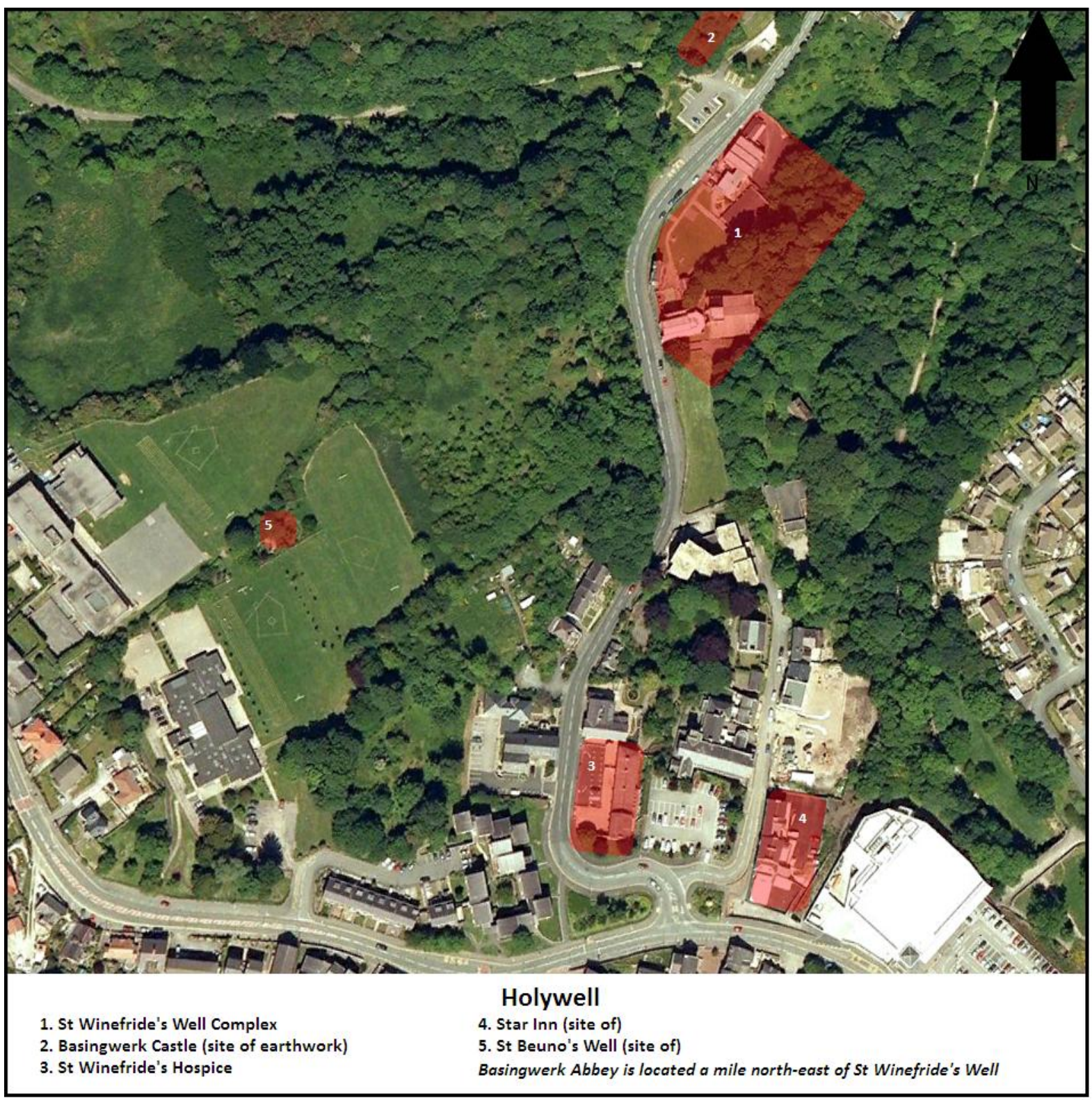

Figure 68. Map of central Holywell with relevant sites marked. Original satellite image reproduced from (C) 2011 Google.

Holywell has often been described as the 'Lourdes of Wales', deriving its name from an anglicised version of the original Welsh name 'Trêffynnon' ('Town of the Well'). It owes its fame and identity entirely to the Winefride cult; so it is unsurprising that the Medieval fabric of pilgrimage can still be identified in this small town (Adair, 1978, 164). We have a number of primary sources and itineraries for Winefride's Well and the surrounding region to draw upon to use in conjunction with archaeological evidence. The most obvious building in the complex of St Winefride's Well is the vaulted well house and bathing pool, but there also remains St Winefride's chapel, St James' church, 
and the Cistercian Basingwerk Abbey a mile to the north has a historical link to the well complex, especially in the custodial sense - being a source of accommodation for the wealthy, a haven for the sick and staffed by the monks who also maintained the well. The actual well has its origins as a (natural) spring, which according to religious legend sprung forth as a result of Winefride's decapitation and healing. The inner basin shown in Figure 70 below (without the vaulted canopy which is $15^{\text {th }}$ century) was the original construction used to capture the 'holy waters' as they emerged from the earth and flowed down the Greenfield valley towards Basingwerk Abbey and the Dee Estuary (Charles-Edwards, 1962, 22).

\section{St Winefrid's Well}

Whereas 'between 1138 and 1398 devotion to Saint Winefride was confined to North Wales and its Marches, and in South Wales to Euias and Erging', by the early $15^{\text {th }}$ century her cult had gained such attention over the Marchlands that the feast day of St Winefride became a major pilgrim centre throughout both England and Wales (Charles-Edwards, 1962, 1). The cult of St Winefride had gained so much spiritual currency, that the mother of the then ruler Henry VII - Margaret Beaufort commissioned at great expense the 'upgrading' of the well house into the intricate Perpendicular Gothic structure which can be seen today (Fry and Hulse, 1994). There are no records which relate as to what structure or open air arrangement surrounded the well prior to the building of this well house. The votive poetry or 'cwyydds' by lolo Goch ( $14^{\text {th }}$ century), and Tudor Aled (late $14^{\text {th }}$ to early $15^{\text {th }}$ century) seem to suggest it was primarily outdoors, with the spring bubbling up through the earth into the (now interior) basin, and then flowing down the valley. Goch tells us that the spring 'ran from the earth', and describes it as a 'clear shining river from the hillside, its water is seen from the meadows, as a wave above its gravelly bed' (Charles-Edwards, 1962, 8). He makes no mention of a well house or any sort of imposing structure, and that the spring and its subsequent stream or river was visible from the valley, which under the current series of arches, bathing pools and concrete is impossible. Below (Figure 69) the plan of the $15^{\text {th }}$ century extended well house displays the star-like design of the central bath, with the Perpendicular Gothic vaulting arching out from this central point and echoing this celestial shape above the actual basin. The purpose of this design may be to reflect similarities between Winefride and the Virgin Mary, a figure who was often equated with celestial imagery. This may be an example of a local virgin martyr being imbued with qualities and characteristics typically identified with Marian cults, through iconography and as a consequence of popularity. St Winefride was for the local population their virgin saint, and links with the universal Virgin cult were to be encouraged. This was the extension financed by the mother of Henry VII, Margaret Beaufort (Adair, 1978, 163). As at many popular shrines, pilgrims would have been guided around the basin by the monks from Basingwerk Abbey, while the outer pool (not pictured) was reserved for actual interaction and immersion (Adair, 1978, 163). To the east of the central basin survives a large statue of St Winefride, for votive offerings of candles and prayers as the pilgrims circulated the well house chamber. Visible beneath the waters in this central basin is the stone upon which St Beuno is said to have stood whilst saying farewell to St Winefride, and was an additional feature of reverence for the laity. Medieval carvings in amongst the vaulting show pilgrims being carried on the backs of others, suggesting that the sick were carried into the water in order to cure them (Adair, 1978, 164). 
St Winefride's chapel sits directly on top of the well house, constructed in the $15^{\text {th }}$ century at the same time as the well house, and was the recipient of many votive gifts: 'In 1439 Isabel, Countess of Warwick, gave her gown of russet velvet to deck the image of the Saint in the chapel at Holywell. So valuable were the offerings at Holywell that the chapel was not destroyed by Henry VIII but leased to William Holcroft' (Charles-Edwards, 1962, 4). The Anglican church of St James which lies directly next to St Winefride's chapel and well house is a $18^{\text {th }}$ century rebuilding of a $7^{\text {th }}$ century church founded by St Beuno, and originally dedicated to St Winefride. As patron of pilgrims, St James is a highly appropriate dedicatory choice. There is a well site to St Beuno up in the valley side adjacent to the road leading down to Winefride's Well. This is an overgrown and untended site with little or no stonework remaining, being essentially reduced back to its original spring form, and the

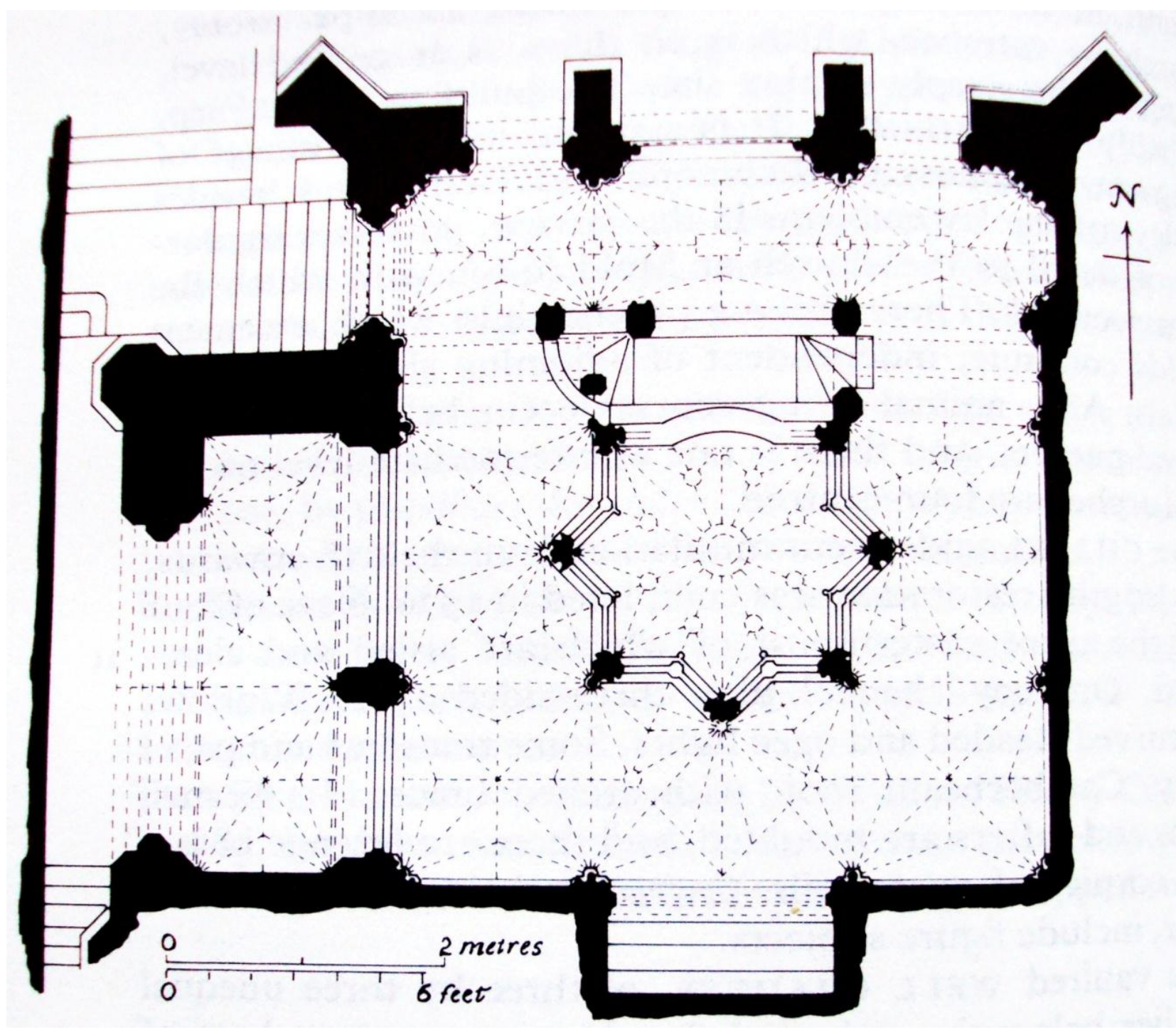

Figure 69. Plan of St Winefride's Well. Reproduced from Hubbard, 1986, 372 


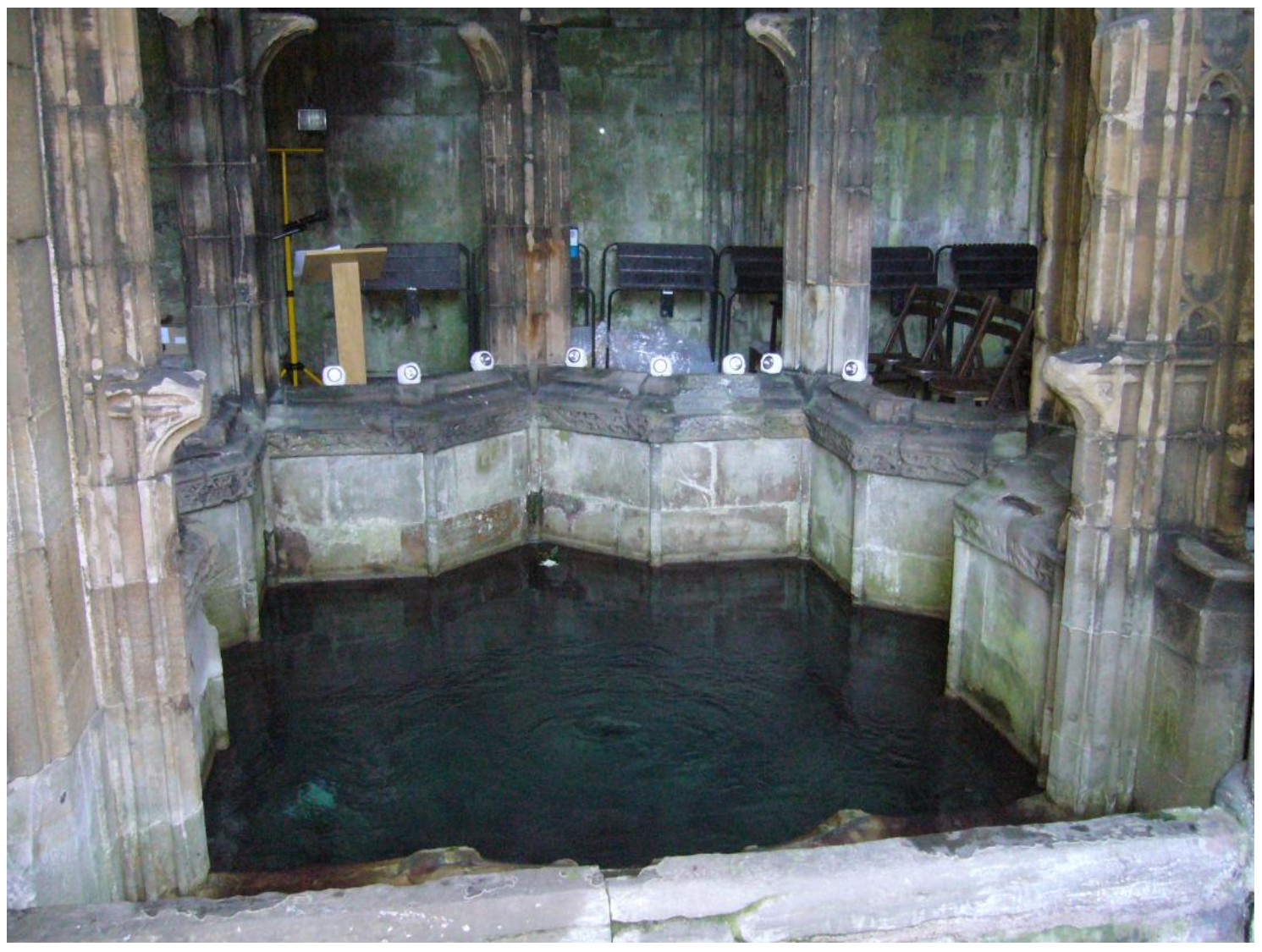

Figure 70. The inner original basin at St Winefride's Well. Photograph taken by author.

surrounding estate is known as 'Beuno's gardens'. According to the Flintshire Churches Survey, 'the church is said to have been founded by St Beuno in the $7^{\text {th }} \mathrm{C}$ and dedicated to his niece, St Winefride. The 'Churche of Haliwell' is first recorded in a documentary source in 1093, when the wife of Hugh Lupus, Earl of Chester, added the church to her husband's previous bequest to the monks of St Werburgh's at Chester.' (http://www.cpat.demon.co.uk/projects/longer/churches /flint/idxflin.htm)

\section{Basingwerk Castle}

Also overlooking the well is a modest earthwork known as 'Basingwerk Castle' or 'Holywell Castle', and is of Norman origin with a history spanning five centuries. Originating as a frontier stronghold at the northernmost end of Watts Dyke, this timber and earth construction was destroyed at some point prior to 1155 during the reign of King Stephen. In 1157 Henry II rebuilt the castle during his stay visiting St Winefride's Well. After being captured by Dafydd ap Owain during Henry II's failure to advance beyond the Berwyn Mountains, it was re-captured, burnt and rebuilt by Ranulf III, Earl of Chester, to protect the pilgrims arriving at the Well. This role was fulfilled until after twice changing ownership it was made strategically redundant by the construction of a stone castle at Flint by Edward I - however it was likely that it was still used informally as a deterrent to thieves and bandits wanting to prey on pilgrims (Lewis, 1849, 431). A legend has grown up around this construction, that it sprung from the earth by the hand of St Werburg (patron saint of Chester) to protect a pilgrim in danger from the Welsh. Pennant records that 'The first notice I find of it is in the life of St Werburg, by Bradshaw, who informs us that Richard, on his return out of Normandy, where he had been 
educated, began his reign with an act of piety. He attempted, in 1119, a pilgrimage to the well of St Wenefrede; but, either in going or returning, was attacked by the Welsh, and obliged to take shelter in Basingwerk. He applied to St Werburg for relief; who miraculously raised certain lands between Flintshire and Wiral, and thus gave means to his constable to pass to his assistance: which sands, from that time, were called The Constable's Sands.' (Pennant, 1796, 192) Another site of interest is the track leading past Basingwerk castle to the well complex. Its name 'Holway' may be a corruption of 'Hollow way', and it is certainly sunken in comparison to the ground around it. This may be the result of erosion due to heavy pilgrim traffic using a route favoured due to the protection offered against thieves by the 'castle'.

Inns

Pilgrims arriving at Holywell would have stayed either in or around the town, with the wealthier visitors lodging at Basingwerk Abbey as guests of the Abbot, a mile north-east down the Greenfield Valley (Lewis, 1849, 78). During the $14^{\text {th }}$ century the parish priest is recorded as planning to open a hospital for sick pilgrims during their anticipated curative stay in Holywell, however, there is no mention of hospitals in Denbighshire or Flintshire by the time of the Reformation (Knowles and Hadcock, 1953). The majority would have taken lodgings at one of the many inns which opened in response to the steady influx of visitors. The current guest house for pilgrims (run by Bridgettine nuns) occupies the site of a former inn (the 'Cross Keys', no doubt a reference to St Peter) which was previously the St Winefride's Convent, and another example is the Glan Yr Afron pub a mile south east of Holywell, which has been open since 1559 (Adair, 1978, 164). Catholics are said to have bought both The Cross Keys and also the local Star Inn so that mass might be said in them. During the Reformation and subsequent anti-Catholic years the justices fined inn keepers for failing to report the names of pilgrims lodging with them, pilgrimage being seen as a papist activity (Adair, 1978, 164).

\section{Basingwerk Abbey}

Some of the most valuable information recording a pilgrim presence in the local landscape comes from royal itineraries, and in the case of Holywell, we have evidence for visits from the following Medieval monarchs; Richard I in 1189 (Alexander, 2002, 264); Edward I's itinerary indicates a visit to Basingwerk (and presumably St Winefride's Well) on the $15^{\text {th }}$ March 1283 (Gough, 1906, 153); Adam of Usk records Henry V visiting in 1416 to give thanks for Agincourt (Given-Wilson, 1997, 263); and the Welsh poet Tudur Aled records a visit by Edward IV, who placed some earth taken from beside the well onto his crown (Charles-Edwards, 1962, 26). By the time of the Reformation the well was such a popular destination that the annual revenue at the Well was f157. 15s. $2 d$ (Lewis, 1849, 134). During the reign of Henry $\mathrm{V}$, Pope Martin $\mathrm{V}$ 'furnished the abbey of Basingwerk with pardons and indulgences to sell to the devotees', which was a sure method to boost revenue and reputation for any pilgrim site (Lewis, 1849, 436). This also shows that the monks of Basingwerk were not only involved in the practical care of the well; they were also involved in the commercial aspects. 
Founded in 1131 by Ranulph, Earl of Chester as a cell for Cistercian monks, Basingwerk Abbey was in all probability the first example of the order's settled presence in Wales (Lewis, 1849, 131). Prior to this a small group monks attended a chapel attached to Basingwerk castle before Bishop Tanner instigated the construction of the Abbey. The building lies at the mouth of the Greenfield Valley, as the waters which flow down from St Winefride's Well drain out into the Dee Estuary. During the building of Flint Castle in the $13^{\text {th }}$ century, Edward I used Basingwerk Abbey as his base and rewarded the monks for their hospitality and loyalty to him by granting them special privileges. Crucially, in 1240 local prince Dafydd ap Llweyln gave the church and shrine of St Winefride's Well to the Basingwerk monks, which boosted their reputation and influence. At its height the abbey is recorded as owning land supporting over two thousand sheep, and substantial territories in England. The abbey was fortified, received an annual income of around £150, and had a dependent, the hospital of St Mary Magdalene at Coventry (Knowles and Hadcock, 1953, 104). The abbey also had a small cell at the nearby Maen Achwyfan (which translates to the 'Stone of Cwyfan' but is also known locally as the 'Stone of Lamentation'), a theme explored later in this chapter. We know little of the high status guests who enjoyed the Abbot's hospitality, however both Tudur Aled and Guttyn Owen both sing praises of the 'extravagant hospitality' of the Abbot Thomas Pennant in the $15^{\text {th }}$ century (Jones, 1926, 169). The abbey was destroyed during the Dissolution, but was in its twilight years by this point; only six monks remained by the time the destruction began. 


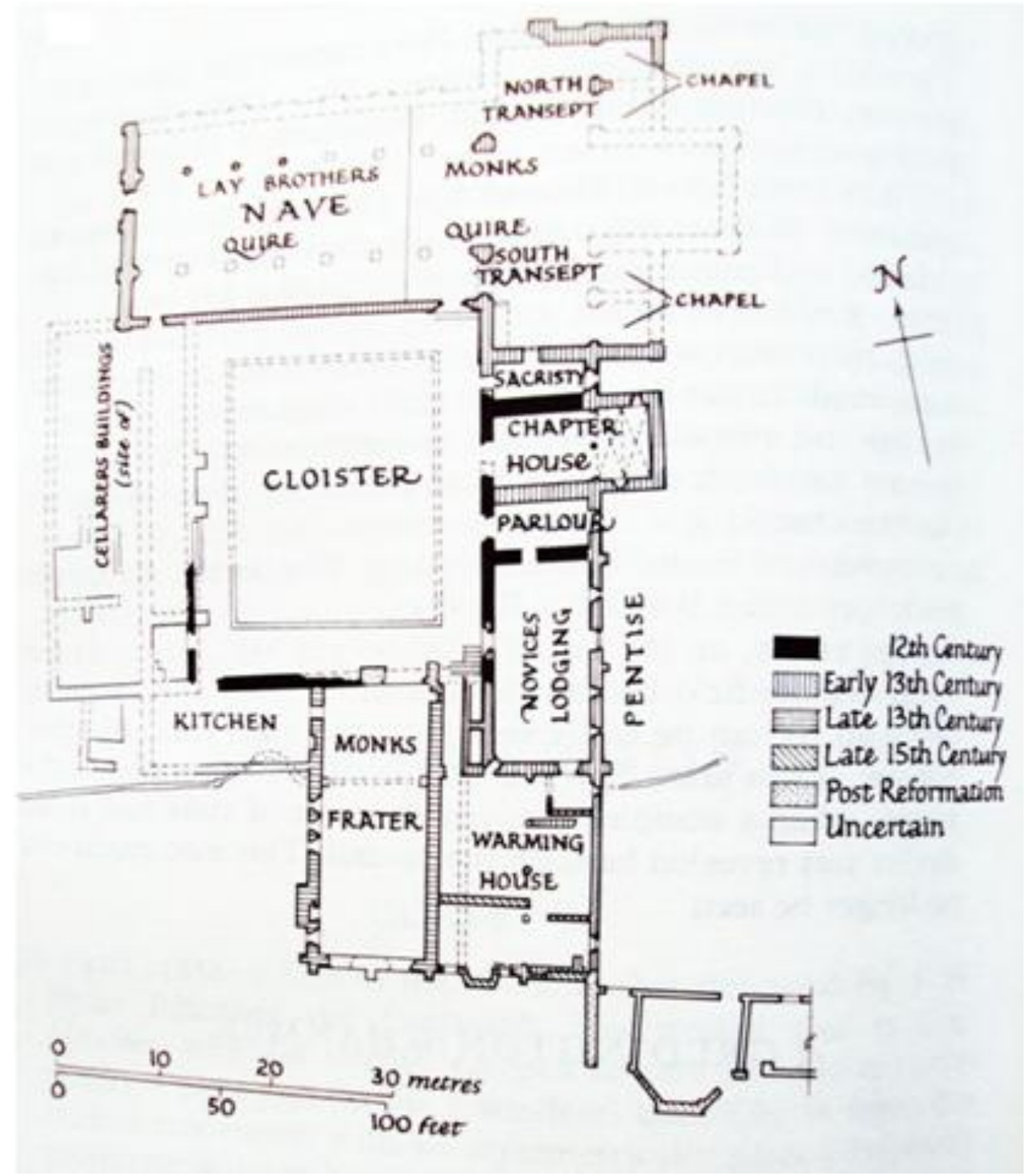

Figure 71. Plan of Basingwerk Abbey. Reproduced from Hubbard, 1986, 354.

The link between Basingwerk and St Winefride's Well is more profound than simple ownership during the $13^{\text {th }}$ century. On a practical level the waters flowing from the well helped to sustain the monks practically, as they powered the Abbey's corn mill (and later helped sustain local industry) thus literally giving the monks their 'daily bread'. However the spring and river also provided a spiritual link between the two sites, as the river may have been seen as a sacralising process for the whole valley. The waters of the well were said to have been born from a miracle, and consequently it could be said that their constant flow through the Greenfield valley was seen as a divine source constantly blessing the landscape, and an ever-present reminder of miraculous events. This hypothesis is expanded upon later in section 5.8. 


\subsection{The Archaeological and Etymological Remnants of Pilgrimage Between St Asaph and Holywell}

\section{St Asaph}

Travels from St Asaph to Holywell were not uncommon, as shown by Gerald of Wales' itinerary and the Welsh Medieval route network evidence from Edward I's travels. The 'Deva-Varae' Roman Road leads broadly from St Asaph to Greenfield Valley, which historically has seen many travellers passing through the region towards the Dee Estuary and Chester. St Asaph lies to the west of Holywell in the hundred of Rhuddlan, and is equally as renowned (although not as popular with pilgrims) for its cathedral, the smallest in Britain. The town is the ecclesiastical hub of Denbighshire, and the cathedral was the focus of the church in North East Wales during the Medieval period (Lewis, 1849, 42). The site occupies a prominent position in the landscape, sitting on the hill at the top of the Medieval High Street. It was originally a monastic complex established by St Kentigern in the $6^{\text {th }}$ century who chose a promising young monk called Asaph to succeed him and whose reputation for piety and miracle working continued posthumously, gaining him patrimony of the town (Lewis, 1849, 42). St Asaph's name can also be found in several points in Denbighshire and neighbouring Flintshire, at Llanasa ('Asa's Church'), Pantasa ('Asa's Hollow'), Ffynnon Asa ('Asa's Well'), Onen Asa ('Asa's Ashtree').

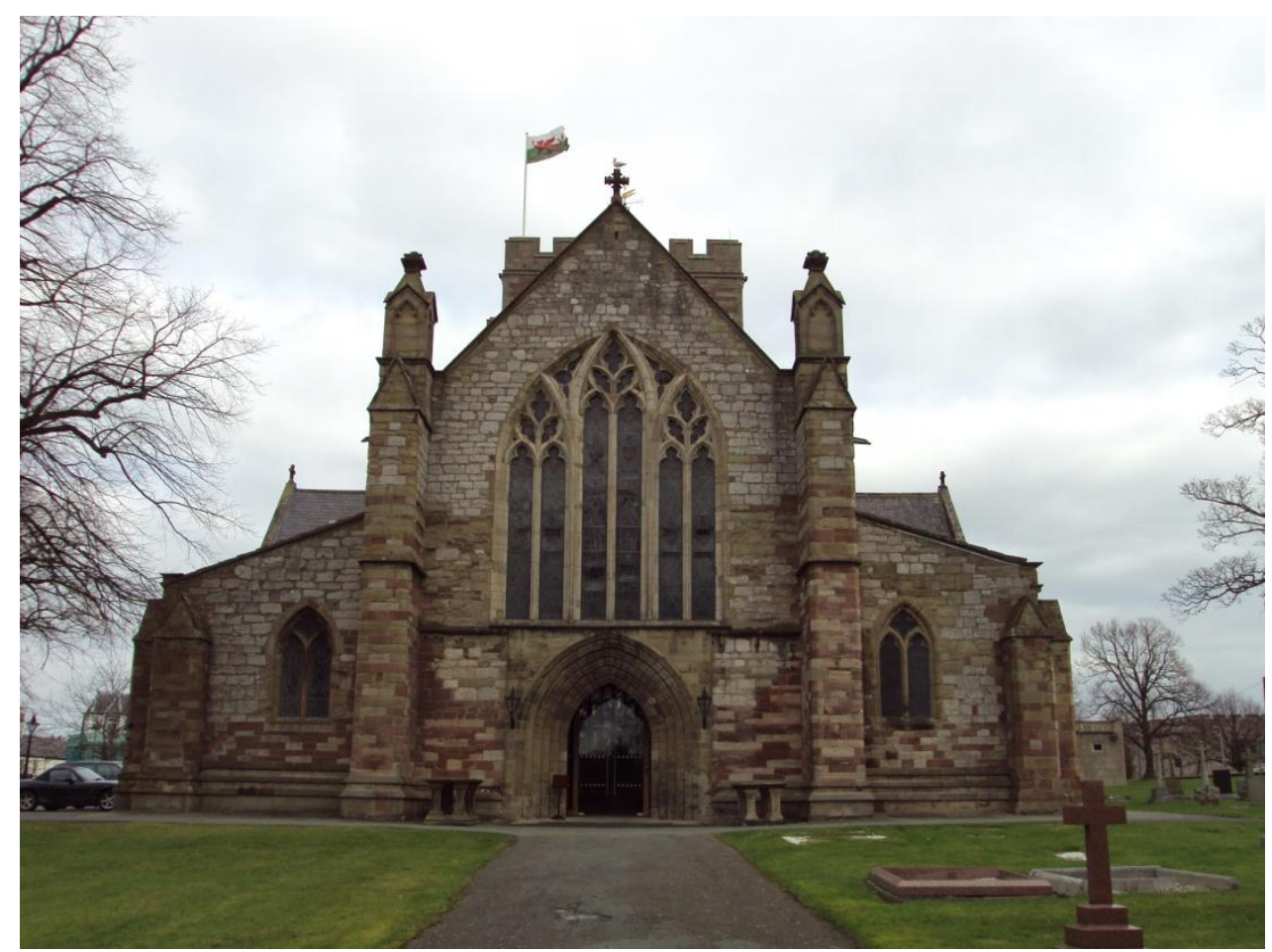

Figure 72. St Asaph Cathedral (east facing). Photograph taken by author.

The cathedral (Figure 72) stands on the site of the original wooden church constructed by St Kentigern in the mid $6^{\text {th }}$ century built to serve the monastic community which grew up around him. A crucial reference to the status of the town of St Asaph and its monastic population is supplied by the 'Vitae St Wenefrede' ('The Life of St Winefride'), where it states that 'St Asaph should be a place of 
great Resort, and a kind of University, where, amongst other inhabitants, there dwelt 965 Monks, 300 of which looked after the Cattle and the Plough, and 300 more were busied in the Offices of the

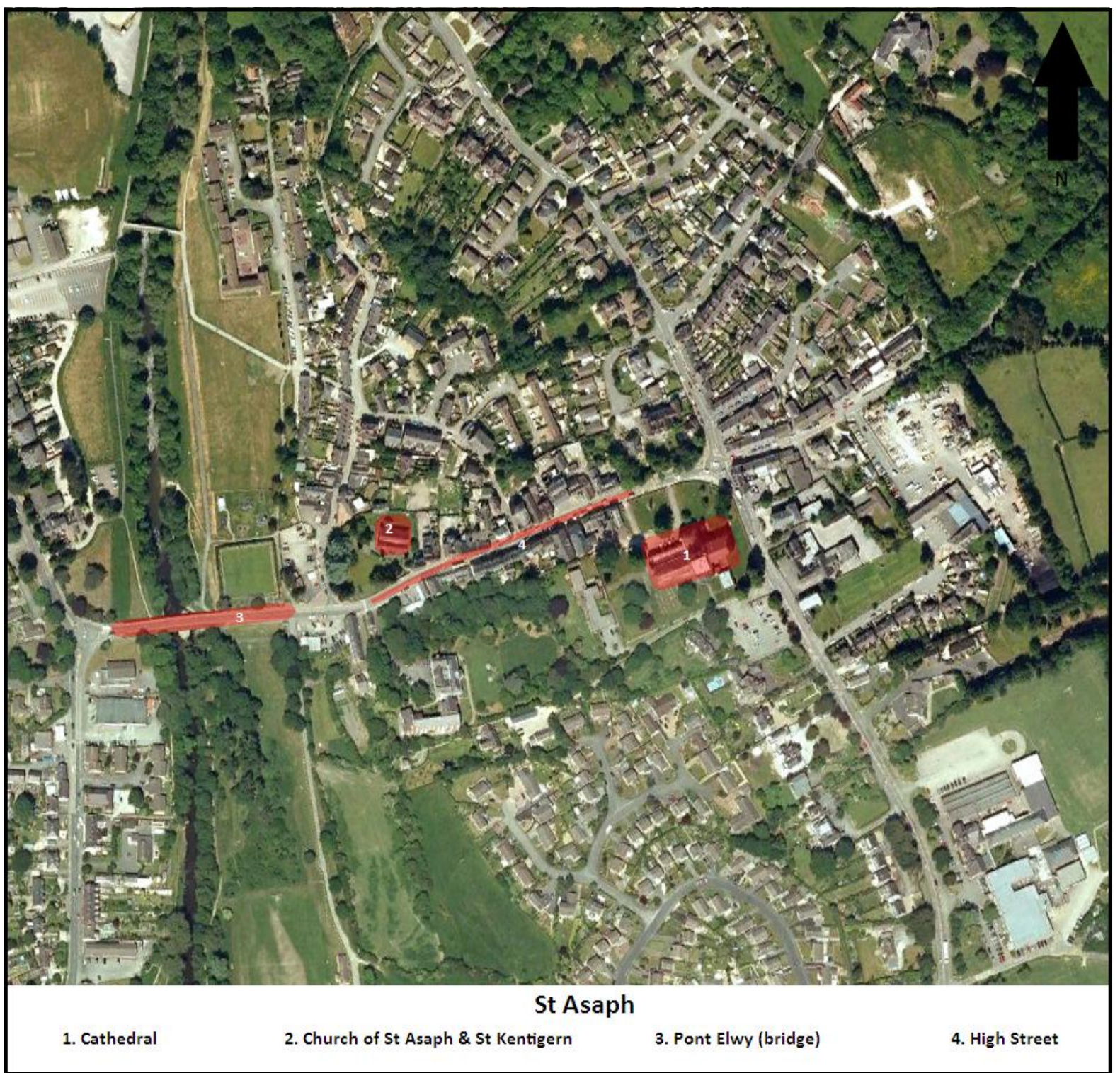

Figure 73. Map of central St Asaph with relevant sites marked. Original satellite image reproduced from (c) 2011 Google.

Monastery, and in providing diet and other Necessaries for the rest: and the remaining 365 students and priests.' (Fleetwood, 1713, 27) This monastic complex existed until the beginning of the $9^{\text {th }}$ century, when the monks were dispersed, although their lands remained under the jurisdiction of the see. During the early $11^{\text {th }}$ century the cathedral was rebuilt in stone through the combined wishes of King Ethelred and the Archbishop of Canterbury in an attempt to conciliate with the Welsh laity - however despite these efforts the locals expelled all Saxon ecclesiastics shortly after and were openly hostile to them (Lewis, 1849, 43). This construction was burnt to the ground by Edward $1^{\text {st }}$, 
and the present building dates from this period of the late $13^{\text {th }}$ century. This rebuilding was strongly urged by the Archbishop of Canterbury and by 1281 the relics of St Asaph had been moved from Llanasa (a small parish in the north of Flintshire, where St Asaph's relics had rested since his death at the start of the $7^{\text {th }}$ century,) to the newly built stone cathedral (Lewis, 1849, 44). The money needed to finance the rebuilding and maintenance of the cathedral was raised in a variety of ways. Pilgrims were encouraged to visit the cathedral by the offer of indulgences, and were also persuaded to give alms towards the upkeep of the building. It is likely that St Asaph's remains were the chief attraction for visitors (and are mentioned by Edward $1^{\text {st }}$ in his letter to Pope Martin IV), as well as the Reliquary in which lay a copy of the Gospel of the Evengalthen (Prestwich, 1997, 208).

Entrance to the town of St Asaph is via two stone arched bridges, one of which crosses over the River Elwy bordering the town to the west, and another bridge to the East, built by Bishop Dafyyd in 1630 to cross the (now diverted) river Clywd (see Figure 74). The Pont Elwy was rebuilt in the $18^{\text {th }}$ century however its situation as the only (surviving) bridge across the Elwy providing access to St Asaph from the east suggests that the bridge has an earlier history. Similarly, the Pont Dafydd which provides access to the west of St Asaph from Rhuallt was constructed in the early $17^{\text {th }}$ century to carry travellers to and from the town. The bridge is wide enough to admit a horse-drawn coach, and was purposely built and cobbled for such transport, servicing a flow of high status travellers to and from St Asaph - which was to be expected as the cathedral was the focus of the Welsh church in the north east of the country.
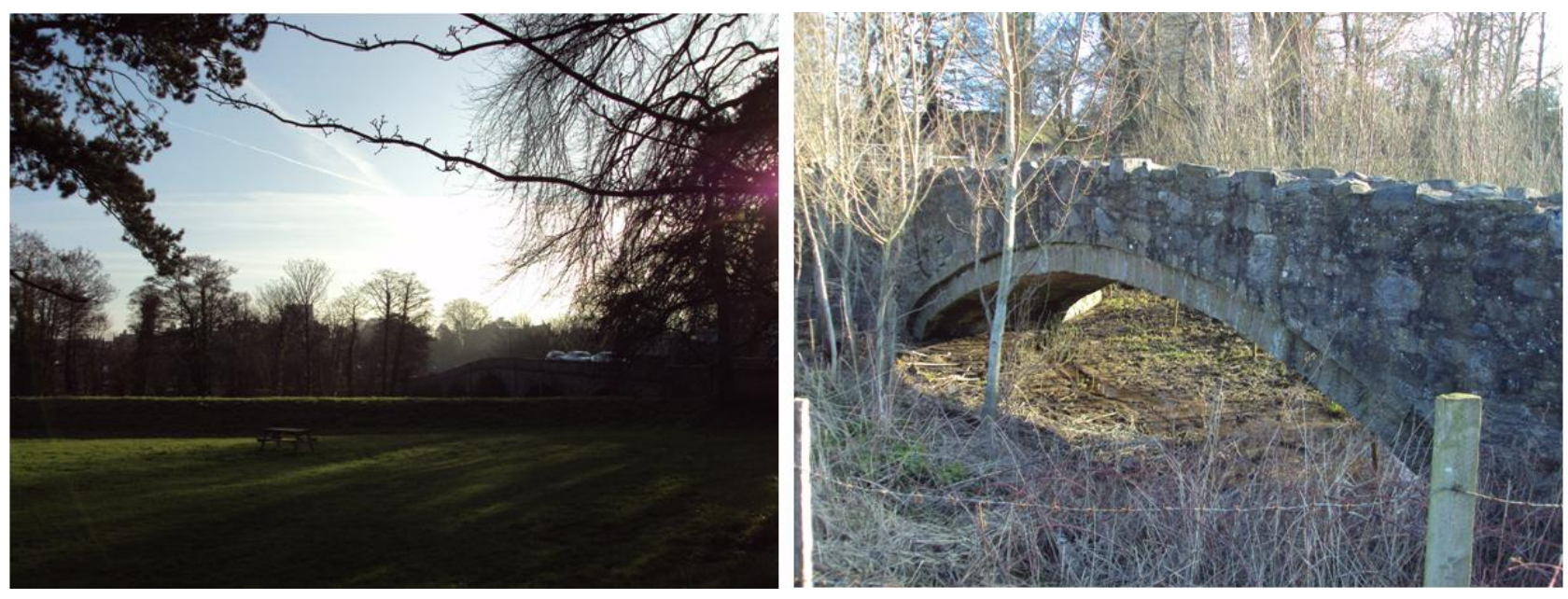

Figure 74. The view of the cathedral approaching Pont Elwy (left), and Pont Dafydd (right). Photographs taken by author.

Beside the Elwy bridge is a $13^{\text {th }}$ century church dedicated to St Asaph and St Kentigern, recalling the monastic origins of the settlement, which acts as a precursor for the visitor of the cathedral at the crest of the High Street. An interesting feature are the 'two parallel aisles, called respectively Eglwys Asaph and Eglwys Cyndeirn, St. Asaph's and St. Kentigern's churches', giving equal reverence to both the founding saint and patron saint of the town (Lewis, 1849, 48). This 
double-knaved church stands immediately opposite the Elwy bridge, and is visually arresting being the first building encountered after crossing the river.

Although now no longer visible, Samuel Lewis records in his mid $19^{\text {th }}$ century 'Topographical Dictionary of Wales', that near the river Elwy in the hamlet of Wigvair was 'Fynnon Vair, or "the well of Our Lady, " situated in a richly wooded dell.' The spring was surrounded by a stone basin, which discharged 'about one hundred gallons per minute: the water is strongly impregnated with lime, and was formerly much resorted to as a cold bath.' Lewis also records that adjacent to the well were the 'the ruined walls of a cruciform chapel, which, prior to the Reformation, was a chapel of ease to St. Asaph' (Lewis, 1849, 29). As mentioned above, St Asaph's etymological presence in the local countryside is rich, and it is highly likely that chapels of ease (small parochial chapels within a parish for those who cannot attend the main parish church) dedicated to him were present around the St Asaph area, given his importance and that of the town in the Welsh ecclesiastical landscape.

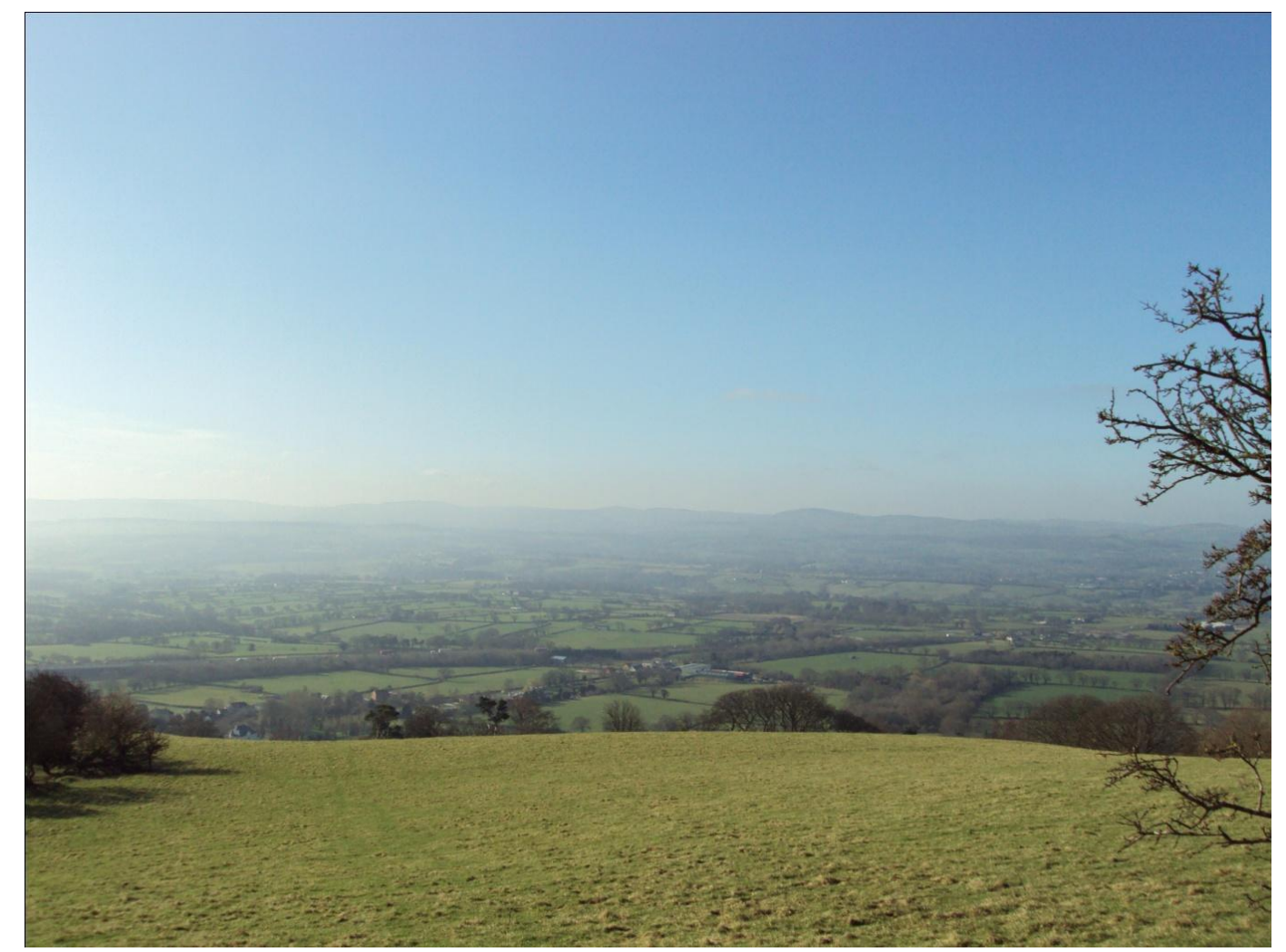

Figure 75. View from the remains of Offa's Dyke abutting Mynydd y Cwm, facing west into the Clwyd Valley. St Asaph cathedral is just visible in the centre of the frame. Photograph taken by author.

\section{Offa's Dyke}

Rising out of the fields a mile east from the Pont Dafydd and St Asaph cathedral, Offa's Dyke was constructed by King Offa of Mercia in the $8^{\text {th }}$ century to protect his kingdom's border from the Welsh tribes, and stretched along the Welsh Marchlands from Chepstow to Prestatyn (Fox, 1955, 4). It is 
recorded by the monk Asser in his late ninth century work 'The Life of King Alfred, where he writes 'His name was Offa and it was he who had the great rampart made from sea to sea between Britain and Mercia.' (Stevenson, 2010, 295) Much has been written about this impressive Mercian legacy, and this is not the place to analyse the history and impact of Offa's Dyke on the Welsh landscape. Instead I will detail the relationship between the pilgrim and the earthwork on a practical level below, and on a sensory level later in section 5.8. The point at which the path on what remains of Offa's Dyke dovetails with the pilgrim's progress from St Asaph occurs immediately after passing through Rhuallt and ascending Mynydd y Cwm, a hill in the Clwydian Range. The path up this hill to Offa's Dyke has 3 wells adjacent to it (with no apparent religious connections) and there are earthen tumuli on the crest of the hill. From this elevation one can see the Iron Age hill fort of Moel Maenefa, a few hundred metres to the south across the course of the Roman road and St Asaph Cathedral (see Figure 75 above).

\section{Maen Achwyfan Cross}

The next significant site the pilgrim would encounter - and a key site in the Medieval landscape of Flintshire - is the Maen Achwyfan (Figure 76 below). The largest free standing wheel cross in Britain, this monument is located a few miles east of Whitford village in a field locally known as Cwyfan's field. This cross is carved with intricate motifs which demonstrate both Celtic and Viking influences (Hull, 2003, 18). Maen Achwyfan was originally known as Maen Machwyfan, or 'the stone of Cwyfan's field' (Hull, 2003, 18). Cwyfan was a disciple of Saint Beuno who accompanied him to North Wales in the $7^{\text {th }} \mathrm{C}$, so this use of his name may suggest that the cross was erected on his frequent preaching spot, or is in some way closely connected to his activities. The parish of Llangwyfan in the south of Flintshire also bears St Cwyfan's name, tying his activities into the local landscape. At Montgomery in Denbighshire, there is a standing stone dedicated to St Beuno, and this is called the Maen Beuno. This may indicate a tradition to honour these highly local saints by marking their presence in the landscape with monuments where locals, who possibly felt themselves part of the saint's tradition and legacy, could come to make their devotions. It has also been suggested that the nearby Galli Fawr Grange whose remains are present in the south end of the field containing the Maen Achwyfan incorporated this cross into their worship patterns. Within this small field we have a microcosm of how these local saints are intimately connected both with each other, and with the landscape. Both Winefride and Cwyfan were closely associated with Beuno. The use of this cross by the small cell in outdoor worship demonstrates the reverence shown to Cwyfan in this area, as does the intricacy of the carving on the entire cross. The cell was dependent on Basingwerk and staffed by their monks - Basingwerk was also intimately associated with St Winefride's Well, which was a small well dedicated to St Beuno. Thus other links emerge between the saints which produce a community of local figures bound to their native environment. 


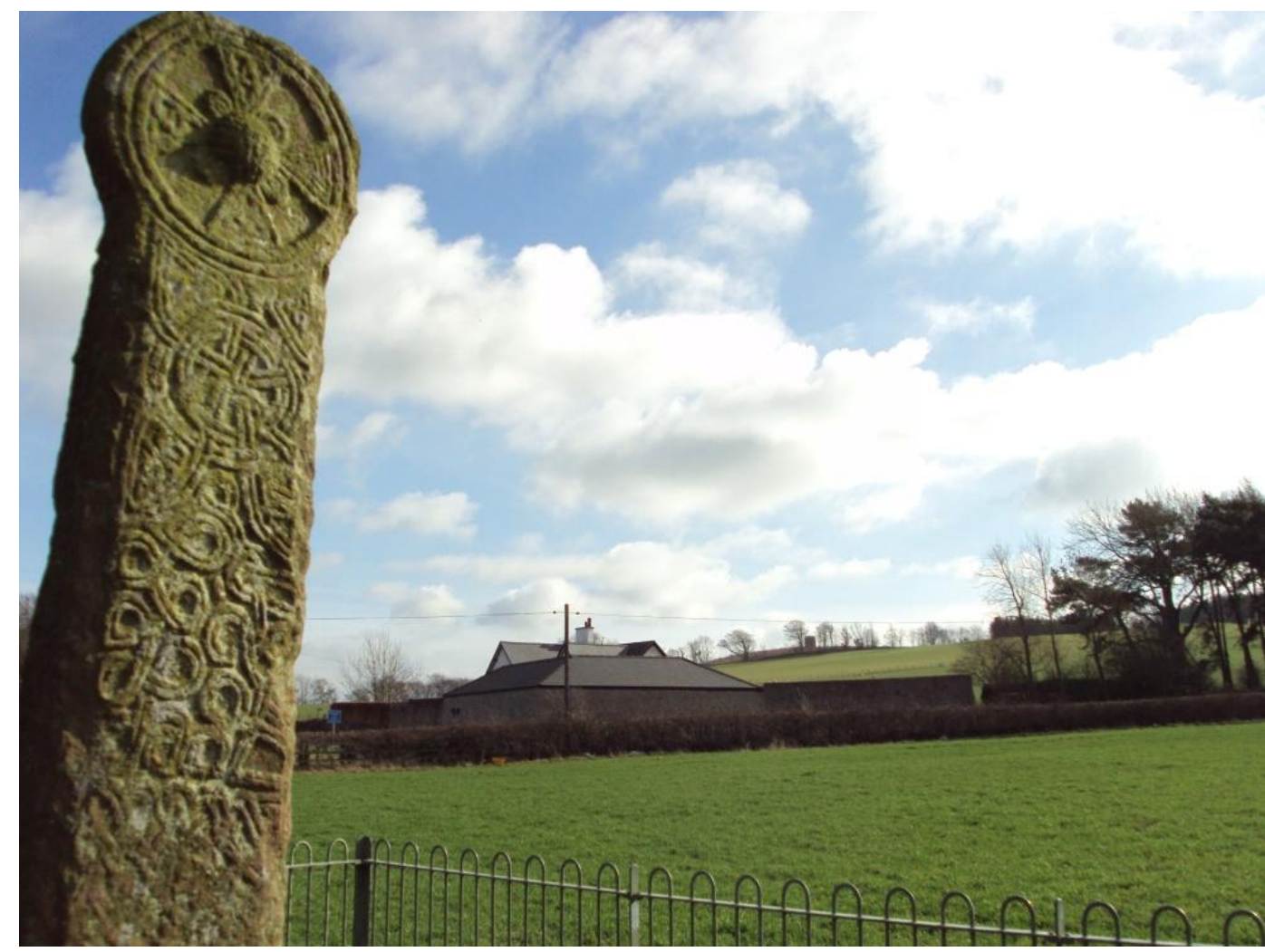

Figure 76. The Maen Achwyfan Cross with the Garreg Tower visible (centre). Photograph taken by author.

Visible from the Maen Achwyfan cross, and occupying the hill Coed y Garrag, the Garreg Tower is a $16^{\text {th }}$ century beacon tower which looks out over the Dee Estuary. Included in its panorama are Holywell/Greenfield Valley, Chester, Liverpool and even Snowdonia to the south west. Little is known about this monument save for its function as a coastal navigation and defence beacon (Lloyd, 1964, 153). However, according to Clwyd-Powys Archaeological Trust's Historic Environment Record the site has Roman origins as the location of a pharos or lighthouse (http://www.cofiadurcahcymru .org.uk/arch/index.html. However, this is debated by scholars. If indeed there was a structure on this site during the Medieval period, then for the pilgrim or any traveller the Garreg Tower site could have provided a convenient landmark by which to set directions, or survey and 'map' the remaining journey down towards Holywell.

\section{Whitford}

Situated in Whitford (or Chwitffordd one of the 'ancient parishes' of Flintshire) and visible from Coed y Garreg, the parish church of St Beuno and St Mary is first recorded as 'Widford' in the Domesday Survey however its dedication and alleged history of being founded by St Beuno himself would indicate an origin in the $7^{\text {th }}$ century. No structural remains which pre-date the $15^{\text {th }}$ century remain, however two six foot blocks of stone with incised crosses have been discovered in the churchyard, which pre-date the Norman period (Davies, 1958, 35). References to the church can be found in the Taxatio of 1254 (Norwich) as the Ecc[lesi]a de Flytford, and the Taxatio of 1291 (Lincoln) as Ecc[lesi]a 
de Chwytford (Thomas, 1874, 203). This would have been the final church the pilgrim encountered prior to arriving at Holywell, and the presence of St Beuno in the dedication may have given the church meaning within the pilgrim's journey, their destination being the site of perhaps his greatest miracle: the resurrection of his niece Winefride. 


\subsection{Pre-Reformation churches in Denbighshire and Flintshire: Their Dedications, Role in the Parish, and Relevance to Pilgrims}

St Winefride's 'locality' was significantly larger than many other local Welsh saints, and she also benefited from a hagiographical and familial link with another favoured saint, St Beuno (or St Mungo in Scottish dedications). Aside from the well complex deriving from her miraculous 'recapitation', the most significant high status sites bearing her image or name are her shrine in Shrewsbury Abbey (destroyed during the Reformation) and the cathedral seal of St Asaph. This seal (see Figure 77 below) depicts St Winefride in a abbesses' wimple, bearing a crozier in one hand and a reliquary in the other, with the reliquary resembling a design which was found at her shrine in Holywell (Gray, 2000, 35). Being iconographically tied to the powerbase that was St Asaph says much about her status as a miracle worker and in the hierarchy of local saints in the Welsh ecclesiastical landscape. It also illustrates potential links between the two sites of St Asaph cathedral and St Winefride's Well (albeit a non-hagiographical one), but that there was a connection between the two figures in the minds of the clerics who designed the seal and the laity, is highly probable. Portrayed in her capacity as an Abbess, the Winefride figure can be said both demonstrating both her life's work and her role after death, bearing both her crozier - caring for her flock when living and her reliquary - which wrought miracles and protected her followers posthumously, an important role in the eyes of the laity and especially the pilgrim.

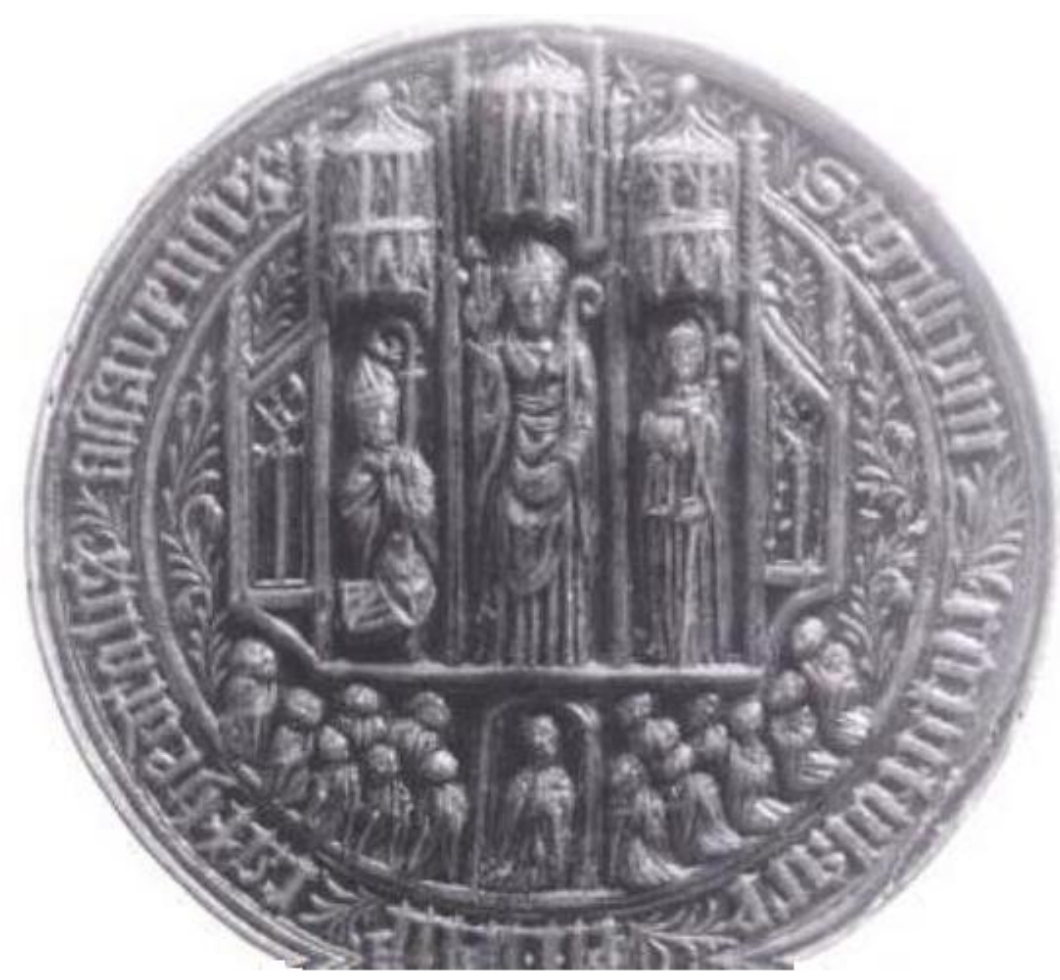

Figure 77. Seal of St Asaph Cathedral showing St Winefride with crozier and reliquary (featured standing on the right). Reproduced from Williams, 1993, 126. 


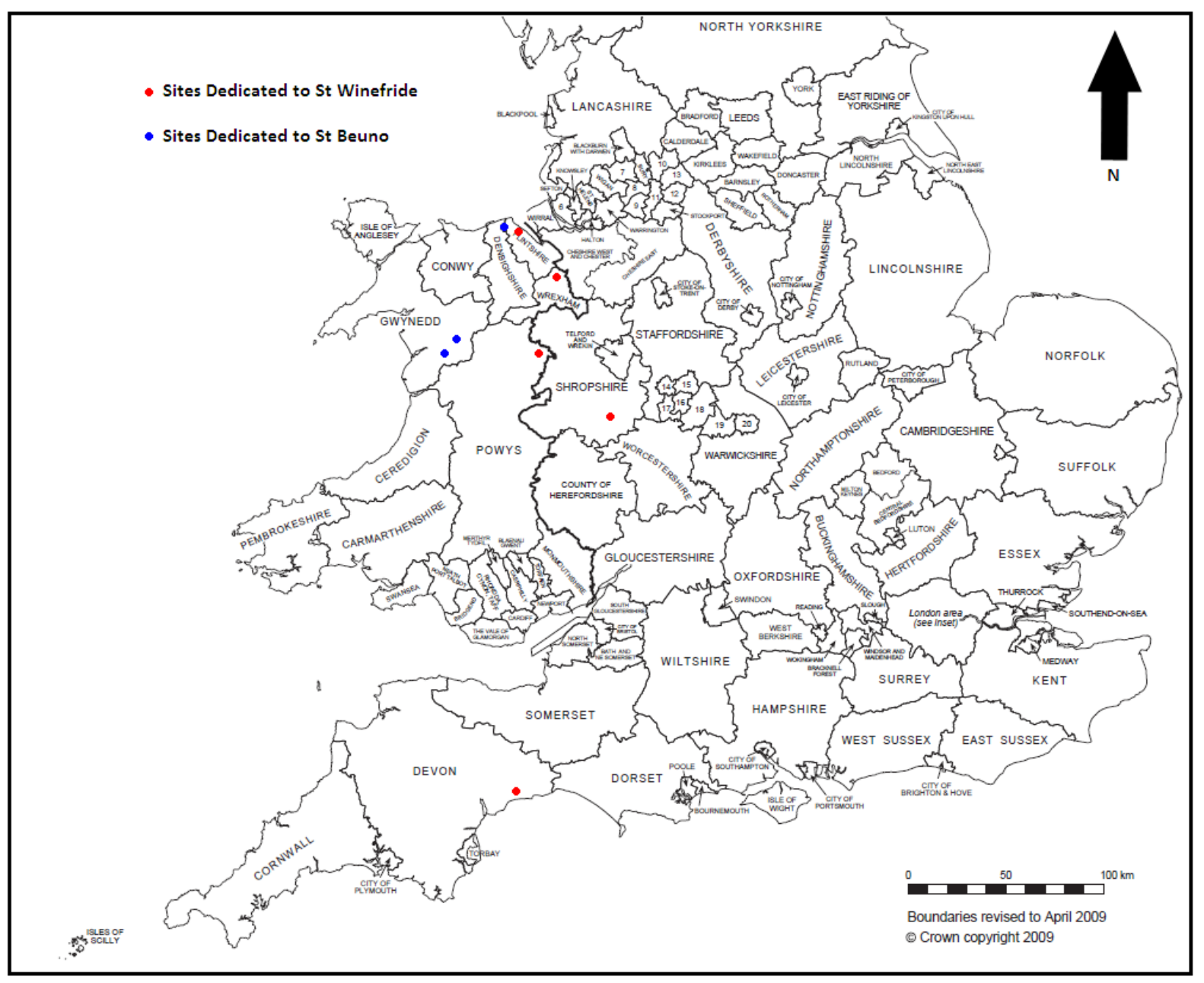

Figure 78. Map displaying distribution of church, well and spring sites dedicated to St Winefride and her uncle St Beuno. Redrawn from the Ordnance Survey GB Coastline and Administrative Boundaries Map.

Figure 78 (above) shows the distribution of 9 church sites bearing dedications to St Winefride, and also (due to his familial and hagiographical connection) of her uncle St Beuno. The northern Marchlands of Wales bear the most references to these two saints, and this is unsurprising as both figures originated in this area and had their ecclesiastical bases here. St Winefride's dedications seem to suggest a strong presence in the Marchland areas (with one anomaly in Devon), whilst those of her uncle follow areas where he was said to have worked miracles. St Beuno's pattern also reflects his movement within the Welsh landscape (primarily the north) and his interactions with Winifrede (Baring-Gould and Fisher, 1907, 214). As I have mentioned above, the road network around the Marchlands was particularly comprehensive due to the regular skirmishes between Welsh and English soldiers, and in Figure 78 we can see three Winefride dedications which effectively follow a relatively major route leading down from Holywell via Chester to Telford. Whether this signifies a favoured route to Holywell from the mid Marchlands is unclear, however Offa's Dyke follows a broadly similar path along the borderlands which may tie the earthwork in further to the Holywell cult. Her dedications also could be said to occupy the space between Holywell in Flintshire and Shrewsbury in Shrophire, whose Abbey possessed her relics until just prior to the Reformation. The Marchlands held a particularly comprehensive travel network, and 
consequently a series of Winefride specific site dedications between these two destinations could suggest travel between the two, or in a similar manner to the correlation between the movement of the remains of St Cuthbert around Northumbria and dedications in his name, the journey undertaken by monks with St Winefride's relics between her abbey in Gwytherin (Denbighshire), Shrewsbury (Shropshire) and back to Holywell (Flintshire) may have resulted in these dedications. This suggestion is given further weight by the well dedicated to her in Oswestry in Shropshire, where local legend has it that her body lay overnight during the journey to Shrewsbury and on that spot a spring emerged with curative powers (Rees, 1836, 295).

Figure 79 below shows the tally for dedications in surviving or recorded pre-Reformation churches in both Flintshire and Denbighshire, with ninety in total. As is to be expected (and is the case in most English counties) St Mary the Virgin is the most frequent dedication, followed by St Michael which is in keeping with the celestial hierarchy. What is immediately noticeable from these figures is the popularity and strong presence of the local or 'celtic' saint cults - 'celtic' being used here with reference to the saints' own origins in what are habitually referred to as 'celtic' regions (such as Wales, Scotland, Ireland, Gaul, Iberia). However the majority of these saints possess only a single dedication, typically in a settlement which incorporates their name into the settlement title. This is particularly true in Denbighshire, where 37 settlements have names with a 'Llan-' prefix followed by the Cymraeg spelling of the saints' names. For example, Llangollen has a church dedicated to St Collen and Llannefydd has a church dedicated to St Nefydd.

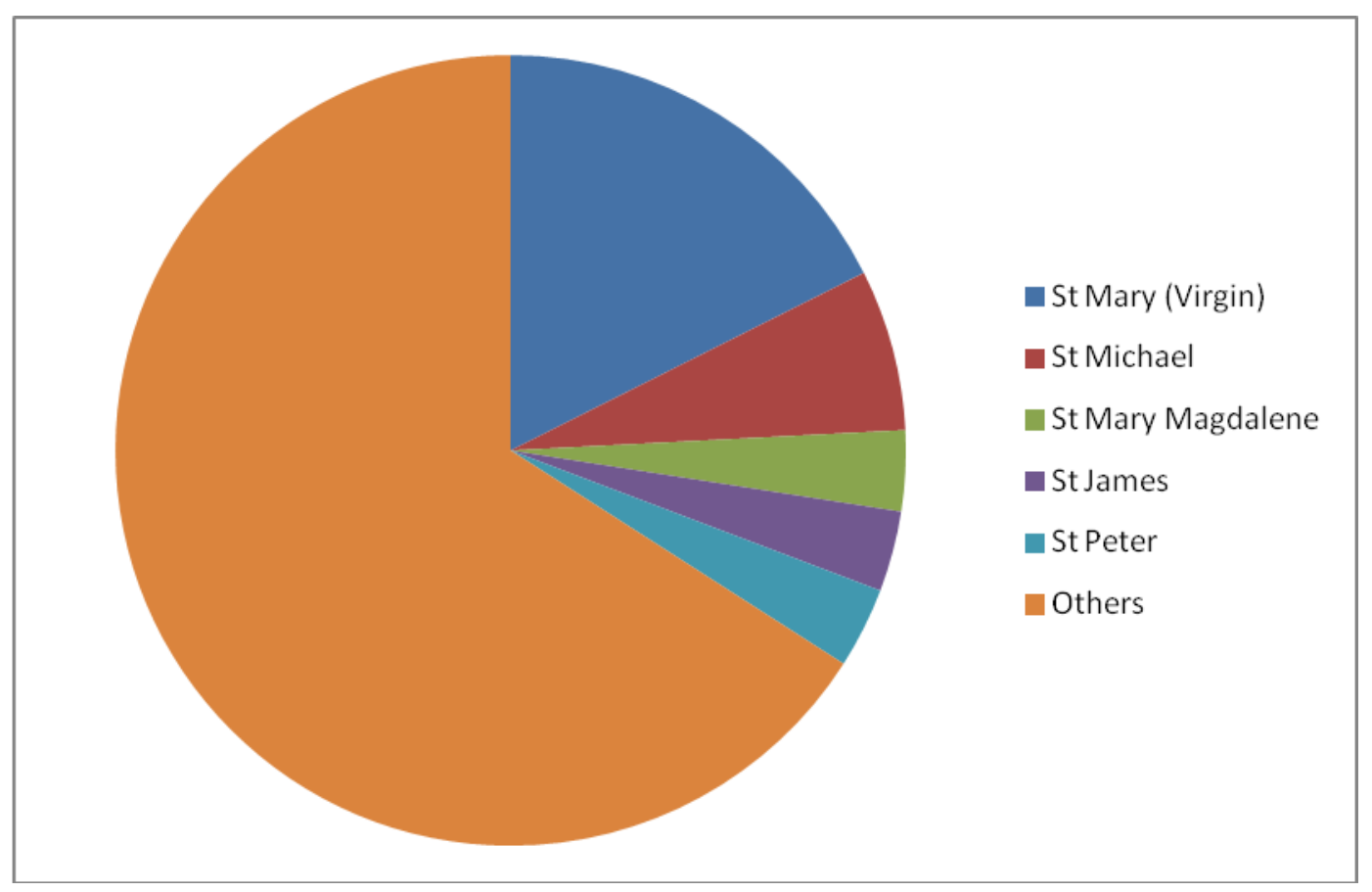

Figure 79. Chart Showing Frequency of Universal Saint Dedications in Surviving Flintshire and Denbighshire preReformation Churches. 


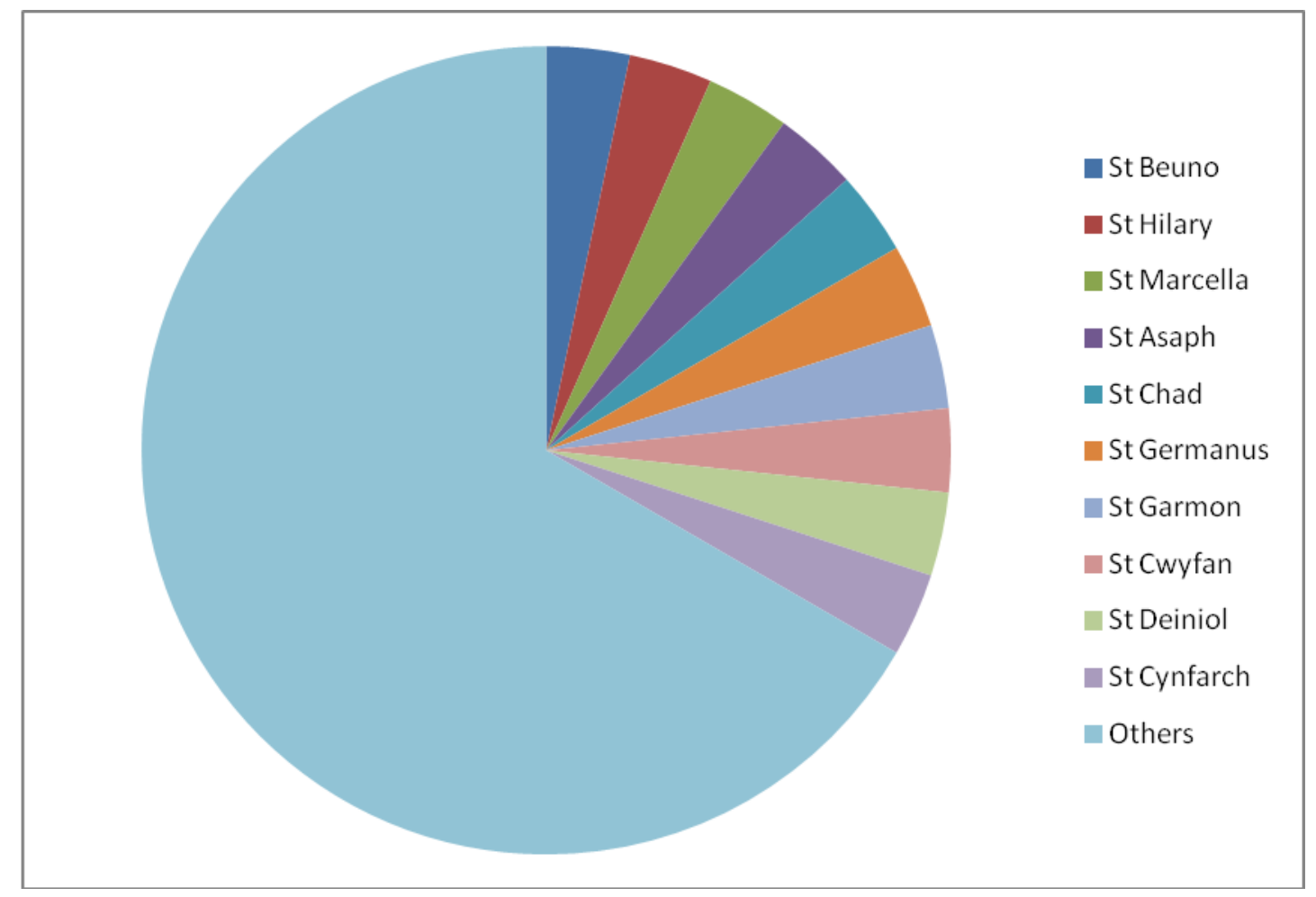

Figure 80. Chart Showing Frequency of Local Saint Dedications in Surviving Flintshire and Denbighshire preReformation Churches.

Interestingly, whilst throughout Wales 'David and Winefride are represented more frequently that other Welsh saints because they were recognised by the Roman church', St David does not feature in the pre-reformation church dedications of Flintshire and Denbighshire, perhaps due to a stronger sense of local identity than that of the kingdom, diocese or 'nation' (Gray, 2000, 39). Figure 80 above tallies these local saints whose dedications are recorded, and there are 60 non-universal saints dedications in total out of the 90 pre-Reformation church sites in Denbighshire and Flintshire. Out of these 60, the only saints who have a repeated mention (i.e. twice) are St Beuno, St Hilary, St Marcella, St Asaph, St Chad, St Germanus, St Garmon, St Cwyfan, St Deiniol and St Cynfarch. Most of these churches at 'Llan-' settlements either have a confirmed Early Medieval date, or are likely to derive from that period but can only be traced back to the 13th century via their mention in the 1254 Norwich Taxation. The presence of so many localised saint dedications emphasises their highly location specific nature, and supports the theory that spiritual localism was highly prized among the North Welsh laity. St Winefride's Well is an excellent example where this localism meets the universal saint cult, being intimately tied to the local landscape in terms of etymology and site dedications, yet receiving pilgrims from all destinations and statuses, including several monarchs. St Winefride does not appear in this multiple dedication chart due to the majority of her surviving sites being either wells or springs, a tradition to which her name is deeply attached, although it is possible that churches bearing her name were rededicated when so many were rebuilt in the 19th century with the creation of new parishes. 


\subsection{The Sensory Dialogue Between the Pilgrim and the Landscape from St Asaph to Holywell}

\section{St Asaph:}

In order to access St Asaph one must cross either the Clywd or the Elwyd rivers (Figure 81 below). The two bridges which span the rivers provide liminal experiences, not just physically (crossing a bridge leads the traveller from one area to another) but also in moving from the 'wild' and profane landscape surrounding St Asaph, into the town itself with its own patron saint, cathedral and history of sanctity. Consequently the Elwy and Clwyd act as natural border separating St Asaph from the rest of Denbighshire, which combined with the hill top and the cathedral's prominence, make the visual experience of moving towards or away from the settlement similar to that of Ely, the "holy island in the fens'. The cathedral tower only disappears from view when the traveller crests Offa's dyke outside of Rhuallt, and remains the most striking monument within the surrounding Clwyd Valley. Returning to St Asaph itself, the approach from the east involves crossing over the Pont Elwy, from which the High Street stretches uphill to the cathedral. Next to the bridge is the aforementioned $13^{\text {th }}$ century church of St Asaph and St Kentigern which serves to promote the cult of the eponymous town's saint and a reminder of the antiquity of the site on which the cathedral was built. In moving up the High Street, funnelled through the markets and shop fronts and progressing onto higher land (in a real and spiritual sense) this path up to the cathedral may have assumed a processional significance in the mind of pilgrim hoping to pray for a safe journey - in this instance to Holywell.

When approaching from the west, one must cross the Pont Dafyyd to enter the town. Now redundant due to the A55, it lacks its original context within St Asaph but it may have connected with Chester St leading up into the town, or a route which led directly up to the cathedral area. In either case the general sensory effect is the same: the cathedral is starkly visible against the skyline, and dominates the visual range of the traveller. The cathedral is the central focus of the town; whichever approach the traveller takes this monument is visible from all areas within the river boundaries, and being situated at the apex of the Bryn-Paulin hill it fulfils the role of both an ecclesiastical axis for the region and the spiritual centre of the town housing the relics of St Asaph. However the hill's height combined with the press of buildings makes it difficult for a pilgrim to read the landscape ahead; this is only detectable during the ascent towards Offa's Dyke, some 3 miles North East. 


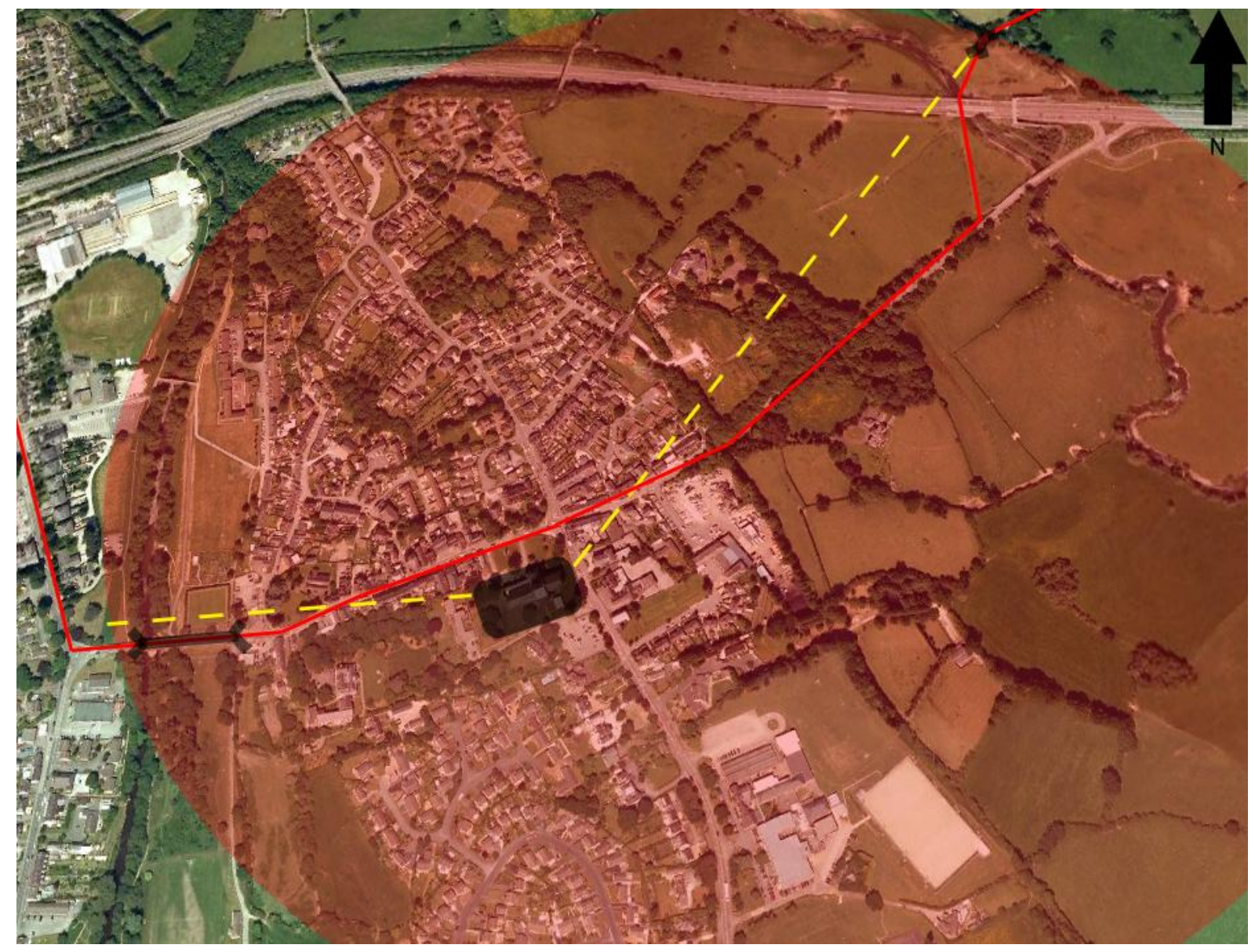

Figure 81: Map showing location of bridges in relation to St Asaph (black lines), the line of visibility (yellow) to St Asaph cathedral (black square) from the two bridges, and the distance one can see from the cathedral site (red shaded). Original satellite image reproduced from (c) 2011 Google.

\section{Offa's Dyke:}

Between St Asaph and Offa's Dyke are fields, villages and hamlets, which offer little in the way of transitional zones, opportunities for landscape legibility, thresholds, frontiers or even sanctuaries. The ascent and subsequent cresting of the Dyke however offers an unrivalled elevation in the landscape, leading the traveller out of the Clwyd valley into the borderlands between Denbighshire and Flintshire, and is therefore an important feature of the pilgrim's journey towards Holywell. The Dyke offers a commanding view of the Clwyd region (see Figure 82 below) including St Asaph cathedral and the Moel Maenefa hill-fort, as well as a swift means of exiting the Clwyd valley and Denbighshire. The earthwork's entirety may also have been used by a variety of travellers, not just pilgrims, as it provided a fairly comprehensive north-south route on elevated ground which would have connected the wayfarer with constant visual references and landmarks to confirm the selected route. However, with reference specifically to its role in the pilgrim landscape between St Asaph and Holywell, I would argue that it fulfilled two roles, as both a mapping tool and in its capacity to lift the traveller out of the valley. 
In relation to mental mapping the earthwork offers an opportunity unrivalled until reaching the $16^{\text {th }}$ century Garreg Tower (encountered later outside of Whitford) to assess the landscape both behind and ahead of the pilgrim, spatially orienteering the traveller within the landscape. St Asaph's cathedral is visible for the final time (see Figure 82), and this may be a point where brief prayer was appropriate. Within pilgrimage the relationship between religious monument and landscape is of great significance, acting as a visual reference point and (when bells are rung) as an audible demonstration of Christianity's dominance over nature in this area.

Offa's Dyke and its ascent also provide both a transition to higher ground and movement out of the Clwyd valley to the uplands of Denbighshire and Flintshire. This shift is foremost physical, the ascent being steep and rapid, and clearly visible to travellers as the valley drops away behind them. However there is also a mental aspect to the movement from lowland to upland, out of the Clwyd valley. The 'home' of St Asaph, is left behind along with the typical confines of daily existence, and the pilgrim travels out of their 'normal' sphere of experience into an area where they are the outsider, thus fulfilling the concept of a pilgrim as a temporal exile amongst society. Therefore the dyke is the first major feature of the landscape to actively carry the pilgrim out and into another area which may be unknown to them, and doing so in an elevated state by which they can observe the landscape in a manner closer to a divine perspective, with the Clwyd valley stretching out below.

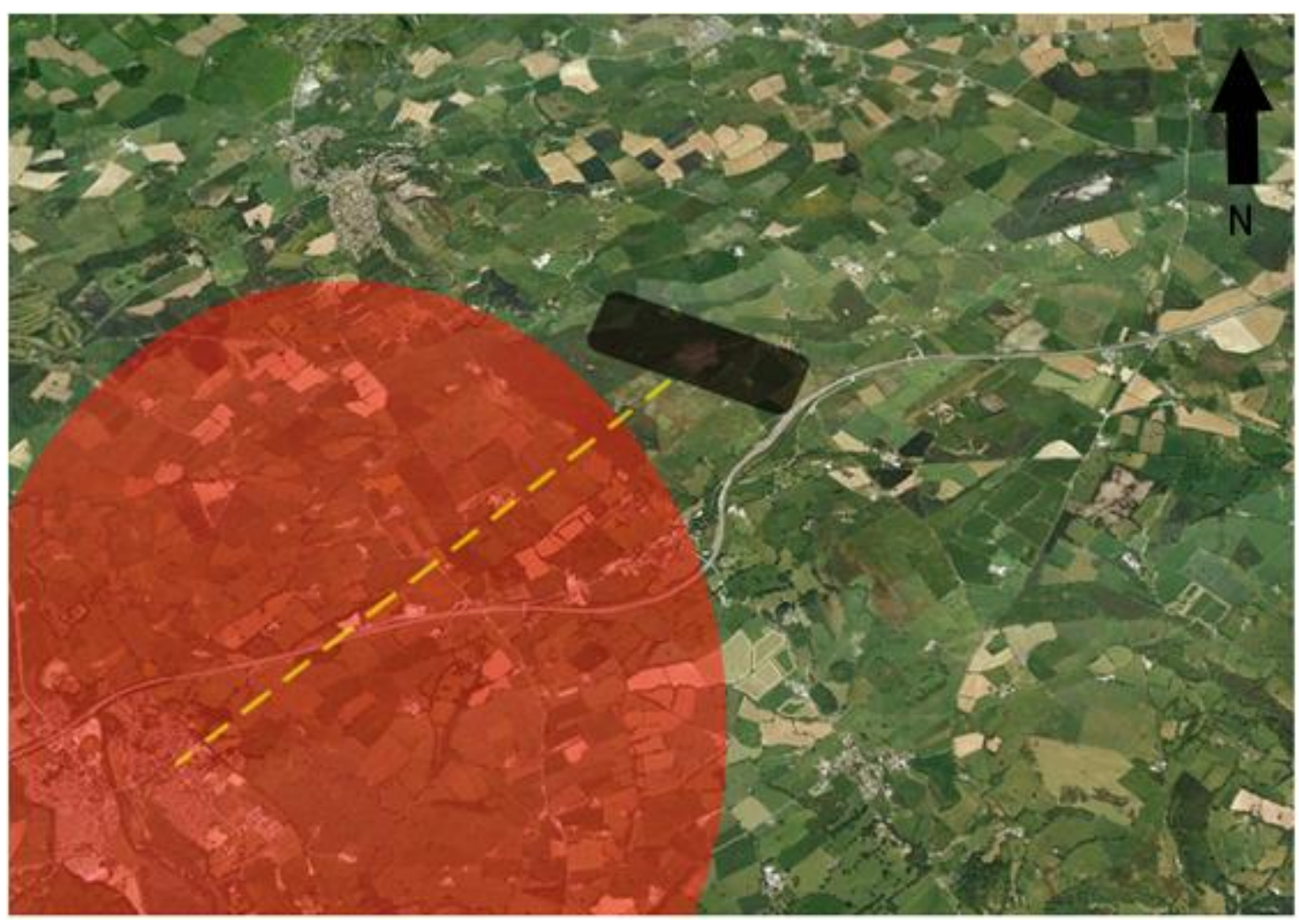

Figure 82. Radius of view from Offa's Dyke (dark lozenge) into the Clwyd valley (red shaded) with sight line to St Asaph cathedral (yellow). Original satellite image reproduced from (c) 2011 Google. 


\section{Maen Achwyfan (In Cwyfan's Field):}

Having left Offa's Dyke one gently descends into an agricultural landscape, reaching the Maen Achyfan free standing cross and the nearby hill atop of which is the Garreg Tower. The visual impact within the immediate landscape must first be considered. The cross, 12 foot high, is visible from the enclosure, and from any southern approach. The cross is a focal point within the landscape from which the terrain to the north gradually rises away. So visually prominent, it may have been used as a preaching cross (it is too richly decorated to serve as a mere boundary marker), or as the climactic site in a penance trail for the Cistercian monks living at the $12^{\text {th }}$ century chapel site a few hundred meters to the south (built by and dependant on Basingwerk Abbey). Whatever the true function of the cross, the pilgrim would certainly be struck by its size and beauty, its centralising presence within the immediate landscape, and the visual metaphor (combined with the chapel) of Christian dominance within the area.

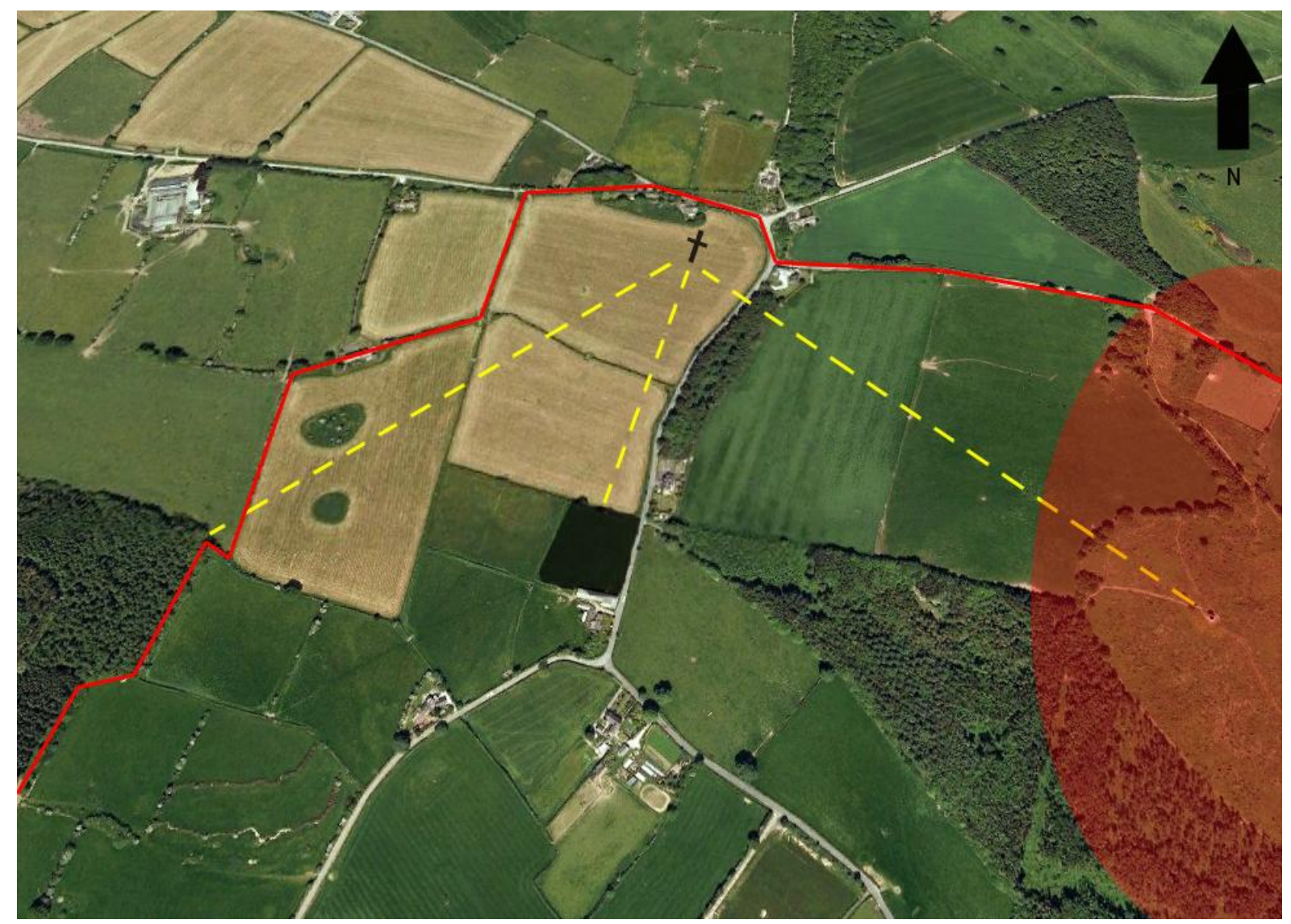

Figure 83. Map displaying visual interplay (yellow) between sites around and including the Maen Achwyfan Cross and the Grange (shaded black) near Whitford, Flintshire, and the panoramic expanse offered by the Beacon Tower (red shaded). The route taken is shown in block red. Original satellite image reproduced from (c) 2011 Google. 
Liminal experiences also occur when approaching Maen Achwyfan, as when one approaches a sacred monument (especially as a believer), there is a distinct transition between the profane space outside and the sacred area inside or immediately surrounding a site. This may be demarcated by a boundary (such as in a Greek sanctuary), wall, complex, or simply subjectively by the proximity of the pilgrim to the monument. The 'sacred space' at Maen Achwyfan may be determined by the field boundary in which the cross stands. The height of the cross also enables visual play between surrounding sites (see Figure 83). As previously mentioned, the purpose of the cross may be varied, however 100 years prior to the building of the chapel it would have certainly been a standalone site (likely devoid of connected built monuments), a preaching site for a local community, or a lamentation/commemorative site. The subsequent building of the chapel, and perhaps the beacon tower half a mile south east, introduces the possibility of lines of sight and use for monastic activities, and it is this chapel which lays the strongest claim to a spatial and spiritual relationship with the cross.

\section{Coed y Garreg:}

The aforementioned Garreg Tower is situated on nearby Coed y Garreg. This hilltop offers a complete panorama over the surrounding landscape, including down to Holywell and the coast. Setting out from St Asaph in the mid-morning at an average walking speed of 3 to 4 miles an hour, the pilgrim would arrive in this area after midday, and this hilltop of Coed y Garreg would have offered an attractive resting point (Ohler, 1989, 45). The panorama highlights future landmarks which indicate the direction to Holywell, the relative distance and direction of the town itself, and also the opportunity once again to contemplate the landscape which hosted so many miracles in the name of St Winefride and St Beuno, and other local saints.

\section{The Well; Its Approach, Rituals, and Relationship to Surrounding Sites:}

The final area of interest is the approach to Holywell and, crucially, St Winefride's Well. The town owes its stature and existence to this site, and attracted a huge number of pilgrims firstly from the local area and then, towards the latter half of the $14^{\text {th }}$ century, from the rest of Britain. Consequently, the noise (especially on feast days or major liturgical celebrations) created by the faithful hoping for a cure, and the bells from St Beuno's Church (now dedicated to St James) would be one of the most noticeable sensory experiences when arriving at Holywell. The pilgrim could either enter Holywell from the south west, and walk through part of this small market town down to the well, or take a path which leads briefly through woodland and next to Basingwerk Castle, arriving outside the well (see Figure 84 below). The creation of this earthwork, reinforced by the Ranulf III (Earl of Chester) in 1209 to protect the lucrative pilgrim trade produced by the well, combined with the efficiency with which the path leads one to the well suggests that this was an approach commonly used by pilgrims (Poole, 1951, 69). The small area in which the well lies is a cluster of ecclesiastical buildings, with the Chapel of St Winefride (early $16^{\text {th }}$ century), the Church of St 
Beuno/St James $\left(7^{\text {th }}\right.$ century site), the Well of St Beuno, and connected by a valley path is Basingwerk Abbey (whose monks formally cared for the well site).

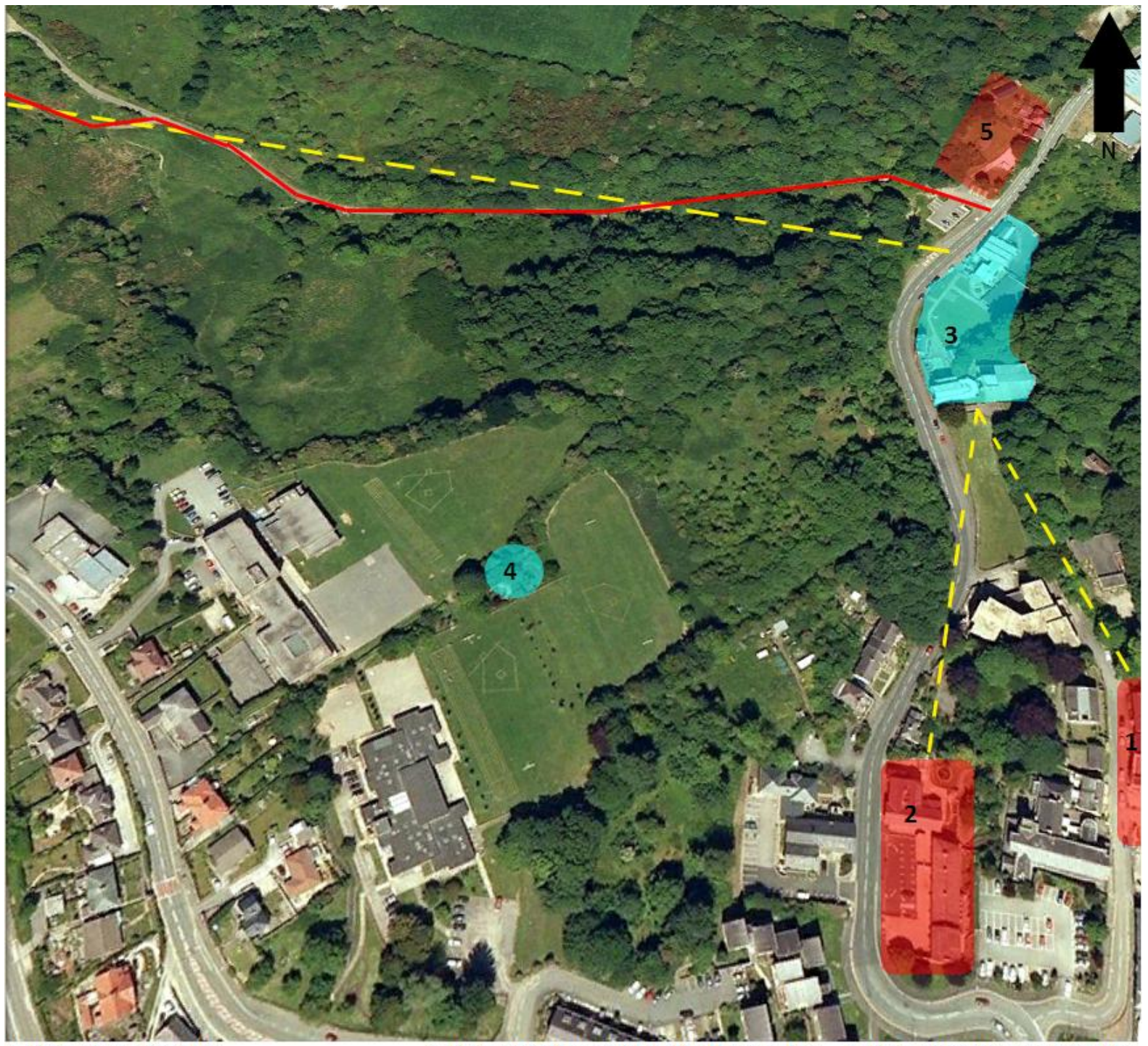

1. Site of the Star Inn

2. Site of Pilgrim Hospice
3. Site of St Winefride's Well Complex

4. Site of St Beuno's Well

Figure 84. Map showing sites at Holywell, and visual interaction (yellow) between sites and the western approach to the town (red/blue). Basingwerk Castle is shown in dark grey. Original satellite image reproduced from (c) 2011 Google.

When entering Holywell from the west via a forested track leading past the Basingwerk Castle earthwork, the well site is visible only during the descent to the track from the surrounding fields, and when emerging from the woodland opposite the well. Returning to the concept of St Winefride's influence over the region, this arrangement may be bear similarities to Walsingham's 'Holy Mile' which is marked by the Slipper Chapel. The visual element of gaining sight of Holywell marks the radius of Winefride's 'divine presence' and protection, in this case from the Coed $y$ 
Garreg, and then progressively drawing nearer to the site of Winefride's miraculous return to life we see an increasing sacralisation of the landscape until one finally arrives at the valley and well. The churches and well house complex postdate the well as a pilgrim destination (even the well house is a $16^{\text {th }}$ century construction), and the well will be presented as it was during the height of its popularity because these are the structures which survive and are visible to the pilgrim today. As the site lies on the valley floor, the well house is invisible until one is within the courtyard, and the forested path allows little sight of the church tower until the pilgrim emerges opposite the site. The transition from profane to sacred space here is complex; the open courtyard (complete with Statue of St Winefride) offers a buffer zone between the outside world and the spring 'shrine', the pinnacle of sacral importance. However, the spring also feeds the river which runs along the valley floor down to Basingwerk Abbey and out into the Dee Estuary, thereby linking the two spaces (sacred and profane), the well and abbey, and sacralising the valley itself as a carrier of water brought forth by a miracle. Consequently, it may be that the entire Greenfield Valley was viewed as a sacred space leading out to the Irish Sea, with the well as both the source and the core of this spiritual landscape.

St Winefride's Well remained a centre for pilgrimage before and after the Reformation, and attracted royal attention from Wales and England (as described in the documentary evidence above). The outer bathing pool (early $16^{\text {th }}$ century) is a large rectangular bath, and allowed pilgrims to enter the waters from the spring, many no doubt hoping for cures. C.T Longley, a cleric and church historian wrote 'This ritual is as old as the pilgrimage itself. Maen Beuno, Beuno's Stone, connects us directly with the time of St Winifred. The Medieval 'Lives' say that Beuno sat on this stone when he told Winifred that anyone coming to the Well and asking something in her name, 'might receive an answer to their request at least at the third time'. This was understood to mean that the petitioner should bathe three separate times. After the building of the present Well this meant three dips in the little bath. A carving opposite this bath shows how healthy pilgrims carried the sick through the waters on their backs. (Fry and Hulse, 1994, 3) An interesting question is whether interaction with the original basin be more highly prized than the larger bath the spring fed into, possibly being of higher sacred status and closer to the 'source' brought about by St Winefride's miracle. However, as is mentioned in the Prior of Shrewsbury's Vita St Wenefrede, the entire area of Holywell was seen as under divine protection, so the approach to the bath and well could only have exponentially more sacred, rather than sharply divided, and miracles attributed to St Winefride (and to a degree St Beuno) were not solely restricted to the well site itself. 


\subsection{Conclusions}

Travel around Medieval Wales was enhanced by industrial, ecclesiastical and military activity, producing a series of major routes built and expanded upon the original Roman road system. Livestock and transhumance also added another sequence of rough tracks which connected otherwise isolated settlements with market centres; these were all routes which were exploitable by the pilgrim. With the range of local saints throughout Wales, an intimacy existed between the laity and their church's spiritual patron, often so unique to the locale that no other (surviving) dedication exists for that particular saint. Archaeologically, the survival of pilgrim shrines, way-stones, rural well houses and crosses depends principally on the impact of the Dissolution and Reformation. In this case the study of the cathedral at St Asaph, the Maen Achwyfan and St Winefride's Well illustrate the multiple functions they performed within their setting, potentially as boundary markers, preaching points, visual guides towards the pilgrim's goal site, and all as sites worthy of veneration in their own right. The movement in between these areas and monuments defines the concept of the sacred journey, using and exploiting elevations in the landscapes between St Asaph and Holywell for practical purposes, but also consciously treading through environments which hosted so many local miracles, saints and religious folklore.

To a lesser extent we can see the Clwyd valley in a similar light with St Asaph as its spiritual hub, although the river performs a very different function than at Holywell. Here the river Clwyd does not carry waters born of a miracle but instead provides a threshold for those entering the town of St Asaph; one must traverse the waters at the appropriately bridged point in order to gain entry. An interesting point of enquiry would be historical records of flooding of the Clwyd River. The valley floor is essentially a flood plain, and if the river did flood and temporarily swamp the surrounding landscape, then St Asaph would be turned into an island, much like Ely in the fens, altering both its status and also perceived role (possibly as a sanctuary) within the region during the floods. In any case the two towns of Holywell and St Asaph, both cult centres and linked by a Roman road, are separated by 15 miles of landscape which, as I have described, present numerous opportunities for reading the landscape, encountering sites which held great religious and national significance, and exposure to natural elements. As with all pilgrim sites, St Winefride's Well offered the Medieval pilgrim a tangible link with the divine, and its enduring popularity is owed in part to this continuous tactile presence of the miraculous spring. However unlike other miracle sites which were based upon a single event, at Holywell the spring was continuous and remained just as potent as the day it was first 'discovered'. Its flowing waters made the entire valley a conduit for sacred movement, both for the river created by the well and the monks at Basingwerk Abbey, as well as the pilgrims and clerics who visited the site. 


\section{Chapter 6: Camelford to Bodmin}

\subsection{Introduction to the case study}

Medieval Cornwall has long been perceived as a culturally isolated anomaly in the English historical and archaeological record, and it is only relateively recently that this erroneous view is changing. By time of the Dissolution, Bodmin had become the most influential ecclesiastical site in Cornwall, with strong ties to Exeter, a series of religious houses, churches and guilds within the city walls, a regular and well-attended market, and one of the pre-eminent saint cults in the county; that of St Petroc. Approximately fourteen miles north of Bodmin along what will be referred to in the text below as the 'Camel River valley' lies the small market town of Camelford. This town is located along a significant access route to the north of the county, and the valley is well equipped with networks of tracks, paths and lanes which lead the traveller southwards towards Bodmin.

This chapter will explore the growth and maintenance of the St Petroc cult, combined with an analysis of the Medieval Cornish road network which facilitated its diffusion, alongside discussions of the nuances of a pilgrimage within such a localised landscape, and the sites which may have been of relevance to a pilgrim along the journey. Compared to the previous case study chapters $(3,4$ and 5$)$ this emerges as the most localised, and the text below presents my findings, analysing how this pilgrim experience might differ in terms of landscape, material culture and accessibility from that of the more universally found Roman saint cults which commanded so much attention in Medieval Britain. 


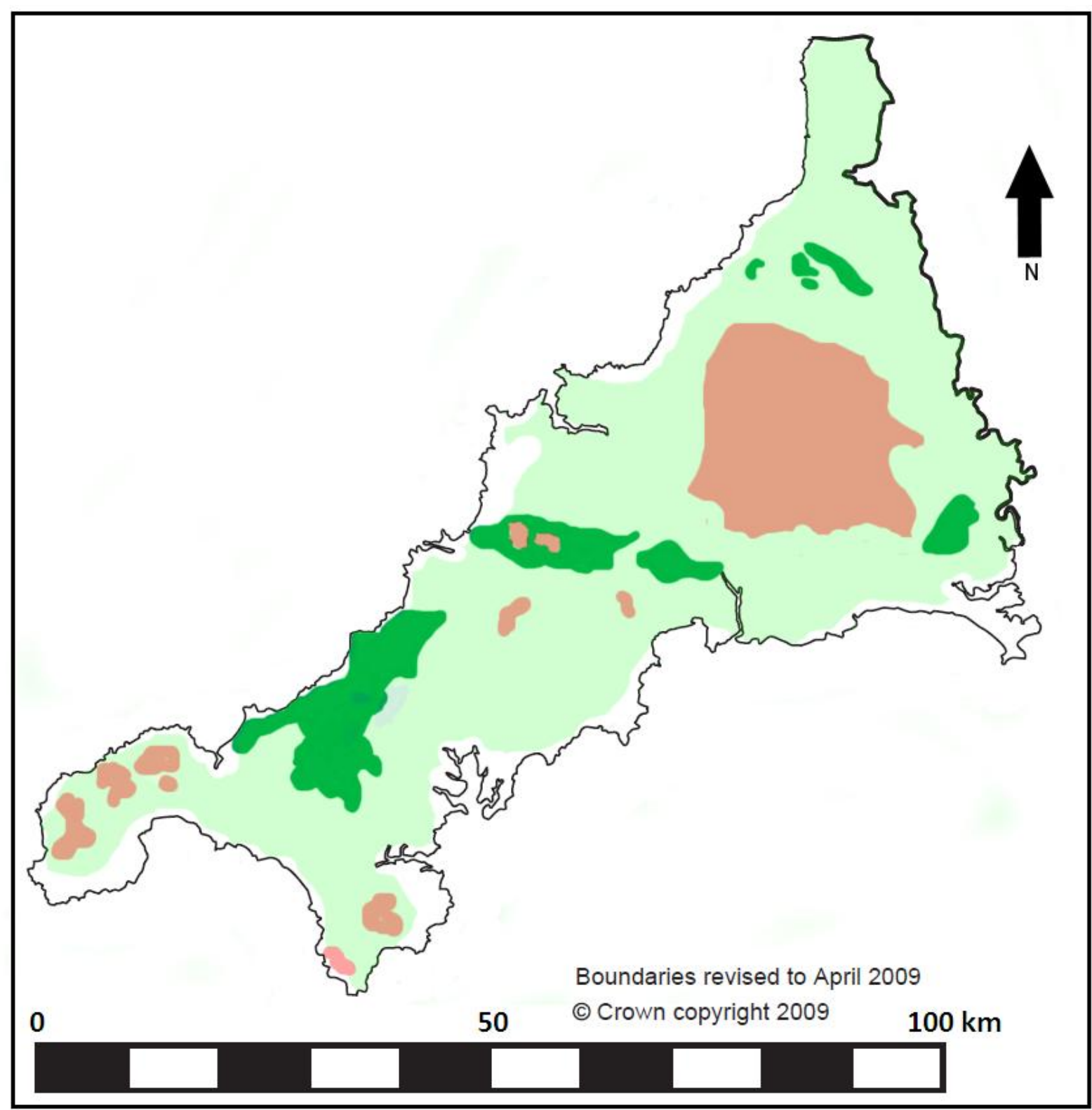

Figure 85. Map of Cornwall displaying the uplands (red), anciently enclosed land (light green) and recently enclosed land (dark green), according to the Cornwall \& Scilly Historic Environment Record. Redrawn from the Ordnance Survey GB Coastline and Administrative Boundaries Map.

\section{Environmental:}

The landscape of Cornwall is amongst the most varied in Britain, encompassing moorland, river valleys, woodlands and heaths. A granite based spine runs along the county from east to west upon which lie the uplands of Bodmin Moor, Land's End and St Austell (Postan, 1972, 5). These uplands are often surrounded by fertile pastoral field systems, and thickly wooded river valleys are common near the south coast. Historically, the settlement pattern has frequently taken advantage of the fertile grounds on the upland peripheries (such as the Camel valley) or followed the coast (Johnson 
and Rose, 1994). The northern coastline is considerably more rugged than its southern counterpart, with a fiercer exposure to the Atlantic in terms of currents and winds (Barton, 1964, 7). The Historic Landscape Characterisation (HLC) for Cornwall labels the areas between the towns of Camelford and Bodmin as the Camel and Allen valleys, Bodmin Moor, and Incised River Systems with Woodland (deep wooded river valleys) respectively, the land being principally a mixture of ancient enclosures, upland rough ground and steep sided valleys (Herring, 2006, 44). There are areas of recently enclosed land (19th century) around the Bodmin Beacon and elsewhere around the Bodmin environs, but these are the exception rather than the rule (Herring, 2006, 44). The built environment of the Camel river valley is composed of villages, paths, lanes, churches and wells, and this valley and its immediate landscape are highly fertile, reflected in a long tradition of farming (Cornwall County Council, 1996). The HLC indicates that the area in which my fieldwork takes place has seen minimal alteration from its Medieval state, still retaining its manorial character as a patchwork of villages with fields and enclosures serving the local population, with minimal modern urban expansion into the valley and forests (Cornwall County Council, 1996). This has important implications for my data, in particular aspects such as lines of visibility, elevation and legibility of the landscape, as the retention of the Medieval fabric of an environment allows an assessment of these aspects in relation to the pilgrim experience.

\section{Economic:}

In the 'Victoria County History of Cornwall, Volume l', William Page asserts that 'Climate, mineral wealth, and geographical position are the three elements which have determined in the past and which still determine the occupations of the inhabitants of Cornwall.' (Page, 1906, 513) Estuaries along the coastline provide shelter for fishing craft, the county has rich climactic conditions allowing sub-tropical flora to flourish, thereby giving rise to the three principal historical industries of Cornwall; fishing, mining and agriculture (Page, 1906, 513).

\section{Mining}

The ores found in Cornwall are largely non-ferrous particularly tin, which I have used here to exemplify Cornish mining, a complex and lengthy topic in its own right. The first documented evidence of tin extraction come from the accounts of Diodorus Siculus in the $1^{\text {st }}$ century BC (Booth, 1814,310 ) of visits by Gallic, Iberian and Phoenician traders in the first millennium BC. One example, demonstrates how quickly material could be transported over contemporary routeways; tin was transported by boat to Gaul then by horseback in thirty days south to Marseille (Page, 1906, 522). Cornish tin was a substantive reason behind the high level of cross-channel contact with Brittany from the Late Bronze Age onwards (Quinnell, 1986, 121). Surprisingly there seems to be a hiatus during the Roman period and no recorded use of tin mines in Cornwall in Anglo Saxon times. Also omitted from Domesday, it has been suggested that this is because tin was not royal property but in the charge of local barons and earls who paid a round tax on the mine (Preston-Jones and Rose, $1986,138)$. However, by the late $14^{\text {th }}$ century, the mining industry in Cornwall had expanded exponentially. A patent roll from Richard II's Close Rolls in 1391 describes a commission which was appointed to survey 'the newly found mines of gold, silver, lead, and tin, and other metals, and to set the necessary workmen and labourers to work them in the king's advantage.' (Maxwell, 1922, 385) 
The most common method of processing the tin involved 'streaming' (running water over tin rich stones which lay on the ground surface - thus removing unwanted material from the 'shode' or tin rich stones, leaving the ore exposed), and open cast working of the lodes or tin ore veins, which involved digging several shallow pits or shafts into the hillside (Hatcher, 1973, 168). This process was described by Camden in 1607 (Camden, 1701, 24).

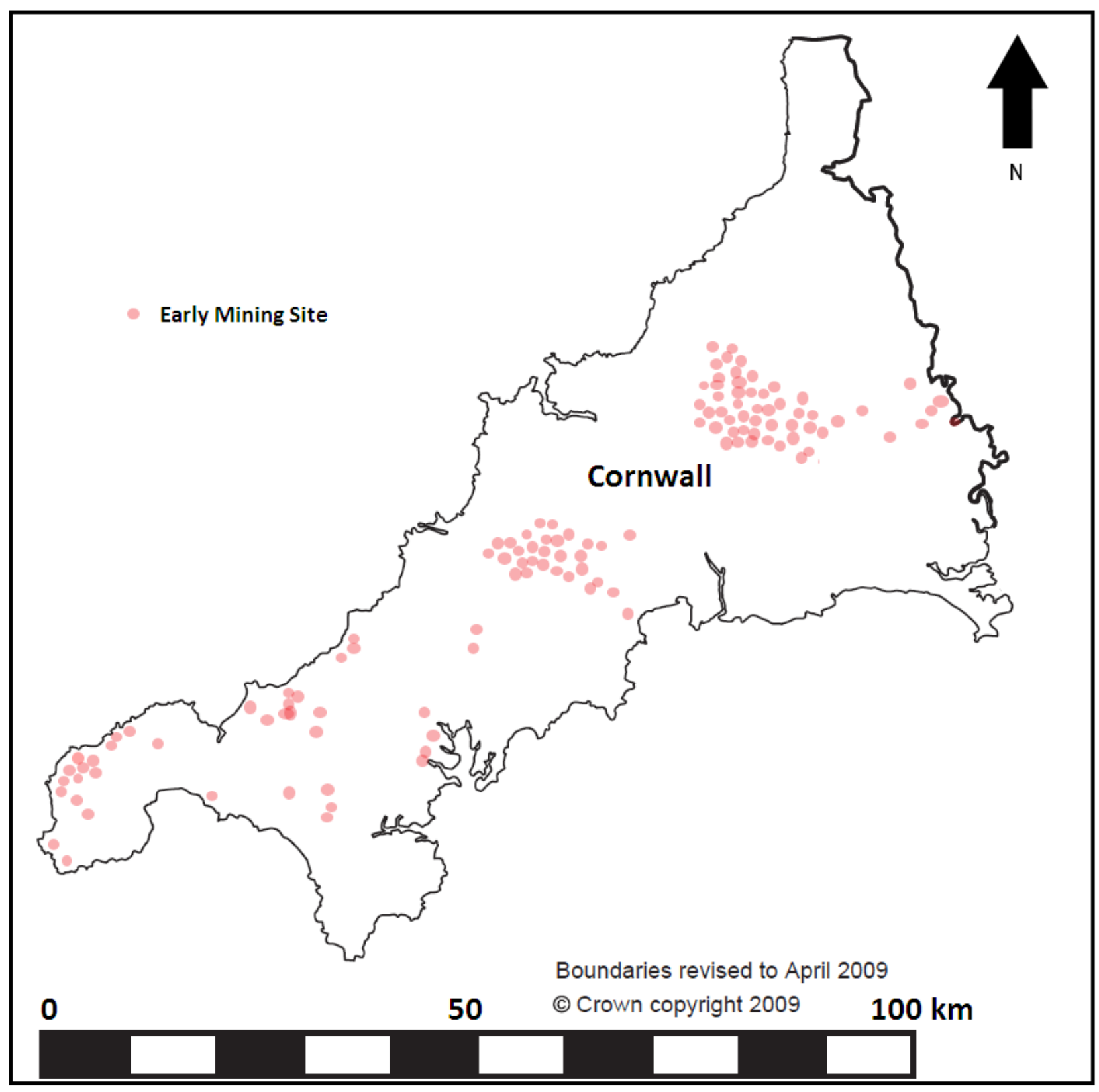

Figure 86. Map of early mining sites in Cornwall, according to data from the Cornwall \& Scilly Historic Environment Record. Redrawn from Ordnance Survey GB Coastline and Administrative Boundaries Map. 
Whilst the mining industry formed a lucrative portion of the Cornish economic landscape, the most prevalent activity was agriculture. Areas of Prehistoric farmland are clustered around and within the West Penwith region (see Figure 87 below), the Lizard Peninsula, and around the fringe regions of Bodmin Moor, most of which continued to be farmed in 'strip-field' fashion throughout the RomanoBritish period, especially within the Penwith area (Page, 1906, 360). Lowland Cornwall is largely still defined by the field patterns developed between the $14^{\text {th }}$ and $17^{\text {th }}$ centuries, where strip fields are enclosed by hedges and deeply cut tracks, lanes link farming settlements, parish villages, churches, and roughly one third of the available pasture land was used for transhumance grazing during the summer months (Herring, 2006, 85). The fringe lands around Bodmin Moor still reflect the Cornish Medieval arrangement and network of hamlets and field systems, where each hamlet (two to ten households) would be surrounded by 'improved' land, a series of which formed a settlement attached to a larger estate or manor (Johnson and Rose, 1994, 27). The majority of these field boundaries maintain their Medieval (or earlier) origins; large strips which are spatially linked to the accompanying settlement, 'strip farming was ubiquitous in the south-western [Medieval] landscape' (Turner, 2006b, 17). This is exemplified by the deserted Medieval village of Carwether on the eastern side of the Camel river valley, four miles south of Camelford. Situated on an elevated valley edge, and with views stretching across both the valley and to east Bodmin Moor, it is surrounded by small pasture field strips (still in use today for grazing sheep) which show slight residual evidence of terracing (Herring, 2006, 78). The five principal markets recorded at the time of the Domesday survey were at Launceston, Liskeard, Bodmin, St Germans and Marazion - all except for Liskeard being ecclesiastical centres (Ravenhill, 1967, 328). 


\section{Ecclesiastical}

Irish and Welsh missionaries were the first to spread Christianity in Cornwall, their work in the kingdom of Dumnonia (which corresponds to Cornwall, Devon and western Somerset) roughly from the $4^{\text {th }}$ to $8^{\text {th }}$ centuries, saw the first religious institutions being introduced to Cornwall in the $5^{\text {th }}$ century (Olson, 1989, 8). One of these unnamed institutions is mentioned for the first time in the written record by Gildas in the $6^{\text {th }}$ century, when he writes that 'Constantine, ruler of Dumnonia [Cornwall] murdered two royal youths under the cloak of a holy abbot in a place of worship.' (Olson, $1989,8)$ The influence of these missionaries and saints from what are popularly labelled 'Celtic' regions can be seen in terms of saint names and the architecture of the churches developing from the input of Welsh, Breton and Irish cultural contact. An example of this distinctiveness is described

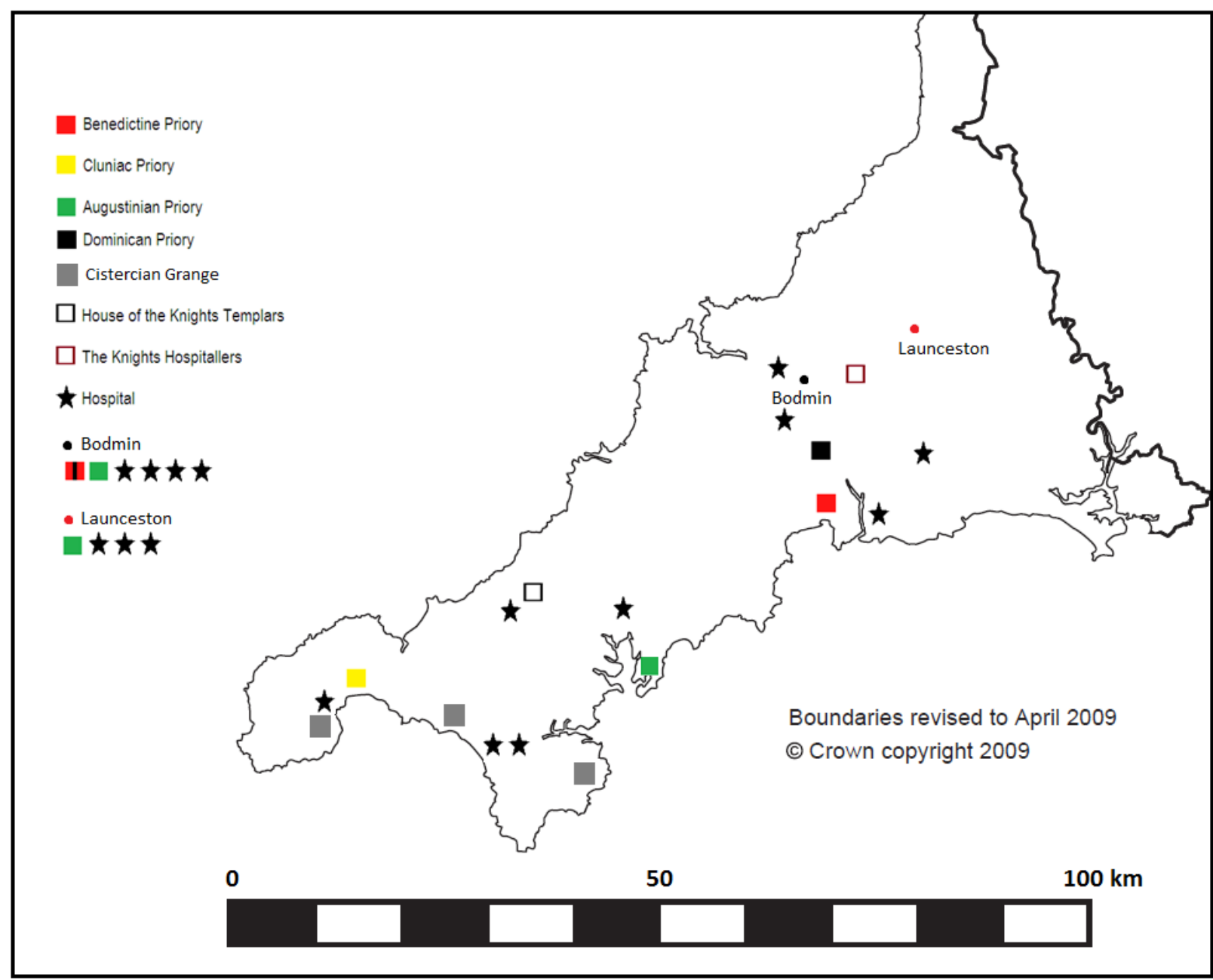

Figure 87. Distribution of post $11^{\text {th }}$ century Medieval religious houses in Cornwall. Data from Knowles and Hadcock, 1953. Redrawn from the Ordnance Survey GB Coastline and Administrative Boundary Map.

by James Rattue, 'The arrangement of a well-chapel within a few yards of a church is almost universally Celtic and displays once again how thoroughly different Cornwall is from the rest of the country', this arrangement being found almost exclusively in Cornwall and nowhere else with any 
degree of frequency in England (Rattue, 1994, p68). However it is important not to think of Cornwall as a region which is culturally isolated from the rest of England, rather as integrated though differently shaded, with strong ties to neighbouring Gallic and 'Celtic' countries (Turner, 2006a, 15). The economic aspects shown above demonstrate Cornwall played a crucial role in the industry and economy of the south west in general, frequently interacting with neighbouring Anglo-Saxon Wessex and overseas traders. Though geographically on 'the periphery' of England and less 'Anglo Saxon' in cultural descent than the southern central heartland of Wessex, Cornwall was not a cultural island of 'Celticism' in England. However it had a strong regional identity and I use 'Celtic' here solely as a convenient collective term for those countries and cultures which have been commonly referred to as such in the past.

Preston-Jones and Rose suggest that 'it is probable that the most important early Christian settlements in Cornwall originated in the late 5th or 6th centuries as daughter houses of Welsh monastic communities.' (Preston-Jones and Rose, 1986, 155) These Welsh influenced foundations were settlements which typically included a church, and usually contained the element 'lan' in their names (Preston-Jones and Rose, 1986, 156). This is corroborated by the high number of parishes which begin with 'Ian' in Cornwall and Wales, stemming from the fact that 'lan originally meant 'enclosure' but, used as it clearly is in Christian religious contexts and in association with recognisable saints' names, it must have acquired a specialised meaning of 'sacred enclosure'.' (Olson, 1989, 3) The distribution patterns of the 'lan' settlements in Cornwall reveal gaps that are frequently filled with 'eglos' ('church') name elements, which tend to be located further inland on valley sides or spurs (Preston-Jones and Rose, 1986, 156). Several monastic institutions were set up by missionaries of Welsh origin, however by the Norman Conquest the majority of these estates had been claimed or usurped by the Anglo Saxon and Norman lords, resulting in most of the early 'Celtic' monastic communities disappearing from Cornwall by the time of the Domesday survey in 1086 (PrestonJones and Rose, 1986, 160). There are numerous charters from the $9^{\text {th }}$ to $11^{\text {th }}$ centuries which detail Cornish land gifts from Kings Egbert, Alfred, Athelstan, Edmund, Eadred, Edgar, AEthelred II, Cnut and Edward the Confessor to various churchmen and lords, which may have interrupted the activities of 'native' religious houses, and further detail is found in Finberg's 'The Early Charters of Devon and Cornwall' (1953). Those which did survive became either collegiate churches (i.e. churches staffed by canons or 'secular clergy' and presided over by a dean or provost) such as at Crantock, Perranzabuloe and St Buryan, or were re-founded as Augustinian institutions (Launceston, St Germans and Bodmin), and Friaries are found in Truro and Bodmin in the $13^{\text {th }}$ century (all of which are listed in Appendix E). This later Medieval period saw Cornwall's religious framework expand and become merged into the Diocese of Exeter (Preston-Jones and Rose, 1986, 160).

From a comparison of the early pre-Conquest monastic sites in Cornwall, and those which were either in use or founded after the $11^{\text {th }}$ century (see Figure 88 above), it is clear that a significant amount of these earlier monastic sites influenced by Welsh and Irish missionary work did not survive past the initial years following the Norman Conquest. The sites themselves are scant in the archaeological record, due to the nature of their design consisting of 'a congeries of detached cells, each suitable for the habitation of one or more monks. The cells, like the churches of the period, were 
commonly of wood, sometimes of stone.' (Taylor, 1916, 63) The archaeological evidence for the presence of these institutions comes chiefly from inscribed stones and pottery sherds (Olson, 1989, 36). The Augustinian order took charge of the two major Cornish ecclesiastical sites (Bodmin and Launceston), and smaller orders appropriated other existing institutions (Truro, St Carrok, St Keverne (Knowles and Hadcock, 1953)). However the majority of the early 'Celtic' monastic sites are not present in the 1953 Knowles and Hadcock catalogue, which suggests that some may have been abandoned after the Conquest, or some were recycled as parish churches and hermitages (Olson, $1989,17)$. In terms of key ecclesiastical sites in Cornwall, perhaps the most celebrated example of continuation of the early monastic sites was situated just offshore of the southern Cornish coast; St Michael's Mount. The Archangel Michael was said to have appeared to some local fishermen on the side of the mount in 495 AD (Adair, 1978, 96). It has been suggested that veneration of this feature reached much further back into antiquity with the Cornish regarding the mount as a holy hill in the ocean, in part from its use as a hill fort, market and haven for sea traders prior to the coming of the missionaries (Adair, 1978, 96). The monastic complex was constructed in the $12^{\text {th }}$ century by the Abbot of Mont St Michel in Normandy, with St Michael's Mount intended as Mont St Michel's daughter house (the site being gifted thus by Edward the Confessor). Numerous relics were procured to place on display for visiting pilgrims such as a tooth from St Apollonia (Beal, 1996, 7). This link between the two sites survived until Henry $V$ dissolved the alien priories in England in 1425, whereby it passed to the protection of the Convent of Syon (Middlesex), however it continued to host large numbers of pilgrims throughout the following centuries, escaping the excesses of the Reformation (Adair, 1978, 99).

Locally there were many surviving parish churches and holy wells (recorded in Appendix D) and a high ratio of local saints reflected in their dedications, such as St Adwenna, St Brioc, St la, St Carantoc, and some, such as St Petroc and St Neot were famous beyond the county (Turner 2006a, 83). These numerous regional holy figures resulted in a correspondingly high amount of religious houses, the most famous of which are St Germans Priory and Bodmin Priory - the latter housing the relics of St Petroc, and the subject of my fieldwork. Bodmin held the most religious institutions, and constituted the most influential ecclesiastical site in Medieval Cornwall, containing the following houses; an Augustinian Abbey (previously a Benedictine Priory), a Friary, and four hospitals, two of which (St Anthony and St Laurence) catered exclusively for lepers and local poor/sick members of the laity (Knowles and Hadcock, 1953). There were also numerous chapels and guilds in the town (Jankulak, 2000, 13). It is not known for whom the other two hospitals (St George and St Margaret) catered, but it is entirely possible that poor travellers were granted a night's board, given the shrine of St Petroc (complete with the saint's relics) and the well of St Guron were both within the town walls a combined focal point of Cornish pilgrimage (Knowles and Hadcock, 1953, 255). The Bodmin Priory of SS Mary and Petroc was destroyed during the Dissolution period in 1539 along with St Petroc's shrine (Jankulak, 2000). Originally founded by St Petroc as a monastic community in the $6^{\text {th }}$ century, it came under Benedictine rule in the mid-10 ${ }^{\text {th }}$ century, and then Augustinian in 1124 (Henderson, 1963, 224). The town features prominently not only in the ecclesiology of the county, being the centre of one of Cornwall's primary saint cults (St Petroc) whose cult is recorded as being 'a significant presence in the medieval Cornish landscape', but it also was an important market town, 
well linked into overland trade routes, receiving high volumes of both sacred and secular human traffic (Jankulak, 2000, 41). A short biography of its patron saint, Petroc, is provided below.

\section{St Petroc:}

Born in the 6th century, Petroc is often referred to in hagiographic records as the son of an unnamed Welsh king. The prime source of information about Petroc comes from the two manuscripts entitled Vita Petroci, the first of which from its Latin is judged to have been written approximately a century either side of the Conquest in either Wales or Cornwall, and was later copied (the second Vita Petroci), amended and abridged several times (one example being the Vita metrica in the Gotha manuscript (Jankulak, 2000,5)). These Vitae record that after receiving his teachings in Ireland, Petroc embarked on a mission in Cornwall where he took over a monastery in Lanwethinoc, which then became Padstow (literally 'Petroc's Place'). The hagiographic tradition tells us that after thirty years at Padstow, an angel appeared to Petroc and bid him set out into the wilderness with a few of his most trusted monks to form a hermitage (Spencer, 1991, 69). In his wanderings he found St Guron, a hermit in what is now Bodmin, who briefly joined him and together they founded Bodmin Priory as a monastic community, enlarging the hermitage constructed by Guron (Jankulak, 2000, 11). Guron subsequently left to found another cell further south along the coast, in what is now called 'Gorran'. This enlarged hermitage became the now vanished Bodmin Priory, which became the religious capital of Cornwall during the Medieval period (Jankulak, 2000, 11). St Petroc died in 564 $A D$, and his remains were buried in Padstow then subsequently moved to Bodmin probably during the $10^{\text {th }}$ century, although there is some debate over the exact timing of his translation and this is elaborated upon in section 6.4 below.

A dossier of hagiographic records were compiled by monks at Bodmin which place the saint's travels mainly within the standard locales for a 'Celtic' saint: Cornwall, Wales (the place of his birth and lineage), and Ireland, but also allege that Petroc travelled to Rome and even India in his own pilgrimages (Jankulak, 2000). The Gotha manuscript, a $14^{\text {th }}$ century compendium of 'Celtic' and Anglo-Latin hagiographies (and the only copies of the extant texts dealing with Petroc) records that so powerful was the saint's spirit that one woman who first visited the shrine of St Swithun in Winchester and was only partly cured, came to St Petroc's shrine and was fully restored to health (Jankulak, 2000, 17). He may also have possessed an affinity with the sea, as another miracula in his hagiography records Cornish fishermen imploring many saints for help in a storm, yet only by invoking St Petroc's name did they quell the waves (Jankulak, 2000, 17). 


\subsection{The Road Network of Medieval Cornwall}

\section{Prehistoric and Roman origins:}

The second millennium BC saw Cornwall emerge as one of the most active areas of Prehistoric mining, competing on an international level with Mitterberg (near Salzburg in Austria), the site of a prodigious mining and processing industry, and more locally with the Welsh mining industry and the Mount Gabriel mine in Ireland (Weisgerber and Pernicka, 1995, 160). Routes were required to link the source sites, where the ore was mined, with processing sites (from smelting to metal working), and finally points of trade (i.e. ports, markets) As one of the primary suppliers of tin in the later Bronze Age, Cornwall would have needed an efficient route network in order to extract, process and export the metal. Therefore an intricate network of tracks and routes was required to traverse the county from its interior where the ore was found to the processing and distribution sites, as well as intersecting tracks which tied the numerous farming settlements to agricultural market centres (Cleland, 1927, 233). These areas of Prehistoric farmland were primarily in the south west, an area which also has a long history of maritime activity due to its peninsula coastline and sheltered aspects in Mount Bay (Cornwall County Council, 1996).

The 'Saint's Way' is a collection of footpaths and tracks which link the north and south coastlines from Padstow to Fowey via a series of hill forts, Neolithic monuments, villages and churches (Gill and Colwill, 1987, 68). It is commonly said that this long distance walking path was a route commonly used by missionaries when they arrived in Cornwall, although other more historically grounded explanations suggest that the route was frequented by early traders (Gill and Colwill, 1987, 68). The 'route' is in essence a connected network of tracks, and whether these tracks were linked in order to provide a grand crossing of the county, or merely connected in a coincidental way to afford movement between sites, is currently unknown (Gill and Colwill, 1987, 42). However, the trackways do connect prehistoric and Medieval landscape elements, and may represent part of the evolving larger network of accumulating trails and roads which allowed day to day movement and communication across the length and breadth of Prehistoric, Roman and Medieval Cornwall (Turner, 2006b)

The archaeological record demonstrates a high degree of continuity in terms of settlement distribution from the Iron Age through the Roman occupation, with Cornwall being generally termed one of the least Romanised counties in England (Taylor et al, 1906, 470; Todd, 1987, 13). There a very few examples of archaeologically confirmed Roman forts in Cornwall, one of the largest being Tregear at Nunstallon near Bodmin, with others at Lostwithiel and Calstock (Payton, 2004, 79). As stated above, the Roman presence in Cornwall is less archaeologically visible than in other areas of Britain, consistently primarily of trading posts (the nearest major Roman settlement in the West being Exeter), small Romano-British towns and villa complexes, with the re-use of existing settlement areas being a common feature - examples of this are found in the Carn Euny site near 
Penwith and the Chysauster site near Penzance (Saunders, 1991, 15). Ivan Margery's 'Roman Roads in Britain' (1973) shows a Roman road running through Exeter and down the centre of Cornwall, potentially passing by Bodmin following the course of the modern A30, which was established as a turnpike road in 1795. It is highly unlikely that this was the only route connecting the Cornish interior with Devon and the rest of England and we can confidently assume a high volume of tracks, long distance paths and trails existed across the county connecting settlements and mining. However it is probable that this Roman road was the most formalised and built route penetrating the interior and linking the county with the rest of the emerging Roman road network in Britain (Margary, 1973).

\section{Medieval:}

The profitable mining industry in Cornwall continued to expand, distributing via existing trading roads which were further developed through the Medieval period. The lengthy history of agricultural settlements throughout the county also contributed to the localised networks of tracks and deep lanes which are visible today, as the current Cornish settlement distribution is still based on its Medieval predecessor (Preston-Jones and Rose, 1986, 141). In their survey of Bodmin Moor, Preston-Jones and Rose state that across Cornwall 'approximately 7,500 farms have their first record in the later medieval period; some 340 are mentioned in the Domesday Book, and a few feature in pre-Norman charters... Thus any reasonably detailed modern map of Cornwall is essentially a map of medieval Cornwall, with later additions.'(Preston-Jones and Rose, 1986, 141) This can be said to apply equally to the route network which has evolved out of a $14^{\text {th }}$ century 'cobweb of tracks and paths... separated by stretches of unenclosed downland' (Preston-Jones and Rose, 1986, 142). If we accept this premise, then we can begin to apply data from cartographic and textual sources to build a picture of the Medieval Cornish route network. These sources derive from accounts by early 'national tourists', including Richard Carew, John Ogilby and John Leland, all of whom included Cornwall on their tours between the $16^{\text {th }}$ and $18^{\text {th }}$ centuries. The map which John Ogilby drew to accompany his 1675 publication 'Britannia' shows 'a series of roads radiating in continuous lines from London to every part of the kingdom [which] at considerable intervals in the south and midlands, and with still less frequency in the north, these radial lines are intersected by cross-roads', reaching all the way down to St Buryans in Cornwall's westernmost extent (Stenton, 1936, 1). The famous $17^{\text {th }}$ century cartographer John Speede's map of Cornwall (in 'The Theatre of the Empire of Great Britaine', 1610) shows a distribution of settlement similar in density to that of today, indicating a well-established, broadly spread yet well-connected population, and this premise is corroborated by Matthew Symonds 1637 map of Cornwall which provides distance tables between towns and villages, indicating a healthy route network and a measureable level of accessibility across the county.

Unlike the other case studies addressed within this thesis, Cornwall does not feature prominently in the royal itineraries of Edward I, Edward II, or John, all sources which have previously revealed the shape of the major Medieval route networks in the counties of Cambridge and Norfolk (Ely to Walsingham), Wiltshire and Hampshire (Salisbury to Winchester), and Denbighshire and 
Flintshire (St Asaph to Holywell), presented in Chapters 4, 5 and 6 of this thesis. From this absence we must conclude that these monarchs, who visited much of their kingdom, did not venture very far into the south western peninsula (Hindle, 1976, 216). The reasons for this are unknown, and we can speculate about a perception of Cornwall being too 'parochial' and lacking hospitality fit to entertain a king. However, as we will see below the Bodmin Prior was expected to entertain high status guests - so it was assuredly not due to a lack of accessibility (Orme, 2010, 152).

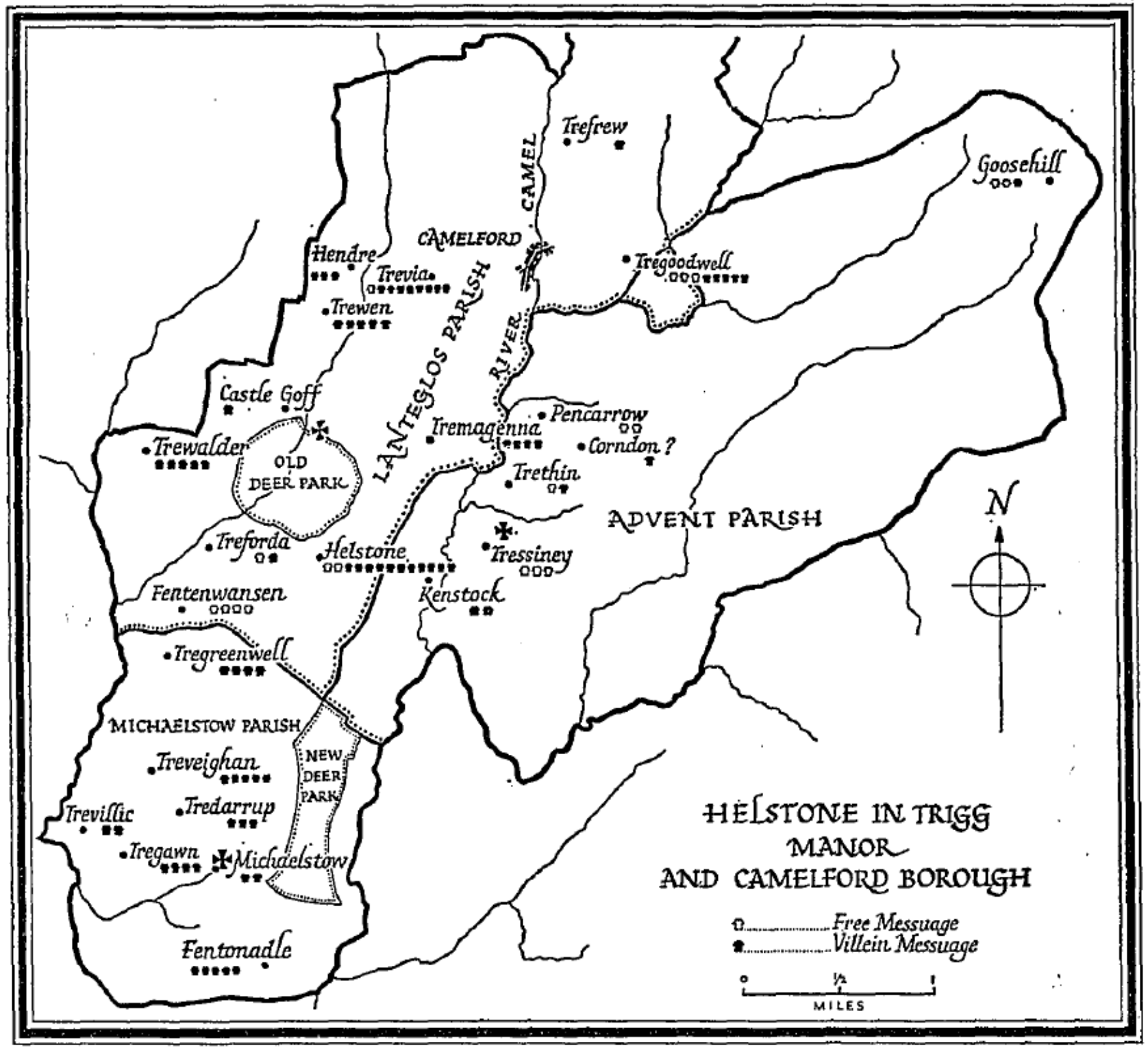

Figure 89. Distribution of Free and Villein (peasant or serf) Messuages in the Camelford Borough in the $14^{\text {th }}$ Century. Reproduced from Beresford, 1964, 19.

An example of the settlement density and its need for effective communication networks (which has relevance here as it encompasses the area which acts as the study's origin point) is found in Camelford Borough. Figure 89 above displays the high frequency of both free and villain 'messuages' in the borough during the $14^{\text {th }}$ century (a messuage being a plot of land for a house with 
outbuildings). The lanes we can see today (and on the initial early $19^{\text {th }}$ century Ordnance Surveys) which run between the sites of these settlements in the borough owe their origins to the Medieval tracks (with their eroded depth in the landscape) and roads which linked the tenement farming communities to each other and that of the manorial centre that made up these feudal complexes (Preston-Jones and Rose, 1986, 142). Also shown are the parish churches, whose accessibility in relation to the parish communities was of vital importance (French, 2001). This example is not an isolated one, as other records demonstrate that these high density messuage distributions in river valleys across Cornwall were common, and thus we can expect to see a similar network of paths and tracks connecting these communities with each other, the parish church, and out to the nearest market or trade centre (Beresford, 1964, 20). The extent of the antique tracks and paths throughout this valley are revealed by Sir John Maclean in his 'History of Trigg Minor' (1874). A significant route is described as leading from northern Devon and Cornwall through Stratton, Camelford, and Michaelstow, down through the Camel valley to Bodmin, 'with various tracks passing through Advent, St Breward and St Hellands, and the series of tracks and paths which form a localised network throughout this valley are provided with a primarily Medieval origin.' (Maclean, 1874, 283)

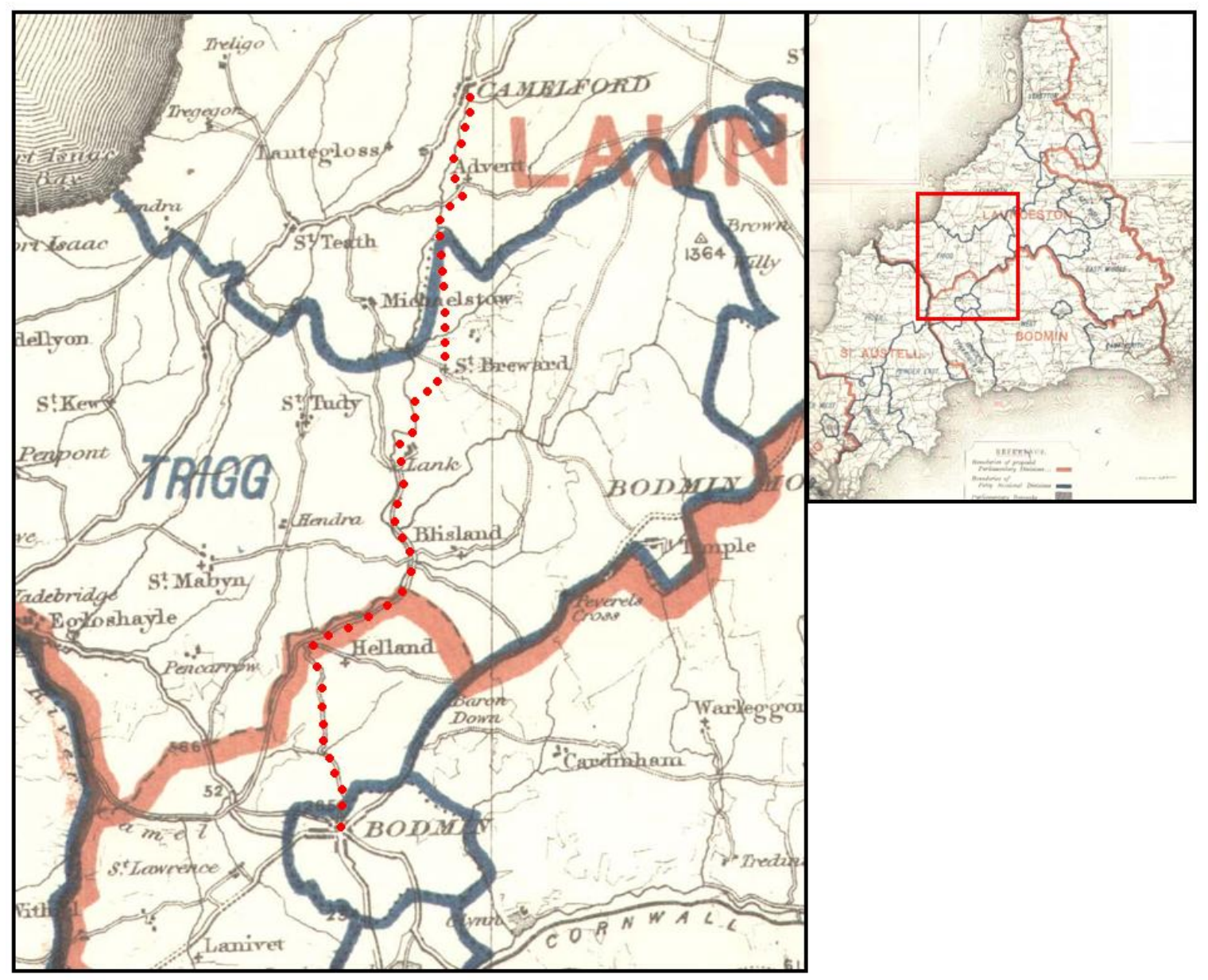

Figure 90. Route taken from Camelford to Bodmin including key sites, plotted on the 1885 Report of the Boundary Commissioners for England and Wales. A detailed map is presented in Appendix B. Reproduced from the Boundary Commission, 1885, 155. 


\subsection{The Cult of St Petroc: Origins, Growth and the Shrine}

\section{From Padstow to Bodmin:}

St Petroc arrived in Padstow during the early $6^{\text {th }}$ century, after spending what the hagiographic traditions maintain were twenty five years of training and instruction in Ireland, having abandoned his privileged lifestyle as a young Welsh prince (Jankulak 2000, 41). It is in Padstow that we can see the beginnings of the reputation and legacy of one of Cornwall's greatest saints; 'The earliest sign of a cult of St Petroc is, arguably, the existence and prominence of his primary cult site, Padstow.' (Jankulak, 2000, 42)

The blurring of strongly rooted hagiographic tradition and a lack of detailed historical information makes the early history of Padstow uncertain. The original name of Padstow was 'Lanwethinoc', which pairs 'lan' ('enclosure' or 'sacred enclosure') with the alleged head of the informal monastic community there, Wethenoc, whom Petroc superseded, and thus Padstow's original name meant 'the enclosure of Wethenoc' (Preston-Jones, 1992, 123). The name 'Padstow' is English in origin ('Stow' broadly meaning 'meeting place'), and so this ecclesiastical settlement shifted from being centred on Wethenoc and his hermitage to the meeting place of St Petroc and his monks, after St Petroc's death (Julyan, 1983, 32; Gelling and Cole, 2000, 152). The English influence in this name is attributed between the $9^{\text {th }}$ and $10^{\text {th }}$ century, when the settlement became 'Petrocstow' ('Petroc's-place') and then 'Aldestow' ('old place'), which became corrupted to Padstow (Julyan, 1983, 32). Little is recorded of St Petroc's monastic community in Padstow, and all that remains of this complex is the site of St Petroc's Church. The monastery is alleged to have been originally constructed in the $6^{\text {th }}$ century by St Petroc when he first arrived in Padstow, however the Anglo Saxon Chronicle confirms that it was utterly destroyed by Viking raids in 981 AD; 'In this year was St. Petroc's-stow plundered; and in the same year was much harm done everywhere by the seacoast, both upon Devonshire and Wales' (Swanton, 1998, 95). Two subsequent rebuilds of St Petroc's church have taken place, in the $12^{\text {th }}$ century and in the mid-15 ${ }^{\text {th }}$ century (Lysons and Lysons, 1814, 254).

The hagiographic accounts do not agree on the duration of St Petroc's time at Padstow, or on the exact events prior to his alleged meeting of St Guron and founding Bodmin. There are varying numbers of years spent with selected brethren in the wilderness after leaving Padstow, with one manuscript (Vita II) stating that St Petroc's time in Padstow and Nantfenton (an 'unnamed cell' in the wilderness) totalled sixty years (Grosjean, 1956, 48). What is consistent in the hagiographies is the notion that St Petroc was divinely instructed to abandon this small cell and wander further into the wilderness to establish a new site. It was during this period that he was in the Camel river valley and came across the small hermitage where a man named Uuron or Guron was dwelling, who gave St Petroc his abode and searched for a new site for himself (Olson, 1989, 68). This site became Bodmin, with a well site dedicated to St Guron being established next to the church of St Petroc (Olson, 1989, 68). 
The veracity of this account has debated by modern scholarship, because a lack of archaeological and contemporary written evidence calls into question not only the presence of St Petroc in Bodmin, but the concept of a monastery at Padstow existing at all before the $8^{\text {th }}$ century (Olson, 1989, 69). An alternative proposed by Olson (1989) and Jankulak (2000) sees a small community at Padstow springing up around the teachings of St Wethenoc (around which a small community may have formed, hence 'Lanwethinoc') and St Petroc, whose church described above may have had a holy well attached (Rattue, 1994, 68). It has been recorded that a spring flowed where he was said to have died, which cured eye ailments and internal illnesses (Grosjean, 1956, 145). There have been two reasons put forward to account for the shift from Padstow to Bodmin:

I. In the early $9^{\text {th }}$ century King Ecgbert granted the estates which encompassed Padstow to the Bishop of Sherborne, effectively depriving the community of their estates (Olson, 1989, 69).

II. The Danish raids of 981 which destroyed this church would have been a logical impetus for this community to retreat inland (Olson, 1989, 69).

Bodmin has easy access to the Camel River, and is sheltered by the valley, making it an attractive and less-exposed site to develop the cult of St Petroc and establish a monastic presence (Olson, $1989,70)$. However, the constant reference to St Guron or Uuron being at the site prior to St Petroc may suggest an initial community existing at the site when those from Padstow arrived in Bodmin between the $9^{\text {th }}$ and $10^{\text {th }}$ century, and 'the evidence does not, however, compel us to accept that there was no monastery or collegiate church at Bodmin before the plausible shift of religious activity from Padstow as a result of the raid of 981.' (Olson, 1989, 72) What is clear from the evidence is that this community from Padstow were primarily responsible for Bodmin becoming one of the great saint cult centres of Britain, and a town of influence and power within the ecclesiastical and economic landscape of Medieval Cornwall. Medieval Bodmin has been described as a 'magnificent citadel of churches, 13 or more chapels, hospitals, guild houses, a Friary and a vast Priory', and was one of the most colourful jewels of the Cornish territory, with each denomination and order performing liturgies and celebrations throughout the year (Worcester, 1969, 86).

\section{Bodmin Priory}

Vita II describes St Petroc fortifying Bodmin, which 'can perhaps be interpreted as further explaining a memory or evidence of its fortification', possibly erected by those arriving from Padstow in lieu of the recent spate of Viking raids (Grosjean, 1956, 120). It has been suggested that the name 'Bodmin' (or 'Bodmyn' as it appears in earlier itineraries) derives from the Cornish for 'Abode of the Monks', Bod' meaning dwelling and 'menegh' being connected with monasticism as either a plural of 'monk' or similar to the Breton 'minihi', meaning refuge or sanctuary (Jankulak, 2000, 53). As such this would be in keeping with what the town was to become (Gelling and Cole, 2000, 150.) In Knowles and Hadcock's compendium of religious houses in Medieval England and Wales, Bodmin is recorded as being under Benedictine rule in 936 AD (Knowles and Hadcock, 1953, 128). Given that the raids 


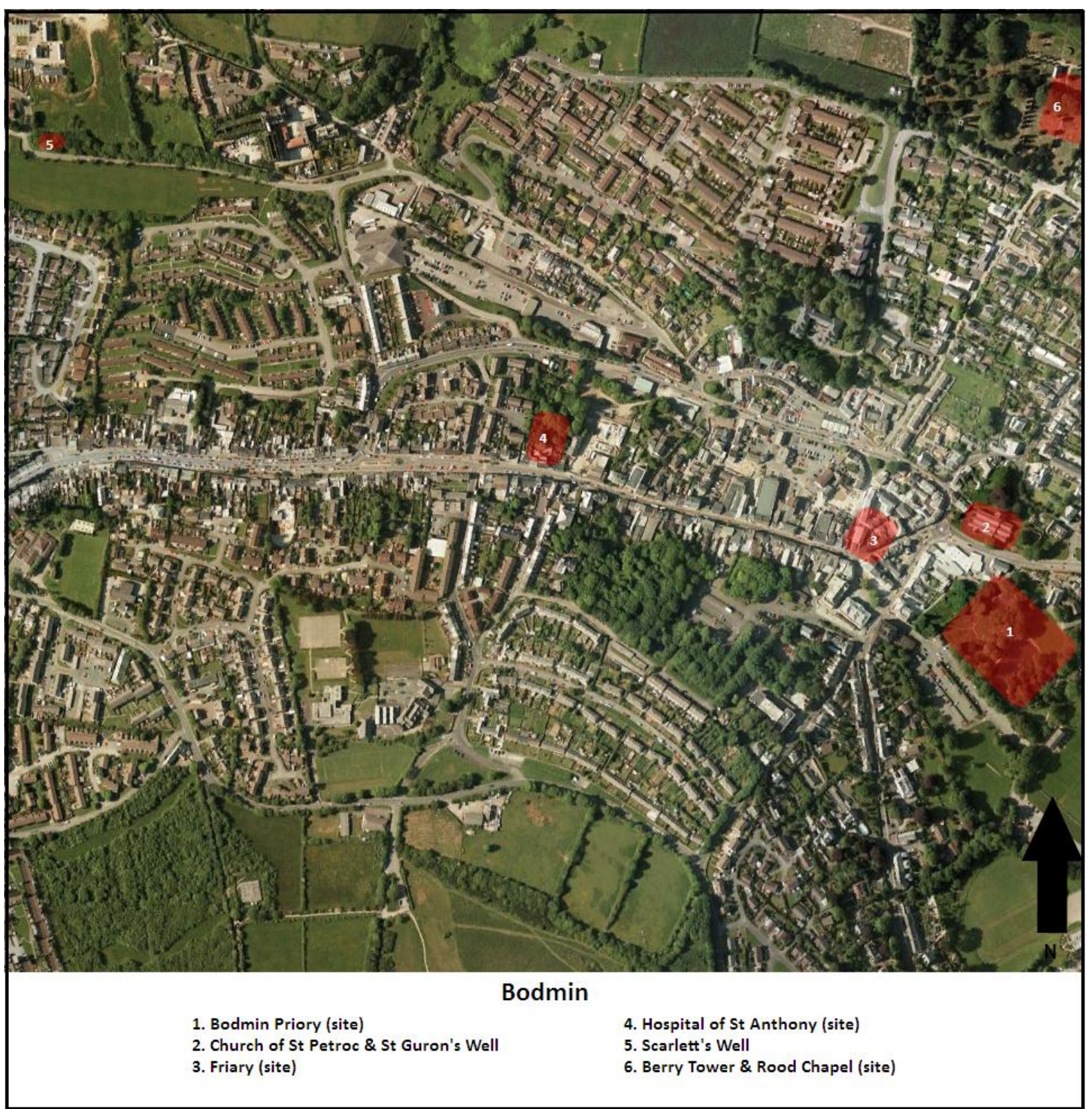

Figure 91. Map of central Bodmin with relevant sites marked. Original satellite image reproduced from (C) 2011 Google.

recorded in the Anglo Saxon chronicle do not take place until $981 \mathrm{AD}$, it appears that a small group of monks, either independently (possibly with the Guron figure) or with some of those whom had travelled down from Padstow previously, had established a form of Benedictine community - an order who were the first to develop the monastic rule and very powerful in this pre-conquest period (Jankulak, 2000, 59). The town was the see of Cornwall from 930 - 980 AD, when it moved to Saint Germans, and Bodmin was the wealthiest Cornish minster to survive the Norman Conquest (Olson, 1989, 72). 


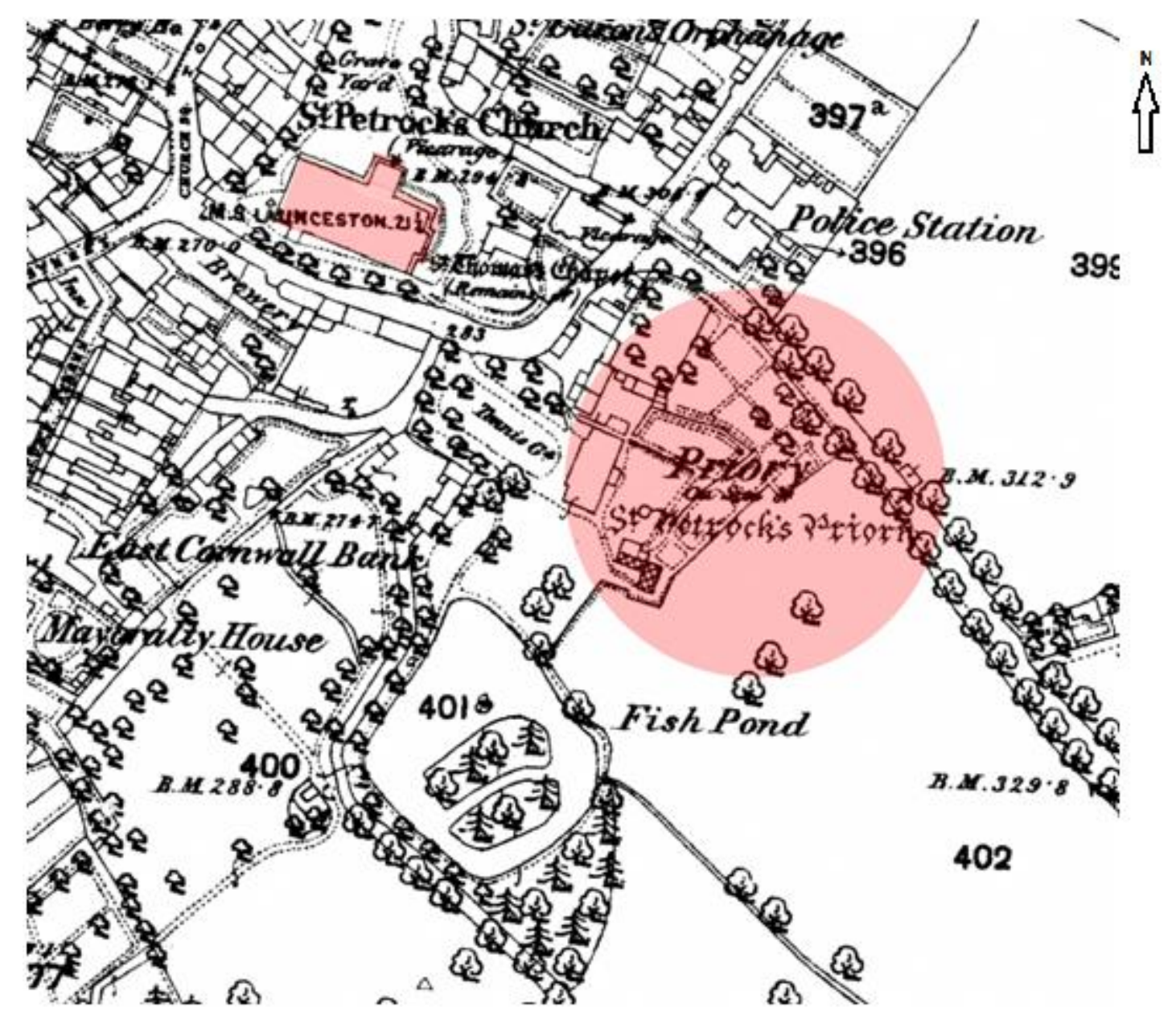

Figure 92. 1881 OS Map of central Bodmin, highlighted are the sites of the Priory church and cloisters (right) and St Petroc's Church (left). Map sourced from http://www.old-maps.co.uk. Highlighting is authors own.

Bishop Warelwast of Exeter re-established the monastery under Augustinian rule in 1124 and it stayed so until the Dissolution period in 1539 (Knowles and Hadcock, 1953, 128). Figure 92 above shows that Bodmin Priory occupied a site less than a hundred metres south of the Church of St Petroc, however it is only in the written record that Bodmin Prioy is now visible. The Priory is recorded as having a cloister directly south of the church (with a door on the cloister's north side providing access to the church), a dormitory, refectory, chapter-house, sub-prior chamber and a prior's chamber with a private chapel (Orme, 2010, 143). An almonry existed on the outer edge of the precinct, where visitors were entertained and food distributed to the poor, and surrounding this entire complex was a high perimeter wall with a gatehouse on the western face (Orme, 2010, 142). The Priory site is located on the main road which led from Exeter to Launceston and into Cornwall via Bodmin, and was the main thoroughfare into the county until the early 20th century; consequently the road held a high flow of human traffic. With regard to hospitality, the priors were expected to entertain and accommodate notable visitors, and this was so frequent an occurrence at Bodmin Priory that in $\mathbf{1 5 3 0}$ the prior made a formal complaint to the Bishop in Exeter about the 
burden of accommodating travellers at a moment's notice (Orme, 2010, 152). The taxation records of 1291 indicate the substantial lands and wealth accumulated by the Priory; with a total figure per annum reaching over $£ 100$, and its properties and estates extended in one direction to Cubert, and in the other to St Endellion, with others in north-west Devon at Hollacombe and Newton St Petrock (Hingeston-Randolph, 1889, 470; Orme, 2010, 151). The destruction of the priory during the Dissolution was so comprehensive that all that remains of this once celebrated pilgrim site are the remains of sculpted masonry which lie in the ornate hedges surrounding a public park situated on part of the priory's footprint (see Figure 93 below). The architectural historian Edmund Sedding has suggested that the fragments of carved masonry indicate that the priory was 'one of the finest buildings in Cornwall', and that the 'Norman architecture in Bodmin Priory must have been equal to any specimen in Great Britain' (Sedding, 1909, 27). The relics of St Petroc were initially kept in what is now the Church of St Petroc, the site of the Benedictine house, and were transferred to the newly built Priory church of Augustinian canons on October 8th 1124, and it is likely that a lavish shrine was constructed around them to confer prestige on the new house. As with the priory at Walsingham (Chapter 3), William Worcester's Itineraries provide a brief but succinct description of this shrine from his visit in 1478, calling it 'beautiful' and mentioning that it faced the Lady Chapel, a fact corroborated by Leland in his account written in the mid-16 ${ }^{\text {th }}$ century (presumably from a visit prior to 1539), which notes that 'the shrine and tumbe [tomb] of S/Petrok yet stondith in the'est part of the chirche' (Worcester, 1969, 86; Leland, 1907, Vol. I, 180). The Priory church did not play a parochial role (that was fulfilled by the church of St Petroc), but the laity were allowed freely into the building to venerate the shrine, pray and listen to services (Orme, 2010, 155). This regular use of the Priory church by townspeople is highlighted by a penance imposed on the prior in 1274, which required the 'services conducted on county business days should be said in low voices, with the choir doors shut', which suggests that visitors would usually be present, and the their exclusion was an anomaly (Orme, 2010, 155).

A gilded shrine is mentioned in the Miraculae when the saint's relics (including a skull) are taken to petition Henry I in the $12^{\text {th }}$ century, and this reliquary box is still preserved by St Petroc's church in Bodmin (Grosjean, 1956, 172 - 173). The casket (see Figure 94 below) is of Norman origin, made of painted ivory, bound with bronze and dates from the late $12^{\text {th }}$ century (Jankulak, 2000, 33). In 1177 St Petroc's relics were stolen by 'Martin', an Augustinian canon, and taken to the Abbey of Saint-Méen in Brittany (Grosjean, 1956, 137). The hagiographic accounts describe the journey undertaken to retrieve them, and the rescue party of monks from Bodmin eventually tracked them to the Abbey, where they were grudgingly returned in their ivory shrine box and the party made its way back to Winchester to display the relics to Henry II, who kept some for his own private devotion (Grosjean, 1956, 137 - 148). Upon presenting the relics to the king, there was a ceremony of the relics' reinstallation in front of the king, including an examination of relics, reading of patent letters and blessing the king with the relics, followed by the continuation of the ritual of reintegration which constituted the journey back to Bodmin with St Petroc's relics (Stubbs, 1868, Vol. I, 180). During this journey the procession stopped at Exeter and Launceston, where they sang hymns, held processions, sermons, vigils, and blessings with the relics, and upon arriving at Bodmin they celebrated numerous masses, exhibited the relics, and granted indulgences (Stubbs, 

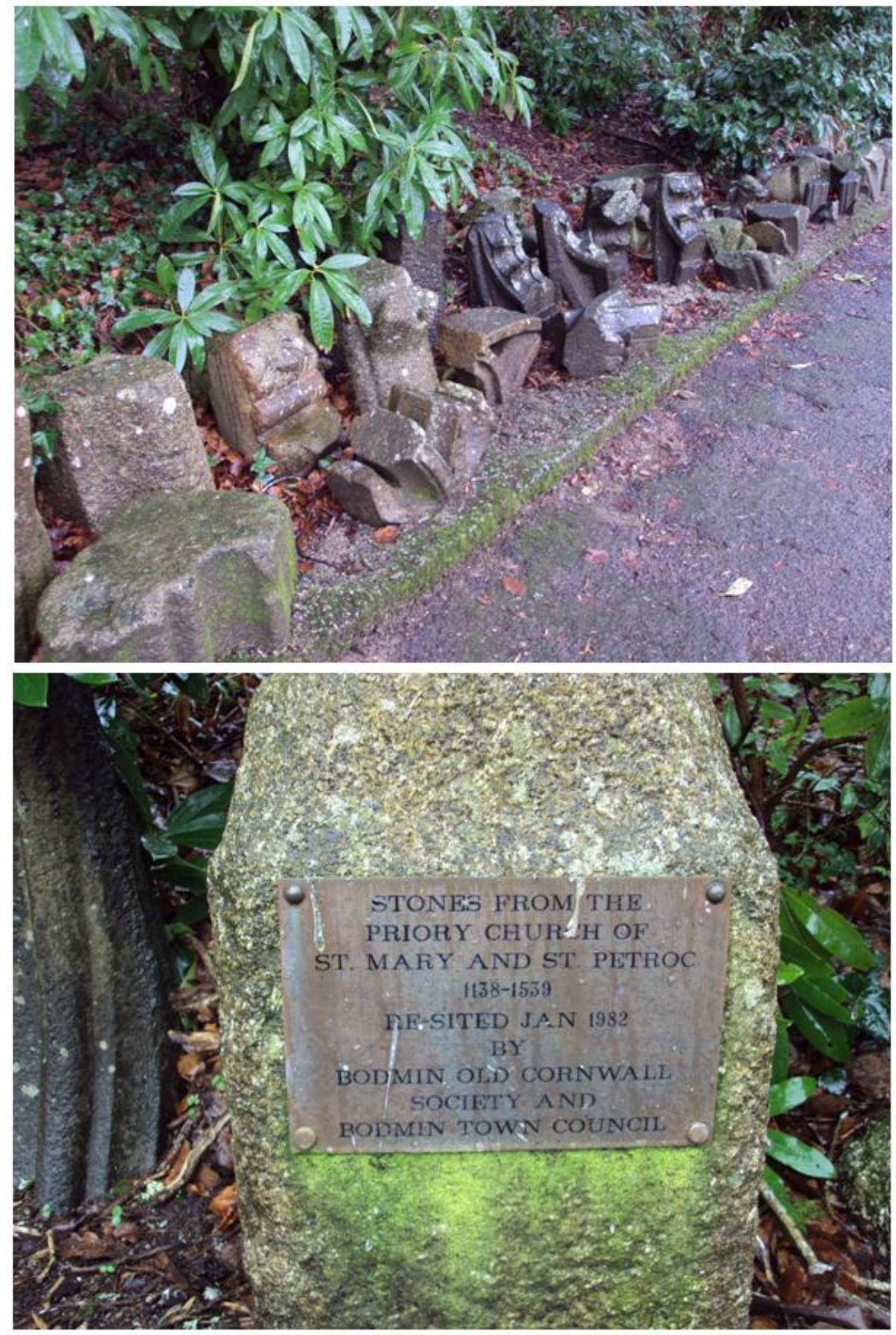

Figure 93. Fragments of sculpted masonry from the Bodmin Priory. Photographs taken by author. 


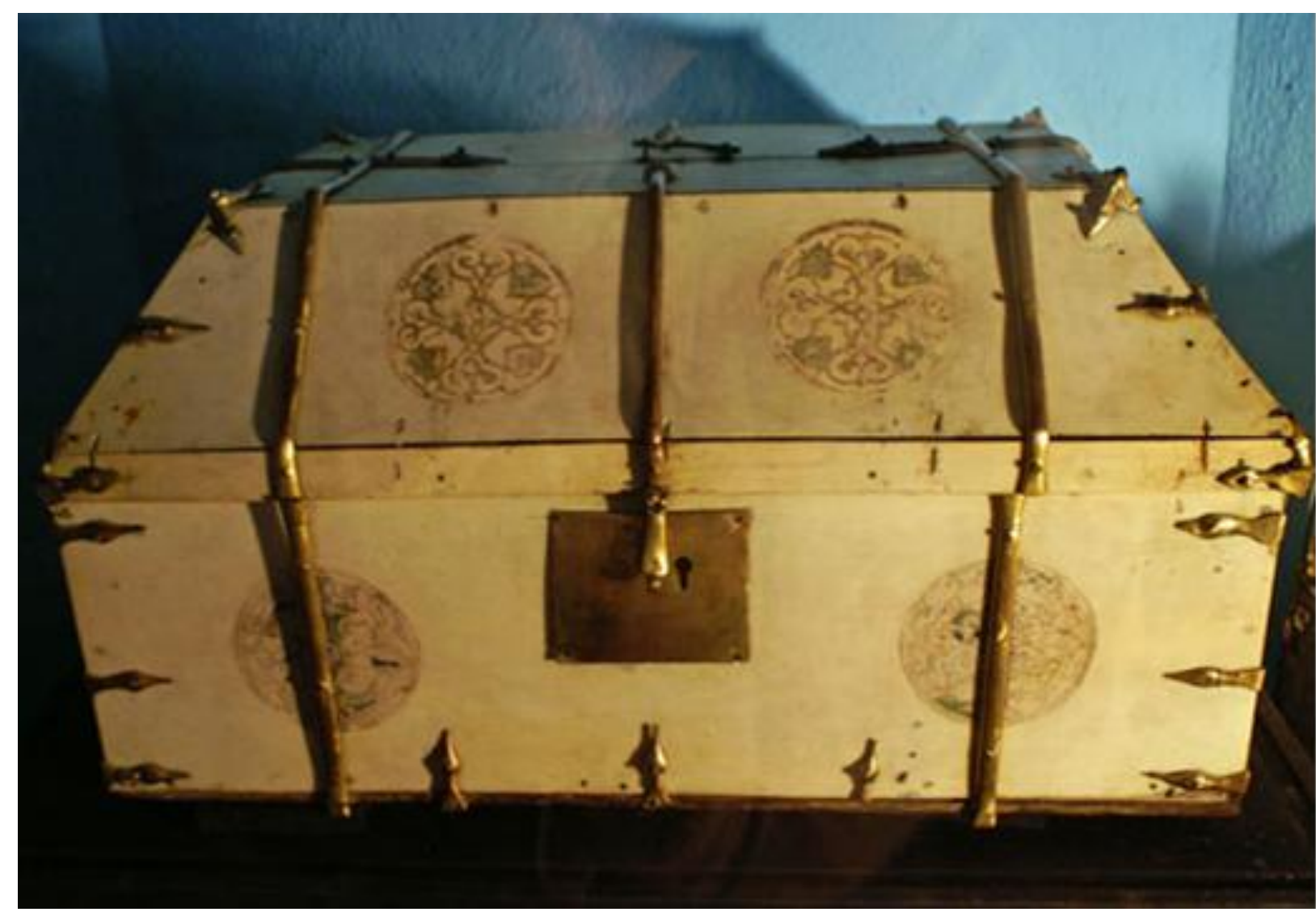

Figure 94. $12^{\text {th }}$ century ivory casket which contained the relics of St Petroc, now in the Bodmin church of St Petroc. Photograph taken by author.

1868, Vol. I, 180). The keen interest of King Henry II in retrieving the relics and the ceremonious procession back across the breadth of southern England to Bodmin illustrates the level of popularity and status that the cult of St Petroc enjoyed, not only within the saint's local county but also at the highest level of society and in the surrounding regions.

The presence of the Bodmin Gospels, compiled in the $10^{\text {th }}$ century, also attest to the significance of St Petroc to the laity. As a 'manumission of slaves', these manuscripts record those who were freeing their slaves, the slaves themselves and what they gave at the altar of St Petroc (Olson, 1989 58). In the second Vitae, we read of St Petroc appearing posthumously in a vision to an ailing 'tribunus', ordering that he free the criminals in his custody and he would then be healed (Jankulak, 2000, 68). This incident coupled with the recorded transactions at the shrine of St Petroc on behalf of the freed slaves, suggests that St Petroc held a special function for those who were not free men, perhaps acting as an unofficial patron. The Bodmin scriptorium recorded these manumissions and compiled a hagiographic dossier for St Petroc, featuring 'the names of kings and bishop invoked on their margins', further indicating the popularity of the cult of St Petroc through its steady reception of high status guests (Jankulak, 2000,71). One notable example of the link between St Petroc and slaves recorded within the Manumisson is that of an individual purchasing a female slave and her son 'at the [priory] church door in Bodmin', paying a fee to 'Aeilsige the portreeve', 
entering the church and freeing the two individuals 'on St Petroc's altar' (Kirkham, 2005, 13). Therefore the slaves were bought specifically to be freed in order to benefit the buyer's soul (Kirkham, 2005, 13). Recorded gifts to the Priory church included 20s. in the 1420 will of John Urban from Southfleet, and six silver gilt bowls with covers in 1512 from Dame Thomasine Percival of London (Orme, 2007, 55 and 144). A well is recorded as existing in the priory grounds which was dedicated to St Petroc, which now lies beneath a copse in the Priory Park. A $17^{\text {th }}$ century granite basin is visible, but the structure is partially submerged in the park's pond (see Figure 95 below).

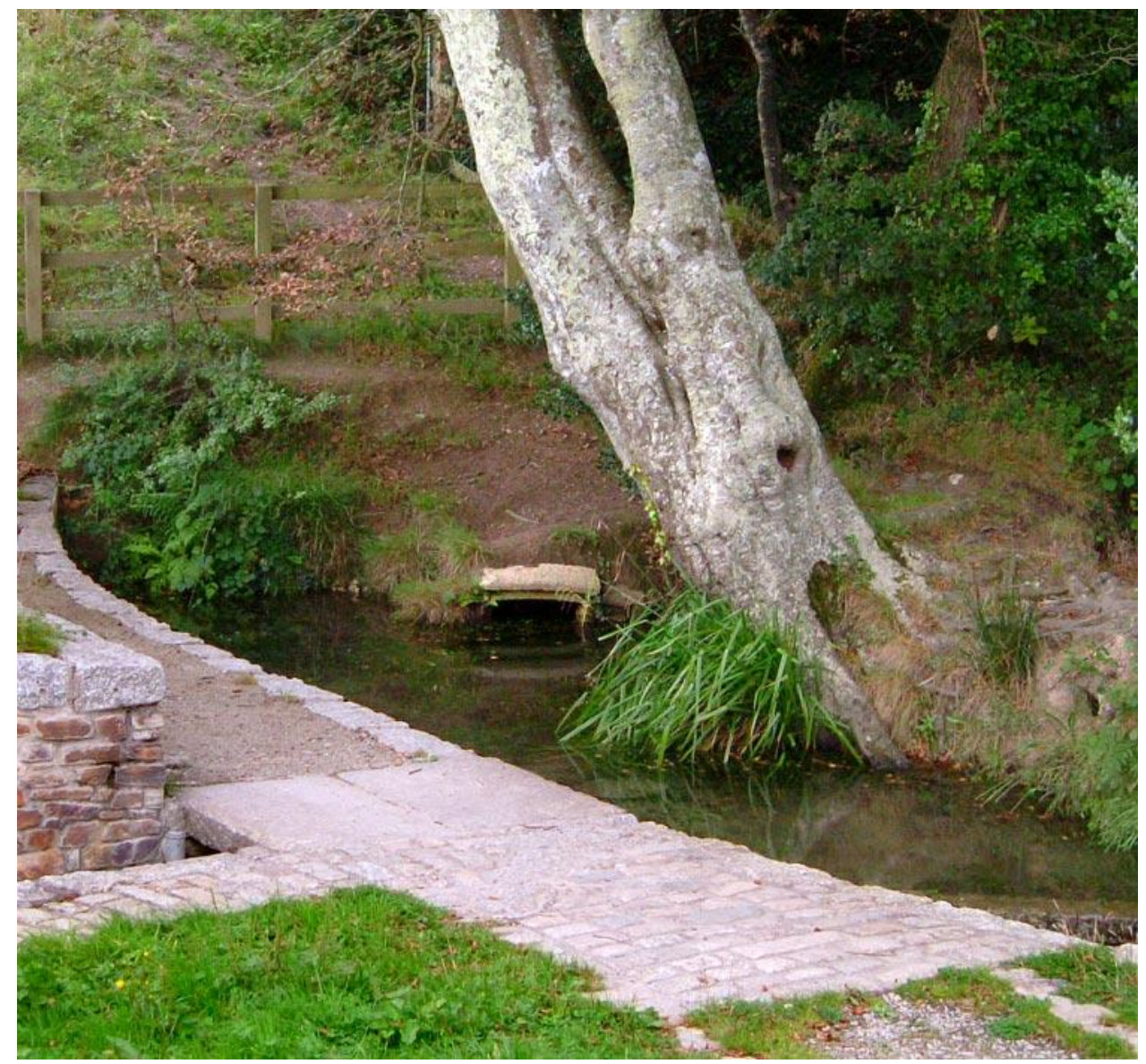

Figure 95. St Petroc's Well (centre) in Priory Park. Reproduced from http://arc.nationalwellsindex.org.uk/

The feast days of St Petroc feature not only within the Bodmin Gospels, but are also recorded in the $11^{\text {th }}$ and $12^{\text {th }}$ century English church calendars of Bury St Edmunds, Crowland, Exeter Cathedral, Glastonbury, Wells, Winchester and Worcester, under the following dates (Wormald, 1934, 77):

$$
\begin{gathered}
14^{\text {th }} \text { June }- \text { Death } \\
14^{\text {th }} \text { September }- \text { Exaltation } \\
8^{\text {th }} \text { October }- \text { Translation }
\end{gathered}
$$


These dates are also mentioned by William Worcester during his visit to Bodmin in the mid- $15^{\text {th }}$ century (Worcester, 1969, 86 - 89). Following the pattern we have discerned from previous case studies and research by other scholars in field of pilgrim behaviour, it is highly likely that these dates would have represented peaks in the attendance figures by pilgrims and featured processions around Bodmin bearing both the relics of St Petroc and the consecrated host (Frost, 2009, 45). It is likely that both St Guron's Well and St Petroc's Church featured heavily within the processional route around the city given their relevance to the town's founding legend, and also there may have been an element of boundary re-affirmation, 'blessing' the town's defensive walls (Frost, 2009, 45).

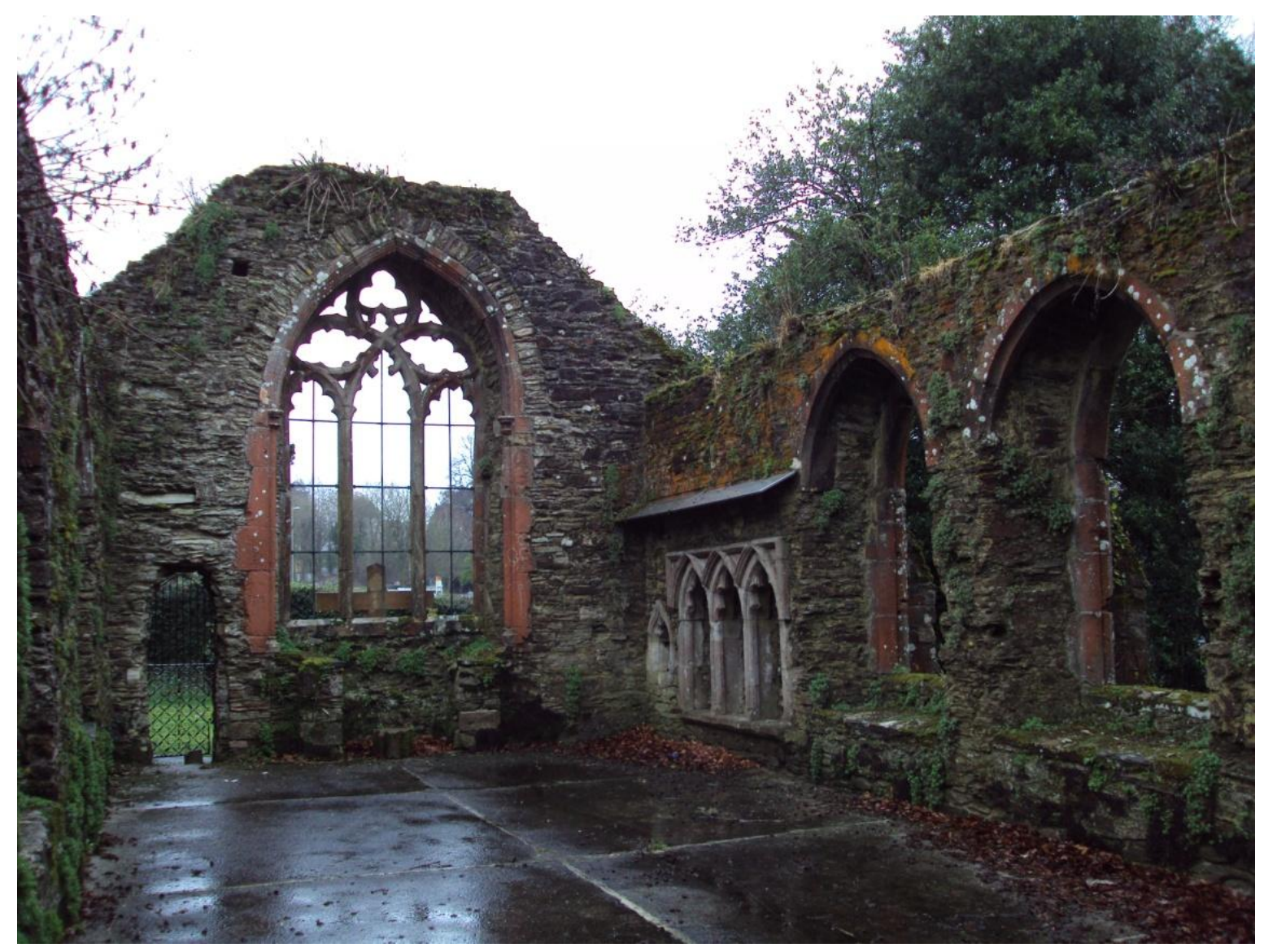

Figure 96. Remains of the Chapel of St Thomas Becket. Photograph taken by author.

\section{Church of St Petroc}

The church of St Petroc stands on the site of the original Benedictine monastic building. Originally constructed in the $12^{\text {th }}$ century, the church was substantially rebuilt in 1442 , but does retain some of its $12^{\text {th }}$ century fabric. Whilst the Priory was the dominant religious site in Bodmin, the church of St Petroc played the lesser role of parochial parish church, being first recorded as such in 1256, and is recorded in the Domesday Survey as presiding over 68 houses and a market (Orme, 2010, 155; Williams and Martin, 2002, 375). Next to the eastern end of the church is the ruined chantry chapel 
of St Thomas Becket (see Figure 96 above). This chapel was first mentioned in Bishop Brantingham's 1377 Register, where Richard Juyl is recorded as granting permission 'to have divine offices celebrated in his presence by a duly qualified priest in the chapel of St Thomas the Martyr' (Lysons and Lysons, 1814, 325). Little is known of the relationship between the church and the pilgrims, but its proximity to the Priory and dedication to St Petroc would have made it a logical site for inclusion on a pilgrim itinerary in Bodmin.

\section{St Guron's Well}

Adjacent to St Petroc's church is a structure commonly known as St Guron's Well (see Figure 97 below). This is a structure in two parts, consisting of an impressively solid granite well house standing directly next to the western door of the church, with the waters emerging below at street level through carved gargoyle heads into a trough, before disappearing under the roads of the town. The catalogue of Cornish holy wells compiled by Quiller-Couch and Clark (1894) states that the current well house is of $16^{\text {th }}$ century date, as are the gargoyles, and originally the water from the well ran through the churchyard (7 feet below the current level) into the town roads (Quiller-Couch and Clark, 1894, 46). This is corroborated by Richard Carew's notes in his 1602 'Survey of Cornwall', where he writes that the water 'runneth throw the churchyard, the ordinary place of burial for towne and parish. It breedeth therefore little cause for marvaile that every generall infection is here first admitted and last excluded.' (Carew, 2000, 127) This belief is recorded as redundant at the time of Quiller-Couch and Clark, but it may provide a clue as to a role of the well in the sacral landscape of Bodmin. As a curative well blessed by a saint so closely linked St Petroc, it played a role as a reminder and touchstone to that earliest time in Bodmin's religious history when it was first blessed and passed on from St Guron. It is possible that being located next to St Petroc's church it was used for baptisms when the water flowed through the churchyard.

\section{Scarlett's Well}

Still visible and recorded in Quiller-Couch and Clark's catalogue, 'Scarlett's Well' lies on the western approach to Bodmin, and flourishes alongside the brook which originates in the grounds of the priory and joins the Camel river at Dunmeer. The well has a history of curative properties; in the past locals bathed their eyes in the waters which provided a 'never-failing cure' for eye ailments (Couch and Clark, 1894, 46). Carew writes that the fame of the well 'grew so far and so fast that the folk ran flocking thither in huge numbers from all quarters', and a leaden bulla of Pope Clement VI (1342 1352) was found in the trough (Carew, 2000, 127). The name 'Scarlett' likely derives from the name of the Scarlett family, three of whom represented Bodmin in parliament between 1312 and 1341 (Maclean, 1874, 239). 

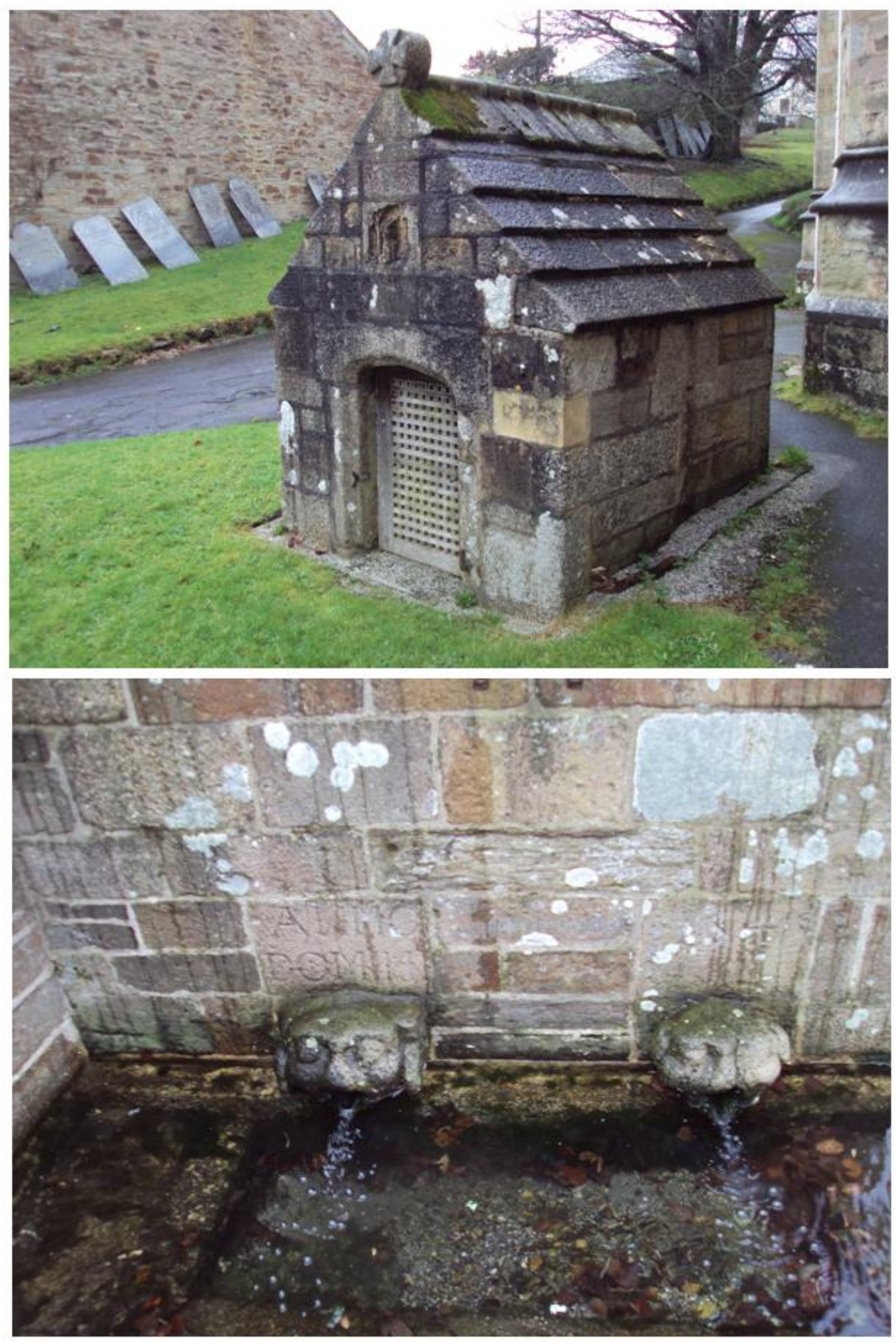

Figure 97. St Gurons Wellhouse (top) and trough (bottom). Photographs taken by author. 


\section{Franciscan Friary}

Bodmin Friary was established in 1240 in what is now Fore Street, under the patronage of the Earl of Cornwall, and was abandoned in 1538 (Knowles and Hadcock, 1953, 189). The Friary lay at the junction of Fore Street, Honey Street and St Nicholas Street, with Leland describing it in the 1530s as being south of the market place, so that it lay in the heart of Bodmin (Leland, 1907, Vol. I, 180 184). The domestic buildings are recorded as including a Great Chamber, other chambers, a frater (refectory), kitchen, brewery and a buttery (Orme, 2010, 155). The Friary was converted into a market hall after the Dissolution, but prior to that enjoyed a profitable and active role in Bodmin's ecclesiastical life (Midmer, 1979, 71). One record upon which we can rely is that of William Worcester whose detailed dimensional records were of great help when examining Walsingham Priory. From his mid- $15^{\text {th }}$ century manuscript he writes that by 1253 the Friary church had been built, because one Robert Clapethoyre claimed sanctuary there in that year. The church was $150 \mathrm{ft}$ long by $60 \mathrm{ft}$ wide, had a 'fine east window and hammer beam roof', and was filled with tombs of benefactors (Worcester, 1969, 87). The church lay south of the gatehouse, and was formally dedicated to St Francis in 1352 (Orme, 2010, 155). By the late $19^{\text {th }}$ century nothing substantial remained of the Friary. Some fragments of Friary's masonry are alleged to remain in shops along Fore Street, although these are likely to have been the result of stone salvaging after the Friary was destroyed (Midmer, 1979, 71). Shire Hall along Crinnick's Hill held the county Assize Courts (1837 1998), occupying part of the site of the Friary, and until the last century there was a building to the south of the Friary which was thought to have been the Friar's chambers (Midmer, 1979, 72).

\section{Hospitals}

The hospital and almshouse of St Anthony was first mentioned in a late $15^{\text {th }}$ century will by a John Carminow from Bodmin, who left 3s. 4d. to 'the poor of the hospital of St Anthony' and five other wills mention the hospital from 1501 to 1553 (Orme, 2007, 102). The hospital appears to have been associated with the chapel of St Anthony on the western end of Fore Street, and consisted of a number of small dwellings which housed the poor and could have been used by poor travellers for temporary shelter (Orme, 2010, 159). Wills from the late $15^{\text {th }}$ and early $16^{\text {th }}$ century indicate the presence of a hospital or lazar house associated with a chapel of St George, however its fate after 1531 is unknown (Orme, 2007, 102). The hospital of St Lawrence was a leper hospital which stood on the roadside southwest of Bodmin. As was frequently the case for lazar houses it was situated on a boundary, in this case by a bridge crossing the stream between Bodmin and Lanivet, which being close to a busy road gained the hospital significant donations (Orme, 2010, 162). However it would not have been attended by pilgrims, fearing contagion or simply not being able to make use of a lazar house as healthy individuals, and thus they would have used either the inns of Bodmin or the two other alms houses of St Anthony and St George for accommodation. However it must be noted that the concept of lepers as being completely marginalised from society, and conceptualised simply as 'outsiders' is a product of Victorian scholarship and currently undergoing a re-examination in scholarship (Roffey and Marter, 2012, 13). All of the hospitals are now destroyed. Other chapels lined the routes into the town, and were not attached to a hospital but were cared for by the guilds in Bodmin (Orme, 2010, 163). These included the chapels of St Anne (located close to Dunmere 
bridge, to the west), St Margaret (eastern road), St Nicholas (western road), and St Leonard (southeastern road (Lewis, 1848, 291)).
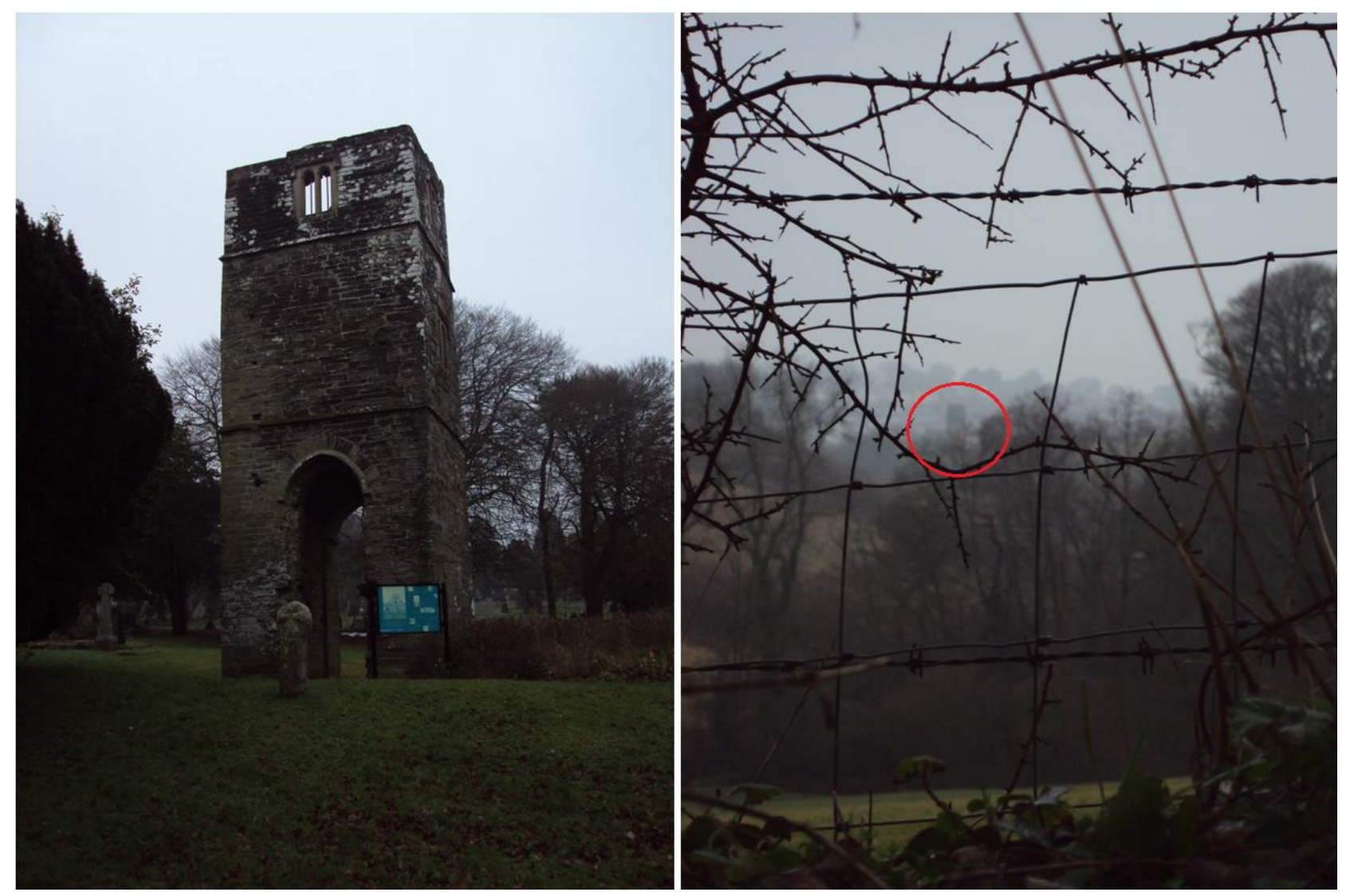

Figure 98. Berry Tower (left) and its visibility from the northern approach to Bodmin (right, with tower circled). Photographs taken by author.

Berry Tower (Church of the Holy Rood)

The Guild Chapel of the Holy Rood and its Berry Tower were built during the early $16^{\text {th }}$ century, the Berry site at the top of the hill looks down into Bodmin and is highly visible in the landscape (see Figure 98 above). Building started in 1501, and by that point there were three guilds situated on this hill; St Christopher's, the New Guild, and the Holy Rood Guild, whose chapel was established here in the late $15^{\text {th }}$ century and became a centre in its own right for the Cult of the Holy Rood, with (unusually) the right of burial and baptism (Olson, 1989, 54). Olson suggests that this may have been the site of an earlier Medieval settlement (prior to Petroc) than the town and religious establishment in the valley below (Olson, 1989, 54). The sizeable tower is visible from several miles when the traveller draws near Bodmin, acting as a landmark, and doubtless played a role in the directions passed on to a traveller when following the route down the Camel river valley to Bodmin. 
The 2005 Historical Character Survey of Bodmin did not reveal any remnants of Medieval fabric in the current inns and pubs within the town, however a great many shops along Fore Street retain their $18^{\text {th }}$ and $19^{\text {th }}$ century features. It is reasonable to argue, following similar examples in market and saint cult towns such as Salisbury,that these were built on the footprints of earlier buildings, which likely included inns catering for numerous visitors to the town (Haskins, 1912). Being situated along the primary road into Cornwall, leading down from Exeter via Launceston, Bodmin would have received a large amount of passing human traffic, both secular (such as merchants) and ecclesiastical. Using other similar towns (such as Salisbury or Winchester, both trade centres with their own saint cults) as comparative examples, Bodmin must have had many inns and guesthouses which offered accommodation. Doubtless the most notable visitors to Bodmin were entertained (however grudgingly) by the prior, and the poorest could hope for aid from the hospitals and alms houses mentioned above. It is likely that many travellers used inns within Bodmin, which despite not featuring in itineraries and the archaeological record, based on the examples of the previous case studies were indeed present and ready to capitalise from the steady stream of arrivals. 


\subsection{The Distribution of Pilgrim Souvenirs and Relics Relating to the Petroc Cult}

Bodmin was the chief town of Medieval Cornwall, and the county's premier ecclesiastical power base with a saint cult whose influence stretched far to the east of Britain, but curiously neither an archaeological nor written record survives indicating a pilgrim souvenir industry. Throughout Britain there was a 'colossal output of pilgrim souvenirs, of which only a tiny proportion - a few thousand, many of them mere fragments - now survives', and this reflects an issue raised earlier within this thesis, and which shall be explored in more detail in the Chapter 7 (Spencer, 1998, 13). In essence, does the lack of a souvenir industry relating to this cult point merely to a lack of found artefacts (which does not negate the existence of such an industry), or does it reflect a deeper issue; a difference in the manner in which St Petroc's cult was venerated by and sold to the laity? The well in the priory grounds would logically have been a feature of the pilgrim experience at the Priory, and following the evidence laid out by other cults such as Our Lady of Walsingham and that of St Thomas Becket, then it would seem likely that some form of ampullae holding these spring waters would have been available for purchase. However this cannot necessarily be assumed, as the celebrated cult site of St Winefride's Well in Holywell (Chapter 5) does not appear to have a record of pilgrim souvenirs or ampullae, with early visitors instead taking stones from the well to sanctify vessels of water in their own homes (Fleetwood, 1713, 85).

Relics feature prominently in the hagiography of St Petroc, with the theft of his relic casket in 1177 from the shrine in Bodmin priory church being one of the most detailed episodes in Vita II (Jankulak, 2000, 144). Outside of Bodmin and Cornwall 'three main centres of the diffusion of the liturgical cult of St Petroc emerge: significantly, perhaps, all three claimed relics of the saint at some time.' (Jankulak, 2000, 147) These were Exeter, Glastonbury and Winchester, and Salisbury may also have played a significant role in promoting St Petroc's cult (Olson, 1989, 42). That Exeter should feature St Petroc amongst its collection of relics is unsurprising; Devon in general shows evidence of a considerably early liturgical cult of St Petroc, and the see of Exeter adopted both St Germanus and St Petroc as 'duel patrons of the superseded Cornish diocese' (Jankulak, 2000, 151). The manuscripts which reveal details about these relics were primarily inventories of church property, and show that they vary from pieces of funeral shroud ('some of St Petroc, and some of the cloth in which his body was wound' was possessed by Reading Abbey (Jankulak, 2000, 215)), to ribs, vertebrae, hair (St Petroc's bones, clothes and hair were preserved in Exeter Cathedral in the $11^{\text {th }}$ century) and unidentified slivers of bone (Conner, 1993, 184). Exeter also had a parish church dedicated to St Petroc within the city grounds (Orme, 2009, 178). Exeter and the two other principal sites of diffusion of St Petroc's cult via his relics (Glastonbury and Winchester) can be seen as those which gave rise to the six other sites (Lyme Regis, Salisbury, Reading, Canterbury, Shrewsbury and Waltham) obtaining or claiming to possess relics of the saint as well, and were responsible for spreading the fame of St Petroc beyond the south-west of England (Jankulak, 2000, 151). 


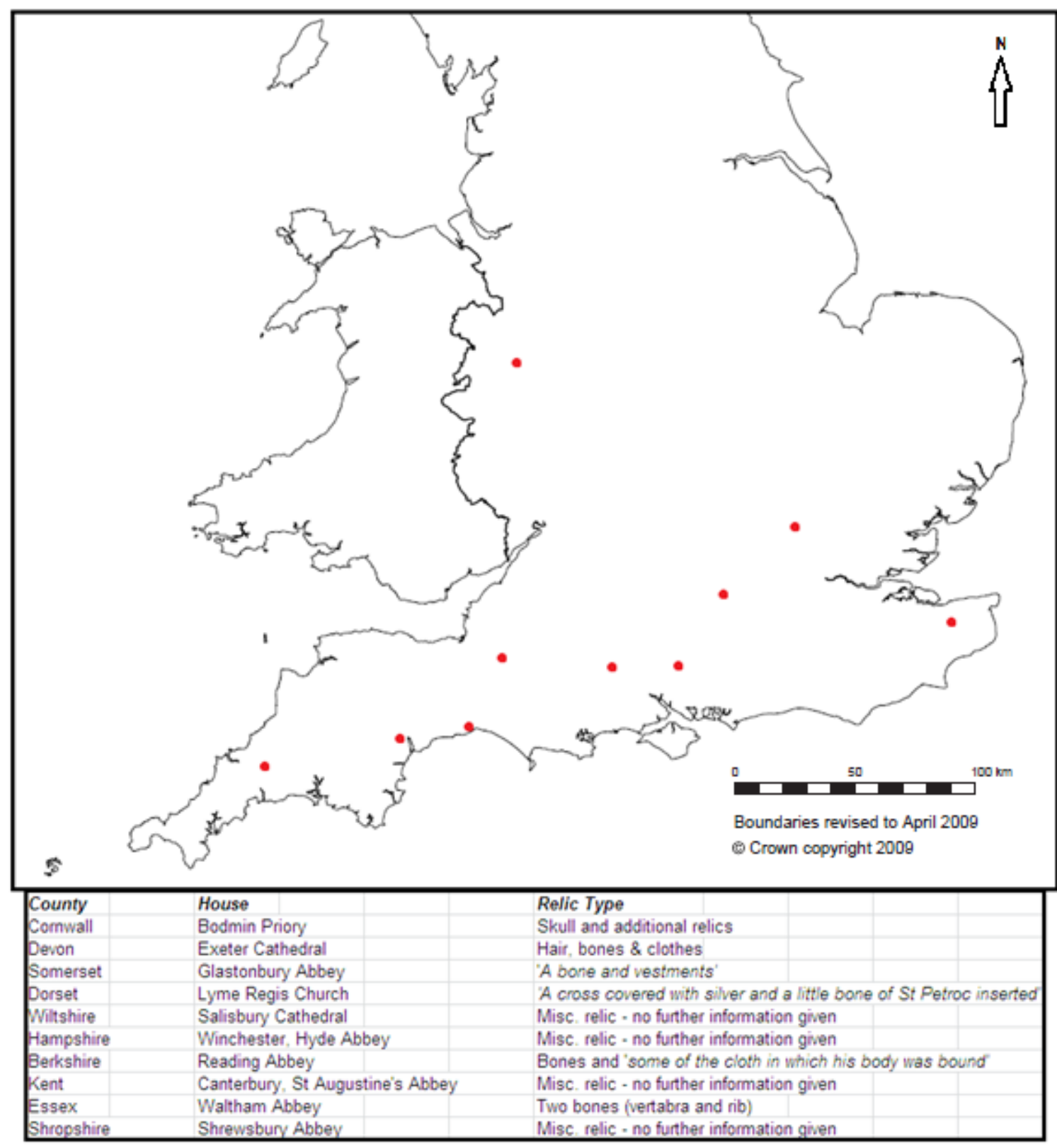

Figure 99. Distribution of reputed St Petroc relics in England (not concurrently) during the Medieval period. Data reproduced from Jankulak, 2000, 214-216. Redrawn from the Ordnance Survey GB Coastline map.

When the distribution of these relics is mapped (see Figure 99 above), there is a clear bias towards the south-central and south-west of England, as expected given the origins of the saint. Another feature of the distribution pattern which might be of relevance is that it broadly follows the route from London to Cornwall, which is the route that the relic casket took back to Bodmin Priory. Whether this event influenced the propagation of the saint's cult along this route is uncertain, however the distribution does mirror the major medieval road network between London and Cornwall as shown in royal itineraries and contemporary cartographic sources. Certainly destinations such as Exeter, Winchester, Salisbury, Reading and Canterbury were all pilgrim centres of varying degrees of fame, and if these relics of St Petroc were genuinely interred there then they too would 
have received some degree of devotion and diffusion amongst the laity. There are no surviving recorded instances of these relics working miracles, but their presence would have succeeded in furthering the presence of the cult in general consciousness. 


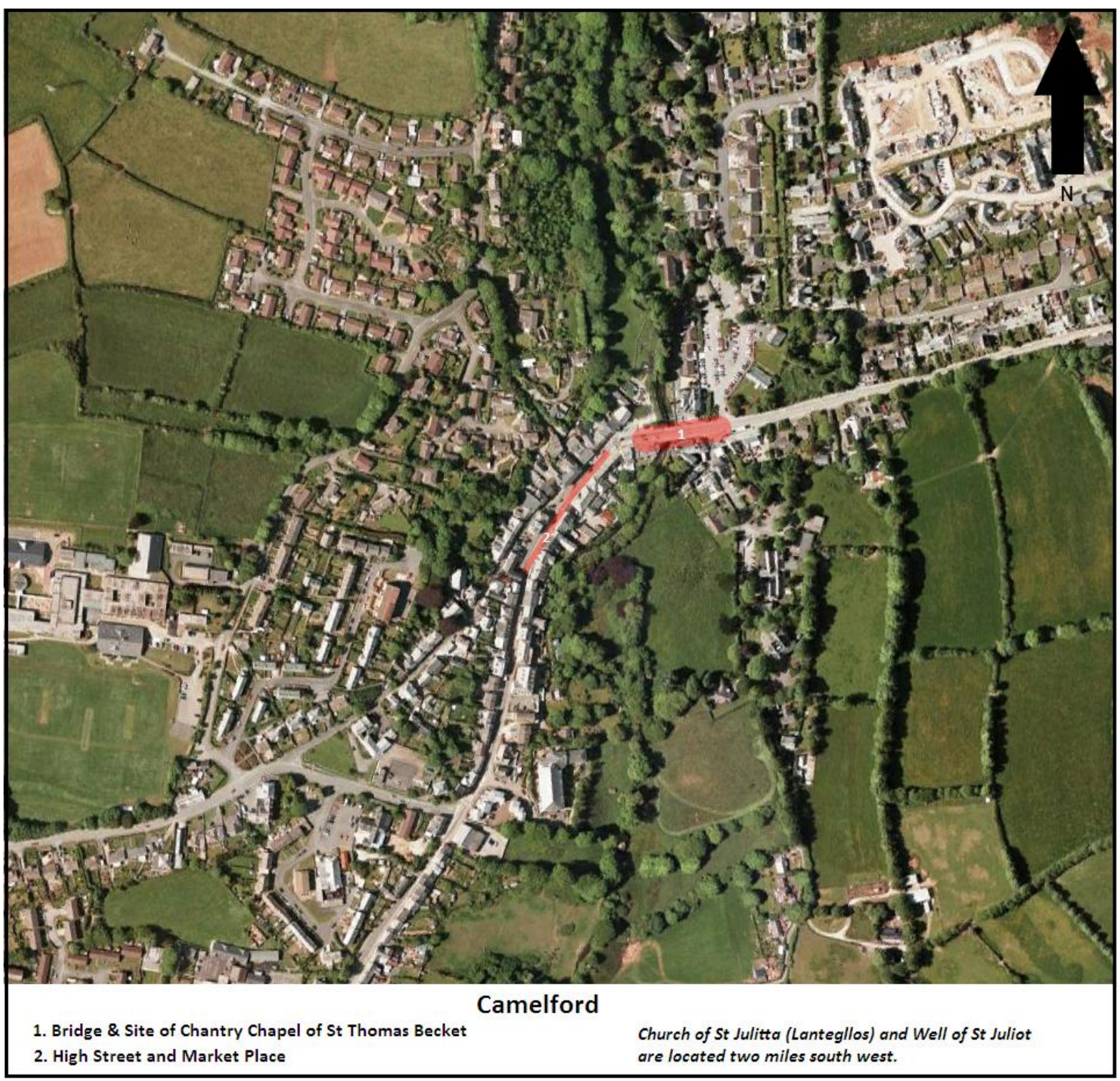

Figure 100. Map of Camelford with relevant sites marked. Original satellite image reproduced from (c) 2011 Google.

\section{Lanteglos-by-Camelford}

\section{Camelford}

Both the settlements of Camelford and Lanteglos lie within the parish of Lanteglos-by-Camelford in the Camel valley, approximately fourteen miles north of Bodmin. The valley skirts the western hinterland of Bodmin Moor, and is dominated by small, Medieval field patterns which follow the river Camel course southwards. Being located at one of the main river crossing points in the Camel valley ('Camel-ford'), Camelford has historically been the site of several convergences, including that 
of a 'great battle' in 823 between Cornish Britons and Saxons from Devon, and an enduring myth places the death of Arthur (during his battle against nephew Mordred) less than half a mile north at Slaughterbridge (Lewis, 1848, 497). Camden writes in his late $16^{\text {th }}$ century chorographical survey of Britain: 'At the Springhead of this river Alan standeth the little village Camelford, otherwise Gaffelford. Leland judgeth it was in old time called Kamblan, who writeth also that King Arthur our Hector was there slaine.' (Camden, 2010, 241) In 1259 Richard Earl of Cornwall made Camelford a free borough, and granted the burgess a market (held on Friday), and this was confirmed by Henry III in the same year, with the fair initially being held on St Swithun's feast day, but later also extending to 'the Friday after March 10th, May 26th, July 17th and 18th (the former day being noted for the sale of sheep and lambs), and Sept. 6th, chiefly for cattle.' (Lewis, 1848, 497) This privilege made Camelford an important local trade spot, helped by its location on a significant Medieval route leading from mid-Cornwall into northern Devon, now known as the A39 or 'Atlantic Highway'. This position makes it likely that those pilgrims undertaking a pilgrimage to Bodmin from the north east or Devon (as stated above, Devon held a significant Petroc cult) would have passed through Camelford, with the Camel valley providing an effective conduit down to the northern outskirts of Bodmin. During the $14^{\text {th }}$ to $16^{\text {th }}$ centuries, a chantry chapel existed near the river bridge dedicated to St Thomas the Martyr and St Mary, built by the town burgesses who paid a priest to say Mass here daily, and despite being in a state of 'official confiscation' after the Dissolution the building survived as a ruin until the late $18^{\text {th }}$ century when it was demolished (Sheppard, 1980, 67).

\section{Lanteglos}

Lanteglos church stands one and a quarter miles south west of Camelford, and serves as parish church to both Camelford and the hamlet of Lanteglos. 'Lanteglos' derives from the Cornish 'Nant-Eglos', meaning a church within a valley, which has led to suggestions that the establishing of Christian site here took place soon after the arrival of the first Welsh missionaries (Holmes, 1983, 40). Further clues which point towards the antiquity of Lanteglos come from the dedication of the church - St Julitta. Julitta was one of the daughters of the Welsh king Brecham, who is thought to have been instrumental in introducing Christianity to Cornwall in the $6^{\text {th }}$ century, and many of Brecham's other offspring are represented in the Cornish landscape, with St Adwenna (another missionary daughter) being the dedication of nearby Advent church (Lewis, 1848, 497). The road which leads from St Julitta to Camelford (via St Juliot's well, see Figure 101 below) is distinctly eroded and sunken into the landscape, resulting in high banks in some stretches, which may suggest many centuries of use by the laity of Camelford visiting their parish church. The current building dates from the $12^{\text {th }}$ century, however the only Norman fabric detectable is present in the north wall and transept, as the church underwent a substantial rebuild during the $15^{\text {th }}$ century.

St Juliot's Well or 'Jetwells' is 500 feet north of the church, reached by a descending track from the main road, leading down to the banks of a small unnamed river. In the past the well's waters were reputed to have curative properties for skin ailments, and during the late $18^{\text {th }}$ century draining of the marshland which surrounded the well, a labourer allegedly discovered a Medieval golden circlet believed to have been purposefully left as an offering to the well's patron (Maclean, $1874,310)$. The structure is small, roofed and eroded, with a grooved stone step at the foot of the 
opening. A small niche is present, but the interior walls are so thoroughly covered with moss it is difficult to discern the depth. The wells waters have been diverted into an underground stream and so it has been dry for many years, however the large thorn tree which overshadows the well is covered with tied ribbons, indicating that the lack of flowing water has not dissuaded visitors (see Figure 101 below). Maclean suggests that this may have been a site connected with the church, and used for baptisms (Maclean, 1874, 310 and Broadhurst, 1989, 1).

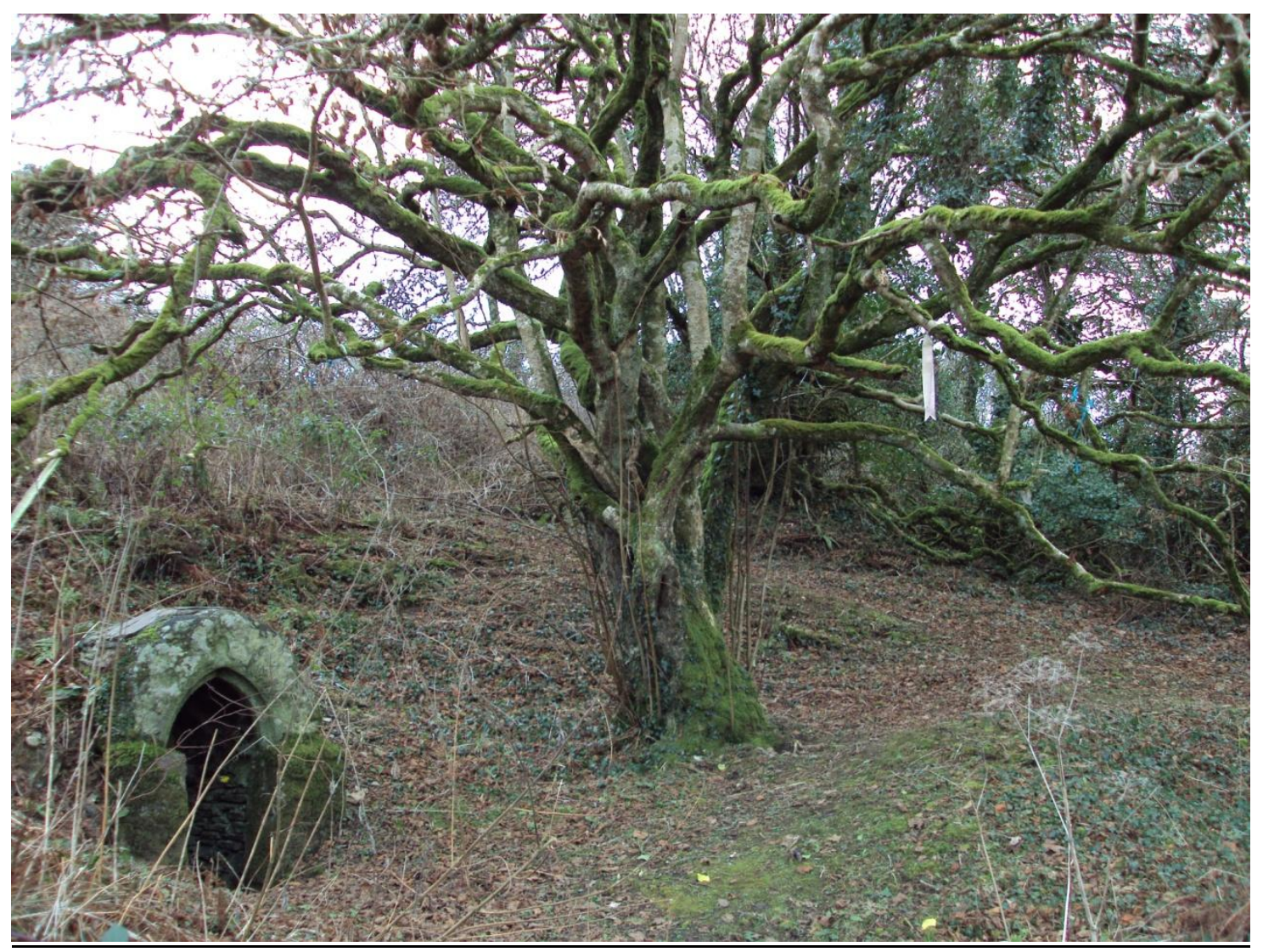

Figure 101. St Juliot's Well, near Camelford and Lanteglos parish church. Note the ribbons tied on the branches of the neighbouring tree. Photograph taken by author.

\section{Advent}

A mile south from Camelford, along one of the many lanes which connect the farming settlements of the Camel valley, the Bodmin-bound pilgrim comes across the church of St Adwenna, in Advent parish. Both Adwenna and Julitta are linked hagiographically by their father King Brecham, and initially St Adwenna's was a chapel of the Lanteglos parish church (Maclean. 1874, 318). The church was constructed in the $13^{\text {th }}$ century, and sits on a noticeable rise in the landscape, at the upper limit of the eastern valley slope. It sits within a banked circular graveyard, and access prior to the $20^{\text {th }}$ century was through a still-present path cutting though the field holding both church and graveyard (Maclean, 1874, 318). The $14^{\text {th }}$ century tower bells would have had an extensive range across the 


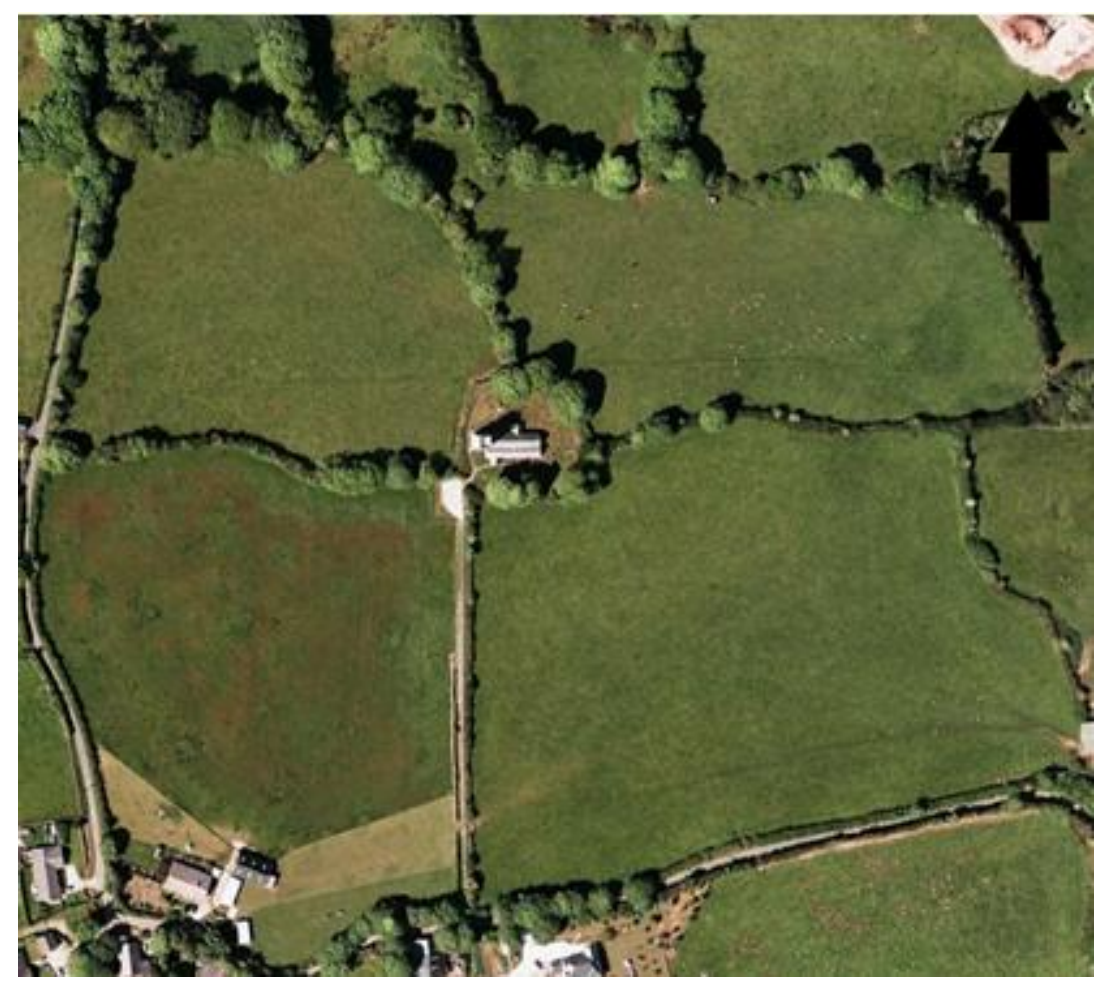

Figure 102. St Adwenna's church in circular graveyard within field system. Original satellite image reproduced from (c) 2011 Google.

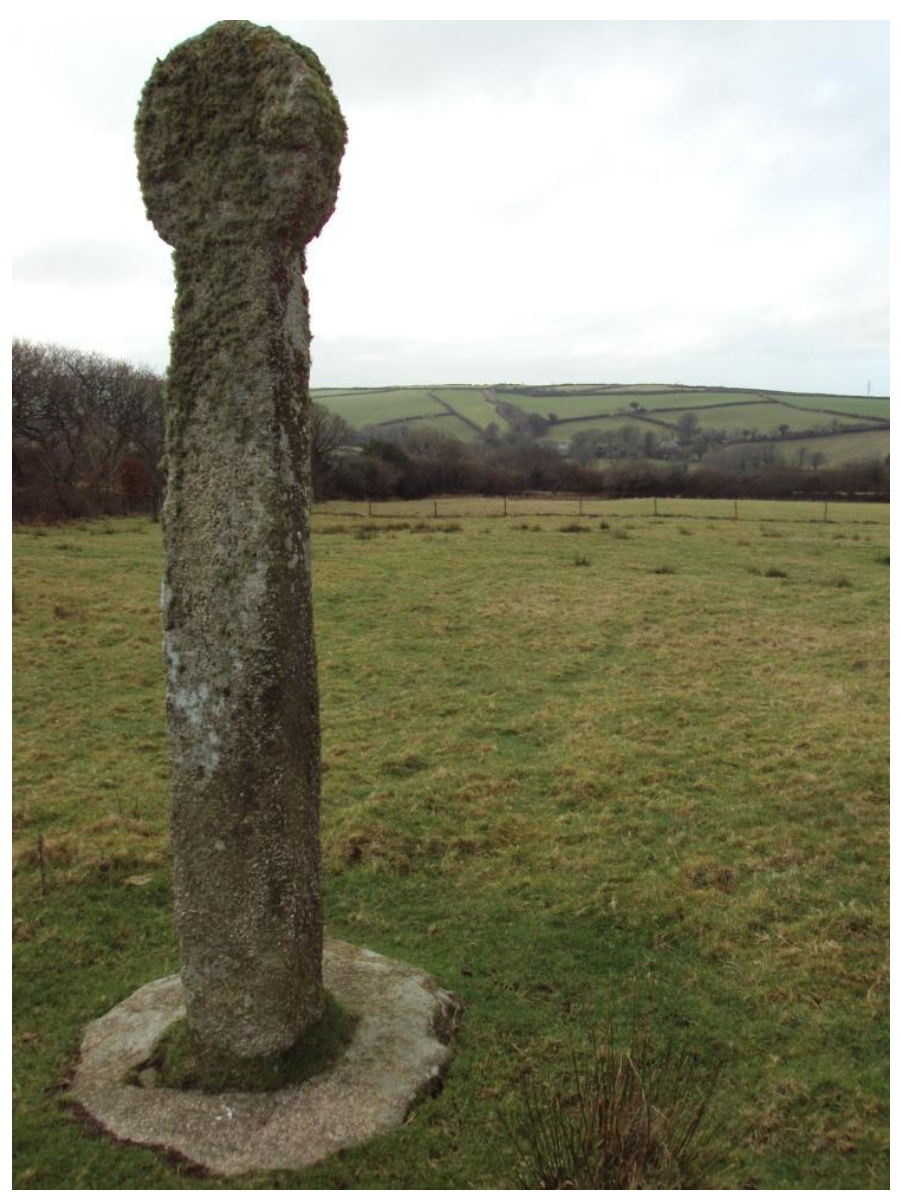

Figure 103. Free Standing Wheel Cross near Advent Church. Photograph taken by author. 
valley, demarcating approximately the parish boundary and forming a highly identifiable landmark on the horizon for the pilgrim. The situation of churches on prominent positions in the landscape becomes a frequent feature of travel through this valley towards Bodmin.

In addition, 'there were particularly dense clusters of crosses in the landscape around some important Cornish collegiate churches such as St Neot and Bodmin.' (Turner, 2006b, 35) Crosses were a defining characteristic of the Medieval Cornish terrain, and approximately 700 examples of these monuments remain, fifty of which bear distinctive Early Medieval decoration (Preston-Jones, 1999). Free standing crosses often fulfilled multiple functions as directional aids, preaching posts and boundary markers, with a high frequency of more simply decorated crosses appearing in the later eleventh century (Turner, 2006a, 162). One such example lies in the field opposite Advent church, standing over 8 feet tall, which likely acted in part as a signpost towards the church for those travelling from around the parish to St Adwenna's (see Figure 103 above). It also might denote a place for the pallbearers carrying coffins to the church to rest, as there are no records of specific 'corpse roads' (routes used primarily to transport the dead to burial grounds) in this vicinity (Maclean, 1874, 319). The most common role of crosses in Medieval Cornwall could arguably be that of the 'Churchyard Cross', which were often set up close to a church and are thought to delineate a boundary between spatial use i.e. profane and sacred (Turner, 2006b, 34). In a more general role as a landmark the cross may also have acted as a notable site which featured in directions passed on to travellers unfamiliar with the immediate landscape, and the potential role of this cross for the traveller is further explored in the penultimate section in this study.

\section{Carwether}

Whilst not being specifically relevant to the pilgrim, the remains of Carwether village (see Figure 104 below), south of Advent church, was a site which the traveller would have encountered on their way down the Camel valley, and so is worthy of a brief mention in this section. Situated near the 'Devil's Jump' on the uppermost limit of the Camel valley, the Carwether site displays occupational continuity from the Iron Age to perhaps as late as the $19^{\text {th }}$ century (Johnson and Rose, 1994, 36). Bordered by pasture fields currently used for grazing sheep, the settlement remains show evidence of three Medieval longhouses, twelve ancillary buildings, and small garden or paddock plots, all surrounded by a strip field system typical of this region (Johnson and Rose, 1994, 36 and Turner, 2006a, 34). The name Carwether has been thought to contain the Cornish element 'ker', which suggests its pre-Medieval origins lie in the rounds of the Iron Age or Romano British period (Holmes, 1983,12 ). There is a clearly visible banked track-way (part of which one uses to reach these upper slopes) leading from the settlement to a spring at Devil's Jump. This site provides us with an impression of the small feudal/agricultural settlements which, as we can see in the distribution map of $14^{\text {th }}$ century Messuages in Camelford Borough (Figure 89), were commonly distributed throughout this valley. 

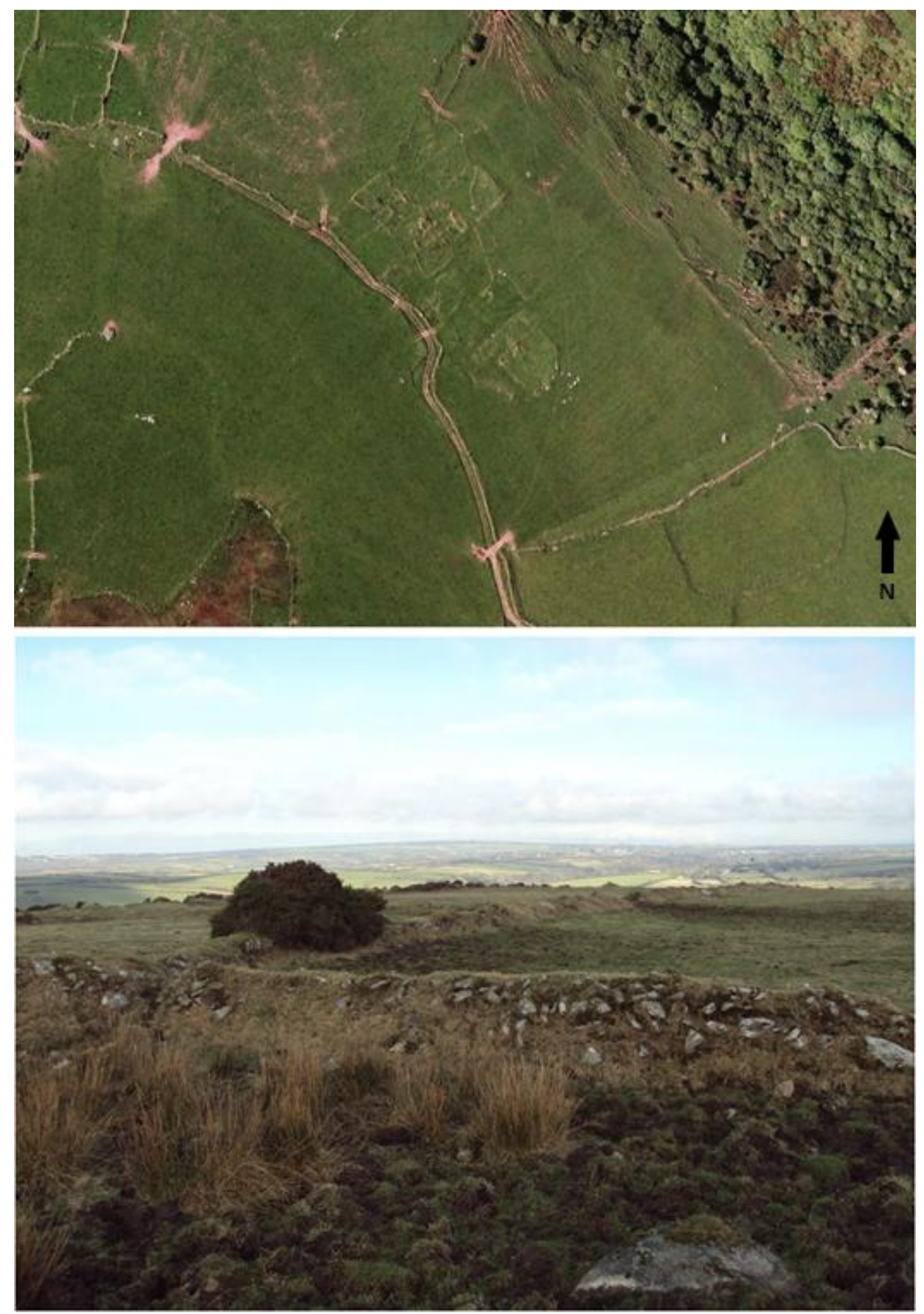

Figure 104. Aerial image of Carwether DMV (top), and ground level appearance facing east towards Bodmin Moor (bottom). Original satellite image reproduced from (C) 2011 Google, photograph taken by author. 


\section{St Breward}

Six miles north of Bodmin and known from 1580 to the late $19^{\text {th }}$ century by its corrupted form 'Simonward', is the parish of St Breward (Maclean, 1874, 1). Bounded by Advent parish to the north, St Clether to the east and Blisland on the south, with Bodmin Moor stretching away to the west within its parish boundary, St Breward parish covers just over nine thousand acres and encompasses 'two of the loftiest hills in the county', Roughtor and Brown Willy (Maclean, 1874, 3). The highest church in Cornwall at $700 \mathrm{ft}$ above sea level, the parish church (dedicated to St Branwalder in 1278) is first mentioned in a $12^{\text {th }}$ century deed, in which 'the church of St Brewvered de Hamthethi was granted to the priory of Tywardreth by William Peverell', lord of the manor (Maclean, 1874, 1). The original structure was built in the Norman style, and underwent significant alterations during the $14^{\text {th }}$ century. The tower retains its $12^{\text {th }}$ century character, with carved figures holding bottles or (eroded) musical instruments in the corbels over the bell chamber which are thought to signify an event from the life of St Branwalder, about whom very little is known outside of two cursory mentions in the 'Exeter Martyrology' (Doble, 1965, 119). The sole source of hagiography for St Branwalder (also referred to as St Breward or St Branwalator), the Exeter Martyrology recounts that this British monk preached in Cornwall and the Channel Islands with St Samson, and may also have visited Brittany (Doble, 1965, 119). St Breward's feast days occur on the $9^{\text {th }}$ February and the $6^{\text {th }}$ June (Doble, 1965, 119).

Several hundred feet further south into St Breward parish are the remains of a small track leading down to the valley floor, a substantial structure which houses a holy well (see Figure 105 below). The Monasticon records two nearby chapels in 1442 dedicated to St Michael and St James, which might account for the well being dedicated at points in its history to St Branwalder, St Michael and St James (Dugdale, 1718, i. 183). In their catalogue of Cornish holy wells, Quiller-Couch and Clark record that 'when inquiring the way to this well, the locals did not know it by the recorded name but spoke of it as "The Holy Well at Chapel", indicating a survival in local tradition of the association between the well and one of the chapels previously mentioned (Quiller-Couch and Clark, 1894, 24). Curative properties of the well's waters are also recorded, particularly in reference to eye complaints, a feature which seems to be common to many Cornish wells (Quiller-Couch and Clark, 1894, 24). The structure which houses the well whilst not extravagant in size or design, has thick walls, a curved stone roof and a window-like opening for access to the waters. It receives little recognition in the written record, yet its size and seemingly un-altered fair condition indicate that potentially it was a notable local feature, which would have received attention from those passing through the parish. 


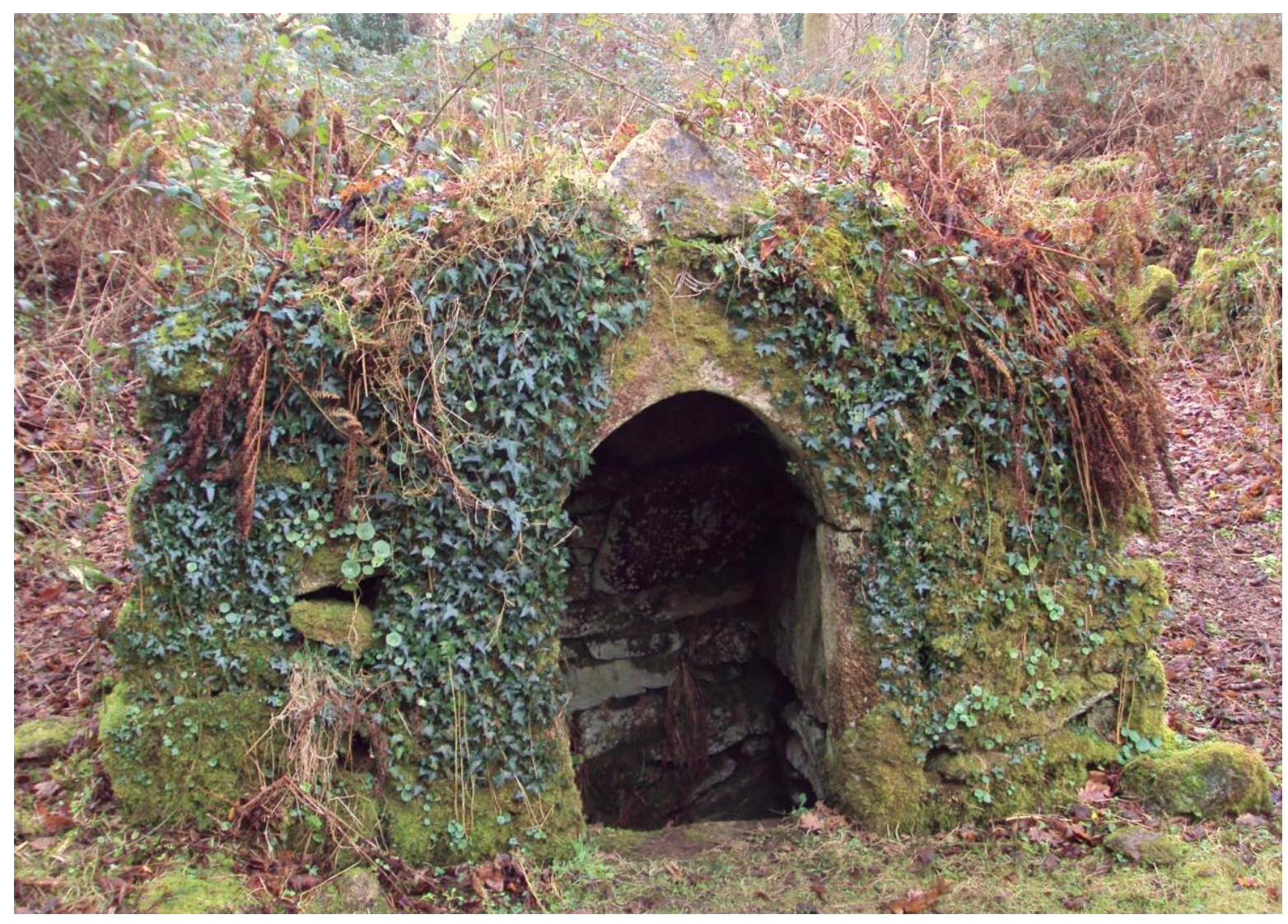

Figure 105. Holy Well at St Brewards. Photograph taken by author.

\section{Helland}

The final parish encountered prior to arriving in Bodmin, Helland, is first mentioned in the written record in an Episcopal register in 1285, and aside from an historical local cloth industry in Clerkenwater is an entirely agricultural parish (Maclean, 1874, 2). There are two prehistoric earthworks near Lower Helland (known locally as 'Penhargard Castle' and 'Lower Helland Castle'), both connected by paths, and when considering the small lanes which run across the Helland 'we may also conclude that the existing roads through the parish, from Bodmin through Clerkenwater to Helland-Bridge, and from Council Barrow to the same place, though in some parts slightly diverted, are ancient roads.' (Maclean, 1874, 6)

The church of St Helena was formally endowed by the Prior of Bodmin, and this dedication may be referenced in the name of the parish, Helland, although this differs from other more obvious parish eponymous dedications from the corruption of Helena to Helland and the loss of the 'St' element (Davies, 1838, 150). The oldest stonework in the church dates to the $13^{\text {th }}$ century; however it is situated on the site of an earlier church (Maclean, 1874, 6). The dedication to St Helena is unusual within this landscape, being neither a local missionary saint nor 'Celtic' in category. The mother of Emperor Constantine I, Helena is credited with finding the relics of the True Cross, however in a legend whose diffusion is credited to Geoffrey of Monmouth Helena is presented as a daughter of the British King Cole of Camulodunum, and holy wells dedicated to her were found 
across the country (Harbus, 2002, 90). This perceived 'British' connection, promoted by Monmouth to the laity in the $12^{\text {th }}$ century, may help explain the presence of this dedication in a landscape primarily rooted in British saints, a trend further explored in the following section of this chapter. The hagiographic or 'religious myth' elements of such tales aim to promote an idea of what the past should be like, placing a saint or event within the daily rhythms of the general laity (Harvey, 1997, 15). 


\subsection{Pre-Reformation churches in Cornwall: Their Dedications, Role in the Parish, and Relevance to Pilgrims}

There is a high variety and intense localisation of the dedications found in Cornwall's one hundred and eighty five surviving pre-Reformation churches (the data for which are supplied in Appendix D). What is most striking is that St Petroc's dedication frequency outweighs that of the most common dedicatory figure in most British regions, St Mary the Virgin. The work of Graham Jones shows only three dedications for Mary in Cornwall dating before the $17^{\text {th }}$ century (Jones, 2007, 129). Unlike other counties in Britain, the universal saints are under-represented. For example, St Peter holds just two dedications at Landrake and Shevioc, one of which is shared with St Paul, the latter apostle's only surviving dedication in Cornwall. So varied and unique are the majority of the dedications to what can be considered 'minor' or local saints that plotting their dedications shows no pattern. Their variety is too great to represent in a graph, and the frequencies for recurring saints are so low that no distribution patterns in relation to a 'universally preferred saint' can be determined from these data. It is likely that for at least some of these dedications there is corruption within the names, and if plotted with their 'original' saint names certain frequencies would be evident. However the determination of 'original' names from their subsequent corrupted forms is so prone to error, thanks to the multitude of factors which prompt the corruptions of names from one dialect to another (in the case of some Cornish saints for instance, from Welsh to Cornish to Latin), that I have not attempted it due to the theme of linguistic corruption not being central to the scope of this thesis. This apparent lack of regular dominance by the universal saints suggests a spiritual landscape which differs to the others discussed in this thesis, and one which may have operated within a different framework of saint preference. As stated above, whilst we should be careful of portraying Cornwall as a complete anomaly within the British ecclesiastical landscape or as an isolated bastion of 'Celtic' Christianity within an country dominated largely by Anglo-Norman and Roman saint cults, there can be no doubt that an element of cultural difference was prevalent in the Cornish ecclesiastical landscape, at least in terms of primary parish church dedications (Turner, 2006a, 3).

Undeniably, the arrival and presence of missionary saints from Roman Britain, Wales, Ireland and Brittany in Cornwall have left their mark within the parish names and church dedications to a degree which outweighs many other regions of England, and the county has more in common in this regard with Wales than (for example) Wiltshire (Handley, 2001, 178). The locations of the earlier churches to appear in Cornwall are worth noting, as those such as St Felicitas' at Phillack being surrounded by extensive burial grounds, which may have been in use since the Iron Age (Turner, 2006b, 30). This may be a legacy held by the circular banked graveyard which surrounds the church of St Adwenna in Advent parish, as suggested by Thomas' model for church development (i.e. from unenclosed burial ground to enclosed cemetery to a church within a graveyard (Thomas, 1971, 48 68)). However, caution must be applied when investigating this aspect as the 'church and circular banked graveyard' sites are exceptional in the record (Petts, 2002, $24-46)$. These early sites often bear a similarity to those found in Wales, with their parish name being constructed from 'Ian( $n)^{\prime}$ followed by a form of their patron saint's name (either in a Cornish or Latin rendition), six of which 
survive that feature circular or curvilinear churchyard boundaries, including St Kew, Lanivet, Madron and Lewannick (Turner, 2006b, 31). However, it is by the $11^{\text {th }}$ century that we see the full flourishing of Cornwall's ecclesiastical landscape, with its varied saint dedications and cults, and in the $12^{\text {th }}$ century another expansion in church building or restoration. This creates the impression of a vibrant sacral environment with a mixture of saints being celebrated from a variety of origins, and is at odds with the long held $19^{\text {th }}$ century view of Cornwall as an isolated 'Celtic' enclave, populated by lonely simple monasteries, hermits and holy wells (Turner, 2006a, 3).

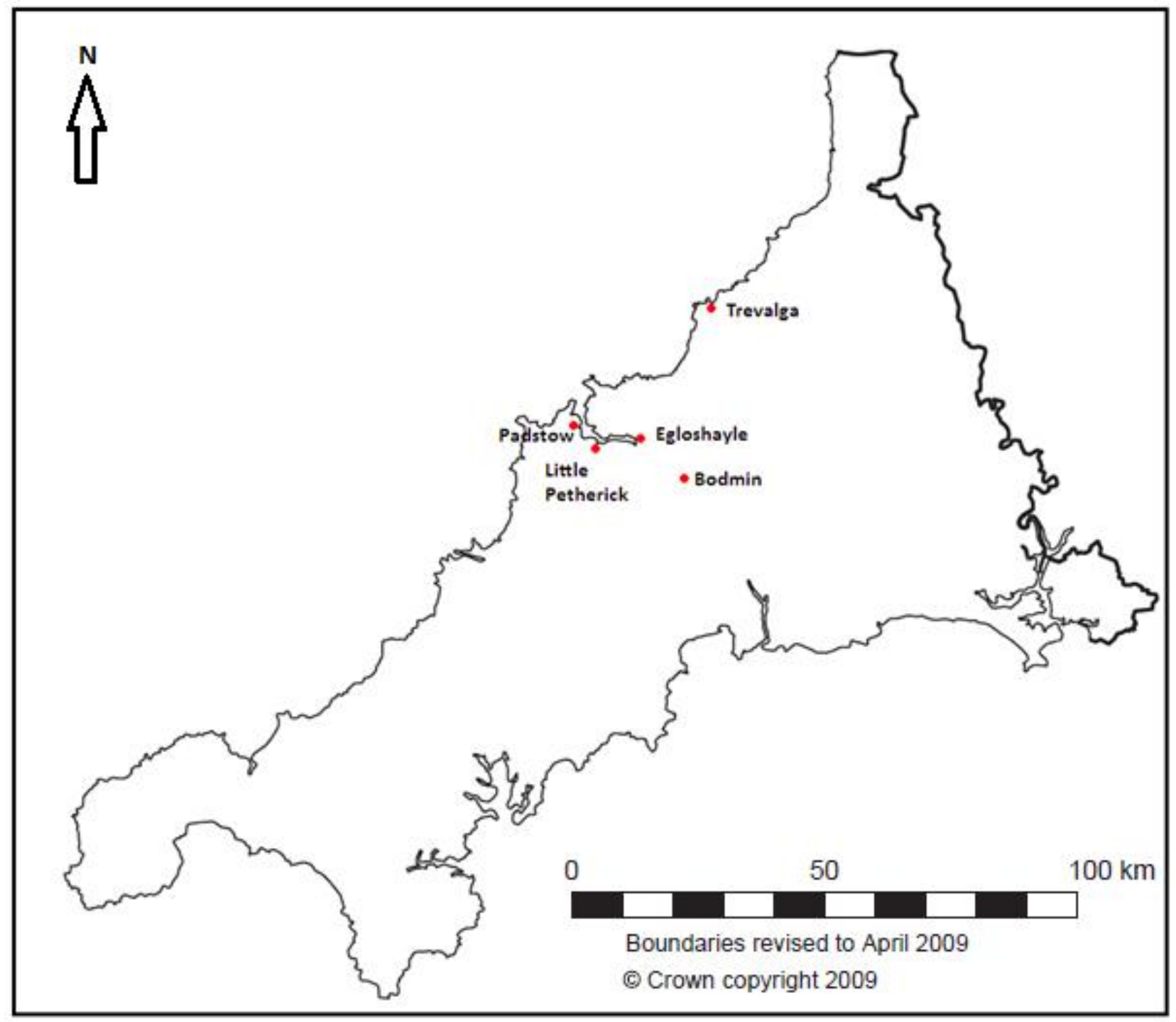

Figure 106. Map of Dedications to St Petroc in Cornwall. Redrawn after the Ordnance Survey GB Coastline and Administrative Boundaries Map.

With reference to this study and the cult of St Petroc, the five (surviving) church dedications for St Petroc in Cornwall are located in Padstow, Little Petherick, Egloshayle, Bodmin and Trevalga. These are shown above in Figure 106 above. What is immediately apparent from this distribution 
pattern is that five of the six sites form a route from Padstow to Bodmin, following the mouth of the Camel River inland via Little Petherick and Egloshayle. This may reflect the route taken by the original monastic community when it moved from Padstow to Bodmin with the relics of St Petroc, suggesting stopping points along the journey or local miracles connected with the relics, now lost from the written record. Mentioned in the Domesday Survey, the presence of a Petroc dedication in northern coastal parish of Trevalga may be due to his hagiographical connection to quelling storms and protecting fishermen, both of which were central to the concerns of small fishing communities such as those at Trevalga (Ravenhill, 1967, 330). 


\subsection{The Sensory Dialogue Between the Pilgrim and the Landscape from Camelford to Bodmin}

\section{Leaving Camelford:}

Camelford's position in the floor of the Camel valley gives the market town a sheltered aspect, and marks the main descent of the Camel River from the hinterlands of Bodmin Moor down into the town of Bodmin itself. Camelford is one of the larger settlements on the western periphery of the Moor, and forms part of a cultivated and settled river valley landscape which contrasts with the physical and 'spiritual' wilderness aspects that a moorland embodies, and the relationship between these aspects and recurrent role of wilderness in Christian biblical and folk tales has been outlined in the previous chapters. Briefly, the wilderness performs a dualist function, as both a landscape of hardship and fear, where temptation and danger lurk, but also allows for revelation, asceticism and contemplation. Bodmin Moor is an environment which accompanies the traveller at a distance for roughly half of the journey, until the valley turns south-west at St Breward and the moorland falls out of sight.

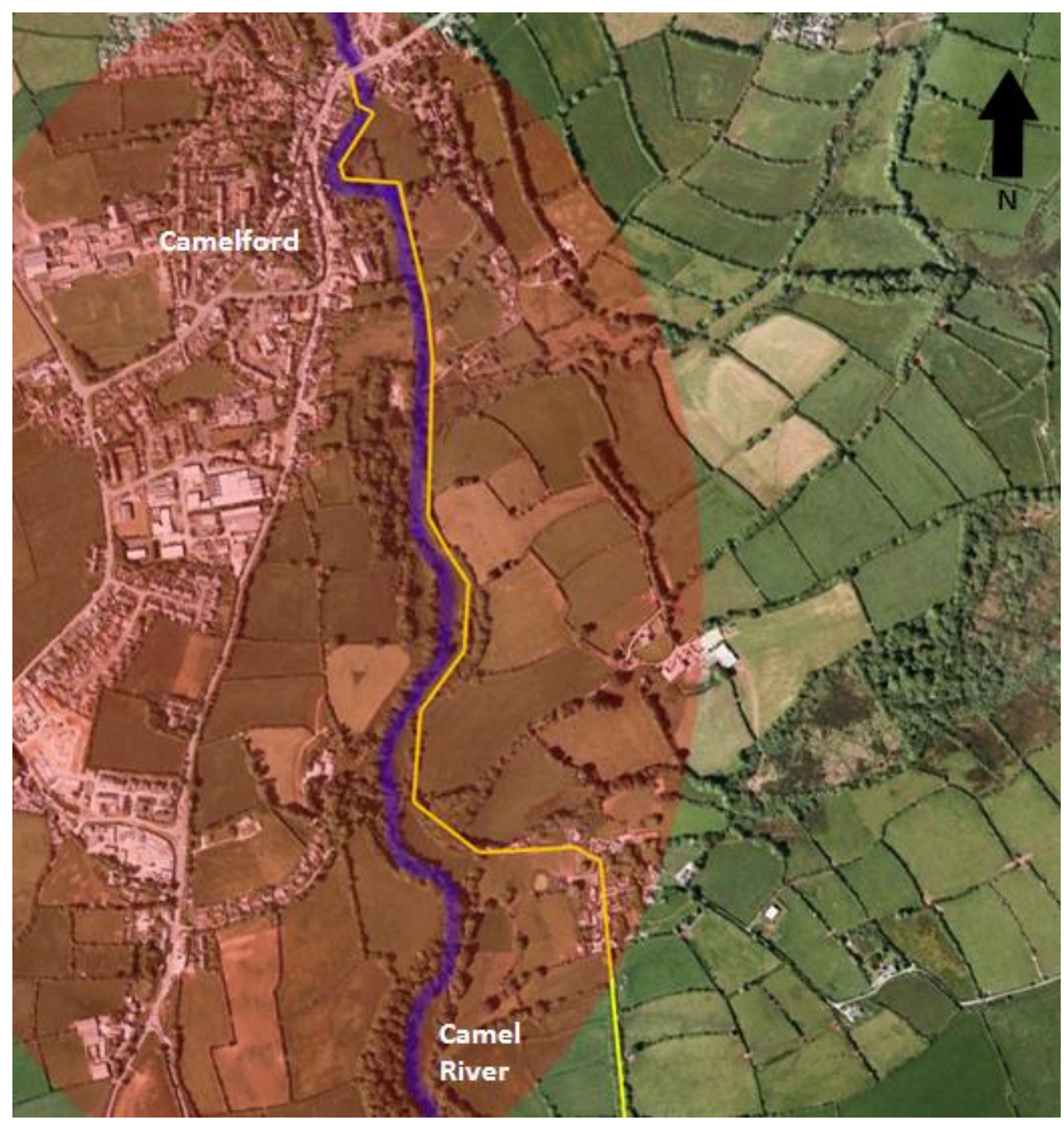

Figure 107. Map of the route taken out of Camelford, following the Camel River. Shaded is the view extent from when the first ascent is made. Original satellite image reproduced from (c) 2011 Google. 
The first stage in the journey south towards Bodmin involves following the river out from the bridge at the centre of the town, where (as stated above) the chantry chapel of St Thomas Becket stood from the $14^{\text {th }}$ century up to the Dissolution. This guiding aspect of the river is one which is repeated throughout the journey, as the Camel River forms an effective reference point for travellers who broadly follow its course southwards into Bodmin. The river can be followed south for roughly half a mile before an ascent of thirty metres takes the traveller up into the valley sides. What is immediately apparent during the climb via a small lane to the hamlet of Pencarrow is the view over the valley floor and Camelford below. The traveller is swiftly taken out from an environment of comparative activity in the town, to a highly rural landscape which due to its elevation leaves them exposed to high winds. Reference points within the landscape begin to be visible and can begin to be absorbed into the travellers own 'interior map', corroborating any directions received prior to the journey.

\section{Advent Parish and St Adwenna's Church:}

The traveller now finds themself moving along the upper limit of the Camel River valley, alongside open field systems which reach down to the valley floor. The church tower of St Adwenna becomes visible as one moves south, a defining landmark amidst the rural surroundings and one which watches over this parish caught between valley and moorland. Reaching the church from the north requires traversing a field which rises up to reveal firstly the tower and then main body of the church. This process of 'revealing' the church to the traveller gives a processional aspect arriving at the church, as it is first identified by its bells which extend over its parish and an extent of the valley, but the physical building is secluded within four closed fields. In Figure 108 below are the routes of approach and departure travelling north to south to join the road, and the broken line indicates the route which joins the standing cross (discussed above) to the church of St Adwenna. The role of this church in the landscape is curious, as its visibility is obscured by the highly hedged lanes which approach it from the north, although these lanes may lie lower within the landscape than they did several centuries ago through persistent usage. Yet the circular banked graveyard which encloses the church also surrounds it with trees, further isolating the building from a profound visual role within the landscape - however as with the hedged lanes, the antiquity of these trees is unknown. The church is also the easterly most religious house in the Camel valley, and lies just outside the hinterland of Bodmin Moor (a mile to the east). It is speculative, but the church may have fulfilled a protectorate role within its parish in terms of being a spiritual beacon within the settled and fertile landscape of the valley, against the real and imagined wilderness of Bodmin Moor, a location of tors, outlaws, malign folklore, remote farmsteads and forbidding landscapes. Whilst the relics of St Petroc were fairly disparate, his cult was concentrated within Cornwall and Devon, and so it is reasonable to suggest that the traveller would have had at least some knowledge about Bodmin Moor and likely, if reliant on the impressions of others, that the moor would not have been presented favourably (given its harsh conditions and the Medieval attitudes towards nature, discussed in Chapter 2. The role of the cross (discussed above), although multifaceted in a general sense could have acted primarily as a waymarker or directional aid, in a series of landmarks which formed a distinctive set of journey stages leading towards Bodmin. 


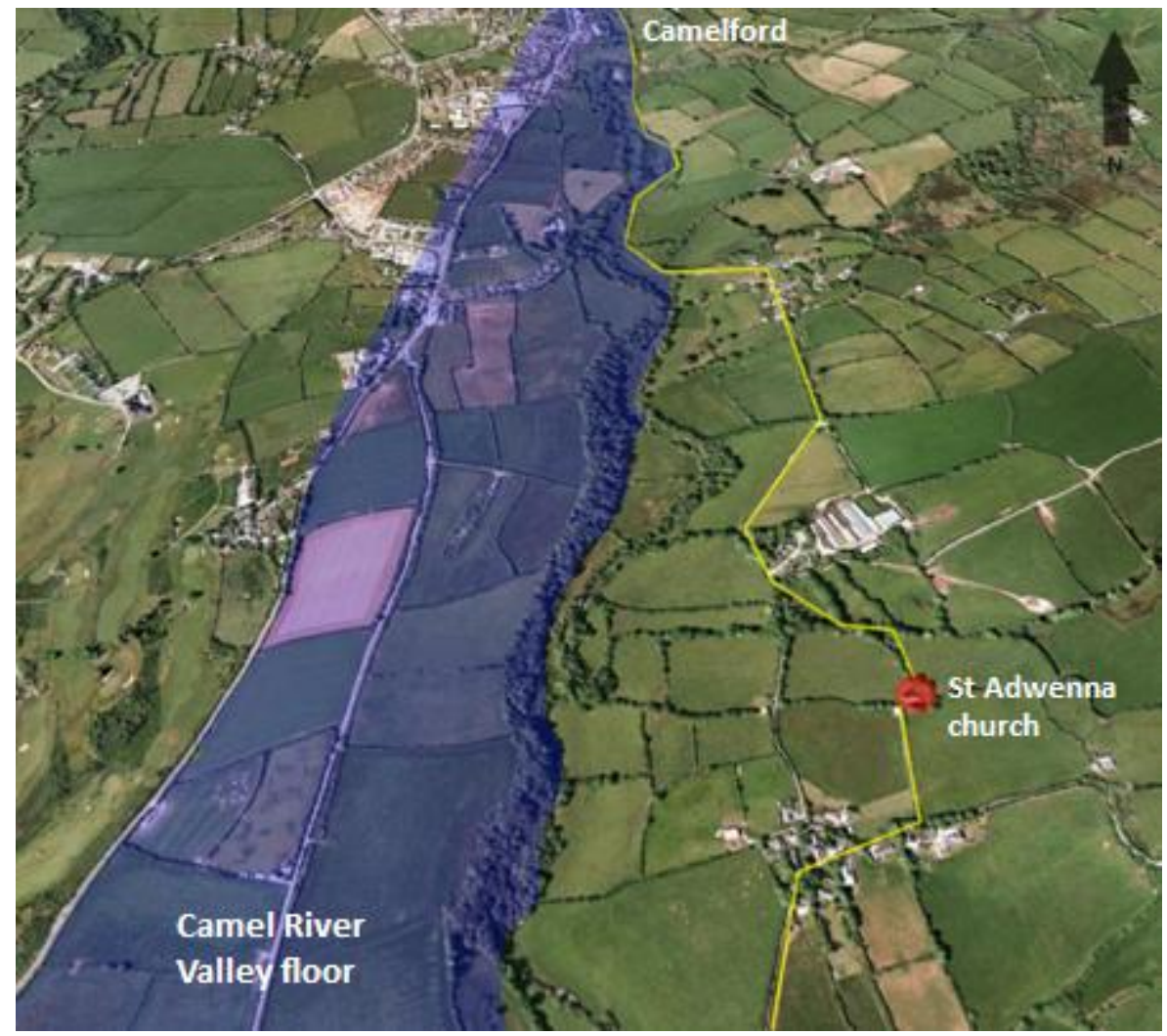

Figure 108. Camel River valley floor (blue), with route and St Adwenna's church. Original satellite image reproduced from (C) 2011 Google.

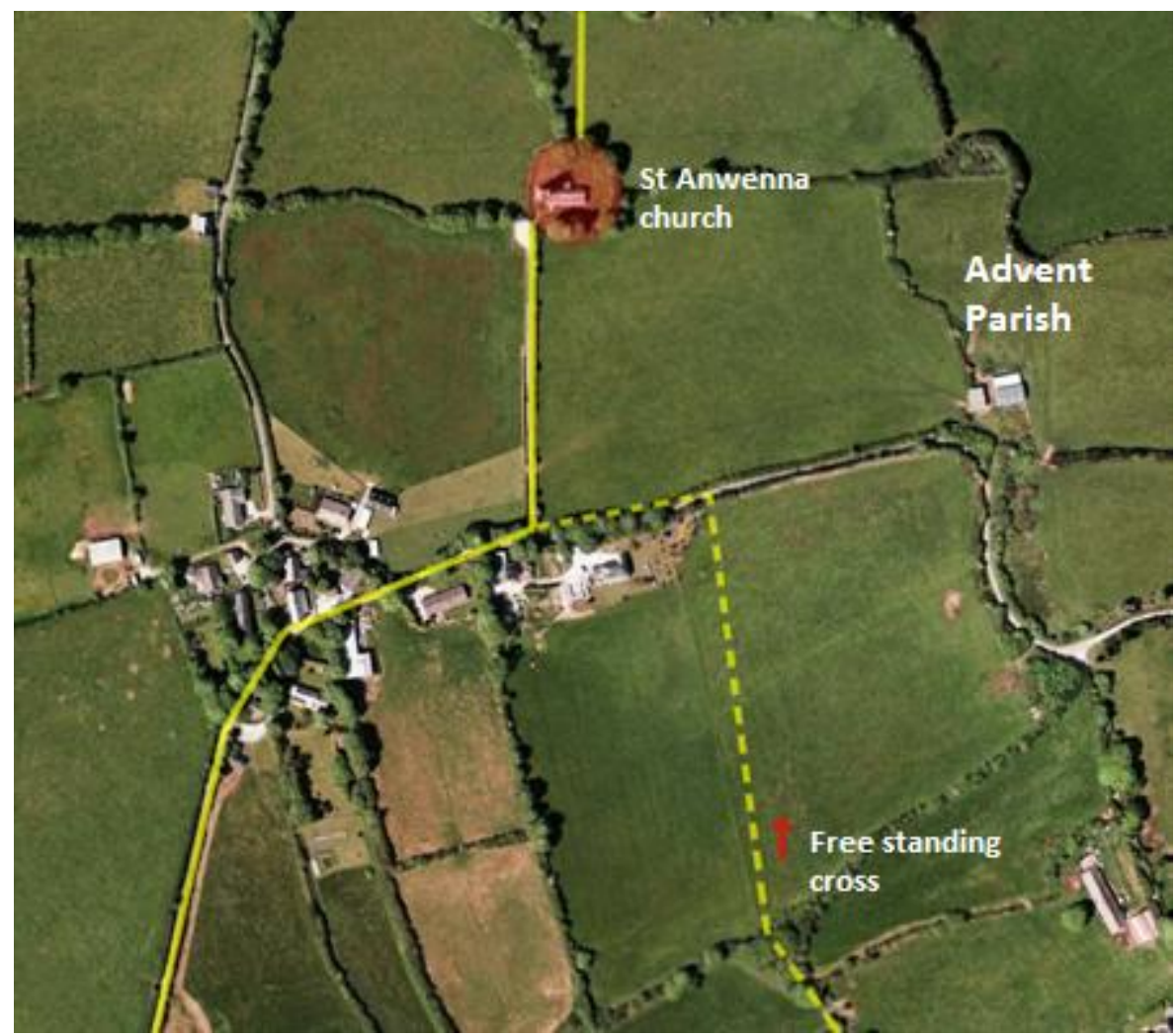

Figure 109. St Adwenna's church in relation to the route, and the free standing cross. Original satellite image reproduced from (C) 2011 Google. 
Another factor which is enhanced in the next 'stage' (below) is that by removing oneself from and travelling above the lower, settled and more fertile flood plains of the valley floor, the pilgrim is placed within an 'outsider' landscape, a liminal area between flood plain and moorland (and thus by extension sanctuary and wilderness), and this mental (and at times physical) seclusion fulfils the aspect of peregrinus, the 'exile', detached from the world and moving constantly towards a sanctuary - in this case not 'Heavenly Jerusalem' but the more immediately accessible Bodmin.

\section{Carwether and the valley-top pasture}

From the parish church of St Adwenna in Advent, the pilgrim can continue in a relatively straight trajectory towards St Breward by utilising the series of local tracks and paths which traverse the pastures found at the top of the valley. Beginning this upland journey at the site of Carwether, a series of multi-period earthworks overlook the small valley and Bodmin moor to the east, which was inhabited during the Medieval period (see Figure 110 below). This elevated and exposed travel has the advantage of giving surrounding views across the area, with key sites such as St Branwalder's church in St Breward being visible at intermediate points, whilst still retaining the Camel River in the

valley floor below as a reference point. To the east is small acute valley, out of which rises the outer (farmed) western extremities of Bodmin Moor, and the immediate west contains pasture fields which roll down towards the Camel River. These two distinct landscapes enable the traveller to easily follow the middle territory between them along the side of the valley, followed by a swift descent and ascent into St Breward parish. This is an exceptionally exposed stretch, where (as during my fieldwork) no shelter is available during heavy rain. However during fine weather long distance views include across a substantial extent of Bodmin Moor to 'Brown Willy' (the highest point on the moor), as well as across the Camel valley, and the elevated ground of St Breward. The extent of this vista, not only useful in the process of self-orientation within the landscape with regard to preinformed landmarks, also allows for a furthering of the process of removing oneself from earthly society (and in this we can refer mainly to those things which represent comfort and human companionship), which has already begun when leaving Camelford. The landscape in these uplands is not lush as in the valley floor, but neither is it as cragged and bleak such as in the moorland to the west. The environment occupies a middle ground or liminal state between the two environments, where they converge and begin the transition into each-other, and it is across these pastures that the pilgrim travels in his own liminal state, held between pious and practical concerns such as prayer and physical travel. The image of St Breward visible in the immediate distance, rising out of the valley floor also acts as a draw and a continuous point of reference for movement across the rural tracks and paths through these fields. 

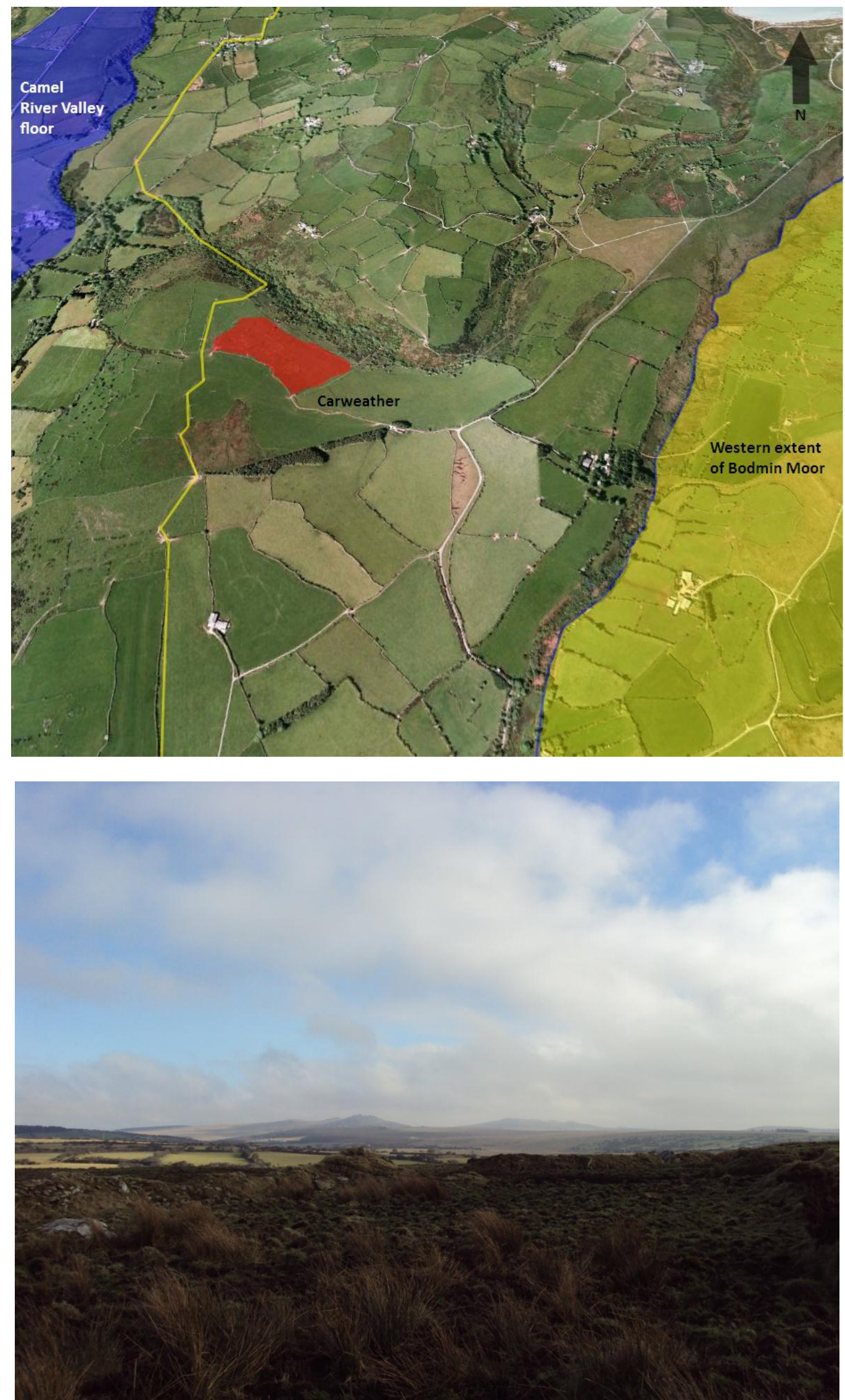

Figure 110. Map of Carwether and Upland section (top), and view from uplands east to Bodmin Moor. Original satellite image reproduced from (c) 2011 Google, photograph taken by author. 


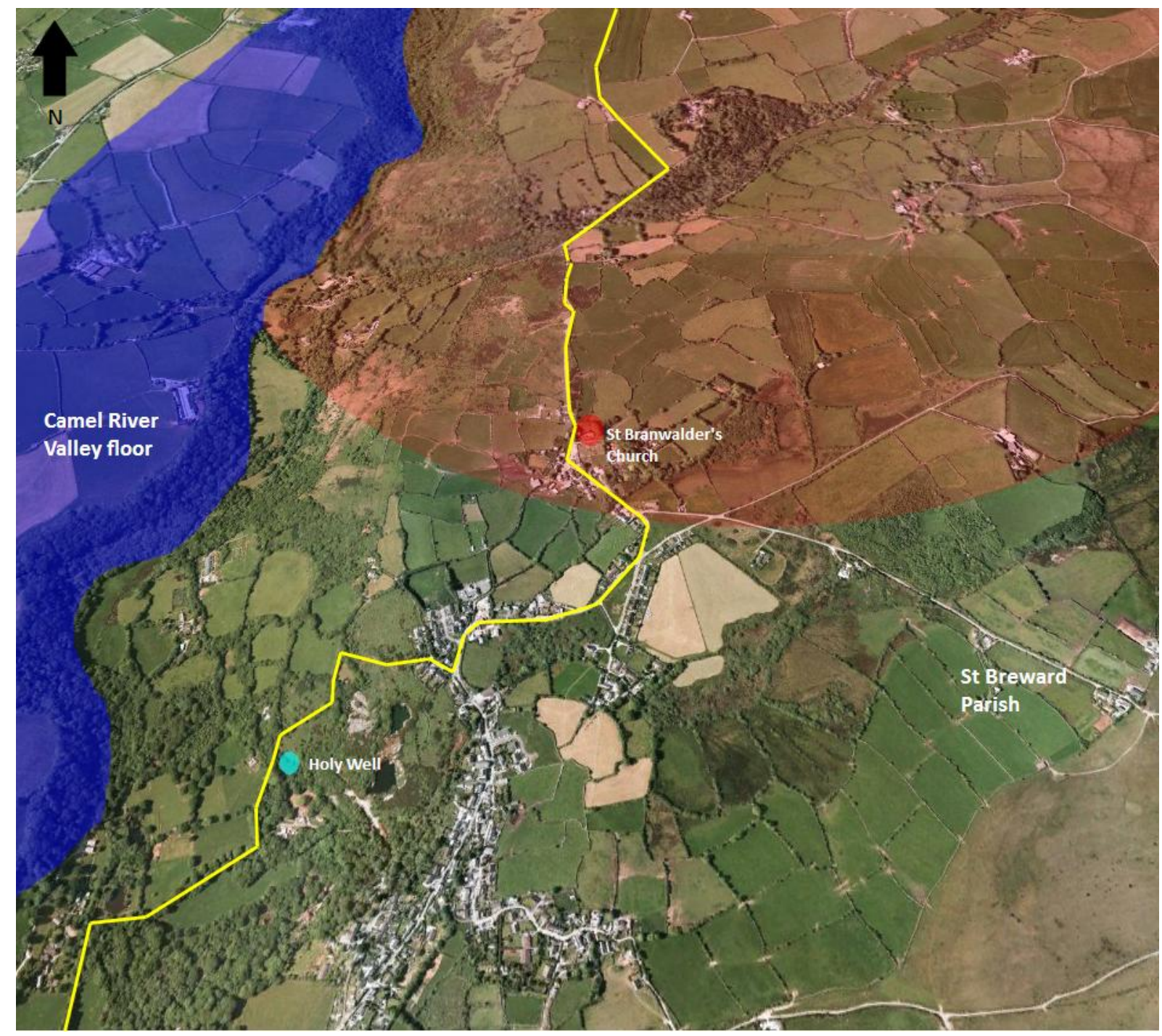

Figure 111. The southern approach to St Breward, the church's visibility and the locations of the church and well sites. Original satellite image reproduced from (C) 2011 Google.

\section{St Breward:}

As has been stated above, the village of St Breward is preceded by a rise in the terrain, placing the church on an apex in the landscape, from which the settlement descends slowly towards the valley floor. Figure 111 above shows the general area along the southern approach from which at points St Branwalder's church tower is visible in the distance, however this only refers to the uplands along which I travelled. St Branwalder's church fulfils the role for which St Adwenna's church in Advent parish (see above) holds so much potential, as a readily accessible visual reference point for the route and an axis for the St Breward parish territory, which extends in all four directions from the building. For the pilgrim, it also marks a return to a settled, sheltered and safe environment compared to the exposed pastures and upland through which they have just travelled. 


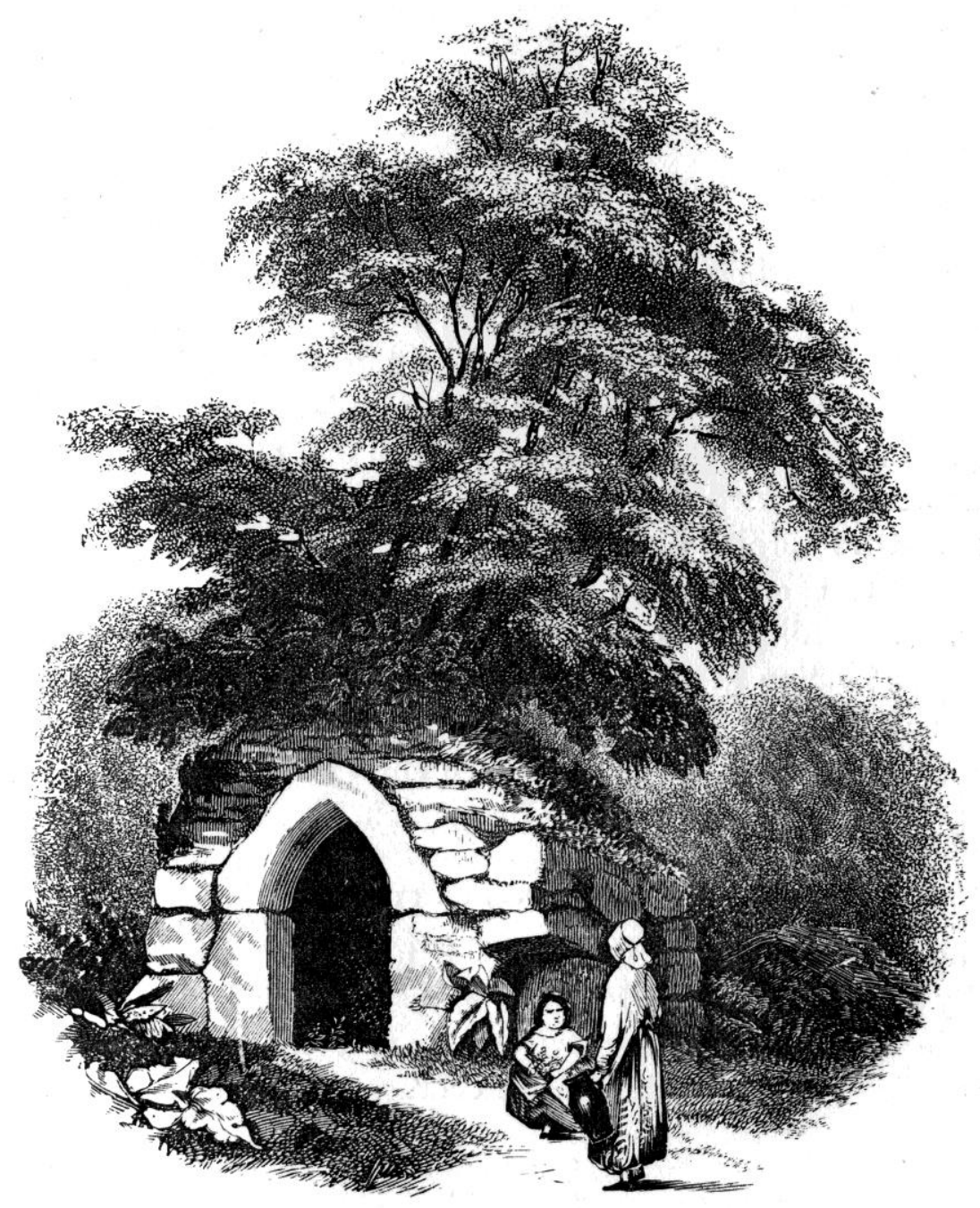

ST. BREWARD'S WELL.

Figure 112. $19^{\text {th }}$ century sketch of the holy well in St Breward. Reproduced from Quiller-Couch and Clark, 1894,

25.

In contrast to this high visibility, the holy well between the village and the valley floor (whose historical dedication seems to have been either varied or unverifiable) is almost hidden. The path is kept open, and even taking into account a degree of negligence in upkeep today, the well is still not readily accessible and lies in sheltered, secluded surroundings, overhung by beech trees with a view down across the valley floor. Figure 112 above presents a romanticised view of the well (erroneously attributed to St Breward) sketched in the $19^{\text {th }}$ century, contained in Quiller-Couch and Clark's 1894 catalogue of Cornish holy wells. Whilst, in a similar manner to Turner's painting of Salisbury cathedral in Chapter 4, there is undoubtedly a level of artistic license present which removes the immediacy of the downward slope and the closeness of the foliage, it does provide a impression of the secluded atmosphere of the well, being surrounded by ferns and patches of woodland which lead to the valley floor. The situation of the site means that its presence is not advertised in the landscape, and is therefore only revealed to the eye when at the site. In a sense, the visual isolation of this site emphasises its role within a local landscape, giving it a subtlety and 
lack of monumentality that works with the natural and folkloric surroundings in which it is located, rather than competing for attention. These attributes combined with the unexpected revelation of the site as one descends the rural path produce a 'personal' experience, both peaceful and secluded, allowing the pilgrim to concentrate on its sacral qualities and enjoy the liminality of the space which links the earthly and the miraculous.

\section{From Woods to the Uplands of St Hellends}

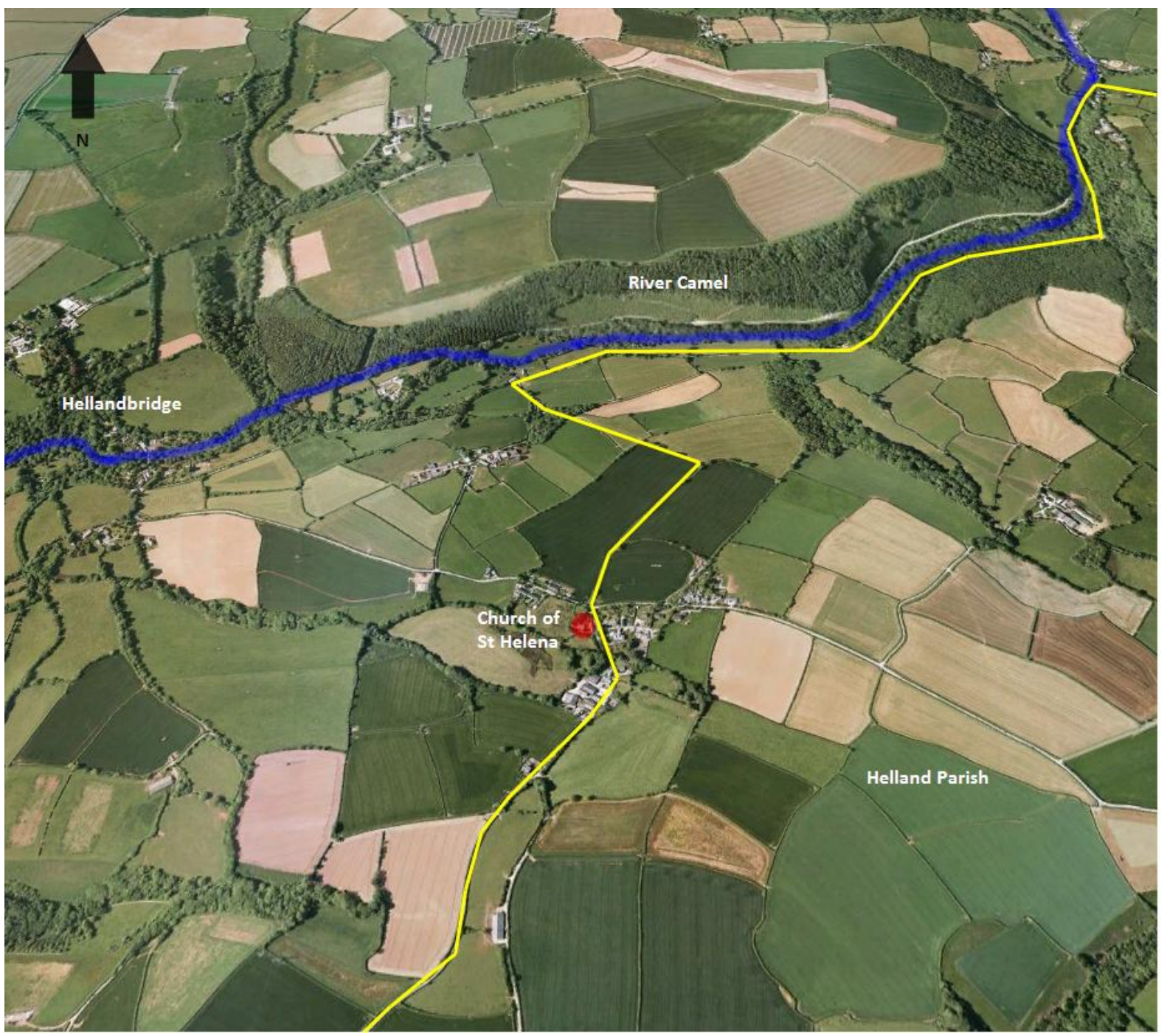

Figure 113. The journey through the woodlands, and the exiting ascent into the uplands of Helland Parish. Original satellite image reproduced from (c) 2011 Google.

After leaving St Breward behind, the traveller continues along the small road which leads to the hamlet of Blisland, then down into the heart of the valley floor and into one of the most unique 
environments experienced so far. A series of small woodlands converge along the banks of the Camel River, and open out in the east onto small enclosed pastures, allowing the traveller to move through intermittently enclosed and open environments - but always sheltered, and adjacent to the Camel River which has been a companion in one form or another since leaving Camelford.

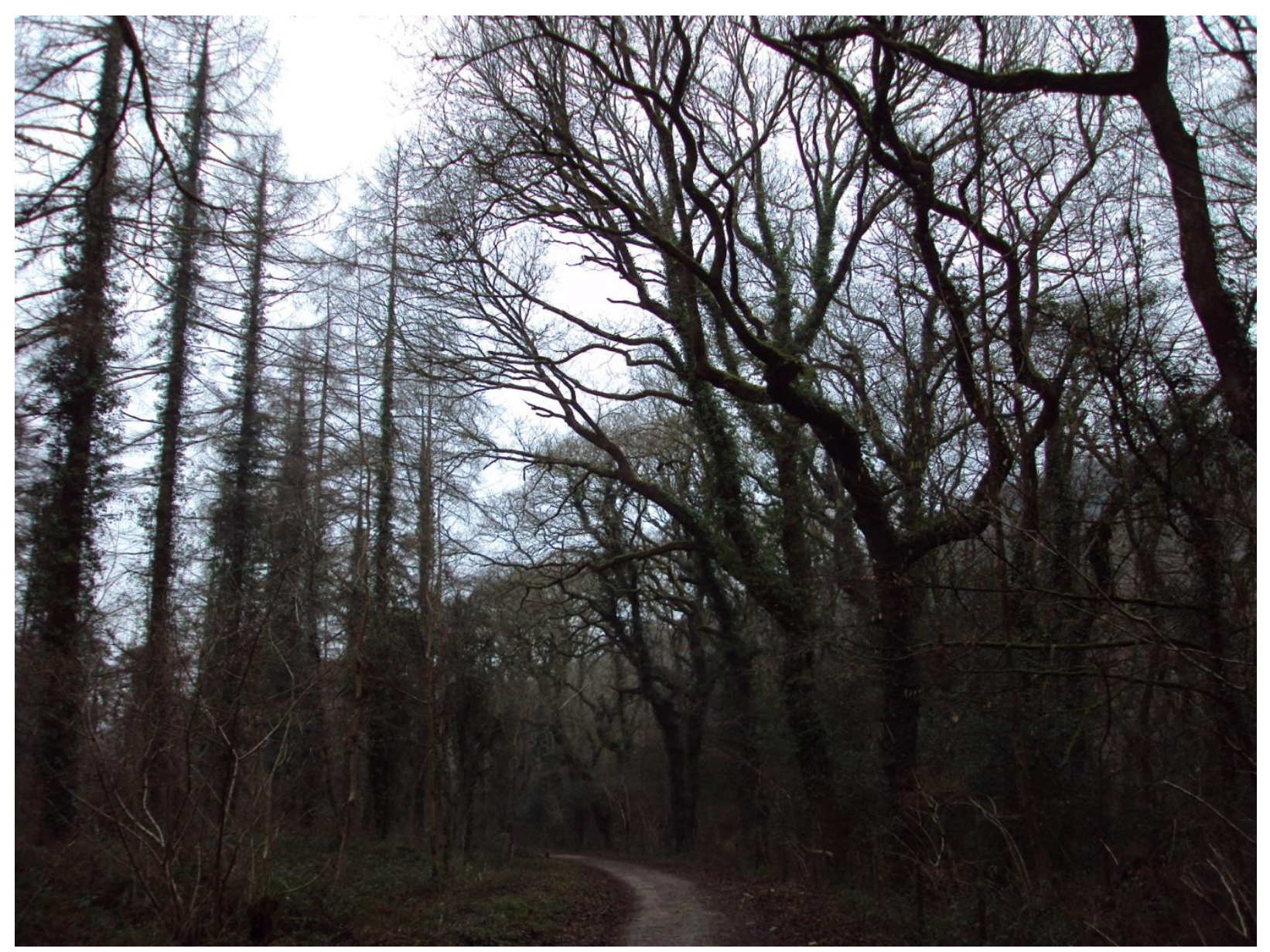

Figure 114. The path through the woodlands in the Camel River valley floor during early February. Photograph taken by author.

The contrast between exposed travel on the uplands previously encountered and movement through this wooded valley floor is not only physical. Hemmed in by the woodlands, the traveller is given no option in terms of direction other than the prescribed path, and is reliant on this path and the Camel River for guidance towards Bodmin; tree cover obscures any other reference points in the landscape. As has been discussed in previous chapters, woodlands can be experienced as liminal environments, offering a landscape which treads between the supernatural and reality. The vision of the traveller cannot penetrate through the surrounding trees, obscuring sight lines, the degree of which is influenced by seasonality, specifically leaf cover. There are common aspects of discomfort and images which are regarded as reinforcing positive impressions of the divine (Fumagalli, 1994). Typically, fair weather, spring growth and birdsong constitute 'positive' images of wooded surroundings, whereas heavy cloud cover, bare trees and rain or even snow can promote the feeling 
of hardship and even trepidation. Figure 114 above represents the woodlands in the last days of winter (early February), and whilst still bare, the vegetation does not allow for a great visual panorama. The traveller is surrounded and propelled along the trail, trusting its direction in relation to the Camel River which is audible but not visible, just thirty metres from the path, bearing some relation in terms of blind trust (or faith) to the motif 'the Lord is my shepherd'. The rushing water may also have drowned out the sound of church bells (St Helena's church in Helland is less than a mile to the south), producing a sense of isolation and lack of Christian protection or presence in these woodlands during the darker months. This trail breaks into open ground on numerous occasions, and near Hellandbridge makes its penultimate ascent into the uplands towards Helland village and St Helena's church. This parish abuts the northern extent of Bodmin Parish, and is highly rural, placing the traveller back within an environment with which they have become familiar over the past eleven miles. Helland sits between two woodlands (the series of woodlands from which the traveller has just come, and Helland Wood in the south-east) on a rise of roughly eighty metres. This ascent emphasises the transition out of forest into the upland landscape, a process of transition defined by its topographical shift uphill, which we can see occurring again in the final section.

\section{Bodmin}

The final approach to Bodmin is bounded by Clerkenwater, two miles south from Helland village. This small hamlet lies in a depression in the landscape, crossing a wooded small tributary of the Camel River, effectively marking the transitional space between the Helland and Bodmin parish territories. The topographical encounter at Clerkenwater provides almost a blueprint for spatial transition and liminality; there is a descent from one territory (Helland) into a boundary or 'neutral' area (Clerkenwater hamlet), a river is crossed (the 'Clerkenwater Leat'), a small woodland is traversed which hides the surrounding landscape, and an ascent is made into the next territory whereupon the tree cover drops away revealing the sight of Berry Tower in the distance, which marks the journey's end. The sight of the Berry Tower would resonate on two levels, as it provides a practical reference point confirming the traveller's proximity to Bodmin and correct direction and in doing so would also confer relief and some pleasure. The extent to which tower bell was audible is not known, however this may have contributed (with its visibility) to the monument's impact in the landscape immediately north of Bodmin.

Upon arriving at the tower site after having travelled along the small lane which leads through a series of fields, what is immediately striking is the view down into Bodmin itself. Located on a hill overlooking the town, the Berry Tower is visible from a number of points within Bodmin the extent is shown in Figure 115 below. Thanks to the destruction of both the Priory and the Friary, it is impossible to make an assessment of their visibility from this point based on experience, however one may assume that given William Worcester's description of Bodmin as a 'magnificent citadel of churches' during his visit in the mid-15 ${ }^{\text {th }}$ century, it is likely that their visual impact was substantial (Worcester, 1969, 86). The church of St Petroc does at least survive, and this is clearly discernible 


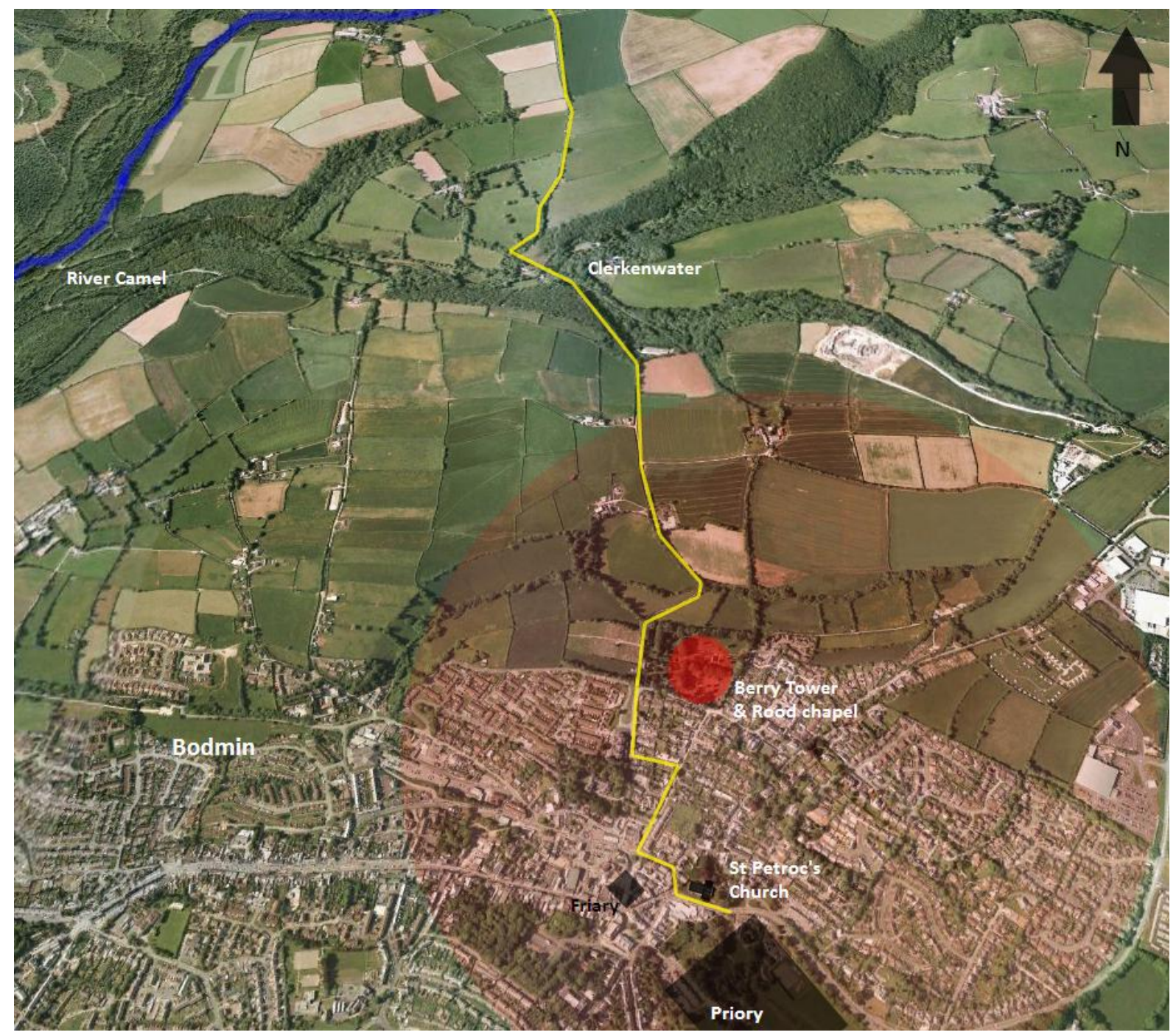

Figure 115. The approach to Bodmin. Shaded in light red is the radius of visibility for the Berry Tower. Original satellite image reproduced from (C) 2011 Google.

from the Berry Tower position, before descending into the heart of Bodmin. The churches, religious houses, chapels and guild buildings in Bodmin would surely have made an impressive sight, especially when viewed as a whole from an elevated perspective. Moving downhill into the town, after the relative isolation provoked by the landscapes previously encountered, it is possible that the myth of St Petroc would be brought home to the pilgrim. The miracles and establishment of a monastic community dedicated to his cult, helped by St Guron, in this 'special' location ('the 'abode of the monks') would surely have had a strong impact on the pilgrim entering the town proper, with the clamour of the church bells, trade, and above all, the activity at the Priory, hanging heavily in the air. The density of sacred sites concentrated in Bodmin made the town the spiritual hub of the region, and may have been almost overwhelming to the pilgrim. It is still possible to appreciate the sudden impact of urban noise, the approach being buffered from Bodmin's sounds by its low lying aspect. Only when nearing the top of the hill on which the Berry Tower stands does the audible aspect of the townscape become obvious, and is a marked contrast with the comparatively silent landscapes of the valley and uplands. Settlement outside the town is minimal and rural, with 
sporadic examples of wells or parish churches, yet a high density of sacred sites are located within the town boundary. The town itself is set within a valley floor and thus enjoys both shelter from the extremities of local weather, and is essentially 'cradled' by the surrounding landscape. These elements combine to produce one of the most delineated examples of 'wilderness' and 'sanctuary' boundaries encountered within this thesis. Moving downhill into the centre of the town, the pilgrim traverses into the sacral heart of the Bodmin region, a bustling centre of ecclesiastical and economic activity where guilds and churches dominate the skyline. The Priory would have been easily identifiable due to its size and sounds and, depending on feast days, with other pilgrims moving towards to the site. In essence as the pilgrim descends the hill into Bodmin they are plunged into a religious nerve centre, the home of the most influential cult in Medieval Cornwall. 


\subsection{Conclusions}

As a result of Henry VIII's campaign of the Dissolution, Bodmin represents one of the great 'vanished' pilgrim centres of Britain, visible mainly in the written record and only in fragments of its once great Augustinian priory. Fortunately through a combination of contemporary documents including will registers and church rolls, and later $16^{\text {th }}$ and $17^{\text {th }}$ century travellers accounts (most notably of William Worcester, Richard Carew and John Leland) it is possible to place Bodmin into its rightful context as an ecclesiastical centre for the region, well equipped in sites (and a prime local saint cult) to tempt and maintain pilgrim traffic. Bodmin's landscape was composed of a series of religious sites which both led travellers into the city along the main road with wayside chapels, and permeated the heart of the town in the form of the priory, friary and churches. The maintenance of such sites depended on the interest and access of the laity, and the road network which fed both into and through Bodmin linked the town not only with other larger centres within Cornwall and beyond its borders but also with the myriad villages and hamlets in the local area. This was thanks mainly to the primary activities which helped sustain Cornwall (i.e. mining, farming and fishing), which furthered the need for accessibility in the county, and beyond for production and trade.

St Petroc's cult was maintained primarily by the Bodmin Priory, with a handful of local church dedications outside the town in Cornwall, and a strong localised presence in north-west Devon. However the spread of his relics throughout the south of England indicates that although actively worshipped in a local sense, a knowledge and appreciation for his cult reached far beyond the borders of the English south-west, further shown during the $12^{\text {th }}$ century by the legendary theft and transportation of his relics to the Abbey of Saint-Méen in Brittany, and the personal interest of Henry II to retrieve them (Grosjean, 1956, 137). It was the presence of St Petroc's relics at key ecclesiastical centres such as Exeter which helped the diffusion of his cult, bringing pilgrims towards Bodmin from the surrounding area. With Camelford as a town sited on the road used by travellers from north Cornwall or north-west Devon into the interior, the primary landscape types encountered by a pilgrim travelling south from Camelford to Bodmin were upland pastures and wooded valley floor/Camel River flood plain. The parish churches encountered demonstrate (in the microcosm of the Camel River valley) the extreme degree of locality found in their dedications, with two of these four saints (St Adwenna and St Branwalder) not featuring anywhere else in surviving Cornish pre-Reformation church dedications. The ultra-local nature of these saint dedications suggests that these particular saints were intimately tied to their 'local' landscape (i.e. the parish over which their church presided), thus each parish presented not only a new topographic environment to the pilgrim, but also a new spiritual one. Commonly miracles attributed to the saint would occur on a local level thereby creating a series of 'religious folklore' sites around the parish, however for this to be a factor in the pilgrim's experience it would depend on them having a knowledge of this locality. A factor which did not depend on prior information (aside from directions and referenced landmarks) would have been the experience of the topography. As stated above, the primary environments are uplands, frequently used as pasture or arable fields. The pilgrim is therefore moving through what are peripheral landscapes, above the fertile, sheltered and 'civilised' valley floor and between this environment below and Bodmin Moor to the east. With the concept of 
the pilgrim as one removed from normal society and a temporary exile (see Chapter 2), then these marginal uplands populated primarily by livestock and only intermittent villages are highly appropriate environments as they force the pilgrim into this role, resembling at times the conceptualised 'wilderness' referenced in scripture and theological texts. We have one example along this route of the standing crosses which are so frequently found in Cornwall, and given their prevalence throughout the county it is fair to suggest that this example may not have stood alone in the valley (Turner, 2006b, 31). These monuments, alongside the elevated churches and River Camel were candidates for inclusion in oral directions, key landmarks which formed and constituted a series of stages along a journey from Camelford to Bodmin; the River Camel and the valley floor being in close proximity for two-thirds of the route.

This case study represents one of the most local examples of pilgrim travel. The entire journey is conducted within a small area of the county, broadly following a natural feature from one town to another in order to worship a saint whose popularity was largely centred on Cornwall and north-west Devon. But in this we can find elements of intimacy which are potentially lacking from the more universal cults. St Petroc's movements and miracles were largely confined to Cornwall, especially the central areas, and combined with the antiquity of his cult and his hagiographical links to other Cornish saints (such as St Guron), his cult was rooted in the very landscape which propagated and promoted it. Any pilgrimage should be an intimate experience, but when the entire aspect of the cult is laden with 'locality' (from which you originate) then this element becomes intensified, and less touristic - an aspect which can be found in larger pilgrim drives such as Walsingham, Canterbury or Santiago de Compostela, and this may account for a lack of St Petroc's pilgrim souvenir industry, however this is speculation, and will be further discussed in the following Chapter 7. 


\section{Chapter 7 - Responses, the Pilgrim Experience and Cultural Comparisons}

\subsection{Introduction}

This chapter focuses, drawing upon the data and preliminary conclusions offered in the case studies, on how a pilgrim perceives their interaction with a landscape, and the journey through it. The interaction is not truly mutual, as the landscape does not change in a physical sense but the manner in which it is approached allows the traveller to perceive their interaction with the environment in a wide variety of ways. There are themes which can be commonly addressed through the analyses performed in the previous four chapters; however the application of my method to these studies serves to treat each journey as a interrelating whole. This is in order to identify nuances embedded within the interaction of the pilgrim with landscape which vary depending not only on their geographical and topographical aspect, but also on the nature of the cult (i.e. universal versus highly local). Through this treatment of the pilgrim journeying process the concepts, themes and aspects my method has revealed in each case study can be identified or applied to pilgrimage across the spectrum of the saint cult hierarchy. In addition I have analysed the possible perception of biblical motifs within the landscapes, and the use of the Medieval road network by pilgrims as illustrated through available recorded routes, accommodation and other lines of evidence. To clarify my terminology in this section, when I use the term 'Medieval laity' or simply 'laity', I refer to the entire spectrum of the religious Medieval population. In 'secular' I refer to the non-religious aspect of society (primarily in the modern context), and with the term 'secular journey' I refer to travel undertaken in the Medieval period for primarily commercial or at least not explicitly religious/pilgrim reasons such as merchants, peddlers and administrators.

With pilgrimage being a phenomenon composed and influenced by a number of motives, practises, external and internal forces, it is unwise when seeking to address 'the journey' - an element so central to the concept of pilgrimage as to be its primary motif - to draw out single specific elements for analysis without relating them to each other. Consequently below I will outline several key themes which have emerged within the course of this research, that all revolve around the 'movement' of the pilgrim and intersect with each other, linked to examples provided from my case studies. For example, one particular area of interest is the discrepancy in pilgrim souvenirs throughout Britain, showing a clear difference between the Marian cult of Walsingham in Norfolk (Chapter 3) and the 'Celtic Christian' well-cult of Winefride (Chapter 5), an aspect which is addressed in more detail below. Other areas include the variance in topographies encountered within the case studies, seasonal climatic variation and land management (such as lambing and harvesting) and their impact upon the pilgrim journey; areas which have not been discussed before in relation to each other and pilgrimage. The 'post-pilgrim' experience is also briefly discussed, exploring from a theoretical point of view the mental impact of the journey upon the pilgrim after their return home, and finally I offer some conclusions from this thesis and areas which would profit from further research in the future. 


\subsection{Response to Research Questions and Methodology}

Returning to the beginning of this thesis, in Chapter $1 \mathrm{I}$ outlined four research aims which were to be explored through the four case studies, drawing out sub themes within these aims which are addressed below, citing relevant examples from Chapters 3 through to 6 . These aims were as follows:

1. To develop a methodology which addresses the study of pilgrimage from an interdisciplinary perspective within the Medieval Western context, considering the processes motivating pilgrims, the practicalities of sacred travel, and the experiential aspects encountered en route.

2. To identify the surviving archaeological evidence for Medieval pilgrimage, and compare this record with that offered by the documentary data.

3. To differentiate between the pilgrims' experience and interaction with the landscape with that of 'secular/commercial travellers' (such as merchants).

4. To explore this sensory dialogue between pilgrim and landscape through theories of liminality and perception applied to topographical data.

Analyses should follow their methodology, and the interdisciplinary nature of this thesis' investigations are clearly demonstrated through the use of both primary and secondary data drawn from various sources, and addressed through historical, archaeological and anthropological perspectives. I argue therefore that the research contained in this thesis demonstrates success in developing a methodology that comprehensively addresses pilgrimage's journeying context and answers the remaining research aims as fully as is currently possible. The results of the penultimate sections in chapters 3 through to 6 (which address the sensory elements of movement) support my decision to omit Canterbury from this study. Their investigations integrate spatial responses to visual reference points, the impact of topography upon the body of the traveller, the contemplative aspect of 'slow travel', the unfolding of the landscape (in a similar manner to the strip maps produced by Matthew Paris mentioned in Chapter 1.5, see Figure 5) and other issues based upon anthropological and theological research. Therefore they rely upon a degree of survival in the surrounding landscape's Medieval landscape, and the motorways and extensive suburban sprawl of the south east would not be conducive to these investigations. Consequently despite Canterbury's high status as a pilgrim centre, with the focus of this thesis being on the journeying context and the current body of scholarship on Canterbury covering Chaucer, the urban spaces of Canterbury, and the cathedral itself in extensive detail, it has remained the case that it would not have been an appropriate study for consideration in this research as the sensory investigations of movement from London to Canterbury would have been largely hampered by modern infrastructure. 
The methodology provides a comprehensive list of monuments, building types, natural features (found predominantly within British and European landscapes) and ephemeral sources such as folklore which would have had an impact upon the journeying experience and have not been considered together before. These categories, expanded upon and backed by referenced scholarship within Chapter 2, provide a core of potential data sets that can be modified as is appropriate within the relevant cultural or geographical context. Analyses of the following aspects, performed in this thesis for each case study, can be performed in multiple cultural and historical contexts, and emphasise the flexibility of the methodology:

i. The environments of the study area (environmental, economic and ecclesiastical), the contemporary road networks.

ii. The development of the cult.

iii. Its material culture.

iv. Remains of the aforementioned data categories between the origin site and the shrine site.

v. Dedications in religious buildings within the local area.

vi. Sensory perceptions and encounters within the landscapes along the route, based upon anthropological and theological concepts such as visibility, liminality and scriptural motifs.

With the exception of the material culture (whose absence in the form of souvenirs for three of the four case studies provides an interesting series of questions nonetheless), all of these aspects were able to be addressed for each study area with the data categories mentioned above and in Chapter 2.4. With regard to the sensory perceptions there is without doubt a subjective element to these suggestions. However, this has been kept to a minimum in order to concentrate on concrete aspects such as sight lines between pilgrim and monument, zones of topographical/spatial transition and liminal areas, as defined by Turner $(1978 ; 1992)$ and van Gennep (2004). Where they do arise, in connection with liminality and possible reflections of Christian motifs (for example, wilderness and sanctuary) they are clearly stated as speculative, and serve to illustrate the personal nature of both pilgrimage and travel, especially through rural or remote environments.

The use of Knowles \& Hadcock's extensive catalogue of religious houses in England and Wales has provided the backbone of examining the broader ecclesiastical landscape in the four case study areas. The 'archaeology of pilgrimage' is still an emerging field, as demonstrated by the work of Stopford (1994) and Candy $(2007 ; 2009)$ and thus there is no definitive methodology so far for dealing with this complex and multifaceted phenomenon in the archaeological record. However, my 
thesis' use of primary sources (including monastic accounts and itineraries), the material record (where possible), and existing scholarship on relevant sites makes use of the principle avenues of data and available research, providing a data framework for my fieldwork to operate in. Through this varied source material I have been able to establish the pilgrim presence in both the archaeological and historical records relating to the case studies, in the manner in which they were encountered along the route, echoing the itinerary style found in some of my primary sources. The provision of guest quarters in religious houses such as Castle Acre (Chapter 3 ) and St Swithun's Priory (Chapter 4), hospitals, the records of pilgrim donations in churches, cathedrals and shrines, contemporary surveys (such as by William Worcester), and data from the Portable Antiquities Scheme and local Historic Environment Records, all build a cohesive picture of a strong pilgrim presence within the British landscapes covered in this thesis. Logically this picture can be extended to other areas in Britain with cult centres, including the major cults of St Cuthbert (Durham) and St Edmund (Bury St Edmunds), and more localised shrines such as St Candida (Whitchurch Canonicorum).

In response to my research aim of differentiating between the experience of the route depending upon ones role as a traveller (i.e. commercial, leisure or pilgrim), I have taken into account the distributions of settlements and religious houses, the existing infrastructure of Roman roads, prehistoric tracks and journeys outlined in written records (such as the itineraries of Edward I and John, Gerald of Wales, Erasmus, Leland and Camden). It has therefore been possible in this thesis to posit the movement of the pilgrim around these landscapes using an extensive route network, choosing routes which when not formally mentioned, take into account opportunities for visibility and ease of access/orientation, such as following the river Camel from Camelford to Bodmin in Chapter 6. The dualism of pragmatism and ritual in terms of original purpose of the route is cyclic. The routes used to travel to a sacred destination are used initially for their practicality, being safer than diversions across tracts of countryside, especially on the longer routes through unfamiliar landscapes. Through verbal exchanges between pilgrims these roads and trackways, which have their origins in trade and communication networks, become the accepted routes for pilgrims towards a specific site. This is exemplified in the 'Palmer's Way' (Chapter 3) which uses a series of major routes leading up from London into Norfolk that were primarily established for commerce (Hindle, 1978, 38). This additional use by palmers and pilgrims leads a route to acquire a 'ritual' element of its own, culturally linked to pilgrimage, becoming popular sites for the erection of roadside shrines and crosses, again demonstrated in the reputed high volume of wayside chapels that lined the Palmers Way upon its entry into Norfolk (Webb, 2000, 79). This further cements a 'pilgrim identity' onto the route, and produced changes in the natural landscapes surrounding the routes, modified through the building of hospitals, accommodation houses, shrines, relic centres and sometimes the growth of settlements, all profiting from this 'new' class of traveller. These landscapes then become embedded in the popular consciousness of both pilgrims and those to whom they tell of their travels as 'landscapes of pilgrimage', particularly over long distance routes such as the Camino de Santiago de Compostela. During the trialing of my methodology between Roncesvalles and Pamplona along the Camino de Santiago de Compostela, it was evident from talking to modern pilgrims that the landscapes through which they travelled were not seen as part of the broader collective of 'Spanish countryside', but instead were intricately linked to the idea of the 
pilgrimage, and were almost isolated from neighboring landscapes by their exclusive link to the Camino. These environments, with associated landmarks such as the free standing crosses one finds on the outskirts of Bodmin Moor and the Camel Valley, come to represent the very process of pilgrimage.

Recent scholarship on the concepts of sacred and profane spatial relationships make clear that, both within ecclesiastical and domestic settings, uses of space could be both simultaneous and (to modern minds) at times contradictory in nature (Hamilton and Spicer, 2005, 1). By extension this approach can be applied to the tracks and roads which carried a variety of travellers across familiar landscapes. The route which may have recently led the drover or merchant to a market centre becomes re-cast in the pilgrimage role. The market centre is also the saint cult centre (as demonstrated by regional centres such as Bodmin or Winchester), the merchant or drover is now the pilgrim, and the route is not merely a convenient and practical link from A to B but a penitent process, and an allegory for the peregrinus concept of earthly exile, albeit briefly. This is not to suggest that the pilgrim undertakes a form of temporary amnesia. Clearly the route is also recognised and appreciated in its practical role as well, offering both a link from the settlement of origin and the sacred destination, and potential for attached memories accumulated from previous travels along its length. However, the manner in which the pilgrim's mental attitude is biased towards a spiritual interpretation of the surroundings provided a platform for a different type of interaction with the environments than encountered on a secular journey. It is this multi vocal aspect of the journey which I have explored through my methodology. It addresses through anthropological, archaeological and theological approaches a range of monuments and natural feature which bear significance within both a pilgrim and practical context. For example, the river is an obstacle to travel, which must be crossed; the act of crossing is about moving across a boundary which can be both practical (a geographical, topographical or territorial shift) and spiritual, running water being a central motif of Christianity, recollecting the baptism of Jesus in the River Jordan, and the liminal experience of moving through a border, a space between two definable bounded areas. This has not been previously considered to any detailed degree within the context of Christian pilgrimage in the Medieval West, especially with regard to specific case study landscapes in Britain. Therefore the development and application of my methodology to this area is a valuable framework for future research into the pilgrim experience, one whose scope is only limited by the number of environments and pilgrim routes within Christendom and beyond. 


\subsection{The Landscape \& the Monument}

The diversity of the environments in these four example case studies, each unique in their topography, elevation and situation, gives distinct characters to each journey - characters which are only truly appreciated when these journeys are walked by the researcher, as in the case of my fieldwork. In the methodology (Chapter 2), variety in landscape type counts as a key factor in choosing my pilgrimage sites, as does the unique cultural identity of the landscape (i.e. East Anglian, Cornish, Welsh and the affluent lands of Wiltshire/Hampshire). This is in order to represent and investigate a spread of topographies which, in as much as can be done in the scope and space of this thesis, can cover the majority of landscapes commonly encountered in Britain, such as coastal, heath, grassland, agricultural, urban, valleys forested and elevated. Notable in their absence are the extremes, such as mountains and islands, which would afford a unique experience, however given the length of this thesis it is not possible to cover every single landscape type, and I leave these travels to future research.

The longer the journey, the greater numbers of people and experiences encountered and gathered (some of whom were profane as shown in Piers Plowman with its 'immoral pilgrims' travelling to Walsingham), all of which increase experiences to recount when returning home (Langland, 2009, 183). It could be argued that this large scale also reduces the personal nature of the journey. By joining people travelling towards a great religious centre, one is part of a multitude in unfamiliar landscapes, which do not echo individual memories of experiences like the environments 'back home'. Conversely, smaller local pilgrimages (in terms of the saint cult and distance) embodied by Camelford to Bodmin, and St Asaph to Holywell, may not bring the same level of prestige for the pilgrim in their home community, though were spiritually just as rewarding. However, through examination of local pilgrimages lacking the universal appeal and attention of (for example) Santiago, Rome or on a lesser scale Walsingham, a different form becomes apparent. The landscapes encountered would very likely have been familiar to the traveller, perhaps within one day's travel, a distance commonly covered on foot for commerce or communications (Hindle, 1976, 209). Thus we are presented with two main interpretive possibilities for local pilgrim movement;

1. The familiarity of the environments encountered helped prevent the pilgrim from distraction by exotic sights, producing a greater opportunity for the contemplative element of travel.

2. That undertaking the role of 'pilgrim' with both its immediate and deeper meaning, of which the laity would have some basic knowledge through the local priest and his sermons, would bring about a different appreciation and interaction with environments which, whilst familiar, had not previously been encountered during a heightened spiritual state. 
It could be argued that the local pilgrimage journey most closely mirrored those undertaken by the original Syrian monastic pilgrims, who ventured out from their monasteries to visit those wild holy men who found truth in the wilderness, following the example of the itinerant prophet John the Baptist (Le Goff, 1988, 49). The larger scale routes encountered in Christendom such as those which moved towards Rome (the Via Romea) and Santiago (the Camino de Compostela) required a different approach and adoption of the pilgrim exile status. These journeys could range from a few days to months, and whilst one was 'outside society', travel was typically undertaken in shifting groups for safety through environments which, whether malign or enjoyable, were always 'foreign' and experienced within a community of travellers. Solo travel versus the group experience is not a subject for debate in this thesis, but it is an important psychological element which would have coloured the journeying experience for the traveller. This is an aspect of this thesis that needs to be emphasised, in that the fieldwork was conducted from a solitary perspective; unlikely as it is in these times to be able join a walking party towards a shrine. This clearly has produced interpretations on the sensory level which are more attuned to the contemplative experience of pilgrimage than the jocular 'Canterbury Tales' experience. However it would be impossible in a project of this length to be all things to all men - a holistic analysis can be made of the routes within the framework of my methodology, but it is unwise to speculate on group experiences when one has encountered the routes alone.

Taking the case of Walsingham, the pilgrimage to such a universal cult site (i.e. Marian and highly popular outside of its national borders) can involve several days of travel across differing regions and contrasting landscapes, giving the scale of the journey and symbolic representation of the 'journey through life' greater significance. This is mirrored particularly well in the procession of landscapes between Ely and Walsingham, whereby the pilgrim moves from darkness of the fens towards the pastoral and agricultural upland landscapes of northern Norfolk and the shrine of Our Lady, 'England's Nazareth', bearing similarities to the movement from the 'City of Destruction' to the 'Celestial City' in Bunyan's 'Pilgrims Progress'. The pilgrim moves from an environment which offers physical danger (i.e. the fenland landscape) and also spiritual risk (from the 'Black Shuck' devil hound of local folklore), into a landscape which is seen as an extension of the Holy Land (Westwood and Simpson, 2005, 500). Also linked to this concept is the use of wayside shrines, which serve to mark the way not only geographically, but we can also see them as stage markers towards the divine state encountered at the shrine site, the penultimate beacon in the landscape of the 'Palmer's Way' being the Slipper Chapel. Along this journey the pilgrim leaves familiar surroundings and society becoming 'marginal' or 'liminal' in nature, following the liminal process outlined by van Gennep; that of separation, liminality and aggregation (Gennep, 2004, 184). There is a transition from the profane to sacred state whilst remaining 'outside society' - both in a literal sense through travel and also socially in their traveller status. Arrival at the location of the shrine, typically urban to some degree, marks the peak of the spiritual progression, for example moving into the well complex at Holywell, entering the 'Holy Mile' of Walsingham and the subsequent interiors of sacred space, and descending into the urban environments of Bodmin and Winchester at whose heart lay the respective priories and cult centres of St Petroc and St Swithun. On completing the pilgrimage they return to normal life, and the repercussions of pilgrimage on normal life are discussed in detail further below. The recurrence of liminality and the spiritual state induced through pilgrimage maintain a mutual relationship. The greater the religious fervour with which the journey is 
approached and encountered, the higher the awareness of scriptural and divine motifs or signs, whether established motifs or imagined. This state, removed from daily life and moving from one liminal encounter to another within the landscape, engenders a perpetual state of transition and marginality from profane society during the pilgrimage.

During local pilgrimage - especially with a highly local saint cult - the landscape of the area was already symbolically charged in the minds of the laity through Christian dogma laced with relevant regional motifs, and the local saint through miracles or other events. Aspects of this can be seen in the cult of St Petroc, where the area between Bodmin and Padstow formed the alleged route of his relics. North of Bodmin the territories amongst and bordering the moorland have become popularly associated with his supposed period in the 'wilderness' with a small band of his fellow monks (Grosjean, 1956, 48). Similarly, the town of Holywell and the immediate landscape surrounding it are recorded in St Winefride's hagiographic texts as the sites of miracles (see Chapter 5). These are not only linked to the Abbess and her well, but also linked to her uncle (and resurrectionist) St Bueno, whose deeds are recorded in place names and local religious folklore (Fleetwood, 1713, 29).

Looking beyond the small scale routes, which are more intimately linked to their local saint by virtue of proximity to the saint's environment, longer universal routes also construct their own myths and traditions. This is due at least partially to the culture of 'travelling' which grows up around them - and not solely through pilgrims. Long distance travel within a group - even amongst strangers, but who might band together temporarily for protection - creates swift and strong bonds, if only for the period of the journey. Past events along the route would be embellished and re-told to travellers in towns, inns, or along the road. This begins the process of forming a mental landscape which whilst not strictly made of memories (as memories are experienced by those directly involved in an event), does at least become memorial in nature (Bell, 2003, 64). Memorial nature is sustained through maintaining a record of occurrences involving past travellers, local legends often distorted through constant re-telling. Thus these mental landscapes are also evolving with every fresh retelling and encounter, building a narrative tradition, a collection of legends and tales involving a route maintaining relevance to those travelling along it. The ever changing 'pilgrim community' which moved throughout Christendom was bonded through being temporarily 'exiled', and proclaiming themselves as being 'outside' normal society for the duration of the journey through their donning of the pilgrim cloak. It is highly likely that throughout this ephemeral network of pilgrims, there were a series of 'travellers tales' which constituted part of the pilgrim journeying culture and served to bond travellers together through their re-telling. The orally transmitted 'knowledge' of 'the route' in the form of directions, tales and advice formed an aspect of the perception of the landscapes through which the pilgrim moved, raising their attention to particular landmarks or view-points. Examples of areas for extra-interaction are highlighted throughout the case studies, most notably within the penultimate section of each study, where elevation is revealed as a key topographical factor in landscape perception and interaction. Where these view-points function not just as practical location finder in helping to create a 'pilgrim landscape' depends largely on the surrounding topography and built environment. This is because (as stated above) the sight of 
certain landscapes triggers certain emotional responses. With regard to the built environment, an abundance of Christian monuments (including churches, wayside crosses, monastic houses) spread across the landscape would further emphasise the sacral aspect of the journey, establishing a linear progressions between sacred sites both behind and ahead of the pilgrim. This may also act as a metaphor for the pilgrim being on the 'pilgrimage of life', making a progression towards heaven via a series of sacred encounters and revelations as represented by the physical journey.

Moving away from the mental and 'inner' aspects of a 'pilgrim landscape', the physical reality of movement through and interactions with these topographies would not be possible without a comprehensive route network. The factors which sustained the development, refinement and evolution or decline of certain routes centred primarily around commerce and communications, with border regions such as the Welsh marchlands also being affected by troop movements. Contrary to pilgrim routes which spanned across mainland Christendom, pilgrims in England, and arguably across Britain, were generally not subject to the closure of routes for political reasons (i.e. war, border disputes) in the same way as their continental counterparts (Matthews, 2007, 1). Commercial or administrative hubs which had developed from initially ecclesiastical settlements helped determine the road network, as these sites offered a range of both spiritual and secular services which attracted both pilgrim and merchant alike. Visitor numbers had a cumulative effect on the wealth of the settlement including disposable income, with sites such as Salisbury demonstrating the swift rise of inns once a pilgrim cult was established (Frost, 2009). Thus the care of routes entering the settlement lay within its administrative jurisdiction, with guilds in certain parishes creating 'social clubs in which young adults could interact and practise the shared and rotating responsibilities...from repairing hedges and highways to laying out the dead' (Jones, 2007, 181). These arrangements did not put the state of Medieval roads beyond reproach, as we can see in Chapter 3 as the Bishop of Ely allowed an official causeway linking the town with the surrounding fens to decay, and established his own access point, charging for entry. Between settlements, route maintenance was more ad hoc, and there are recorded long standing disagreements between parishes as to who exactly should be caring for particular stretches of road (French, 2001, 26). Frequently in wet weather, routes were churned up by cart wheels and hooves, which made travel along them arduous at best, which highlights the dependency of travel on weather conditions. Whilst not comparable to the extremes of the Alpine passes on the route to Rome (the Via Roma/Francigena), weather would have influenced the accessibility of the lesser cult centres, such as shrines in remote monasteries. This was especially true for rural local cults, whose available route networks were primarily formed from tracks and drover roads such as in the Camel Valley with its predominantly agricultural settlements, rather than one of the great Medieval highways such as Watling Street or Ermine Street. The data for Medieval climate are not discussed here, but research supports the existence of a 'Medieval Warm Period'. This represents a time of uncharacteristically warm and mild climatic conditions from the mid $10^{\text {th }}$ century to the $12^{\text {th }}$, resulting in increased crop yields (Hughes and Diaz, 1994, 112). This helped create surplus income, funding an increase in cathedral building, and by extension may have in part contributed towards the rise in saint cult shrines during this period, and could have eased travel by greater maintenance of routes whose surfaces were susceptible to bad weather. 
In the shorter term, weather also has an impact on pilgrimage, and not solely on a personal level. For instance, elevated routes in areas of heavy winter snowfall might be preferable to those lower down in valleys, where windblown snow piles thickly and makes walking difficult and dangerous. This is less frequently found on exposed ridge-ways, such as those between valleys. Snow also transforms a landscape, so that even the familiar could appear foreign, when the usual landmarks were obscured by drifts elevation offered an opportunity to take bearings (see Figure 116 below). However, other forms of precipitation such as heavy rain may force the traveller to take a more sheltered route in order to avoid a soaking and the danger of slipping downhill. In these cases forested tracks such as those through copses along the Salisbury to Winchester route, or the valley floor woodlands which follow the river Camel in Cornwall would be preferable, despite their dangers (both real and imagined) of outlaws and supernatural encounters. As has been highlighted in the sensory sections of chapters 3 through to 6 , woodlands were often seen as 'otherworldly' due to their limited interior visibility (Le Goff, 1988, 54). Winter would clearly have been a less desirable time to undertake a pilgrimage, however as described below, many feast days take place over this season, such as the Deposition of St Wilfred, at Ripon Cathedral. This took place on the $12^{\text {th }}$ October, which also was around the time of the Winter Fair, and received substantial donations from visiting pilgrims (Webb, 2000, 79). King Edward I is recorded as staying for two weeks at Walsingham in Febuary 1289, and the winter of 1296 - 1297 saw Edward visiting many notable pilgrim shrines in Britain after his successful campaign in Scotland (Webb, 2000, 123). Clearly pilgrimage in winter was not commonplace, but certainly in existence.

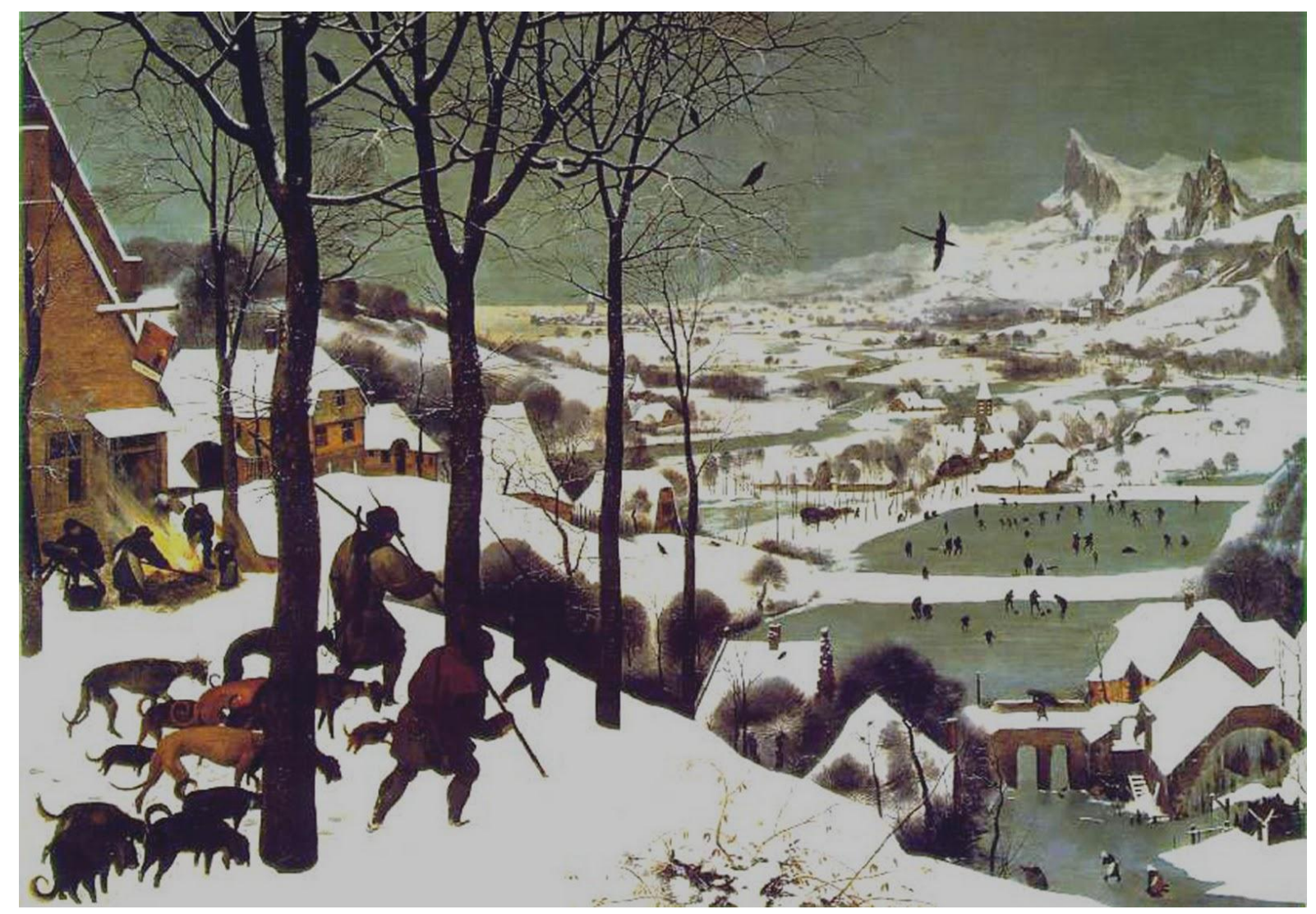

Figure 116. 'Hunters in the Snow' by Pieter Bruegel, 1565. This demonstrates the transformative effect that snow has upon a familiar landscape. 
Weather conditions would not only influence any choice of route made prior or during the journey but also colour the inner dialogue between pilgrim and landscape. Perhaps the most transformative example of this would be fog or heavy mist. This obscures recognisable landmarks and nullifies any viewing advantages of elevated travel. On a deeper level, as an element or weathersetting commonly found in folklore, supernatural and divine tales, fog or mist creates a liminal environment between the factual and fantastical through this obscuring of the familiar, providing an 'otherworldly' aspect to the landscape much like the role of the forest or woodland in the popular imagination. This is amply demonstrated by the sight of Ely cathedral rising out the fenland mists (see Figure 117 below), as has been described by William Defoe in Chapter 3, but which bears repeating here:

'As these fenns appear cover'd with water, so I observ'd too, that they generally at this latter part of the year appear also cover'd with foggs, so that when the Downs and higher grounds of the adjacent country were gilded by the beams of the sun, the Isle of Ely look'd as if wrapp'd up in blankets, and nothing to be seen, but now and then, the lanthorn or cupola of Ely Minster.' (Defoe, 1724, 79)

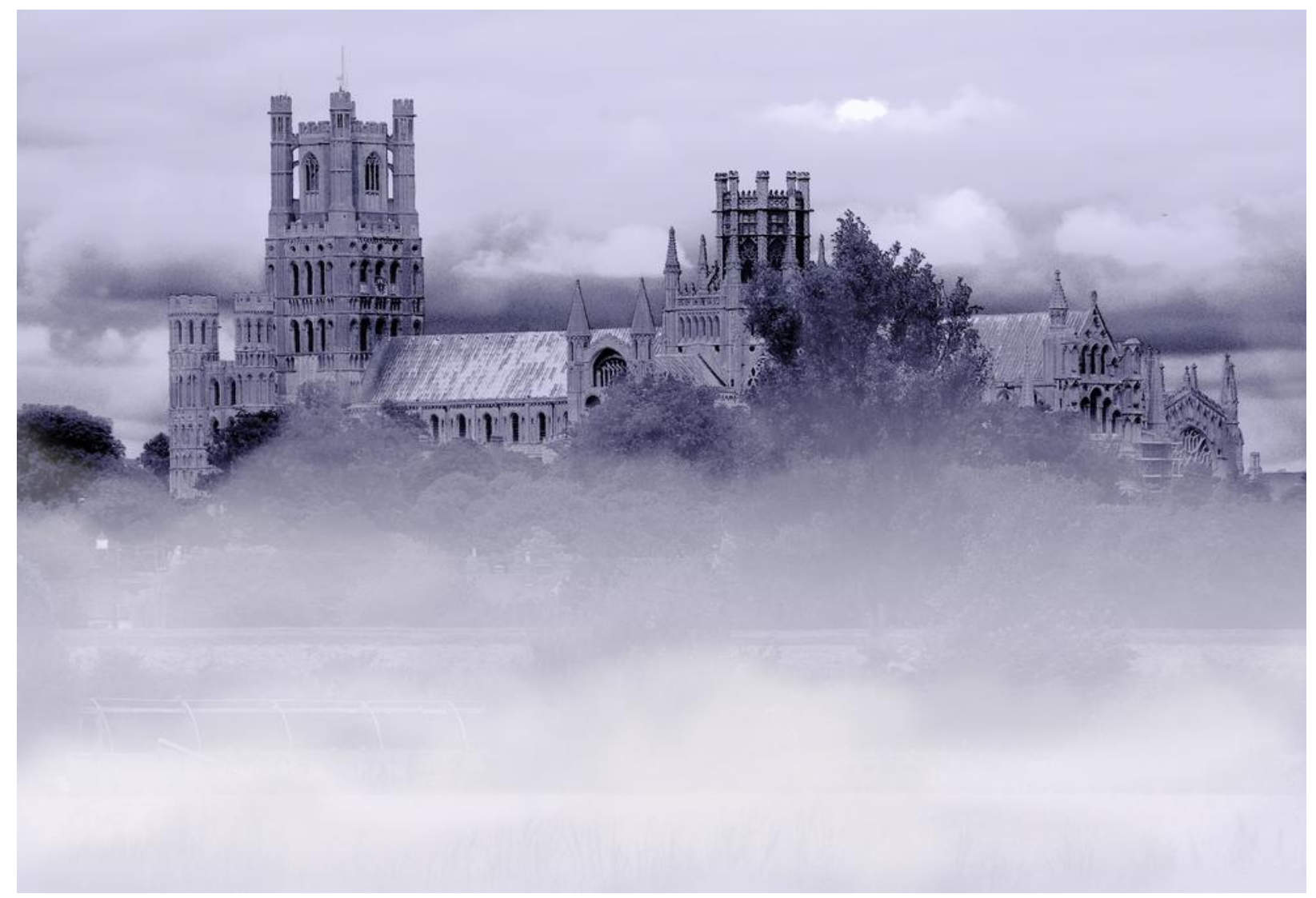

Figure 117. Ely Cathedral rising out of the fenland mists. Photograph reproduced from www.englandschurches.co.uk

The cycle of the seasons profoundly impacted the pilgrim experience, altering the accessibility and frequency of use for routes, the visual context of the environment, and the availability of time to the rural laity. Amongst the many saints celebrated in winter, St Winefride's 
feast day fell on the $3^{\text {rd }}$ of November. Whilst harsh weather may have dulled the attraction of her shrine for those travelling from longer distances, it is highly likely that the laity of Flintshire, some of Denbighshire and the northern Marchlands made journeys to Holywell on this day to maximise the efficacy of their prayers. December $4^{\text {th }}$ marked the feast day of St Oswald, in which (as discussed in Chapter 4) rogations and processions were held around Salisbury to celebrate his translation in the new cathedral. Donations at his shrine show a marked increase on this day, demonstrating the impact that a feast day had on the profits of monastic coffers (Wordsworth, 1901, 33). The liturgical celebrations of Christmas would have revolved around the local parish church, and we see no mention of British feast days between the $24^{\text {th }}$ and the $30^{\text {th }}$ of December in the Roman Martyrology, suggesting that pilgrim traffic was predominantly static during this period (Henisch, 1999, 31). November and December would largely have been characterised by cold, frost and in some cases snow, which not only made travel dangerous but also in some cases impossible due to routes being covered from view or inaccessible (Ohler, 1989, 7). January and February are typically shown in calendar manuscripts as being cold and wet.

The advent of May saw farm labour begin again in earnest, as winter gave way to early spring. The roads still showed the effects of winter, however 'travelling conditions improved almost daily' (Ohler, 1989, 8). Ploughing begun on Epiphany Eve or Twelfth Night ( $5^{\text {th }}$ January) and lasted 4 weeks until Candlemas ( $2^{\text {nd }}$ February) and by May crops were growing (Jones, 2007, 181). Easter lay in spring, marking the midpoint of the liturgical year. Celebrations at the ecclesiastical centres featured in this thesis such as Winchester, Salisbury, Ely, Bodmin and St Asaph would have been lavish and likely involved a series of processions around the town walls or settlement boundaries, feasting to mark the end of Lent. In the rural parishes the communities would gather around the church at daybreak to observe the Easter Vigil (Hughes, 1995, 20). Farm duties during the lambing season in March may have curtailed some pilgrim travel, but both shepherds and pilgrims experienced a sight connected with learnt religious motifs (a theme expanded below). This would have been especially visible in areas such as Flintshire and Denbighshire (St Asaph to Holywell), where the primary land-use revolved around sheep pasture. It is also likely that spring saw the reemergence of merchants on the roads, as they tried to beat rivals by starting out early on the year's trading routes (Ohler, 1989, 8). This would suggest particular visibility of commercial travel on the four primary 'king's roads' of England (Icknield Way, Ermine Street, Watling Street and the Fosse Way), as due to their status and role as the nation's transport arteries they were more likely to have been repaired and maintained during and after winter weather.

With grain stores at a yearly low and the harvest beginning in late July/early August (see Figure 118 below), early July would have been a time of shortage. This may have been a good time to make a pilgrimage with less agricultural commitments at home, the prospect of being fed through charitable alms en route, and the desire to ensure divine blessings for the forthcoming harvest. The presence of deliberately deposited ampullae in many Medieval rural arable contexts suggests this connection between the harvest period and pilgrim activity, with 57 of the total 569 artefacts being found in Norfolk (Anderson, 2010, 182 - 203). Many of these objects bore markings relating to a Marian cult, and the premier Marian cult in Medieval England was at Walsingham, so it is possible 
that during July Walsingham saw an increase in pilgrims from rural communities both within Norfolk and further afield.

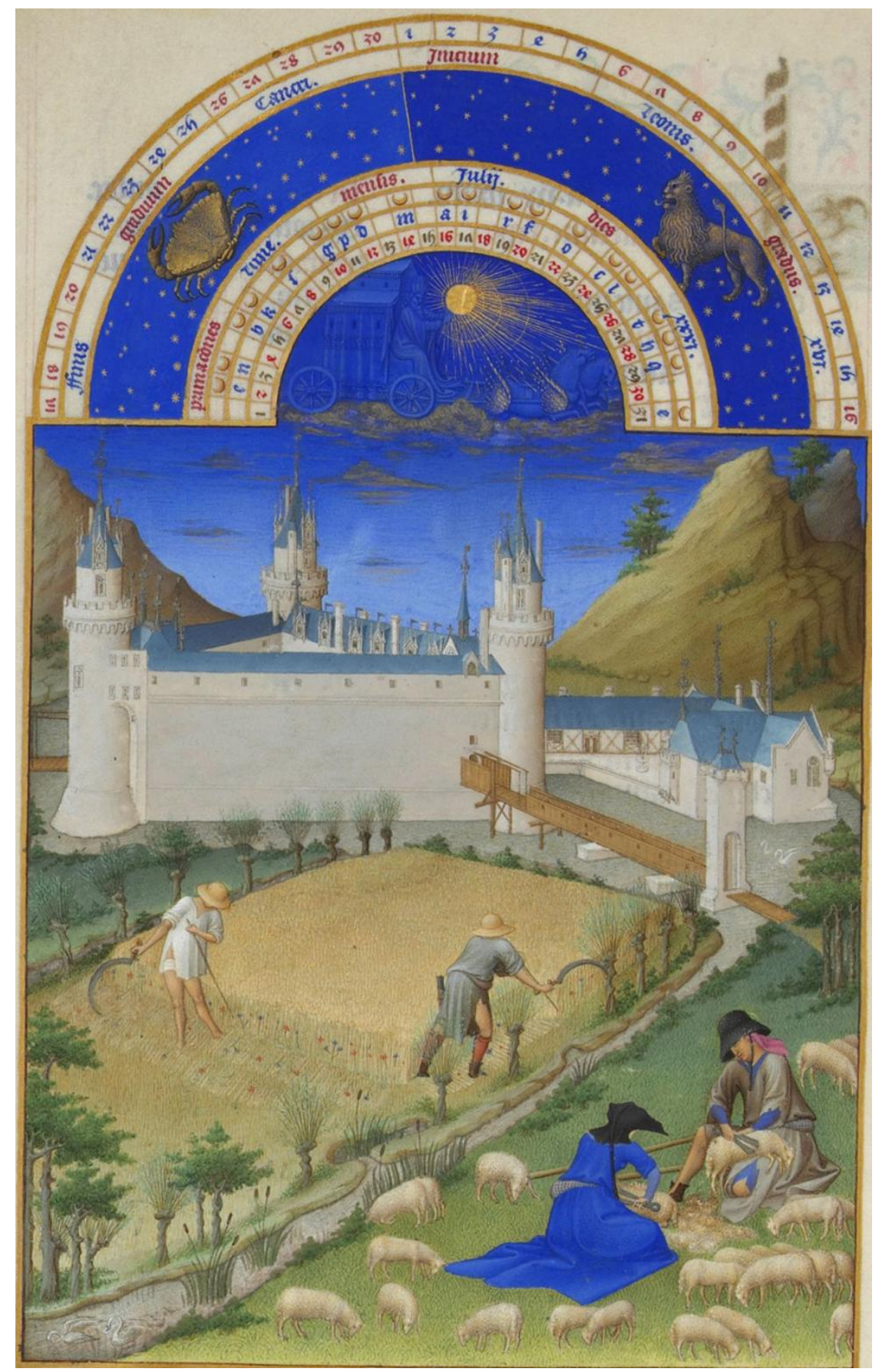

Figure 118. The July panel from the Très Riches Heures du Duc de Berry, 1489, showing the beginnings of the harvest. Reproduced from http://humanities.uchicago.edu/images/heures/july.jpg

Throughout the year there were large markets and fairs, granted through charters, where merchants, pedlars and farmers traded and sold, particularly in the summer months. Other smaller one day markets held weekly were the foci of local trade the length and breadth of Britain. At Ely 
the feast of St Ethelreda ( $23^{\text {rd }}$ June) was a major fair which lasted 7 days (beginning 3 days before her feast day) and attracted attention from around the fenland region (Blanton, 2007, 242). Sited near the border with Norfolk, a highly agriculturally prosperous county during the Medieval period, Ely was a significant destination for both religious and commercial activity. This fair in particular would have increased pedestrian traffic along incoming causeways and business for inns along the city High Street. According to Pugh, 'Booths were erected all round the precinct walls, at the gateways, in the streets, and on the wharves. By the 15th century agents of great commercial firms bargained here over the sale of iron and timber.' (Pugh, 1953, 50) This is indicative of a significant increase in numbers over this period, and for the pilgrim who integrated this feast day into a journey towards Walsingham (or even as a final destination in its own right) would have amplified the importance of St Ethelreda's cult. It is likely that, in preparation for this influx of visitors, the access routes to Ely, such as the causeways, were well maintained to maximise trade and economic benefit for the community. This could be an advantageous visiting week for pilgrims in terms of the feast day, a popular choice for pilgrimages, and also as the time when the surrounding route network was in best repair. There is however the issue of accommodation, which would have been in great demand during this week. Further along the route towards Walsingham, the pilgrim encountered Swaffham. This town was granted a charter for a market and two annual fairs by King John in the $12^{\text {th }}$ century, which transformed the town into a commercial hub for the region (Lewis, 1848, 281). The market was held each Saturday, with the fairs held 'on July 21st and November 3rd, for sheep and cattle.' (Lewis, 1848, 281) This would suggest many livestock along routes entering and exiting the town, probably supported by drover roads leading from farms into the principle route network, which saw seasonal peaks of use during the summer and early winter. For the pilgrim this would involve joining (if not already travelling with companions) a loud and slow train of beasts and men into and from Swaffham, with the Castle Acre estates to the north (and Walsingham) likely supplying a large portion of the traffic.

The feast days of many major local saints fell in October; these were of great importance within their respective regions, stimulating pilgrim activity on a local level (Duffy, 2005, 47). During the early autumn, the days were still generally warm, however as winter approached any worsening weather rendered travel more arduous than usual. Rural valley routes, such as that presented in the Camelford to Bodmin chapter, may have been flooded, causing the pilgrim to ford with difficulty. Before fenlands in Cambridgeshire and Norfolk were drained they would also have been strongly influenced by the seasonal weather conditions of the late autumn and throughout winter. Heavy rains could have made the lower causeways and access routes to Ely flooded or more dangerous than usual. The psychological impact of thick fogs lying across this marshy landscape should not be underestimated, particularly in terms of superstition, orientation and landmark visibility. One aspect of this fenland landscape in particular which is interesting to consider are the purgatorial effects that autumn brings, echoing the descriptive motifs of shapeless mist and disorientation that personify this realm. These murky conditions and lack of reference points are metaphors traditionally associated with the spiritual limbo of purgatory which Dante describes to great effect (Armour, 1983). This connection also has resonance with the idea of travel in general, as those in purgatory are described in theological terms as wayfarers (Healy, 2003, 125). The autumn/winter crossover also occupies a liminal space in the liturgical year, marking the transition from the end to the 
beginning of the Christian cycle which occurs on the first Sunday of Advent in late November or early December.

An extensive body of literature addresses the role of the pre-historic monument in the landscape (Tilley, 1997; Tilley, 2008; Pryor, 2004; Gingell, 1992), although the role of the sacral monument in the Medieval landscape (especially of Britain) has received less attention, featuring primarily only in the research of Turner (2006) and Walsham (2011) as discussed in chapters 2.3 and 2.4. This is curious given the importance attributed to buildings such as the parish church within the lives of the Medieval laity. It can be seen within my case studies in numerous examples just how integral the visibility of monuments within the landscape was to the pilgrim experience of travel, and this ties into two of my research aims:

3. To identify the surviving archaeological evidence for Medieval pilgrimage, and compare this record with that offered by the documentary data.

4. To differentiate between the pilgrims' experience and interaction with the landscape with that of 'secular/commercial travellers' (such as merchants).

Across the routes and environments I have investigated in this thesis, monumentality in the landscape has ranged from minor wayside shrines and free-standing crosses, to parish churches and imposing religious houses. Each individual site represented a touchstone with the divine in varying degrees, which depended on factors such as reputation, saint affiliation, scale and situation within the landscape. This multifaceted aspect of the religious monument within its setting is not restricted to the Medieval or Christian cultural context, and other examples of this will be given further below, but first I will deal with this theme in relation to the case studies, and landscapes of Medieval Christianity.

The ecclesiastical sites represented a 'matrix of points of access to the divine', imbuing the landscape with a series of defined orthodox encounters that reaffirmed Christ's dominion over the earth (Walsham, 2011, 49). A primary aspect of these monuments with relation to pilgrims was their visual quality within the environment. From the numerous built encounters within the case studies of this thesis, it is likely that many of the crosses or church towers were erected with their line of sight in mind, pre-determining to a degree the initial impression of the site to the arriving visitor. Examples can be drawn from the case studies, such as the intricately decorated Maen Achwyfan cross (Chapter 5), which stands in a field in Whitford parish (see Figure 119 below). Crosses form one of the most layered elements in the built landscape, representing directional aids, preaching spots, memorials, and boundary markers. There is also a moral role contained within the cross' form and decoration. Throughout the landscapes of Christendom, free-standing cross iconography frequently involved themes such as the Virgin and Child, the Passion and Crucifixion, and the Apostles. 


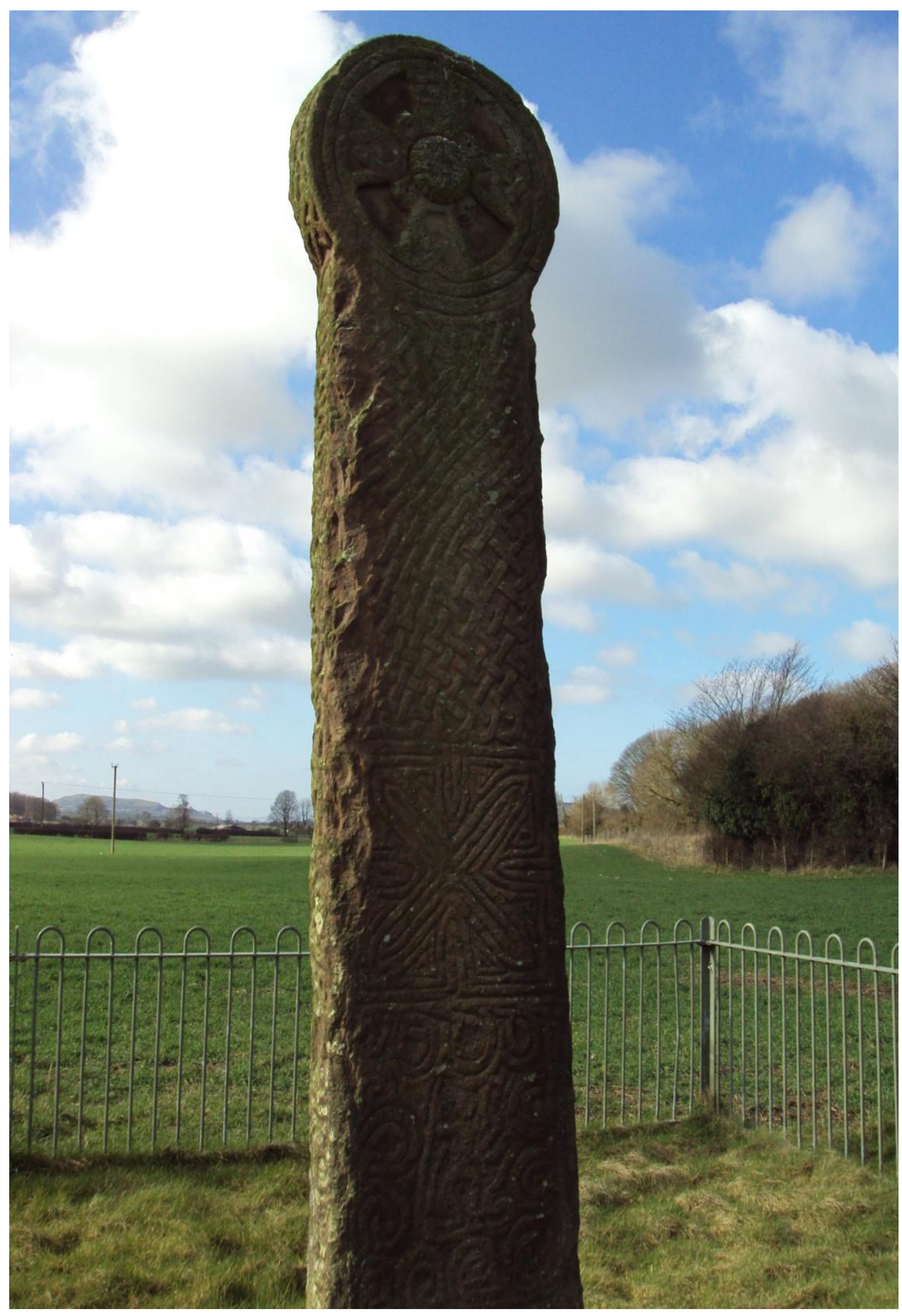

Figure 119. The Maen Achyfan Cross along the St Asaph to Holywell route, Flintshire. Photograph taken by author. 
Combined with the instantly recognisable shape of 'the cross' (i.e. crucifix) on which they were carved, they served as a reminder to all travellers of the Christian values and moral tales into which they were initiated through baptism (Walsham, 2011, 61). Within locations which correspond to the concept of 'wilderness' or a locus horribilis, the cross performed a guiding role in a physical sense, and also as explained above with the iconographic references, in a spiritual sense, 'leading' the pilgrim through the landscape. Bodmin Moor and its hinterland, which the Camel River borders, is an excellent example of this concept, with the lands around Bodmin Moor containing the highest concentration of crosses in Cornwall (Turner, 2006a, 37). One of these crosses is discussed in Chapter 6 standing in a field outside Advent church, the 'Dorniert Stone' cross exists in the village of St Cleer, and there is (amongst others) another example at St Neot. Marking the boundaries of parishes, and functioning as directional aids and preaching posts, these multi vocal monuments were purposefully placed in visible locations. Both the Maen Achwyfan cross and Advent church cross are easily discernible against their landscapes, being located within an open flat field within a depression (Maen Achwyfan), or against a rise in the landscape which makes their profile visible from the valley floor (Advent). They exist as a focal point for sacral activity, a connection point which (as outlined in Chapter 1.3) allows one to be 'closer' to the divine force(s), where we are able to experience their power more fully and establish a relationship with them; in the case of the free standing cross, through prayer (Davidson and Gitlitz, 2002, xvii).

In terms of the differences of perception to commercial travellers and pilgrims, these crosses could be seen as stepping stones through the wilderness. Also offering multiple interpretive options were the 'beacons of faith', the church towers which were commonly highly visible, especially when elevated or located within traditional flat landscapes such as Norfolk. To parishioners, these towers expressed 'personal honour [and a family's lordship] and parish unity' (Thiery, 2009, 67). To those pilgrims intimate with the local parish landscape, these elements combined with the personal memories bound up with events surrounding the church would have been encountered upon the sight of the tower, or on hearing the church bells (Thiery, 2009, 67). The tower represented the honour of the parish. However for those who were not 'local' to the parish, and were perhaps passing through to a different pilgrimage destination, what would the sight of St Breward's church perched on a hill overlooking the Camel valley have offered, or that of Cranwich church with its amplified bell tower? In practical terms the church offered shelter, in poor weather the open doors of the church would have been an invitation for both prayer and respite for the weary. The symbolism of the tower is that of defiance for the mundane, for 'escaping from the trials of earthbound reality and approaching the celestial realm. It is an expression of the archetypal appetite for giganticism.' (Jackle, 1987, 49) We can also see this within the monumentalism of the cathedrals in this thesis: Ely, Salisbury and Winchester. Designed to provoke awe in the laity, the pilgrim would be particularly receptive to the sensory overload these buildings provided both inside and out, and the sheer scale of the cathedral, especially visible in the towers of Salisbury and Ely, would have acted as a vast touchstone with the divine, reaching from the earth up to the heavens. In its own humbler way, the parish church tower also presents for the pilgrim 'Jacob's ladder', bridging heaven and earth (as did the church interior, being a space of prayer and communion with God). The tower was typically higher than any built aspect of the surrounding parish environment and the case of a 
plateau or plain, higher than any natural feature. An example of this is the church of St James in Hockwold cum Wilton, which lies on the edge of the now-drained fens in the borderlands between Norfolk and Cambridgeshire, and whose tower is highly visible during the approach from the Ely. 


\subsection{Possessions, the Personal Element \& Post-Pilgrimage}

Pilgrim souvenirs have commonly been used to point towards the origin or shrine sites of individual pilgrimages. The conceptualising of the souvenir during the journey has been largely been unexplored by scholars other than in suggesting that they conferred legitimacy to the pilgrim, thereby endowing a certain level of status or prestige and granting them access to pilgrim accommodation. However, the universality of the 'official souvenir' as a manner of either appropriating some of the power or curative properties of a shrine for later use, or as identifying oneself as 'a pilgrim' should be at least discussed with regard to negative evidence, the lack of substantial surviving material record, especially in connection with highly local saint cults in immediately accessible landscapes. Whilst not being an explicit focus of my research, pilgrim souvenirs form a valuable data set, which has helped inform about the broader religio-cultural landscapes that pilgrims created, through distribution patterns for badges and ampullae, and in addressing the contexts in which they were deposited. One intriguing question that has been raised thorugh the analysis of these data sets where possible, is in their absence for all but the most universal cult represented in my case studies; that of Our Lady of Walsingham. The archaeological record only reveals souvenirs for this Marian cult, and is devoid of souvenirs within the contexts of St Swithun, St Winefride and St Petroc. Crucially, is this absence in material culture simply because they remain undiscovered, or does this represent a mixed approach towards pilgrimage's material culture where the idea of 'souvenirs' or 'talismans' takes many forms, i.e. not solely manufactured trinkets. Whilst it is reasonable to assume that the predominant reason for this discrepancy in pilgrim badge representation in the archaeological record may be in part attributable to lack of discovery, preservation or indeed deposition (the objects were not discarded), why are there none attributed to three of the saints cults discussed here? Therefore the possibility of variances in the concept of souvenir forms should be considered. This may constitute another aspect of the cultural landscape of pilgrimage, linked to concepts of identity imparted through either the localism or universality of a saint cult which are briefly addressed below in relation to the Holywell case study (Chapter 5), and deserved to be investigated more fully in the future.

Returning from the Holy Land in the early $7^{\text {th }}$ century, some Medieval pilgrims are recorded as possessing souvenirs such as 'dried flowers from the garden of Gesthsemane, stones or dirt from Golgotha, [and] pinches of dust from places Christ had walked' (Janin, 2006, 67). At this time there were purpose made souvenir containers for holy water from the river Jordan and remnants from other biblical sites. However, there was also evidently a desire for a souvenir which was both free, and with a personal interaction between the pilgrim and the site beyond commercial exchange. At St Winefride's Well, in its original form as a spring, pilgrims frequently removed stones from the water course, which are attested as being used to sanctify or bless water in the home (Fleetwood, 1713, 85). There is no material evidence of 'official' souvenirs such as badges or ampullae in the archaeological or historical record. Given the prestige of the site this is surprising, particularly with regard to ampullae an obvious container for the spring's waters. There is the possibility that souvenirs did exist, however they have not survived due to intricate designs or general fragility. However it seems likely (based on Fleetwood's research transcription of Winefride's hagiography) that a preference existed, at least prior to the $15^{\text {th }}$ century well house construction, for organic and 
personally chosen artefacts which had a direct link to the miraculous source. From this example it is worth briefly considering other possibilities for 'found souvenirs', and the folkloric record points towards flowers and herbs as being closely linked with hagiographies, cures, and emblems of certain saints (Jones, 2001, 128). This 'found' aspect may well reinforce the localism of a saint cult in the mind of the pilgrim, being a plant which may be very particular to that area, or grow in abundance either around the saint shrine site or at sites which are linked to events from their lives. By selecting a natural object associated with the saint or site the pilgrim has a tactile link to the site which may represent a more intimate connection than a bought object such as a badge or ampulla. Whether or not these artefacts served to impress or bestow prestige on the bearer in the same manner as 'official' souvenirs requires further research.

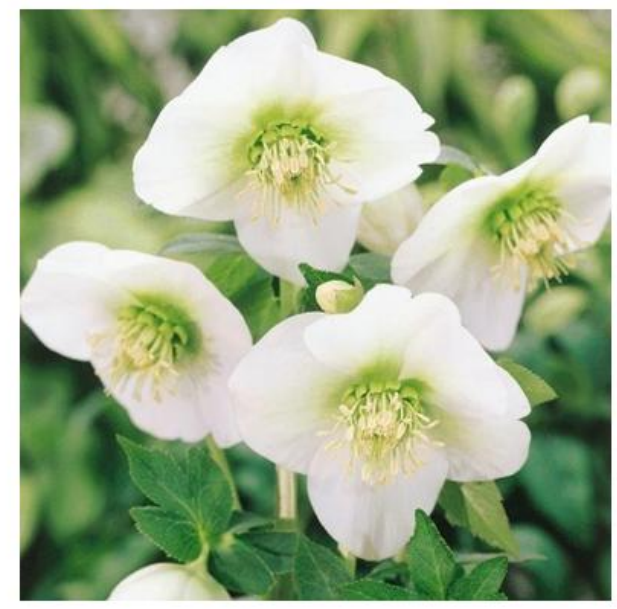

Christmas Rose (Helleborus neger) - St Agnes

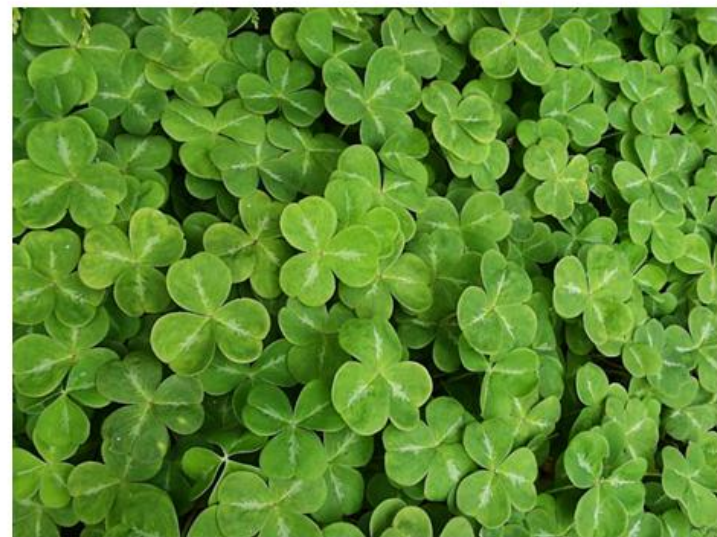

Shamrock (Trifolum repens) - St Patrick

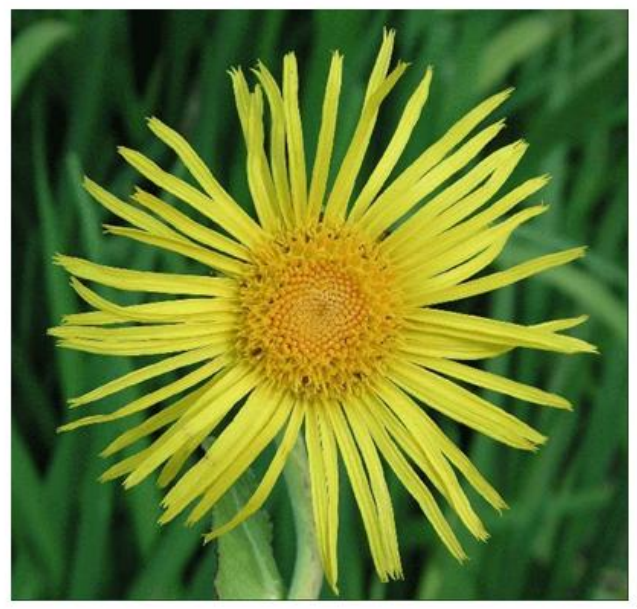

Elecampane (Inula helenium) - St Helen

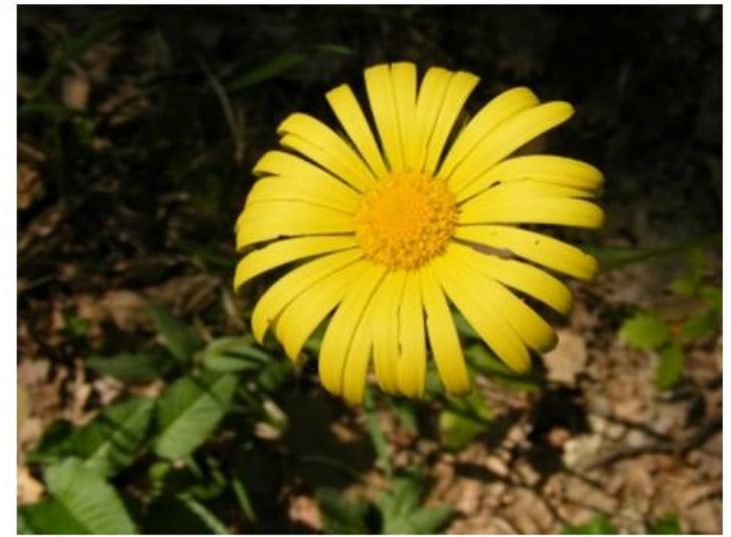

Marigold (Tagetes erecta) - Virgin Mary

Figure 120. Examples of flowers which bear relations to saints in plantlore, and may have been used in the context of 'found souvenirs'. Photographs reproduced from http://www.brc.ac.uk/plantatlas/

In terms of specific floral associations, whilst it is not the purpose here to list each religiofolkloric association between saint and flower it is worth giving a few brief examples found within British landscape. St Agnes is closely linked in English folkloric tradition to the 'Christmas Rose' 
(Helleborus neger - see Figure 120 above) due to her association with purity and the correspondingly white leaves of the flower (Friend, 1883, 274). In a $17^{\text {th }}$ century estate map of Leighton Bromswold (Huntingdon), a chapel and well of St Helen is situated in 'Alycon Payne Close', a corruption of 'Elecampane' (see Figure 120 above), an Anglicised term for Inula helenium, and this herb is also known as 'Elen's Spignel' in Wales (Jones, 2001, 128). The root of this plant has long been used in medicinal folklore to cure stomach complaints, with a history of use stretching back to Classical Antiquity and a mention in Pliny the Elder's $1^{\text {st }}$ century 'Natural History' (Jones, 2001, 128). The Shamrock (Trifolum repens - see Figure 120 above) is famously associated with St Patrick in Ireland, where it is said to have formed a teaching aid for the saint when explaining the mystery of the trinity, the three leaves uniting into one stalk (Friend, 1883, 274). St John's Wort (Hypericum perforatum) has traditionally been gathered on the eve of St John's day (June $24^{\text {th }}$ ) and is also known as 'Chase Devil', and thus may have been gathered en route for protective purposes (Friend, 1883, 274). Marigold (Tagetes erecta - see Figure 120 above) is one of the principal flowers dedicated to the Virgin, and on the feast day of the Annunciation or 'Lady-Day' ( $25^{\text {th }}$ March) were used as decoration inside churches - it is also claimed that the Marigold owes its name to Mary i.e. 'MaryGold' (Friend, 1883, 274). There are numerous other plants which are claimed to be linked to the Virgin, however the issue of etymological corruption makes definitive statements difficult - for example Rosemary does not derive from the Virgin's name but in fact is an Anglicised version of the Latin Rosemarinus (Friend, 1883, 81). Amongst others, a highly prized flower which has a proven record of association with Mary and could be found within Medieval Christendom was the Rose, which represented favoured position in the Christian pantheon as 'Heaven's Rose', cultivated roses were an early introduction into Britain. The Dog Rose (Rosa canina) is native to Britain and has an identification riddle associated with it, 'The Five Brethren of the Rose', that has survived from the Medieval period indicating its commonality (Mabey, 1996, 191). Within English meadows, another flower bearing a strong Marian association and a candidate for a 'found souvenir' from an 'Our Lady' shrine is Lady's Slipper (Lotus corniculatusis), a flower which whilst rare, used to be found in open woodlands, but currently survives at a single site in Yorkshire (Mabey, 1996, 439). The folkloric and religious symbolism of these plants and others would have been commonly known during the Medieval period. This was due to the reliance on local flora for medicinal or pseudo cures, and also through the parish priest's regular sermons with scriptural and theological instruction presented in terms the laity could relate to through their immediate environment, history and experiences. Therefore a pilgrim travelling along towards Walsingham might pick a stem of Marigold or Lady's Slipper to serve as both a reminder of Mary's presence in the local landscape and as a symbol of her Walsingham shrine.

Other visual symbolic associations to consider are the fauna seen during the journey. During a pilgrimage the traveller was more open to spiritual encounters and interpretations, and their association with scriptural themes found in sermons and religious iconography would be more mentally prominent. The most obvious example of this would be found during the Spring lambing season. The 'Lamb of God' is one of the prime motifs of Jesus Christ often found in the 'Agnus Dei' form (typically a lamb holding a banner emblazoned with a cross), representing his role as a sacrifice for mankind's sins and lying at the heart of Christian teaching (Ferguson, 1961, 20). The image of the dove is also central to the Christian doctrine, representing primarily the descent of the Holy Spirit upon Jesus during his baptism, recorded in the Gospel of John: 'And John bare record, saying, I saw 
the Spirit descending from heaven like a dove, and it abode upon him' (John 1: 32). Within the Christian artistic tradition the dove is frequently featured in images which contain Jesus and God as part of the holy trinity, or the ascent of the spirit. A commonly used motif within literary transmitted Christian scripture (and therefore through sermons), the laity would have been well aware of the bird's religious 'significance'. It is also recorded that despite being ruinous to new sown crops by eating the seeds, the killing of doves by children guarding the fields incurred heavy penalties thanks to their association with Christ (Bennett, 1937, 139). Finally, we turn to a shadowy figure within European folklore; the fox. Frequently anthropomorphised in folk tales as 'Reynard' (particularly during the Medieval period in French and German ballads), the fox was hunted initially as vermin, and later for sport and its fur, although it was generally considered inedible (Varty, 1999: Griffin, 2007: Thomas, 1984). A common figure in Medieval sculpture, the fox was also thought to be a missive from the devil, and as such became an emblem of malicious cunning and guile. The symbolic and iconographic aspects of animals in Christianity are far greater than can be discussed here, however these three examples represent common animals likely to have been visible in the four case studies discussed in chapters 3 through to 6 . Their possible role as an allegory should be considered when discussing the perceived qualities of landscape for spiritual interpretation and meaning to a pilgrim. Culturally inherited triggers such as these anthropomorphised qualities attributed to animals, or spiritually derived qualities from plants, can set off a chain of recollections and associations. These would be highly personal and varied. However, given the general attributes of the above, we can speculate about broad trends of appreciation for encounters with (for example) the Marigold plant clustering around a Marian shrine, the lone fox watching the traveller from a distance, or the sight of a dove gradually ascending.

Having discussed the concept of the pilgrim landscape along the journey towards the shrine and the subsequent desire for a token, souvenir and memory from the site to return home with, I will now consider the 'retrospective pilgrim landscape'. This encompasses the consequences of the pilgrimage process felt by the traveller after their return home and re-integrated with familiar surroundings. I would argue that it is through the recollection of the journey, once returned home, that the pilgrimage begins to 'make sense' or is contextualised by the pilgrim. Recovered from fatigue, the pilgrim is left with a sequence of internalised encounters - typically rosier than the reality - which mark key aspects of the journey. These memory series' can be worked through at leisure, providing a meditative recollection and private internal journey which offers limitless personal encounters with sites of sacred significance on a mental level. The re-lived journey of the imagination also offers an ever increasing collection of visual details which may not have been appreciated by the pilgrim in the physical encounter. These, whilst appearing insignificant at first, may become more relevant during recall in the future, when their image is triggered through a related phenomenon (a certain smell, or sound or feeling which is similar to that experienced around this 'minor encounter' along the pilgrimage route). The memory would then become related to a present event in daily life, thus providing a sense of life's inherent design, and auspicious encounters that refresh the importance of the completed pilgrimage in the mind of the pilgrim. Similarly concepts and lessons heard in sermons or other doctrinal transmissions may take on greater meaning to the pilgrim-cum-layman after the journey, relating ideas of exile to their own experience. This recalls the idea of Victor Turner, that through conducting a pilgrimage we are 'going to a far place to understand a familiar place better' (Turner, 1992, 35). This is the legacy of pilgrimage as a 
transformative process which renews itself in the daily life of the laity, a 'post-pilgrimage' experience.

In this vein, whilst meditations on earthly and heavenly Jerusalem are well attested within the monastic setting, they were not exclusive to them. Meditative or contemplative states are not restricted to the 'learned', or spiritual or devotional thoughts, and it is unwise to subscribe to the commonly held opinion that the laity were entirely ignorant about such matters and practises of faith (Gurevich, 1998, 2). Undoubtedly they had less opportunity for such prolonged states of contemplation or recollection; daily life was concerned with more physical matters not significant periods for contemplation, unlike the monastic lifestyle. However the laity would not have been unfamiliar with the processes of 'inner travel', either through 'day-dreaming', contemplative devotional moods, recalling events for oral transmission or practically through remembered landmarks and reference points within the route for future orientation purposes. The laity should be credited with powers of contemplation, recognising and operating within dualist sacred and profane spaces and engaging with their own spirituality on an intimate practical level. Pilgrim guides of the $13^{\text {th }}$ and $14^{\text {th }}$ century, as well as travel literature in general, aimed to 'move [the] reader by telling him something about the East...to arouse the zeal and devotion of the readers, and the personal element in the pilgrim books was intended to serve that end.' (Hyde, 1990, 13 - 15). These texts show a clear desire to motivate pilgrims to undertake their own journey, however they were primarily targeting the wealthy and literate classes. They may also have been used by those who had already performed their own pilgrimages, to encourage or refresh their own recollection of the journey within themselves, and thus aid contemplation.

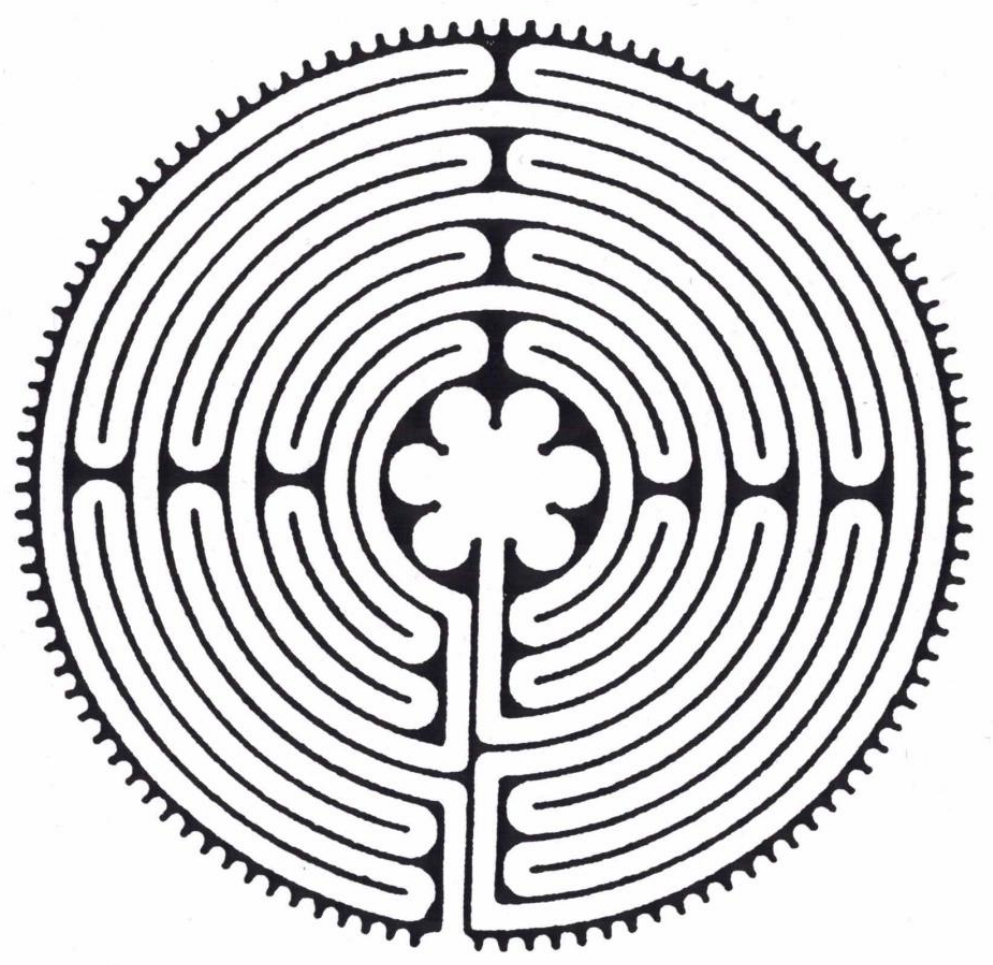

Figure 121. Christian labyrinth motif, used within Chartres Cathedral. Reproduced from www.labyrinthos.net 
Similarly, by extension the labyrinth motif seen in several church roof bosses (e.g. Saint Mary Redcliffe in Bristol) and cathedral floors (such as Rheims, Amiens and Chartres - see Figure 121 above) of $12^{\text {th }}$ and $13^{\text {th }}$ century date could be said, whilst not explicitly designed for ex-pilgrims, to have been most understood or appreciated amongst the laity by veterans of pilgrimage. These designs are both multicursal (with dead ends) and unicursal (a single clear route (Doob, 1990, 3)). Earlier uses of the labyrinth contained hellish or purgatorial overtones, and towards the later Medieval period these became replaced with more beneficial and contemplative meanings such as 'God's cosmic labyrinth', through which one journeys; however the salvation aspect remains omnipresent (Doob, 1990, 123). This is speculative, however I would argue that these highly layered concepts of finding gnosis and the interior salvation which lie both at reaching the core of the labyrinth and also in tracing ones way out, might have resonated strongly with those who had experienced the process of long distance travel, and whom had the memory and extensive mental space inherited from the journey. In terms of design the labyrinth motif may not have been created exclusively for replicating pilgrimage or to cater for the minds of ex-pilgrims, but they may have found a particular resonance in walking or tracing the routes within and without, representing their own journey towards heavenly Jerusalem through earthly exile. Through these tools, each systematic recollection of the pilgrimage brings closer the officially 'desired' permanent (earthly) state of peregrinus. This post-pilgrimage aspect of the pilgrim's experience, including the possible effect of the journey upon the mind and the implications for the pilgrim's re-entry into society, would benefit greatly from further study, in order to assess the holistic impact of the pilgrimage on the life of the laity. 


\subsection{Beyond the Borders of Britain}

Within the context of Christendom, the three principle pilgrimage destinations of Santiago de Compestela, Rome and Jerusalem offered exotic cultural interactions within a variety of unfamiliar landscapes. Yet the experience of the route and of the journey was also influenced by whether it was solo or in a like minded group. In the case of the latter, the interaction with exotic landscapes may have been dulled, partially insulated from foreign culture. However it has been the purpose of this thesis to explore the potential areas for interaction, based on the direct dialogue between pilgrim and landscape from both a theoretical and practical point of view. The pilgrim site may have translated the concept and presence of the divine into comprehensible, tactile experience for the laity, but the journey remains the key to understanding the impetus of the pilgrim phenomenon across Medieval Christendom. Transmitted within the movement through a series of environments, each replete with opportunities for contemplation, penance, encounters with 'tradition' (i.e. liturgy and miracle sites), the supernatural (i.e. folklore) and the profane element of touristic curiosity, pilgrimage presented the laity with a personal and active interaction with the precepts and trials of their faith. The microcosm of the journey embodied the lifelong 'transformation' and movement towards heaven. It is unlikely that the pilgrim was a tabula rasa in terms of their expectations of the journey. Likely they had received advice, direction or some manner of passed knowledge about the route (particularly if it extended outside their immediate locale), not least through the scriptural, liturgical or sermonic references to pilgrimage heard in church services. I do not think however that this negated the personal aspect of the pilgrim journey. Instead it served to place the idea of the pilgrimage within a cultural framework - not just Christian or British, but if learned from for example a neighbour, then with the references of their local identity. This further personalised the dialogue with the experiences en route, and not a collective phenomenon that operated solely within a system of defined rituals and processes. The pilgrim landscape was just that - a landscape for each pilgrim, which could be relived through meditation after the journey's end.

The flow of English pilgrims across the Channel in search of these shrines is far better attested in the written record than those moving within the country. Webb suggests that this is because 'the appointment of attorneys by intending pilgrims ('crusaders' and others) is frequently registered in the Patent Rolls, especially after the mid-thirteenth century, as are the English royal safe-conducts and permissions to travel.' (Webb, 2001, 164) The itineraries of pilgrim movement around Europe throughout the Medieval period, as well as pilgrim instructional literature (including guide books such as the Codex Calixtinus) demonstrates the extraordinary appeal that pilgrim travel held for the Medieval laity. Despite Jerusalem offering the most intrinsic sites to the Christian faith, and Rome being the seat of Christian power, it is the Camino de Compostela de Santiago that has retained its place as Europe's premier pilgrim route - even amongst those who regard it as a cultural and challenging trek for non-religious reasons (Candy, 2009, 2). As explained in Chapter 2, my methodology was trialled along a small stretch of the Camino, between the entry to Spain at Roncesvalles and the cathedral city of Pamplona, the capital of the Navarre region. The formalised nature of the route allowed for an assessment of the 'ideal' range of sites, path types/maintenance, and varied landscapes encountered, allowing me to build a complete catalogue of what possible monuments could be encountered relating to pilgrimage. This was then re-dressed in relation to cultural considerations within the British archaeological record, such as the dissolution of the 
monastaries which destroyed many accomodatory options for pilgrims and reliquary shrines. The Camino's popularity amongst Medieval pilgrims provoked a sustained and profitable development of the hospitality, souvenir and ecclesiastical industries and ensured that long stretches of the route were maintained on a regular basis. This, combined with the sharp contrast in landscape types from the Pyrenean peaks and lush environments of the Navarre, through the arid plains of La Rioja and the volume of pilgrims along the route, made for an entirely different pilgrim experience to, for example, the local pilgrimage to St Petroc's shrine in Bodmin, or the longer route across the Fens and uplands of Norfolk to Walsingham. As has been discussed throughout the thesis, landscape plays a central role in the journeying experience, in both a physical and psychological sense. Distances such as crossing Spain, or from Canterbury down to Rome would have presented a scale unimaginable to many beyond description as a number of days travel (Birch, 2000). This was a period in which maps were restricted, only afforded by the elite and often inaccurate, so such journeys were difficult to imagine, both in length and destination. The pilgrimage to Rome provides a rich area for study, where the motives for pilgrimage were even more varied than other pilgrim destinations. As the administrative centre of the Western church, it allowed visitors to combine both business and piety, and provides a fascinating future area of research in terms of the travelling culture and experience. The cultural interactions provided by journeying into and across Christendom (especially into the Holy Land) were combined with the knowledge of being in the physical setting for much of the sermon material heard back in the home parish church. A confluence of this mythical quality of the landscapes and sites (exotic, unfamiliar and yet the setting for so many well known events in the Christian mythos) with the sheer scale of the journey and being removed from 'normal' societal rhythms of behaviour, would have been a profound experience. However on the negative side of the pilgrim experience there were dangers such as illness, injury or being attacked en route, and perhaps the most unexplored but equally important possibility of the destination simply not measuring up to one's preconceptions. For example, the destination overcrowded by fellow pilgrims perhaps undesirable, and odorous, visiting the sites in intense heat, being cheated by peddlers and innkeepers, or unfamiliar foods, all detracted from the aesthetic experience. These areas would benefit from future study in a holistic and interdisciplinary sense including analyses of itineraries, inn records, quality of souvenirs and possibly skeletal studies for evidence of illness or injury on those burials identifiable as pilgrims through their material culture.

Whilst this thesis has dealt exclusively with pilgrimage in the Medieval Christian West (specifically Britain), we must not lose sight of the universality of the phenomenon, and data from comparative religious studies between cultural contexts are vital to discover if there are fundamentals which underlie the journeying process as a whole. Within post-Constantinian Europe the rise of martyr cults brought about the 'imaginative Christianization of the mundus', bringing the laity greater opportunity to pray to saints' relics for intercession with God, but the concept and attraction of the saint cult is far from exclusive to the Christian West (Walsham, 2011, 40). The Islamic Sufi tradition (commonly classed as the mystical or esoteric element of Islam) hosts a large number of holy men whose memory and shrines receive thousands of devotees. Whilst the Ka'ba remains the central axis of the Hajj, lesser shrines which celebrate the deeds and reputations of local Sufi mystics and teachers are common throughout much of the Islamic world (Green, 2012, 13). This is partly due to the escalation in shrine building and establishment of pilgrimage traditions to these 
sites during the $12^{\text {th }}$ century, and 'the existence of so many Christian pilgrimage institutions in the Islamic west, and their recognition as pilgrimage sites by Muslims from an early period', may have influenced this rise in saint cult pilgrimage (Green, 2012, 92). These shrines' relationship to their surrounding landscape also relies on the connection between event and place, and can be seen as being especially relevant to those pilgrims from a certain area or with certain specific wishes, which one also finds in lore of Christian holy wells in (for example) Cornwall. Monotheistic elements make Christianity and Islam (and to an extent Judaism) suitable for comparative study, however caution should be applied when considering the Medieval contexts of these religions, given their numerous ideological shifts and nuances. Extrapolating out into pantheist or even technically non-deistic traditions (e.g. Buddhism) we can however still broadly see that within the act of pilgrimage 'places or locales are created through the life paths of individuals and groups. Over time they become invested with meaning and significance for persons through repeated activities, experiential perspective, movement, memory and storytelling.' (Owoc, 2008, 72) There is no pilgrimage which is devoid of site or landscape be it mental, by contemplation, or physical through travel, working on this notion of transience or liminality. The Sanskrit term tirthyatra stems from Yatra, which implies the act of travelling, and Tirtha which evokes the image of a ford, both forming a notion of crossing over, and moving between heavenly and human realms of experience (Coleman and Elsner, 1995, 138). This expresses a common theme which has emerged in my case studies, where liminal spaces offer the opportunity for an experience beyond the normal daily realm; forested areas emerge as particularly popular in the imagination for these transient events, as does the act of crossing a river or fording a stream in many hagiographic accounts (Candy, 2007, 77). This dialogue between the pilgrim and the journeying process involves not only a 'movement through space but also an active process of response as the pilgrim encounters both the journey and the goal.' (Coleman and Elsner, $1995,206)$ Accompanying this is the rhythmic pattern of walking which the traveller falls into over long distances, which saves on energy and has the potential to keep the body systematically moving whilst the mind is in contemplation.

Within Christian pilgrimage, the pilgrim may visit sites along the route which tie into the life or hagiography of the saint whose shrine they are headed. This functions as a reconstruction of the saint's biography, learning and recalling elements of their life which are engrained through monuments or association with natural sites across the landscape. This idea of the 'biographical landscape' is surprisingly best expressed in the $5^{\text {th }}$ century Chinese Buddhist monk Fa-hsien's fourteen year pilgrimage across northern India, in which every site relating to the Buddha's life is visited, and some which were believed to relate to his former lives (Beal, 1906). Here the biography of the Buddha is 'inscribed as a map onto the landscape', and one finds a parallel, of smaller scale, in the church dedications, holy wells and crosses commemorating St Cuthbert and his post-mortem movement around the landscapes of Northumbria in the $9^{\text {th }}$ and $10^{\text {th }}$ century (Coleman and Elsner, 1995, 176). Other aspects of the travelling Buddhist pilgrim's relationship with landscape are also highly reminiscent of Christian pilgrimage theory, particularly the relationship between the pilgrim and their environment. The $9^{\text {th }}$ century diary of Ennin (or Jikaku Dashi), a Japanese Buddhist Abbot at Mount Hiei monastery near Kyoto, records his pilgrimage to Mount Wa-t'ai in China - a site sacred to the Boddhisattva of Wisdom (Monju or Manjushri). The account describes how when entering such a sacred landscape one is automatically predisposed to search for divine signala in even the 
most mundane encounters, an aspect we find in itineraries detailing pilgrimages to Jerusalem during the Medieval period such as the Itinerarium Burdigalense (Chareyon, 2005):

'When one enters the region of His Holiness (Monju), if one sees a lowly man, one does not dare to feel contemptuous, and if one meets a donkey, one wonders if it might be a manifestation of Monju. Everything before one's eyes raises thoughts of Monju. The holy land makes one have a spontaneous feeling of respect for the region.' (Reischauer, 1955, 255)

This echoes both the social transformation raised by Turner (1978), that normative boundaries of status are reduced during pilgrimage. It also illustrates the heightened state of 'awareness' or 'exile' status that a Medieval pilgrim might adopt in the Christian West, that allowed him/her to move outside of normal society and encounter the world in a different manner, even if, in the case of local pilgrimage, the landscapes were familiar. The sacred quality of a landscape transmitted through reputation, sacred sites, and in some cases the monumental or imposing topography itself, constructs a dialogue with the pilgrim, causing the journey to become the process which endures after the pilgrimage has ended. For this reason alone, and there are many facets of study that the journey provokes, research into the travelling aspect of pilgrimage in the Medieval West deserves far more attention than it is currently afforded. As discussed in Chapter 2.1, this Buddhist experience of the landscape echoes that of Hamilton \& Spicer, who suggest that for Medieval Christians 'the mundane landscape was, and is, interwoven with sacred sites' (Hamilton \& Spicer, 2005, 4). This is one of the fundamental underpinnings not only of pilgrimage in the Medieval context, but also of the Medieval worldview, and thus emerges in my research as a core methodological consideration. Also echoing the peregrinus aspect, and preceding it chronologically, are the earliest Vedas, in which is contained the phrase 'Evil is he who stayeth among men' (Bhardwaj, 1973, 145). Transposed from the original nomadic origins of the Vedic culture, the virtue of movement and travel has been invested with a religious quality that evolved to treat Hindu sites as not separate, but mythological and indelibly linked to the landscape that holds them. The Ganges issues forth 'from the locks of Shiva's hair' which are represented by the Himalayan foothills, forming a sacred geography that the pilgrim moves through, passing sites both natural and man-made that hold not only the biographies of holy men, but of deities (Coleman and Elsner, 1995, 140).

This brief reference to comparative religions shows their value in helping to understand Christian pilgrim behaviour and motivation. From the examples above taken from other pilgrim cultures, and my detailed case studies, it is possible to see the advantages and multiple applications of a holistic method for analysing pilgrimage in identifying common, universal threads of experience, practicality and motive in pilgrim travel. The elements listed above provide a small sample of those with counterparts or similar concepts in a wide variety of traditions pointing towards the potential for applying the methodology, developed here to deal with Medieval Christian pilgrimage, to a wider sample across cultural and temporal contexts. Using the methodology applied throughout the case studies, and in this concluding discussion, I have shown some of the possibilities for research that a holistic approach encompassing multiple source material, physical and mental 
responses, and an interdisciplinary theoretical background can bring to bear in offering a new dimension to pilgrim studies, one that can hope to reach an understanding of the commonality of the pilgrim experience. This commonality could be said to be the rendering of a deity's omniscience (especially in monotheist traditions) more comprehensible through the provision of a site at which one can be confident in being 'closer' to it. Such as our own inability to truly grasp the vast dimensions of space, the concept of a god or spiritual power being literally everywhere at once is difficult to ceomprehend. By having selected locations in which, for whatever reason, the god is more accessible or 'especially present' the laity are more able to grasp (and feel comfortable with) the complex ideology of omniscience i.e. 'he/she/it is everywhere, but by travelling here this is somewhere I can appeal to and feel his/her/its presence more directly'. This I feel, is one of the underlying and most fundamental qualities of pilgrimage across all cultures, and would benefit from greater research in a comparative religious context. 


\subsection{Conclusions and Routes for Further Research}

'To come to know the individuality of a landscape through careful seeing and reflection is a considerable achievement; but to identify the broader principles implied in that landscape requires an effort of imagination that makes it possible to grasp the whole nature of something of which we only know a fragment.' (Relph, 1979, 28)

As has been outlined within Chapter 1, the scholarship of pilgrimage in the Medieval context has long been weighted towards the material souvenir culture, and architectural studies of the shrine sites themselves. In previous pilgrim scholarship there is a reticence to engage with the landscape and the journey, despite this element constituting the majority of the pilgrim experience and ideological background. In this thesis I have tried to redress this imbalance specifically within the context of Medieval British pilgrimage. The following aspects have been achieved and revealed, and are explained more fully below:

1. The development of an interdisciplinary methodology, using multiple source material and data, that deals with the practical and sensory elements of pilgrim travel in the British context.

2. The identification of Medieval British pilgrimage and pilgrim travel in the archaeological and historical record.

3. The analysis of Medieval travel from a specifically 'pilgrim' perspective, including relevant practicalities and theological elements.

4. Demonstrated potential pilgrim narratives for the four case studies, which cover a suitably varied set of landscape types, cultural contexts and shrine scales within Britain.

5. Identified potential differences in the experience of universal and more highly localised pilgrimages from both physical (i.e. travel practicalities, material culture, devotional practises) and sensory perspectives.

The pilgrim journey is a narrative one, embodying a lifelong journey towards the heavenly realm. By its very definition, travel is the core component of pilgrimage, and the journey is inseparable from the landscape as both a physical process and mental engagement. Any 
interdisciplinary study of pilgrimage must function dually, as both an investigation of the collection of physical routes, built environments and material pilgrim culture. In the course of this research I have developed a methodology which has proven capable of considering a wide variety of data sets and multi-disciplinary concepts. This is uniquely demonstrated in its use of multiple source and data types, the addressing of various theoretical elements from different disciplines and in extrapolating identified conclusions into other cultural contexts for comparison. In applying it to the four case studies of Walsingham, Winchester, Holywell and Bodmin this research has successfully brought to light these physical and mental processes involving topography, visibility, monument siting, spatial transition, accommodation and other practicalities of travel. Through this methodology, and the use of varied data sources, this research has explored the abstract nature of Medieval pilgrimage as a multi-layered process. This centres on ideas of collective (in this case Christian) and personal identity along the route - the peregrinus identity - and the relationship with the world through which one travels. Here the theological underpinnings of pilgrimage have also been taken into account through the analysis of potential Christian motifs that were visible in the landscape, such as wilderness, sanctuary and the allegory of 'life's journey'. In particular, the later Medieval context offers a fertile environment for the study of pilgrimage from this interdisciplinary and 'travel-centric' aspect owing to the numerous ideological shifts towards the post-Medieval 'Enlightenment'.

The period represents a transition across the longue durée in terms of how the laity engaged with and demonstrated their faith through action, with pilgrimage forming an important element. Whilst as a practise pilgrimage engaged with the laity across the social spectrum, the written record is selectively biased towards high status pilgrims. This should not, however, obscure the significant presence of the non-literate majority enacting their own devotional behaviours through pilgrimage. This presence is revealed through donation records at pilgrim shrines (such as at Ely cathedral) and in the construction of hospitals noted as catering primarily for pilgrims (such as the Hospital of St John the Baptist in Winchester). In the words of le Goff, our understanding of pilgrimage's role in both movement through the Medieval landscapes and as a social phenomenon must be 'a total one' (le Goff, 1982, xi), and the research in this thesis has shown that this is not only a desirable aim, but also a realistic aim within the framework of a methodology that is able to identify these diverse records through its interdisciplinary and multi-source approach such as the one I have developed in this thesis.

Relph's experiential definition (above) of understanding 'landscape' underlines the conception of holistic landscape research embraced within this thesis, in exploring these personal elements of interaction with environments along the route networks. The case studies themselves clearly do not cover all of the possible landscapes, pilgrim shrines and route networks across Medieval Britain, and it has neither been the aim, nor would it be achievable to address all pilgrim routes of Britain within the scope of this thesis. The environments around Bodmin, Winchester, Walsingham and Holywell provide a varied topographical palette (including coasts, uplands, fens, and river valleys), which are combined with a range of saint cults of differing Christian cultural backgrounds, such as 'Celtic', Anglo-Saxon, and Marian/Roman. Therefore, while not a 
geographically complete survey, it does address the major cultural and environmental landscapes that would have been encountered by the Medieval pilgrim in Britain.

From addressing the economic landscapes of Norfolk, Wiltshire, Hampshire, Flintshire, Denbighshire and Cornwall, I have shown that commerce, agriculture and regional administration were the essential factors in shaping the development of the Medieval road networks. It has also emerged that whilst Pilgrims were not directly responsible for creating roads, by establishing a tradition of movement along a set of routes to a pilgrim destination they actively promoted several long distance travel networks. The itineraries of kings and priests, especially Edward I, have provided invaluable evidence as to the extensive nature of the main route network of Medieval Britain. When considered in conjunction with the myriad of local rural trackways, drover routes, paths linking agricultural settlements and others, the practical questions of pilgrim mobility within the landscape appear to be less 'how' and more 'why'; their movements are not in doubt, but we need to understand why they chose certain routes over others, and whether these choices were made on a solely practical basis or held a deeper resonance. Along the four routes which I have analysed in chapters 3 through to 6 , this line of investigation has emerged in the final section of each case study as a difficult but absorbing area of study, and one which has not been addressed before. From these case studies, we can see that essentially the travelled 'pilgrim landscape' is not defined solely by the physical road or the cult centre, but is instead perpetuated by and within the pilgrim moving through it. The pilgrim weaves a narrative from concrete elements such as settlements, religious houses, route networks and the physical topographies through which they pass; a dialogue perceived by the pilgrim between them and the landscape. It is a landscape of 'memory, myth and tradition' (Coleman and Elsner, 1995, 48). This dialogue is performed through reacting to learned information, religious folklore, and the pilgrim's familiarity or unfamiliarity with the route, which then engenders either recollections or new observations. If the history or scale of the route is illustrious enough, this then becomes a meta-narrative, in which the 'heritage' of the pilgrimage plays a larger role in their consciousness than histories or non-pilgrimage related tales of the landscapes through which the route passes. At this point the route can be said to possess its own 'culture' through collective oral histories and traditions, and the manner in which it has shaped the surrounding regions (both culturally and economically). The route has then become its own cultural phenomenon, and in effect both an imagined landscape and a real influence in shaping the human development of the physical landscapes that the pilgrim traverses.

Locality, or the extent to which the pilgrim was familiar with the landscape, provoked a different appreciation of the journey, as to whether the pilgrim was immune to or distracted by the novel exoticism or 'foreign' landscapes through which they travelled. The overall theory in this regard which I have provided with regard to these case studies is that the intimacy with which the pilgrim knew the environment through which they travelled heightened the duality of their experience, the role of both 'a local' and also of 'an exile'. They were simultaneously bound to the landscape through daily habit or experience, but also encountering it within a different ideological role, as the 'peregrinus'. This multivocal aspect can be applied to more examples of smaller local shrines beyond Britain, where the local people encountered their own environment with a different 
temporary outlook, whilst retaining their cultural and personal associations within the route. A local knowledge and use of existing minor routes such as drover trails or field tracks would also provide a different experience to (for example) joining a flow of pilgrims and merchants along Watling Street towards Canterbury in terms of scale, contemplation, noise, atmosphere and quality of the road. Within the sphere of the localised saint cult, attended mainly by those who lived within the vicinity, the local community felt intimately connected to both the saint and the landscape over which their protective hand fell. The potential for this 'personal' relationship between cult and society to provide a meaningful pilgrim experience - especially if the saint's origins were local - compares well with the more celebrated universal sites of pilgrimage. However these universal cults do not lack a personal aspect, as evidenced in the devotions and donations that they engendered from the laity; it is a different, more overawing experience, one of being confronted with a legendary figure rather than a relatable one. Combined with the ability of the local traveller to navigate the landscape and appreciate the nuances of folklore and history personally and generally of the area, we see local pilgrimage as providing a crucial opportunity for divine contact that can be translated to all members of the laity through their own cultural context. An example of this would be the case study of St Asaph to Holywell, whose landscape is defined both by sites of religious miracles and presence (Maen Achwyfan, Holywell itself), and by parish names bearing reference to highly localised saints (see Appendix D). The landscapes crossed by the pilgrim really are their own, and are transformed from the daily topographies encountered into religious motifs echoing parish sermons.

From the fieldwork performed along the routes, I have demonstrated that the pilgrimage journey provided an opportunity for both contemplation and engaging with 'the spirit' with minimal interaction through priestly intermediaries, away from the distractions and responsibilities of daily life, and undoubtably this temporary freedom from obligation was a contributing factor to pilgrimage's enduring appeal. In the broader universal context, pilgrimage is made up from a 'composite of different elements - such as ritual, organised travel, objects of veneration, the construction of temporary 'communities' at special sites, sacrifices of time and effort, requests and offerings directed towards sacred figures - all of which occur in other spheres of life.' (Coleman and Elsner, 1995, 205) An archaeology of pilgrimage which relies solely on archaeological evidence inevitably builds an incomplete picture; it must also draw upon the anthropological and experiential record and its corresponding theory such as the works by Turner (1978) and Altenburg (2003) discussed in Chapters 2.1 and 2.3. By its very nature, pilgrimage as an activity is not restricted to the 'physical realm', despite being a very physical process in terms of travelling and interacting with sacred sites. It therefore leaves a record that transgresses the purely archaeological one and finds itself represented not only in the remains of religious houses, shrines, souvenirs and other forms of material culture, but also in art, music, literature, theology and folklore. Thus, isolating pilgrimage as a phenomenon separated from the world around is inappropriate; as a process it is designed to facilitate removal from the profane world, but the practicalities of travel and the social interactions involved within its practise are replicated to some degree in the daily ritual of life. The theological implications of pilgrimage are therefore essential to any researcher, and I believe that my methodology has successfully taken into account these areas, addressing as much as possible the 'total experience' of the pilgrim journey, its physical and mental interactions on multiple levels. As a consequence, we can see pilgrimage operating on two levels; the ideologlical and the practical, the metaphor for life and the temporary physical journey for spiritual benefit - these are not 
incompatible as proven by pilgrimage's enduring appeal across the majority of cultures and time. This thesis, whilst opening lines of inquiry into broader areas of pilgrim research, concentrates on the context of Medieval Britain, and is therefore applying theoretical approaches to the theological and practical aspects of pilgrimage in this cultural setting and period. The ecclesiastical landscape of Britain was indelibly altered during the Reformation, which whilst not entirely ending pilgrim activity, severely curtailed it and its visibility in the archaeological and historical record. But what of other Christian countries which were not subjected to Henry VIII's dissolution of monastic houses, and branding of pilgrimage as an act of papist sympathy? Application of this methodology to longer Christian routes across cultural boundaries adds another layer of interest, addressing reactions to and perceptions of exotic and unfamiliar social, topographical and cultural landscapes. The sheer volume of shrines and saint cults in the Medieval West, nearly all of which would have been the object of pilgrimage at some level, and the study of the route networks across mainland Europe provides a rich potential for expanding the study of Medieval pilgrimage into a holistic landscape analysis across Christendom. For example, several stages of the Camino de Compostela de Santiago have already been the subject of study. However pilgrimage on the later Medieval 'Via Romea' between Britain and Rome has yet to be addressed in a detailed manner, which is surprising given its importance and link to Rome, with its spiritual role in Christendom and administrative status. This was the grand 'Age of Faith', with Jerusalem as the font of Christianity, and Rome as its organisational centre, and so we must see the 'Eternal City' and the route(s) that lead there across numerous natural and territorial boundaries as a logical extension for study with the methodology used in this thesis.

Throughout this research I have addressed the core themes which I believe underpin the Medieval Christian pilgrim experience, and are fundamental to 'pilgrim travel' across a wider spectrum of cultures. These are;

i. The availability of routes and their physical elements (including but not limited to direction, length, and exertion).

ii. The built environment through which they pass (including both explicitly religious and general commercial/agricultural settlements).

iii. The collections of landscapes encountered, with regard to their potential physical and mental effects upon the pilgrim in regard to their cultural background.

The landscapes have a symbolic quality which can, to the mind of the pilgrim, echo elements of their own religio-cultural background - the foundation for the pilgrimage - and transforms the journey into, as Turner writes, a 'kinetic ritual' (Turner, 1978, 4). Archaeology is by its nature, interdisciplinary, and ideally suited to marrying varied source material and data to address the root of what this kinetic ritual meant in a historical context for the laity, and for the demographics of travel around Medieval Christendom (and indeed further afield with examples such as the Hajj, or the biographic pilgrim sites of Siddhartha in northern India). Aspects of social theory, landscape archaeology, and anthropological studies can be (and here, have been) combined with the 
archaeological and historical record to produce a more nuanced 'archaeology of pilgrimage' which is flexible enough to be tailored to a specific cultural context, but retains integrity as a consistently applied method, allowing for comparative analysis between sites and routes. The 'pilgrim landscape' of Medieval Britain existed for each pilgrim as a collection of topographies that offered multiple experiences. Localised aspects of the pilgrim's area such as regional events, religious history such as sites of miraculous events and folklore fed into a broader environment which could represent elements of Christian scripture. Populated by parish churches (one of the key monuments in the Medieval landscape), wayside crosses, rural settlements and religious houses, the built environment of these landscapes were linked via what has emerged as an extensive network of tracks and roads. These generally offered a series of options for travelling to the pilgrim site, and the pilgrim's choice in route may have reflected the role of the 'kinetic ritual', not solely relying on the practical element of efficient travel, although this undeniably played a role, but also taking into account sacred sites of significance such as holy wells and miracle locations. The higher the number of sites where one can reach and venerate the divine, then the more enhanced the 'value' of the pilgrimage in terms of demonstrating piety and devotion to gain God's favour. I would argue that this applies not only in terms of the long distance routes with their evolving culture of pilgrim veneration, but also to the local routes whose saint cult sites were well known to the local laity and had a strong attachment to their regional identity as a whole. The validity of 'the route' is confirmed through the agency of its pilgrims. Each has a highly personal and, to a varying degree, a shared experience of enacting that which the parish sermons taught about the peregrinus motif - that they were exiles in this world, and striving towards communion with their homeland; heavenly Jerusalem - and each pilgrim maintains and develops the 'culture' of the route through their own retelling after the journey's end.

With pilgrimage being such a popular and intimate form of devotion, with parallels across the world, I hope that this thesis has, like the routes themselves, helped to keep the evolving culture of pilgrim studies fresh and forward looking. With pilgrimage being a metaphor for the most important journey, that of life itself, and so highly valued by the Medieval laity, the study of this period is incomplete without a rounded appreciation of this process. By deconstructing the pilgrim experience within Medieval British landscapes, I hope to have to made some replication of the role of the itineraries and guides used within this thesis; thereby allowing the reader to undertake their own contemplative and exploratory journey along these multivocal pilgrim landscapes and proving that an interdisciplinary approach to the field of pilgrim studies can provide the most holistic appreciation of this crucial phenomenon. 


\section{Bibliography}

Adair, J. 1978. The Pilgrims' Way. London: Thames and Hudson.

Addyman, P. V., Hopkins, B. G. and Norton, G. T. 1972. A Saxo-Norman pottery kiln producing stamped wares at Michelmersh, Hampshire. Medieval Archaeology, Vol. 16, 127-30.

Alexander, M. 2005. The Sutton Companion to Folklore, Myths and Customs of Britain. Sutton Publishing Ltd.

Alighieri, D. 1998. Dante: The Divine Comedy. Oxford World Classics. Translated from Italian to English by C. H. Sisson. Oxford: Oxford University Press.

Allcroft, A. H. 1908. Earthworks of England: Prehistoric, Roman, Saxon, Danish, Norman and Medieval. London: Macmillon and Co.

Altenberg, Karin. 2008. Experiencing Landscapes. Stockholm: Almqvist and Wiksell International.

Anderson, W. 2010. Blessing the Fields? A Study of Late-Medieval Ampullae from England and Wales. Medieval Archaeology, Vol. 54, 182 - 204.

Anne Wilson, C. 1973. Food and Drink in Britain From the Stone Age to Recent Times. London: Constable.

Aquinas, T. 2007. Catena Aurea: Commentary on the Four Gospels, Collected Out of the Works of the Fathers, Volume III Part 1; The Gospel of St Luke. New York: Cosimo Press.

Armour, P. 1983. The Door of Purgatory: A Study of Multiple Symbolism in Dante's Purgatory. Oxford: Clarendon Press.

Armstrong, K. 2011. Jerusalem: One City, Three Faiths. London: Random House Publishing.

Ashurst, J and Dimes, F. 1998. Conservation of Building and Decorative Stone. Oxford: Elsevier Butterworth-Heinemann.

Astill, G and Grant, A (eds). 1988. The Countryside of Medieval England. Oxford: Blackwell Press Atchley, E. 1909. A History of the Use of Incense in Divine Worship. Aberdeen: Longmans, Green and Co. 
Attwater, D and John, C. 1993. The Penguin Dictionary of Saints. New York: Penguin.

Baring-Gould, S and Fisher, J. 1907. The Lives of British Saints. London: The Honourable Society of Cymmrodorian.

Barton, D. 1964. A History of Copper Mining in Cornwall and Devon. Truro: Truro Bookshop.

Beal, S. 1906. Buddhist Records of the Western World. London: Paul, Trench, Trübner and Co.

Beal J F. 1996. Representations of St Apollonia in British churches. Dental History Journal, Vol. 30, 319.

Bede. 1990. Ecclesiastical History of the English People: With Bede's Letter to Egbert and Cuhbert's Letter on the Death of Bede. Text translated from Latin to English by Leo Shirley-Price. London: Penguin Classics.

Bell, D. 2003. Mythscapes: Memory, Mythology and National Identity. British Journal of Sociology, Vol. 54, No. 1, 63-81.

Bender, B and Winer, M (eds). 2001. Contested Landscapes: Movement, Exile and Place. Oxford: Berg Press.

Bellezza, J. 2002. Antiquities of Northern Tibet: pre-Buddhist Archaeological Discoveries on the High Plateau. Delhi: Adroit Publishers.

Bennett, H. 1937. Life on the English Manor: A Study of Peasant Conditions, 1150 - 1400. Cambridge: Cambridge University Press.

Bentley-Cranch, D and Marshall, R. 2005. Roof Angels of the East Anglian Churches; A Visitor's Handbook and Guide. Published online, accessed 5/07/2011 at: http://www.roof-angels.org.uk/

Beresford, M. 1959. Six new towns of the Bishops of Winchester. Medieval Archaeology Vol. 3, 187215.

Beresford, M. 1964. Settlement in Medieval Cornwall. The Agricultural History Review. Vol. XII, No. 1, $13-28$

Bethell, D. 1972. 'The Making of a Twelfth Century Relic Collection' in Popular Belief and Practise: Read at the Ninth Summer Meeting and the Tenth Winter Meeting of the Ecclesiastical History Society. Cuming, G and Baker, D (eds). Cambridge: Cambridge University Press Archive. 
Bhardwaj, S. 1973. Hindu Places of Pilgrimage in India: A Study in Cultural Geography. New York: Berkley Press.

Bishop, C. 2007. Text and Transmission in Medieval Europe. Cambridge: Cambridge Scholars Publishing.

Blanchard, I. 1981. 'Lead Mining and Smelting in Medieval England and Wales' in Medieval Industry.

D. W. Crossley (ed). London: Council of British Archaeology.

Blanton, V. 2007. Signs of Devotion: the Cult of St AEthelthryth in Medieval England, 695 - 1615. Pennsylvania: Penn State Press.

Biddle, M. and Barclay, K. (1974) "Winchester Ware." in V. I. Evison, H. Hodges and J. G. Hurst, eds., Medieval Pottery from Excavations: Studies presented to Gerald Clough Dunning, with a bibliography of his works, John Baker, London, 137-66.

Birch, D. 2000. Pilgrimage to Rome in the Middle Ages: Continuity and Change. New York: Boydell and Brewer Ltd.

Birrell, J and Vauchex, A. 2006. Sainthood in the Later Middle Ages. Cambridge: Cambridge University Press.

Blair, J. 1988. 'Minster Churches in the Landscape' in Anglo-Saxon Settlements. D. Hooke (ed).

Oxford: Blackwell Press.

Blick, S. 2001. Comparing Pilgrim Souvenirs and Trinity Chapel Windows at Canterbury Cathedral. Miratus, September, $1-27$.

Blick, S (ed). 2007. Beyond Pilgrim Souvenirs and Secular Badges: Essays in Honour of Brian Spencer. Oxford: Oxbow Books.

Blick, S and Tekippe, R (eds). 2005. Art and Architecture of Late Medieval Pilgrimage in Northern Europe and the British Isles. New York: Brill Academic Publishers.

Bloch, M. 1951. Les Caractères Originaus de I'Histoire Rurale Française. Paris: A.Colin.

Blomefield, F. 1808. An Essay Towards the Topographical History of the County of Norfolk. Vols 1-9. London: W. Bulmer and Co.

Boardman, S. 2009. Saints' Cults in the Celtic World. Woodbridge: Boydell Press. 
Boertjes, K. 2005. 'Pilgrim Ampullae from Vendôme : Souvenirs from a Pilgrimage to the Holy Tear of Christ' in Art and Architecture of Late Medieval Pilgrimage in Northern Europe and the British Isles Vol. 1, Sarah Blick and Rita Tekeippe (eds). Brill Publishing: Michegan.

Bollard, J. 2008. The Mabinogi: Legend and Landscape of Wales. Michigan: University of Michigan Press.

Bond, Francis. 1914. Dedications and Patron Saints of English Churches: Ecclesiastical Symbolism, Saints and their Emblems. London: Oxford University Press.

Bond, H. 1960. The Walsingham Story Through 900 Years, 1061-1961: A Tribute for the 9th Centenary of the Shrine. Walsingham: Greenhoe Press.

Bonney, D. 1972. 'Early Boundaries in Wessex' in Archaeology and the Landscape. P Fowler (ed). London: Baker Press.

Booth, G. 1814. The Historical Library of Diodorus the Sicilian in Fifteen Books. London: W. McDowell.

Boulter, B. 1928. The Pilgrim Shrines of England. London: Phillip Allan and Co Ltd.

Bourdieu, P. 1977. Outline of a Theory of Practice. Cambridge: Cambridge University Press.

Bradley, R. 1994. Prehistoric Land Divisions on Salisbury Plain: The Work of the Linear Ditches Project. London: English Heritage.

Bradley, R. 2000. An Archaeology of Natural Places. London: Routledge.

Brewer, J (ed). 1864. 'The King's Book of Payments, 1509' in Letters and Papers, Foreign and Domestic of the Reign of Henry VIII, Volume 2: 1515 - 1518. London: Longman, Green, Longman and Roberts.

Bridbury, A. 1982. Medieval English Clothmaking: An Economic Survey. London

Brill, E and Timperley, H. 2005. Ancient Trackways of Wessex. Stroud: Nonsuch Publishing Ltd.

Brock, S. 1973. Early Syrian Asceticism. Numen, Vol. 1, Fasc. 1, April 1973, 1 - 19.

Brown, A. 1995. Popular Piety in Late Medieval England: The Diocese of Salisbury, 1250-1550.

Oxford: Oxford University Press.

Brown, I. 2004. Discovering a Welsh Landscape: Archaeology in the Clwydian Range. Cheshire: Windgatherer Press. 
Brück, J. 2005. Experiencing the Past? The Development of a Phenomenological Archaeology in British Prehistory. Archaeological Dialogues, Vol. 12, No. 1, $45-72$.

Bunyan, J. 2008. Pilgrim's Progress. Oxford: Oxford University Press.

Burket, W. 1985. Greek Religion. Harvard: Harvard University Press.

Burnham, H. 1995. A Guide to Ancient and Historic Wales: Clwyd and Powys. London: HMSO

Burton-Christie, D. 1993. The Word in the Desert: Scripture and the Quest for Holiness in Early Christian Monasticism. Oxford: Oxford University Press.

Butler, Rev. A. 1866. The Lives of Saints: Vol. VI:I July. London: Gillan and Sons Press.

Butler, L and Morris, R. 1986. The Anglo Saxon Church: Papers on History, Architecture and Archaeology in Honour of Dr H. M. Taylor. Research Report no. 60. London Council for British Archaeology.

Butlin, R. 1993. Historical Geography: Through the Gates of Space and Time. London: Edward Arnold Press.

Camden, W. 2010. Brittania; Or, a Chorographical Description of Great Britain and Ireland. London: Ecco Press.

Cantor, L. 1982. 'Forests, Chases, Parks and Warrens' in The English Medieval Landscape. Cantor, L (ed). London: Croom Helm Press.

Candy, J. 2007. The Archaeology of Pilgrimage on the Camino de Santiago de Compostela: A Landscape Perspective. Glasgow: Glasgow University (PhD Thesis). Unpublished.

Candy, J. 2009. The Archaeology of Pilgrimage on the Camino de Santiago de Compostela; $A$ Landscape Perspective. BAR International Series. Oxford: Archaeopress.

Carew, R. 2000. The Survey of Cornwall 1602. London: Tor Mark Press.

Carr, A. 1938. Medieval Wales. Basingstoke: Macmillan.

Carr, D. 2001. The First General Entry Book of the City of Salisbury, 1387-1452. Salisbury: Wiltshire Record Society.

Cartwright, J. 2003. Celtic Hagiography and Saint's Cults. Cardiff: University of Wales Press.

Chambers, J. 1877. Divine Worship in the Thirteenth and Fourteenth Centuries. London: B. M. Pickering. 
Champion, T and Champion, S. 1981. 'The Iron Age in Hampshire' in Archaeology in Hampshire. Shennan, S. J and Schadla-Hall, R.T (eds). Aldershot: Hampshire Field Club and Archaeological Society.

Chandler, J (ed). 1998. John Leland's Itinerary: Travels in Tudor England. Stroud: Sutton Publishing Ltd.

Charles-Edwards, T. n.d. Saint Winefride and Her Well: The Historical Background. Holywell: W.Williams and Son,

Charyon, N. 2005. Pilgrims to Jerusalem in the Middle Ages. Columbia: Columbia University Press.

Childs, W. 1999. 'The Perils, or Otherwise, of Maritime Pilgrimage yo Santiago de Compostela in the Fifteenth Century' in Pilgrimage Explored, J.Stopford (ed). London: Boydell \& Brewer.

Clark, G. 2004 'Going Home: Soul Travel in Late Antiquity' in Travel, Communication and Geography in Late Antiquity. Ellis, L and Kidner, F.L (eds). Aldershot: Ashgate Press

Clay, R. 1909. Medieval Hospitals of England. London: The Antiquaries Book Series.

Cleland, H. 1927. Commerce and Trade Routes in Prehistoric Europe. Economic Geography, Vol. 3, No. 2, 232- 238 .

Coad, J and Coppack, G. 1998. Castle Acre Castle and Priory. London: English Heritage.

Cobbet, W. 2005. Rural Rides. London: Penguin Classics, New Edited Edition.

Coleman, O (ed). 1960. The Brokerage Book of Southampton, 1443-1444. Vol. II: 1444, Southampton Records Series, 6. Southampton: Southampton University Press.

Coleman, S and Elsner, J. 1995. Pilgrimage Past and Present: Sacred Travel and Sacred Space in the World Religions. London: British Museum Press.

Conner, P. 1993. Anglo-Saxon Exeter: A Tenth-Century Cultural History. Woodbridge: Boydell and Brewer

Connerton, P. 1989. How Societies Remember. Cambridge University Press

Connolly, D. 1999. Imagined Pilgrimage in the Itinerary Maps of Matthew Paris. The Art Bulletin, Vol. 81, No. 4, December 1999, 598 - 622

Cook, G. 1957. The English Cathedral Throughout the Centuries. London: Phoenix House. 
Cornwall County Council. 1996. Cornwall Landscape Assessment, 1994: A report prepared by Landscape Design Associates and Cornwall Archaeological Unit. Truro: Cornwall County Council

Countryside Commission. 1995. The Cranborne Chase and West Wiltshire Downs Landscape. Cheltenham: Countryside Commission.

Cowell, A. 1999. A Play in the Tavern: Signs, Coins and Bodies in the Middle Ages. Michegan: University of Michegan Press.

Crane, T. 2004. Jacques de Vitry: The Exempla Or Illustrative Stories from the Sermones Vulgares of Jacques de Vitry. Montana: Kessinger Publishing.

Crook, J. 1993. Winchester Cathedral: Nine Hundred Years 1093 - 1993. Chichester: Philimore Publishing.

Crook, J. 2000. The Architectural Setting of the Cult of Saints in the Medieval West. New York: Oxford University Press.

Crook, J. 2011. English Medieval Shrines. Woodbridge: Boydell Press.

Crowley, D (ed). 1980. A History of the County of Wiltshire: Volume 11: Downton hundred; Elstub and Everleigh hundred. London: Institute of Historical Research.

Cummins, J. 2002. 'Veneurs s'en Vont en Paradis: Medieval Hunting and the 'Natural' Landscape' in Inventing Medieval Landscapes: Senses of Place in Western Europe. Howe, J and Wolfe, M (eds). Florida: University Press of Florida.

Cunliffe, B. 1970. The Saxon Culture-Sequence at Portchester Castle. The Antiquaries Journal, Vol. 50, No.1, $67-85$

Cunliffe,B. 1991. Danebury : an Iron Age hillfort in Hampshire Vol.4, The excavations, 1979-1988:

The Site. London: Council for British Archaeology .

Daniels, D. 1992. Place and the Geographical Imagination. Geography, Vol. 77, No. 4, 310-322.

Darby, H. 1962. The Domesday Geography of England Vol.3: The Domesday Geography of South-East England. Cambridge: Cambridge University Press.

Darby, H. 1967. The Domesday Geography of England Vol.3: The Domesday Geography of SouthWest England. Cambridge: Cambridge University Press.

Darby, H. 1968. The Draining of the Fens. Cambridge: Cambridge University Press. 
Darby, H. 1974. The Medieval Fenland. Newton Abbot: David and Charles.

Davidson, L and Gitlitz, D. 2002. Pilgrimage: From the Ganges to Graceland. An Encyclopaedia, Volume 1.California: ABC-CLIO Inc.

Davies, G. 1838. The Parochial History of Cornwall, Founded on the Manuscript Histories of Mr. Hals and Mr. Tonkin; with Additions and Various Appendices. London: J. B. Nichols and Sons.

Davies, Canon Ellis. 1958. 'Whitford Church (St Beuno and St Mary)' in Lead Mining Industry in North Wales in Roman Times. Graham Webster (ed). Caernarvon: Gwenlyn Evans Ltd.

Defoe, D. 2005. A Tour Through the Whole Island of Great Britain. London: Penguin Classics, Reprint Edition.

DeGray Birch, W (ed). 1898. Liber Vitae: Register and Martyrology of New Minster and Hyde Abbey Winchester. Winchester: Warren and Son.

Denbighshire County Council. 2000. Clwydian Range Are of Outstanding Natural Beauty Management Strategy. Ruthin: Denbighshire County Council.

Deplem, Mathieu. 1992. Ritual, Anti-Structure and Religion; A Discussion of Victor Turners

Processual Symbolic Analysis. Journal for the Scientific Study of Religion, Vol. 30, Vo. I, 1- 25.

Dickinson, J. 1956. The Shrine of Our Lady of Walsingham. Cambridge: Cambridge University Press.

Dickinson, J. 1961. Monastic Life in Medieval England. London: A.C. and Black.

Dietz, M. 2005. Wandering Monks, Virgins and Pilgrims: Ascetic Travel in the Mediterranean World $A D 300$ - 800. Pennsylvania: Pennsylvania University Press.

Dobson, B. 1991. The English Monastic Cathedrals in the Fifteenth Century. Transactions of the Royal Historical Society, Sixth Series, Vol. 1, 151- 172.

Doob, P. 1990. The Idea of the Labyrinth: From Classical Antiquity through the Middle Ages. London: Cornell University Press.

Draper, P. 1978. The Retrochoir of Winchester Cathedral. Architectural History, Vol. 21, 1- 103.

Duffy, E. 2005. The Stripping of the Altars: Traditional Religion in England 1400 - 1580. Yale: Yale University Press.

Dugdale, W.1718. Monasticon Anglicanum: or The History of Ancient Abbies, Monasteries, Hospitals, Cathedral and Collegiate Churches, With their Dependancies in England and Wales. London: R.Harbin Printers. 
Dunlop, G. 1940. Pages from the History of Highclere. Oxford: The Holywell Press.

Dunn, M. 2000. The Emergence of Monasticism: From the Desert Fathers to the Early Middle Ages. Oxford: Blackwell Press.

Dunn, M.J and Davidson, L.K (eds). 2000. The Pilgrimage to Compostela in the Middle Ages. London: Routledge.

Dyas, D. 2001. Pilgrimage in Medieval English Literature, 700-1500. Cambridge: Cambridge University Press.

Eason, D. 1957. Medieval Religious Houses of Scotland. London: Longmans Green and Co.

Eade, J and Coleman, S. 2004. Reframing Pilgrimage: Culture in Motion. London: Routledge Press.

Edwards, J and Hindle, B. 1991. The Transportation System of Medieval England and Wales. Journal of Historical Geography, Vol. 17, No. 2, 123-134.

Edwards, N. 1997. Landscape and Settlement in Early Medieval Wales. Oxford: Oxbow Books.

Edwards, B. 2006. Medieval Hampshire $1066-1540$. Accessed $12^{\text {th }}$ December 2011, available here: http://thehumanjourney.net/pdf_store/sthames/phase3/County/Late\%20Medieval/Late\%20Mediev al\%20Hampshire.pdf

Eck, D. 1999. Banares, City of Light. New York: Colombia University Press.

Elad, A. 1995. Medieval Jerusalem and Islamic Worship; Holy Places, Ceremonies, Pilgrimage. Leiden: Brill Publishing.

Eliade, M. 1959. The Sacred and the Profane: The Nature of Religion. Translated from French to English by Willard Trask. New York: Harcourt, Brace and World.

Esposito, J. 2011. Islam: the Straight Path. Oxford: Oxford University Press

Evans, G. 1993. Philosophy and Theology in the Middle Ages. London: Routledge

Farmer, D.H. 1987. The Oxford Dictionary of Saints; $2^{\text {nd }}$ edition. Oxford; Oxford University Press.

Fegen, E. 1914. The Journal of Prior William More. Edited for the Worcester Historical Society. London: Mitchell Hughes and Clarke.

Feldhaus, A. 2003. Connected Places: Region, Pilgrimage and Geographical Imagination in India. New York: Palgrave Macmillan.

Ferguson, G. 1961. Signs and Symbols in Christian Art. Oxford: University Oxford Press. 
Fernio, E. 2008. Four Routes to Spain and the Architecture of the Pilgrim Churches. London: Confraternity of St James Publishing.

Finberg, H. 1953. The Early Charters of Devon and Cornwall. Department of English Local history Occasional papers No. 2.Leicester: University College of Leicester.

Finucane, R. 1977. Miracles and Pilgrims: Popular Beliefs in Medieval England. Worthing: Littlehampton Book Services.

Fleetwood, W. 1713. The Life and Miracles of St Winefride with Historical Observations Therein as Related by Robert, Prior of Shrewsbury 1167. London: S. Buckley Publishing.

Flemming, A. 2006. Post-processual Landscape Archaeology: A Critique. Cambridge Archaeological Journal, Vol. 16, No. 3, $267-280$.

Foltz, M. 2000. Religions of the Silk Road: Overland Trade and Cultural Exchange from Antiquity to the Fifteenth Century. New York: Palgrave Macmillan.

Fox, C. 1955. Offa's Dyke: A Field Survey of the Western Frontier of Mercia in the Seventh and Eighth Centuries $A D$. London: British Academy.

Frank, G. 2000. The Memory of Eyes: Pilgrims to Living Saints in Christian Late Antiquity. Berkley, Los Angeles and London: University of California Press.

Frankfurter, D. 1998. Pilgrimage and Holy Space in Late Antique Egypt. Leiden: Brill Publishing.

Freeman, C. 2011. Holy bones, Holy Dust: How Relics Shaped the History of Medieval Europe. Yale: Yale University Press.

French, K. 2000. People of the Parish. Pennsylvania: Pennsylvania University Press.

Friend, Rev. H. 1883. Flowers and Flower Lore, Vol. 1. London: W. S. Sonnenschein and Company.

Frost, C. 2009. Time, Space, and Order: the Making of Medieval Salisbury. London: Peter Lang Publishing.

Frost, P. 1994. Clwyd Metal Mines Survey 1993. CPAT Report no. 88.

Fry, R and Hulse, T. 1994. Holywell, Clwyd. Source Holy Wells Journal, Autumn 1994, Issue 1. Retrieved on 15/02/2011, from website http://people.bath.ac.uk/liskmj /living-spring /source archive/ cntsnew.htm

Fuller, T. 1662. The History of the Worthies of England in Three Volumes. London: Read Books, 2010 Reprint. 
Fumagalli, V. 1994. Perceptions of Nature and the City in the Middle Ages. Translated from Italian to English by Shayne Mitchell. Cambridge: Polity Press.

Furnival, F and Stone, W. 1909. The Tale of Beryn with a Prologue of the Merry Adventure of the Pardoner with a Tapster at Canterbury. London: Kegan Paul, Trench, Trubner and Co, Ltd.

Gasquet, A. 1904. English Monastic Life. London: Methuen.

Gelling, M. 1984. Place Names in the Landscape: The Geographical Roots of Britain's Place Names. London: Phoenix Press.

Gennep, A. 2004. The Rites of Passage. Translated from French to English in 1960 by Monika Vizedom and Gabrielle Caffee. London: Routledge.

Gibbons, A. 1891. Ely Episcopal Records. Lincoln: James Wiliamson

Gill, M. 2007. 'Monastic Murals and Lectio in the Later Middle Ages' in The Art and Architecture of English Benedictine Monastaries, 1300 - 1540: A Patronage History. J. Luxford (ed). Woodbridge: Boydell and Brewer Press.

Gingell, C. 1992. The Marlborough Downs: A Later Bronze Age Landscape and its Origins. Devizes: Wiltshire Archaeological \& Natural History Society.

Giraldus, Cambrensis. 1978. The Journey through Wales and the Description of Wales. Translated from Latin into English by Lewis Thorpe. Harmondsworth: Penguin Books.

Given-Wilson, C. 1997. The Chronicle of Adam Usk 1377 - 1421. Oxford: Clarendon Press.

Gjerset, K. 1969. History of the Norwegian People, Volumes I and II. Michigan: University of Michigan Press.

Golledge, R (ed). 1999. Wayfinding Behaviour: Cognitive Mapping and Other Spatial Processes. Baltimore: John Hopkins University Press.

Golledge, R. 2003. 'Human Wayfinding and Cognitive Mapping' in Colonization of Unfamiliar Landscapes: The Archaeology of Adaption. Marcy Rockman and James Steele (eds). London: Routledge.

Gough, H. 1900. The Itinerary of Edward the First Throughout His Reign, AD 1272 - 1307, Exhibiting His Movements From Time to Time So Far as They Are Recorded. London: Paisley Press.

Grace, T. 2006. Love's Pilgrimage: The Holy Journeys in English Renaissance Literature. Newark: University of Delaware Press. 
Gray, M. 2000. Images of Piety: The Iconography of Traditional Religion in Late Medieval Wales. BAR British Series 316. London: Archaeopress

Green, N. 2012. Sufism: A Global History. New York: Wiley and Sons Press.

Greenway, D. 1991. Fasti Ecclesiae Anglicanae 1066-1300: volume 4: Salisbury. London: Institute of Historical Research.

Greenway, D. 1996. Henry, Archbishop of Huntingdon: Historia Anglorum (History of the English People. Oxford: Oxford University Press.

Griffin, E. 2007. Blood Sport: Hunting in Britain Since 1066. London: Yale University Press.

Grinsell, L. 1958. The Archaeology of Wessex. Taylor and Francis.

Grinsell, L. 1967. Barrow Treasure in Fact, Tradition and Legislation. Folklore, Vol, 78, No. I, 1- 38.

Grosjean, P (ed). 1956. Vies et miracles de S. Petroc. Analecta Bollandiana, Vol. 74, 131- 188.

Gurevich, A. 1992. Medieval Popular Culture: Problems of Belief and Perception. Translated from the Russian to English by János Bak and Paul Hollingsworth. Cambridge: Cambridge University Press.

Gurney,D. 1995. 'Small Towns and Villages of Roman Norfolk' in Roman Towns in Eastern England and Beyond. A. Brown (ed). Oxford: Oxbow Publishing.

Gwynn, A and Hadcock R. 1970. Medieval Religious Houses of Ireland. London: Longman Press.

Hadcock, R. 1950. Map of Monastic Britain: South Sheet. Chessington: Ordnance Survey Publishing. Hamilton, S and Spicer, A. 2005. Defining the Holy: Sacred Spaces in Medieval and Early Modern Europe. Aldershote, Ashgate Press.

Hamilton, S, Whitehouse, R et al. 2006. Phenomenology in Practice: Towards a Methodology for a 'Subjective' Approach. European Journal of Archaeology, Vol. 9, 31 - 71.

Hamilton-Thompson, A. 1919. Visitations of Religious Houses in Diocese of Lincoln. Canterbury and York Society, Vol. 24.

Hampshire County Council. 2010. South East New Forest Coastal Plan: Integrated Character Assessment. Hampshire County Council.

Handley, M. 2001. The Origins of Christian Commemoration in Late Antique Britain. Early Medieval Europe, Vol. 10, No. 2, 177 -199.

Harbus, A. 2002. Helena of Britain in Medieval Legend. Woodbridge: Boydell and Brewer. 
Hardy, T. 1835. Rotuli de Liberate ac de Misis et Praestitis, regnante Johanne. Reprint 2010 BiblioBazaar

Hardy, T (ed). 1835. Close Rolls, Rotuli litterarum clausarum, 1204-1227, Volumes I and II. London: H. M. Stationery Publishing.

Hare, J. 1994. 'Agriculture and Rural Settlements in the Chalklands of Wiltshire and Hampshire from c. $1200-1500$ ' in The Medieval Landscape of Wessex. M. Aston and C. Lewis (eds). Oxford: Oxbow Books.

Hare, J. 1999. Growth and Recession in the Fifteenth-Century Economy: The Wiltshire Textile Industry and the Countryside. The Economic History Review. Vol. 52, No. 1, 1- 26.

Hare, J. 2012. A Prospering Society: Wiltshire in the Later Middle Ages. Hatfield: University of Hertfordshire Press.

Harper-Bill, C (ed). 2005. Medieval East Anglia. Woodbridge: Boydell Press.

Hart, R. 1864. The Shrines and Pilgrimages of the County of Norfolk. Norwich Archaeological Society Transactions Vol. 6, 277-94.

Harvey, D. 1997. The Evolution of Territoriality and Societal Transitions in West Cornwall. Landscape History Journal. Vol. 19, $113-123$.

Harvey, J. 1969. William Worcestre: Itinieraries. Oxford: Clarendon Press

Hase, P. 1994. 'The Church in the Wessex Heartland' in The Medieval Landscape of Wessex. M. Aston and C. Lewis (eds). Oxford: Oxbow Books.

Haskins, C. 1912. The Ancient Guilds and Companies of Salisbury. Salisbury: Bennet Brothers.

Hatcher, J. 1970. Rural Economy and Society in the Duchy of Cornwall, 1300-1500. London: Cambridge University Press.

Hatcher, J. 1973. English Tin Production and Trade Before 1550. Oxford: Clarendon Press

Heale, M. 2007. Training in Superstition? Monasteries and Popular Religion in Late Medieval and Reformation England. Journal of Ecclesiastical History, Vol. 58, No. 3, July, 417 - 439.

Healy, N. 2003. Thomas Aquinus: Theologian of the Christian Life. Farnham: Ashgate Publishing Ltd.

Hearn, M. 1944. Canterbury Cathedral and the Cult of Beckett. The Arts Bulletin, March 1944, Vol. 76, No. 1.

Heath, S. 1911. Pilgrim Life in the Middle Ages. London: Unwin Press. 
Henderson, C. 1963. Essays in Cornish History. Truro: Barton Press.

Henisch, B. 1999. The Medieval Calendar Year. Pennsylvania: Pennsylvania University Press.

Heslop, T. 2005. 'Swaffham Parish Church: Community Building in Fifteenth-Century Norfolk' in Medieval East Anglia. Christopher Harper-Bell (ed). 246 - 272. Woodbridge: The Boydell Press.

Hindle, P. 1976. The Road Network of Medieval England and Wales. Journal of Historical Geography, Vol. 2, No. 3, $207-221$.

Hindle, P. 1998. Medieval Roads and Tracks. Oxford: Shire Publications Ltd.

Hindley, G. 2006. The Anglos Saxons: The Beginnings of the English Nation. London: Robinson Publishing.

Hingeston-Randolph, F. 1889. The Registers of Walter Bronescombe (A.D. 1257-1280) and Peter Quivil (A.D. 1280-1291), Bishops of Exeter, with Some Records of the Episcopate of Bishop Thomas de Bytton (A.D. 1293 - 1307), Also the Taxation of Pope Nicholas IV A.D. 1291 (Diocese of Exeter). London: George Bell and Sons.

Hirsch, E and O'Hanlon, M (eds). 1995. The Anthropology of Landscape: Perspectives on Place and Space. Oxford: Clarendon Press.

Hockey, S. 1975. The Account Book of Beaulieu Abbey. London: The Royal Historical Society (Great Britain).

Holloway, J. 1992. The Pilgrim and the Book: A Study of Dante, Langland and Chaucer. New York: Peter Lang Publishing.

Holmes, J. 1983. 1000 Cornish Place Names Explained. Redruth: Turan Press.

Hope, R. 1893. The Legendary Lore of the Holy Wells of England; Including Rivers, Lakes, Fountains and Springs. London: Stock Publishing.

Hopewell, P. 1995. St Cross; England's Oldest Almshouse. Chichester: Phillinine Press.

Hopper, S. 2002. To Be a Pilgrim: The Medieval Pilgrim Experience. Stroud: Sutton Publishing.

Howard, D. 1980. Writers and Pilgrims. California: University of California Press.

Howe, N. 1989. Migration and Mythmaking in Anglo Saxon England. Yale: Yale University Press. 
Howe, J. 2002. 'Creating Symbolic Landscapes: Medieval Development of Sacred Space' in Inventing Medieval Landscapes: Senses of Place in Western Europe. Howe, J and Wolfe, M (eds). Florida: University Press of Florida.

Hubbard, E. 1986. The Buildings of Wales Volume II: Clwyd (Denbighshire and Flintshire). Middlesex: Penguin Books.

Hughes, A. 1995. Medieval Manuscripts for Mass and Office: A Guide to Their Organization and Terminology. Toronto: University of Toronto Press.

Hucks, J. 1979. Pedestrian Tour Through North Wales in a Series of Letters. Cardiff: University of Wales Press.

Hughes, M. 1981. 'Settlement and landscape in Medieval Hampshire' in Archaeology in Hampshire. Shennan, S. J and Schadla-Hall, R.T (eds). Aldershot: Hampshire Field Club and Archaeological Society.

Hughes, M. 1994. 'Towns and Villages in Medieval Hampshire' in The Medieval Landscape of Wessex. M. Aston and C. Lewis (eds). Oxford: Oxbow Books.

Hughes, M and Diaz H (eds). 1994. The Medieval Warm Period. Dordrecht: Kluwer Academic Publishers.

Hull, D. 2003. Celtic and Anglo-Saxon Art: Geometric Perspectives. Liverpool: Liverpool University Press.

Hyde, K. 1990. Italian Pilgrimage Literature in the Late Middle Ages. Bulletin of the John Rylands Library, Vol. 72, $13-33$.

Ingold, T. 1993. The Temporality of Landscape. World Archaeology, Vol. 25, 152 - 174.

Ingold, T. 2007. Earth, Sky, Wind and Weather. Journal of the Royal Anthropological Institute (N.S.) Special Issue: S19-S38.

Insoll, T. 2005. 'Archaeology of Cult and Religion' in Archaeology: The Key Concepts. C. Renfrew and P. Bahn (eds). London: Routledge.

Jackle, J. 1987. The Visual Elements of Landscape. Massachusetts: University of Massachusetts Press. James, J. 1987. Travellers Key to Medieval France: A Guide to the Sacred Architecture of Medieval France. London: Harrap Columbus Press 
James, T and Robinson, A. 1988. Clarendon Palace. Society of Antiquaries London Research Report XLV. London. Society of Antiquaries.

Janin, H. 2006. Four Paths to Jerusalem: Jewish, Christian, Muslim and Secular Pilgrimages, 1000 BCE to 2001 BCE. Carolina: McFarland and Co Publishing.

Jankulak, K. 2000. The Medieval Cult of St Petroc. Woodbridge, Suffolk: Boydell Press.

Jervoise, E. 1932. The Ancient Bridges of Mid and Eastern England. London: The Architectural Press. John, J. 1987. Travellers Key to Medieval France: A Guide to the Sacred Architecture of Medieval France. London: Harrap Columbus.

Jolly, K. 1997. Tradition and Diversity: Christianity in a World Context to 1500. New York: M. E. Sharpe Publishing.

Johnson, N and Rose, P. 1994. Bodmin Moor, An Archaeological Survey. Volume 1: The Human Landscape to c1800. London: English Heritage.

Johnston, D. 1981. 'Hampshire: the Roman Period' in Archaeology in Hampshire. Shennan, S. J and Schadla-Hall, R.T (eds). Aldershot: Hampshire Field Club and Archaeological Society.

Jones, A. 1926. Basingwerk Abbey in 'Historical Essays in Honour of James Tait'. J.G.Edwards (ed). London.

Jones, F. 1954. The Holy Wells of Wales. Cardiff: University of Wales Press.

Jones, G. 1912. Celtic Britain and the Pilgrim Movement. London, Hon. Society of Cymmrodorion.

Jones, P. 1984. Medieval Medical Miniatures. London: British Library Press.

Jones, G. 2007. Saints in the Landscape. London: Tempus Publishing.

Jones, N and Silvester, R. 1996. Clwyd Coastal Survey. CPAT Report no. 194.

Jørgensen, A. 1874. Den Nordiske Kirkes Grundlæggelse og Første Udvikling.2 Volumes. Copenhagen: Unkown Publisher.

Jusserand, J. 1920. English Wayfaring Life in the Middle Ages (XIVth Century). Translated from French to English by Lucy Toulmin Smith. London: T. Fisher Unwin Ltd.

Kamerick, K. 2002. Popular Piety and Art in the Late Middle Ages: Image Worship and Idolotary in England 1350 - 1500. New York: Palgrave Macmillan. 
Keene, D. 1985. Winchester Studies 2: The Survey of Medieval Winchester in Two Volumes. Oxford: Clarendon Press.

Kemp, B. 1990. The Hand of St James at Reading Abbey. Reading Medieval Studies, Vol. XVI, 77-96.

Kightly, C. 1988. A Mirror of Medieval Wales : Gerald of Wales and his Journey of 1188. Cardiff: Cadw Press.

Kirkham, N. 1968. Derbyshire Lead Mining Through the Centuries. Truro: D Bradford Barton.

Kowaleski, M. 2000. The Expansions of the South Western Fisheries in Late Medieval England. Economic History Review, Vol. 53, No. 3, 429 - 454.

Knowles, D, and Hadcock, R. 1953. Medieval Religious Houses of England and Wales. London: Longmans, Greens and Co.

Knowles, D. 1966. The Monastic Order in England. Cambridge: Cambridge University Press.

Langdon, J, Walker, J, and Falconer, J. 2003. 'Boom and Bust: Building Investment on the Bishop of Winchester's Estate in the Early Fourteenth Century' in The Winchester Pipe Rolls and Medieval English Society. Britnell, R (ed). Boydell Press.

Langland, W. 2009. Piers Plowman: A New Translation of the B-Text. Translated from Latin to English by A.Schmidt. Oxford: Oxford World Classics.

Lapidge, M. 2003. Winchester Studies 4.ii: The Anglo-Saxon Ministers of Winchester; The Cult of St Swithun. Oxford: Clarendon Press.

Larking, L. 1857. The Knights Hospitallers in England: Being the Report of Prior Phillip de Thame to the Grand Master Elyan de Villanova for AD 1338. London: The Camden Society.

Lavelle, R. 2003. Fortifications in Wessex c. 800 - 1066. Colchester: Osprey Publishing. Lawson, A. 2007. Chalkland: An Archaeology of Stonehenge and its Region. Salisbury: Hobnob Press. Le Clercq, J. 1961. Monachisme et Peregrination du IXe au XIle Siècle. Studia Monastica, Vol. 3, 33 52.

Lee, V. 1924. The Golden Keys and Other Essays on the Genius Loci. London: The Bodley Head Ltd Le Goff, J. 1982. Time, Work and Culture in the Middle Ages. Translated from the French to English by Arthur Goldhammer. London: University of Chicago Press.

Le Goff, J. 1988. The Medieval Imagination. Translated from the French to English by Arthur Goldhammer. London: University of Chicago Press. 
Letters, S. 2005. Gazetteer of Markets and Fairs in England and Wales to 1516. Centre for Metropolitan History.

Leland, J. 1907. The Itinerary of John Leland in or about the Years 1535-1543. Toulmin Smith (ed). London: George Bell and Sons.

Lewis, C. 1994. 'Patterns and Processes in the Medieval Settlement of Wiltshire' in The Medieval Landscape of Wessex. M. Aston and C. Lewis (eds). Oxford: Oxbow Books.

Lewis, S. 1811. Topographical Dictionary of England. Bibliobazaar 2010 Reprint.

Ley Bazeley, M. 1921. The Extent of the English Forest in the Thirteenth Century. Transactions of the Royal Historical Society, Fourth Series, vol. 4, 140-172.

Linnell, Rev. C. 1962. Norfolk Church Dedications. York: St Anthony's Hall Publications.

Little, A. G. 1935. The Grey Friars of Salisbury. Wiltshire Archaeological and Natural History Society, Vol. 47, 36 - 54. Salisbury: Wiltshire Archaeological and Natural History Society.

Lloyd, G. 1964. Beacon-Watch towers on the North Wales Coast. Archaeologia Cambrensis, Vol. 113, $150-158$.

Longman, J and Meiss, M. 1995. Les Tres Riches Heures: The Medieval Seasons. Paris: George Braziller.

Low, M. 1966. Celtic Christianity and Nature : Early Irish and Hebridean traditions. Edinburgh: Edinburgh University Press.

Lowenthal, D. 1985. The Past is a Foreign Country. Cambridge: Cambridge University Press.

Loxton, H. 1978. Pilgrimage to Canterbury. London: David and Charles PLC.

Lupton, J. 1887. A Life of John Collet, D. D., Dean of St Pauls. London: George Bell and Sons.

Lynch, K. 1960. The Image of the City. Massachusetts: MIT Press

Lysons, D and Lysons, S. 1814. Magna Britannia: Volume 3 Cornwall, A General and Parochial History of the County. London: T. Cadell and W. Davies.

Mabey, R. 1996. Flora Britannica. London: Chatto and Windus Press

Maclean, J. 1874. The Parochial and Family History of the Deanery of Trigg Minor, Cornwall. London: Nichols.

Maclean, J. 1870. A History of Bodmin. London: Burton Press. 
MacKay, A and Ditchburn D (eds). 1996. Atlas of Medieval Europe. London: Routledge Press.

Maddison, J. 2000. Ely Cathedral; Design and Meaning. Ely: Ely Cathedral Publications.

Masschaele, J. 1997. Peasants, Merchants and Markets: Inland Trade in Medieval England. New York: St Martin's Press.

Matarasso, P. 1993. The Cistercian World: Monastic Writings of the Twelfth Century. London: Penguin Publishing.

Matthews, S. 2007 The Road to Rome: Travel and Travellers between England and Italy in the AngloSaxon Centuries. BAR International Series 1680. Oxford: Archaeopress.

Maraco, J. 1973. The Dhammapada. Translated from Pali to English by Juan Maraco. London: Penguin Publishing.

Marks, R. 2004. Image and Devotion in Late Medieval England. Stroud: Sutton Publishing.

Margary, I. 1973. Roman Roads in Britain. London: J. Baker Publishing.

Maxwell, H. 1922. Calendar of Close Rolls, Richard III: Volume 4: 1389 - 1392. London: HM Stationery Office

McCarthy, M R and Brooks, C M. 1988. Medieval Pottery in Britain AD900-1600. Leicester: Leicester University Press.

McNeil, J and Gamer, H. 1990. Medieval Handbooks of Penance: A Translation of the Principal 'Libri Poenitentiales' and Selections from Related Documents. New York: Columbia University Press.

Melville, R. 1982. The Hampshire Basin and Adjoining Areas. London: H.M.S.O. Publishing. Messant, C. 1941. Ruined Churches of Norfolk. London: H. W. Hunt de Mezieres, P. 1969. Le Songe du Vieil Pelerin. Edited by G. W. Coopland. Cambridge: Cambridge University Press.

Midmer, R. 1979. English Mediaeval Monasteries (1066-1540): A Summary. London: Heinemann Milner, M. 2011. The Senses and the English Reformation. Farnham: Ashgate Publishing Mitchell, W. 2002. Landscape and Power. Chicago: University of Chicago Press. de Molen, R. 1973. Erasmus' Commitment to the Canons Regular of St Augustine. Renaissance Quarterly, Vol. 26, No. 4, $437-443$. 
Monger, G. 1997. Modern Wayside Shrines. Folklore, Vol. 108, 113 - 114.

Monger, G and Chandler, J. 1998. Pilgrimage to Kensington Palace. Folklore Vol. 109, $104-108$.

Moore-Colyer, R. 1976. The Welsh Cattle Drovers: Agriculture and the Welsh Cattle Trade Before and During the Nineteenth Century. Cardiff: University of Wales Press.

Morinis, A. 1992. Sacred Journeys: The Anthropology of Pilgrimage. Westport and London: Greenwood Press.

Morris, C (ed). 1984. The Illustrated Journeys of Celia Fiennes 1682 - 1712. London and Sydney: MacDonald Press.

Morris, C and Morris, P. 2002. Pilgrimage: The English Experience from Beckett to Bunyan. Canterbury: Canterbury University Press.

Morris, A. 1992. Sacred Journeys : The Anthropology of Pilgrimage. London: Greenwood Press. Morris, R. 2000. The Blickling Homilies. Cambridge: In Parenthese Publications.

Mulk, I. 1994. 'Sacrificial Places and their Meaning in Saami Society' in Sacred Sites, Sacred Places. Ucko, P (ed). London: Routledge.

Mundee, M. 2009. An Isotopic Approach to Diet in Medieval Spain. Unpublished.

Munroe, E. 1998. On Glory's Road: A Pilgrim's Book about Pilgrimage. New York: Thames and Hudson.

Murphy, P. 2009. The English Coast: A History and a Prospect. London: Continuum International Publishing Group.

Nebolsine, G. 1964. The Pilgrimage Route to Rome. International Centre of Medieval Art; Gesta, Vol. $1,3-8$.

Needham, G. 1966. Aelfric's Lives of three English saints. Exeter: University of Essex Press. Negrín, J. 1979. The Huichol: A Pre-Columbian Culture in Mexico Today. Paris: The UNESCO Courier Press.

Nichols, J. 1849. Pilgrimages to Saint Mary of Walsingham and St Thomas of Canterbury by Desiderius Erasmus. Westminster, London: John Bowyer Nichols and Son.

Nilson, B. 1998. Cathedral Shrines of Medieval England. Woodbridge: Boydell Press. 
Nolan, M. 1983. Irish Pilgrimage: The Different Tradition. Annals of the Association of American Geographers, Vol. 73, No. 3, September, $421-438$.

Nolan, M and Nolan, S. 1992. Christian Pilgrimage in Modern Western Europe. Carolina: University of North Carolina Press.

O'Sullivan, J and O'Carragain, T. 2008. Inishmurray; Monks and Pilgrims in an Atlantic Landscape Vol. 1: Archaeological Survey and Excavations 1997-2000. Oxford: Collins Press.

Ogilvie, E and Sleightholme, A. 1994. An Illustrated Guide to the Crosses on the North Yorkshire Moors. York: Village Green Press.

Ohler, N. 1989. The Medieval Traveller. Text translated from German to English by Caroline Hillier. Woodbridge, Suffolk: The Boydell Press.

Olsen, V. 2004. Late Medieval Pilgrimage Architecture in Northern Europe, c. 1250 - 1520: A Summary of Recent Research and New Perspectives. Peregrinations, Vol. 1, No. 4. Accessed 28/06/2010, at: http://peregrinations.kenyon.edu/

Olson, L. 1989. Early Monasteries in Cornwall. Woodbridge: Boydell and Brewer.

Orme, N. 1996. Church and Chapel in Medieval England. Transactions of the Royal Historical Society, Sixth Series, Vol. 6, $75-102$.

Orme, N (ed). 2007a. Cornish Wills 1342 - 1540. Exeter: The Devon and Cornwall Record Society. Orme, N. 2007b. Cornwall and the Cross: Christianity 500 - 1500 AD. Exeter: University of Exeter Press.

Orme, N. 2009. Exeter Cathedral: The First Thousand Years, 400 - 1550. Exeter: University of Exeter Press.

Orme, N. 2010. A History of the County of Cornwall Vol II: Religious History to 1560. Victoria County History Series. Woodbridge: Boydell and Brewer

Ostkamp, S. 2009. The World Upside Down: Secular Badges and the Iconography of the Late Medieval Period. Journal of Archaeology in the Low Countries, Vol. 1, No. 2, 107 - 125.

Owen, C. 1951. The Plan of the Canterbury Pilgrimage. PMLA, Vol. 66, No. 5, 820-826.

Owoc, M. 2008. 'Monuments as Landscape: Place, Perspective and Performance Practice' in Monuments in the Landscape. P. Rainbird (ed). Stroud: Tempus Publishing. 
Palmer, M and Palmer, N. 2000. The Spiritual Traveller: England, Scotland and Wales; The Guide to Sacred Sites and Pilgrim Routes in Britain. London: Hidden Spring Publishing.

Page, W. 1906. The Victoria County History of Norfolk: Volume 2. London: AandC Publishers.

Page, W. 1906. The Victoria County History of Cornwall; Volume I. London: AandC Publishers.

Page, W. 1912. Victoria County History of Hampshire. London: Institute of Historical Research.

Pearce, J. 1992. Post-medieval pottery in London, 1500-1700, Volume 1 : Border Wares. London: Museum of London.

Payton, P. 2004. Cornwall; A History. Truro: Cornwall Editions Press.

Pearson, M. 2006. In Comes I: Performance, Memory and Landscape. University of Exeter Press.

Pennant, T. 1796. The History of the Parishes of Whitford and Holywell. London: B. and J. White.

Peterson, A. 1994. The Archaeology of the Syrian and Iraqi Hajj Routes. World Archaeology, Vol. 26, No. 1, 47 - 56.

Petts, D. 2002. 'Cemeteries and Boundaries in Western Britain' in Burial in Early Medieval England and Wales. S. Lucy and A. Reynolds (eds). Leeds: Society for Medieval Archaeology. 24 - 46.

Poole, J. 1831. Gleanings of the Histories of Holywell, Flint, Saint Asaph, and Rhuddlan; Their Antiquities and Surrounding Scenery, with a Statistical and Geographical Account of North Wales in General. Holywell, Wales: J.Davies.

Porteous, A. 1928. Forest Folklore, Mythology and Romance. New York: Macmillan.

Postan, M. 1972. The Medieval Economy and Society: An Economic History of Britain 1100 - 1500.

Berkley and Los Angeles, California: University of California Press.

Preston-Jones, A. 1992. 'Decoding Cornish Churchyards' in The Early Church in Wales and the West. Edwards, $\mathrm{N}$ and Lane, $\mathrm{A}$ (eds). Oxford: Oxbow Press.

Prince, H.C. and Kain, R.J.P. 2000: Tithe surveys for historians. Chichester : Phillimore.

Pryor, F. 2004. Flag Fen: The Life \& Death of a Prehistoric Landscape. Stroud: Tempus Publishing.

Pugh, R.B (ed). 1953. Volume 4: City of Ely; Ely, N. and S. Witchford and Wisbech Hundreds in Victoria County History; A History of the County of Cambridge and the Isle of Ely. London: Victoria County History Press. 
Pugh, R \& Crittall, E. 1956. A History of the County of Wiltshire: Volume 3. London: Institute of Historical Research.

Pythinian-Adams, C. 2000. 'Environments and Identities: Landscape as Cultural Projection in the English Provincial Past' in Environments and Historical Change: The Linacre Lectures 1998. P. Slack (ed). Oxford: Oxford University Press.

Quiller-Couch, M and Quiller-Couch, L. 1894. Ancient and Holy Wells of Cornwall. London: C.J. Clark.

Rackham, O. 1986. The History of the Countryside. London: Dent Press.

Rackham, O. 1996. Trees and Woodland in the British Landscape: The Complete History of Britain's Trees, Woods and Hedgerows (Revised Edition). London: Phoenix Giants Press.

Rackham, O. 2002. 'The Medieval Countryside of England: Botany and Archaeology' in Inventing Medieval Landscapes: Senses of Place in Western Europe. Howe, J and Wolfe, M (eds). Florida: University Press of Florida.

Ramsay, G. 1965. The Wiltshire Woollen Industry in the Sixteenth and Seventeenth Centuries. $2^{\text {nd }}$ Edition, Oxford: Frank Cass and Co Ltd.

Randall, H. 1933. Wales in the Fourteenth Century. Antiquity, Vol. 7, No. 27, $329-336$.

Rattue, J. 1995. The Living Stream; Holy Wells in Historical Context. Woodbridge, Suffolk: The Boydell Press.

Ravenhill, W. 1967. 'Cornwall' in The Domesday Geography of South-West England. Darby, H and Welldon Finn, R (eds). Cambridge: Cambridge University Press.

Rees, E. 2001. Celtic Saints in Their Landscape. Stroud: Sutton Publishing.

Rees, N and John, T. 2002. Pilgrimage: A Welsh Perspective. Llandysul: Gomer Press.

Rees, W. 1951. An Historical Atlas of Wales: From Early to Modern Times. Cardiff: University of Cardiff Press.

Reeves, C. 1995. Pleasures and Pastimes in Medieval England. Stroud: Sutton Publishing Ltd. Reischauer, E. 1955. Ennin's Diary: The Record of a Pilgrimage to China in Search of the Law. New York: Ronald Press Co. 
Richards, M. 1969. Welsh Administrative and Territorial Units, Medieval and Modern. Cardiff: University of Wales Press.

Ridyard, S. 1988. The Royal Saints of Anglo-Saxon England: A Study of West Saxon and East Saxon Saint Cults. Cambridge: Cambridge University Press.

Rockman, M and Steele, J. 2003. Colonization of Unfamiliar Landscapes; The Archaeology of Adaption. London: Routledge.

Roffey, S and Marter, P. 2012. Treating Leprosy; Inside the Medieval Hospital of St Mary Magdalene, Winchester. Current Archaeology, Vol. 267, 13-18.

Ruiz, E and Pazzis pi Corrales, M. 2002. Scandinavia, Saint Birgitta and the Pilgrimage Route to Santiago de Compostela. Universidade de Santiago de Compostela.

Rumble, A. 1996. 'An Edition and Translation of the Burghal Hideage, Together with Recession C of the Tribal Hideage' in The Defence of Wessex: The Burghal Hideage and Anglo-Saxon Fortifications. Hill, D and Rumble A (eds). Manchester: Manchester University press.

Russell, J. 1944. The Clerical Population in Medieval England. Traditio, Vol. 2, 177- 212.

Rye, W. 1885. A Popular History of the County of Norfolk. London: Stock.

Safford, E. 1974. The Itinerary of Edward I. London: Swift Publishers Ltd.

Salter, M. 1993. The Old Parish Churches of North Wales. London: Folly Publications.

Salzman, L. 1948. A History of the County of Cambridge and the Isle of Ely: Volume 2. Victoria County History Publications.

Saul, N (ed). 2000. 'Plague and Reconstruction: Bishops Edington and Wykeham at Highclere, 1346 1404 ' in Fourteenth century England, Volume 1. Boydell and Brewer.

Saunders, C. 2001. Chaucer. Oxford: Blackwell Publishers.

Saunders, H. 1930. An Introduction to the Obedientary and Manor Rolls of Norwich Cathedral Priory. Norwich: Janold and Sons.

Saunders, P. 1990. Salisbury Museum Medieval Catalogue: 3. Salisbury: Salisbury and South Wiltshire Museum Trust.

Saunders, A. 1991. Exploring England's Heritage: Devon and Cornwall. Michegan: University of Michigan Press.

Sargent-Baur, B (ed). 1992. Journeys Towards God: Pilgrimage and Crusade. Michigan: Medieval Institute Publications, Western Michigan University. 
Schama, S. 1995. Landscape and Memory. London: Harper Collins Press.

Sedding, E H, 1909. Norman architecture in Cornwal. London: George Bell and Sons Press.

Semple, S. 1998. A Fear of the Past. The Place of the Prehistoric Burial Mound in the Ideology of the Middle and Later Anglo-Saxon England. World Archaeology, Vol. 30, No. 1, 109 - 126.

Sharpe, R. 1995. Adomnán of Iona: The Life of St Columba. London: Penguin Classics.

Sheppard, P. 1980. The Historic Towns of Cornwall : An Archaeological Survey. Truro: Cornwall Committee for Rescue Archaeology.

Shinners, J. 2007. Medieval Popular Religion: A Reader.London: Broadview Press

Short, B. 2006. England's Landscape: The South East. London: English Heritage.

Skelton, R and Harvey, P. 1986. Local Maps and Plans from Medieval England. Oxford: Clarendon Press.

Smith, L. 1907. The Itinerary of John Leland In or About the Years 1535 - 1543; Parts I to III. London: George Bell and Sons.

Soulsby, I. 1983. The Towns of Medieval Wales : A Study of their History, Archaeology and Early Topography. Chichester: Phillimore.

Spencer, B. 1990. Salisbury and South Wiltshire Museum Medieval Catalogue Part 2: Pilgrim Souvenirs and Secular Badges. Salisbury and South Wiltshire Museum.

Spencer, B. 1998. Medieval Finds from Excavations in London 7: Pilgrim Souvenirs and Secular Badges. Museum of London.

Spencer, B. 2010. Pilgrim Souvenirs and Secular Badges. London: Boydell Press.

Stanford, D. 2007. Norfolk Churches. London: Francis Lincoln Ltd

Stenton, F. 1936. The Road System of Medieval England. Economic History Review, Vol. 7, No. 1, November, $1-21$.

Stewart, D.J. 1868. On the Architectural History of Ely Cathedral. London: J. Van der Voorst.

Stevenson, J. 2010. Performance, Cognitive Theory, and Devotional Culture: Sensual Piety in Late Medieval York. London: Palgrave MacMillian. 
Stevenson, W. 2010. Asser's Life of King Alfred: Together with the Annals of Saint Neots Erroneously Ascribed to Asser (1904). Whitefish, Montana: Kessinger Publishing.

Stones, A., Gerson, P., Shaver-Crandell, A., Krochalis, J. 1998. The Pilgrim's Guide to Santiago de Compostela Critical Edition; Volume II; The Text. London: Harvey Miller Publishers.

Stopford, J. 1994. Some Approaches to the Archaeology of Christian Pilgrimage. World Archaeology, vol. 26, No. 1, June, $57-72$.

Stopford, J. 1999. Pilgrimage Explored. York: York Medieval Press.

Stouck, M. 1999. Readings in Medieval Civilisations and Cultures IV: Medieval Saints, A Reader. Michegan: Broadview Press.

Storrs, C. 1995. Jacobean Pilgrims from England to St James of Compostella from the Early Twelfth to the Late Fifteenth Century. Santiago de Compostela: Xunta de Galicia.

Stubbs, W (ed). 1868. Chronica Magistri Rogeri de Houedene Vol. I. London: Longmans, Green and Co.

Sumbler, M. 1996. London and the Thames Valley (4 ${ }^{\text {th }}$ Edition). British Regional Geology Series, British Geological Survey.

Sumption, J. 1975. Pilgrimage: An Image of Medieval Religion. London: Faber.

Swallow, M and Eade, J. 1991. Contesting the Sacred: The Anthropology of Christian Pilgrimage. London: Routledge.

Swanton, M. 2000. The Anglo Saxon Chronicles. Phoenix Press.

Swatos, W and Tomasi, L. 2002. From Medieval Pilgrimage to Religious Tourism: The Social and Cultural Economics of Piety. Westport, Conneticut: Praeger.

Tait, H. 1955. Pilgrim Signs and Thomas, Earl of Lancaster. British Museum Quarterly, Vol. 20, No. 2, September, $39-47$.

Tanner, J. 1744. Notitia Monastica or An Account of all the Abbies, Priories, and Houses of Friars Herefore in England and Wales. London: John Tanner.

Tasker, E. 1993. Encyclopaedia of Medieval Church Art. London: B. T. Batsford Ltd.

Tatlock, J. 1906. The Duration of the Canterbury Pilgrimage. PMLA, Vol. 21, No. 2, $478-485$. 
Tatton-Brown, T and Crook, J. 2002. The English Cathedral. London: New Holland Press.

Taylor, C. 1979. Roads and Tracks of Britain. London : Dent and Sons Ltd.

Thacker, A and Sharpe, R. 2002. Local Saints and Local Churches in the Early Medieval West. Oxford: Oxford University Press.

Thirsk, J. 1967. The Agrarian History of England and Wales: Volume 4; 1500 - 1640. Cambridge: Cambridge University Press.

The Boundary Commission. 1885. Report of the Boundary Commissioners for England and Wales: Parts I and II. London: Eyre and Spottiswoode.

Thiery, D. 2009. Polluting the Sacred: Violence, Faith, and the 'Civilising' of Parishioners in Late Medieval England. Leiden: Brill Press.

Thomas, C. 1971. The Early Christian Archaeology of North Britain. Oxford: Oxford University Press.

Thomson, G. 1918. Roads in England and Wales in 1603. The English Historical Review, Vol. 33, No. 130, April, $234-243$.

Thomas, J. 2012. 'Archaeologies of Place and Landscape' in Archaeological Theory Today (Second Edition). Ian Hodder (ed). Cambridge: Polity Press.

Thomas, K. 1984. Man and the Natural World: Changing Attitudes in England 1500 - 1800. London: Penguin Press.

Thorpe, H. 1964. 'Rural Settlement' in The British Isles: A Systematic Geography. London: International Geographic Congress.

Thorpe, L. 1978. The Journey Through Wales and the Description of Wales by Gerald of Wales. London: Penguin Classics.

Tilley, C. 1994. A Phenomenology of Landscape: Places, Paths and Monuments. Oxford: Berg Press.

Tilley, C. 2008a. Body and Image: Explorations in Landscape Phenomenology. Walnut Creek: Left Coast Press.

Tilley, C. 2008b. 'Phenomenological Approaches to Landscape Archaeology' in Handbook of Landscape Archaeology. B. David \& J. Thomas (eds). Walnut Creek: Left Coast Press.

Titow, J. 1969. English Rural Society, 1200 - 1350. London: Allen and Unwin.

Todd, M. 1987. The South West to AD 1000. London: Longman Press.

Toulson, S. 1978. Drover's Roads of Wales. Aldershot: Wildwood House Ltd. 
Tuan, Y. 1975. Images and Mental Maps. Annals of the Association of American Geographers, Vol. 65 , No. 2, June, $205-213$.

Tubbs, C. 2001.The New Forest : History, Ecology and Conservation. $2^{\text {nd }}$ Edition. Lyndhurst: New Forest Ninth Centenary Trust.

Turner, S. 2006a. Making a Christian Landscape; The Countryside in Early Medieval Cornwall, Devon and Wessex. Exeter: University of Exeter Press.

Turner, S. 2006b. The Christian Landscape: Churches, Chapels and Crosses in Medieval Devon and Cornwall: Shaping an Ancient Countryside. Turner, S (ed). Bollington, Cheshire: Windgather Press.

Turner, V and Turner, E. 1978. Image and Pilgrimage in Christian Culture: Anthropological Perspectives. New York: Columbia University Press.

Turner, V. 1992. 'Death and the Dead in the Pilgrimage Process' in Blazing the Trail; Way Marks in The Exploration of Symbol. E. Turner (ed). Arizona: Tucson Press.

Tymms, W. 1842. Camden's Brittania Epitomized and Continued; Being an Account of the Ancient and Present State of the Counties of England. Vol II; The Western Circuit. London: Henry G Bohn.

Varty, K. 1999. Reynard, Renart, Reinaert and Other Foxes in Medieval England; The Iconographic Evidence. Amsterdam: Amsterdam University Press.

Vaughan, R. 1993. The Illustrated Chronicles of Matthew Paris: Observations of Thirteenth-Century Life. Stroud: Sutton Publishing.

Verdon, J. 2003. Travel in the Middle Ages. Translated from French to English by George Holoch. Notre Dame, Indiana: University of Notre Dame Press.

Vöörbus, A. 1958. A History of Asceticism in the Orient; A Contribution to the History of Culture in the Near East I: The Origin of Asceticism in Persia. Corpus Scriptorum Christianorum Orientalium, Universitatis Catholicae Americae et Universitatis Catholicae Lovaniensis. Vol. 184.

Vöörbus, A. 1958. A History of Asceticism in the Orient; A Contribution to the History of Culture in the Near East II: Early Monasticism in Mesopotamia and Syria. Corpus Scriptorum Christianorum Orientalium, Universitatis Catholicae Americae et Universitatis Catholicae Lovaniensis. Vol. 197. de Voragine, J. 1993. The Golden Legend; Readings on the Saints Volumes I and II. Translated from French to English by William Granger Ryan. Princeton: Princeton University Press.

Wade-Martins, P (ed). 1994. An Historical Atlas of Norfolk. Norwich: Norfolk Museum Service. 
Walker, D. 1990. Medieval Wales. Cambridge: Cambridge University Press.

Walker, J. 1989. Joseph Mallord William Turner; Masters of Art Series. London: Thames and Hudson

Wall, S. 1980. The Animal Bones from the Excavation of St Mary of Ospringe. Archaeologia Cantiana, Vol. 156, $227-266$.

Walsham, A. 2011. The Reformation of the Landscape: Religion, Identity, and Memory in Early Modern Britain and Ireland. Oxford: Oxford University Press.

Ward, B. 1982. Miracles and the Mediaeval Mind: Theory, Record and Event, 1000 - 1215. California: Scolar Press.

Webb, D. 1999. Pilgrimage and Pilgrims in the Medieval West. London: I.B.Tauris.

Webb, D. 2000. Pilgrimage in Medieval England. London: Hambledon and London.

Weber, E. 2005. Travelling Through Text: Message and Method in Late Medieval Pilgrimage Accounts. London: Routledge.

Webster, G (ed). 1958. Lead Mining Industry in North Wales in Roman Times. Caernarvon: Gwenlyn Evans Ltd.

Weinstein, D and Bell, R. 1986. Saints and society: The Two Worlds of Western Christendom, 10001700. Chicago: Chicago University Press.

Weisgerber, G and Pernicka, E. 1995. 'Ore Mining in Prehistoric Europe: An Overview' in Prehistoric Gold in Europe: Mines, Metallurgy and Manufacture. Morteani, G and Northover, J (eds). New York: Springer Publishing.

Weisman, G. 1981. Evaluating Architectural Legibility: Wayfinding in the Built Environment. Environment and Behaviour. Vol. 13, No. 2. $189-204$.

Wells, P. 2008. Image and Response in Early Europe. London: Duckworth Press.

Westwood, J and Simpson, J. 2006. The Lore of the Land: A Guide to England's Legends. London: Penguin Books Ltd.

White, H. 1972. 'The Forms of Wilderness: Archaeology of an Idea' in The Wild Man Within: An Image in Western Thought from Renaissance to Romanticism. Dudley, E and Novak, M (eds). Pittsburgh: University of Pittsburgh Press. 
Wilkinson, John. 2006. Egeria's Travels. Oxford: Aris\&Phillips Publishing

Wille, A. 2004. A Medieval Worldview and it's Relation to Literary Authorities in a Late Medieval Pilgrimage Account. Ennen Ja Nyt, Vol. 4. Only available online here:

http://www.ennenjanyt.net/404/wille.pdf

Williams, G. 1993. A Catalogue of Seals in the National Museum of Wales. Cardiff: National Museum of Wales.

Williams, R. 1993. The Country and the City. London: The Hogarth Press

Wilson, S. 1985. Saints and their Cults: Studies in Religious Sociology, Folklore and History. Cambridge: Cambridge University Press Archive.

Windeatt, B (ed). 2000. The Book of Margery Kempe; The Annotated Edition. London: Longman Publishing.

Woolgar, C. 2006. The Sense in Late Medieval England. Yale: Yale University Press.

Worcester, W. 1969. Itineraries of William Worcestre. Oxford: Clarendon Press

Wordsworth, C. 1901. Ceremonies and Processions of the Cathedral Church of Salisbury. Cambridge: Cambridge University Press Archive.

Wordsworth, C. 1902. The Fifteenth Century Cartulary of St Nicholas' Hospital, Salisbury, with Other Records. Salisbury: Brown and Co.

Wormald, F. 1934. English Calendars before AD 1100. Michigan: University of Michigan Press.

Wright, C. 2004. The Maze and the Warrior: Symbols in Architecture, Theology and Music. London: Harvard University Press.

Yorke, B. 1995. Wessex in the Early Middle Ages. London: Leicester University Press.

Zacher, C. 1976. Curiosity and Pilgrimage: The Literature of Discovery in Fourteenth-Century England. Baltimore: John Hopkins University Press.

Zumthor, P and Peebles, C. 1994. The Medieval Travel Narrative. New Literary History, Vol. 25, No. 4, $25^{\text {th }}$ Anniversary Issue, Part 2, $809-824$. 
Declaration

I, Martin Locker confirm that the work presented in this thesis is my own. Where information has been derived from other sources, I confirm that this has been indicated in the thesis.

Martin Locker 
Volume 1: Thesis

Declaration

Abstract

Acknowledgements

Chapter 1-The Purpose and the Pilgrim

$\begin{array}{lll}1.1 & \text { Research Aims } & 16\end{array}$

$\begin{array}{lll}1.2 & \text { Thesis Structure } & 17\end{array}$

$\begin{array}{lll}1.3 & \text { What is Pilgrimage? } & 19\end{array}$

1.4 Pilgrimage in the Medieval West 22

1.5 Travel in the Medieval West 29

Chapter 2 - The Pilgrim's Presence in Scholarship

2.1 Theorising Pilgrimage: The Current Dialogue 37

2.2 Medieval Pilgrimage in the Archaeological and Historical Record 43

2.3 Liminality, Movement and the Landscape 50

2.4 Methodology: The Need for a New Approach 56

\section{Chapter 3 - Case Study I: Ely to Walsingham}

$\begin{array}{lll}3.1 & \text { Introduction to the Case Study } & 67\end{array}$

3.2 The Landscape of Medieval Norfolk 68

$\begin{array}{lll}3.3 & \text { The Road Network of Medieval Norfolk } & 72\end{array}$ 
3.4 The Cult of Our Lady of Walsingham 81

3.5 The Distribution for Pilgrim Souvenirs 89

3.6 The Archaeological and Etymological Remnants of Pilgrimage 93

$\begin{array}{lll}\text { 3.7 Pre-Reformation churches in Norfolk } & 105\end{array}$

3.8 The Sensory Dialogue 111

$\begin{array}{lll}3.9 & \text { Conclusions } & 122\end{array}$

\section{Chapter 4 - Case Study II: Salisbury to Winchester}

$\begin{array}{lll}4.1 & \text { Introduction to the Case Study } & 124\end{array}$

4.2 The Landscapes of Medieval Wiltshire and Hampshire 125

$\begin{array}{lll}\text { 4.3 The Road Network of Medieval Wiltshire and Hampshire } & 135\end{array}$

$\begin{array}{lll}4.4 & \text { The Cult of St Swithun } & 139\end{array}$

$\begin{array}{lll}\text { 4.5 The Distribution for Pilgrim Souvenirs and Relics } & 150\end{array}$

4.6 The Archaeological and Etymological Remnants of Pilgrimage 154

$\begin{array}{lll}\text { 4.7 Pre-Reformation churches in Wiltshire and Hampshire } & 164\end{array}$

$\begin{array}{lll}4.8 & \text { The Sensory Dialogue } & 168\end{array}$

$\begin{array}{lll}4.9 & \text { Conclusions } & 181\end{array}$

\section{Chapter 5 - Case Study III: St Asaph to Holywell}

$\begin{array}{lll}5.1 & \text { Introduction to the Case Study } & 183\end{array}$

5.2 The Landscapes of Medieval Denbighshire and Flintshire $\quad 184$

$\begin{array}{lll}\text { 5.3 The Road Networks of Medieval North Wales } & 191\end{array}$

$\begin{array}{lll}\text { 5.4 The Cult of St Winefride } & 195\end{array}$

5.5 The Archaeological and Etymological Remnants of Pilgrimage 202

5.6 Pre-Reformation churches in Denbighshire and Flintshire 209

5.7 The Sensory Dialogue 213

$\begin{array}{llr}5.8 & \text { Conclusions } & 220\end{array}$ 


\section{Chapter 6 - Case Study IV: Camelford to Bodmin}

6.1 Introduction to the Case Study 221

6.2 The Landscapes of Medieval Cornwall 221

6.3 The Road Network of Medieval Cornwall 229

6.4 The Cult of St Petroc 233

6.5 The Distribution for Pilgrim Souvenirs and Relics 248

6.6 The Archaeological and Etymological Remnants of Pilgrimage 251

6.7 Pre-Reformation churches in Cornwall 260

6.8 The Sensory Dialogue 263

$\begin{array}{lll}6.9 & \text { Conclusions } & 275\end{array}$

Chapter 7 - Responses, the Pilgrim Experience and Cultural Comparisons

$\begin{array}{lll}7.1 & \text { Introduction } & 277\end{array}$

7.2 Response to Research Questions and Methodology 278

7.3 The Landscape \& the Monument 282

7.4 Possessions, the Personal Element \& Post-Pilgrimage 295

7.5 Beyond the Borders of Britain 301

7.6 Conclusions \& Routes for Further Research 306

$\begin{array}{ll}\text { Bibliography } & 312\end{array}$ 
Volume 2: Appendices

Declaration

Table of Contents

Appendix A Shortlist of Data Recorded for Each Case Study

Appendix B Detailed Maps of the Route Taken for Each Case Study

Appendix C Digitised Data Sheets Recorded for Each Site

Appendix D Surviving pre-Reformation Church Dedications

465

Appendix E Religious Houses Present in Each Case Study County

483

Appendix F Data from Portable Antiquities Scheme for Walsingham Ampullae

Appendix G Data from Portable Antiquities Scheme for Walsingham Badges

493 
List of Figures:

\section{Volume 1}

\section{Chapter 1}

Figure 1 'View of Delphi' by Claude Lorraine, 1672

Figure 2 Map of the main pilgrimage sites in Medieval Christendom by the $14^{\text {th }}$ century

Figure $3 \quad$ Pilgrims represented in stained glass at Canterbury Cathedral

Figure $4 \quad$ Map of the principal fairs and trade routes in western Medieval Europe

Figure 5 Strip map showing the route from London to Chamberry, from Matthew Paris' 'Book of Additions'.

Figure 6 The Mapped Itinerary of Edward I, showing the Road Network Used

Figure $7 \quad$ Illuminated manuscript displaying the four seasons from the $15^{\text {th }}$ century 'Les Tres Riches Heures', commissioned by the Duke of Berry

\section{Chapter 2}

Figure $8 \quad$ Examples of Medieval pilgrim badges and Ampulla (dedication unknown).

Figure 9 Shrine of St Swithun, Winchester Cathedral

Figure 10 Map of Hampshire taken from William Camden's 'Britannia', 1607

Figure 11 'Christ in the Wilderness', by Moretto de Brescia (1498-1554)

Figure 12 Map displaying the case study sites in relation to the major towns/cities of Medieval England and Wales

\section{Chapter 3}

Figure 13 Map of the basic landscape character of Norfolk,

Figure 14 The distribution of the various religious houses and hospitals in Medieval Norfolk 
Figure 15 The distribution of the 11 Hospitals in Medieval Norfolk founded to care for poor travellers and pilgrims

Figure 16 A map of the routes used progressing from Ely to Walsingham (comprising of the Hereward Way, Palmer's Way, and Pilgrim Walk)

Figure 17 Ground plan and sketch of Walsingham Priory

Figure 18 Map of Walsingham

Figure 19 Remains of the Friary, Slipper Chapel and Priory at Walsingham.

Figure 20 Distribution map for ampullae connected to Walsingham cult by iconography.

Figure 21 An ampulla bearing the crowned ' $W$ ' motif of Walsingham and scallop shell relief on the reverse.

Figure 22 Distribution map for pilgrim badges connected to Walsingham cult by iconography

Figure $23 \quad$ Plan of Ely showing relevant sites

Figure $24 \quad$ Plan of Ely Cathedral

Figure 25 Ely Cathedral, Pilgrim Cross at Hockwold cum Wilton (with St James Church behind), St Mary's Church at Cranwich, Castle Acre Priory ruins

Figure 26 The ruins of Castle Acre Priory

Figure 27 Table for saint dedication frequencies for surviving Norfolk pre-Reformation churches

Figure 28 Chart comparing frequency of saint dedications in surviving Norfolk pre-Reformation churches

Figure 29 Map displaying the scatter of surviving St Mary and St James pre-Reformation church dedications across Norfolk

Figure 30 Map of Ely showing Hereward Way and radius of transition between the Isle and the fenland

Figure 31 Map of Blackdyke, showing route along earthwork, radius of elevation, and sight line to St James' Church in Hockwold cum Wilton

Figure 32 The approach to Castle Acre showing the initial line of sight to the Priory and the River Nar creating a natural boundary between the 'wilderness' and 'sanctuary'

Figure 33 The Holy Mile of Walsingham showing the route coming down from Houghton St Giles to the Slipper Chapel leading to the town, including the sight line to the Friary

Figure $34 \quad$ Map showing the proposed sightline to the site of the Priory upon entering Walsingham, and the sacred area of the Priory grounds which housed the shrine to Our Lady 


\section{Chapter 4}

Figure 35 Map showing key landscape characters of Hampshire and Wiltshire; Salisbury Plain, Hampshire Downs, New Forest, Hampshire Basin and the Test Valley

Figure 36 The main production and market centres of Wiltshire textile industry

Figure 37 The distribution of Medieval religious houses throughout Wiltshire and Hampshire

Figure $38 \quad$ Map of route taken between Salisbury and Winchester along the Roman Road.

Figure $39 \quad$ Map of central Winchester with relevent sites located

Figure 40 Plan showing locations of the Old Minster, New Minster and the Norman Winchester Cathedral

Figure $41 \quad$ Conjectural plan of the monastic complex of St Swithun's Priory

Figure 42 Table of curative records for St Swithun

Figure $43 \quad$ Map of the known distribution of St Swithun's relics outside of Winchester

Figure $44 \quad$ The upper skull of St Swithun, relic of Evreux Cathedral

Figure $45 \quad$ Map of central Salisbury with relevent sites located

Figure 46 Late $19^{\text {th }}$ century postcard displaying the Old George Hotel, and photo of surviving $15^{\text {th }}$ century interior fabric

Figure $47 \quad$ All Saints Church, West Winterslow

Figure 48 Mottisfont Priory, Text Valley

Figure 491840 Ordnance Survey maps showing the Roman road entering Winchester, past 'Great Copse Road'

Figure $50 \quad$ Map of churches dedicated to St Swithun across England

Figure $51 \quad$ Map displaying the lands of the Bishop of Winchester in 1224. Several of these held churches or chapels dedicated to St Swithun

Figure 52 Surviving Pre-Reformation Church Dedications in Wiltshire

Figure 53 Surviving Pre-Reformation Church Dedications in Hampshire

Figure $54 \quad$ 'Salisbury Cathedral' by William Turner

Figure 55 Early $20^{\text {th }}$ century tinted postcard of Salisbury cathedral viewed from the south west

Figure 56 Radius from which the cathedral building is clearly visible from the east and the Roman road from Old Sarum to Winchester 
Figure 57 The path of the Roman road accessed on the outskirts of Salisbury

Figure 58 Cobhill Barrow in relation to the Roman road and the distance at which is visible from the western approach

Figure 59 Roman road running alongside Upper and Lower Noad's Copse, including detail of cobbled surface

Figure 60 The Roman Road in relation to the Test Valley and the River Test/flood plain

Figure 61 The West Gate in Winchester

Figure 62 The two basic zones of urbanism presented to the pilgrim during the western approach to Winchester: outer sprawl and the city centre via West Gate

Figure 63 Interior approach via the High Street to Winchester Cathedral, showing the outline of known St Swithun's Priory buildings, St Swithun's probable original burial shrine spot (circle near north transept), the Nunnaminster site, and St John's Hospital in the High Street

\section{Chapter 5}

Figure 64 Map of the Upland and Lowland landscapes of Medieval Wales in the $14^{\text {th }}$ century

Figure 65 Sight line for Moel Maenefa Hill-fort in relation to the Offa's Dyke and Clwyd Valley

Figure 66 Map displaying locations of major Silver and Lead mines in Medieval Britain including Wales

Figure 67 Birds-eye view of Pont Dafydd and potential drover trail near St Asaph

Figure $68 \quad$ Map of central Holywell with relevant sites marked

Figure $69 \quad$ Plan of St Winefride's Well

Figure $70 \quad$ The inner original basin at St Winefride's Well

Figure $71 \quad$ Plan of Basingwerk Abbey

Figure 72 St Asaph Cathedral (east facing)

Figure $73 \quad$ Map of central St Asaph with relevant sites marked

Figure 74 The view of the cathedral approaching Pont Elwy, and Pont Dafydd

Figure $75 \quad$ View from the remains of Offa's Dyke abutting Mynydd y Cwm, facing west into the Clwyd Valley

Figure 76 The Maen Achwyfan Cross with the Garreg Tower visible

Figure 77 Seal of St Asaph Cathedral showing St Winefride with crozier and reliquary 
Figure $78 \quad$ Map displaying distribution of church, well and spring sites dedicated to St Winefride and her uncle St Beuno

Figure 79 Chart Showing Frequency of Universal Saint Dedications in Surviving Flintshire and Denbighshire pre-Reformation Churches

Figure 80 Chart Showing Frequency of Local Saint Dedications in SurvivingFlintshire and Denbighshire pre-Reformation Churches

Figure 81 Map showing location of bridges in relation to St Asaph, the visibility of St Asaph cathedral from the two bridges, and the distance one can see from the cathedral site

Figure 82 Radius of view from Offa's Dyke into the Clwyd valley with sight line to St Asaph cathedral

Figure 83 Map displaying visual interplay between sites around and including the Maen Achwyfan Cross and the Grange near Whitford, Flintshire, and the panoramic expanse offered by the Beacon Tower

Figure $84 \quad$ Map showing sites at Holywell, and visual interaction between sites and the western approach to the town

\section{Chapter 6}

Figure 85 Map of Cornwall displaying the uplands, anciently enclosed land and recently enclosed land, according to the Cornwall \& Scilly Historic Environment Record

Figure $86 \quad$ Map of early mining sites in Cornwall

Figure $87 \quad$ Principal areas of farming and uncultivated ground in Medieval Cornwall

Figure 88 Distribution of post $11^{\text {th }}$ century Medieval religious houses in Cornwall

Figure 89 Distribution of Free and Villein Messuages in the Camelford Borough in the $14^{\text {th }}$ Century

Figure 90 Route taken from Camelford to Bodmin including key sites, plotted on the 1885 Report of the Boundary Commissioners for England and Wales.

Figure $91 \quad$ Map of central Bodmin with relevant sites marked

Figure 921881 OS Map of central Bodmin, highlighted are the sites of the Priory church and cloisters and St Petroc's Church

Figure 93 Fragments of sculpted masonry from the Bodmin Priory

Figure $9412^{\text {th }}$ century ivory casket which contained the relics of St Petroc, now in the Bodmin church of St Petroc

Figure 95 St Petroc's Well (centre) in Priory Park 
Figure $96 \quad$ Remains of the Chapel of St Thomas Becket

Figure 97 St Gurons Wellhouse

Figure $98 \quad$ Berry Tower

Figure 99 Distribution map of reputed St Petroc relics in England during the Medieval period

Figure $100 \quad$ Map of Camelford with relevant sites marked

Figure 101 St Juliot's Well, near Camelford and Lanteglos parish church

Figure 102 St Adwenna's church in circular graveyard within field system

Figure 103 Free Standing Wheel Cross near Advent Church

Figure 104 Arial image of Carwether DMV, and ground level appearance facing east towards Bodmin Moor

Figure $105 \quad$ Holy Well at St Brewards

Figure 106 Map of Dedications to St Petroc in Cornwall

Figure 107 Map of the route taken out of Camelford, following the Camel River

Figure 108 Map of Camel River valley floor with route and St Adwenna's church

Figure 109 Map of Adwenna's church in relation to the route, and the free standing cross.

Figure 110 Map of Carwether and Upland section, and view from uplands east to Bodmin Moor

Figure 111 The southern approach to St Breward, the church's visibility and the locations of the church and well sites.

Figure $112 \quad 19^{\text {th }}$ century sketch of the holy well in St Breward

Figure 113 The journey through the woodlands, and the exiting ascent into the uplands of Helland Parish

Figure $114 \quad$ The path through the woodlands in the Camel River valley floor during early February

Figure 115 The approach to Bodmin

\section{Chapter 7}

Figure 116 'Hunters in the Snow' by Pieter Breugel, 1565

Figure $117 \quad$ Ely Cathedral in fenland mists 
Figure 118 The July panel from the Très Riches Heures du Duc de Berry, 1489, showing the beginnings of the harvest.

Figure 119 Maen Achyfan Cross

Figure 120 Examples of flowers which bear relations to saints in plantlore, and may have been used in the context of 'found souvenirs'

Figure 121 Christian labyrinth motif, used within Chartres Cathedral 
Fieldwork data recorded en route between Ely \& Walsingham:

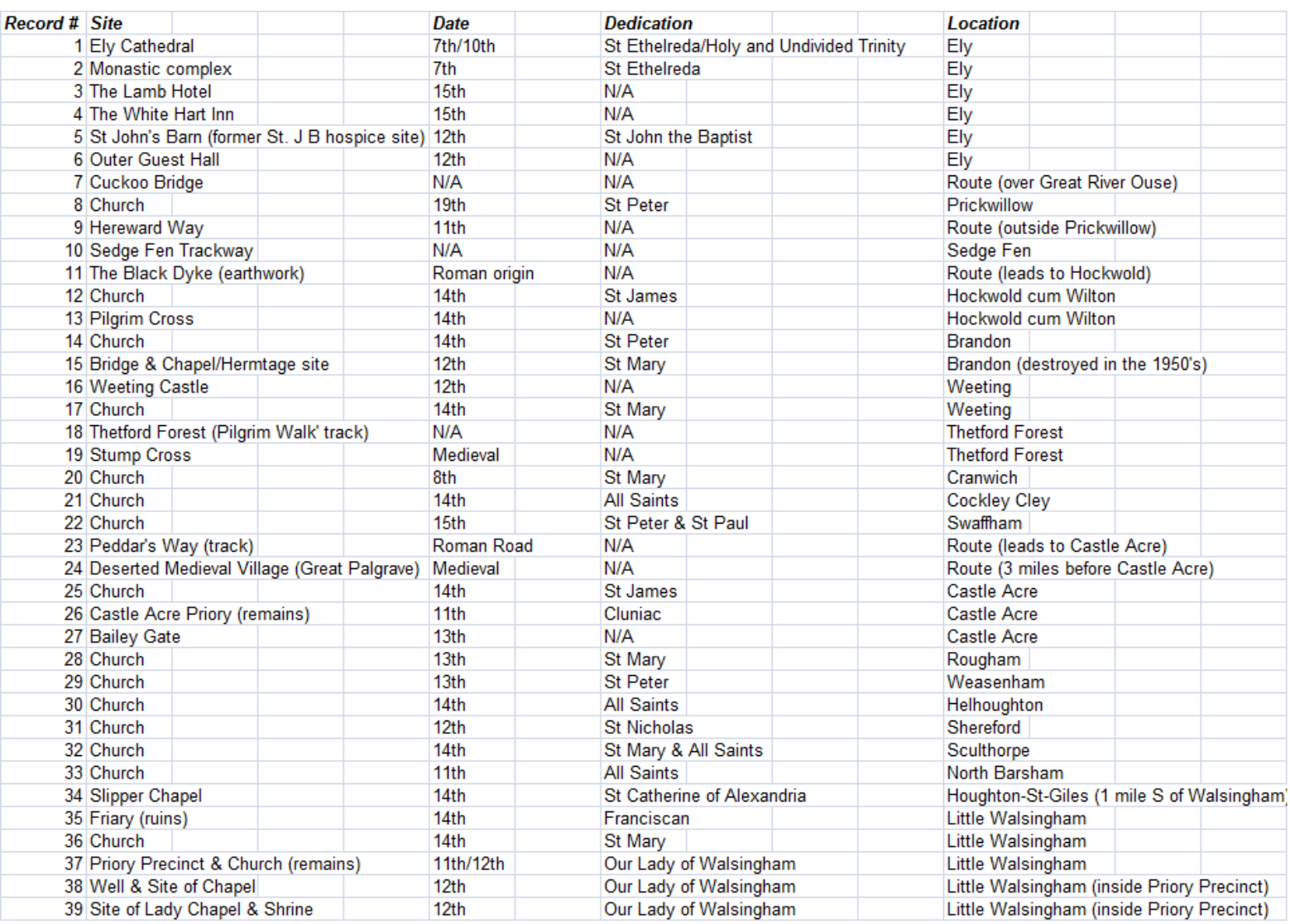

Fieldwork data recorded en route between Salisbury \& Winchester:

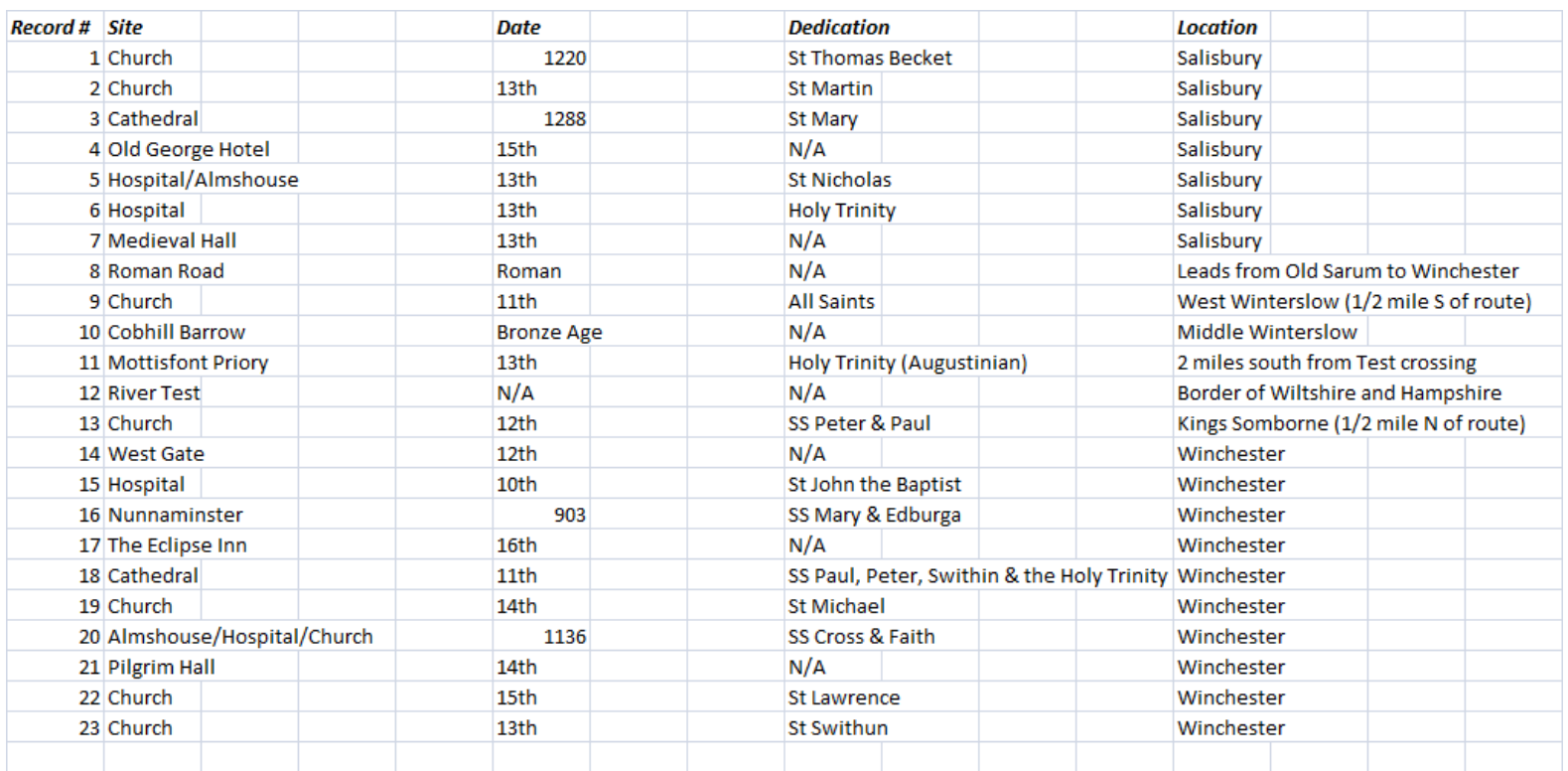


Fieldwork data recorded en route between St Asaph \& Holywell:

\begin{tabular}{|c|c|c|c|c|}
\hline \multirow{2}{*}{ Record \# } & Site & Date & Dedication & \multirow{2}{*}{$\begin{array}{l}\text { Location } \\
\text { St Asaph }\end{array}$} \\
\hline & 1 St Asaph Cathedral & 6th/13th & St Asaph & \\
\hline 2 & Parochial Church & 13th & St Kentigern \& St Asap & St Asaph \\
\hline 3 & Bridge (Pont Elwy) & 17th (pre?) & N/A & St Asaph \\
\hline 4 & Bridge (Pont Dafyyd) & 1630 & N/A & St Asaph \\
\hline 5 & Ascent to Offa's Dyke & N/A & N/A & Rhuallt \\
\hline 6 & Llyn-Helyg Wood \& Lake & N/A & N/A & Near Plas Captain \\
\hline 7 & 7 Glol Enclosure/Woodland & Bronze Age & $\mathrm{N} / \mathrm{A}$ & Near Glol Farm \\
\hline 8 & Possible Boundary stone & $\mathrm{N} / \mathrm{A}$ & $\mathrm{N} / \mathrm{A}$ & In Glol Woodlan \\
\hline 9 & Maen Achwyfan & 11th & St Cwyfan & Penrallt \\
\hline 10 & Garreg Tower & Roman site/16th build & $\mathrm{N} / \mathrm{A}$ & Coed y Garreg \\
\hline 11 & Parochial Church & 7th/14th & St Beuno \& St Mary & Whitford \\
\hline 12 & Basingwork Abbey & 1132 & Cistercian & Greenfield \\
\hline 13 & St Winefride's Well & 7th & St Winefride & Holywell \\
\hline 14 & St Winefride's Chapel & 15th & St Winefride & Holywell \\
\hline 15 & Parochial Church & 7th & St Beuno/St James & Holywell \\
\hline
\end{tabular}

\section{Fieldwork data recorded en route between Camelford \& Bodmin:}

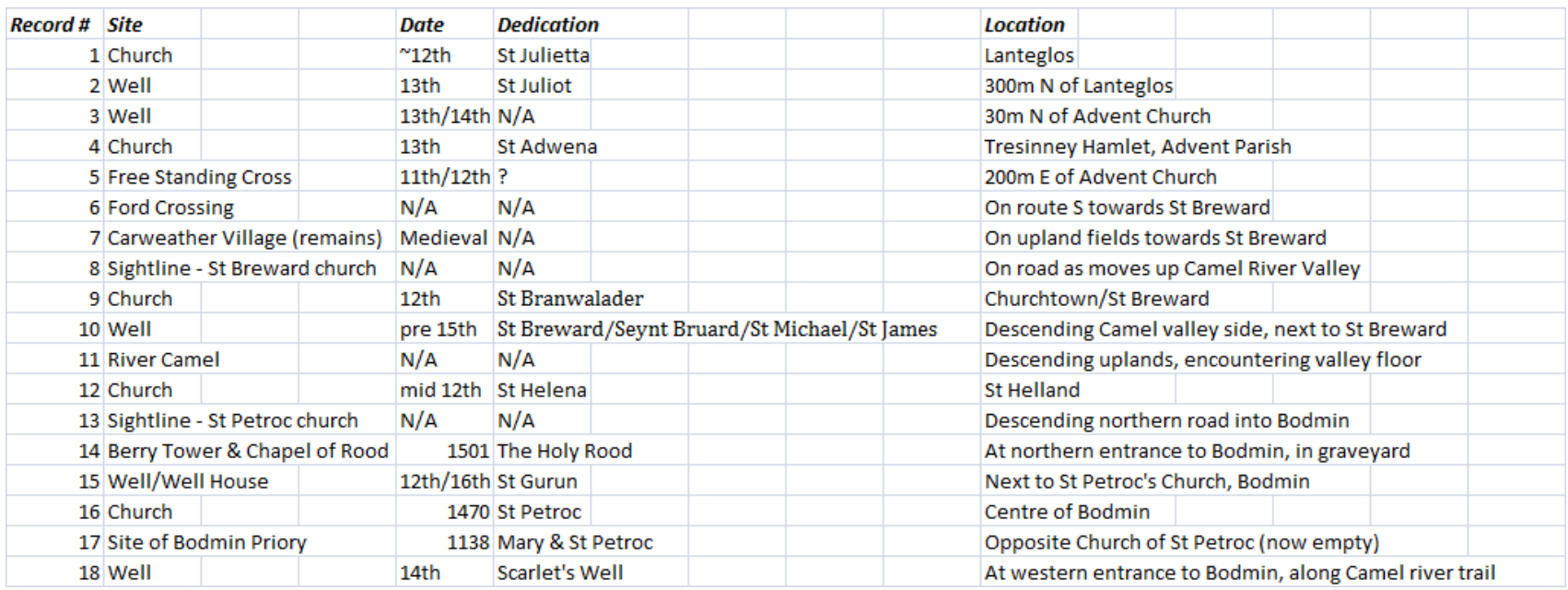




\section{Appendix B}

\section{Detailed Map of Route Taken from Ely to Walsingham:}
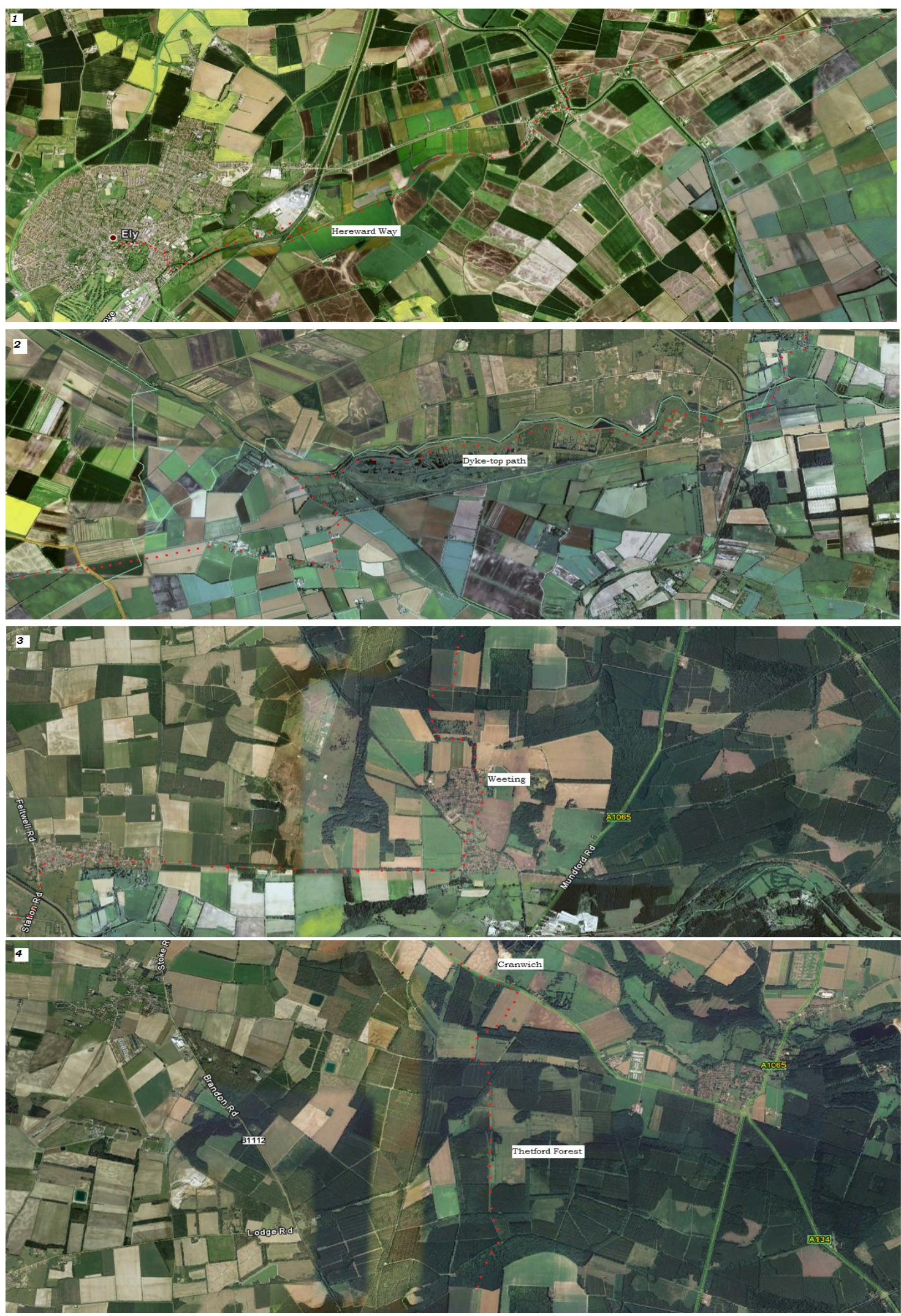

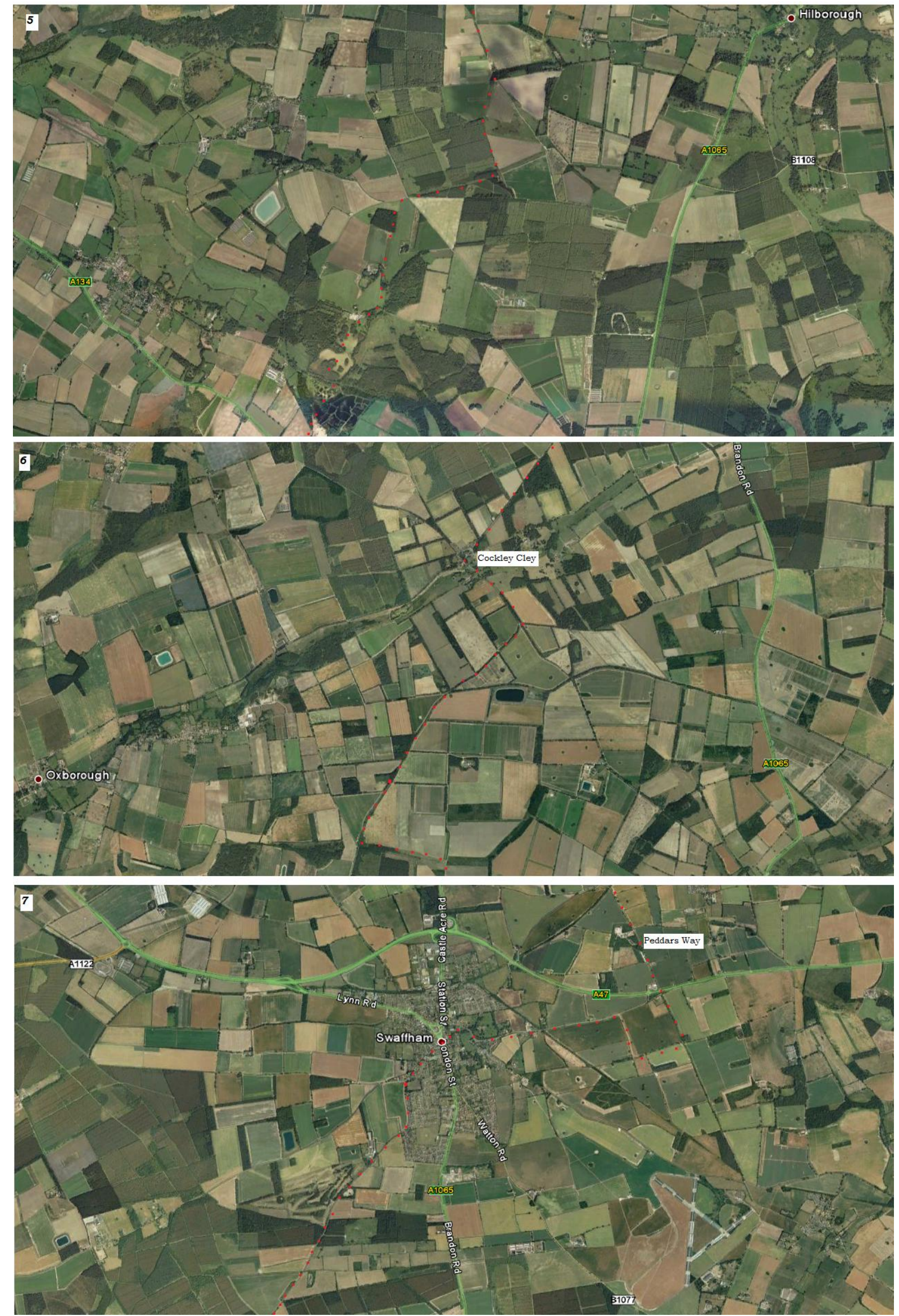

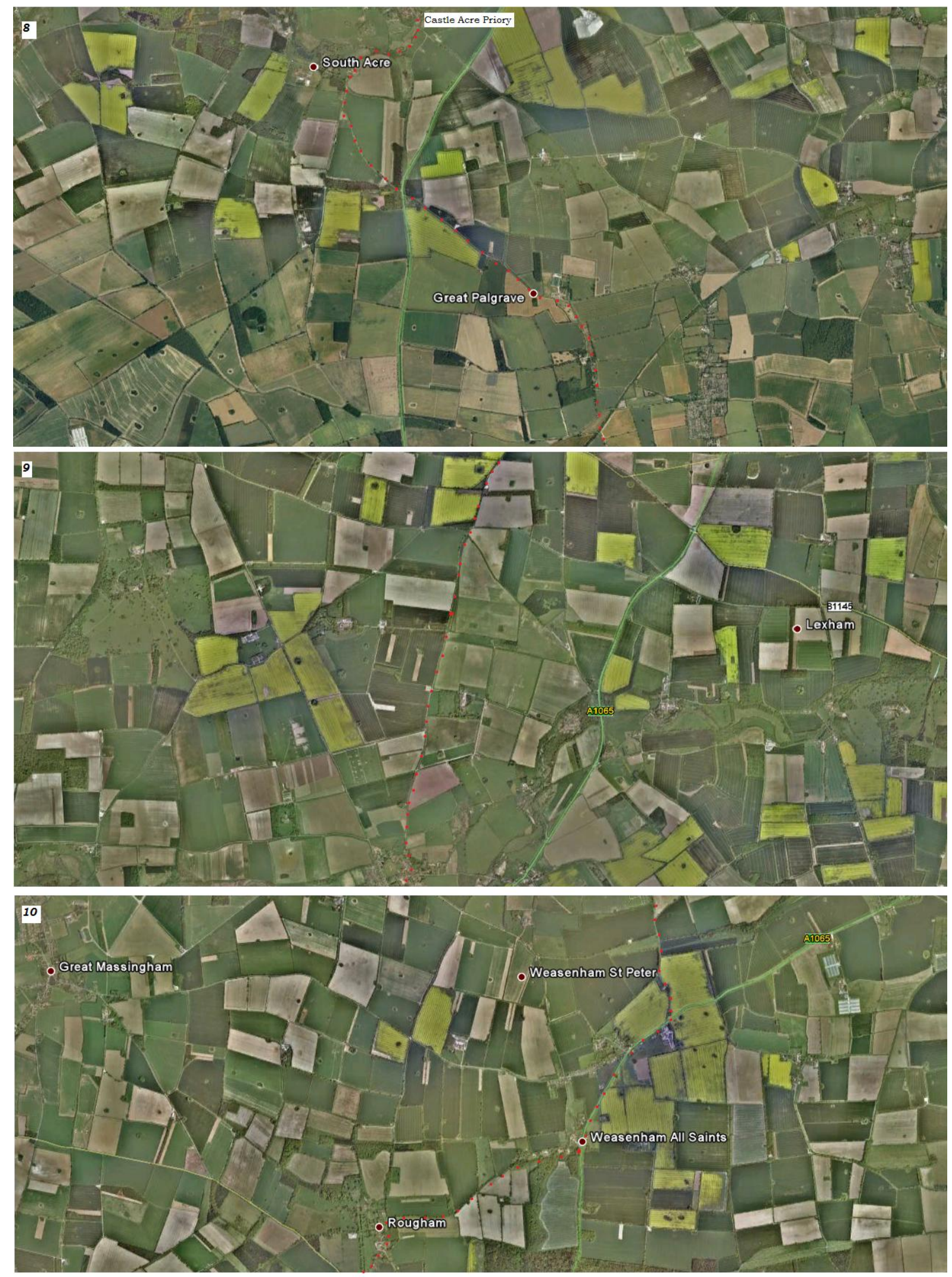


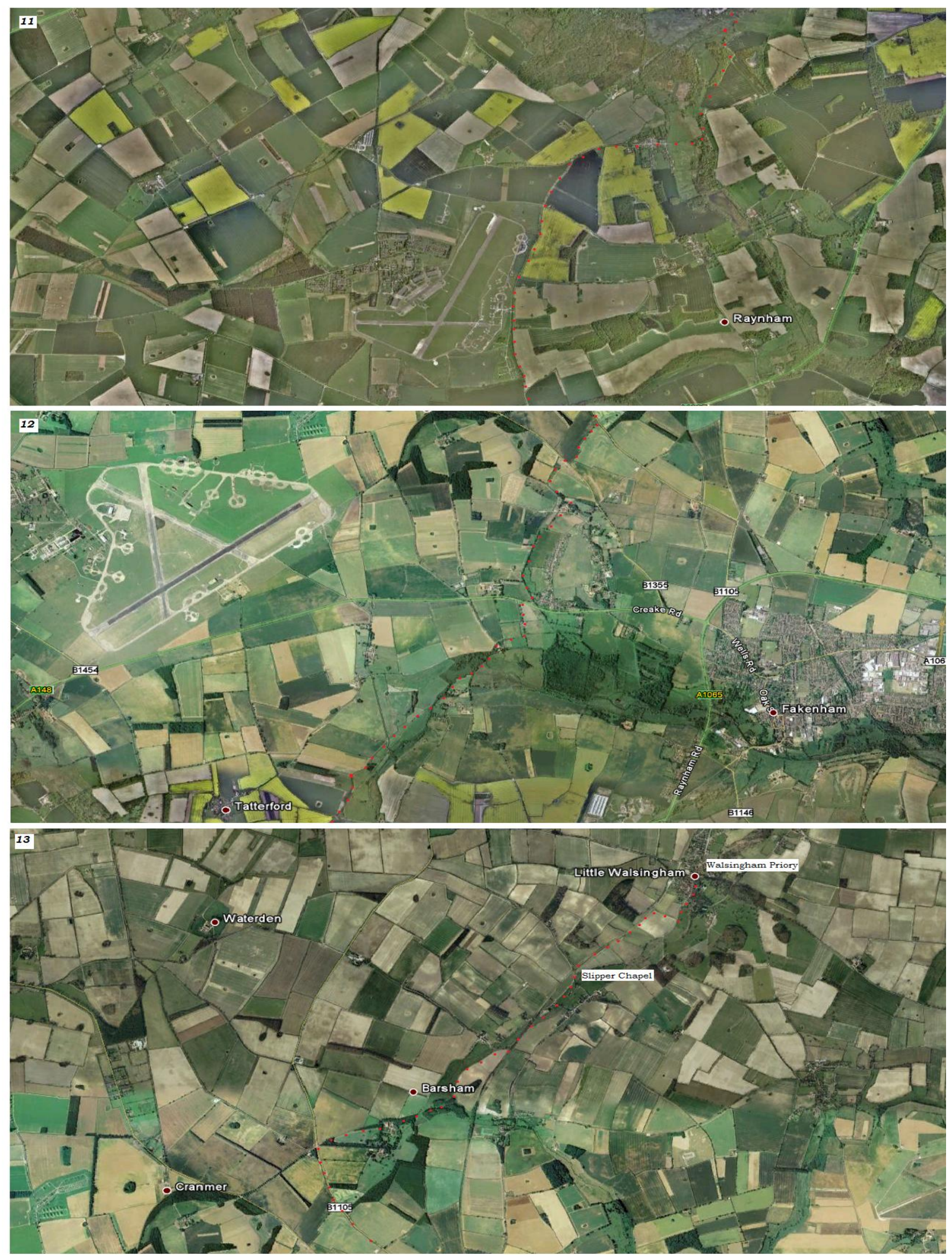




\section{Detailed Map of Route Taken from Salisbury to Winchester:}

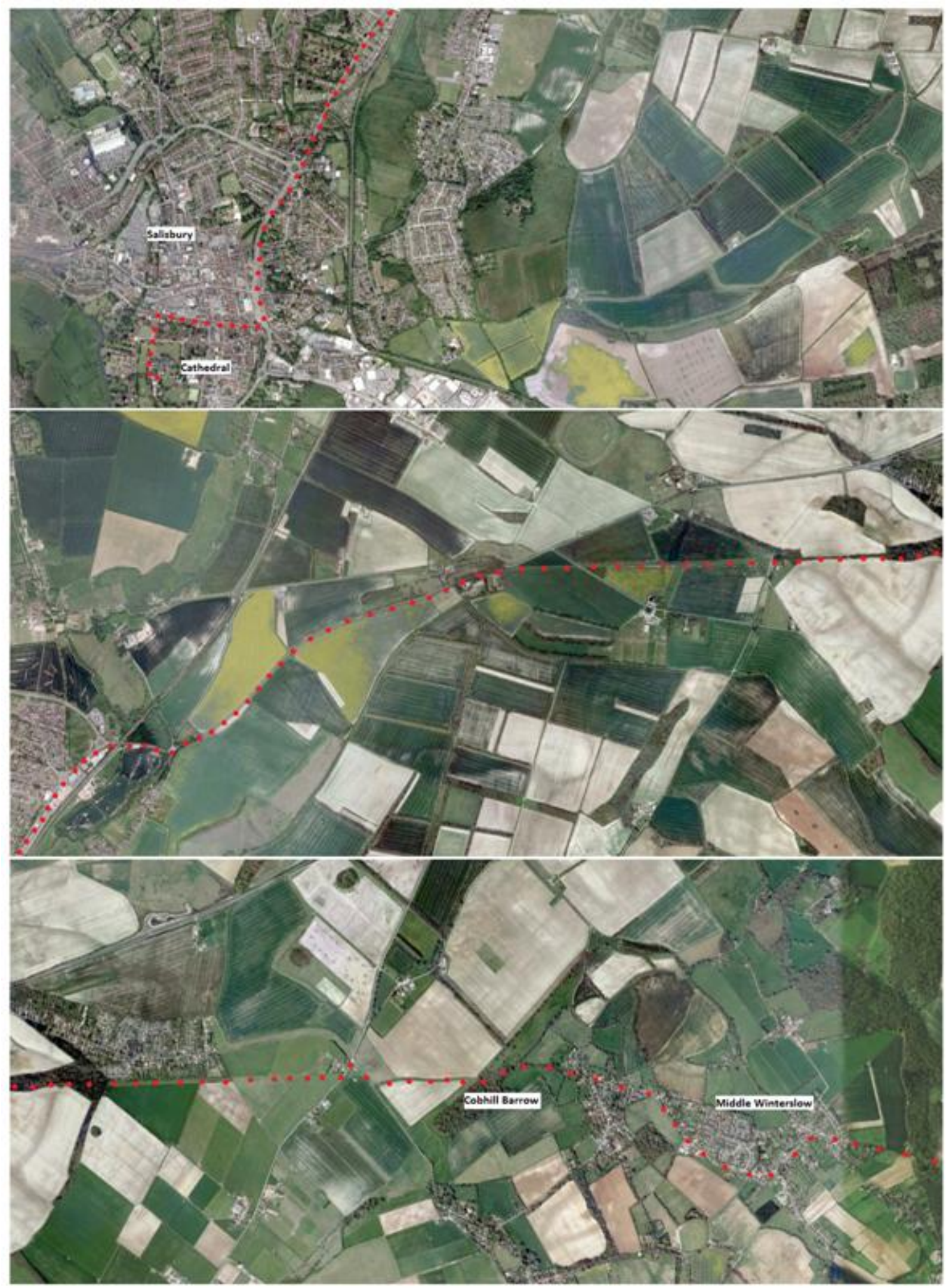



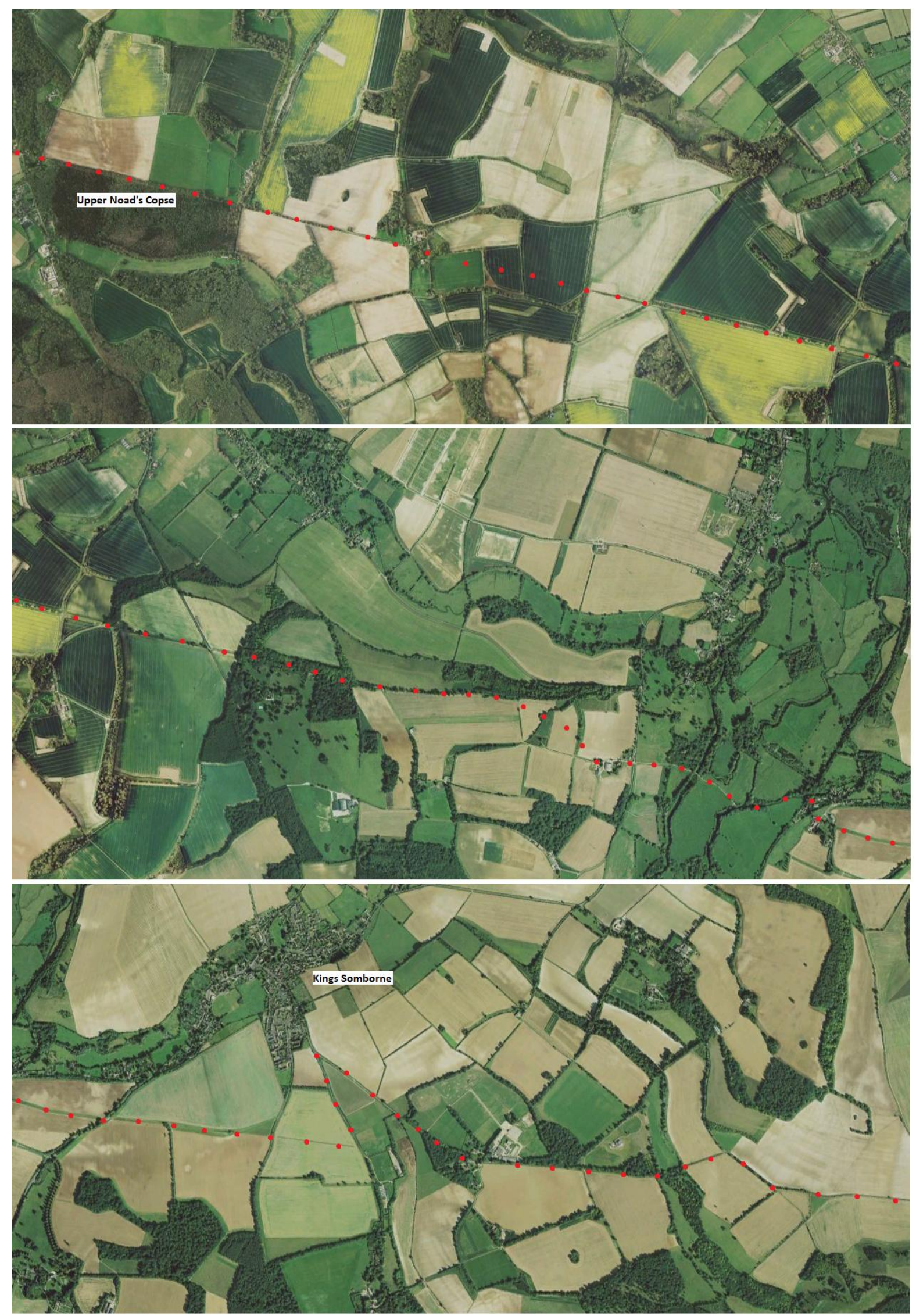


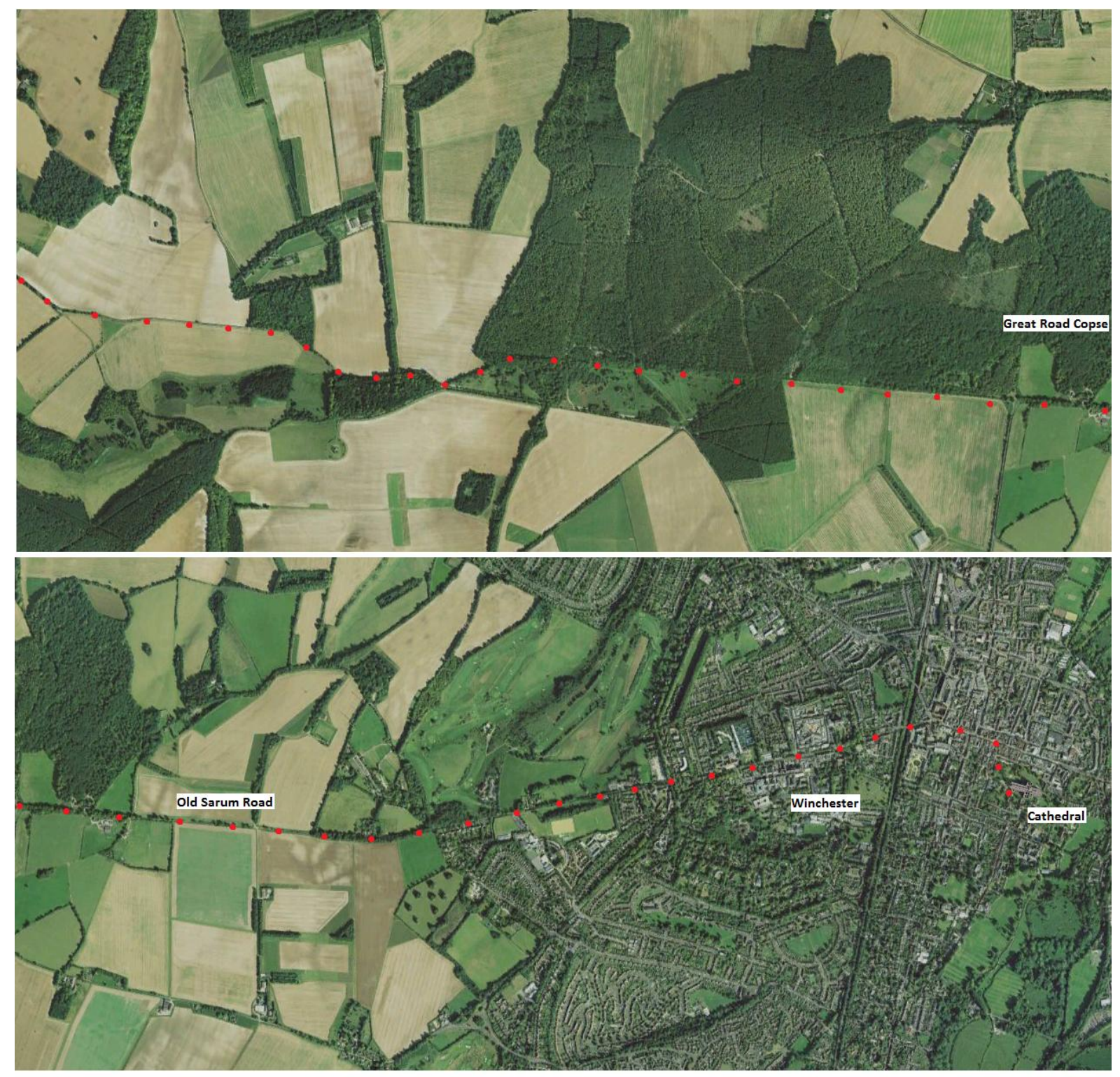




\section{Detailed Map of Route Taken from St Asaph to Holywell:}

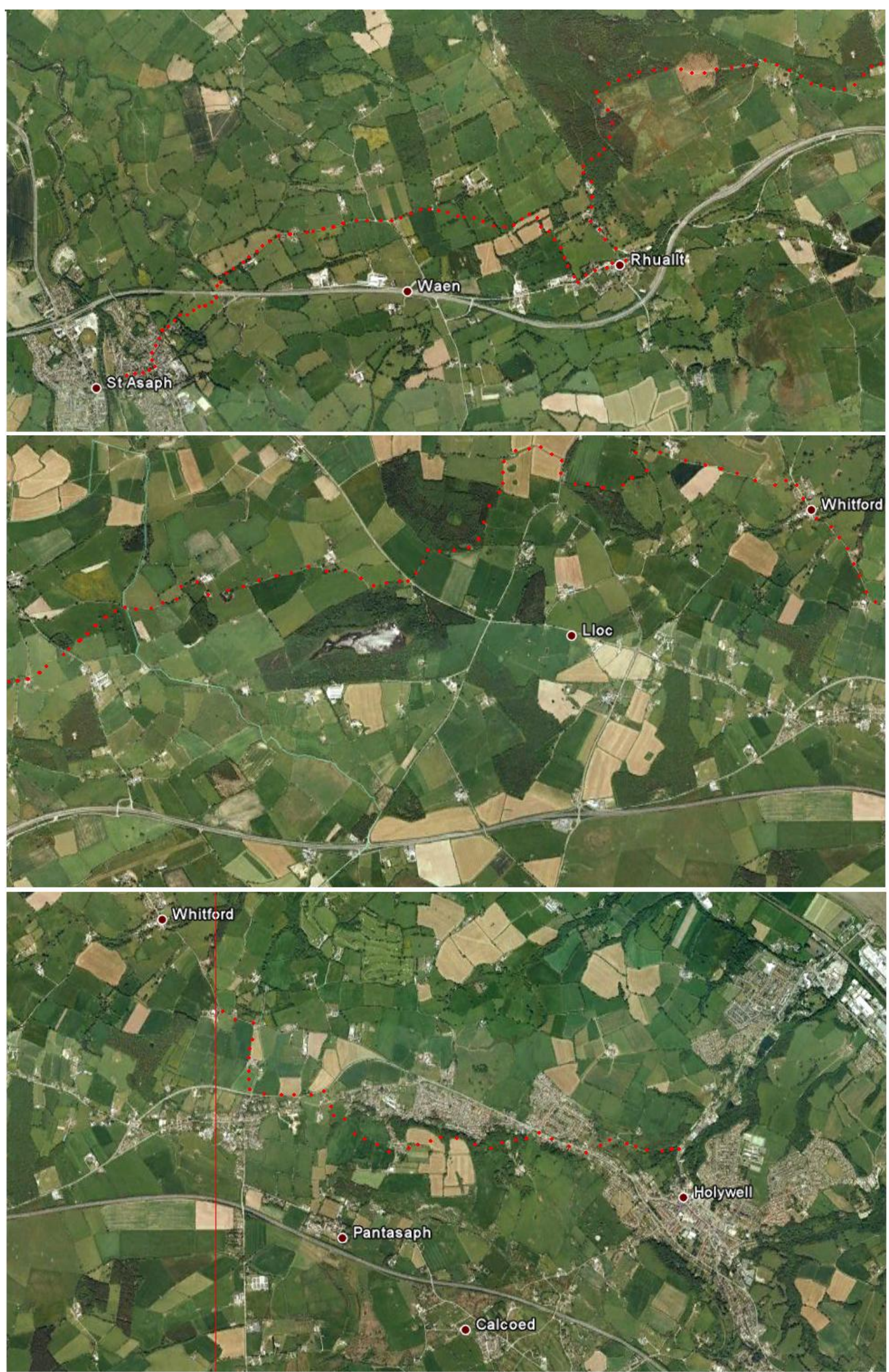




\section{Detailed Map of Route Taken from Camelford to Bodmin:}
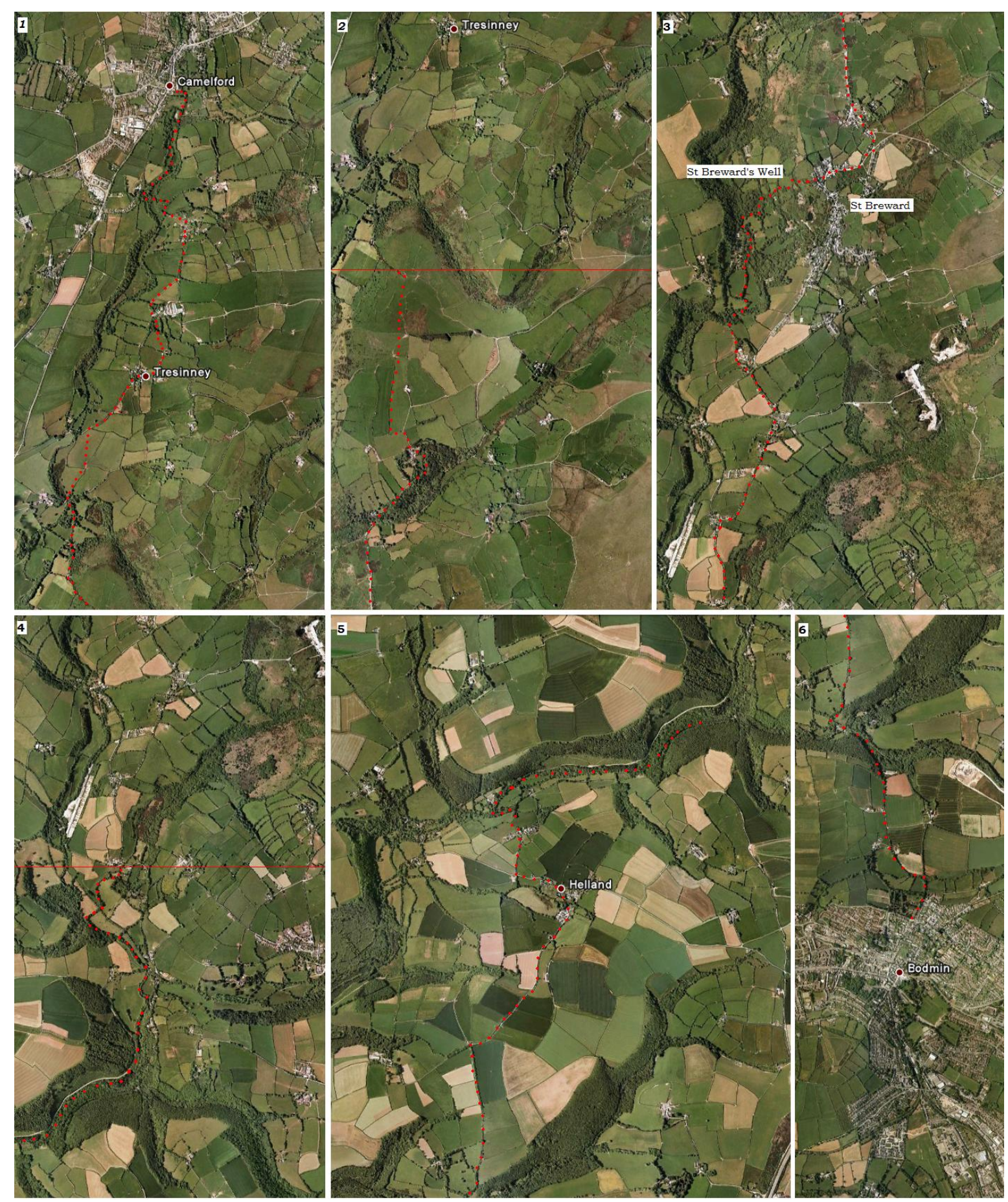


\section{Appendix C}

(All Photos are author's own unless otherwise stated)

Digitised Data Record Sheets for Ely to Walsingham Route:

Date: $15 / 10 / 10$

\section{Record \# 001}

Site/Artefact type: Ely Cathedral

GPS coordinates: \#36 N: $52^{\circ} 23.938 \quad$ E: $000^{\circ} 15.726$

Position related to route: In Ely town centre, next to portico and monastic buildings

Photo/Sketch record number(s): $234-258$

Date of site/artefact (if identifiable): Originally monastery founded in 673. Became cathedral in 1081.

Dedication: Holy and Undivided Trinity, founded by St Æthelthryth(St Ethelreda)

Description of site/artefact (including interior decoration if applicable):

Exterior - Carvings on outside (gargoyles) fashioned from local clunch stone and Purbeck marble. Cruciform plan, with additional transept at Western end. Total length is $537 \mathrm{ft}$, and nave is $250 \mathrm{ft}$, the longest in Britain. Reputed to be one of the seven wonders of the Medieval world. Two towers: the West tower is $215 \mathrm{ft}$ high, and the Octagonal tower is $170 \mathrm{ft}$ high. Many saint carvings have been torn from the building and/or defaced during the Reformation. The Octagonal tower is a later addition, completed in 1340 after the original Norman crossing tower collapsed in 1322.

Interior - The West tower, originally $12^{\text {th }}$ century was extended in the $14^{\text {th }}$ century. On its floor is a Victorian labyrinth, and the wooden interior roof has a $19^{\text {th }}$ century painted scene. The South West transept has Romanesque/Transitional arcading. St Catherine's chapel was completely rebuilt in 1844 after having been destroyed during the Reformation. There remains a Prior's door from the $12^{\text {th }}$ century, with a surviving Norman carving of Christ on its lintel. The Nave is $11^{\text {th }} / 12^{\text {th }}$ century in construction and offers an uninterrupted view to the altar. The South door ('Monks Door') leads to the remains of the cloister. The Octagon 'Lantern' Tower has saint depictions lining the upper octagon or 'lantern', with Christ at its centre. There are also windows in this structure, which light the centre of the cathedral in a particularly affecting way. In the North/South trancepts, parts from the fabric of the cathedral's inception in 1090 survive. The shrine of St Ethelreda who founded the monastery in 673 drew many pilgrims and was consequently destroyed during the Reformation, and there is also a chapel dedicated to St Dunstan and St Ethelwold, the two bishops who re-founded the monastery in 970 . St Edmund's chapel contains a $10^{\text {th }}$ century wall painting depicting his martyrdom, and the enormous Lady Chapel (completed in 1349 and largely ruined by the Reformation forces) was decorated with saint statues, painted walls and stained glass - although none of these remain aside from a patterned fresco behind the altar. 
Surrounding landscape/natural features: South of the cathedral are the meadows, and further $(100 \mathrm{~m})$ is the river Great Ouse.

Visible relation to neighbouring sites/landscape: Adjacent to the cathedral are the monastic buildings, including infirmary sites, and the city of Ely's High Street. The site is on a distinct rise in the landscape, visible for many miles around, and the cathedral is sometimes known as the 'Ship of the Fens' due to its visual prominence in the fenland landscape, similar to Glastonbury Tor's position in what would have been a boggy and waterlogged environment.

Other observations: The name 'Ely' comes from 'Eel-Island'

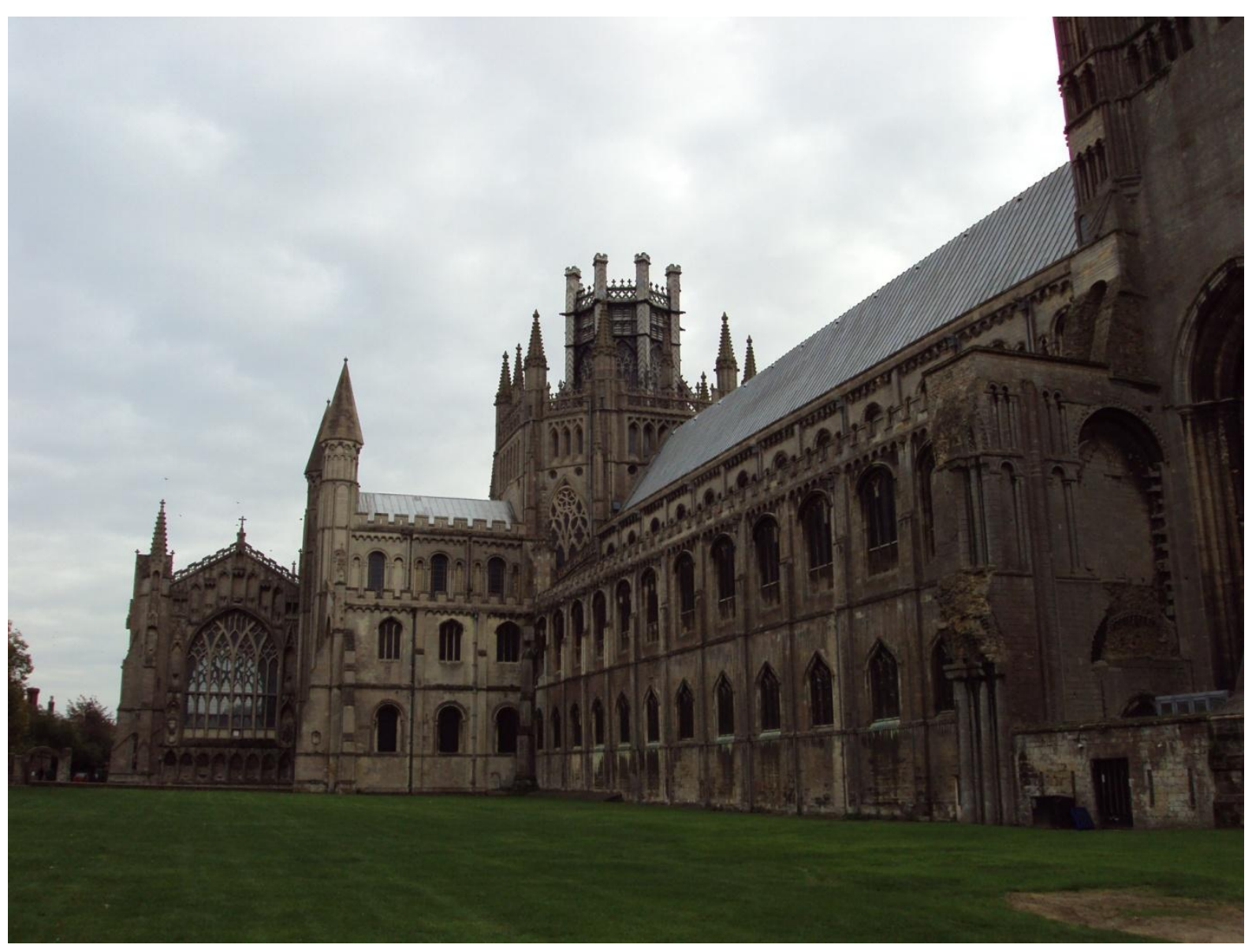


Date: $15 / 10 / 10$

\section{Record \# 002}

Site/Artefact type: Monastic buildings adjacent to Ely Cathedral

GPS coordinates: \#37 N: $52^{\circ} 23.882 \quad$ E: $000^{\circ} 15.863$

Position related to route: $30 \mathrm{ft}$ South of Ely Cathedral

Photo/Sketch record number(s): 259 - 263

Date of site/artefact (if identifiable): $7^{\text {th }}$ century

Dedication: N/A

Description of site/artefact (including interior decoration if applicable): Collection of Romanesque arched monastic buildings which were sacked by Danes in the $9^{\text {th }}$ century, but were re-established in the $10^{\text {th }}$ century by bishops St Dunstan and St Ethelwold who have a chapel dedicated to them in the cathedral. Two features of note with relation to pilgrimage are the surviving names 'Firmary Lane' and 'Black Hostelry', which indicate the potential sites of an hospital and infirmary. The Medieval fabric can be seen in the timbered walls, stone colonnade archways in the walls, roofing tiles and buttress supports.

Surrounding landscape/natural features: As in the case of the cathedral the building complex has meadows to its south, the river Great Ouse and is situated on a rise in the landscape.

Visible relation to neighbouring sites/landscape: Again, these buildings command a view out across the fenland, however given their diminutive size in comparison to the cathedral their visual impact when seen from a distance is minimal.

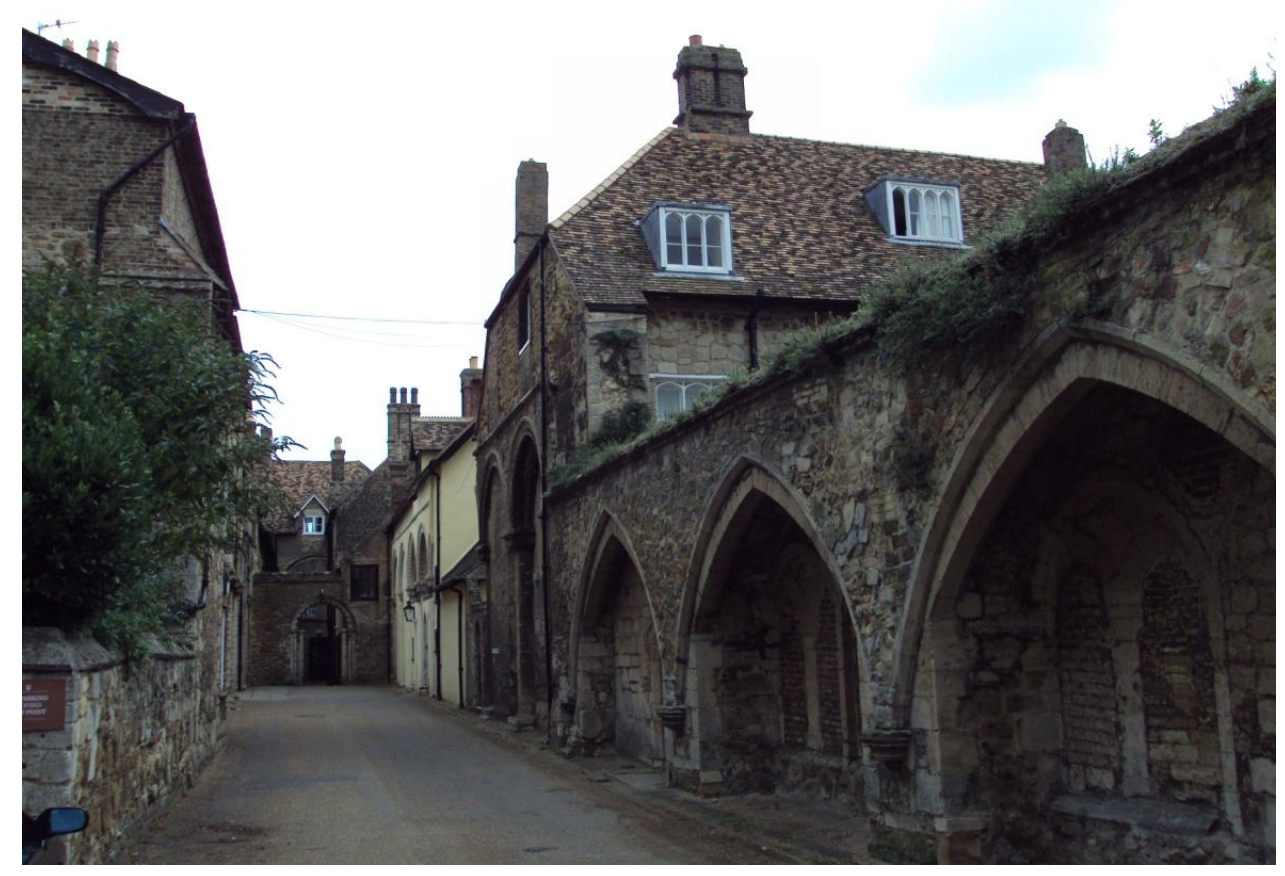


Date: $16 / 10 / 10$

\section{Record \# 003}

Site/Artefact type: River Great Ouse

\section{GPS coordinates: \#38 N: $52^{\circ} 23.882 \quad$ E: $000^{\circ} 16.783$}

Position related to route: Lies at the southerly end of Ely, and accompanies the track out of the village along the route for around a mile.

Point at which visible from the route (GPS):

Surrounding features: Fenland (originally), pasture and flood plain (now) stretching for many miles around. The cathedral is visibile from this point prominently etched against the skyline (north).

Interaction between feature \& pilgrim (slope, shelter, dominance of view etc): The cathedral seems to watch over the pilgrim at this point, as it dominates the northern view. The flat expanses to his/her south and east stretch away and suggest at the length which he/she must travel in the coming days.

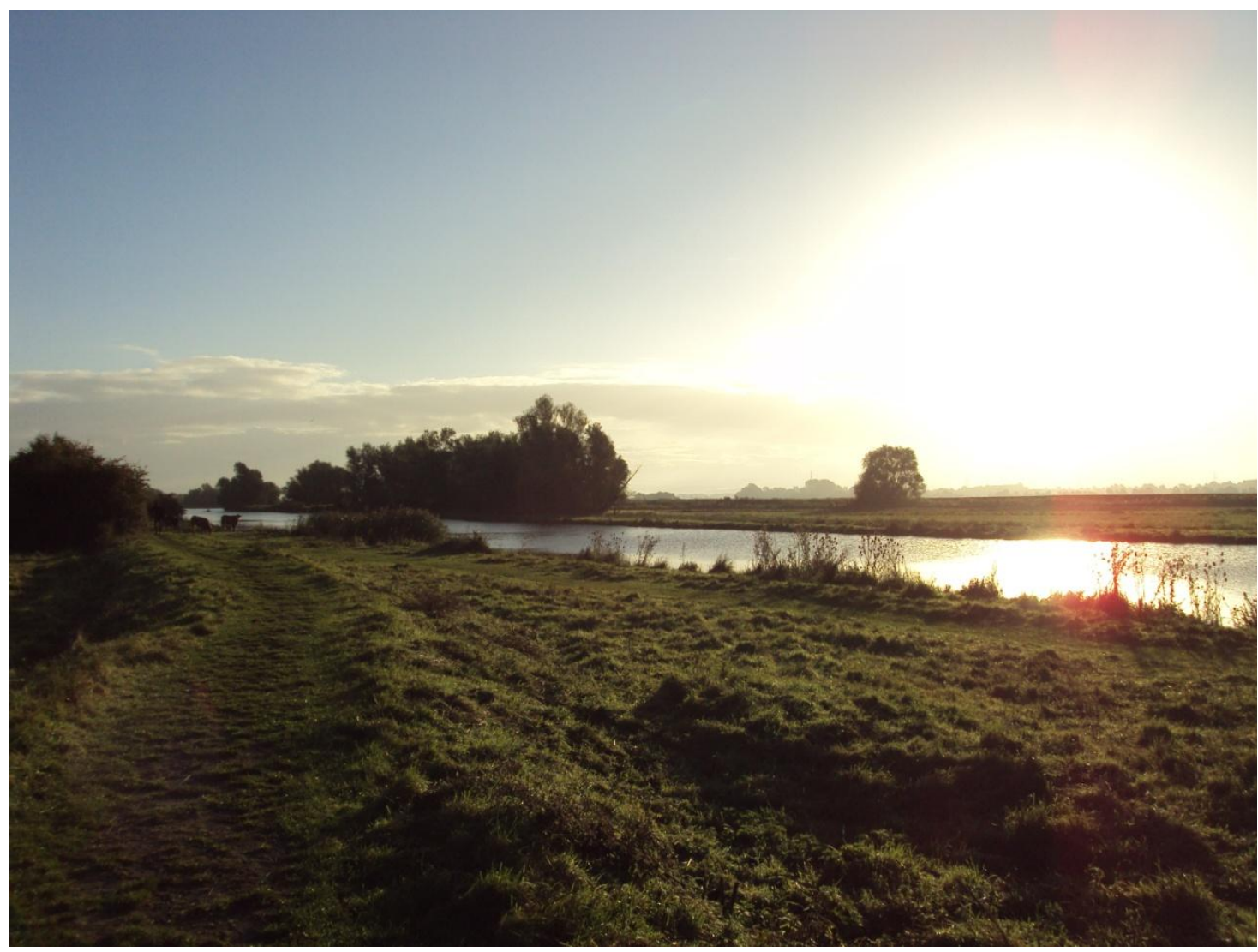


Date: $16 / 10 / 10$

\section{Record \# 004}

Feature: Bridge (Cuckoo) over River Ouse

GPS coordinates: \#39 N: $52^{\circ} 24.018$ E: $000^{\circ} 17.355$

Photo/Sketch record number(s): 69

Position related to route: On route, crossing the River Ouse

Point at which visible from the route (GPS): N: $52^{\circ} 24.018 \quad$ E: $000^{\circ} 17.355$

Surrounding features: Fenland, pasture, factory (now). After crossing the bridge one enters a wooded section.

Interaction between feature \& pilgrim (slope, shelter, dominance of view etc): Possible area of liminal transfer between spaces, crossing over the River Ouse signifying leaving the radius of Ely and entering the 'wilderness'? Crossing water has some significance, both biblical and folkloric, in terms of crossing thresholds, in the same way that entering forests is associated with entering an 'otherworld'.

Other Observations: This area of the river bank/fenland has natural clay pits which were used for brick making, now it is the Rosewell Pits nature reserve.

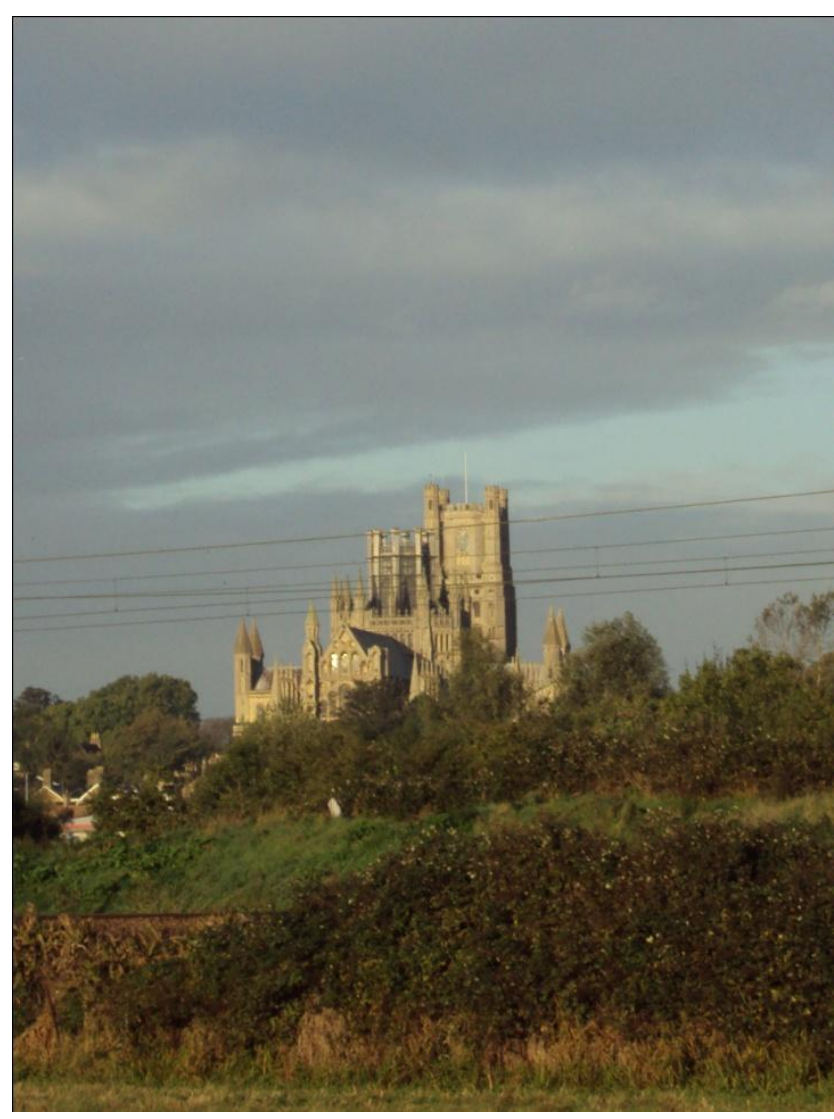

(View from Prickwillow Bridge back towards Ely Cathedral) 
Date: $16 / 10 / 10$

\section{Record\# 005}

Site/Artefact type: Church of St Peter (Prickwillow)

GPS coordinates: \#41 N: $52^{\circ} 25.020 \quad$ E: $000^{\circ} 20.778$

Position related to route: On route as it cuts through Prickwillow

Photo/Sketch record number(s): 272,273

Date of site/artefact (if identifiable): 1868 (possibly built on earlier site)

Dedication: St Peter

Description of site/artefact (including interior decoration if applicable): Small brick and flint structure, cruciform structure in the Early English style. Spire contains a bell dating from 1691 which used to belong to Ely cathedral, and the font is of Italian marble and reputed to have been designed by Sir Christopher Wren.

Surrounding landscape/natural features: Extremely flat fenland/fields, scattering of trees, the River Lark is a few hundred yards away.

Visible relation to neighbouring sites/landscape: Aside from being along the route itself, none discernable.

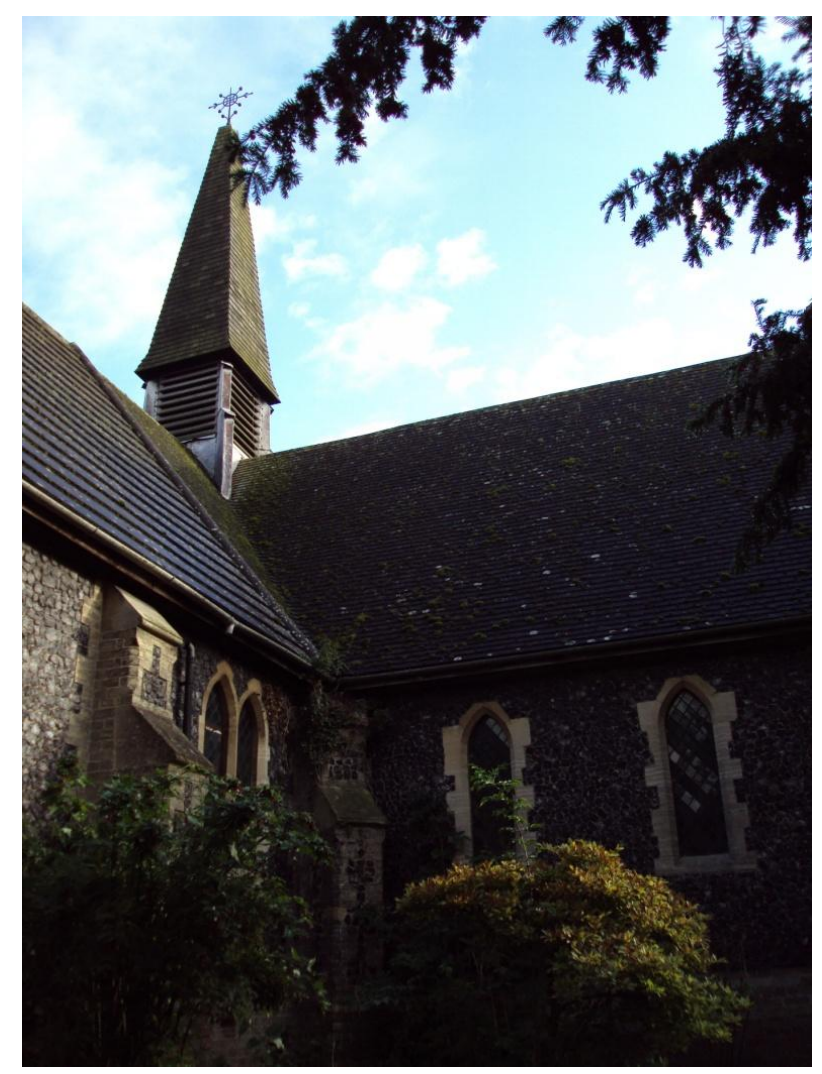


Date: $16 / 10 / 10$

\section{Record \# 006}

Site/Artefact type: The Hereward Way

GPS coordinates: \#40 N: $52^{\circ} 23.968 \quad$ E: $000^{\circ} 17.678$

Position related to route: The route follows this Long Distance Footpath for a few miles at various points between Ely and Sedge Fen.

Photo/Sketch record number(s): 270, 271

Date of site/artefact (if identifiable): $\quad$ Possible $11^{\text {th }}$ century

Dedication: Takes its name from Hereward the Wake, an $11^{\text {th }}$ century leader who fought against William the Conqueror and had his base on the Isle of Ely.

Description of site/artefact (including interior decoration if applicable): Tarmac road (now) set around a foot up from the surrounding landscape.

Surrounding landscape/natural features: To either side of the track is a vast expanse of fen and field, which would no doubt have been boggy and waterlogged for a great deal of the year before the fens were drained in the late $18^{\text {th }}$ and early $19^{\text {th }}$ century.

Visible relation to neighbouring sites/landscape: The Hereward Way links two other paths of antiquity; the Peddars Way and the Viking Way. It runs from Stamford to Brandon, passing through Peterborough, March and Ely, as well as Thetford Forest. Ely cathedral is still visible from this recorded point.

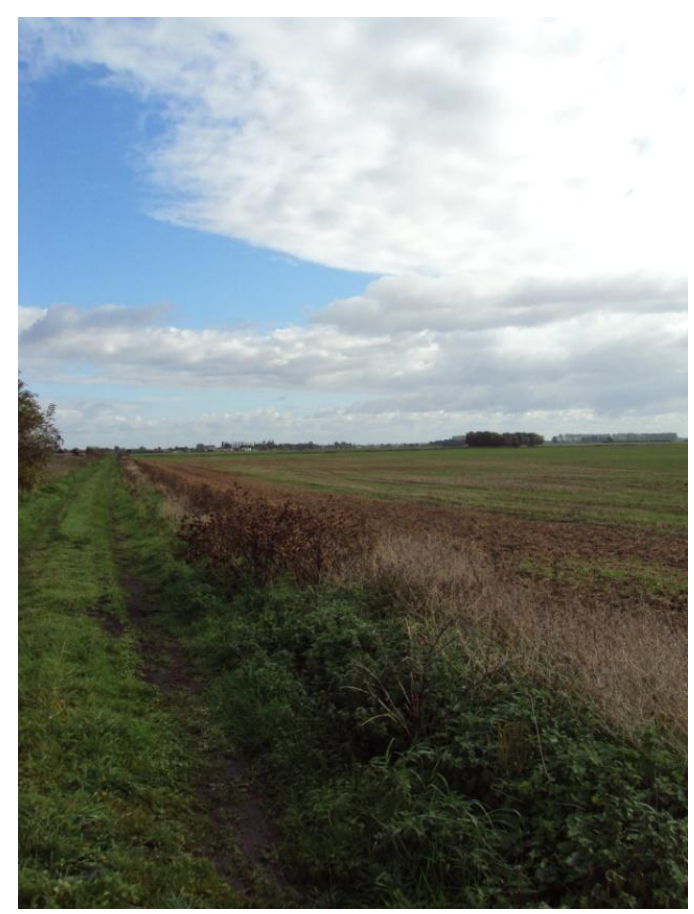


Date: $16 / 10 / 10$

\section{Record \# 007}

Feature: Trackway across farmland (originally fenland)

GPS coordinates: \#42: $\quad \mathrm{N}: 52^{\circ} 25.974 \quad$ E: $000^{\circ} 25.989$

Photo/Sketch record number(s): 276, 277

Position related to route: The route itself across this stretch of countryside.

Point at which visible from the route (GPS):

Surrounding features: Farmland, small wooded windbreaks.

Interaction between feature \& pilgrim (slope, shelter, dominance of view etc): Pilgrim is almost guaranteed solitude along this stretch, it being removed from any settlement. Highly exposed to weather due to flat topography in all directions, without shelter. Consequently the pilgrim could feel very small/humbled by the vastness of the scenery around him/her, and also vulnerable. At God's mercy?

Other Observations: Track is raised slightly from surrounding environment.

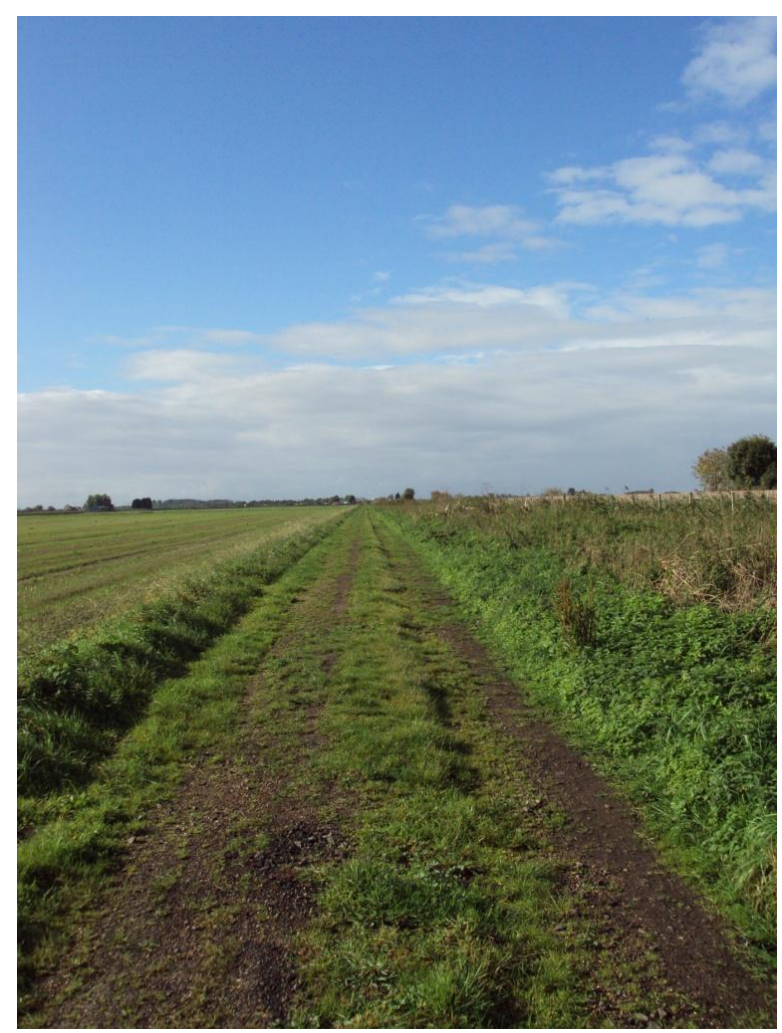


Date: $16 / 10 / 10$

\section{Record \# 008}

Feature: Raised Dyke trackway

GPS coordinates: \#43: N: $52^{\circ} 26.640 \quad$ E: $000^{\circ} 27.963$

Photo/Sketch record number(s): $278-282$

Position related to route: Trackway takes the pilgrim to Hockwold cum Wilton village, around the banks of the Little Ouse river.

Point at which visible from the route (GPS):

Surrounding features: Marshland/wetlands filled with reeds which gives way to the river (Little Ouse) and its banks and floodplain, which the dyke tracks alongside for over three miles. Cows graze here, and there are many birds including herons.

Interaction between feature \& pilgrim (slope, shelter, dominance of view etc): The pilgrim is the on the highest point in the landscape for many miles around (aside from the trees). This would have given him/her a dominant view of the landscape, and also perhaps given a feeling of detachment or 'aboveness' from the world - travelling over the landscape instead of through it. More practically it would also leave one exposed to the weather. As one walks this dyke, it is very easy to fall into contemplating the journey itself, induced by the distance one can see ahead and behind and the visual obviousness of the path/dyke.

Other Observations: The marshland and wetlands are probably the closest comparison as to what the majority of this landscape would have looked like during the Medieval period (as in prior to the draining of the fens). This would suggest that a number of tracks would have been based around ridges or artificially raised on banks to escape the waters and sodden ground, adding an extra level of detachment from the 'normal' world for the pilgrim, in that they travelled over the inaccessible fenland on special tracks, which would have lent a mysterious air to the experience - i.e. one cannot explore the surrounding environment, only observe from a distance. Mists would also have been a factor no doubt, enhancing the unworldly aspect of the experience. 

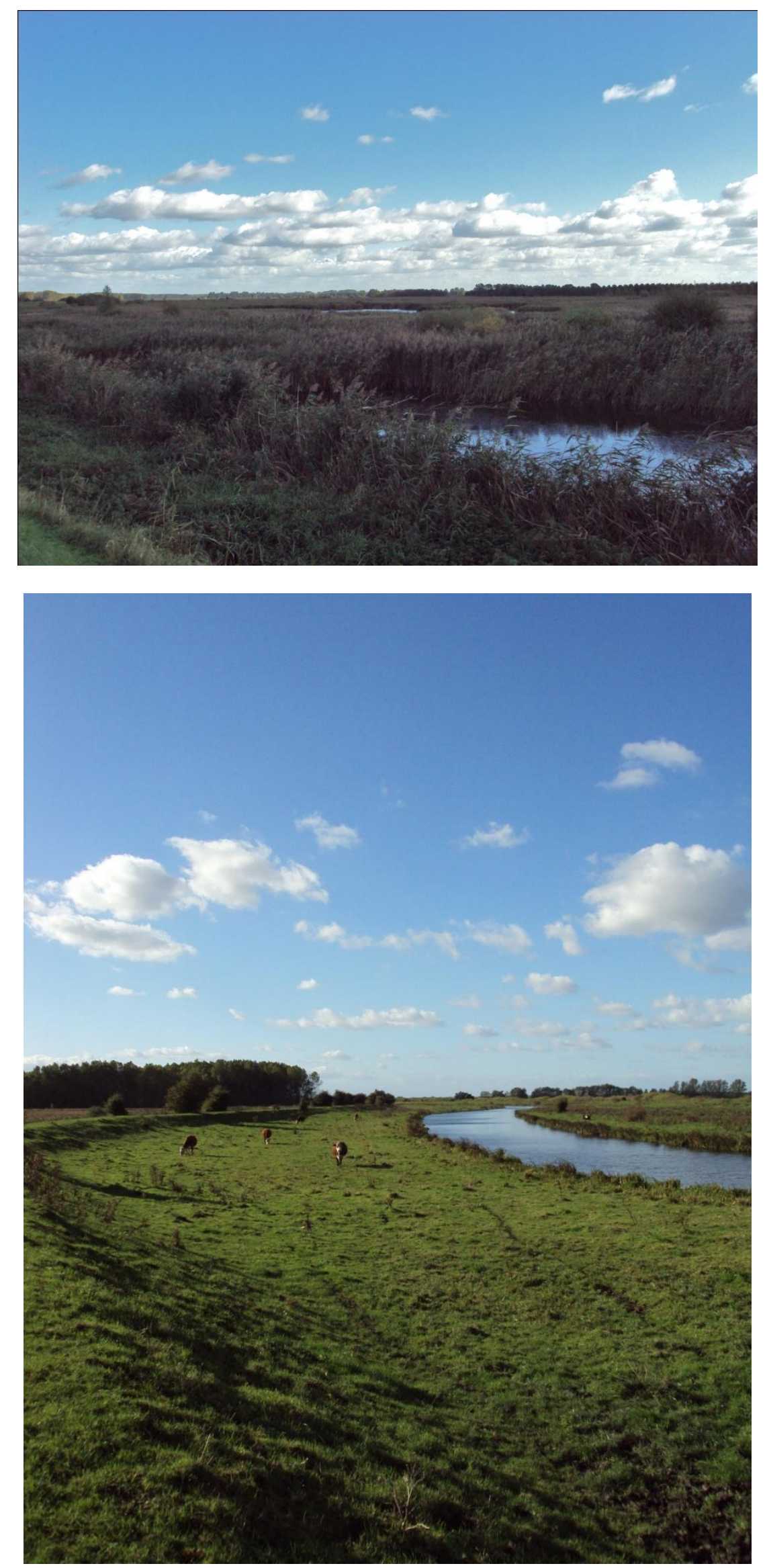
Date: $16 / 10 / 10$

\section{Record \# 009 Norfolk HER Number: 5470}

Site/Artefact type: Church of St James (Hockwold cum Wilton)
GPS coordinates: \#44
$\mathrm{N}: 52^{\circ} 27.723$
E: $000^{\circ} 33.116$

Position related to route: In Church Lane as one enters Hockwold village

Photo/Sketch record number(s): 283

Date of site/artefact (if identifiable): $14^{\text {th }}$ century

Dedication: St James

Description of site/artefact (including interior decoration if applicable): Square tower, flint faced, gothic arch over porch. Interior has richly carved woodwork apparently, but locked on my visit.

Surrounding landscape/natural features: The dyke, river, fields and pastureland.

Visible relation to neighbouring sites/landscape: At entrance to village from the fields. Near the Medieval pilgrim cross which is in the village green at the centre of the settlement, next to the Red Lion Inn.

Other observations: Does the dedication to St James indicate pilgrim presence relating to Walsingham here? Coupled with the Pilgrim cross it seems likely.

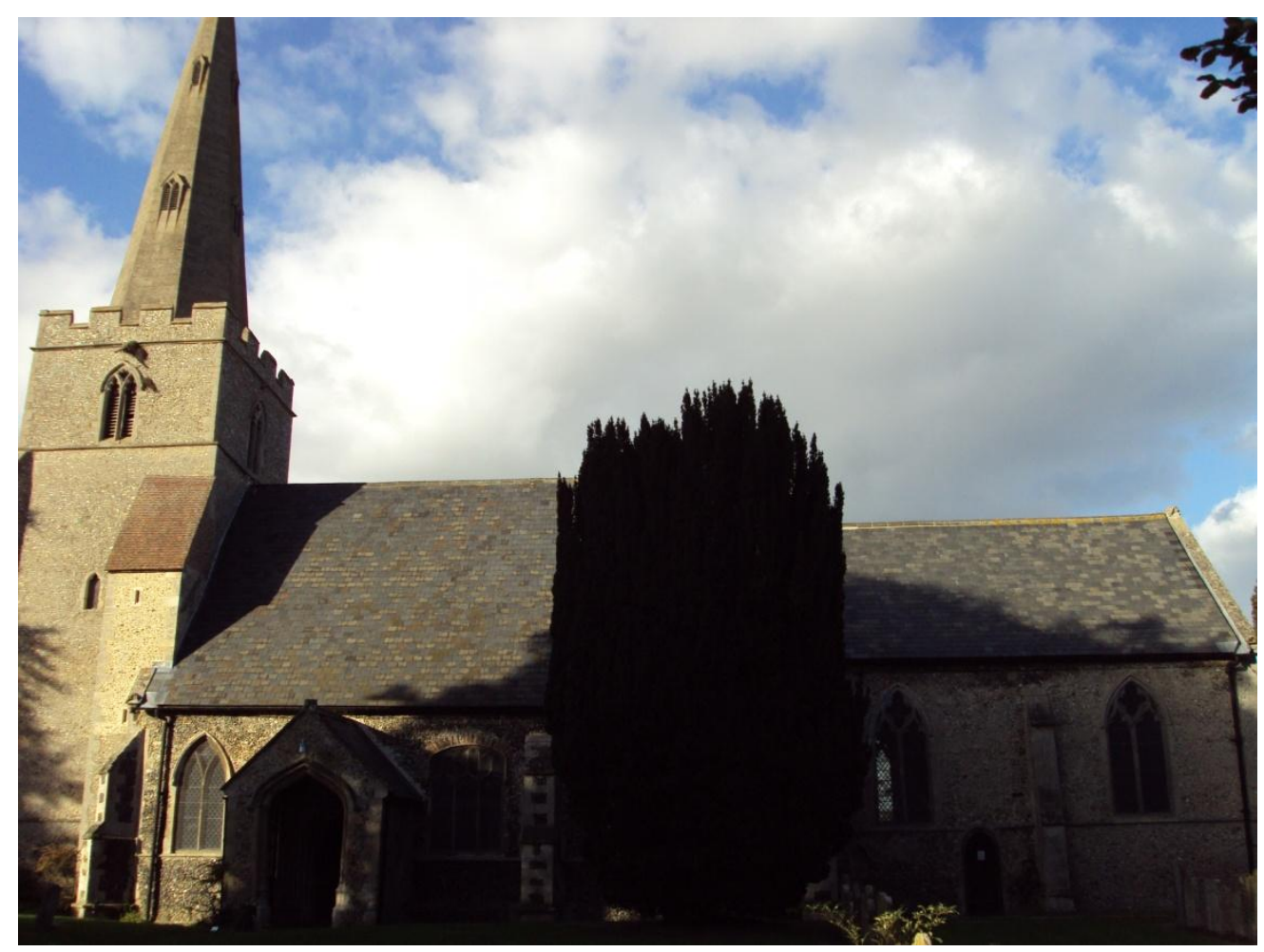


Date: $16 / 10 / 10$

Record \# 010 Norfolk HER Number: 5411

Site/Artefact type: 'Pilgrim' Cross

GPS coordinates: \#45 N: $52^{\circ} 27.792 \quad$ E: $000^{\circ} 33.170$

Position related to route: In 'village green' adjacent to the Red Lion Inn. Stone's throw from Church of St James.

Photo/Sketch record number(s): 285, 286.

Date of site/artefact (if identifiable): $13^{\text {th }}$ century.

Dedication: No recorded dedication or inscription on artefact.

Description of site/artefact (including interior decoration if applicable): Simple stone cross mounted on circular stone plinth. Cross shaft has vertical grooves, and the cross head has a coronet design.

Surrounding landscape/natural features: Fields and fenland.

Visible relation to neighbouring sites/landscape: Very close to St James' church, and on the route through the town on to Brandon.

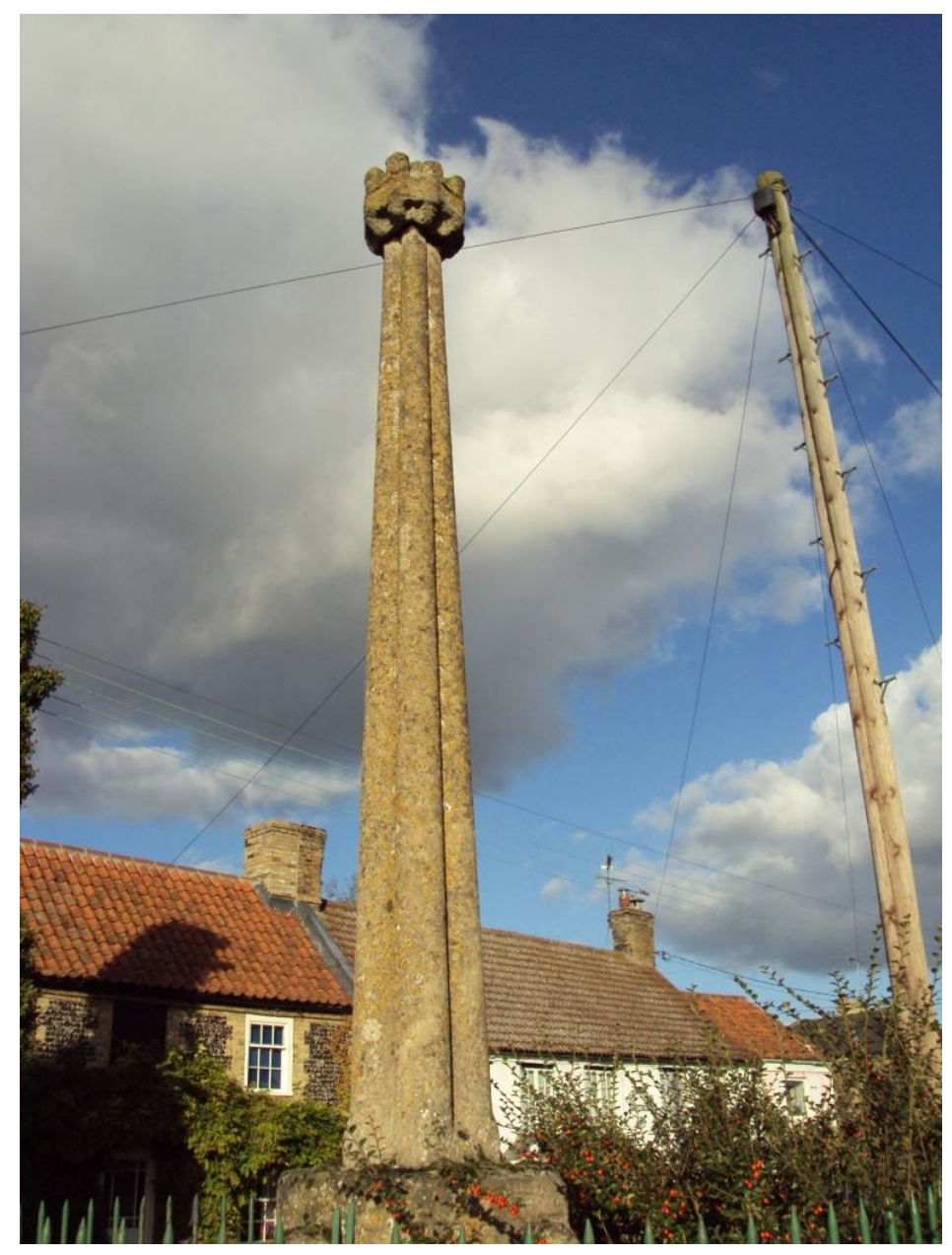


Date: $17 / 10 / 10$

Record \# 011 Norfolk HER Number: 5626

Site/Artefact type: Weeting Castle (ruins)

GPS coordinates: \#46 N: $52^{\circ} 28.276 \quad$ E: $000^{\circ} 36.939$

Position related to route: 50 metres from route and church of St Mary

Photo/Sketch record number(s): $701-703$

Date of site/artefact (if identifiable): 1130

Dedication: N/A

Description of site/artefact (including interior decoration if applicable: Built by Hugh de Plais in 1130 's, originally as a manor house. In the $13^{\text {th }}$ century a kitchen and moat were added to the complex, however the building passed to the Earls of Norfolk and was abandoned in the $14^{\text {th }}$ century, with much of its stone has been robbed for local building material. It was incorporated into the grounds of the now demolished Weeting Hall as an ornamental garden feature. The castle was never actually fortified, with moat designed to display the wealth and status of the de Plais family. The site has a long history of use, from the $10^{\text {th }}$ century until the late $18^{\text {th }}$ century. Archaeological excavations at the far end of the hall have uncovered ditches, burnt daub, post-holes and pottery dating to the Saxon period, suggesting that there was a settlement here prior to the building of the castle.

Surrounding landscape/natural features: Fields, Thetford Forest and pastureland.

Visible relation to neighbouring sites/landscape: The village is visible from this site, being only 50 metres away, and the site would have had an imposing presence amongst the peasantry, reminding them that their feudal lord was ever present. The relevance of the site to the pilgrim is unclear, perhaps reminding them of social hierarchy? However, this may be linked to the temporary 'outsider' status a pilgrim was granted during the journey, allowing them to interact with others usually outside their social standing?
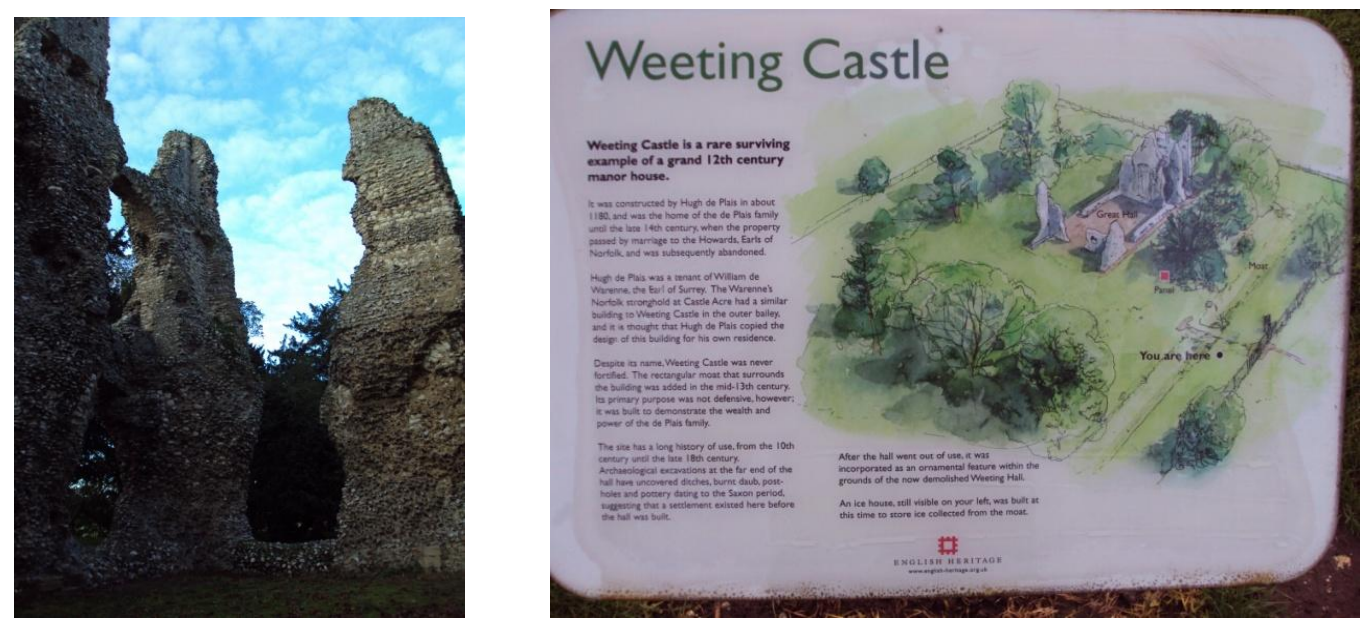
Date: $17 / 10 / 10$

\section{Record \# 012 Norfolk HER Number 5639}

Site/Artefact type: Church of St Mary
GPS coordinates: \#47
$\mathrm{N}: 52^{\circ} 28.290$
$E: 000^{\circ} 36.864$

Position related to route: On route out of Weeting village.

Photo/Sketch record number(s): $290-295$

Date of site/artefact (if identifiable): $\quad$ Medieval (no firm date)

Dedication: St Mary

Description of site/artefact (including interior decoration if applicable): Round tower (rebuilt 1868), timbered porch, $14^{\text {th }}$ century pews (with green man carvings $\times 2$ ), 3 French gothic windows.

Surrounding landscape/natural features: Pasture, fields and Thetford Forest.

Visible relation to neighbouring sites/landscape: Weeting Castle is visible, as is the village (adjacent).

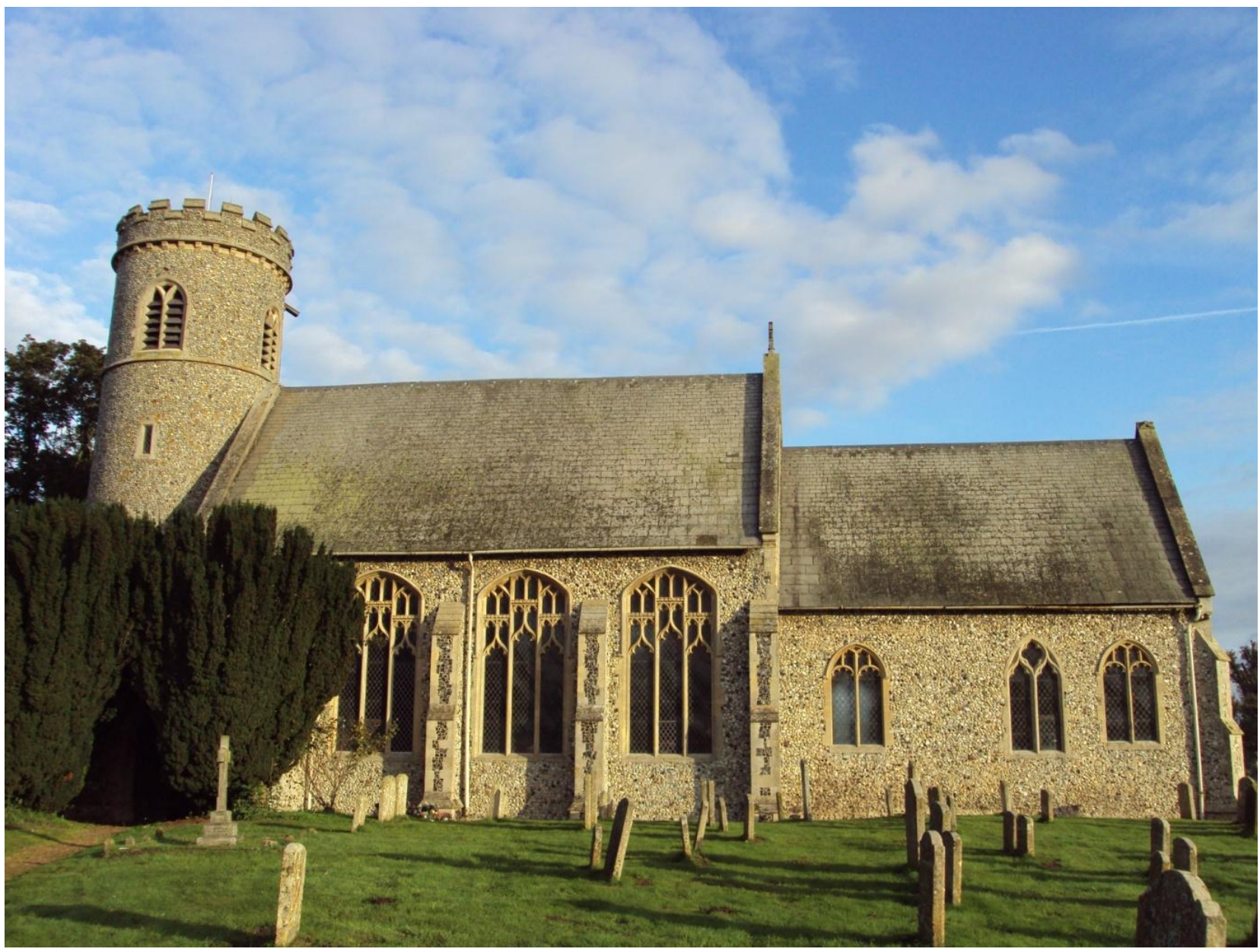


Date: $17 / 10 / 10$

\section{Record \# 013}

Feature: Thetford Forest (route section known locally as the Pilgrim's Walk)
GPS coordinates: \#48
$\mathrm{N}: 52^{\circ} 28.890$
E: $000^{\circ} 36.819$

Photo/Sketch record number(s): 296

Position related to route: Surrounds route for around 2 miles

Point at which visible from the route (GPS):

Surrounding features: Fir/Oak/Bramble, fields prior to woodland proper. Apparently a stump cross in the woodland but I was unable to locate it amongst the foliage.

Interaction between feature \& pilgrim (slope, shelter, dominance of view etc): Coming from very open and flat land into the forest is another potential transitional space - limnal areas? Forests long associated with otherworldly happenings, not necessarily malign - alleged stump cross intended for directional guidance or spiritual protection (or both)? At basic level the forest also offers protection from the weather, a rare feature in this landscape, and encloses the pilgrim - thereby shutting one off even further from the outside world.

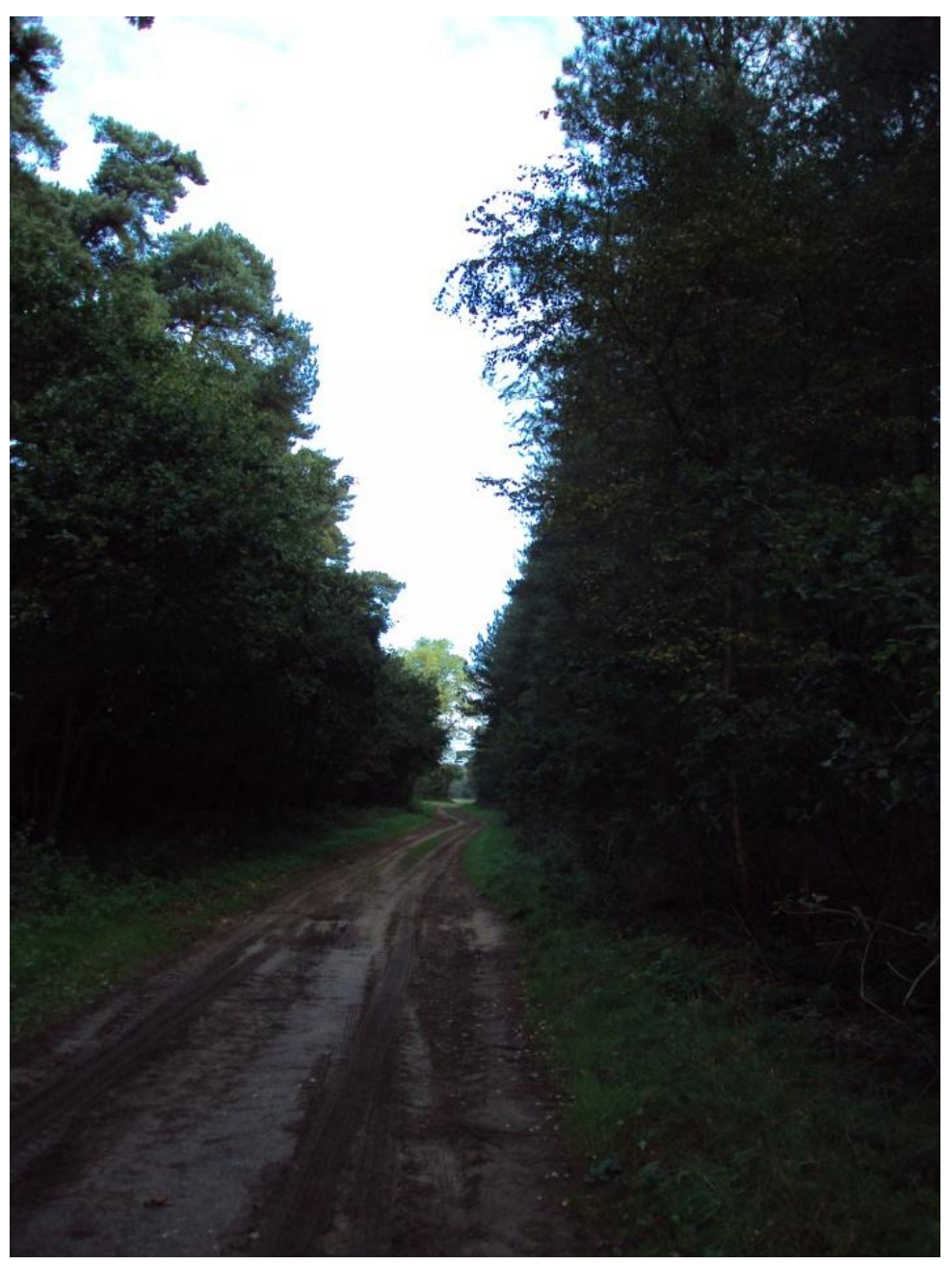


Date: $17 / 10 / 10$

\section{Record \# $014 \quad$ Norfolk HER Number 4976}

Site/Artefact type: Church of St Mary
GPS coordinates: \#49
$\mathrm{N}: 52^{\circ} 31.339$
E: $000^{\circ} 37.581$

Position related to route: $100 \mathrm{~m}$ east of Cranwich Village

Photo/Sketch record number(s): $300-302$

Date of site/artefact (if identifiable): Tower dates from 700 AD.

Dedication: St Mary

Description of site/artefact (including interior decoration if applicable): Round Saxon tower, flint faced walls, thatched roof and an unusual circular graveyard. The tower is one of the oldest in East Anglia, ringed with carstone, and punctuated with sound holes with knotted tracework. The nave is Norman, and the chancel is slightly newer.

Surrounding landscape/natural features: Almost hidden inside a grove filled with what appear to be quite ancient trees (oak).

Visible relation to neighbouring sites/landscape: Top of tower is visible from the track leading down out of Thetford Forest, and presumably due to the sound holes in the tower, the bells are also audible from that distance or greater.

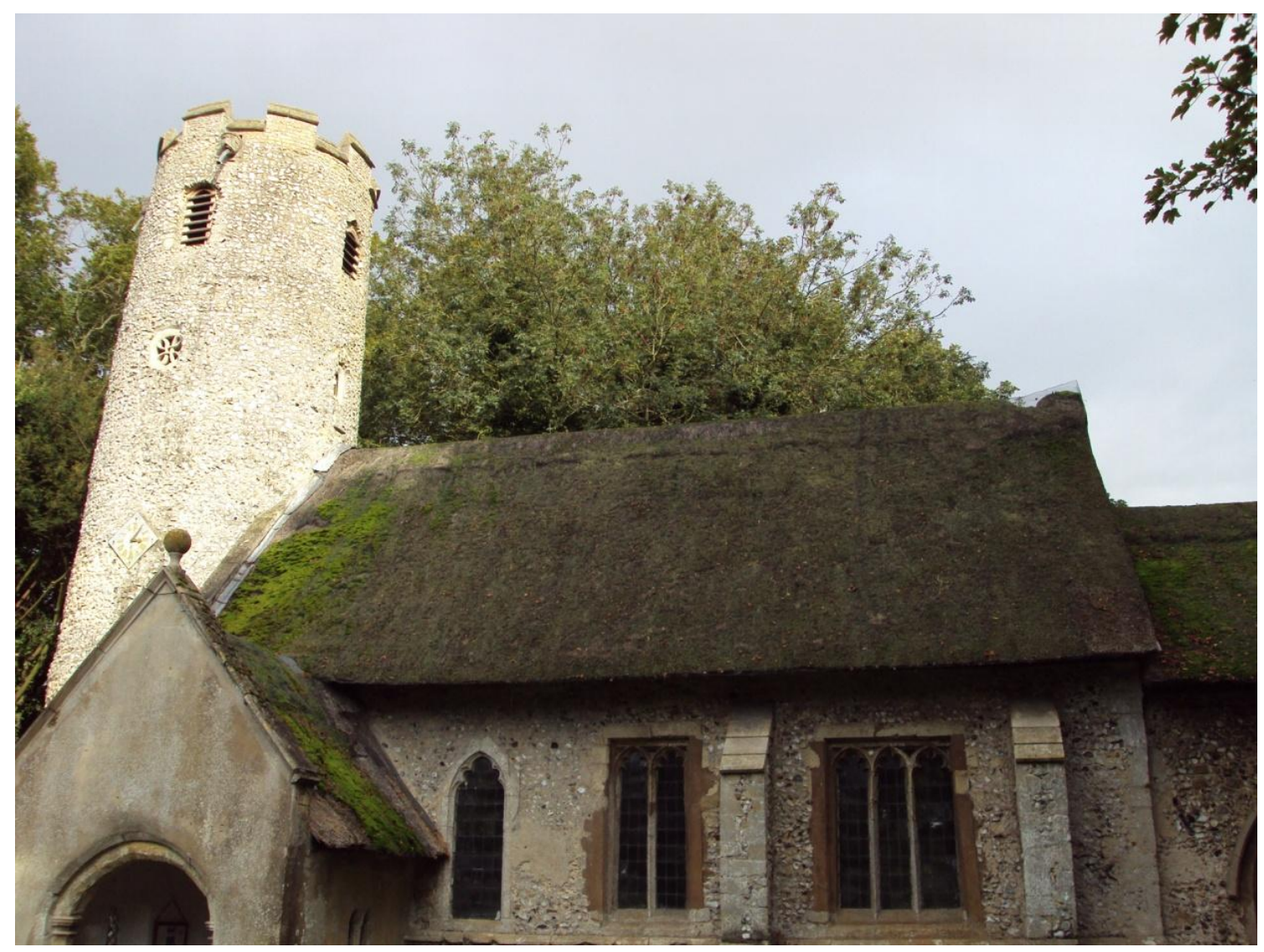


Date: $17 / 10 / 10$

\section{Record \# $015 \quad$ Norfolk HER Number 4592}

\section{Site/Artefact type: Church of All Saints (Cockley Cley)}
GPS coordinates: \#50
$\mathrm{N}: 52^{\circ} 36.349$
E: $000^{\circ} 38.667$

Position related to route: Just off route through Cockley Cley

Photo/Sketch record number(s): $303-308$

Date of site/artefact (if identifiable): $14^{\text {th }}$ century

Dedication: All Saints

Description of site/artefact (including interior decoration if applicable): Chancel, aisles and round tower were built in the early $14^{\text {th }}$ century, with the tower being possible built on pre-existing foundations given its shape. In the doorway one can see carved heads with pointed ears. There were apparently two other churches in the village; St Mary's, which originated possibly in the $7^{\text {th }}$ century and was later converted into a rectory c.1550 and subsequently into a cottage, and St Peter's, which was near the Old Hall and accidentally burnt down during the reign of Elizabeth I, never to be rebuilt.

Surrounding landscape/natural features: Small river, meadows, fields. Situated in a depression in the landscape.

Visible relation to neighbouring sites/landscape: Visible from the road as it winds down into the town. Church and village nestle in the bottom of the landscape, almost hidden from view.

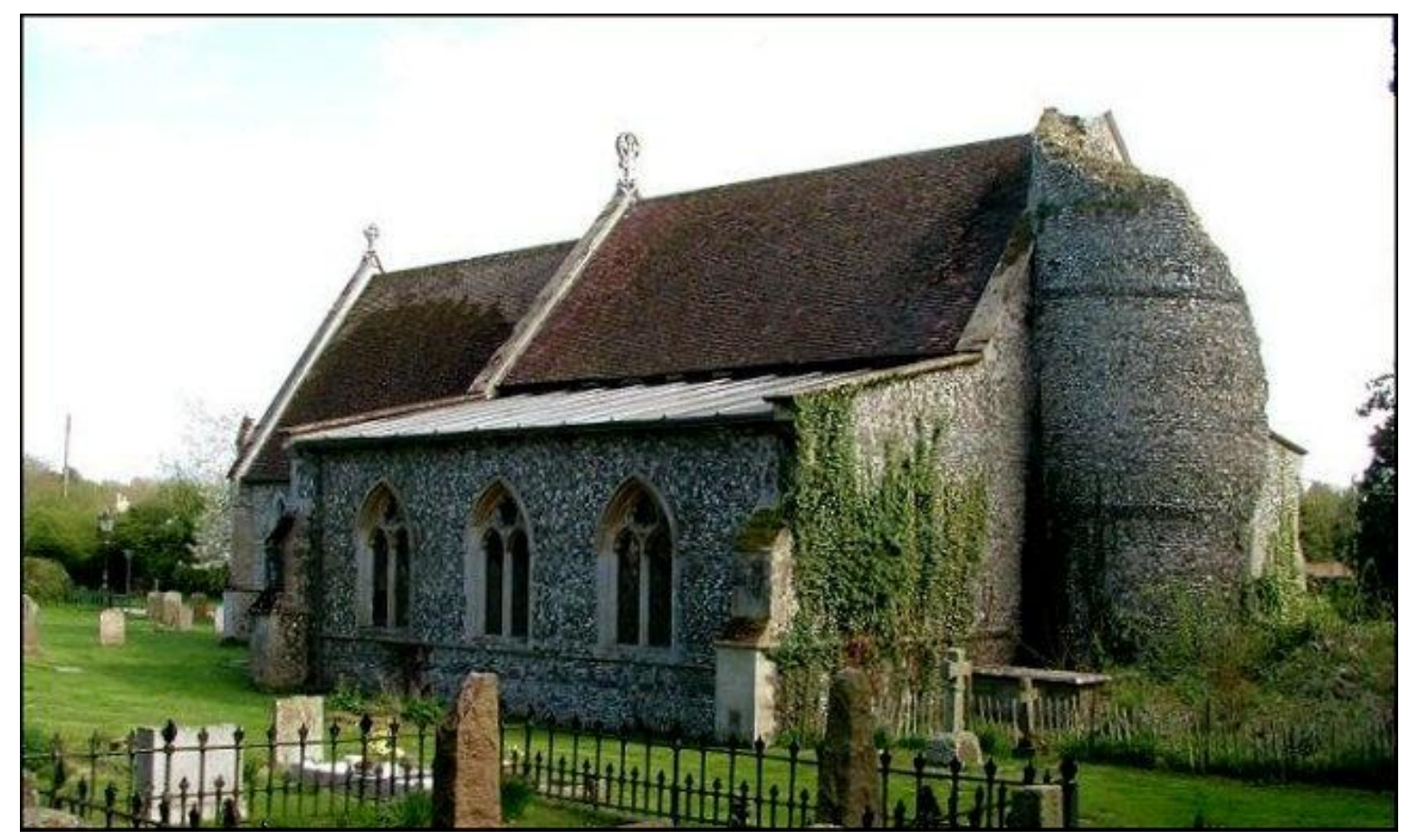

(image reproduced from: http://www.norfolkchurches.co.uk/cockleycley/cockleycley.htm) 
Date: $17 / 10 / 10$

\section{Record \# 016 Norfolk HER Number 2698}

Site/Artefact type: Church of St Peter \& St Paul (Swaffham)

GPS coordinates: \#51 N: $52^{\circ} 38.893 \quad$ E: $000^{\circ} 41.358$

Position related to route: Just off Market Square, Swaffham. Centre of town.

Photo/Sketch record number(s): $309-316$

Date of site/artefact (if identifiable): $15^{\text {th }}$ century

Dedication: St Peter \& St Paul

Description of site/artefact (including interior decoration if applicable): The large square tower was constructed in the $16^{\text {th }}$ century from Barnack stone, and is decorated around its base with large wheels inscribed with the crossed keys of St Peter, the crossed swords of St Paul, shields with various crests and even a swastika motif. It is probable given this amount of ornament that the base would have been painted. The rest of the exterior is unremarkable, but it is the interior which is of note (unfortunately this was locked in my visit). Apparently the nave has a very fine late-medieval wooden angel-roof carved from chestnut. The upper lights in the north aisle are filled with $15^{\text {th }}$ century glass depicting angels and donors to the church.

Surrounding landscape/natural features: Mostly urban, but there are a few fields to the south of the church.

Visible relation to neighbouring sites/landscape: Near the $17^{\text {th }}$ century market cross in the town centre.

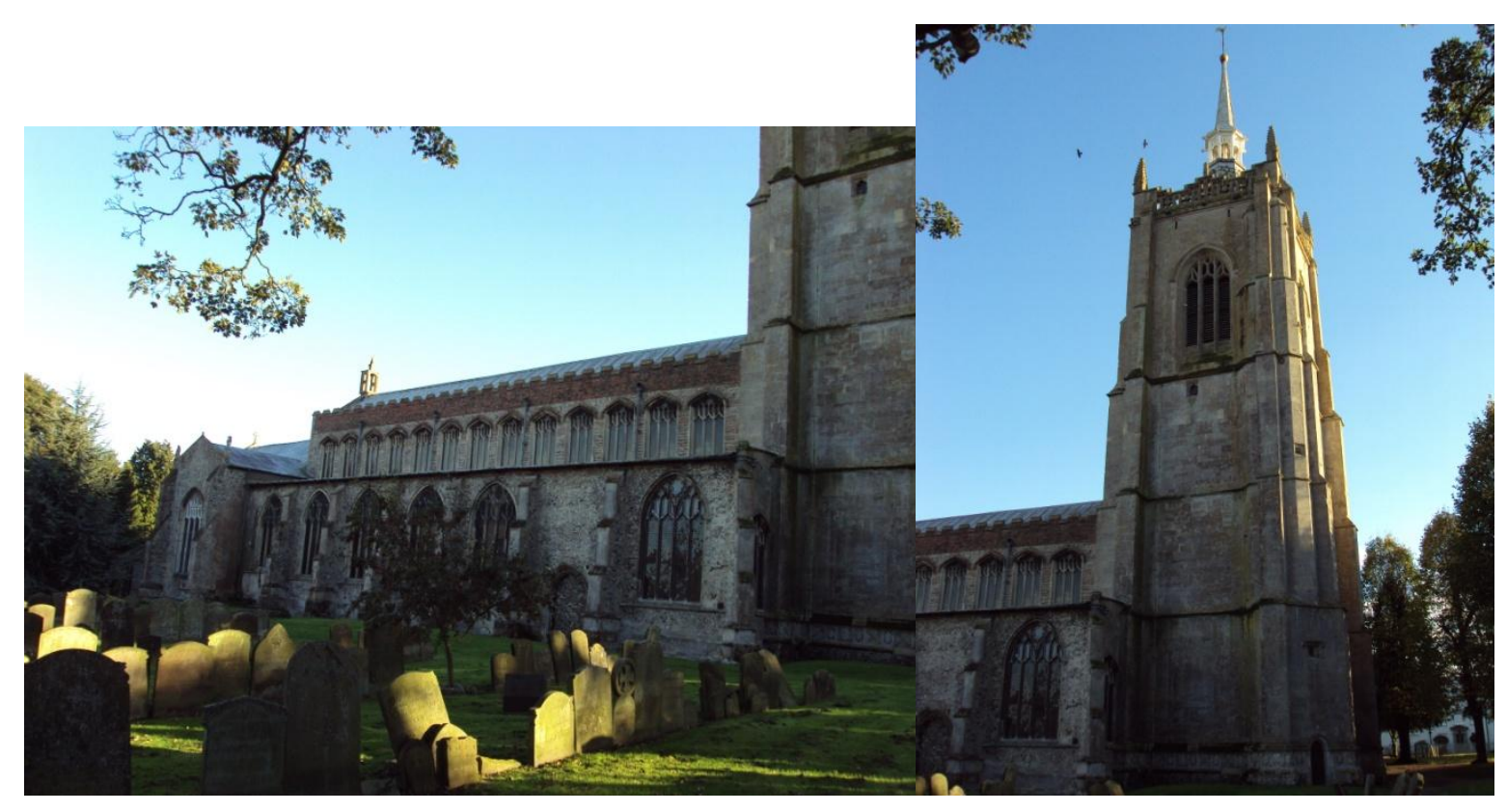


Date: $18 / 10 / 10$

\section{Record \# 017}

Feature: Peddar's Way

GPS coordinates: \#52 N: $52^{\circ} 38.649 \quad$ E: $000^{\circ} 42.608$

Photo/Sketch record number(s): $732-735$

Position related to route: Leads route through fields eventually to Castle Acre (roughly 7 miles).

Point at which visible from the route (GPS):

Surrounding features: Mainly farmland, some forested windbreaks visible in distance, no real settlements on the Way, a few scattered farm buildings and outhouses.

Interaction between feature \& pilgrim (slope, shelter, dominance of view etc): Beginning of Peddar's Way is enclosed by trees and thicket, before moving onto more open lanes. One gradually walks through farmland along the Way which is quite straight for most of its duration. This is unsurprising as the origin of the Way is as a Roman road spanning from the northern Norfolk coast down into Suffolk. The route is at times overgrown by brambles and boughs, which gives an unmistakable feeling of antiquity. It is particularly affecting at dawn (when I departed Swaffham, and many other pilgrims would do similar due to the distance left to cover that day), as the initially section of the route as one turns off the road in Swaffham heading east is heavily enclosed by plant life, and then hacks alongside several fields where many birds pipe the dawn chorus.

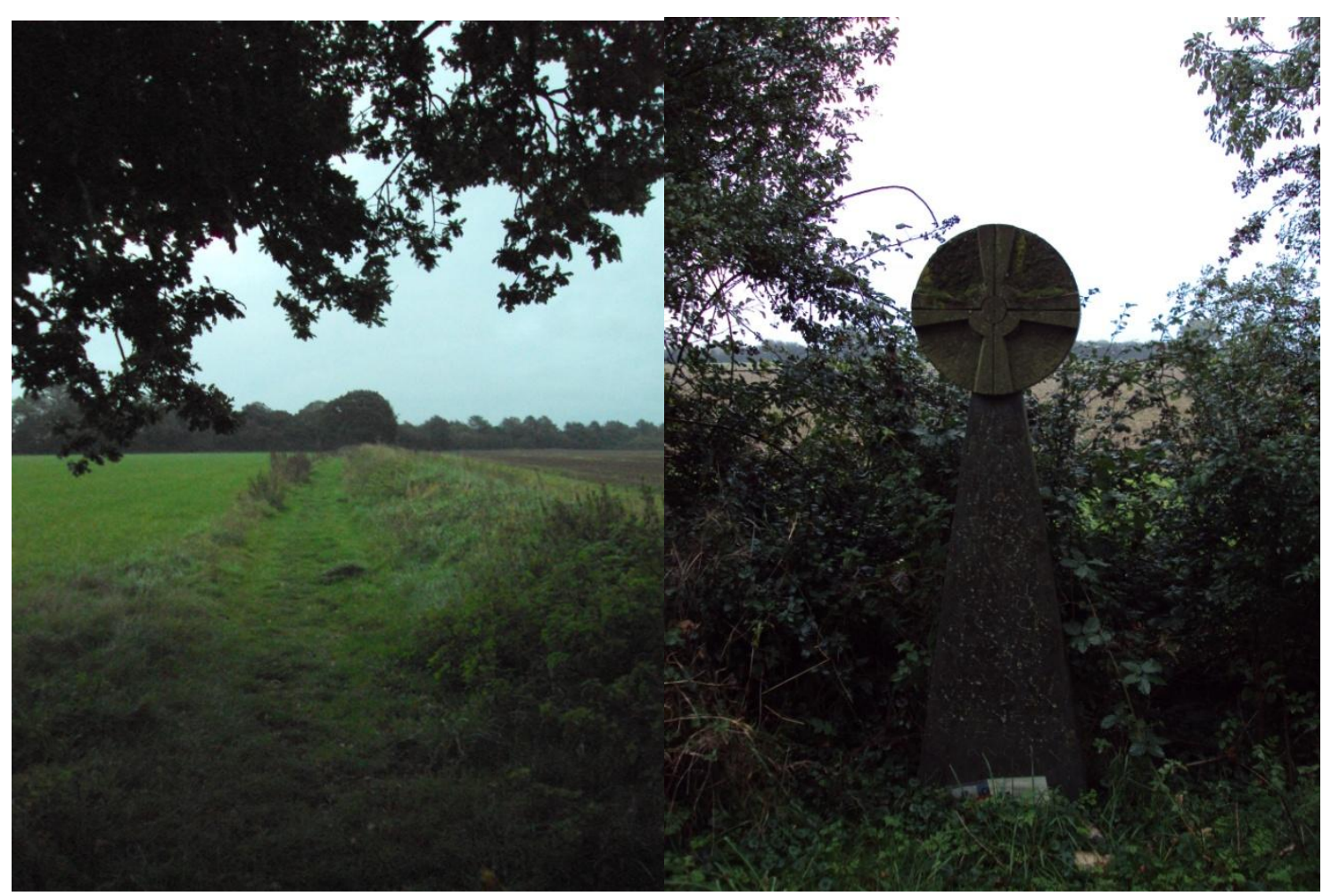

(Left: Peddar's Way. Right: Modern Pilgrim Cross c.1990) 
Date: $18 / 10 / 10$

Record\# 018 Norfolk HER Number: 1058

Site/Artefact type: Remains of Deserted Medieval Village (platform)

GPS coordinates: \#53 N: $52^{\circ} 40.416 \quad$ E: $000^{\circ} 42.831$

Position related to route: Adjacent to route, roughly 3 miles south of Castle Acre

Photo/Sketch record number(s): 736, 737.

Date of site/artefact (if identifiable): $\quad$ No firm date.

Dedication: N/A

Description of site/artefact (including interior decoration if applicable): Deserted Medieval village platform, with two moats. Currently in someone's back garden.

Surrounding landscape/natural features: Surrounded by fields.

Visible relation to neighbouring sites/landscape: Near Peddar's Way just ahead from a track called 'Procession Lane', possibly had good trading/travelling connections with the area due to the Way? Road

Other observations: Name 'Great Palgrave' indicates some level of size or importance? Was there a 'Little Palgrave'?

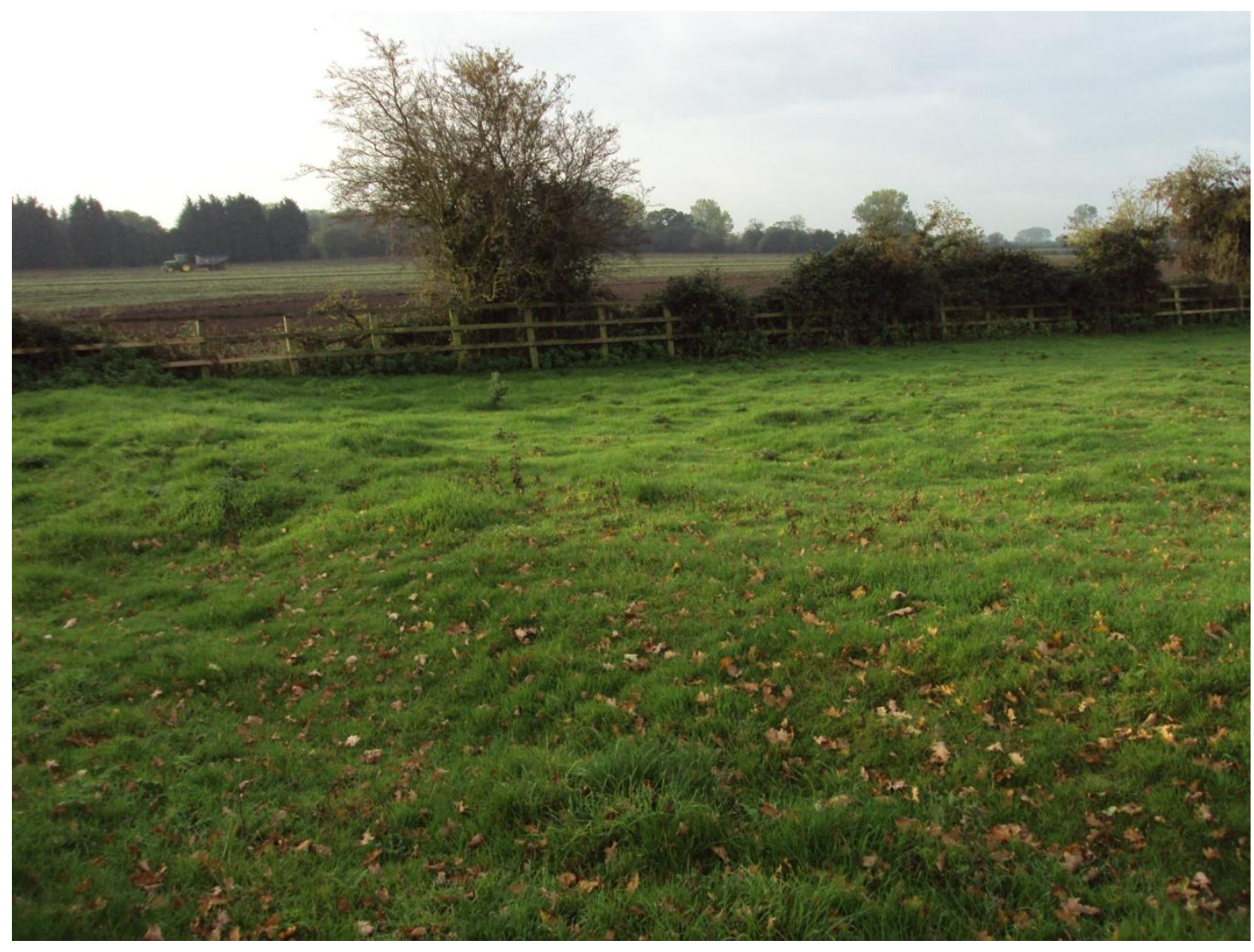


Date: $18 / 10 / 10$

\section{Record \# 019}

Feature: View of Church in Castle Acre from Peddar's Way

GPS coordinates: \#54 N: $52^{\circ} .41 .269 \quad$ E: $000^{\circ} 41.269$

Photo/Sketch record number(s): 743

Position related to route: Church is directly north ( 1mile) from this point on the route.

Point at which visible from the route (GPS): $\quad$ N: $52^{\circ} .41 .269 \quad$ E: $000^{\circ} 41.269$

Surrounding features: Situated on a rise. Surrounded entirely by fields, hence the ease with which the church tower is seen across the farmland.

Interaction between feature \& pilgrim (slope, shelter, dominance of view etc): The church tower in Castle Acre is a welcome site as it indicates that a resting place is soon at hand. In a more religious context, the tower imposes a dominant position over the landscape, emphasising the area's Christian identity. It is highly likely that the Priory would have been even more visible and exerted a similar effect upon the pilgrim, but given its current ruinous state it is impossible to test or experience today. These landmarks also act as memory anchors when recalling the route (possible to relive the pilgrimage through recall), and the site of a tall man made edifice dedicated to God standing watchfully over nature would be a particularly arresting one for the Medieval pilgrim. 

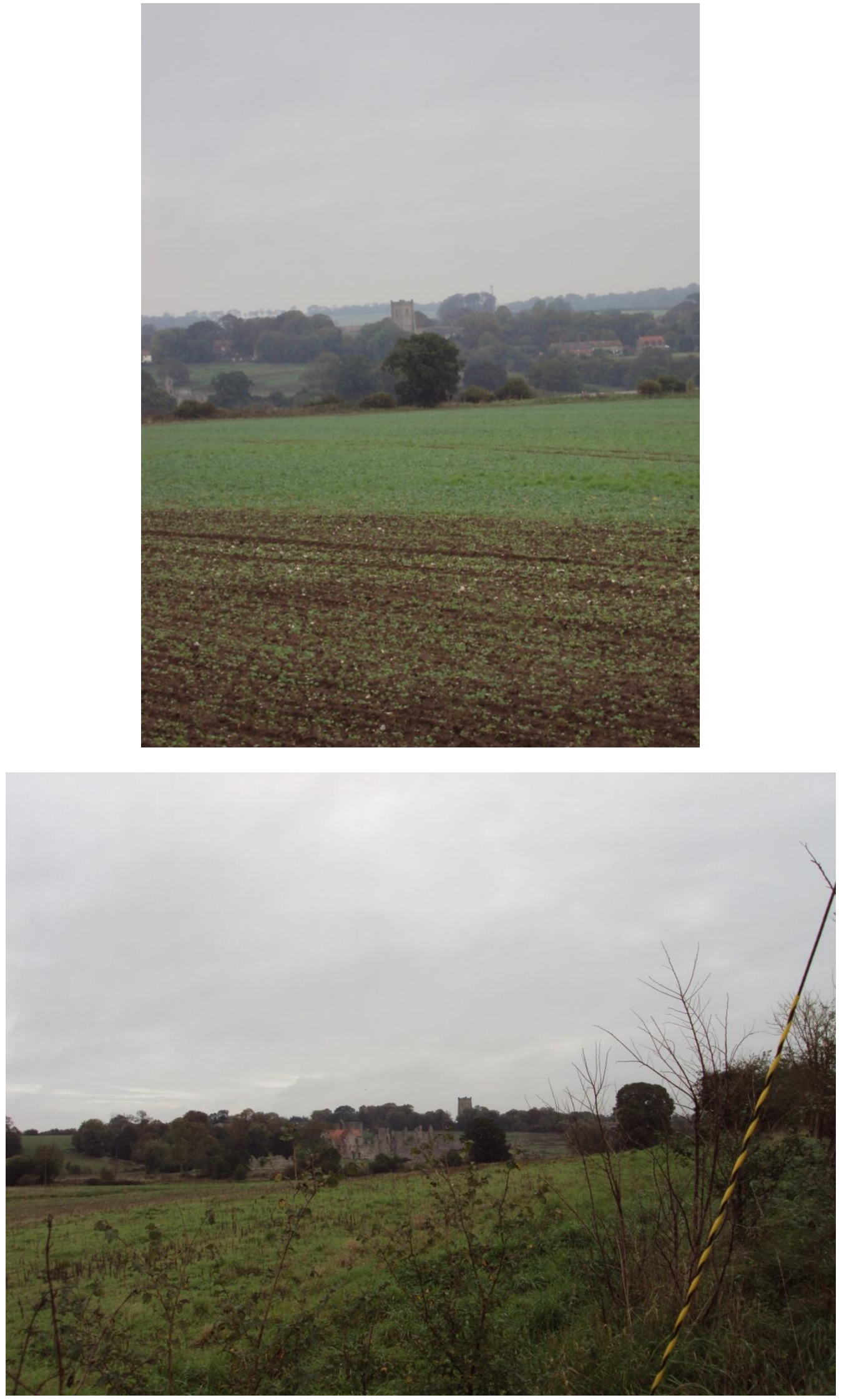

Views of St James' Church and Castle Acre Priory (ruins) from the approach to Castle Acre 
Date: $18 / 10 / 10$

\section{Record \# 020 Norfolk HER Number 4068}

Site/Artefact type: Church of St James (Castle Acre)

GPS coordinates: \#55 N: $52^{\circ} 42.132 \quad$ E: $000^{\circ} 41.149$

Position related to route: Just off Peddar's Way, one Church Lane as it enters Castle Acre.

Photo/Sketch record number(s): 746

Date of site/artefact (if identifiable): $\quad$ early $14^{\text {th }}$ century

Dedication: St James

Description of site/artefact (including interior decoration if applicable): The church itself is a large building, indicating a lot of traffic prior to the $16^{\text {th }}$ century and the dissolution of the Priory and pilgrim route. There is a large perpendicular flint faced tower (square), unadorned. The church was locked, but apparently inside is the Castle Acre Priory font cover (late $15^{\text {th }}$ century), and the hexagonal pulpit, four of whose five panels feature Saints Augustine, Gregory, Jerome and Ambrose (four Latin doctors of the church). These four were a popular devotion in Late Medieval Norfolk. On the roodscreen St James has had his eyes gouged out - he was very unpopular with Anglican reformers due to his connection with pilgrimage. The south aisle encloses the small Medieval St Nicholas chapel, with a couple of screens featuring his monogram.

Surrounding landscape/natural features: To the south is a small river, the valley floor, fields and some patches of woodland. To the east, north and west is the village and priory.

Visible relation to neighbouring sites/landscape: The church is roughly 100 metres from the Priory, and visible from the Peddar's Way roughly 1 mile away up the valley.

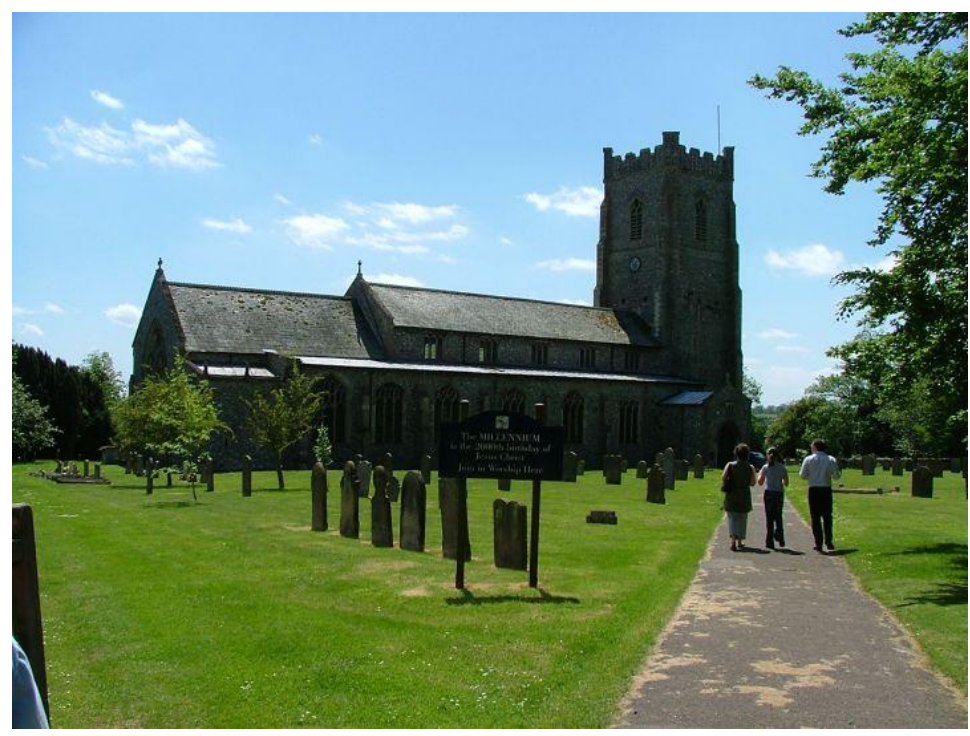

(image reproduced from http://www.norfolkchurches.co.uk/castleacre/castleacre.htm) 
Date: $18 / 10 / 10$

\section{Record \# $021 \quad$ Norfolk HER Number 4096}

Site/Artefact type: Castle Acre Priory

GPS coordinates: \#56 N: $52^{\circ} 42.089 \quad$ E: $000^{\circ} 40.991$

Position related to route: At eastern most end of Castle Acre, overlooking the valley floor.

Photo/Sketch record number(s): 331

Date of site/artefact (if identifiable): $\quad 11^{\text {th }}$ century

Dedication: Cluniac order.

Description of site/artefact (including interior decoration if applicable): The ruins of this priory are in surprisingly good condition, considering its dissolution, with the great west front of the complex remaining almost completely intact, along with the prior's lodgings. The oldest part of the complex is the nave of the church, and throughout the complex there is a great deal of decorated stonework which is typical of the Cluniac order.

Surrounding landscape/natural features: The Priory is set near a small river, and is surrounded by a mixture of (now) thicket/heathland and pastureland.

Visible relation to neighbouring sites/landscape: When in its prime, there can be no doubt that this building would have dominated the view of the landscape for many miles around, and its bells would have been audible for some distance. It also would have been a fundamental stopping point for pilgrims to pay their devotions and possible claim some sort of charity or food from the prior. Merchants and royalty also stayed here, and it is recorded that royalty such as Henry III, King Edward II and his Queen Eleonor stayed at the priory in the prior's lodgings on their way to Walsingham, so it is clear that the priory's fame and influence was great.

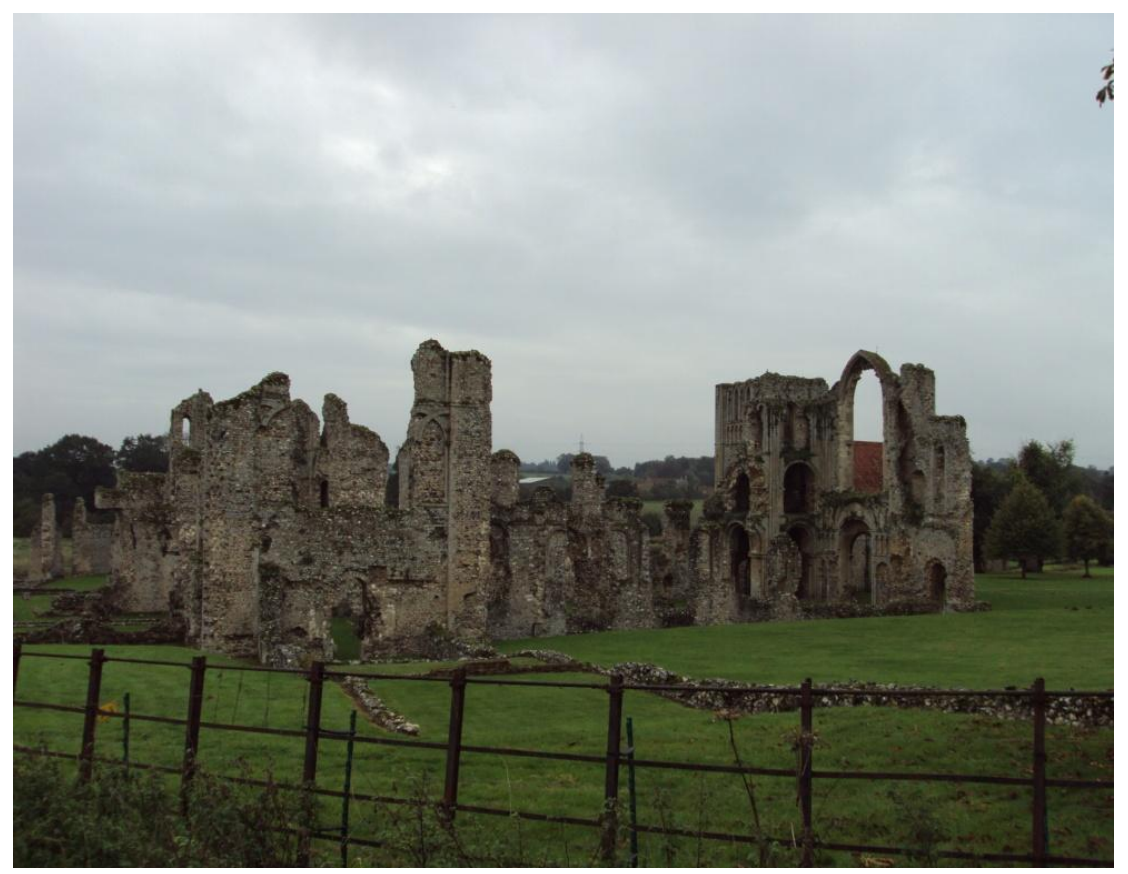


Date: $18 / 10 / 10$

\section{Record \# 022 Norfolk HER Number 46817}

Site/Artefact type: Bailey Gate (Castle Acre)

GPS coordinates: \#57 N: $52^{\circ} 42.210 \quad$ E: $000^{\circ} 41.294$

Position related to route: On Peddars Way through Castle Acre (village centre)

Photo/Sketch record number(s): 302,303

Date of site/artefact (if identifiable): $\quad 13^{\text {th }}$ century

Dedication: N/A

Description of site/artefact (including interior decoration if applicable): The gateway was built from stone (flint faced) to defend the north entrance to a planned town, fortified by earthworks, that ajoined the castle. It is through this gate that pilgrims may have arrived into Castle Acre via the Peddars Way.

Surrounding landscape/natural features: N/A

Visible relation to neighbouring sites/landscape: Entrance for Peddars Way into the town.

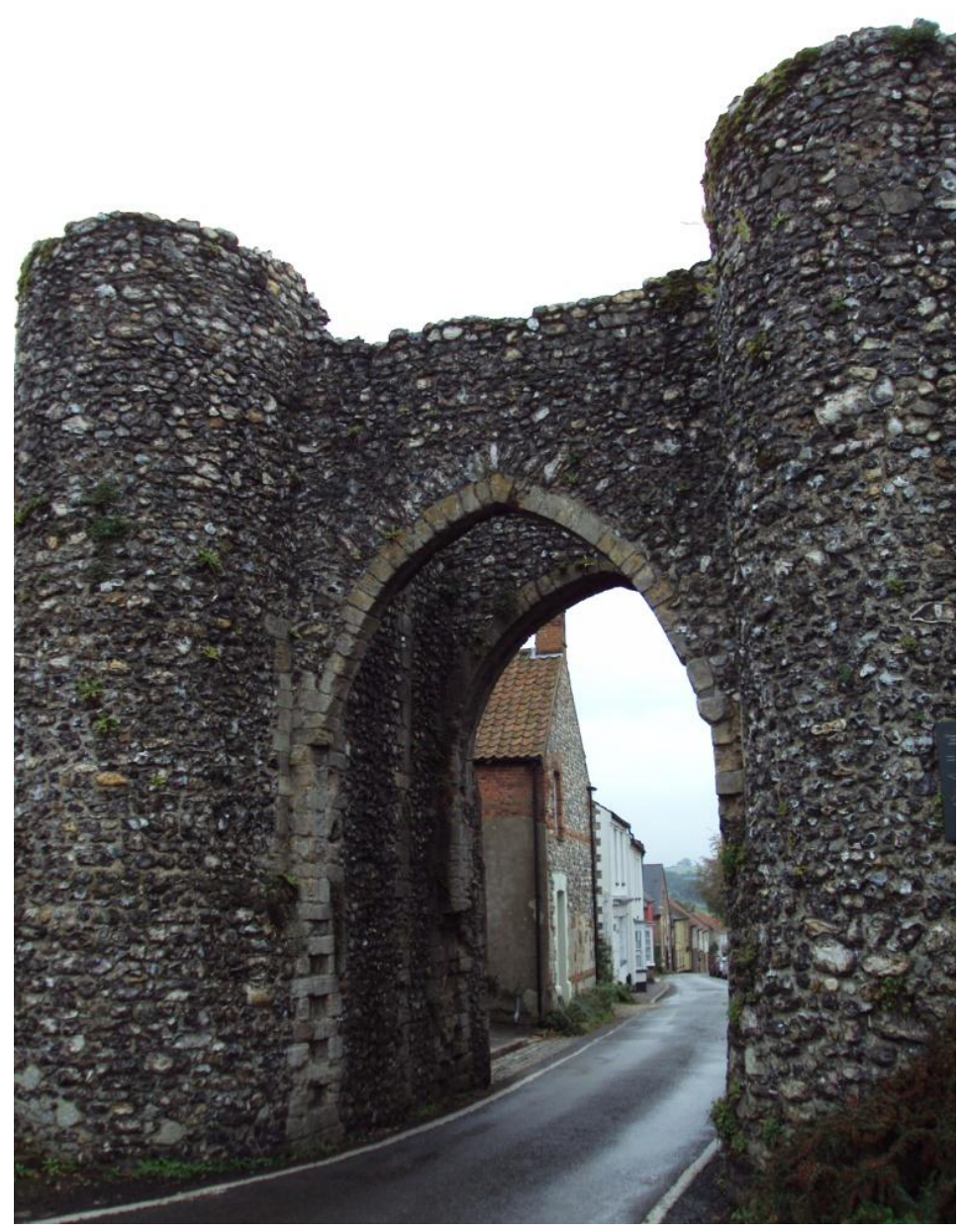


Date: $18 / 10 / 10$

\section{Record \# 023 Norfolk HER Number 3683}

Site/Artefact type: Church of St Mary (Rougham)

GPS coordinates: \#58 N: $52^{\circ} 45.060 \quad$ E: $000^{\circ} 42.673$

Position related to route: On route through Rougham

Photo/Sketch record number(s): $756-759$

Date of site/artefact (if identifiable): $13^{\text {th }}$ century

Dedication: St Mary

Description of site/artefact (including interior decoration if applicable): This church is unusually large considering the size of the village, with a similarly sized graveyard. The tower is $15^{\text {th }}$ century, with dedicatory inscriptions in the flushwork beneath the battlements praying for the souls of Robert Drury and John Tilot. At the south end is a wooden door with ornamental metalwork, and above is a small carving of crucified Christ and Mary, however their faces have been chipped off during the Reformation. Inside, above the nave, is a superb Medieval wooden hammerbeam roof.

Surrounding landscape/natural features: Beyond the village are a series of fields.

Visible relation to neighbouring sites/landscape: The church is at the far northeast end of the village, near the refectory (1950's).

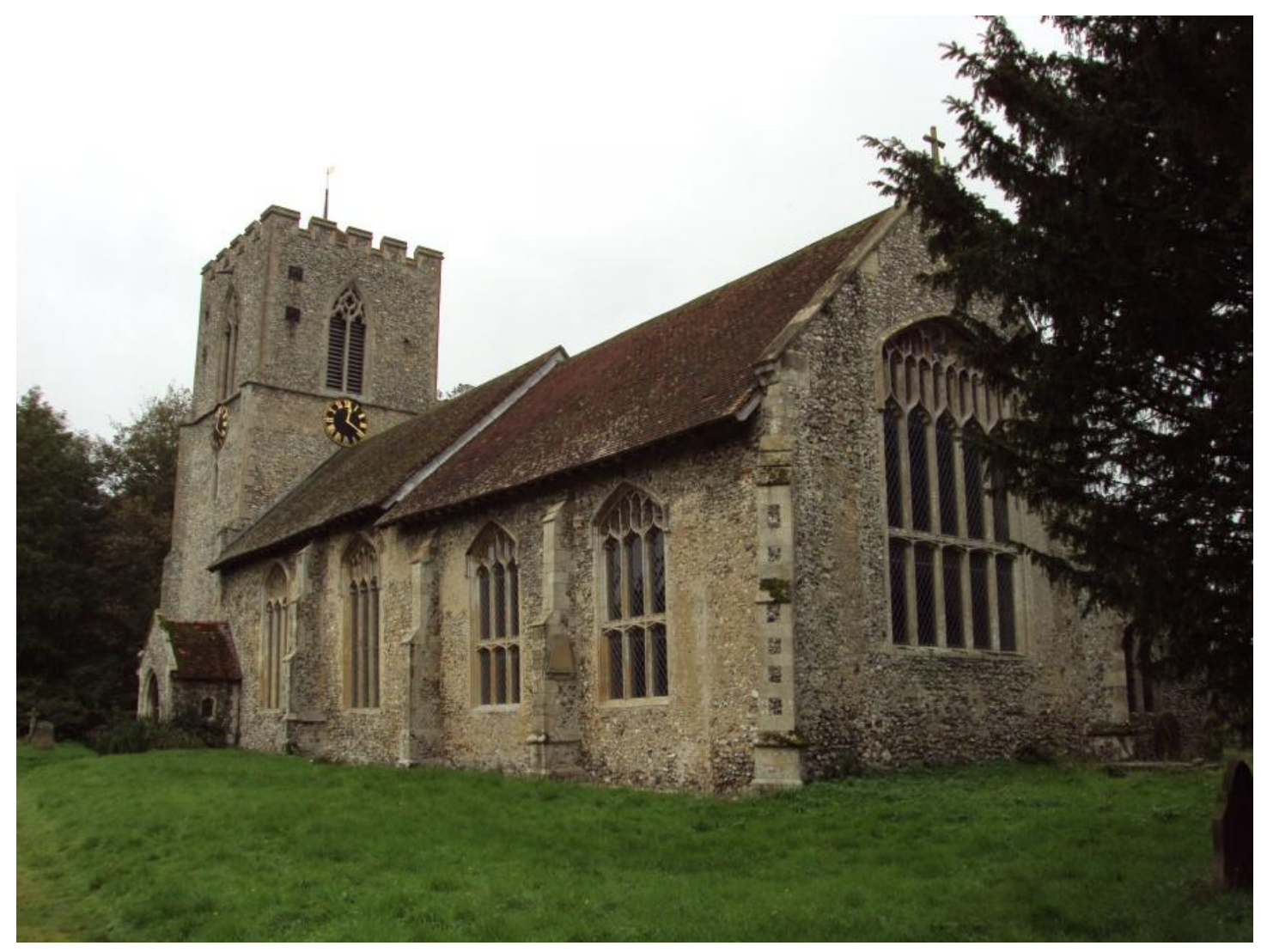


Date: $18 / 10 / 10$

\section{Record \# 024 Norfolk HER Number 3730}

Site/Artefact type: Church of St Peter (Weasenham)

GPS coordinates: \#59 N: $52^{\circ} 46.018 \quad$ E: $000^{\circ} 44.977$

Position related to route: On main road out of Weasenham

Photo/Sketch record number(s): $760-763$

Date of site/artefact (if identifiable): $\quad 13^{\text {th }}$ century origin (tower)

Dedication: St Peter

Description of site/artefact (including interior decoration if applicable): Medieval but with major restoration c.1870. Nave has tall perpendicular window with embattled transoms on north side. South side has fine decorated window at the west end. North porch is $15^{\text {th }}$ century with flush flint work.

Surrounding landscape/natural features: Flat fields, with slight rise to the east. Some hedgerows visible.

Visible relation to neighbouring sites/landscape: Stands tall against the flat landscape, potentially visible for up to a mile in each direction.

Other observations: Churchyard is built up, suggesting many many generations of burial in the small graveyard

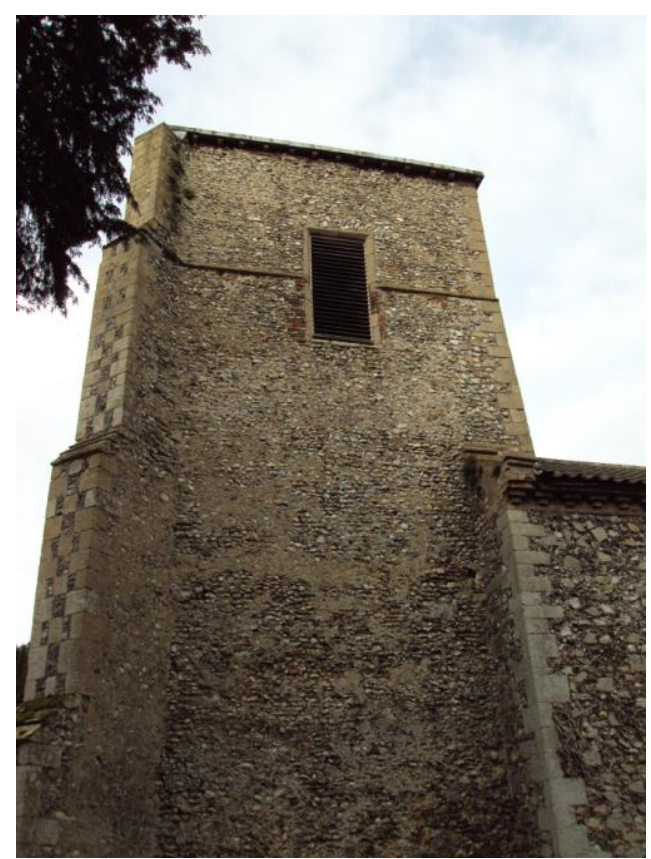


Date: $18 / 10 / 10$

\section{Record \# 025 Norfolk HER Number 2377}

Site/Artefact type: Church of All Saints

GPS coordinates: \#60 N: $52^{\circ} 48.227 \quad$ E: $000^{\circ} 46.267$

Position related to route: On route out of Helhoughton

Photo/Sketch record number(s): $767-771$

Date of site/artefact (if identifiable): $\quad 14^{\text {th }}$ century

Dedication: All Saints

Description of site/artefact (including interior decoration if applicable): Constructed from flint and stone, with some brick dressings. Chancel is $14^{\text {th }}$ century with two bays. Tower at western end is $15^{\text {th }}$ century, nave is late $18^{\text {th }}$ century (rebuilt). Stone octagonal font and two decorated windows with priests door between them.

Surrounding landscape/natural features: Primarily fields, although there is a small boggy piece of land to the immediate east of the church.

Visible relation to neighbouring sites/landscape: No particular impact upon the pilgrim experience discernable, other than that of a prayer spot and resting place in the churchyard.

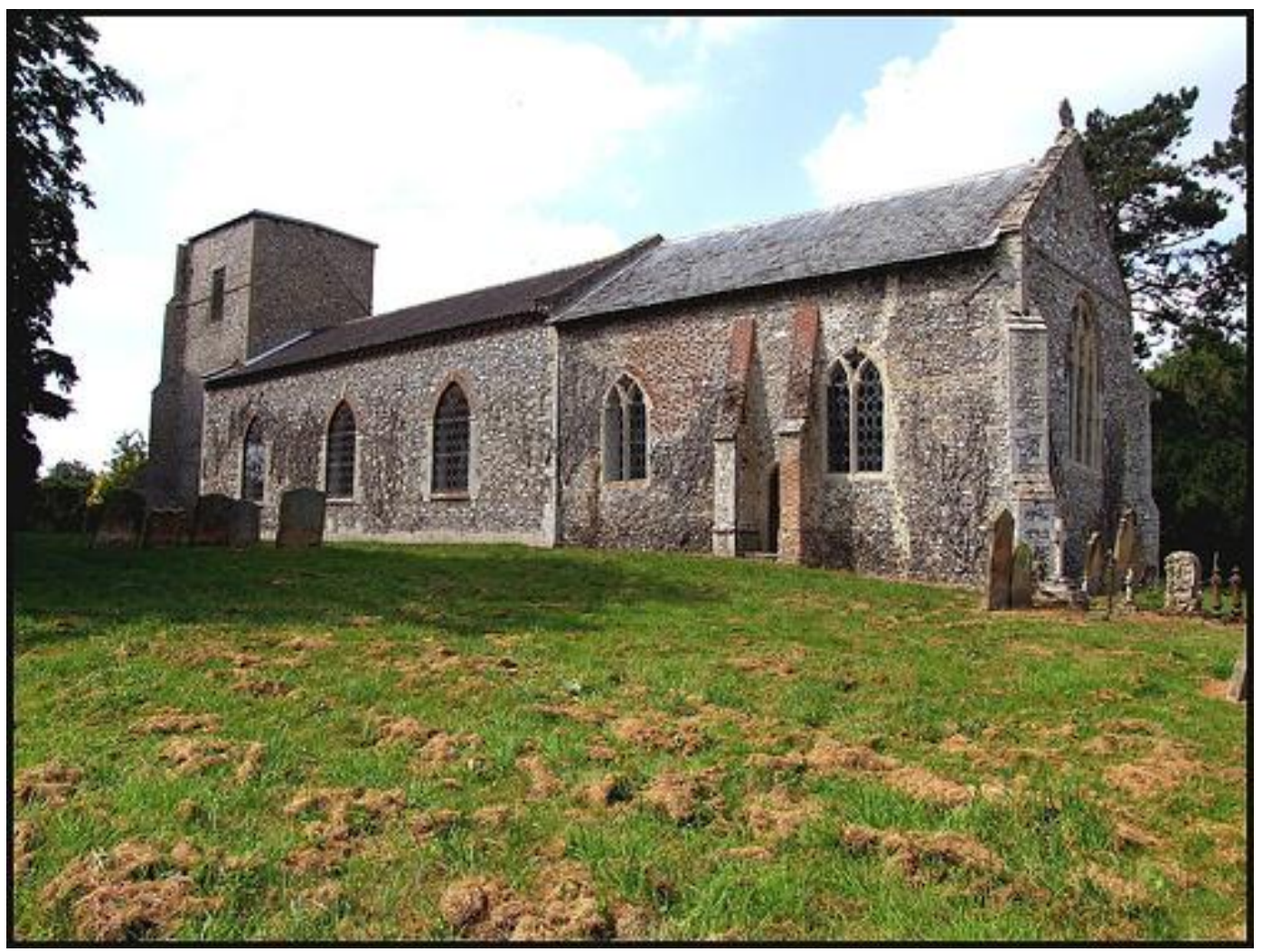

(image reproduced from http://www.norfolkchurches.co.uk/helhoughton/helhoughton.htm) 
Date: $18 / 10 / 10$

\section{Record\# 026 Norfolk HER Number 2354}

Site/Artefact type: Church of St Nicholas (Shereford)
GPS coordinates: \#61
$\mathrm{N}: 52^{\circ} 49.862$
E: $000^{\circ} 48.012$

Position related to route: On route through Shereford

Photo/Sketch record number(s): $774-780$

Date of site/artefact (if identifiable): $12^{\text {th }}$ century

Dedication: St Nicholas

Description of site/artefact (including interior decoration if applicable): Round tower, flint faced. Romanesque arch over porch, gothic windows throughout. Basic whitewashed interior, with medieval font.

Surrounding landscape/natural features: This are of the route is much more pastoral than previous sections, the landscape has a rolling topography, with fields being interspersed by individual trees (primarily oak).

Visible relation to neighbouring sites/landscape: The church is in the village of Shereford, along the route itself. It is situated in a slight dell, so not visible from a great distance.

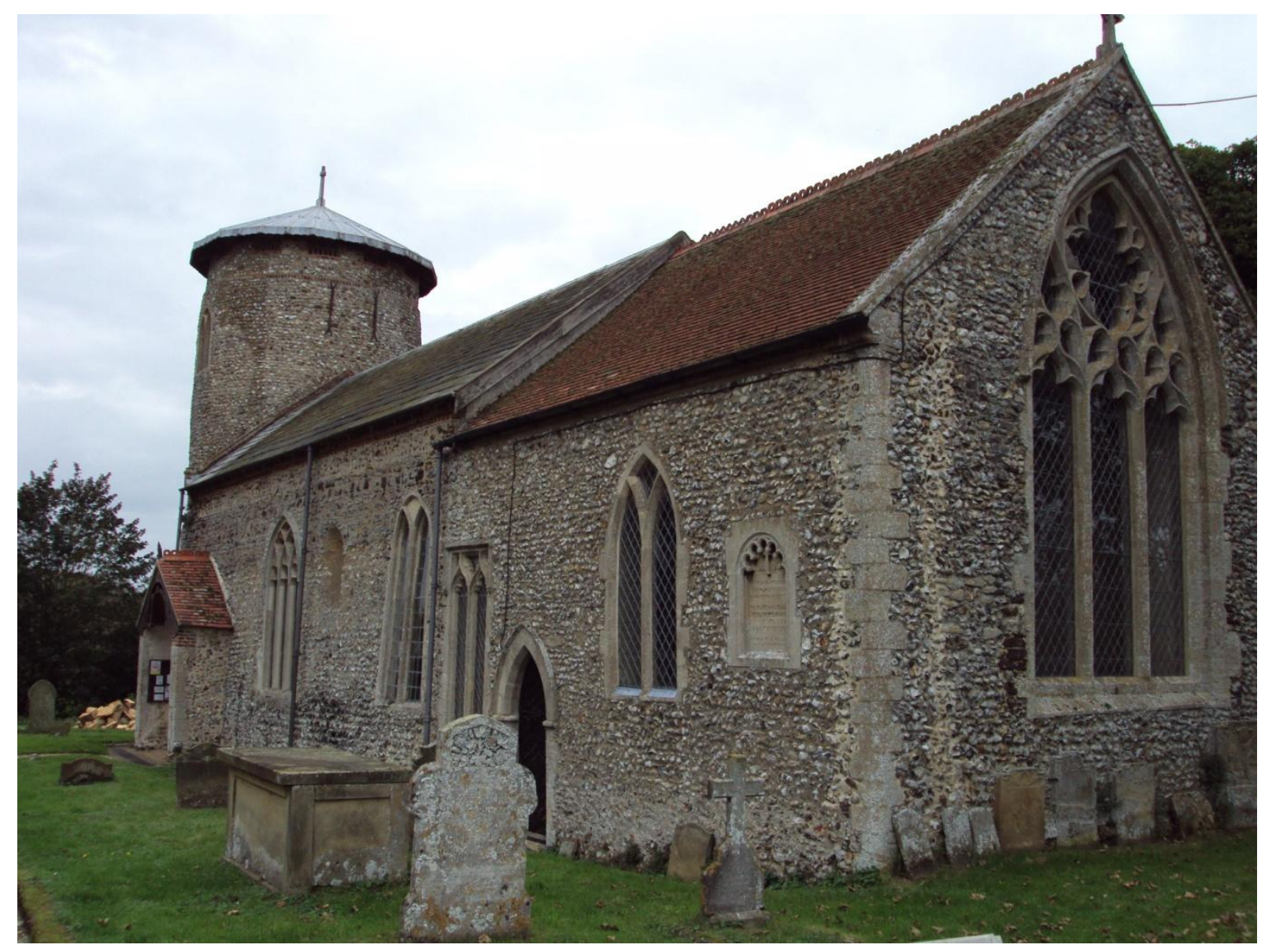


Date: $18 / 10 / 10$

\section{Record \# 027 Norfolk HER Number 1999}

Site/Artefact type: Church of St Mary \& All Saints (Sculthorpe)

GPS coordinates: \#62 N: $52^{\circ} 51.068 \quad$ E: $000^{\circ} 49.175$

Position related to route: 20 metres off route as it leaves Sculthorpe

Photo/Sketch record number(s): 781, 782

Date of site/artefact (if identifiable): $\quad 14^{\text {th }}$ century (extensive rebuild in $18^{\text {th }}$ century)

Dedication: St Mary \& All Saints

Description of site/artefact (including interior decoration if applicable): Perpendicular style (common in Norfolk), built during reign of Edward III by Sir Robert Knollys. Contains fine earlyNorman font, some ancient brasses and stained glass. Locked upon visit.

Surrounding landscape/natural features: Some fields nearby, but principally village and A-road takes up south view. North is a tree plantation and more fields, flat.

Visible relation to neighbouring sites/landscape: Clearly served the village for many centuries, potential prayer spot for pilgrims?

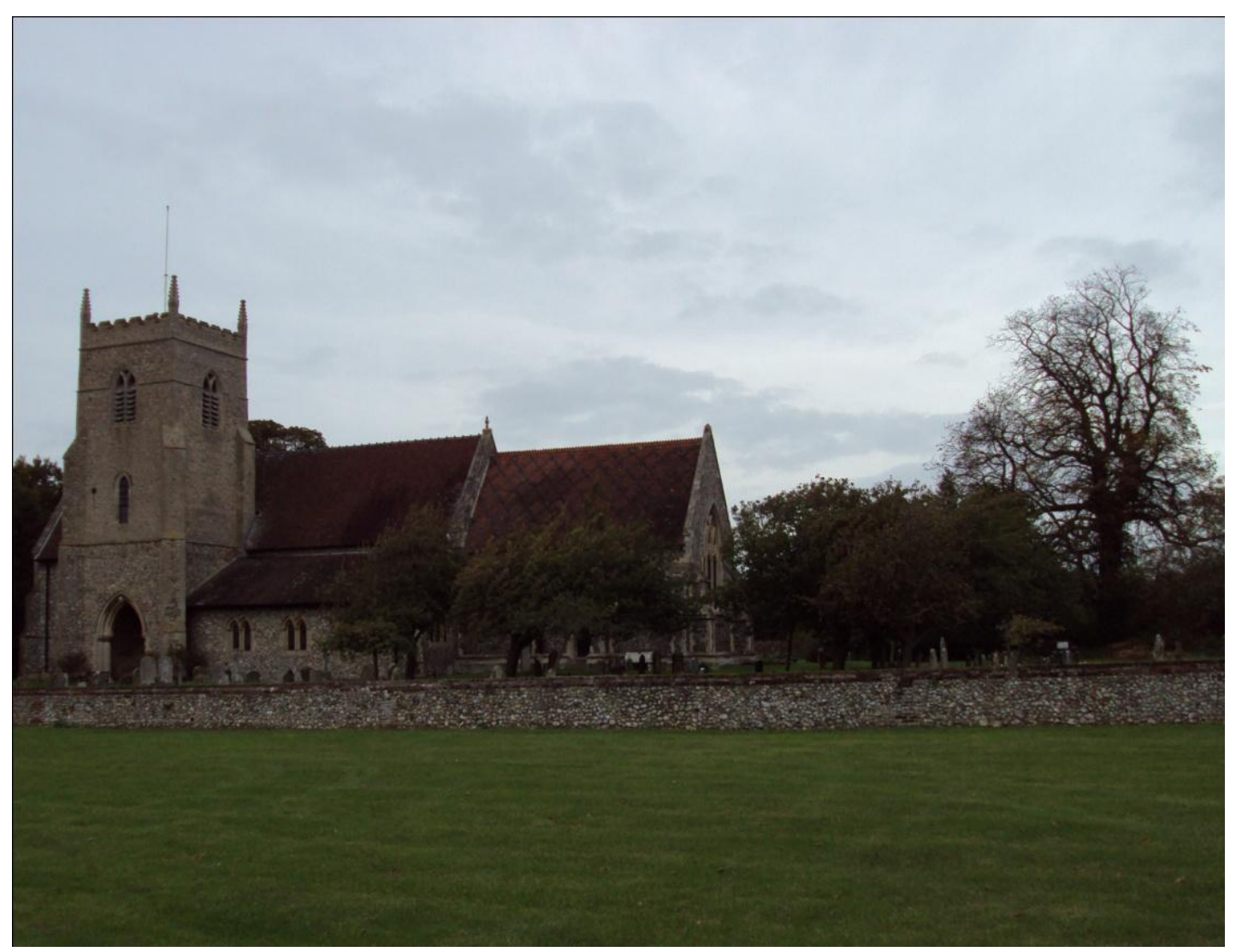


Date: $19 / 10 / 10$

\section{Record \# 028 Norfolk HER Number 12244}

Site/Artefact type: Church of All Saints (North Barsham)

GPS coordinates: \#63 N: $52^{\circ} 52.683 \quad$ E: $000^{\circ} 50.697$

Position related to route: Along lane which runs out of North Barsham, 1 mile before Slipper Chapel.

Photo/Sketch record number(s): 787

Date of site/artefact (if identifiable): Unsure, possibly Saxon (in shape)

Dedication: All Saints

Description of site/artefact (including interior decoration if applicable): Small square church, flint faced, 1 bell, 1 stained glass panel (east window). Truncated at both ends, as when the tower collapsed it took the west end of the nave down as well. Font is of Purbeck marble, and there is an egg timer made from stone carved bones and a skull.

Surrounding landscape/natural features: Rolling fields, trees and pastureland, Very pastoral and verdant. Exceptionally still here.

Visible relation to neighbouring sites/landscape: Along route to Slipper Chapel.

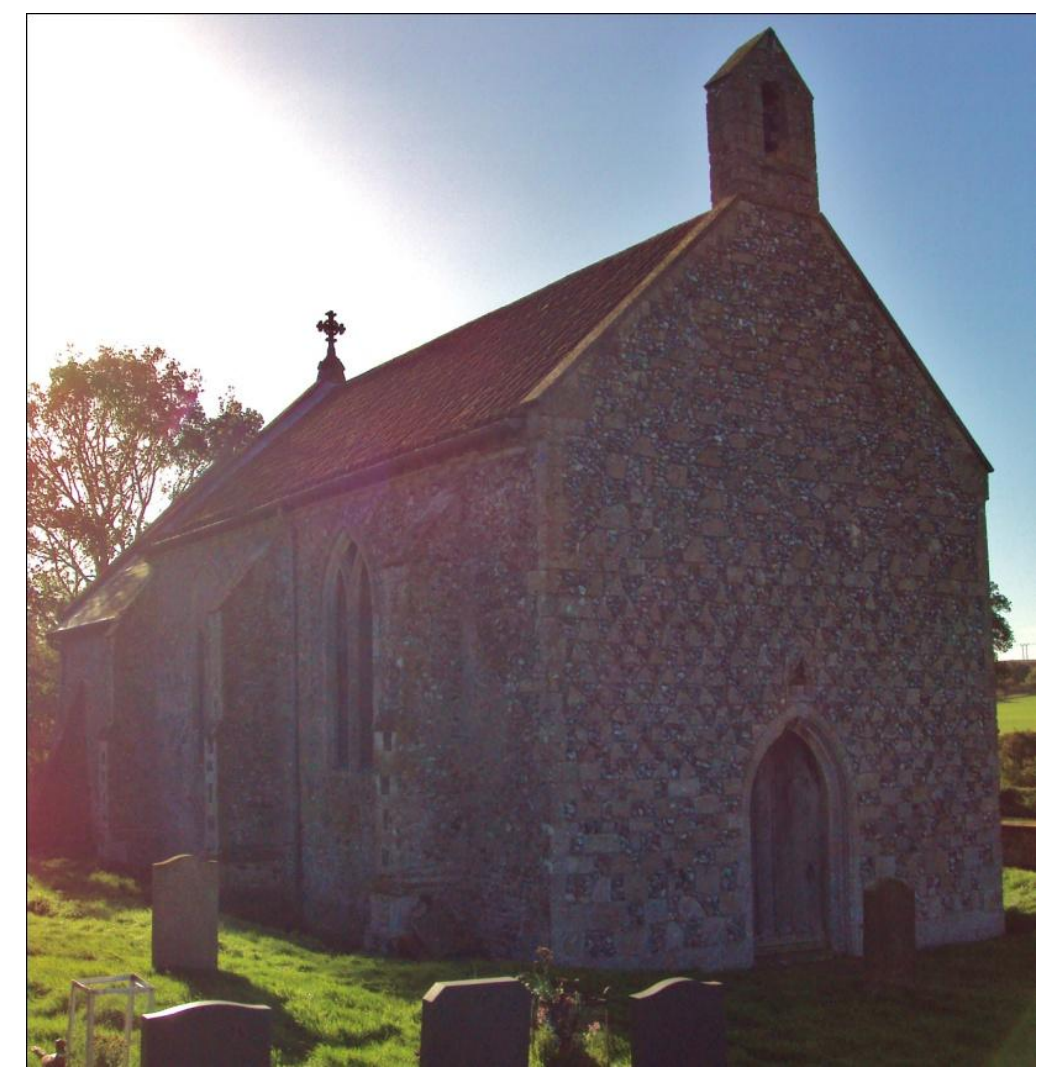


Date: $19 / 10 / 10$

\section{Record \# 029 Norfolk HER Number 2068}

Site/Artefact type: Slipper Chapel

GPS coordinates: \#64 N: $52^{\circ} 52.865 \quad$ E: $000^{\circ} 51.200$

Position related to route: Last chapel on the route to Little Walsingham

Photo/Sketch record number(s): $788-794$

Date of site/artefact (if identifiable): $\quad 1340$

Dedication: St Catherine of Alexandria

Description of site/artefact (including interior decoration if applicable): Small (heavily) restored chapel, flint clad, original stone turrets survive. Most of the building is rebuilt or restored, so little of the original fabric remains. From its dissolution in 1538, the chapel was used as a poor house, a forge, a cowshed and finally a barn until it was 'rediscovered' by local Charlotte Boyd in 1896, who restored it and donated it to the Diocese of Northampton for Catholic use.

Surrounding landscape/natural features: Rolling fields, a small river, paddocks and the nearby (modern) 'Holy Mile walk' to Walsingham.

Visible relation to neighbouring sites/landscape: This marks the penultimate stopping point before Walsingham, however due to its diminutive size it is not visible from any sort of distance.

Other observations: The term 'Slipper' does not come from the practise of removing ones shoes to walk the final mile to Walsingham barefoot, it instead comes from the word 'slipe' or 'slype', meaning to slide - so in effect it means to slide or move out of the rest of England into the holy land of Walsingham, 'England's Nazareth' as it was known, making the transition from profane environment to sacred and leaving the normal world behind thus completing the pilgrimage journeying transformation.

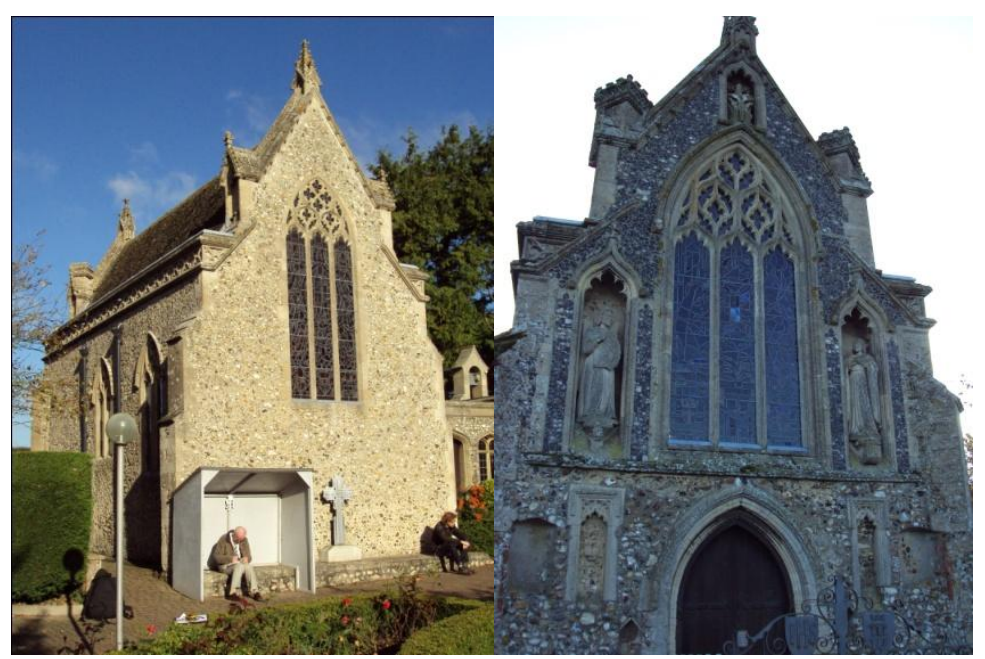


Date: $19 / 10 / 10$

\section{Record \# $030 \quad$ Norfolk HER Number 2036}

Site/Artefact type: Little Walsingham Friary (ruins)
GPS coordinates: \#65
$\mathrm{N}: 52^{\circ} 53.500$
E: $000^{\circ} 52.332$

Position related to route: Situated at the entrance to Walsingham from the Holy Mile.

Photo/Sketch record number(s): 805

Date of site/artefact (if identifiable): $\quad 1347$

Dedication: Linked to Priory complex dedicated to Our Lady of Walsingham. Franciscan Order.

Description of site/artefact (including interior decoration if applicable): Small Friary founded by Franciscans, now highly ruined with sections of outer wall still standing. Unable to assess properly as it is now private property and I could not gain access. Fell under the patronage of Elizabeth de Burgh, Countess of Clare but fell victim to the Reformation.

Surrounding landscape/natural features: River and pastureland, slight valley.

Visible relation to neighbouring sites/landscape: Near Shrine and Priory, 1 mile from Slipper Chapel. Visible from 100 metres from village.

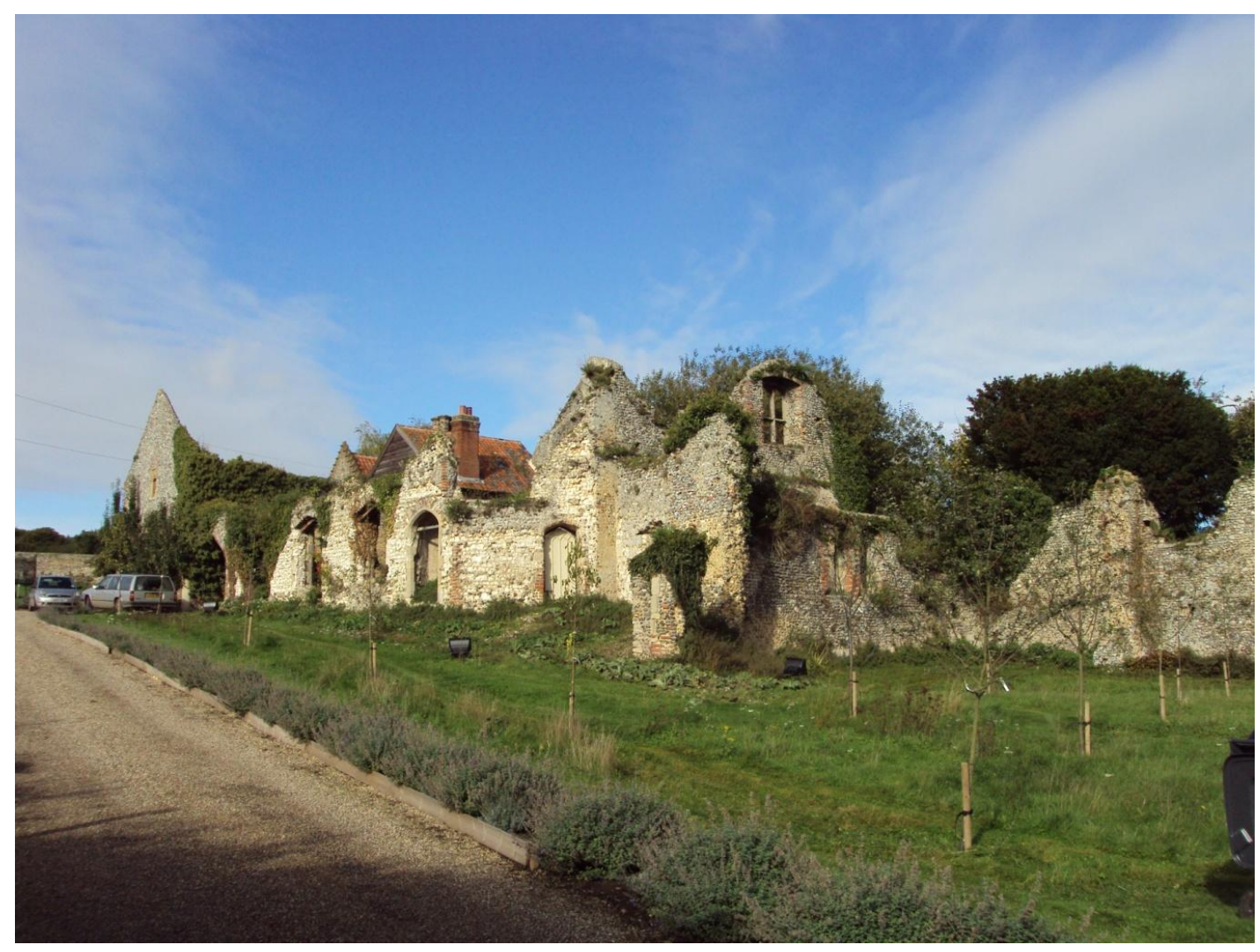


Date: $19 / 10 / 10$

\section{Record \# $031 \quad$ Norfolk HER Number 2063}

Site/Artefact type: Church of St Mary (Little Walsingham)

GPS coordinates: \#66 N: $52^{\circ} 53.468$ E: $000^{\circ} 52.489$

Position related to route: East of High St, on Church Lane.

Photo/Sketch record number(s): $806-812$

Date of site/artefact (if identifiable): $\quad 14^{\text {th }}$ century ( but interior gutted by fire in 1961)

Dedication: St Mary

Description of site/artefact (including interior decoration if applicable): The tower is $14^{\text {th }}$ century Decorated Period with belfry windows. South porch is lined with knapped flints. Font is $14^{\text {th }}$ century and one of the finest in Norfolk, being $14^{\text {th }}$ century and displaying the Seven Sacraments of the church - miraculously it escaped serious defacement during the Reformation. The north transept is known as the Guilds' Chapel, as it was built in 1510 by three local guilds. A chalice brass can be found near the north transept c. 1520.

Surrounding landscape/natural features: Little Walsingham village, pastures.

Visible relation to neighbouring sites/landscape: This doubtless would have been a place for pilgrims to visit prior to the shrine, to offer prayers and thanks and 'clean' themselves from travel in preparation for the shrine.

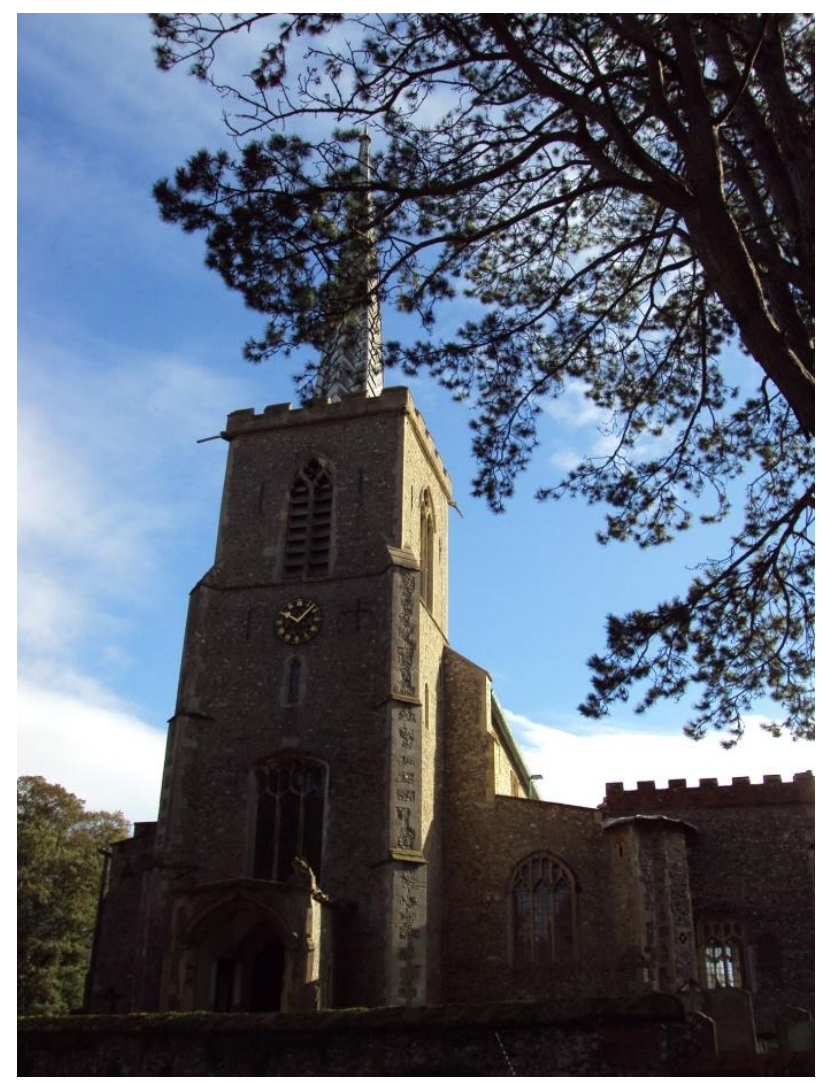


Date: $19 / 10 / 10$

\section{Record \# 032 Norfolk HER Number 2029}

Site/Artefact type: Priory of Our Lady of Walsingham/Original Shrine site.

GPS coordinates: \#67 N: $52^{\circ} 53.620$ E: $000^{\circ} 52.519$

Position related to route: Just off High St, grounds extend to edge of village (east).

Photo/Sketch record number(s): $814-822$

Date of site/artefact (if identifiable): 1061 (shrine) \& 1153 (Priory)

Dedication: Our Lady of Walsingham

Description of site/artefact (including interior decoration if applicable): This site was host to a complex of monastic buildings making up the Priory (unofficially called an Abbey), founded on the site where in 1061 Richeldis de Faverches had a vision in which the Virgin Mary instructed her to build a replica of Mary's house in Nazareth. It was panelled with wood, and contained a statue of Mary in wood and contained (amongst other relics) a vial of the Virgin's milk. All that remains of the priory now after the Reformation is a huge arch which would have housed a magnificent stained glass window.

Surrounding landscape/natural features: The site backs onto pastureland and a small river. This setting is extremely beautiful and peaceful, with a slight rise in the topography to the east, but principally the land is flat with meadows.

Visible relation to neighbouring sites/landscape: St Mary's church bells can be heard from this sight, and the priory would have been a reasonably large complex given Walsingham's status as a pilgrimage centre in Medieval Europe. This site (and Little Walsingham in general) is very much like a 'sacred island' in the Norfolk landscape, an enclave of spiritual renewal and encounter, truly set apart from its surroundings due to its shrine and pilgrim status. 

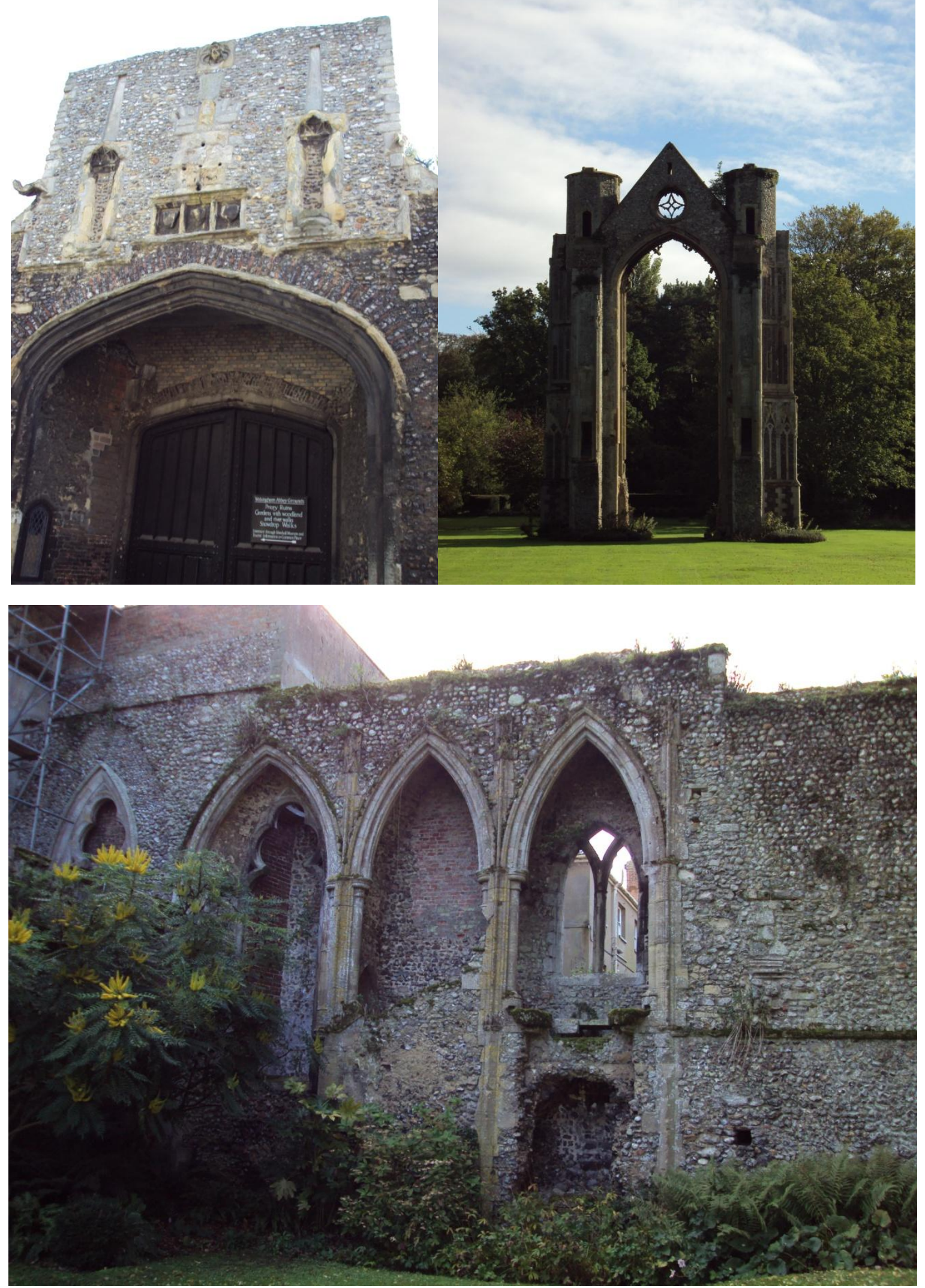

(Clockwise from top left: Priory Gate, Remaining Window Arch from East Chancel, Priory Ruins) 


\section{Digitised Data Record Sheets for Salisbury to Winchester:}

Date: $16 / 11 / 11$

\section{Record \# 001}

Site/Artefact type: Church

GPS coordinates: $\mathrm{N}: 51^{\circ} 04.133 \mathrm{~W}: 001^{\circ} 47.835$

Position related to route: At northern end of High Street, on the route connecting Old Sarum with the new cathedral.

Photo/Sketch record number(s): $1932-1938$

Date of site/artefact (if identifiable): 1220

Dedication: St Thomas Becket

Description of site/artefact (including interior decoration if applicable):

The cruciform core of the church forms the original plan, with a late $13^{\text {th }}$ century chapel added dedicated to St Stephen. The most remarkable aspect of this church is its 'Doom Painting', dating from the late $15^{\text {th }}$ century, and is said to have been a feature of pilgrims returning to Salisbury and coming to the church to give thanks beneath the painting.

Surrounding landscape/natural features: The surrounding landscape is topographically flat, but primarily built upon, being in the commercial centre of the town.

Visible relation to neighbouring sites/landscape: The church's tower is visible from many parts of Salisbury, and is located in a direct line north of the cathedral.

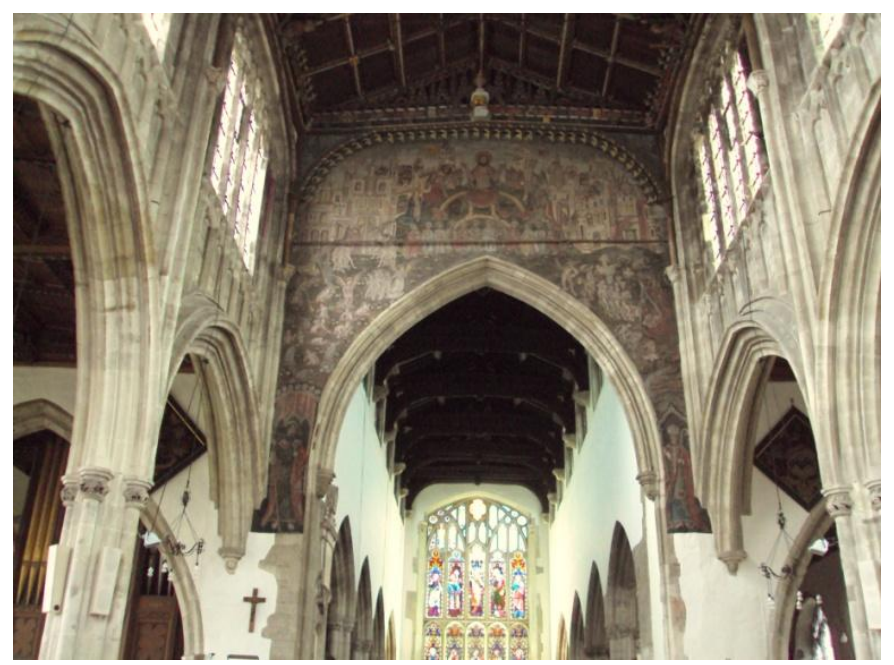


Date: $16 / 11 / 11$

\section{Record \# 002}

Site/Artefact type: Church

GPS coordinates: N: $51^{\circ} 04.168$ W: $001^{\circ} 47.950$

Position related to route: East of cathedral, next to Churchill (Church Hill?) street.

Date of site/artefact (if identifiable): $\quad 13^{\text {th }}$ century

Dedication: St Martin

Description of site/artefact (including interior decoration if applicable):

$13^{\text {th }}$ century chancel and tower, however much of the interior is $19^{\text {th }}$ century thanks to an almost complete refurbishment in the $19^{\text {th }}$ century.

Surrounding landscape/natural features: The surrounding landscape is topographically flat, but primarily built upon. St Martin's parish is the oldest in Salisbury, existing even before Salisbury was built (i.e. was a village and became subsumed into Salisbury).

Visible relation to neighbouring sites/landscape: The church's tower is visible from many parts of Salisbury, and is located in a direct line east of the cathedral.

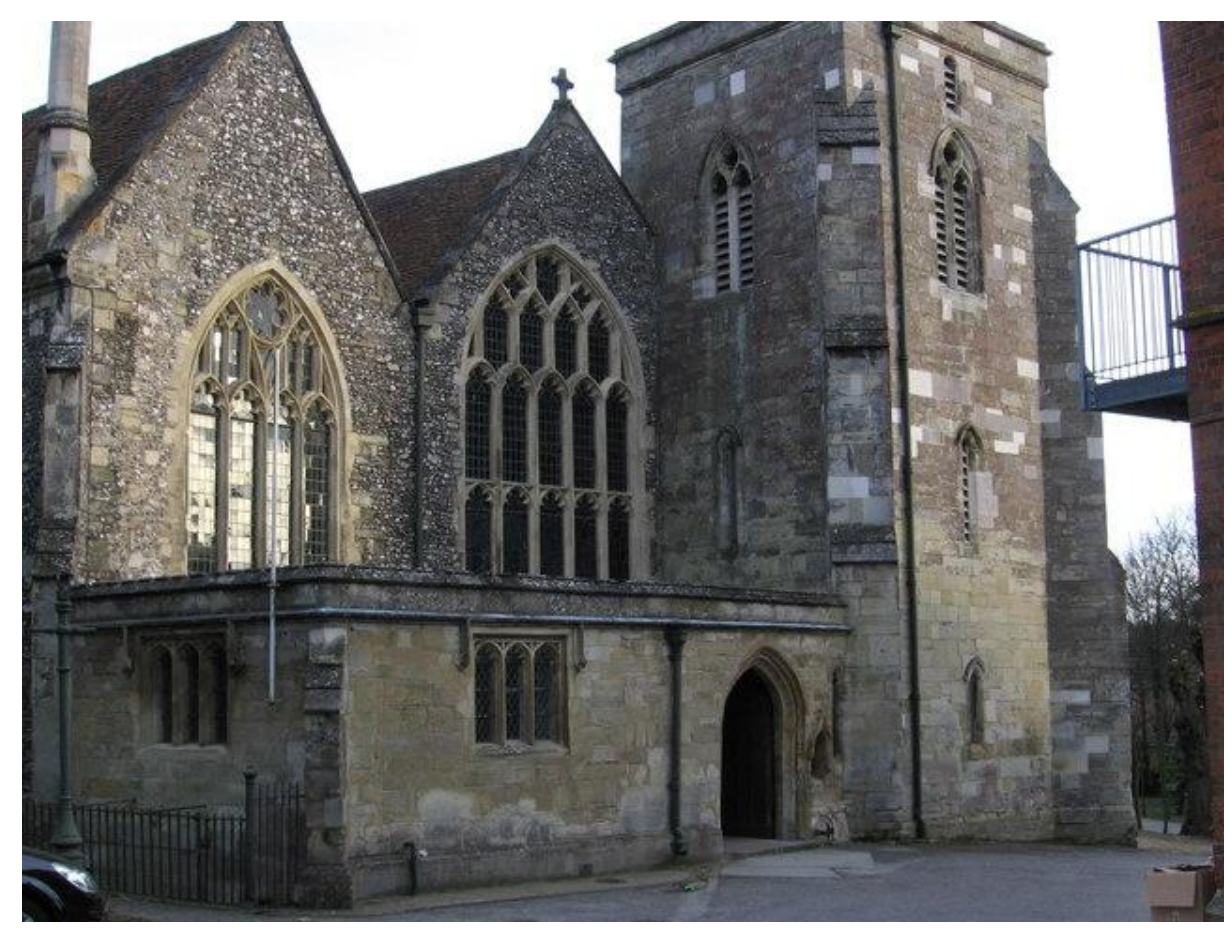

Photo reproduced from http://www.geograph.org.uk/photo/1184177 
Date: $16 / 11 / 11$

\section{Record \# 003}

Site/Artefact type: Cathedral

GPS coordinates: $\mathrm{N}: 51^{\circ} 03.862 \mathrm{~W}: 001^{\circ} 47.917$

Position related to route: Southerly end of High Street, through city gates and in the cathedral close.

Photo/Sketch record number(s): $1931-1951$

Date of site/artefact (if identifiable): 1288 (consecration date)

Dedication: St Mary

Description of site/artefact (including interior decoration if applicable):

Whilst the old cathedral was also Norman and built at Old Sarum, this was destroyed by fire in the early $13^{\text {th }}$ century. The new cathedral was finished and consecrated in 1288 , and houses the shrine of a former Salisbury bishop and saint - St Osmund. The Magna Carta is kept here. The cathedral is early English Gothic, with Britain's tallest tower and spire. A Chapter house and cloisters are also attached to the cathedral. The shrine to St OSmund is located in the retrochoir, consisting of a single stone sarcophagus slab, with lit candles. $15^{\text {th }}$ century records show a great number of richly decorated items (chalices etc) being kept at the cathedral.

Surrounding landscape/natural features: Mainly the town of Salisbury and some water-meadows to the southwest.

Visible relation to neighbouring sites/landscape: Situated in the centre of the Close, the cathedral dominates the Salisbury cityscape, the focal point of both the close and the route from Old to New Salisbury. 

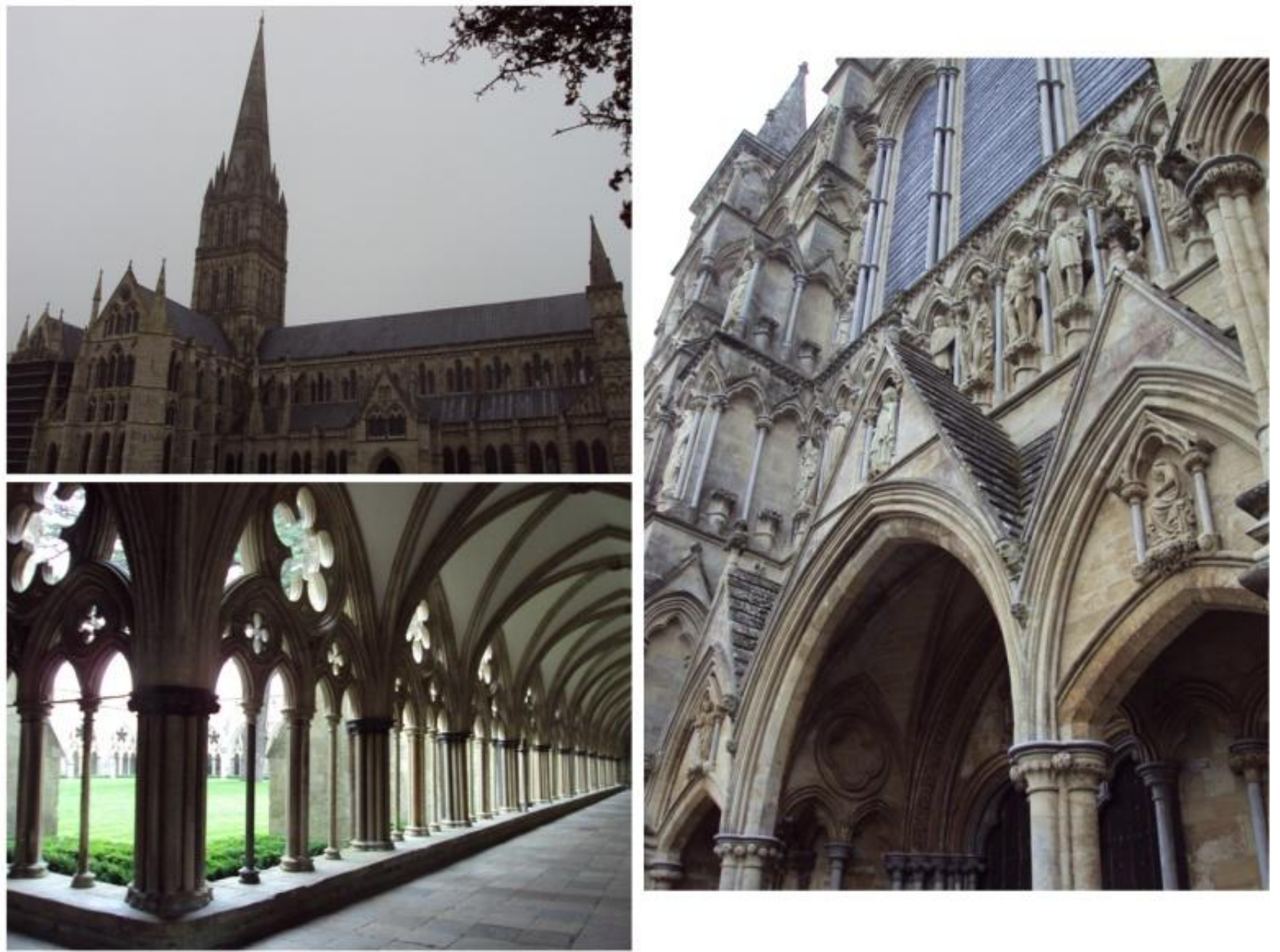
Date: $16 / 11 / 11$

\section{Record \# 004}

Site/Artefact type: Site of Old George Hotel

GPS coordinates: $\mathrm{N}: 51^{\circ} 04.068 \mathrm{~W}: 001^{\circ} 47.848$

Position related to route: On High Street.

Photo/Sketch record number(s): 1954

Date of site/artefact (if identifiable): $\quad 15^{\text {th }} \mathrm{C}$

Dedication: N/A

Description of site/artefact (including interior decoration if applicable):

The most important of the city's Medieval inns, the Old George Hotel (now part of a tea shop and plaza) has $14^{\text {th }}$ century timbers. Other inns were prevalent along this street, but all have since disappeared. The Red Lion in the north east of the city (Milford st) is apparently a $13^{\text {th }}$ century coaching inn, but there is no readily available evidence.

Surrounding landscape/natural features: The city/High Street.

Visible relation to neighbouring sites/landscape: Directly on the road to the cathedral close and cathedral, easily accessible from the route down from Old Sarum, and in from London (arriving from the east) and those arriving from the west.

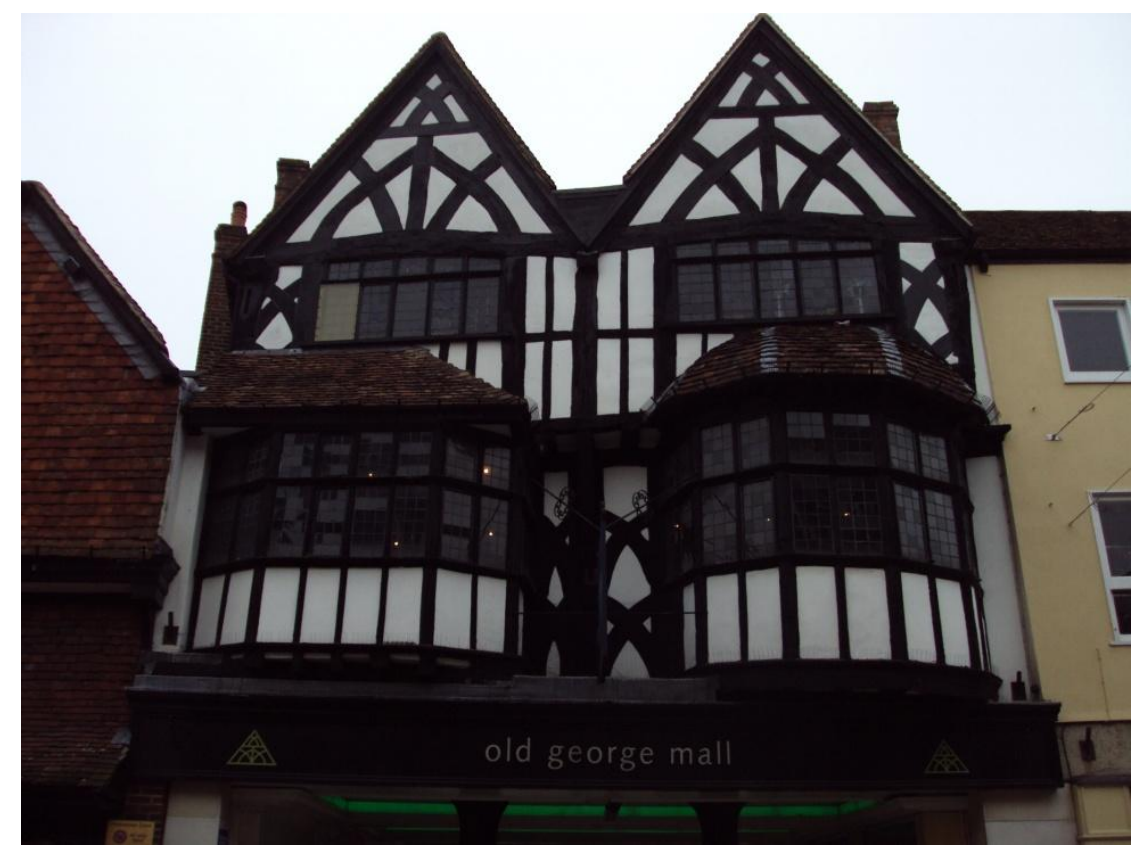


Date: $16 / 11 / 11$

\section{Record \# 005}

Site/Artefact type: Almshouse/Hospital

GPS coordinates: $\mathrm{N}: 51^{\circ} 03.400 \mathrm{~W}: 001^{\circ} 48.014$

Position related to route: South of cathedral, next to bridge crossing Avon (S entrance to Salisbury)

Date of site/artefact (if identifiable): $\quad 13^{\text {th }} \mathrm{C}$

Dedication: St Nicholas

Description of site/artefact (including interior decoration if applicable):

North and South ranges retain some features of the $13^{\text {th }}$ century building, however a major remodelling in the $19^{\text {th }}$ century has blocked most of the Medieval fabric from view. It is still an almshouse and hosts a Christian permanent community.

Surrounding landscape/natural features: River Avon to the south, and the cathedral with Salisbury High Street to the north

Visible relation to neighbouring sites/landscape: Very close to cathedral. On southern entrance to Salisbury so one of the first buildings to greet the traveller.

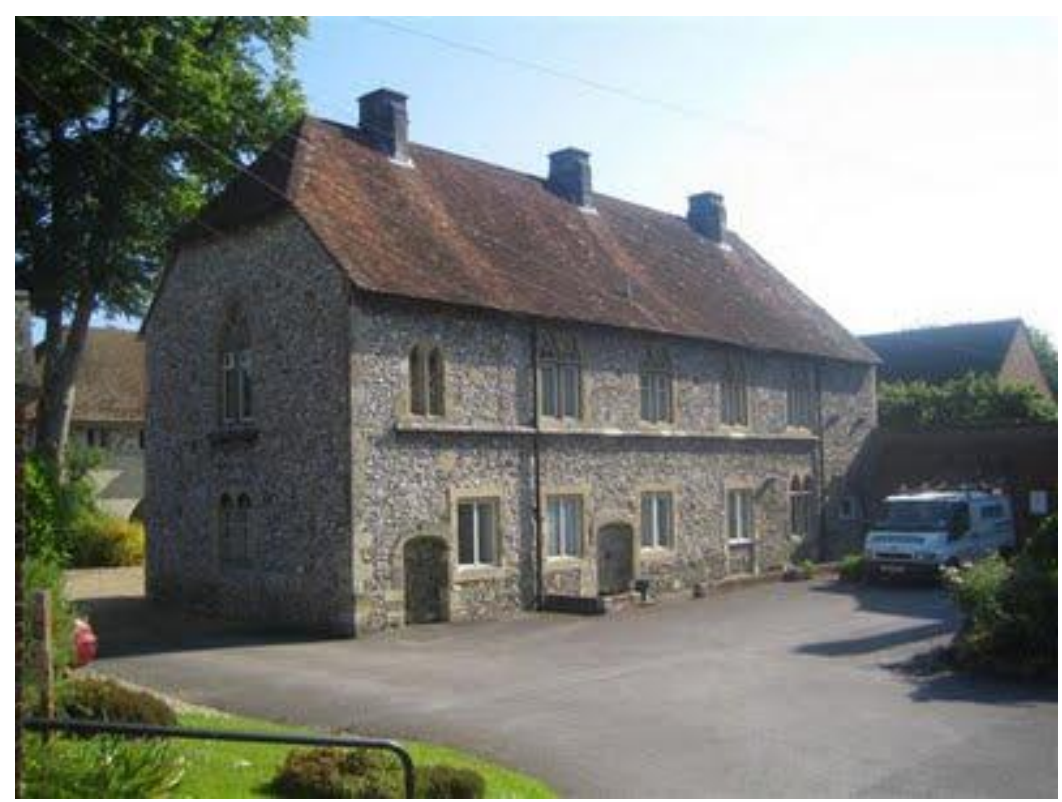

Photo reproduced from http://salisburyandstonehenge.net/photos/saint-nicholas-hospital 
Date: $16 / 11 / 11$

\section{Record \# 006}

Site/Artefact type: Hospital

GPS coordinates: $\mathrm{N}: 51^{\circ} 04.015 \mathrm{~W}: 001^{\circ} 48.037$

Position related to route: East of High Street, on New Street (eastern exit)

Date of site/artefact (if identifiable): $13^{\text {th }} \mathrm{C}$

Dedication: Holy Trinity

Description of site/artefact (including interior decoration if applicable): Now a pub ('The Cloisters'), whitewashed brick. Low tiled roof.

Surrounding landscape/natural features:

Salisbury streets

Visible relation to neighbouring sites/landscape: Near a main street, would have been where those arriving from Southampton entered the town.

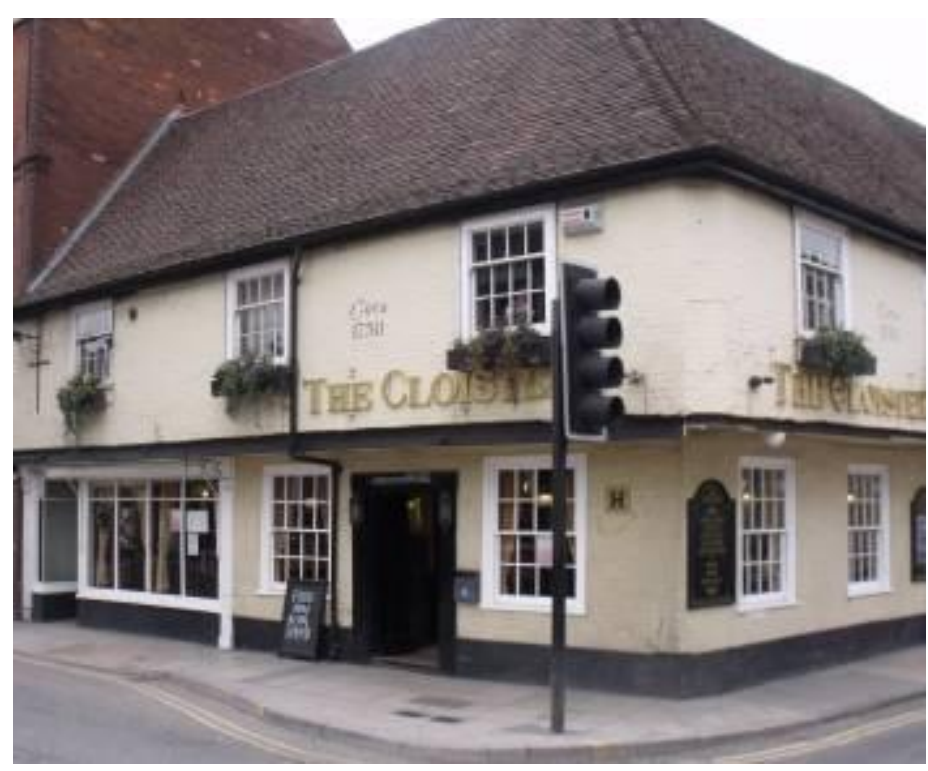

Photo reproduced from: http://www.salisburyvenues.co.uk/The-Cloisters-Pub-Salisbury.php 
Date: $16 / 11 / 11$

\section{Record \# 007}

Site/Artefact type: Medieval Hall

GPS coordinates: N: $51^{\circ} 03.915 \mathrm{~W}: 001^{\circ} 48.021$

Position related to route: Eastern edge of Cathedral close.

Photo/Sketch record number(s):

Date of site/artefact (if identifiable): $13^{\text {th }} \mathrm{C}$

Dedication: N/A

Description of site/artefact (including interior decoration if applicable):

Closed to the public. Timber framed roof, central (original) hearth, minstrel's gallery. Designed for entertaining, possibly a hosting venue for high status pilgrims and guests.

Surrounding landscape/natural features:

The cathedral close/green.

Visible relation to neighbouring sites/landscape: only 200 yards from the cathedral, it would have been within its shadow before modern buildings were constructed. Very much gives the impression of being linked with the hospitality (high status) of the cathedral's guests.

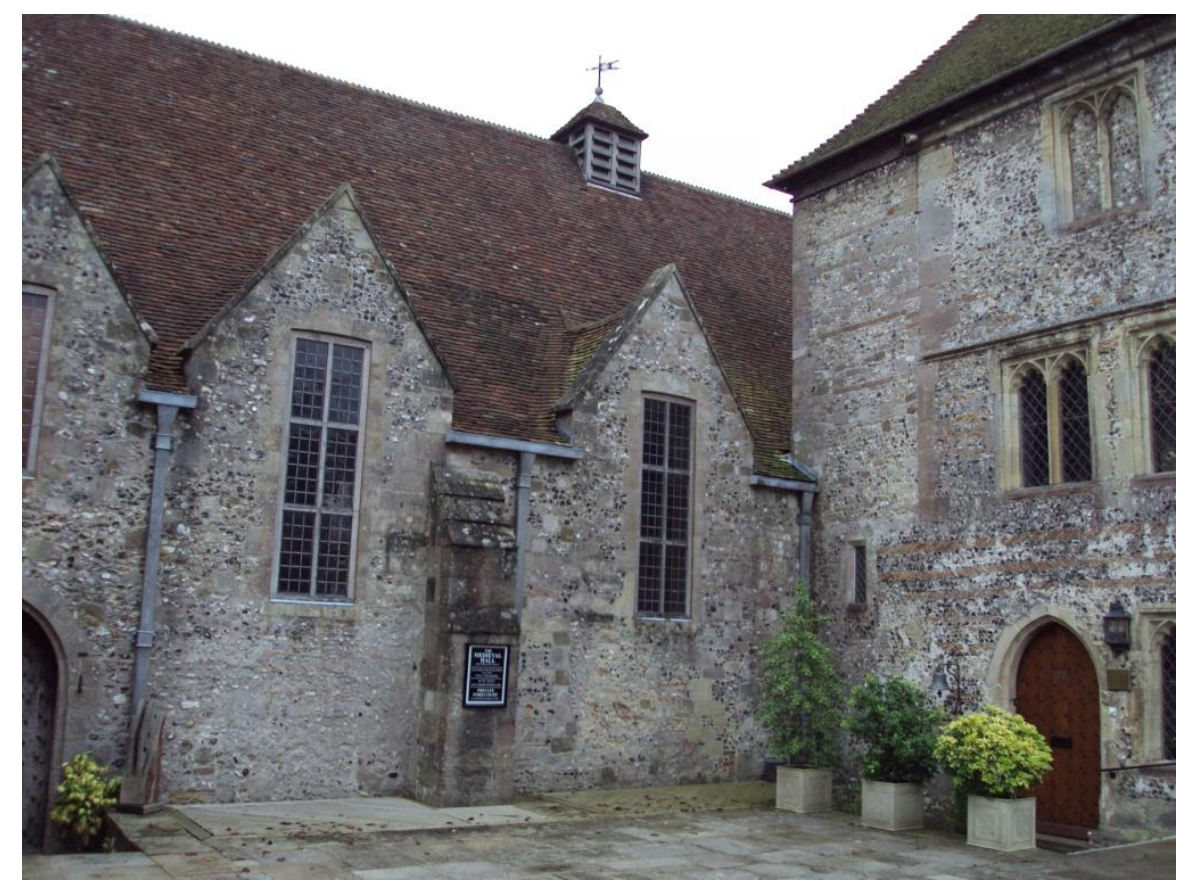


Date: $17 / 11 / 11$

\section{Record \# 008}

Site/Artefact type: Roman Road (course of and surviving track)

GPS coordinates: N/A

Position related to route: Links Old Sarum with Winchester

Photo/Sketch record number(s):

Date of site/artefact (if identifiable): Roman

Dedication: N/A

Description of site/artefact (including interior decoration if applicable):

The road varies in terms of its current visibility and manifestation. Sometimes a currently used road ( e.g. 'Old Sarum rd leading into Winchester), sometimes a surviving cobbled track, sometimes a discernable bridleway and path, other times a crop mark in the fields.

Surrounding landscape/natural features: Countryside of Wiltshire.

Visible relation to neighbouring sites/landscape: Provides most direct route between the two settlements.

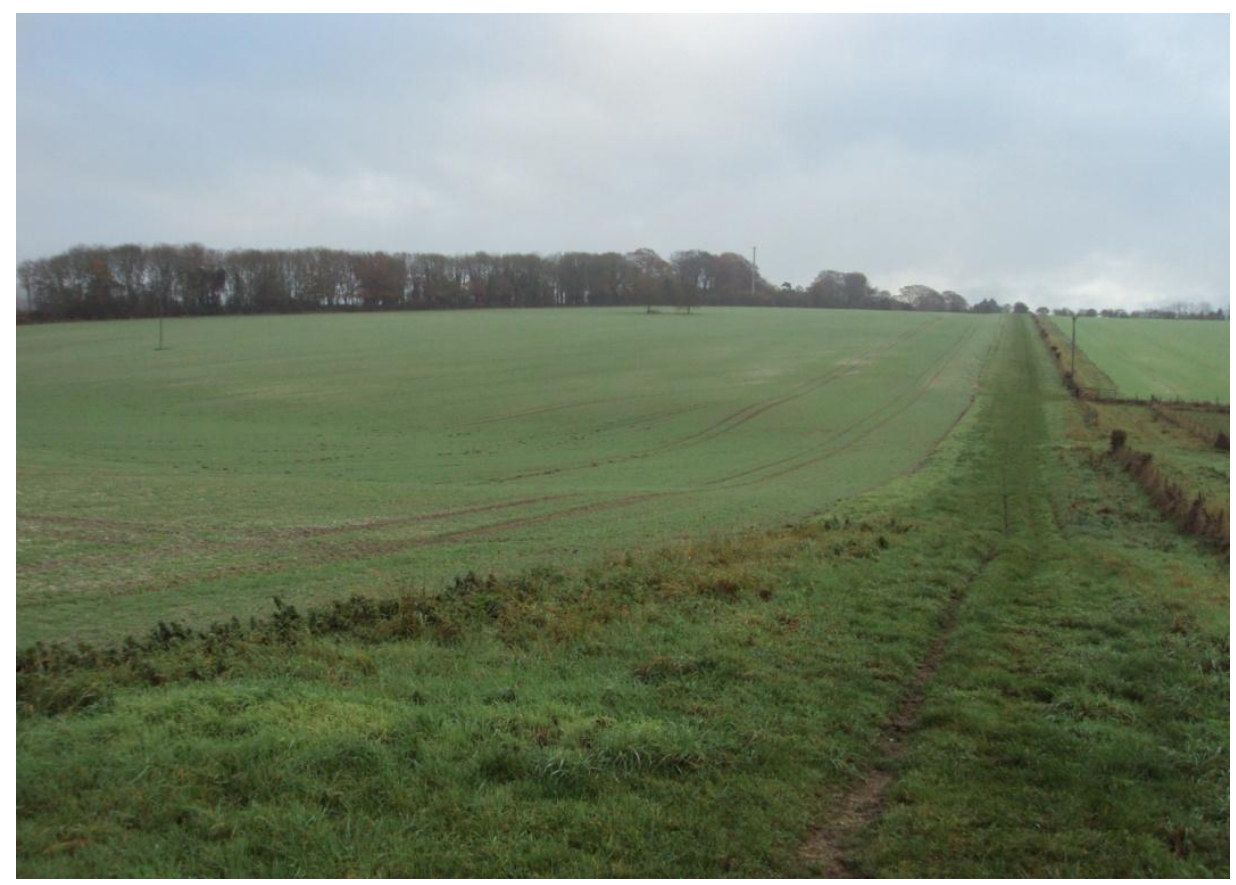


Date: $17 / 11 / 11$

\section{Record \# 009}

Site/Artefact type: Church

GPS coordinates: $\mathrm{N}: 51^{\circ} 05.153 \mathrm{~W}: 001^{\circ} 35.458$

Position related to route: West Winterslow

Photo/Sketch record number(s):

Date of site/artefact (if identifiable): 11th

Dedication: All Saints

Description of site/artefact (including interior decoration if applicable): Small parish church off main high street of village. Perpendicular with flint nodule walls, typical parish church, locked.

Surrounding landscape/natural features: Mainly fields, small patches of forest and parish villages.

Visible relation to neighbouring sites/landscape: a few hundred metres south to course of Roman road.

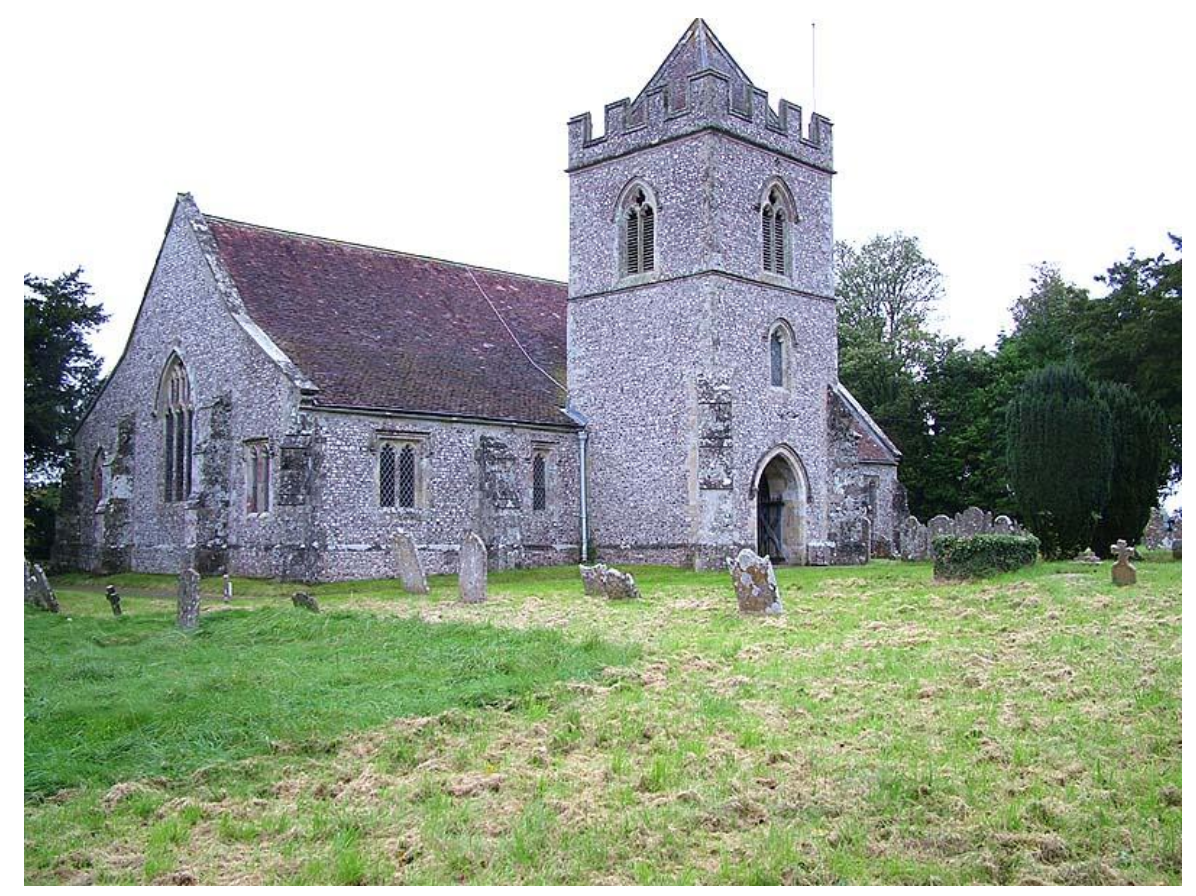

Reproduced from http://history.wiltshire.gov.uk/community/getimage.php?id=3901 
Date: $17 / 11 / 11$

\section{Record \# 010}

Site/Artefact type: Cobhill Barrow

GPS coordinates: $\mathrm{N}: 51^{\circ} 05.153 \mathrm{~W}: 001^{\circ} 35.458$

Position related to route: On route as it enters Middle Winterslow.

Photo/Sketch record number(s):

Date of site/artefact (if identifiable): Bronze Age.

Dedication: N/A

Description of site/artefact (including interior decoration if applicable): Large barrow, covered in fallen leaves, appears as travellers exits small wooded section and begins to enter Middle Winterslow. West \& East Winterslow are the original Medieval settlements, therefore the barrow would have been without an urban context during the Middle Ages. Legend of golden coffin buried in the area. Not particularly noticeable from current path due to incline and tree cover, however if stripped of trees its location on a natural rise in the landscape may have made it a more prominent feature.

Surrounding landscape/natural features: Mainly fields, small patches of forest and parish villages.

Visible relation to neighbouring sites/landscape: Adjacent to course of Roman road

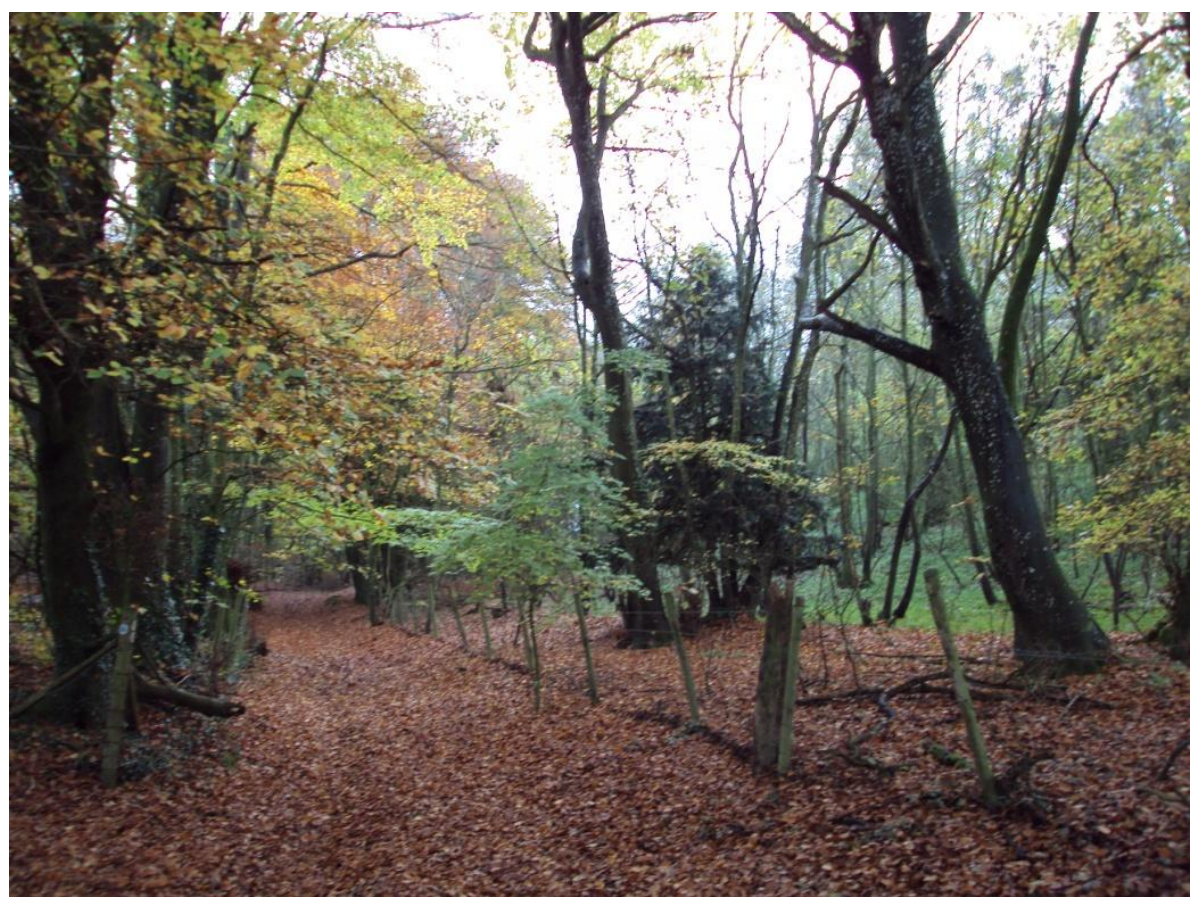


Date: $17 / 11 / 11$

\section{Record \# 011}

Site/Artefact type: Mottisfont Priory

GPS coordinates: N: $51^{\circ} 04.137$ W: $001^{\circ} 30.358$

Position related to route: 2 miles south of River Test crossing

Date of site/artefact (if identifiable): $\quad$ 13th

Dedication: Holy Trinity

Description of site/artefact (including interior decoration if applicable): Large Priory building now part of an estate. Visible remains of Medieval fabric, but mostly replaced by mid-18 $8^{\text {th }}$ century alterations. Church has disappeared. Closed!

Surrounding landscape/natural features: Mainly fields, small patches of forest and parish villages.

Visible relation to neighbouring sites/landscape: Not visible from of Roman road, however may have been a known feature of the local landscape and easy to access.

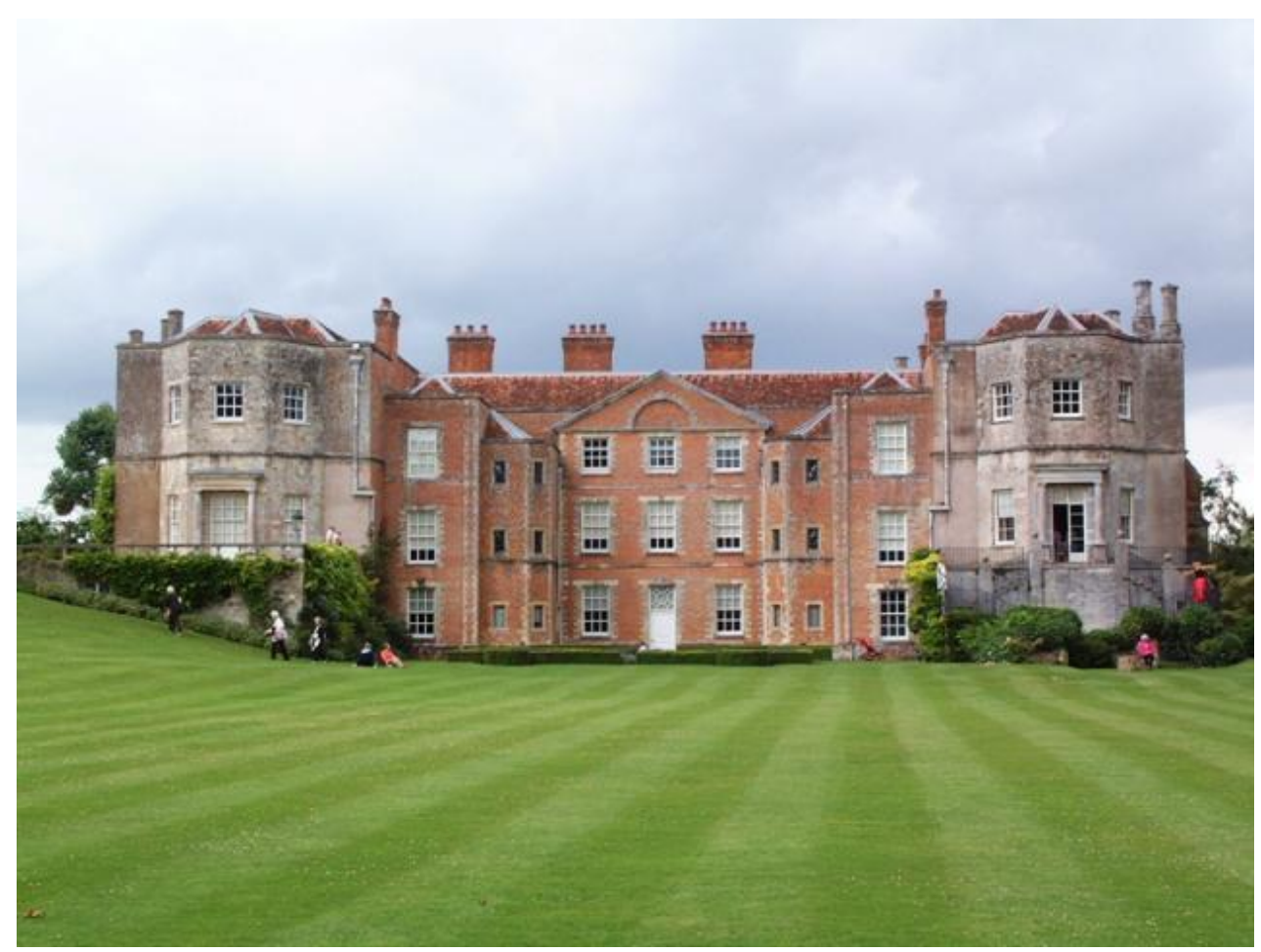

Photo reproduced from http://stockbridge-hampshire.org.uk/stockbridge-hampshire/section/PlacesofInterest/ 
Date: $17 / 11 / 11$

\section{Record \# 0012}

Feature: River Test

GPS coordinates: $\mathrm{N}: 51^{\circ} 04.242 \mathrm{~W}: 001^{\circ} 30.473$

Photo/Sketch record number(s):

Position related to route: On route of Roman road crossing over from Wiltshire to Hampshire (Bossington to Horsebridge).

Point at which visible from the route: Only really visible when one enters the small river valley between the two settlements.

Surrounding features: Small patches of forest, fields and some marshy terrain.

Interaction between feature \& pilgrim (slope, shelter, dominance of view etc): Significant point as marks both the boundary between the two counties, and also a rough halfway marker on the journey between Salisbury and Winchester.

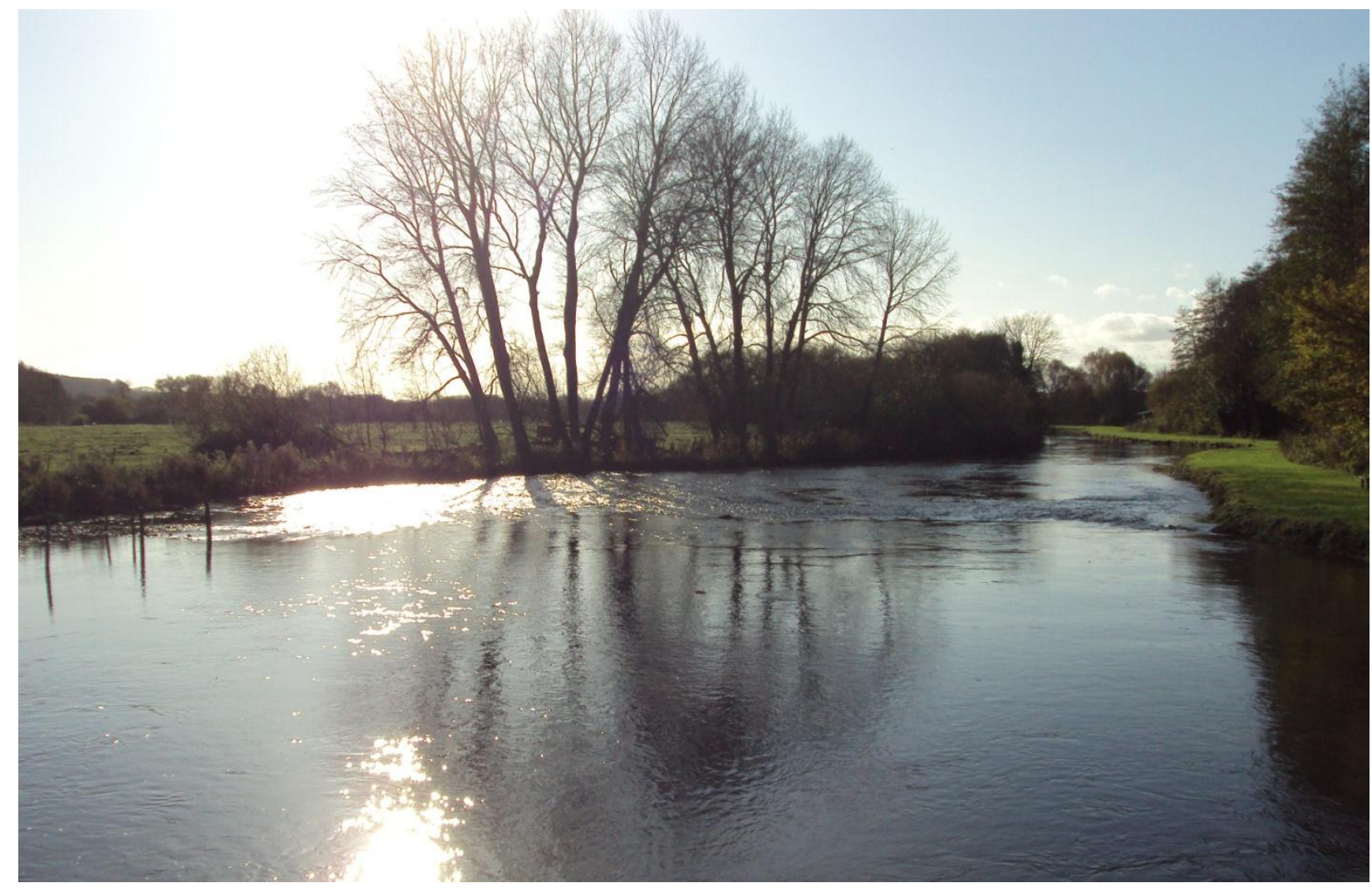


Date: $18 / 11 / 11$

\section{Record \# 013}

Site/Artefact type: Church

GPS coordinates: $\mathrm{N}: 51^{\circ} 03.819 \mathrm{~W}: 001^{\circ} 19.161$

Position related to route: Kings Somborne

Date of site/artefact (if identifiable): 12 th

Dedication: SS Peter \& Paul

Description of site/artefact (including interior decoration if applicable):

Norman church, small spire which is visible from Roman road.

Surrounding landscape/natural features: village of Kings Somborne and agricultural land.

Visible relation to neighbouring sites/landscape: This is just visible from the Test crossing and the Roman road course.

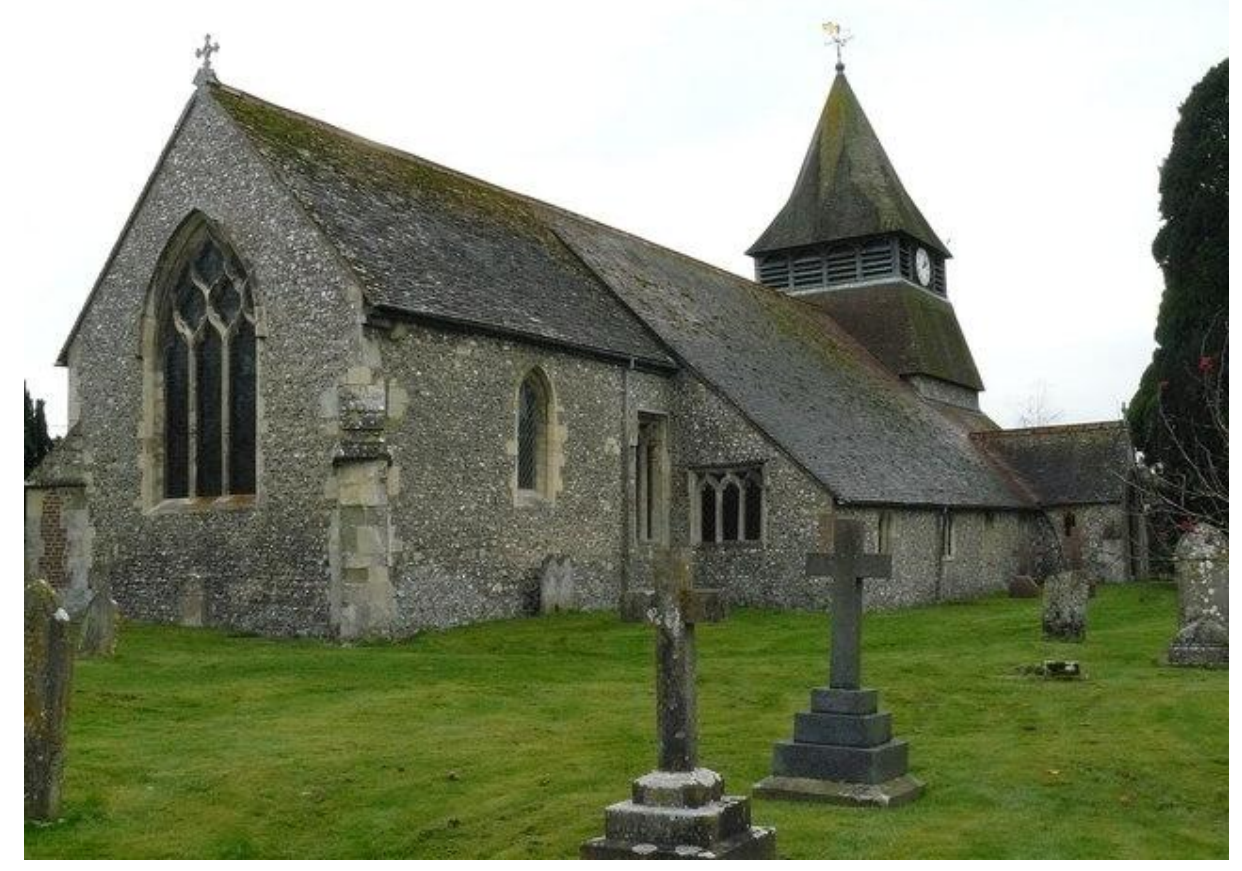

Reproduced from http://www.aboutbritain.com/towns/kings-somborne.asp 
Date: $18 / 11 / 11$

\section{Record \# 014}

Site/Artefact type: West Gate at Winchester

GPS coordinates: $\mathrm{N}: 51^{\circ} 03.814 \mathrm{~W}: 001^{\circ} 19.151$

Position related to route: at entrance to Winchester city proper and High Street from Old Sarum rd/Romsey rd.

Photo/Sketch record number(s): 1192

Date of site/artefact (if identifiable): 12 th

Dedication: N/A

Description of site/artefact (including interior decoration if applicable):

One of two fortified Medieval gateways into the city, Westgate was built in the early $12^{\text {th }}$ century, with later additions from the $13^{\text {th }}$ and $14^{\text {th }}$ centuries. When defensive needs of the city lessened in later centuries it was used as a debtors prison and gaol. There remains the three arches (the central being the original and widest, of a size able to admit arts etc), the parapet, lead lined windows and exterior moulding.

Surrounding landscape/natural features: Around the site are the building of Winchester, and the slope down towards the High street.

Visible relation to neighbouring sites/landscape: This would gateway (along with Southgate, which was sited where Southgate street meets St Swithun street) would be the only way for those arriving at Winchester in the Medieval period to pass through the city walls to the High st and Catehdral close beyond.

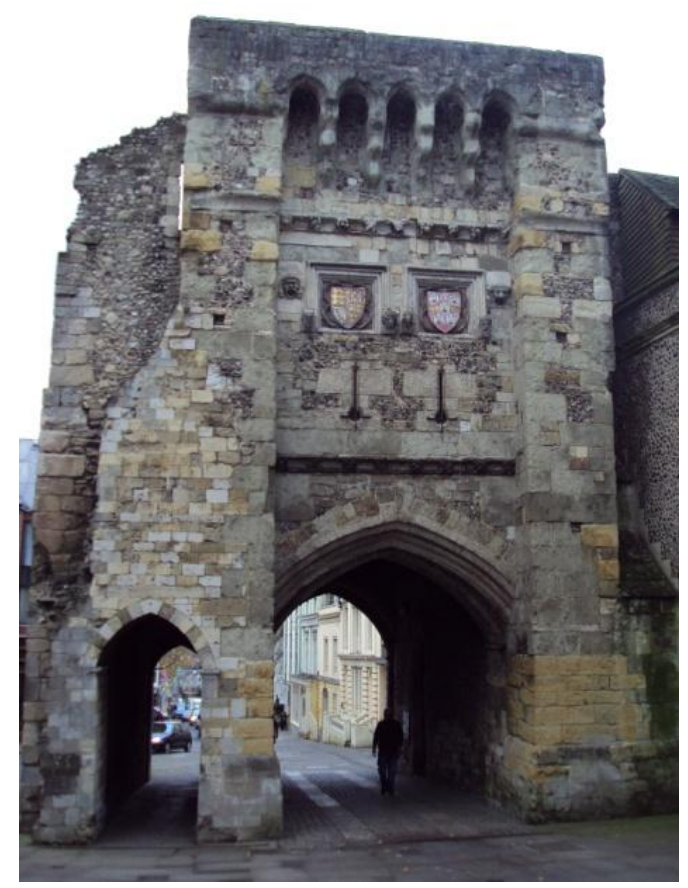


Date: $18 / 11 / 11$

\section{Record \# 015}

Site/Artefact type: Chapel/Hospital of St John the Baptist

GPS coordinates: $\mathrm{N}: 51^{\circ} 03.688 \mathrm{~W}: 001^{\circ} 18.567$

Position related to route: Westernmost end (bottom) of the High Street, before the bridge over the river Itchen.

Photo/Sketch record number(s): 1993

Date of site/artefact (if identifiable): $\quad 10^{\text {th }}$ century

Dedication: St John the Baptist

Description of site/artefact (including interior decoration if applicable):

Believed to have been founded in 935 by St Brinstan, Bishop of Winchester. The house has a vaulted kitchen, part of the original Anglo Saxon Alms-house. Re-founded in 1289 by John Le Devenish, and his descendent (John Devendish) in 1428 founded the chapel present at the north side. Built in order to provide care for 'sick and lame soldiers, poor pilgrims and wayfaring men'.

Surrounding landscape/natural features: The River Itchen \& St Giles Hill. On St Giles Hill a fair was held every September which in the late $11^{\text {th }}$ century was the largest of its kind in Europe.

Visible relation to neighbouring sites/landscape: No doubt in Medieval cityscape (especially looking eastwards and/or down from St Giles Hill) it would have been a prominent feature.

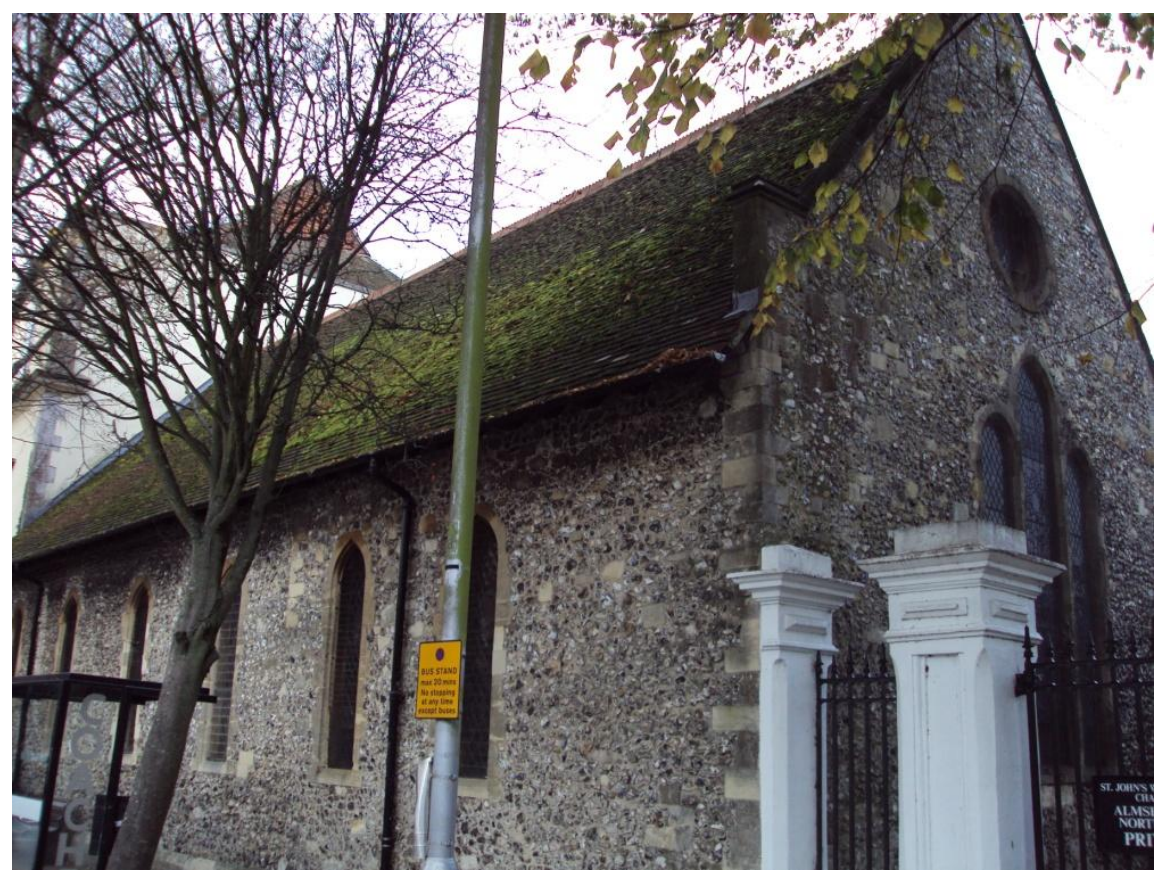




\section{Date: 18/11/11 Record \# 016}

Site/Artefact type: Nunnaminster

GPS coordinates: N: $51^{\circ} 03.675$ W: $001^{\circ} 18.614$

Position related to route: South of Highstreet, near the Cathedral.

Photo/Sketch record number(s): 1994 - 1998

Date of site/artefact (if identifiable): $\quad 903$

Dedication: St Mary \& St Edburga

Description of site/artefact (including interior decoration if applicable):

Founded by Queen Ealhswith, the wife of Alfred the Great, The Nunnaminster (which later became St Mary's Abbey) was one of Winchester's three Late Anglo Saxon monestaries, and one of the foremost centres of at and learning in England. In 964, the Old Minster, New Minster and Nunnaminster were brought into a single enclosure, requiring much rebuilding. Another rebuild after the Norman Conquest saw it being re-named St Mary's Abbey, and it was dissolved in 1539 during the Dissolution. A church existed here which was open to the laity.

Surrounding landscape/natural features: Nearby are St Giles Hill and the River Itchen.

Visible relation to neighbouring sites/landscape: When standing this would have been a fairly large complex, and thus highly visible and influential, not to mention noisy. This contributed to the ecclesiastical complex which surrounded the cathedral, with its own administrative etc buildings.

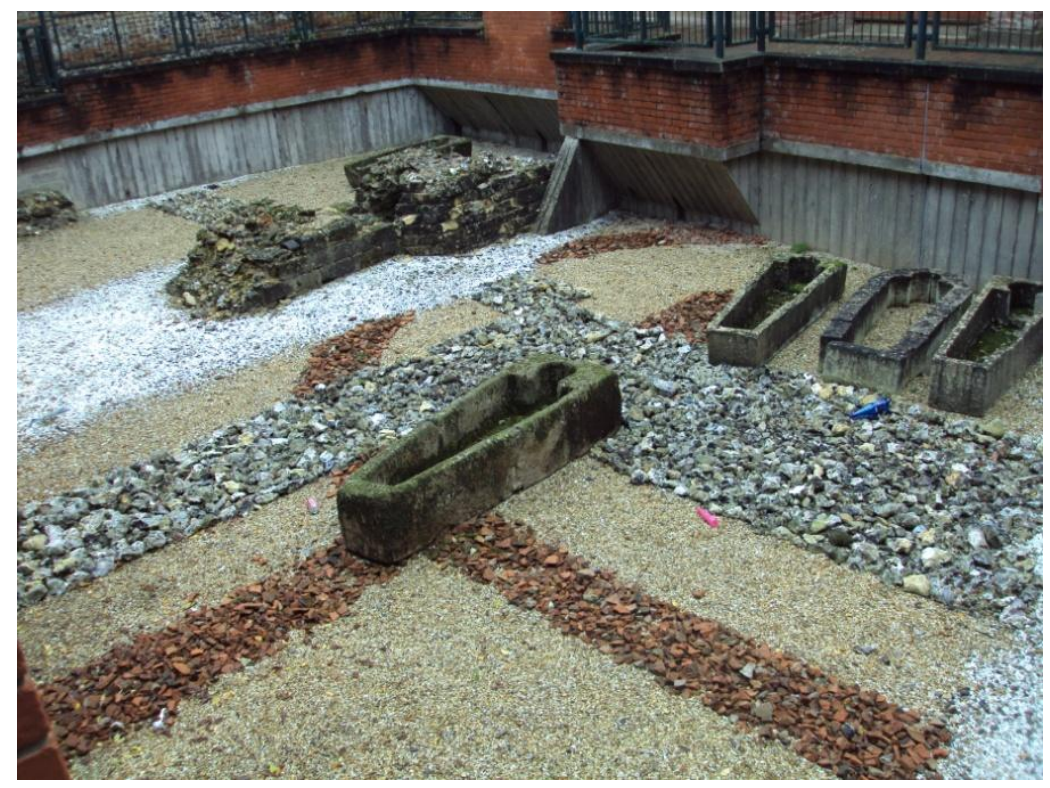


Date: $18 / 11 / 11$

\section{Record \# 017}

Site/Artefact type: The Eclipse Inn

GPS coordinates: $\mathrm{N}: 51^{\circ} 03.723 \mathrm{~W}: 001^{\circ} 18.887$

Position related to route: Between the High Street (Buttercross) and the Cathedral grounds.

Photo/Sketch record number(s): 1999

Date of site/artefact (if identifiable): 16 th

Dedication: N/A

Description of site/artefact (including interior decoration if applicable):

Allegedly built in 1540 although may be older. Was initially a rectory but was later used as an inn. In the 1350's enterprising residents of the High Street started selling souvenirs, food and drink to pilgrims from the bottom of their gardens. These stalls eventually became permanent shops and inns to form what is now The Square, including the Eclipse Inn.

Surrounding landscape/natural features: Town.

Visible relation to neighbouring sites/landscape: Situated in the square adjacent to the Cathedral where markets and traders set up stalls.

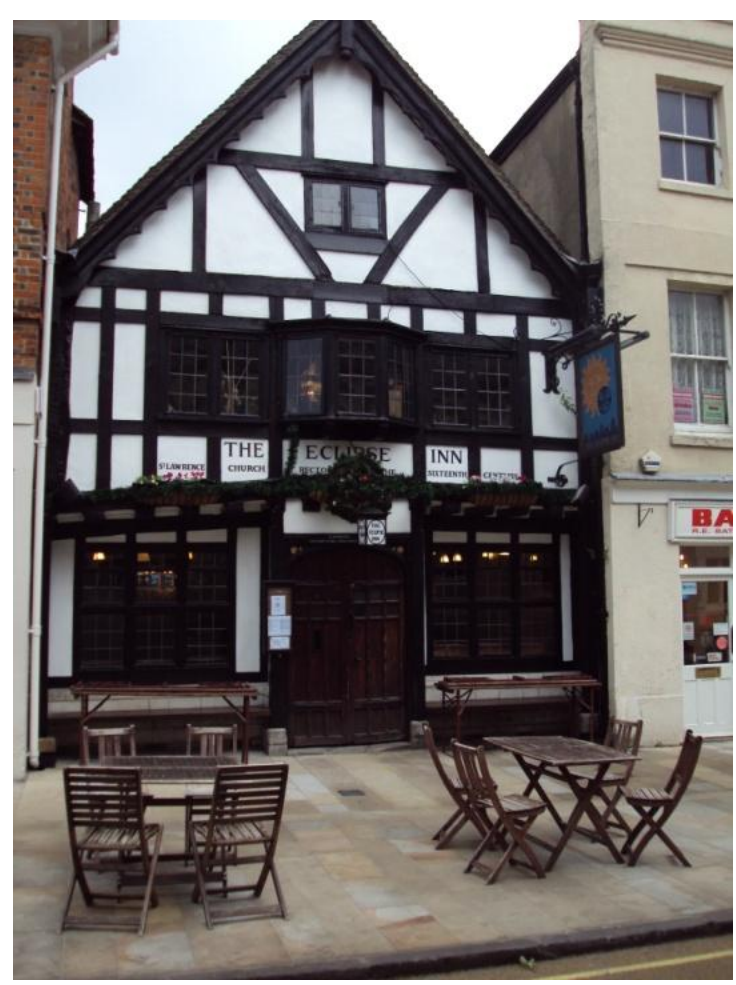


Date: $18 / 11 / 11$

\section{Record \# 018}

Site/Artefact type: Cathedral

GPS coordinates: $\mathrm{N}: 51^{\circ} 03.661 \mathrm{~W}: 001^{\circ} 18.862$

Position related to route: Centre of Winchester, in a Close.

Photo/Sketch record number(s): $2000-2024$

Date of site/artefact (if identifiable): 11th

Dedication: SS Paul, Peter \& Swithun, \& the Holy Trinity.

Description of site/artefact (including interior decoration if applicable):

Completed in 1093, the new minster replaced the Old Minster, and the monks moved into the new cathedral. During the $14^{\text {th }}$ century much of the building was remodelled, and this Gothic style pervades today. The retroquire was remodelled in order to accommodate the droves of pilgrims which arrived to pay tribute to St Swithun. His shrine lay in this eastern most part of the church behind the high altar, and was richly studded with jewels and precious metals. In the late 15t century a limestone screen was commissioned which displayed numerous Saxon bishops and saints, also destroyed in the reformation. The entire cathedral was lavishly decorated, including a series of surviving wall paintings which display Christ being taken down from the cross and placed in his tomb (these are in the Holy Sepulchre Chapel).

Surrounding landscape/natural features:

Surrounded by the greenery of the cathedral close.

Visible relation to neighbouring sites/landscape: All other ecclesiastical sites seem to radiate out from this site. The tower is visible from a great distance (particularly from the elevated points of St Catherine's Hill \& St Giles Hill). 

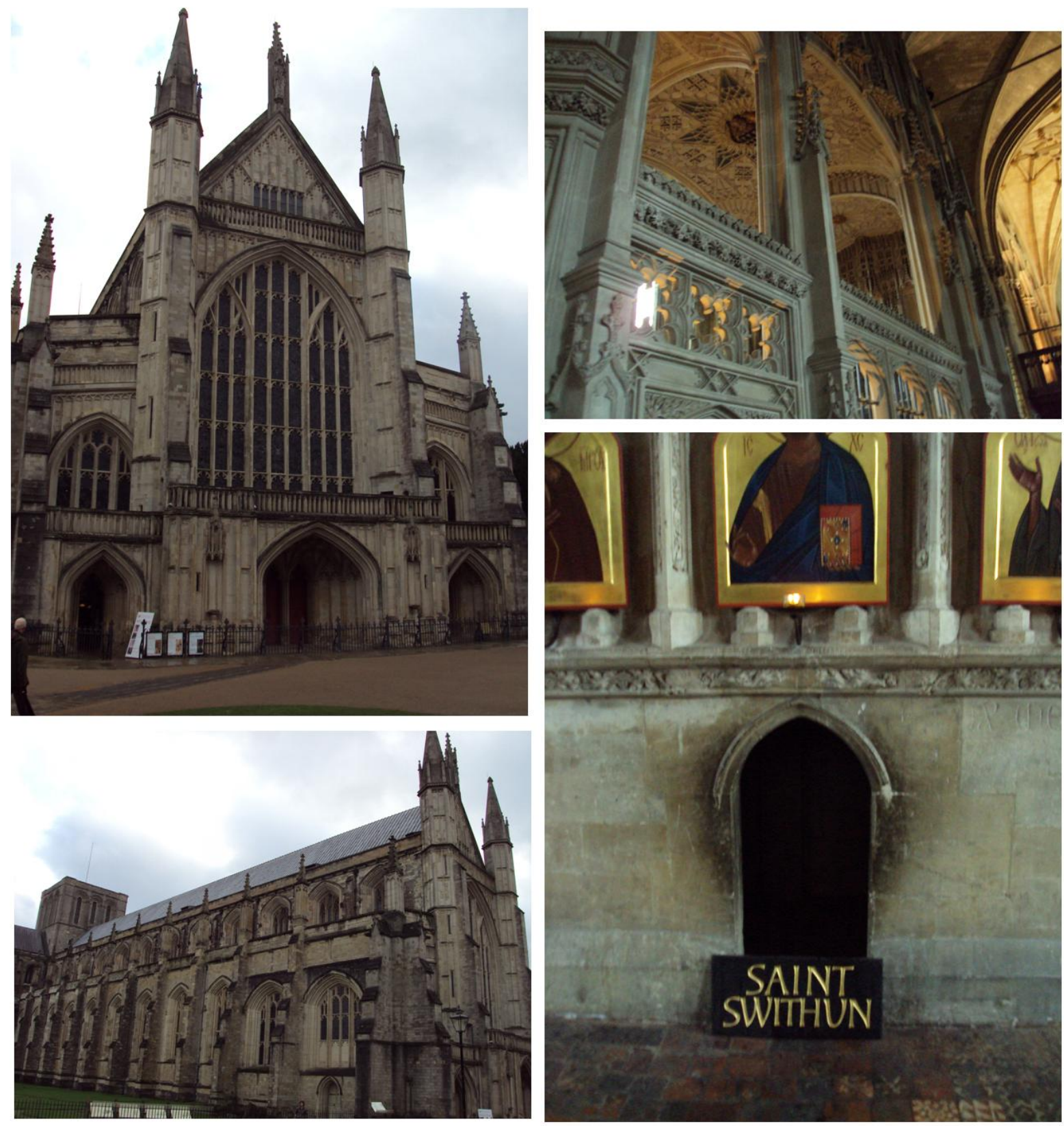
Date: $18 / 11 / 11$

\section{Record \# 019}

Site/Artefact type: Church

GPS coordinates: $\mathrm{N}: 51^{\circ} 03.458 \mathrm{~W}: 001^{\circ} 18.980$

Position related to route: On St Michael's Passage, Kingsgate st. South of Cathedral.

Photo/Sketch record number(s): 2025-2026

Date of site/artefact (if identifiable): Late 14th

Dedication: St Michael

Description of site/artefact (including interior decoration if applicable): Tower with buttressed walls. Flint faced. Near site of Carmelite Friary.

Surrounding landscape/natural features: Winchester college buildings, watermeadows.

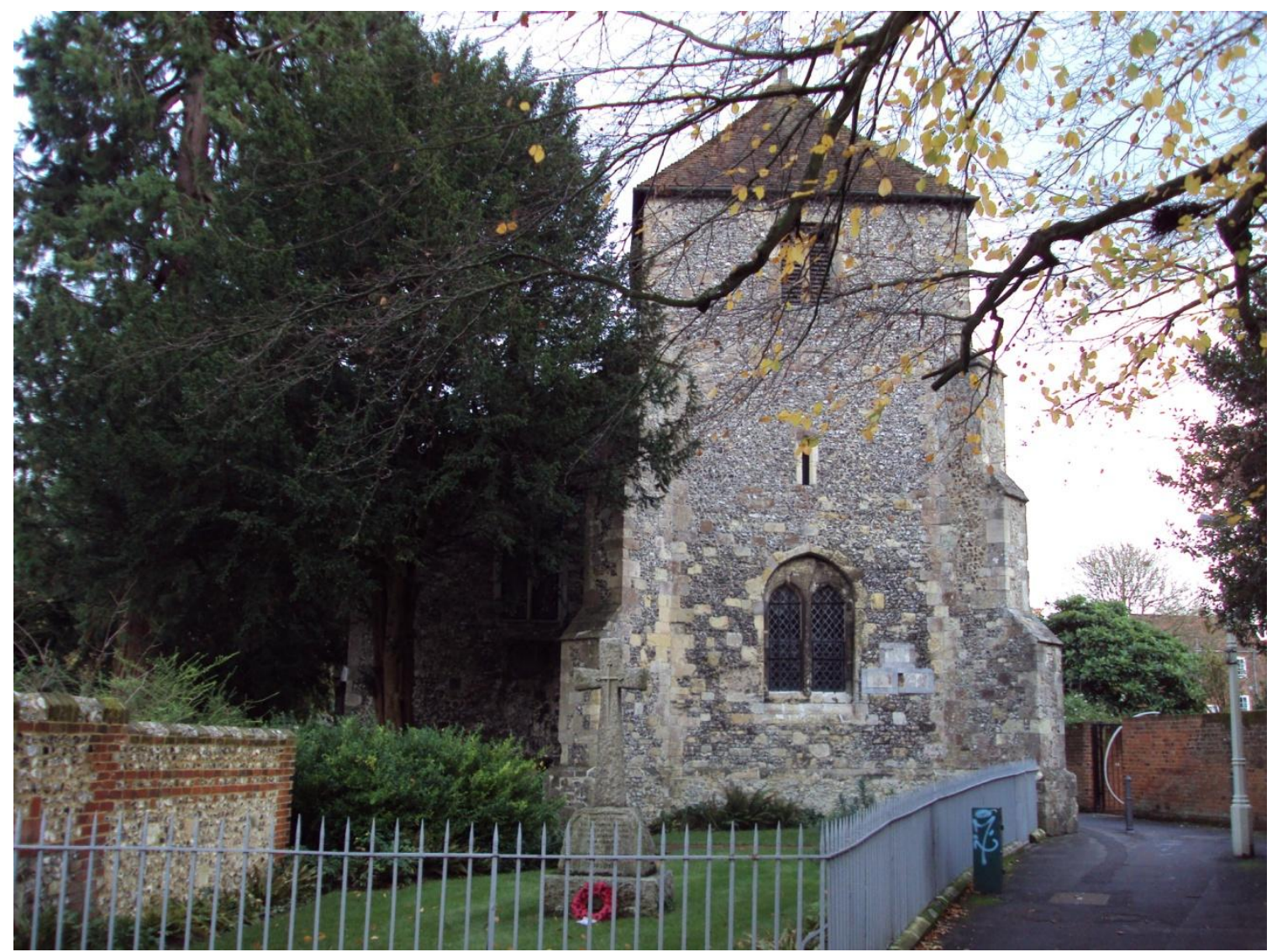


Date: $18 / 11 / 11$

\section{Record \# 020}

Site/Artefact type: St Cross Hospital \& Church of St Faith

GPS coordinates: $\mathrm{N}: 51^{\circ} 02.882 \mathrm{~W}: 001^{\circ} 19.301$

Position related to route: Outer southern perimeter of Winchester, on St Cross rd (a Roman road leading southwards out of Winchester)

Photo/Sketch record number(s): $2027-2028$

Date of site/artefact (if identifiable): 1136

Dedication: St Cross \& St Faith

Description of site/artefact (including interior decoration if applicable):

Founded by Henry of Blois, this complex consisted of a church flanked by hospital buildings. This was enlarged to include a 'hundred men's hall' and further administrative and living quarters in the $15^{\text {th }}$ century, forming two quadrangles. Founded to support 13 men who were unable to work, and to feed 100 men at its gates, it is the oldest charitable institution and largest Medieval alms-house in England.

Surrounding landscape/natural features: It backs onto the River Itchen, and is across the river from St Catherine's Hill. Watermeadows are also spread out from its grounds.

Visible relation to neighbouring sites/landscape: The church's height is more like a small cathedral, and as such is highly visible when viewed from the south (looking towards Winchester) or from the rural land at the west. It is at the southern entrance to Winchester, a convenient point for those arriving from Southampton along the Roman road.

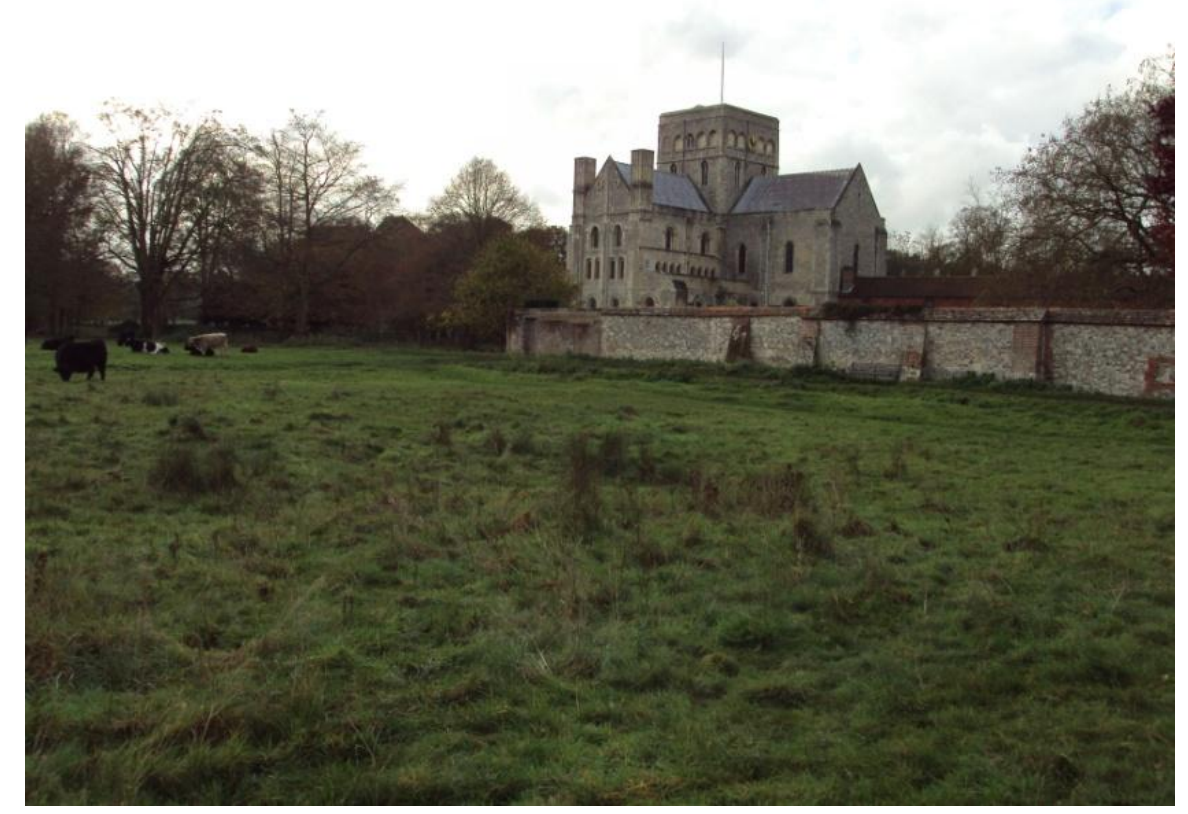


Date: $18 / 11 / 11$

\section{Record\# 021}

Site/Artefact type: The Pilgrims' Hall

GPS coordinates: $\mathrm{N}: 51^{\circ} 03.563 \mathrm{~W}: 001^{\circ} 18.778$

Position related to route: Located in the Cathedral Close, next to the Dean's garden.

Photo/Sketch record number(s): 2035 - 2039

Date of site/artefact (if identifiable): 1300

Dedication: N/A

Description of site/artefact (including interior decoration if applicable):

Six bay medieval building consisting of two halls lying end to end - the north end being the 'Pilgrims' Hall' ( $19^{\text {th }}$ century name). The roof is hammer beam and features some figure head carvings. Was part of the hostelry used to accommodate pilgrims visiting St Swithun's shrine. Left overs from the Deans banquets would be diostributed to those who spent the night at the hall.

Surrounding landscape/natural features: N/A

Visible relation to neighbouring sites/landscape: Proximity to the ecclesiastical complex of the Cathedral at outer perimeter of the Close, hierarchy of function (i.e. for laity not monastic or high status).

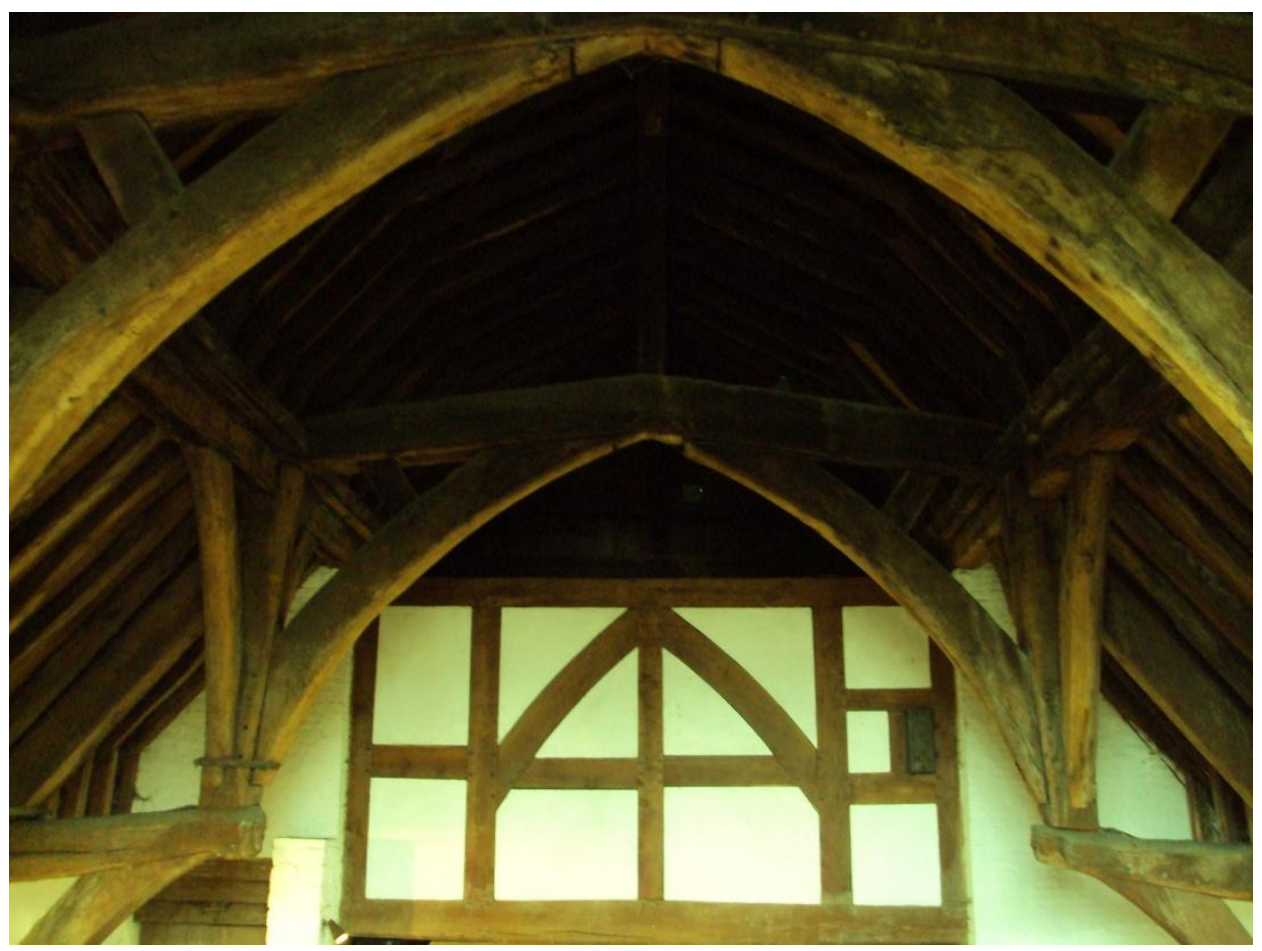


Date: $18 / 11 / 11$

\section{Record \# 022}

Site/Artefact type: Church

GPS coordinates: $\mathrm{N}: 51^{\circ} 03.537 \mathrm{~W}: 001^{\circ} 18.721$

Position related to route: Located in the Cathedral Close, next to the Dean's garden.

Date of site/artefact (if identifiable): $\quad 15^{\text {th }}$ century

Dedication: St Lawrence

Description of site/artefact (including interior decoration if applicable):

Small yet tall church off the High Street. Interior is cramped, stone faced and late Medieval in design.

Surrounding landscape/natural features: Winchester townscape and cathedral green

Visible relation to neighbouring sites/landscape: On route from High Street to Cathedral green - next to Buttercross.

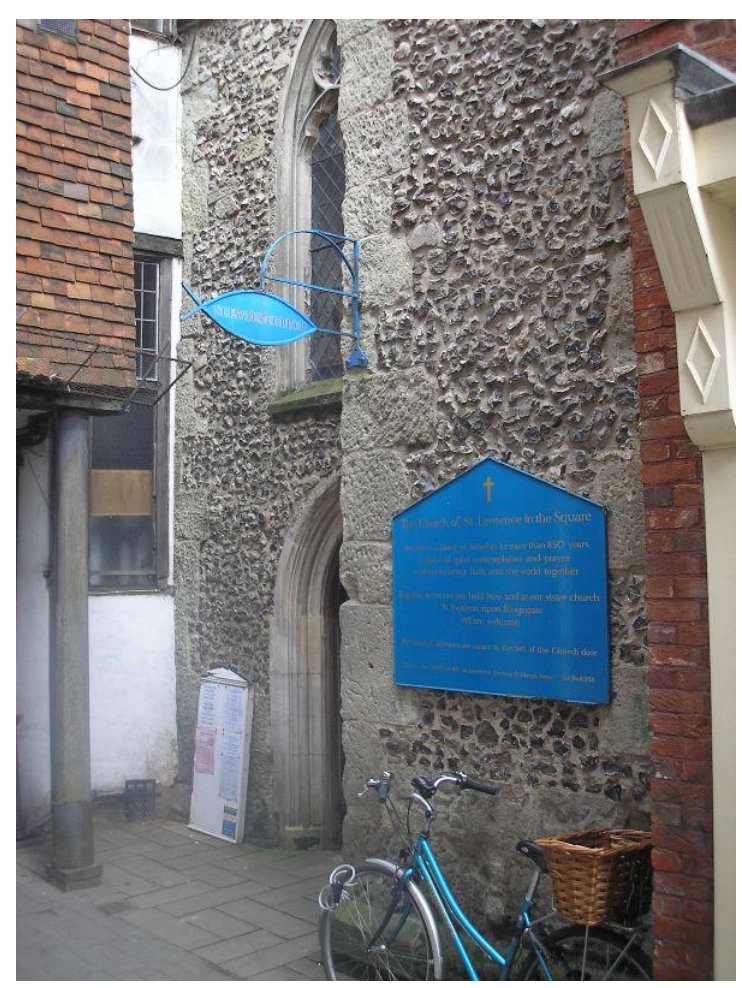

Reproduced from

http://www.genuki.org.uk/big/eng/HAM/churches/Winchester/Winchester_StLawrence.shtml 
Date: $18 / 11 / 11$

\section{Record \# 023}

Site/Artefact type: Church

GPS coordinates: N: $51^{\circ} 03.532 \mathrm{~W}: 001^{\circ} 18.714$

Position related to route: In cathedral close, above Kingsgate

Date of site/artefact (if identifiable): $\quad 13^{\text {th }}$ century

Dedication: St Swithun

Description of site/artefact (including interior decoration if applicable):

Minute church atop the Kingsgate, has remains of Medieval fabric inside.

Surrounding landscape/natural features: Winchester town/St Swithun Priory grounds

Visible relation to neighbouring sites/landscape: Marks the entrance from the secular town into the precinct of the St Swithun Priory

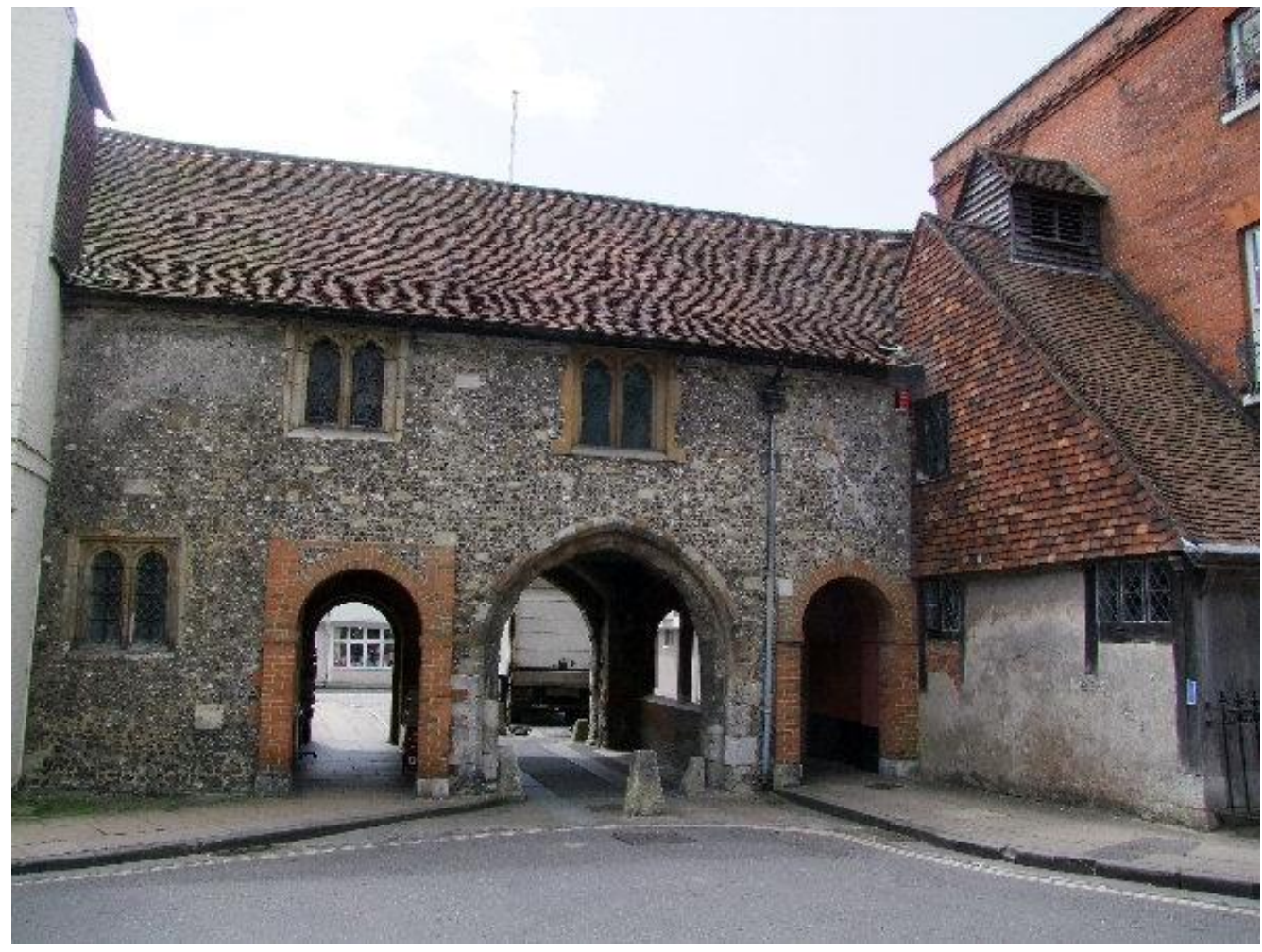

Reproduced from http://www.hampshirechurches.co.uk/church.asp?p=Winchester13 


\section{Digitised Data Record Sheets for St Asaph to Holywell Route:}

Date: $28 / 02 / 2011$

Record \# 001 Clwyd HER number: 102126

Site/Artefact type: St Asaph Cathedral

GPS coordinates: $\mathrm{N}: 53^{\circ} 15.416 \mathrm{~W}: 003^{\circ} 26.526$

\#86

Position related to route: On main high street at west end of town

Photo/Sketch record number(s): 1225 - 1237

Date of site/artefact (if identifiable): $\quad 13^{\text {th }}$ century building, $6^{\text {th }}$ century site.

Dedication: St Asaph

Description of site/artefact (including interior decoration if applicable):

Smallest cathedral in Britain. Built on site of $6^{\text {th }}$ century monastery founded by St Kentigern (St Mungo). Interior has a wooden vaulted roof with foliage scrolls and bosses. Simple Gothic arches with no capitals. The Clerestory window is early $15^{\text {th }}$ century, and the Madonna is Spanish, dating from the late $16^{\text {th }}$ century. The exterior is built from a mixture of local stones - limestone and sandstone.

Surrounding landscape/natural features:

Immediate surroundings are the town of St Asaph, further afield is mostly pasture land for sheep.

Visible relation to neighbouring sites/landscape: Situated at the end of the high street, the cathedral tower is the focal point for the town, visible from the Medieval bridge over the river Elwy at the foot of the hill.

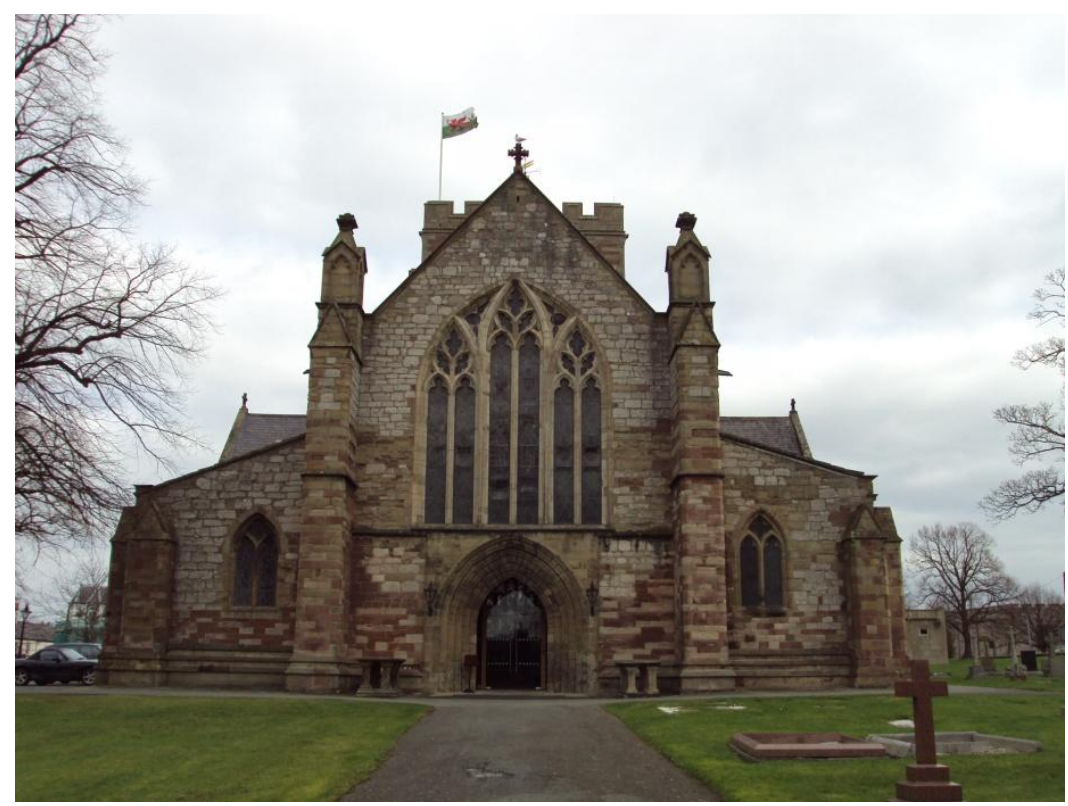


Date: $28 / 02 / 2011$

Record\# 002

Clwyd HER number: 102123

Site/Artefact type: Church

GPS coordinates: $\mathrm{N}: 53^{\circ} 15.424 \mathrm{~W}: 003^{\circ} 26.730$

\#87

Position related to route: Next to Medieval bridge and river Elwy at start of High Street

Photo/Sketch record number(s): 1237

Date of site/artefact (if identifiable): $\quad 13^{\text {th }}$ Century

Dedication: St Asaph and St Kentigern

Description of site/artefact (including interior decoration if applicable): Extensively restored in the $18^{\text {th }}$ century, there are traces of the $13^{\text {th }}$ century fabric on the exterior, including many blocked arches and doorways. Bell fixture, stained glass windows (unremarkable), and small parish graveyard.

Surrounding landscape/natural features: River Elwy, Medieval Bridge, river bank/poplar trees, road leading up the high street to the cathedral.

Visible relation to neighbouring sites/landscape: Can see the cathedral tower from this church, however the church is not very visible from any point as situated in a low part of the landscape and no tower or spire to speak of.

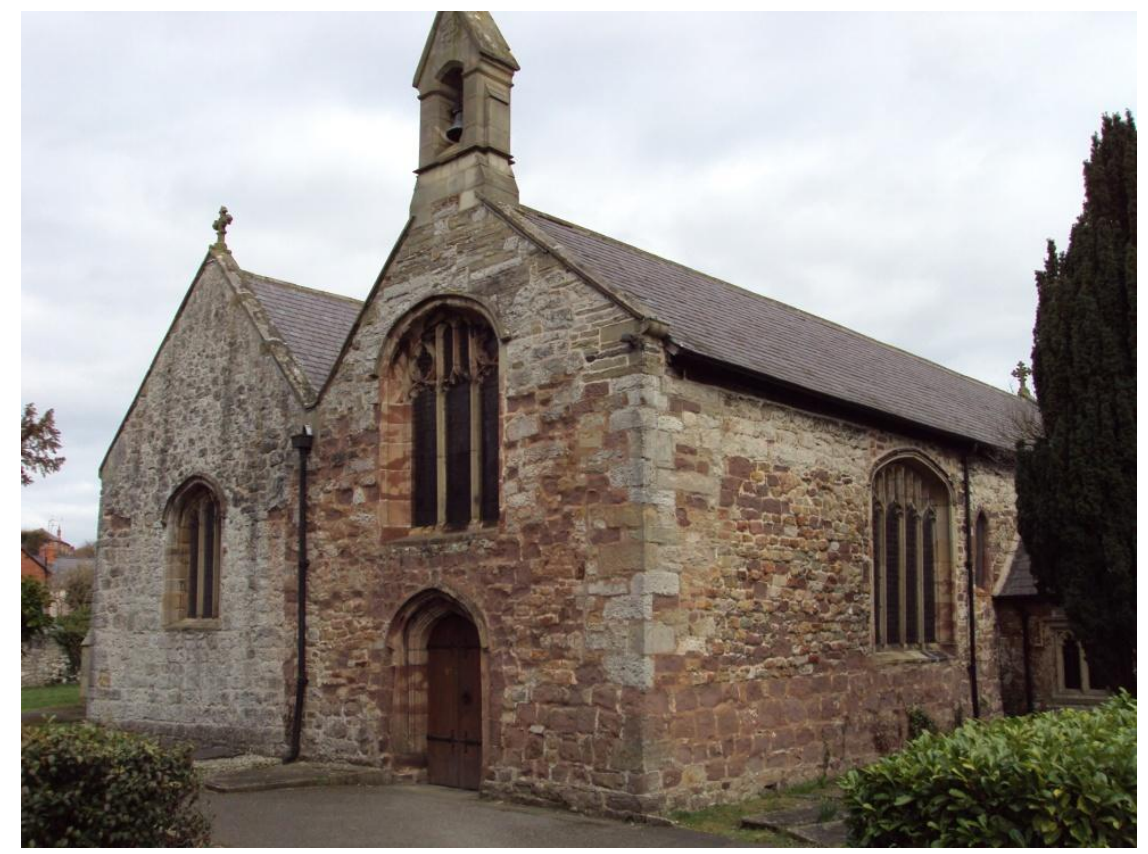


Date: $28 / 02 / 2011$

\section{Record \# 003}

Site/Artefact type: Elwy Bridge Clwyd HER number: 102567

GPS coordinates: N: $53^{\circ} 15.391 \quad$ W: $003^{\circ} 26.843 \quad \# 88$

Position related to route: Spans river Elwy, and connects the road into St Asaph with the High Street and cathedral.

Photo/Sketch record number(s): $1238-1240$

Date of site/artefact (if identifiable): Current bridge is 1770 , but other bridges existed prior.

Dedication: N/A

Description of site/artefact (including interior decoration if applicable):

5 arched shallow bridge, $65 \mathrm{~m}$ long. The arch voussoirs, stringcourses and parapet are sandstone. The tie bar plates have fleur de lys motifs.

Surrounding landscape/natural features: River Elwy, river bank (floodplain?) separates old St Asaph from new urban sprawl.

Visible relation to neighbouring sites/landscape: Link to cathedral \& church, entering the realm of the St Asaph saint cult. Liminal change?

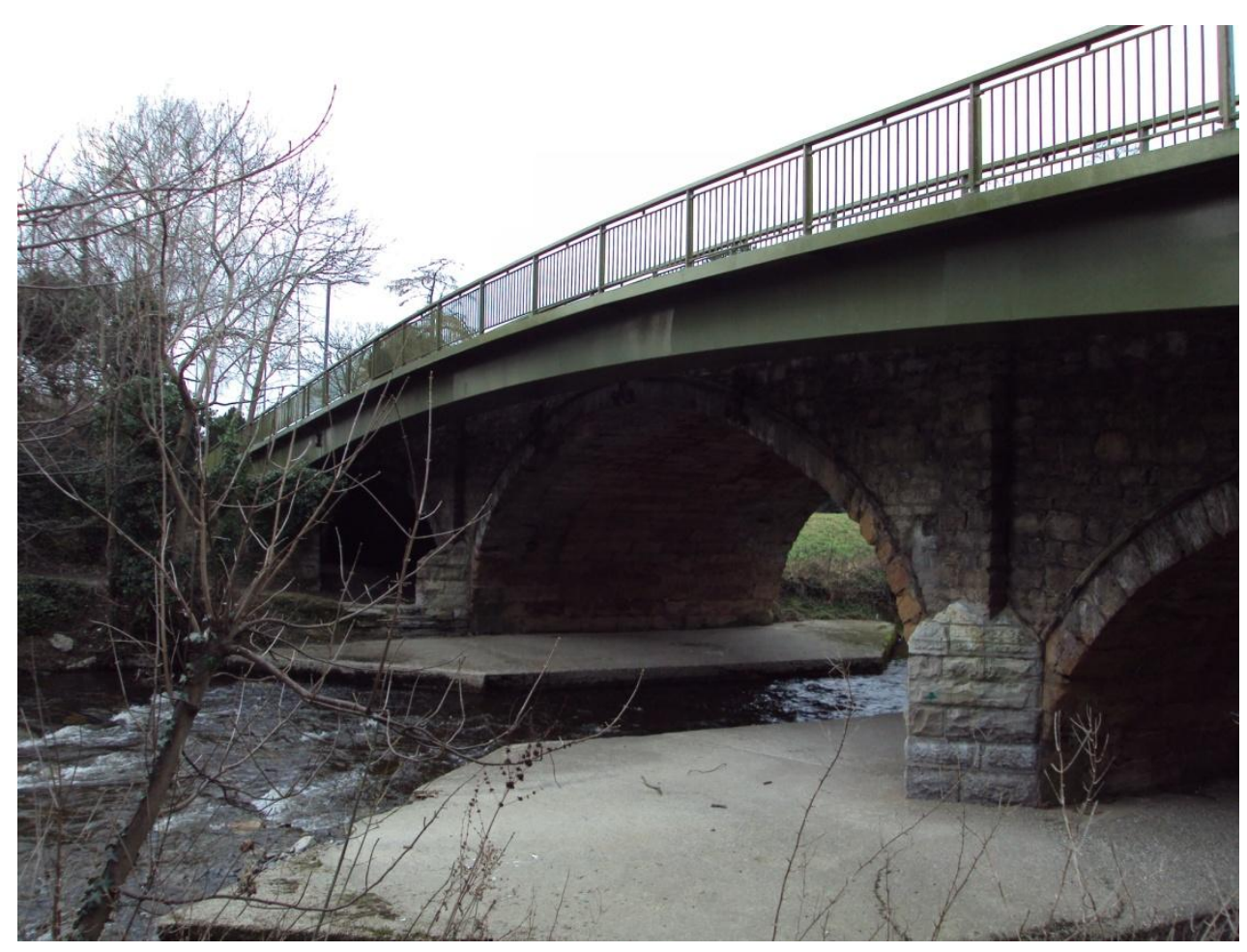


Date: $01 / 03 / 2011$

Record \# 004

Site/Artefact type: Bridge (Pont Dafyyd)

GPS coordinates: $\mathrm{N}: 53^{\circ} 15.816 \mathrm{~W}: 003^{\circ} 26.102$

Position related to route: Leads out of fields onto track to Rhuallt

Photo/Sketch record number(s): 1242

Date of site/artefact (if identifiable): 1630

Dedication: N/A

Description of site/artefact (including interior decoration if applicable): Simple, single arched stone bridge. Cobbled floor, wide enough for a coach (just), river now diverted so redundant. Original metal gate fittings on posts at either end. Built by Bishop Dafydd in early $17^{\text {th }}$ century to carry travellers to and from St Asaph, main route in from this direction, cathedral was focus of Welsh church in NE Wales.

Surrounding landscape/natural features: Pastoral land and paddocks for horses, some tree cover by the banks.

Visible relation to neighbouring sites/landscape: Not very visible now, however may have been more noticeable when in use and not overgrown, with a road or track leading off it to St Asaph's western approach. This and the bridge of the river Elwy are the two conduits out of St Asaph, the two frontiers between the 'city' and the surrounding countryside - with the cathedral on the hill.

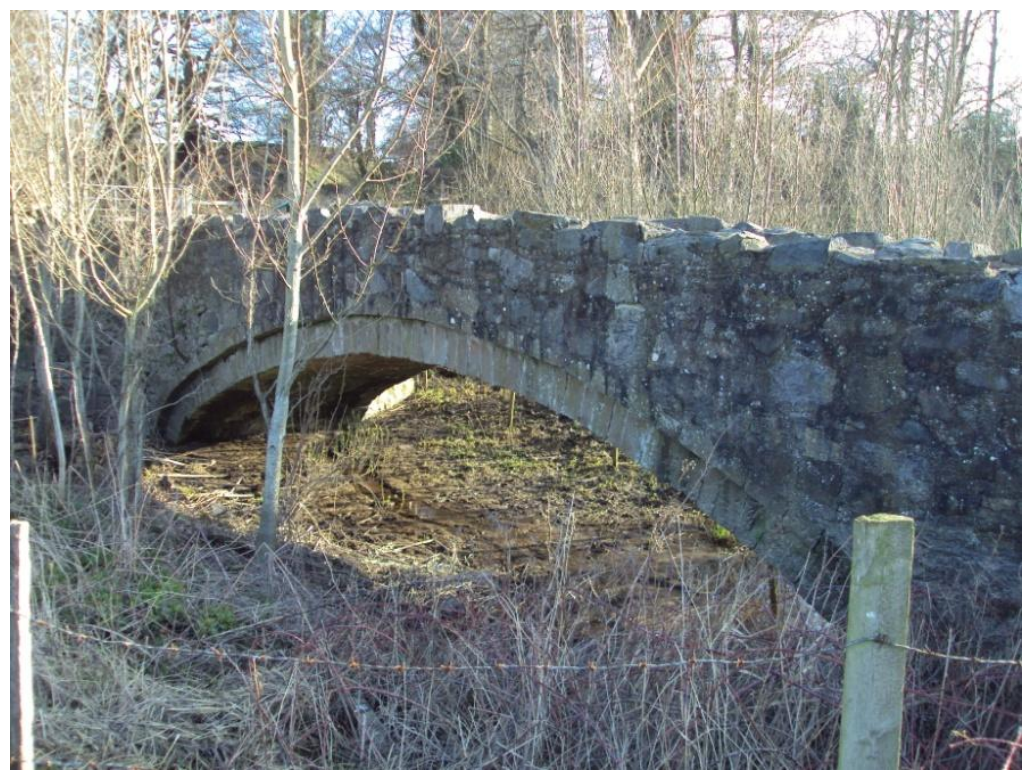




\section{Date: $01 / 03 / 2011$}

\section{Record \# 005}

Feature: Ascent to Offa's Dyke

GPS coordinates: N: $53^{\circ} 16.241$ W: $003^{\circ} 23.259$

Photo/Sketch record number(s): 1245

Position related to route: On the route out of Rhuallt

Point at which visible from the route (GPS): N/A

Surrounding features: From this vantage point, the surrounding basin is visible, with several settlements having church towers or spires as especially prominent features within the landscape. Patchwork of field systems visible, including the entire route taken from the descent out of St Aseph.

Interaction between feature \& pilgrim (slope, shelter, dominance of view etc): The slope is steep, and gaining this point is hard work. Therefore it is highly likely that the pilgrim would have taken time to pause and admire the view whilst regaining his breath. The network of ecclesiastical monuments within the panorama demonstrates a strong Christian influence over the landscape. Potentially the Offa's Dyke was a well known routeway and landmark, and so entering into a large track network stretching across England and Wales may offer interaction with other travellers, and a connection or conduit to a larger 'landscape'. The view offers a vast horizon, which may become a scene for contemplation, including the obvious tower of St Asaph cathedral - this is a landscape dominated by the saint's legacy.

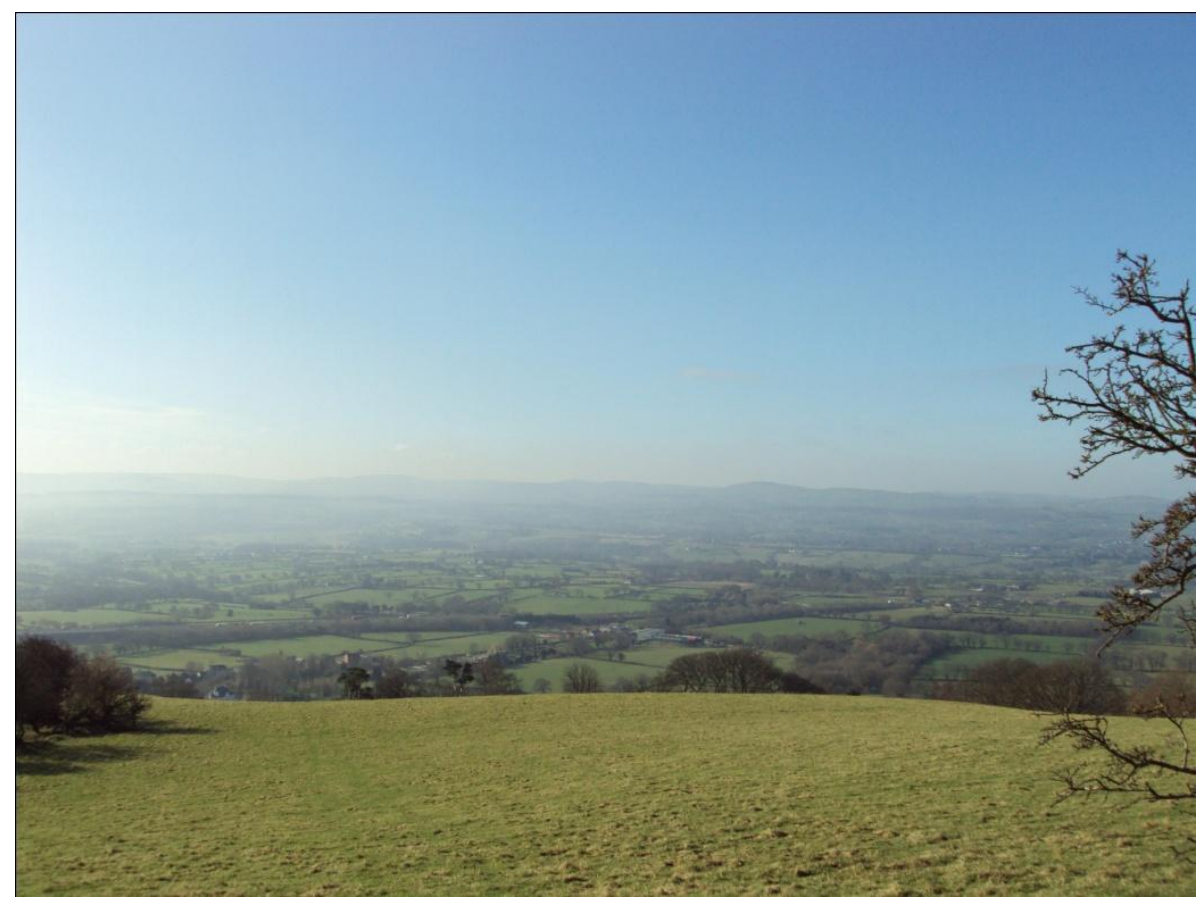




\section{Date: 01/03/2011}

\section{Record \# 006}

Feature: Woodland (Llyn Helyg Wood)\& Lake (Llyn Marl)

GPS coordinates: N: $53^{\circ} 17.276 \mathrm{~W}: 003^{\circ} 19.777$

\#93

Photo/Sketch record number(s): 1247 - 1249

Position related to route: On route approaching A5151

Point at which visible from the route (GPS): N: $53^{\circ} 17.276$

W: $003^{\circ} 19.777$

Surrounding features: Farmland

Interaction between feature \& pilgrim (slope, shelter, dominance of view etc): Flat level, approached through grazing land and fields. Offers shelter from weather, lake is south a hundred feet. Appears to be very old woodland. The lake is $18^{\text {th }}$ century in origin.

Other Observations:
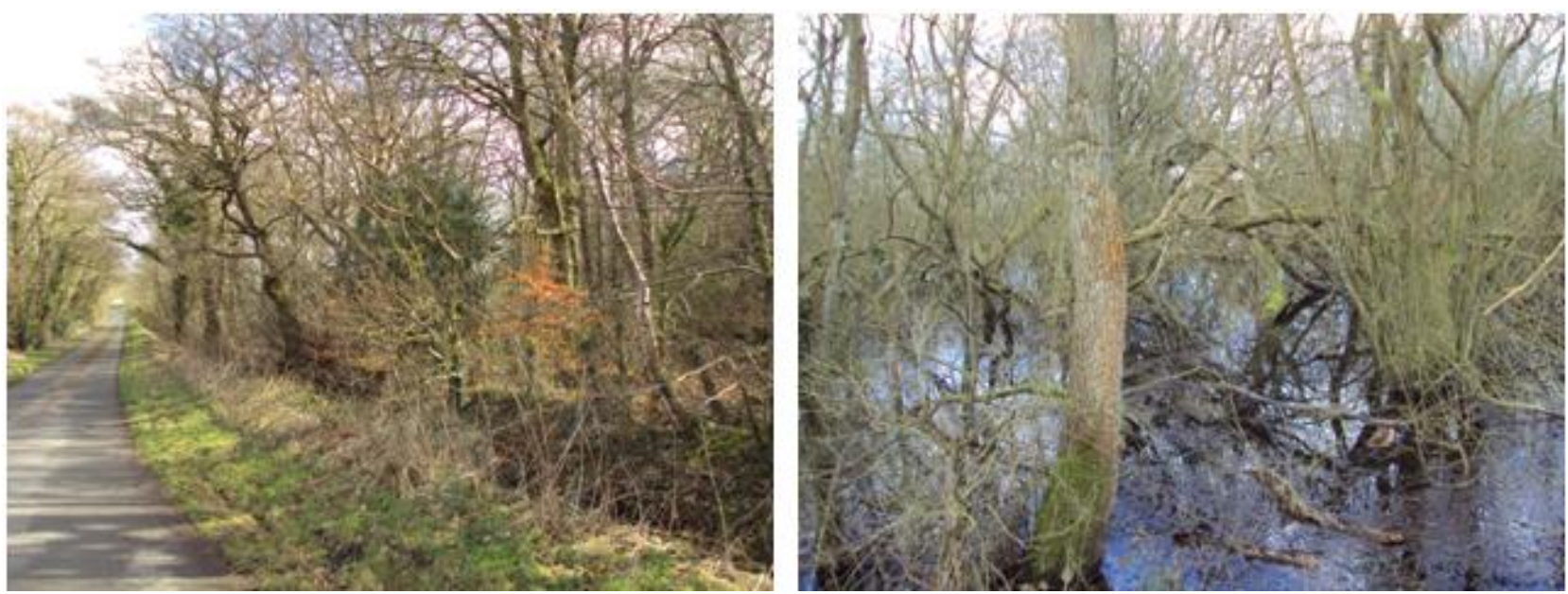


\section{Date: 01/03/2011}

\section{Record \# 007}

Site/Artefact type: Ancient enclosure/Beech woodland (now)

GPS coordinates: N: $53^{\circ} 17.442 \mathrm{~W}: 003^{\circ} 19.396$

\#94

Position related to route: Route skirts around this woodland/enclosure to fields beyond

Photo/Sketch record number(s): $1250-1251$

Date of site/artefact (if identifiable): $\quad$ ? Possibly Medieval, potentially earlier in date.

Dedication: N/A

Description of site/artefact (including interior decoration if applicable):

A hillock which is now covered by a beech plantation. A path runs around this feature, stone lined (rough cobble effect).

Surrounding landscape/natural features:

Mainly farmland, some woodland (such as Llyn Helyg Wood), large hills are visible to the south.

Visible relation to neighbouring sites/landscape: In its current wooded form, this hill is a visible landmark, while the path steers the pilgrim away from the A5151 (or 'London Road' as it is known) and deeper into the pasture lands of rural north wales.

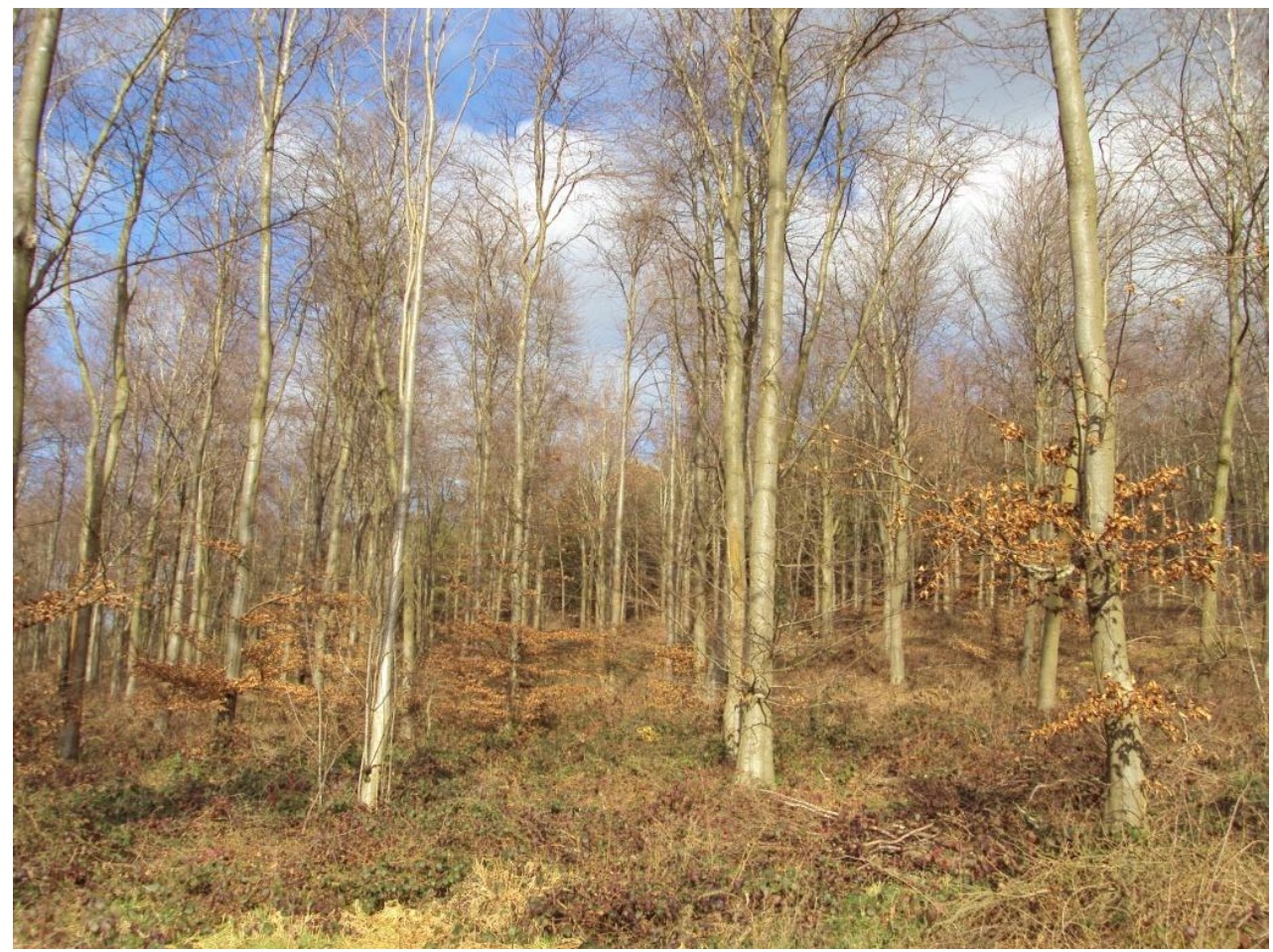




\section{Date: $01 / 03 / 2011$}

\section{Record \# 008}

Site/Artefact type: Large stone at side of path around enclosure.

GPS coordinates: $\mathrm{N}: 53^{\circ} 17.434 \mathrm{~W}: 003^{\circ} 19.210$

\#95

Position related to route: On side of path, hidden by gorse.

Photo/Sketch record number(s): 1253

Date of site/artefact (if identifiable): ?

Dedication: N/A

Description of site/artefact (including interior decoration if applicable): Large unworked upright stone/boulder beside the enclosure path, too large and upright to be naturally occurring.

Surrounding landscape/natural features: Enclosure/beech woodland and farmland.

Visible relation to neighbouring sites/landscape: When uncovered, very visible, potentially a boundary stone for the enclosure?

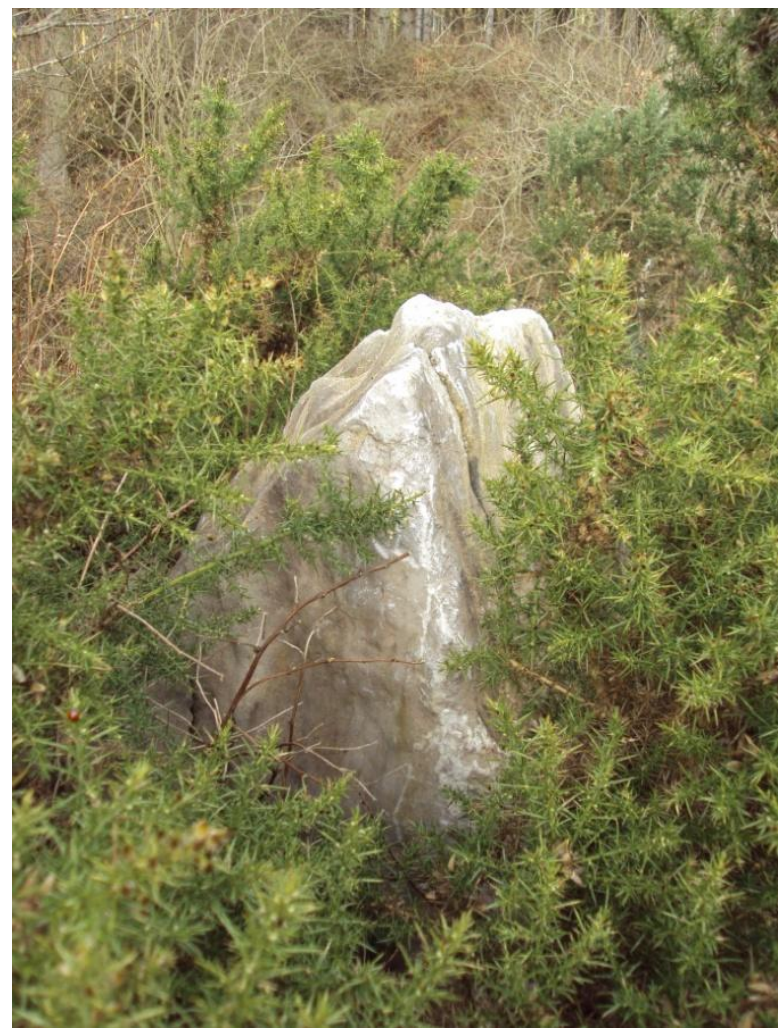




\section{Date: $01 / 03 / 2011$}

\section{Record \# 009 \\ Clwyd HER number: 102328}

Site/Artefact type: Maen Achwyfan - Free standing wheel cross

GPS coordinates: $\mathrm{N}: 53^{\circ} 17.920 \mathrm{~W}: 003^{\circ} 18.515$

Position related to route: In field next to road

Photo/Sketch record number(s): $1256-1260$

Date of site/artefact (if identifiable): $\quad 11^{\text {th }}$ Century

Dedication: Possibly St Cwyfan (hence Achwyfan)

Description of site/artefact (including interior decoration if applicable):

12 feet tall, tallest when cross in Britain. Carvings on both sides of the shaft demonstrate both Celtic and Viking artistic motifs, and may be a penance or lamentation monument. By the $12^{\text {th }}$ century monks at Basingwerk Abbey (nr Holywell) had built a chapel nearby, which may have incorporated this cross into a penance route.

Surrounding landscape/natural features: Principally fields and farmland, with a hill visible in the distance as well as the wooded enclosure previously navigated.

Visible relation to neighbouring sites/landscape: The cross is quite visible within this flat landscape, with its southern aspect visible for over 2 miles (any possibility of being carvings being coloured?). A sight line between this and the nearby $16^{\text {th }}$ century Beacon Tower is identifiable, and potentially with the chapel building (now apparently a house although I was unable to locate this site).
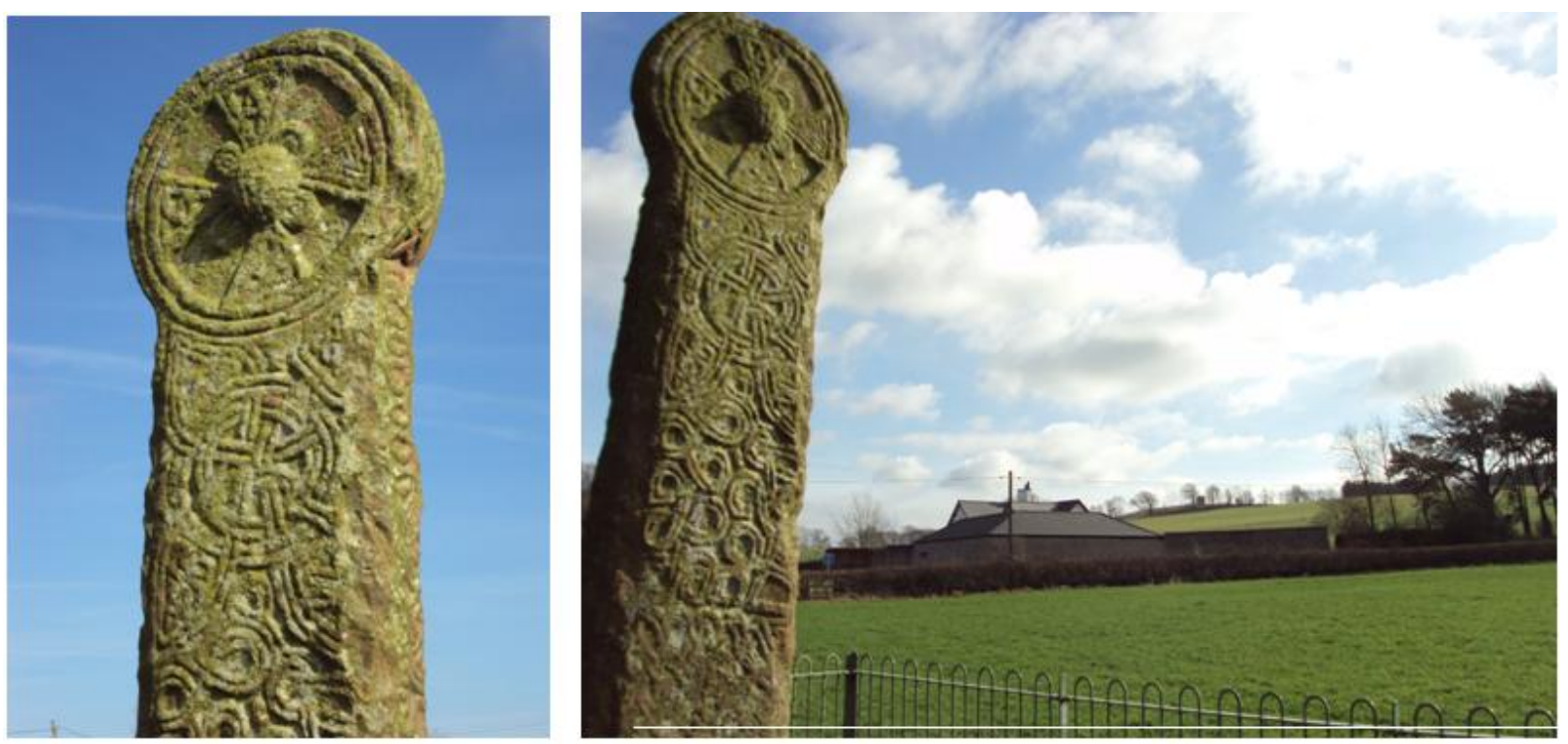
Date: 01/03/2011

\section{Record \# $010 \quad$ Clwyd HER number: 102347}

Site/Artefact type: Beacon Tower

GPS coordinates: N: $53^{\circ} 17.658$ W: $003^{\circ} 18.077$

\#97

Position related to route: Off route, on hill overlooking Cross

Photo/Sketch record number(s): $1261-1264$

Date of site/artefact (if identifiable): 1600

Dedication: N/A

Description of site/artefact (including interior decoration if applicable):

Round stone tower, structurally intact on exterior, beacon tower to warn of pirate attacks on the coast.

Surrounding landscape/natural features: Located on a small hill in a predominantly flat landscape. North east is the Dee Estuary clearly visible and much of the coast, including Liverpool on the other side. Inland one can see a large expanse of fields SW and hills

Visible relation to neighbouring sites/landscape: From this tower one can see the Maen Achwyfan. An excellent vantage point to survey the land from.
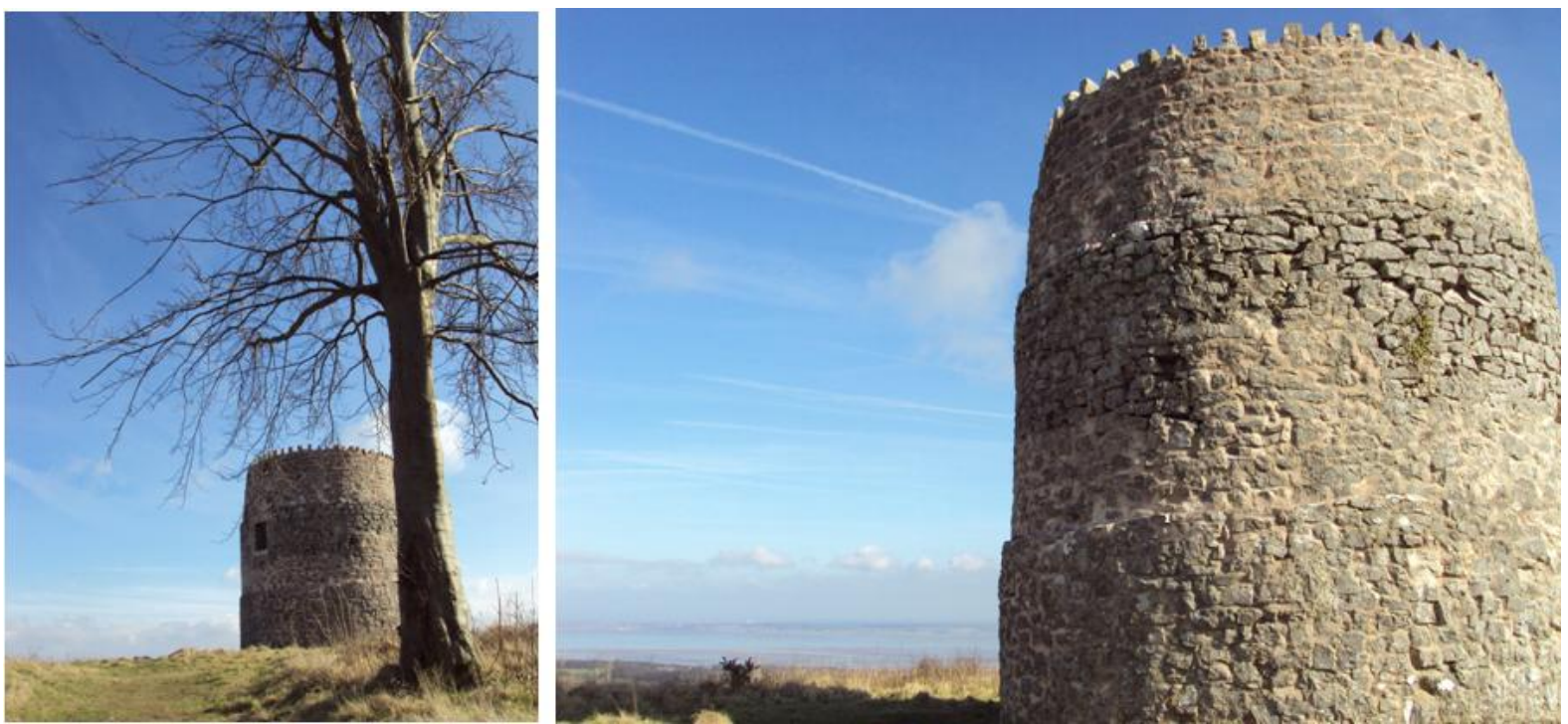


\section{Date: 03/01/2011}

\section{Record \# $011 \quad C l w y d$ HER number: 102360}

Site/Artefact type: Church in Whitford

GPS coordinates: N: $53^{\circ} 17.617 \mathrm{~W}: 003^{\circ} 16.967$

\#98

Position related to route: on road through Whitford village

Photo/Sketch record number(s): 1266 - 1269

Date of site/artefact (if identifiable): Founded by St Bueno $7^{\text {th }}$ Century, $14^{\text {th }} / 15^{\text {th }}$ Century aisle earliest surviving part.

Dedication: St Beuno \& St Mary

Description of site/artefact (including interior decoration if applicable): Church thought to have been founded by St Beuno in C7 and later re-dedicated to St Mary after Norman conquest. C14-C15 $\mathrm{N}$ aisle is the earliest surviving part of the church, with the arcade of C15-C16, and nave and chancel probably of similar date. C19 restoration. Church built in perpendicular style and consists of a continuous nave and chancel with $\mathrm{W}$ tower, $\mathrm{N}$ and $\mathrm{S}$ aisles, and $\mathrm{S}$ porch. Of coursed yellow sandstone ashlar construction with slate roof. Original arch-braced roof survives in the $\mathrm{N}$ aisle, along with much of the window tracery. The church also houses an unusually fine collection of C17-C19 monuments

Surrounding landscape/natural features: Churchyard \& village. Farmland beyond.

Visible relation to neighbouring sites/landscape: Located NW of the cross-roads in the centre of Whitford Village, and approached by lychgates to the $\mathrm{S}$ and $\mathrm{E}$. Church tower can be seen as approaching village.

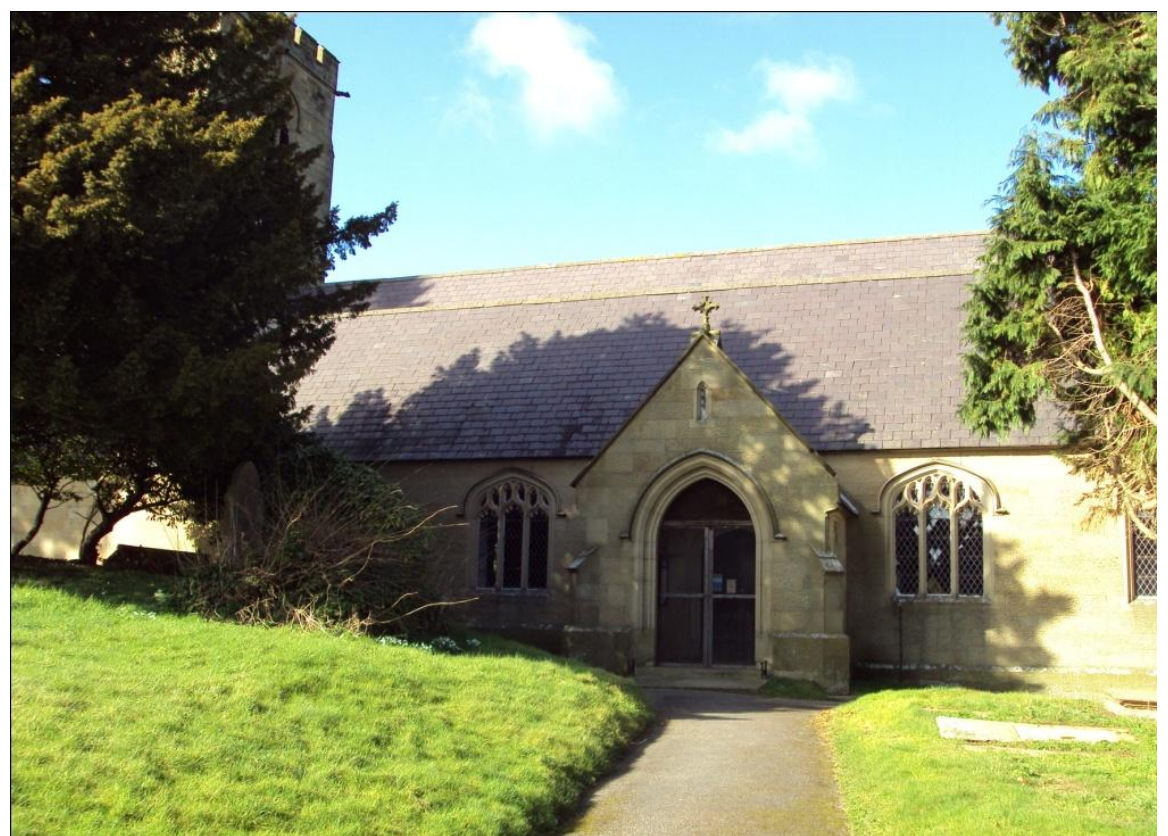




\section{Date: 01/03/2011}

\section{Record \# $012 \quad$ Clwyd HER number: 58879}

Site/Artefact type: Basingwerk Abbey (ruins)

GPS coordinates: $N$ : $53^{\circ} 17.257$ W: $003^{\circ} 12.440$

\#100

Position related to route: At the end of Greenhill valley, $1 \frac{1 / 4}{\mathrm{~m} \mathrm{~N} \text { of Holywell }}$

Photo/Sketch record number(s): $1272-1279$

Date of site/artefact (if identifiable): 1132

Dedication: Cistercian Order

Description of site/artefact (including interior decoration if applicable):

Layout of cloisters and pillar bases are visible. Dissolved in 1536 and pillaged for building stone. Only a little of the 12th-century walling apparently survives, around the cloister and in the east range. Much of the fabric visible today, including the church, dates from the early 13th-century, when the buildings were generally refurbished and extended. The church had seven bays in the nave and two south side chapels in each transept. To its south in the adjoining east range, lay the sacristy, and beyond this the chapter house, which was provided with a vaulted eastward extension which still survives; beside this lay the parlour. To its south the novices' lodgings or 'monk's day room was upgraded, and a warming house added to the end of the range in the 15th century. The entire upper floor would have contained the monk's upper dormitory, with direct access to the choir of the church via a night stair. On the south side of the cloister, the impressive frater or dining-hall dates from a little later in the 13th century. It was provided with handsome lancet windows at its south end, a pulpit, from which readings were given during meals, and a serving hatch, connecting to its kitchens next door. West of the cloister, little survives of the lay brothers accommodations. This range was probably adapted other uses as the lay brethren became harder to recruit. A detached range of buildings south-east of the main complex has been considerably altered by recent use as a farmhouse, but may occupy the site of an original monastic infirmary.

Surrounding landscape/natural features: Dee estuary, town of Holywell, Holywell stream, farmland. Visible relation to neighbouring sites/landscape: Connected to Holywell by road and stream/valley, would have had view out to the coast \& sea. 

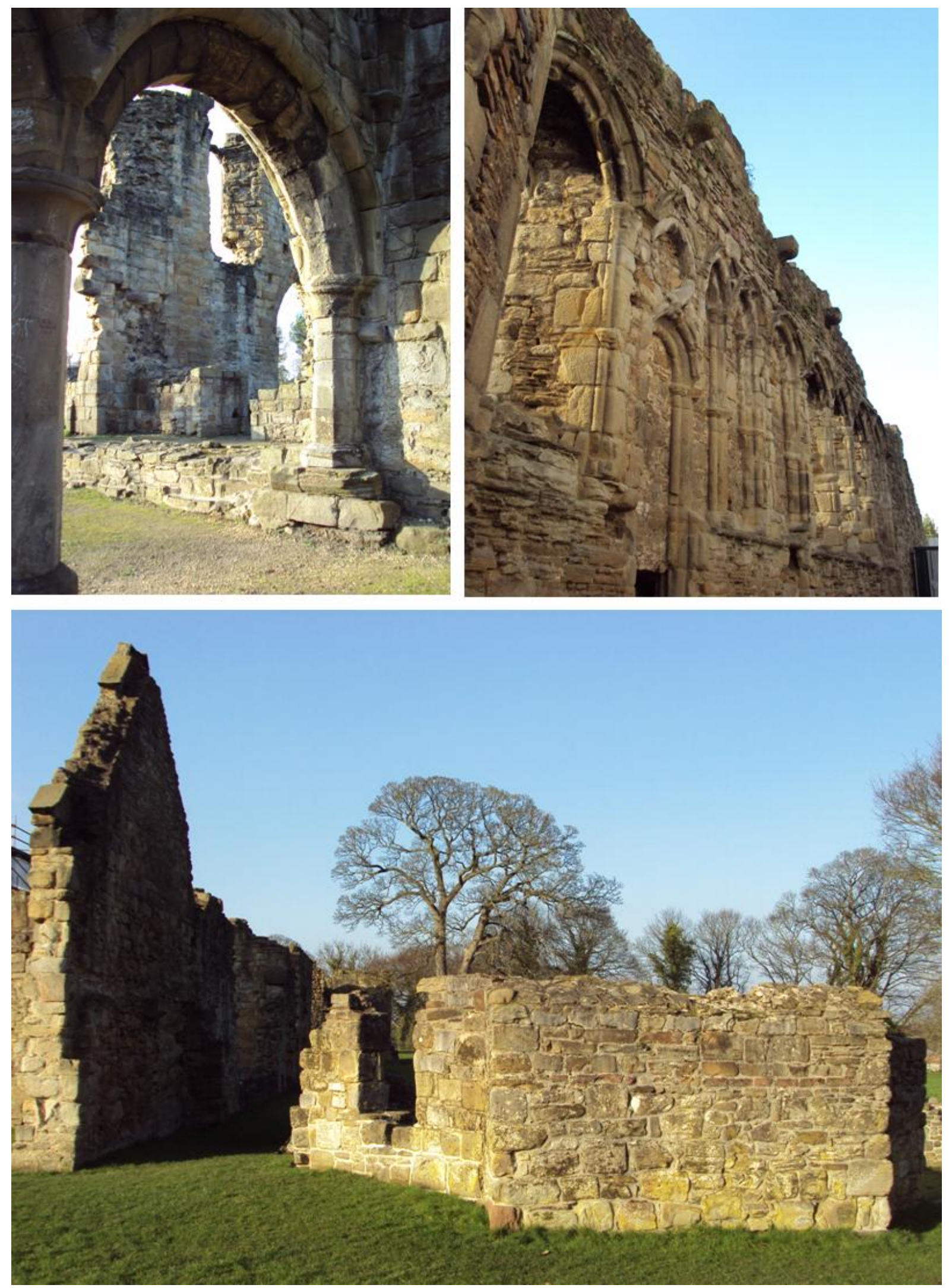
Date: 02/03/2011

Record \# $013 \quad$ Clwyd HER number: 102417

Site/Artefact type: St Winefride's Well

GPS coordinates: N: $53^{\circ} 16.641$ W: $003^{\circ} 13.426 \quad \# 101$

Position related to route: On road as it leaves Holywell

Photo/Sketch record number(s): $1288-1300$

Date of site/artefact (if identifiable): $6^{\text {th }}$ Century site, $16^{\text {th }}$ century rebuild

Dedication: St Winefride

Description of site/artefact (including interior decoration if applicable):

The well is deep square basin located in a vaulted structure, feeding out into a larger rectangular bathing pool. Inside the 'well house' is extensively rib vaulted, with a statue of Winefride and four pillars surrounding the well. Steps lead into the basin, and there is a stone 'canopy effect' above the well. Carvings and ornamented bosses are present on the ceiling.

Surrounding landscape/natural features: Holywell town, forested hillside, coast in distance.

Visible relation to neighbouring sites/landscape: Actual well site is not very visible as it is on a downward slope and covered by the church above, however during the Medieval period it may have been audible as a place of reverence. 

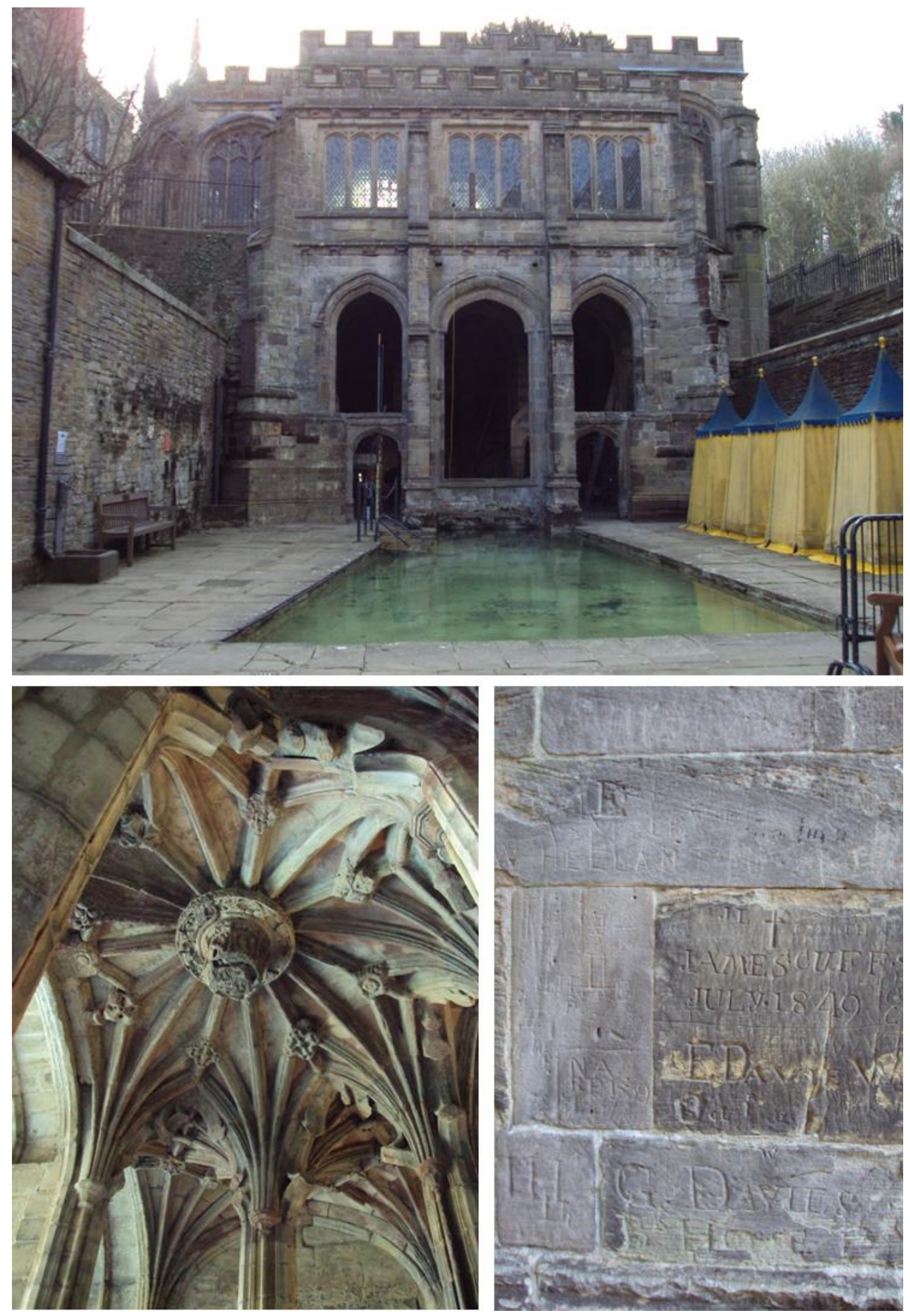
Date: $02 / 03 / 2011$

\section{Record \# $014 \quad$ Clwyd HER number: 16797}

Site/Artefact type: Chapel of St Winefride

GPS coordinates: N: $53^{\circ} 16.633 \mathrm{~W}: 003^{\circ} 13.404$

\#102

Position related to route: Above Holy Well

Photo/Sketch record number(s): $1288-1302$

Date of site/artefact (if identifiable): $\quad 15^{\text {th }}$ Century

Dedication: St Winefride

Description of site/artefact (including interior decoration if applicable): Gothic style chapel, stained glass, crenelated roof, opens out down to the bathing pool, carved creatures on the roof edge. Plain inside with little adornment.

Surrounding landscape/natural features: Same as well

Visible relation to neighbouring sites/landscape: No tower so makes little impression in the landscape.

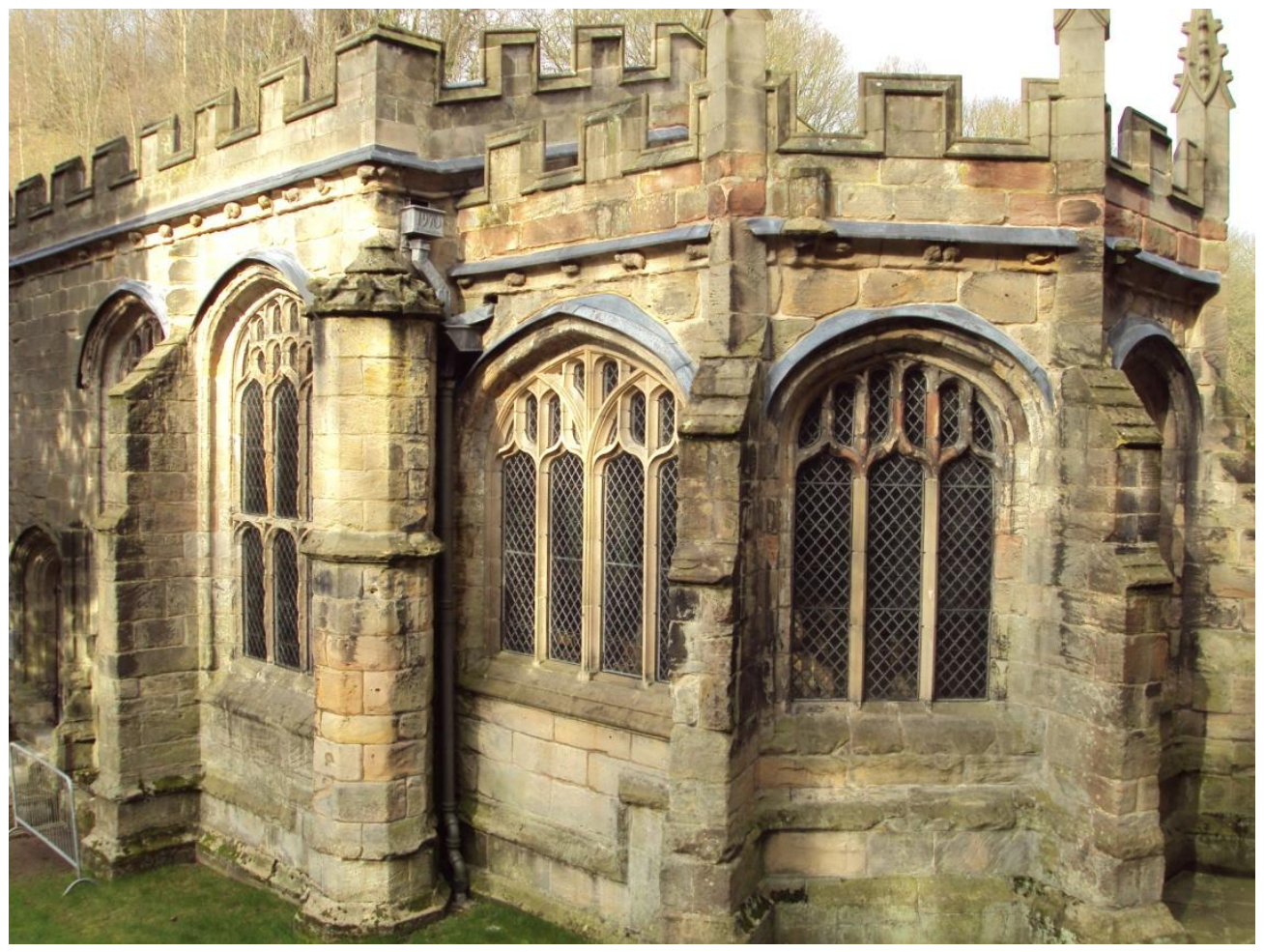




\section{Date: $02 / 03 / 2011$}

\section{Record \# 015 \\ Clwyd HER number: 102416}

Site/Artefact type: Church of St James

GPS coordinates: N: $53^{\circ} 16.633 \mathrm{~W}: 003^{\circ} 13.404$

Position related to route: Next to Winefride's Chapel.

Photo/Sketch record number(s):

Date of site/artefact (if identifiable): $\quad 7^{\text {th }}$ Century

Dedication: St Beuno (originally) St James (now)

Description of site/artefact (including interior decoration if applicable): Site of original church dedicated and founded by St Beuno. Overlooks well site. Rebuilt in $19^{\text {th }} \mathrm{C}$, and now dedicated to St James.

Surrounding landscape/natural features: Same as well.

Visible relation to neighbouring sites/landscape Built above Well so prominent against the hill leading up to Holywell town centre. Visible when emerging from path running by Basingwerk castle.

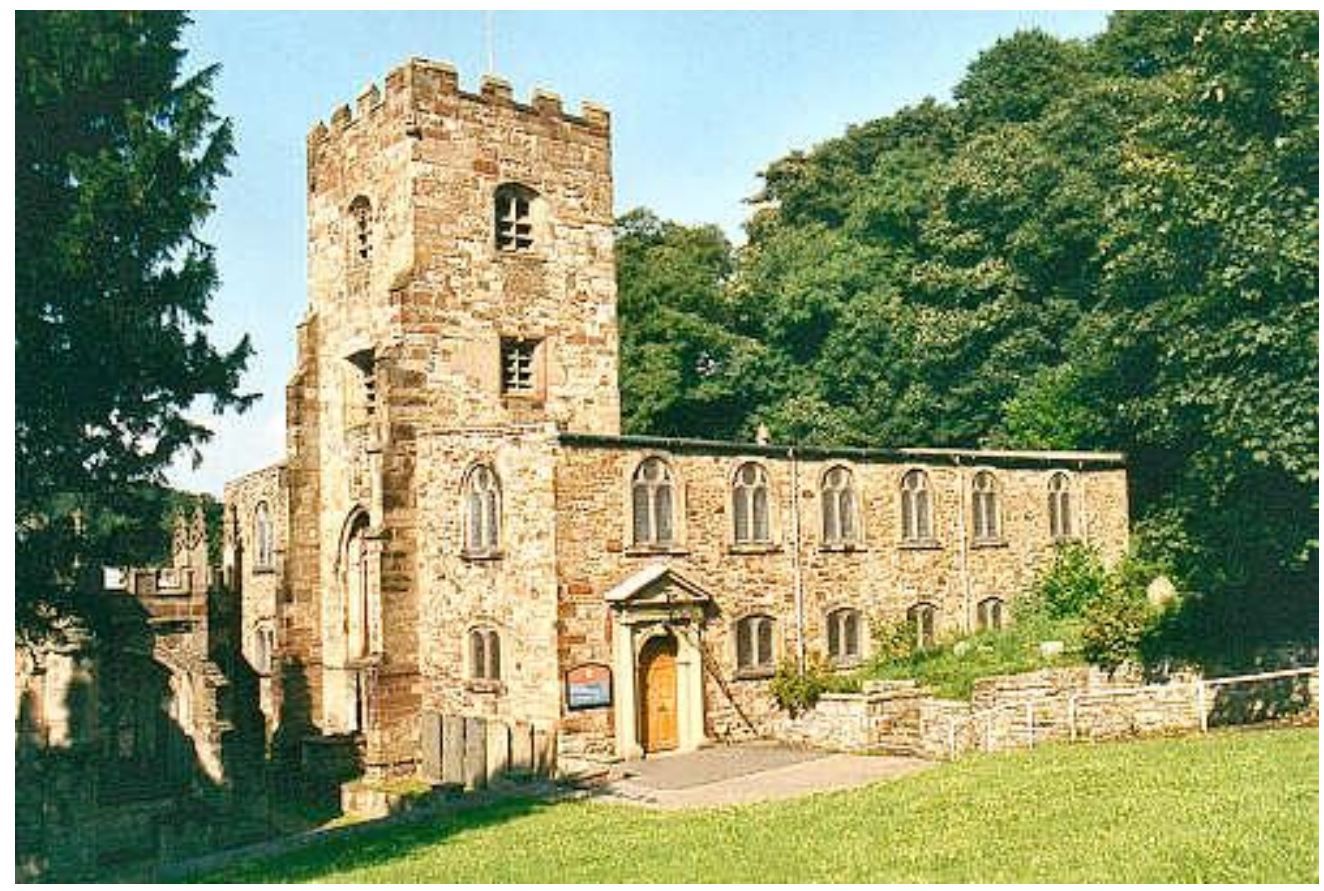

(Photo reproduced from: http://www.clwydfhs.org.uk/churches/Holywell/) 


\section{Date: $02 / 03 / 2011$}

\section{Record \# 016 \\ Clwyd HER number: 89958}

Site/Artefact type: St Winefride's Hospital

GPS coordinates: N: $53^{\circ} 16.617 \mathrm{~W}: 003^{\circ} 13.402$

Position related to route: On road leading to Winefride's Well, 50m SE

Photo/Sketch record number(s):

Date of site/artefact (if identifiable): $\quad$ site is early $17^{\text {th }} \mathrm{C}$

Dedication: St Winefride

Description of site/artefact (including interior decoration if applicable): Secular priests occupied "The Cross Keys" (the former St Winefride's Convent, now the church car park). Both inns served the needs of pilgrims. Both were raided as late as 1718. The Cross Keys was sold; but with the repeal of the penal laws, the opening of the first public chapel in Holywell since the Reformation in 1808, the building of the present St Winefride`s Church in 1833.

Surrounding landscape/natural features: Well, Church (St James), Church (Modern RC, formally St Winefride's convent), Chapel, St Beuno's well nearby?

Visible relation to neighbouring sites/landscape: Within site of well.

Other observations: Now entirely modern

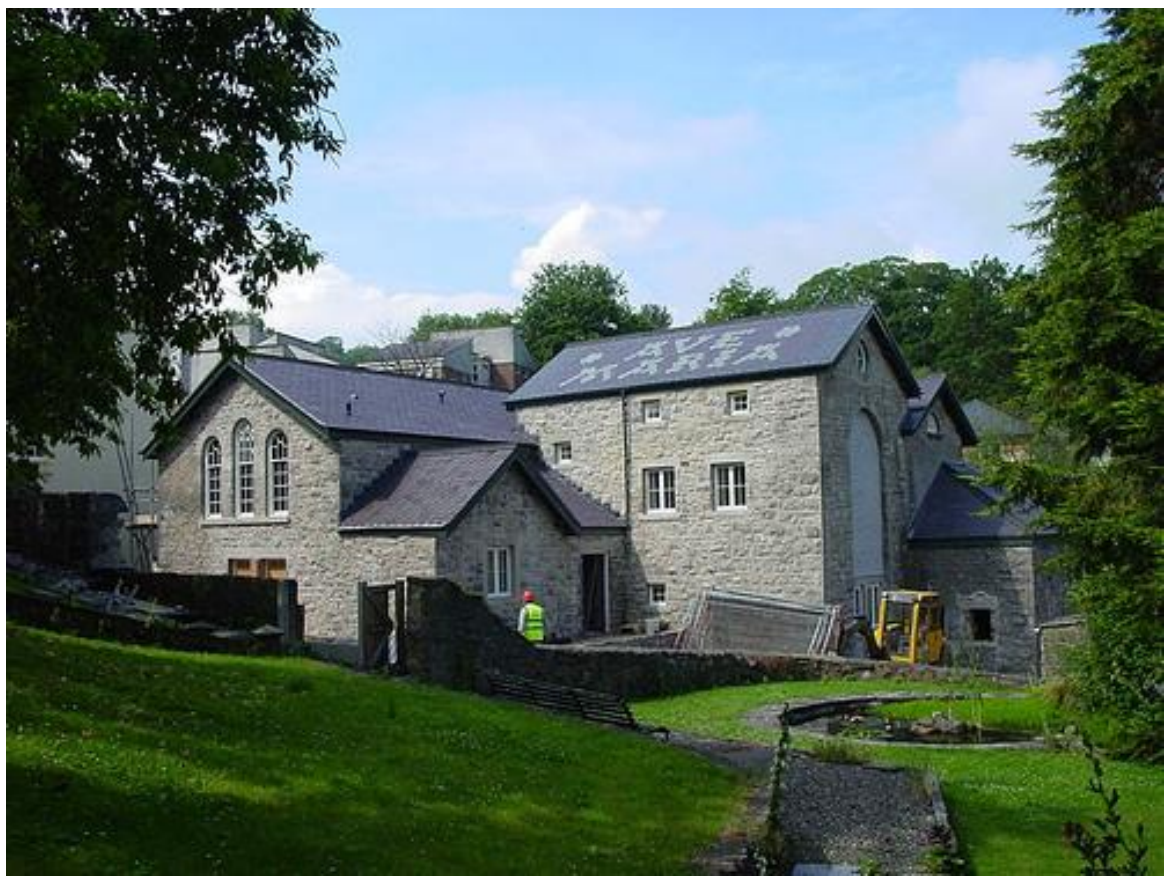

(Photo reproduced from: http://www.francisroberts.com/category/historic-building/ave-maria-hall-holywell/) 


\section{Digitised Data Record Sheets for Camelford to Bodmin Route:}

\section{Date: 07/02/2011}

\section{Record\# 001}

Site/Artefact type: Church

GPS coordinates: N: $50^{\circ} 36.557$ W: $004^{\circ} 42.209$

Position related to route: SW of Camelford, Parish church (in Lanteglos)

Photo/Sketch record number(s): 1 - 9

Date of site/artefact (if identifiable): Norman in origin, built on site of Celtic Monastery. Tower is $15^{\text {th }}$ c.

Dedication: St Julitta

Description of site/artefact (including interior decoration if applicable): Exterior - Square tower, church encircled by graveyard, Tregoodwell Cross in graveyard, ancient Yew trees. Interior - North wall \& transept of Norman fabric. $15^{\text {th }}$ century font with trefoil motifs, white washed walls.

Surrounding landscape/natural features: Dale land, small village, farmlands.

Visible relation to neighbouring sites/landscape: Road leading to church from Camelford is sunken, potentially from centuries of use.
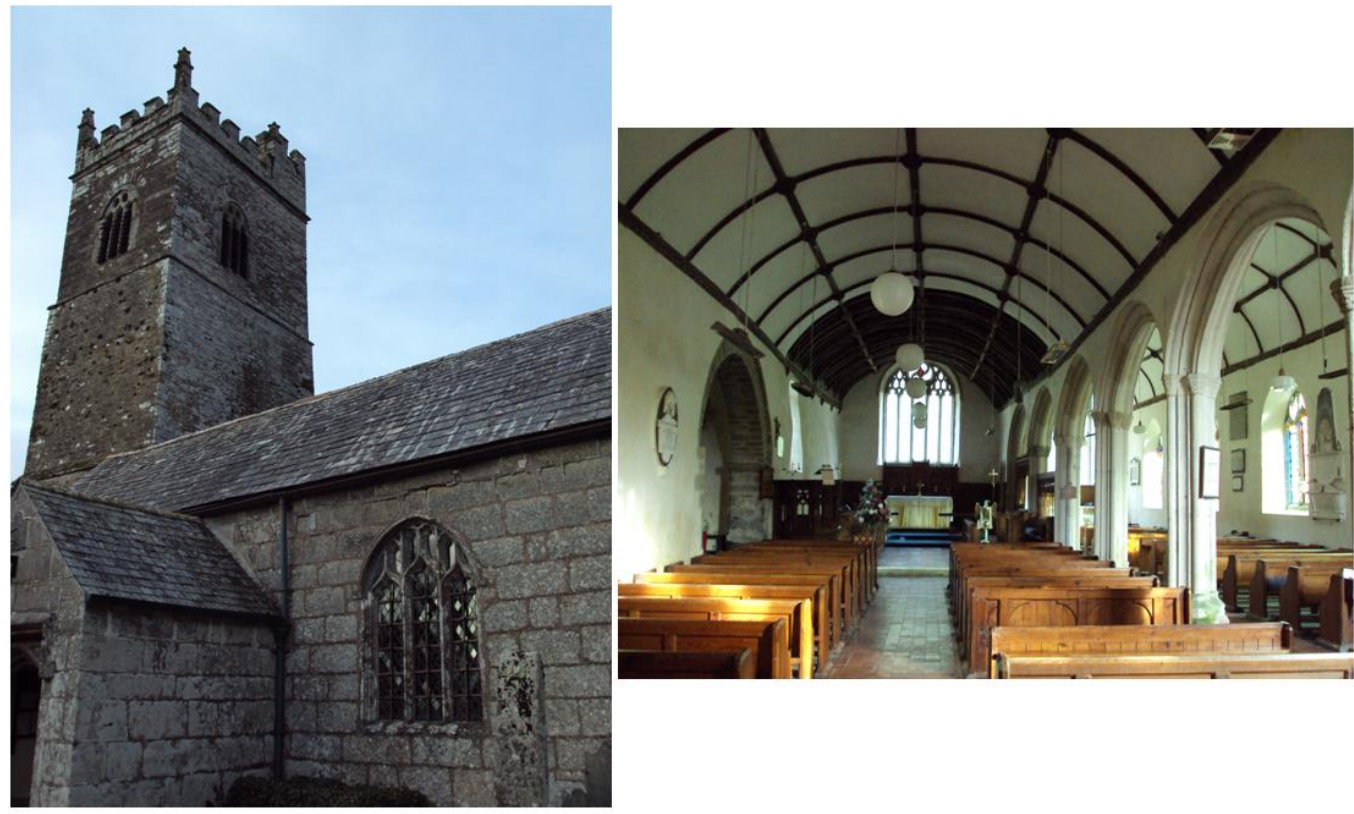


\section{Date: $07 / 02 / 2011$}

\section{Record \# 002}

Site/Artefact type: Well (Holy)

GPS coordinates: N: $50^{\circ} 36.913 \mathrm{~W}: 004^{\circ} 41.992$

Position related to route: $300 \mathrm{~m} \mathrm{~N}$ of church, in river valley

Photo/Sketch record number(s): $10-15$

Date of site/artefact (if identifiable): $\quad \sim 13^{\text {th }}$ century.

Dedication: St Juliot.

Description of site/artefact (including interior decoration if applicable): Small stone arched structure (4ft), carved gothic arch, slate roof, impression at top of arch (eroded carving?).

Surrounding landscape/natural features: River valley, fish ponds, trees. Trees adjacent to well have votive ribbons tied around their branches, and a candle inserted into the well's interior.

Visible relation to neighbouring sites/landscape: Very hidden from connected sites, near river bank amongst undergrowth.

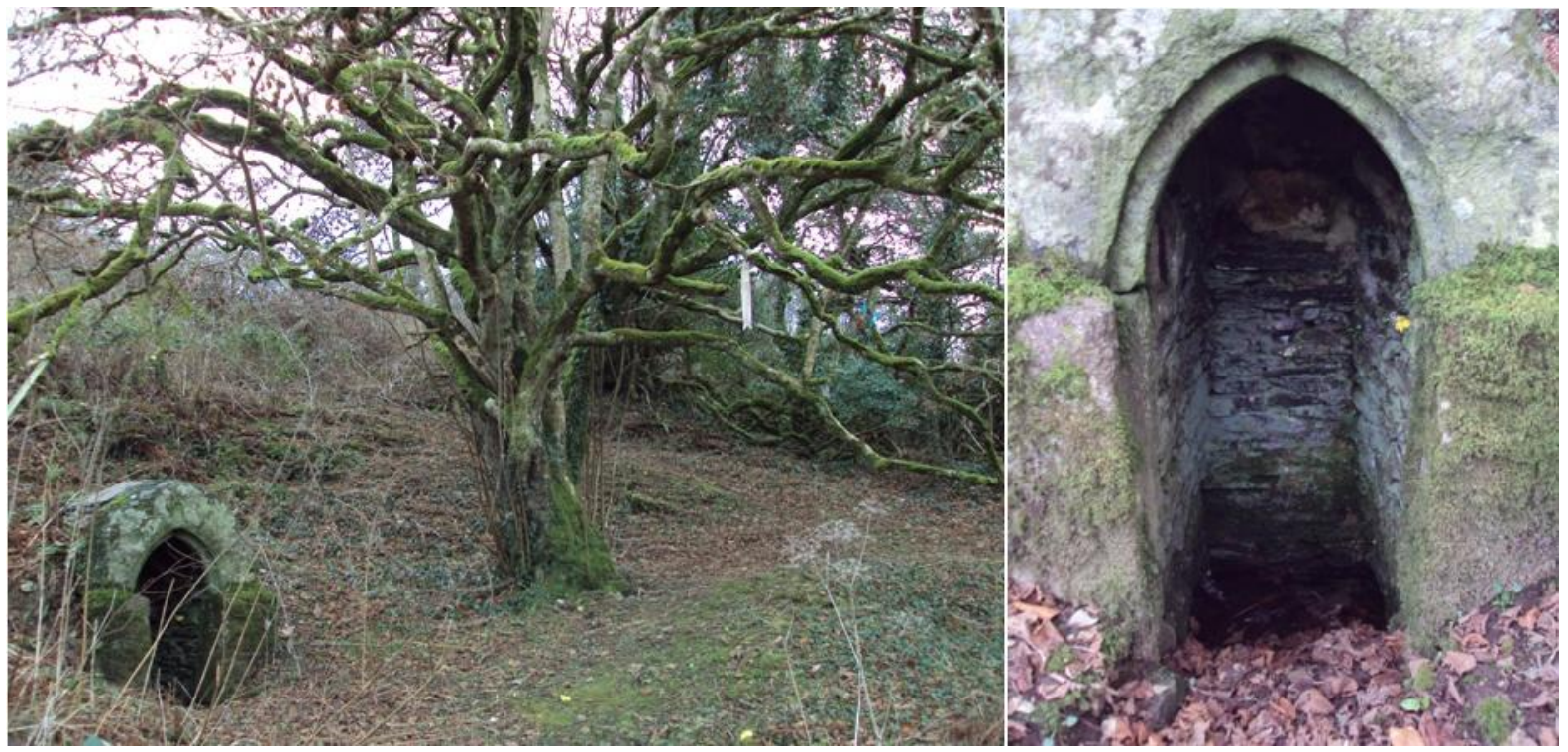




\section{Date: $08 / 02 / 2011$}

\section{Record \# 003}

Site/Artefact type: Well (no record of being Holy)

GPS coordinates: N: $50^{\circ} 36.318$ W: $004^{\circ} 40.8333 \# 70$

Position related to route: On footpath to Advent Church

Photo/Sketch record number(s): 20, 21

Date of site/artefact (if identifiable): $13^{\text {th }} / 14^{\text {th }}$ century

Dedication: N/A

Description of site/artefact (including interior decoration if applicable): Stone Tregalith structure, metal rings hammered into stone for door (?)

Surrounding landscape/natural features: Grazing land, at top of Camel river valley side, although no view due to hedges and trees, and set too far back.

Visible relation to neighbouring sites/landscape: Can see the church at Advent, just over the crest of the hill $50 \mathrm{~m} \mathrm{~S}$.

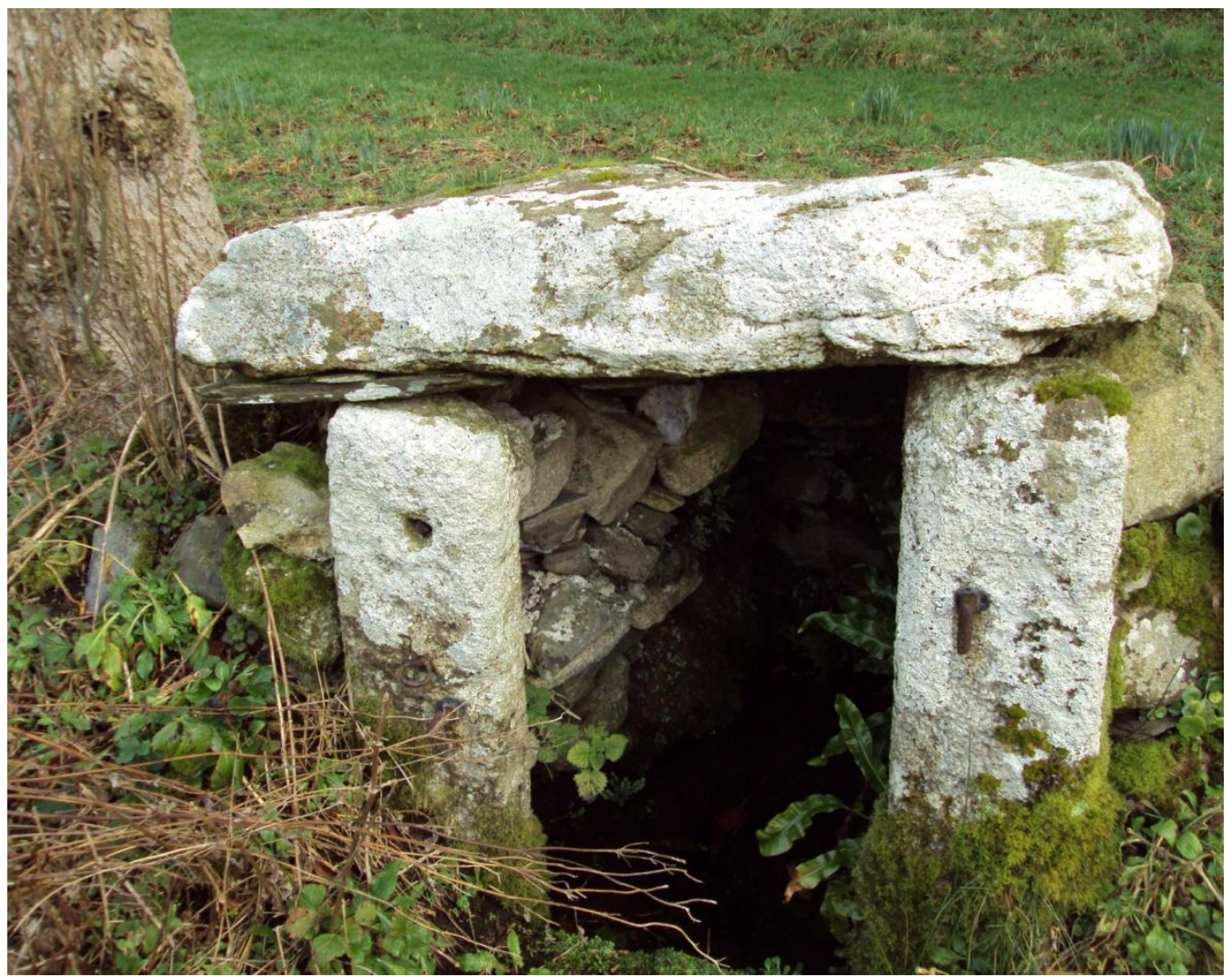


Date: $08 / 02 / 2011$

\section{Record \# 004}

Site/Artefact type: Church at Advent Parish

GPS coordinates: N: $50^{\circ} 36.197$ W: $004^{\circ} 40.784$

Position related to route: On route in Tresinney hamlet

Photo/Sketch record number(s): 24 - 27

Date of site/artefact (if identifiable): $13^{\text {th }}$ century

Dedication: St Adwena

Description of site/artefact (including interior decoration if applicable): Unbuttressed West Tower is $14^{\text {th }}$ c, 5 bells, encircled by graveyard. Inside is plain with a divided Norman transept.

Surrounding landscape/natural features: Hamlet of Tresinney, grazing fields, at crest of Camel river valley.

Visible relation to neighbouring sites/landscape: Prominant in visual landscape, visible for several miles across and beyond valley.

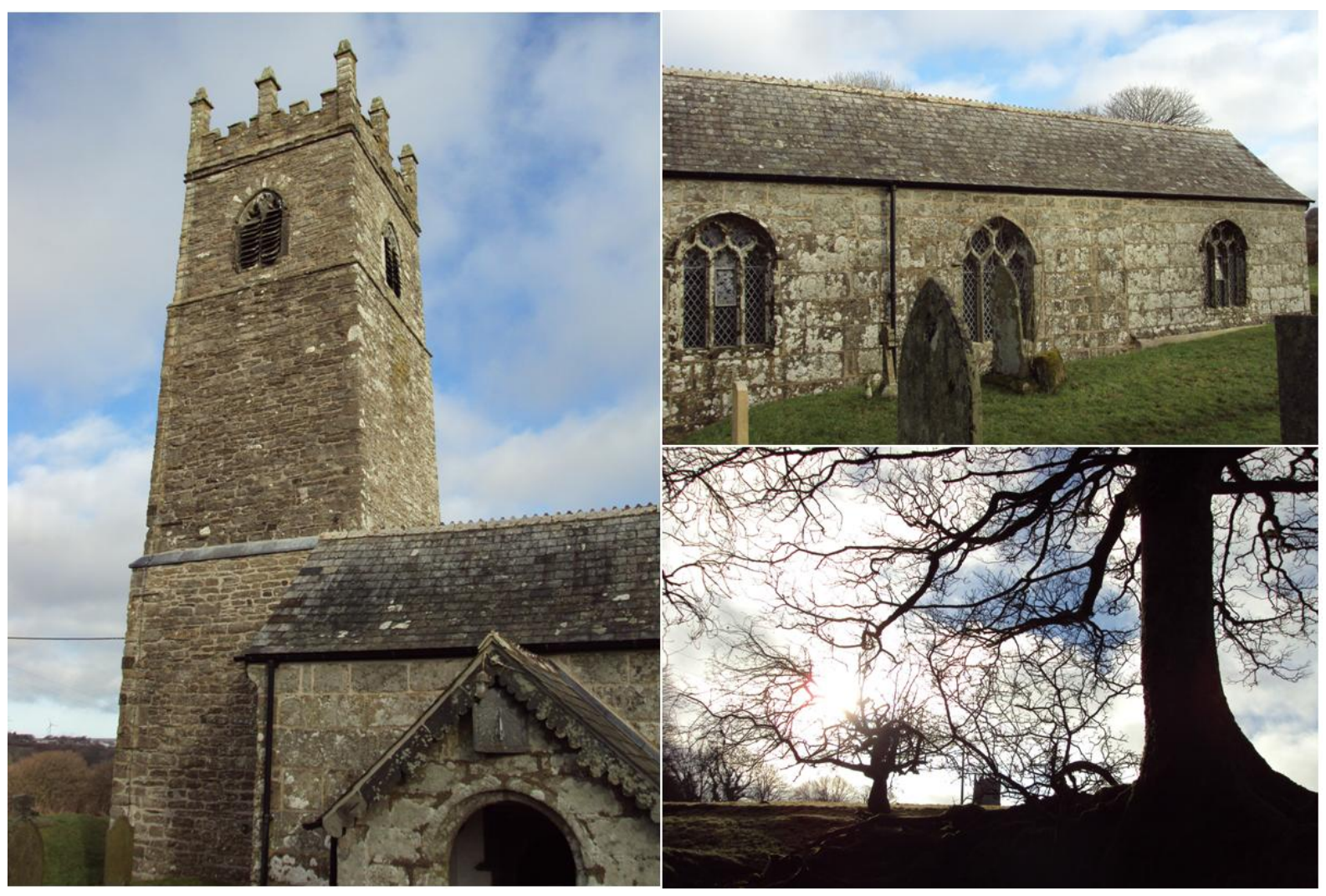


Date: $08 / 02 / 2011$

\section{Record \# 005}

Feature: Ford

GPS coordinates: $\mathrm{N}: 50^{\circ} 35.612 \mathrm{~W}: 004^{\circ} 41.363$

Photo/Sketch record number(s): $28-30$

Position related to route: On path S to St Breward, prior to climbing elevation onto field systems.

Point at which visible from the route (GPS): only visible when directly encountered.

Surrounding features: Farmland, farm house \& some woodland.

Interaction between feature \& pilgrim (slope, shelter, dominance of view etc): Transition point from populated area onto high fields at tope of river valley. Boundary, indicates movement from one parish (Advent) into another (St Breward).

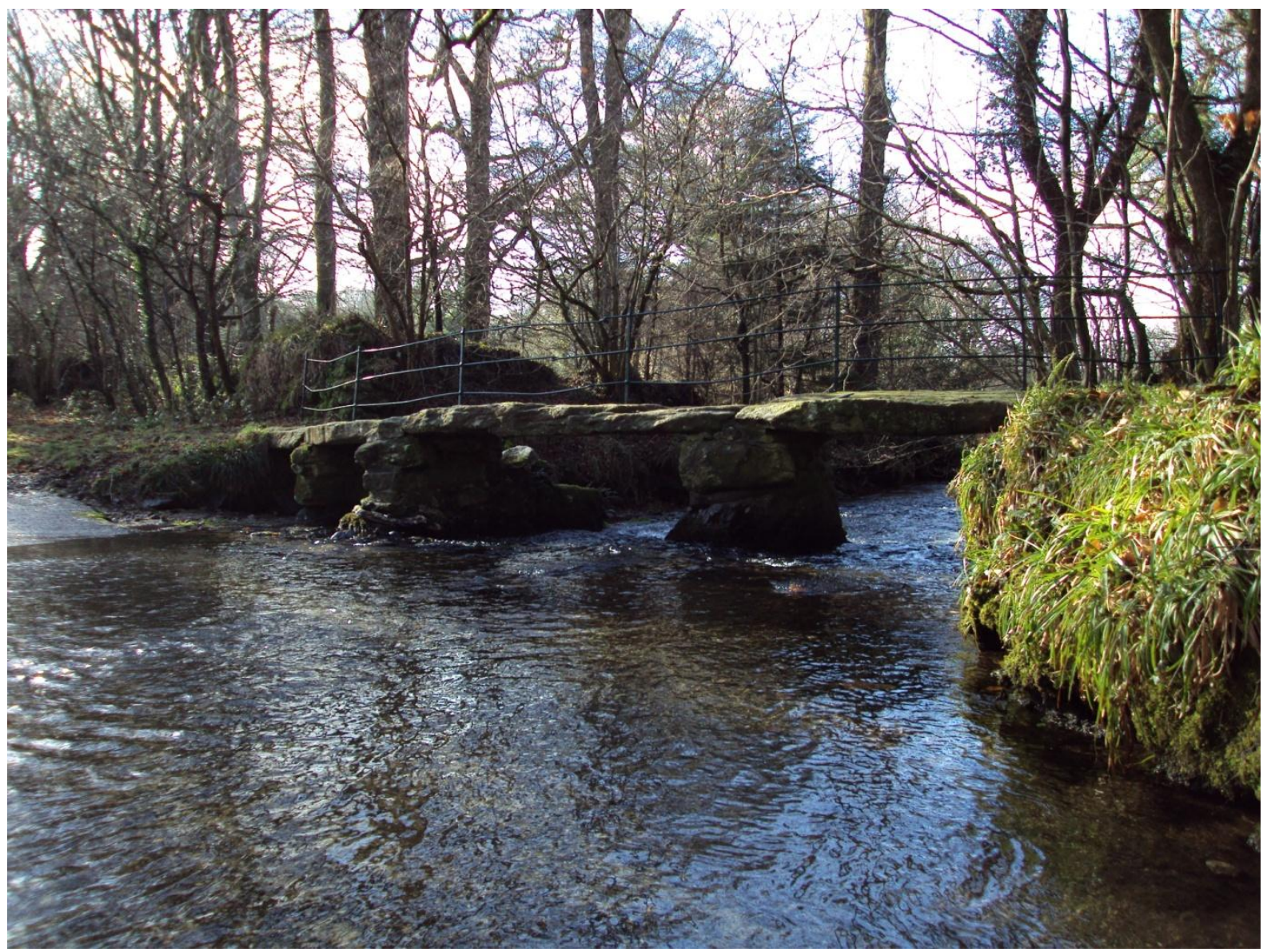




\section{Date: 08/02/2011}

\section{Record \# 006}

Site/Artefact type: Remains of Carweather Village (Medieval)

GPS coordinates: $\mathrm{N}: 50^{\circ} 35.612 \mathrm{~W}: 004^{\circ} 41.363$

$\# 72$

Position related to route: $30 \mathrm{~m}$ uphill (E) from path across upland fields, near Devils Jump

Photo/Sketch record number(s): 33, 35(1110, 1111)

Date of site/artefact (if identifiable): Medieval

Dedication: N/A

Description of site/artefact (including interior decoration if applicable): Series of earthworks remaining on barren hillside of Camel river valley. Clear view to Bodmin Moor and when active would have been very visible against the skyline from valley floor.

Surrounding landscape/natural features: Sheep grazing fields, dells and Bodmin Moor.

Visible relation to neighbouring sites/landscape: Near footpath across fields, invisible (now) until reached, but when active see above.

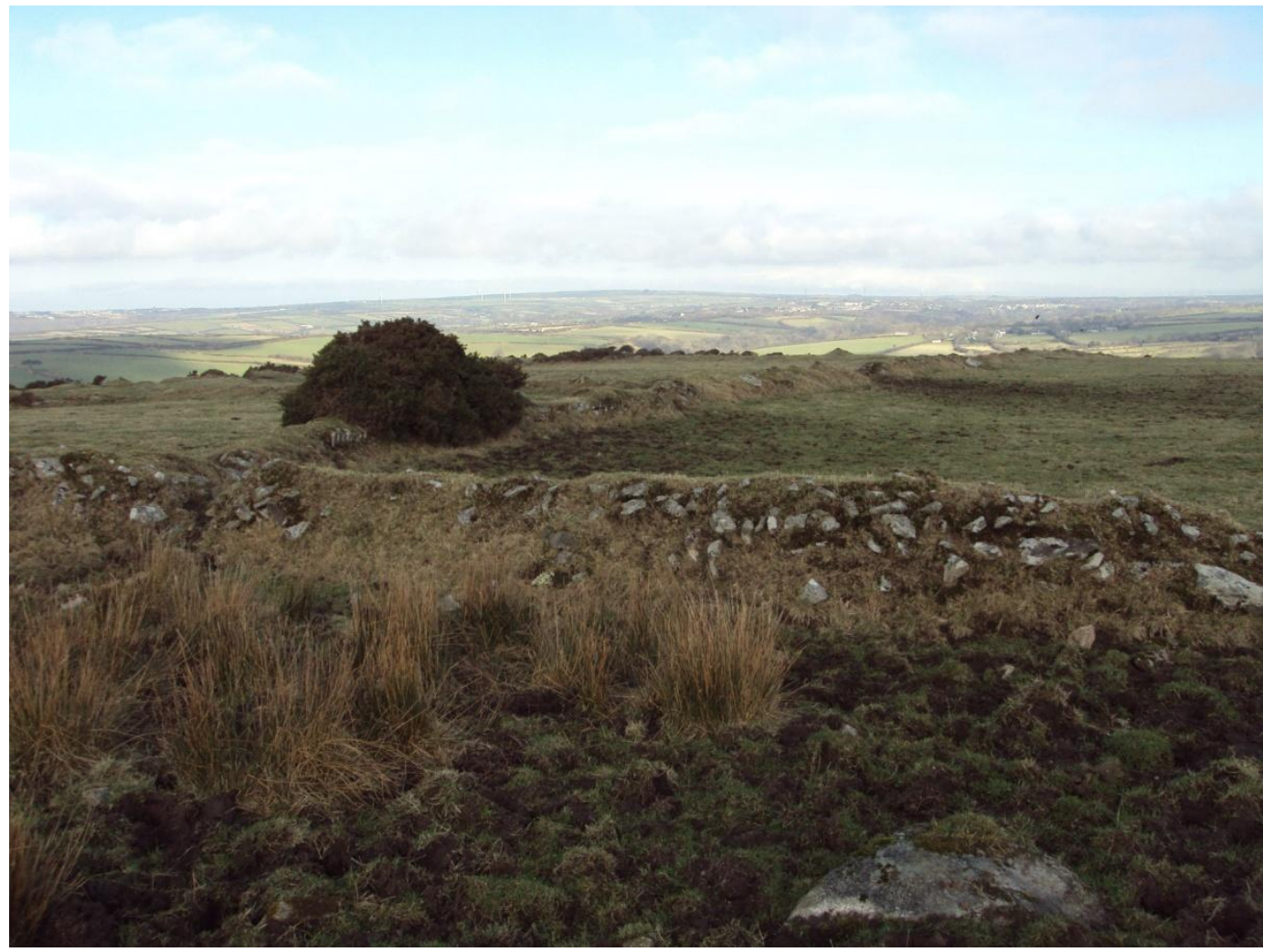


Date: $08 / 02 / 2011$

\section{Record \# 007}

Site/Artefact type: Free standing Cross

GPS coordinates: $\mathrm{N}: 50^{\circ} 36.002 \mathrm{~W}: 004^{\circ} 40.736$

Position related to route: $200 \mathrm{~m}$ E of route $\&$ Advent church.

Photo/Sketch record number(s): 35,36

Date of site/artefact (if identifiable): Medieval, possibly $12 / 13^{\text {th }}$ century.

Dedication: N/A

Description of site/artefact (including interior decoration if applicable): Situated in field, $\sim 3 m$ tall. Bears trace of carved decoration however too eroded to discern.

Surrounding landscape/natural features: Grazing fields, river valley (not visible).

Visible relation to neighbouring sites/landscape: If not obscured by hedgerows then may be visible from road and across the fields.

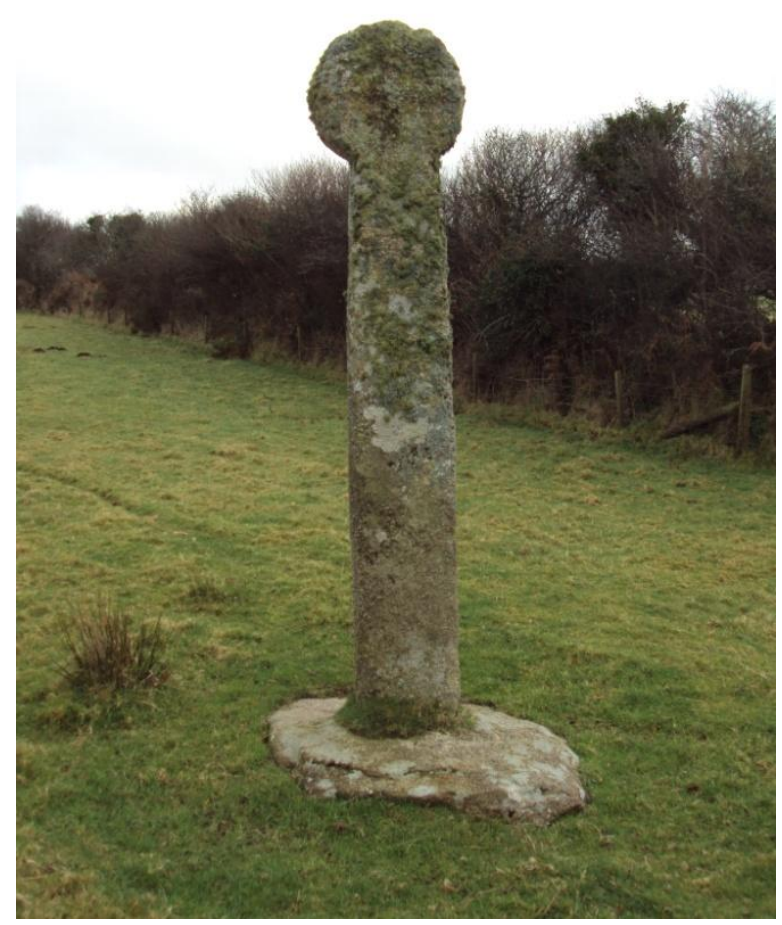




\section{Date: 09/02/2011}

\section{Record \# 008}

Feature: Approaching view of St Breward church tower, hill crest overlooking valley and sight line to Camelford.

GPS coordinates: N: $50^{\circ} 34.010$ W: $004^{\circ} 41.270$

Photo/Sketch record number(s): 45, 46(1130, 1131)

Position related to route: on road approaching village

Point at which visible from the route (GPS): N: $50^{\circ} 34.010$

W: $004^{\circ} 41.270$

Surrounding features: From this elevated point one can see the river valley, fields previously crossed (possible including DMV Carweather), Camelford and the approaching church tower of St Breward.

Interaction between feature \& pilgrim (slope, shelter, dominance of view etc): Church tower is a surprise as previously unseen from path. However, it's elevation may mean that it was visible from other approaches, as it is the 'highest church in cornwall'. May have evoked relief for pilgrims as its presence signified sanctuary after trek over the fields (very exposed, especially In poor weather). Inn next door $\left(11^{\text {th }} \mathrm{C}\right)$. Potential for radius of influence due to height at situation on hill looking over valley.

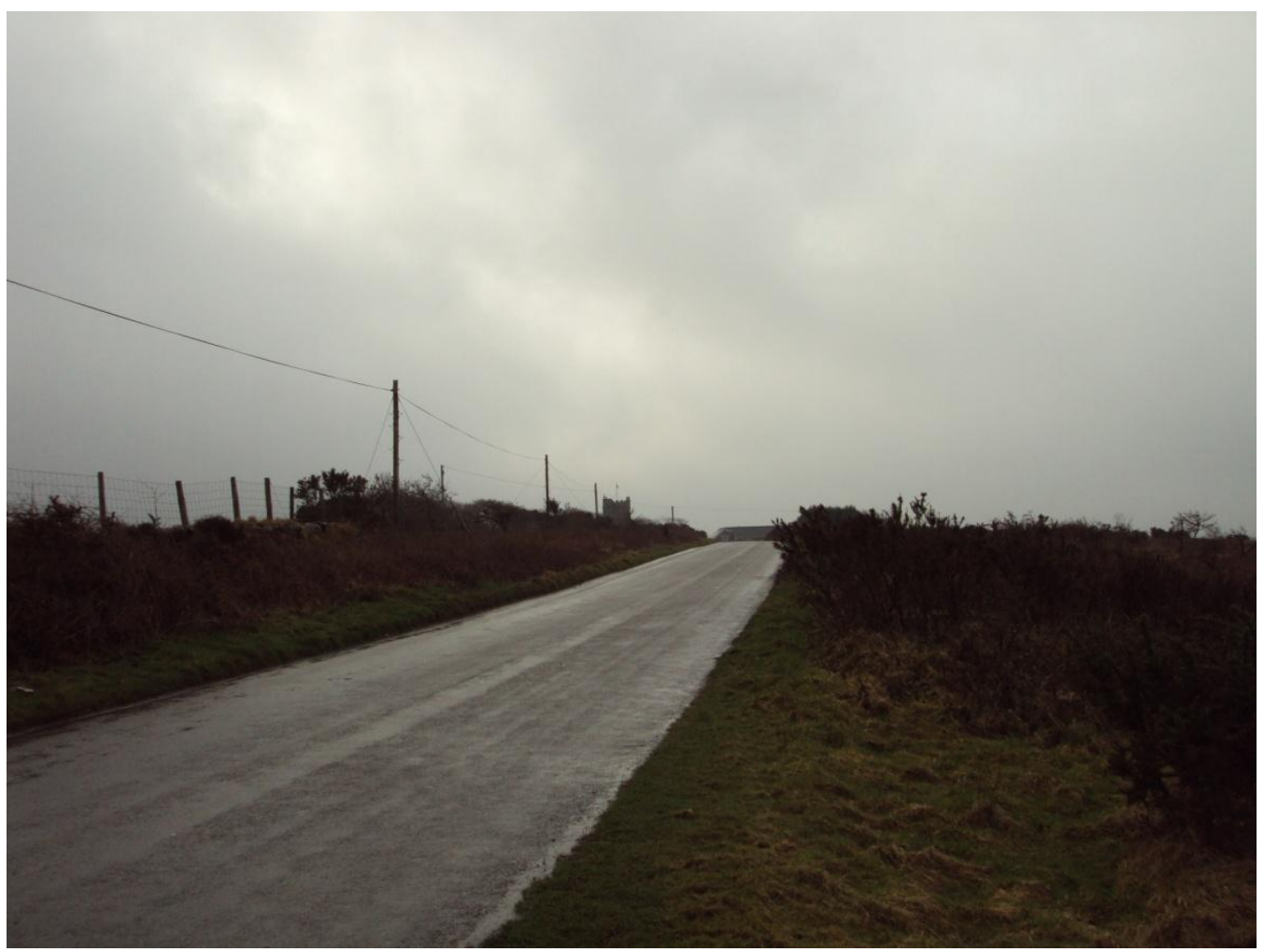


Date: $09 / 02 / 2011$

\section{Record \# 009}

Site/Artefact type: Church at St Breward

GPS coordinates: $\mathrm{N}: 50^{\circ} 33.892 \mathrm{~W}: 004^{\circ} 41.288$

\#75

Position related to route: at entrance to Churchtown/St Breward

Photo/Sketch record number(s): $47-51$

$(11132-11136)$

Date of site/artefact (if identifiable): Norman

Dedication: St Branwalader

Description of site/artefact (including interior decoration if applicable): $15^{\text {th }} \mathrm{C}$ south aisle and tower added. Engraved skulls at $\mathrm{N}$ entrance. Inside is a 'celtic cross' on the altar of great antiquity, plain walls. Built on site of 'Celtic' oratory. Some reliefs of the rood screen survive, with a chequered floor.

Surrounding landscape/natural features: Situated on a hill which overlooks the river Camel \& valley, view many miles distant to hills, woodland and Camelford.

Visible relation to neighbouring sites/landscape: Explained in previous data sheet.

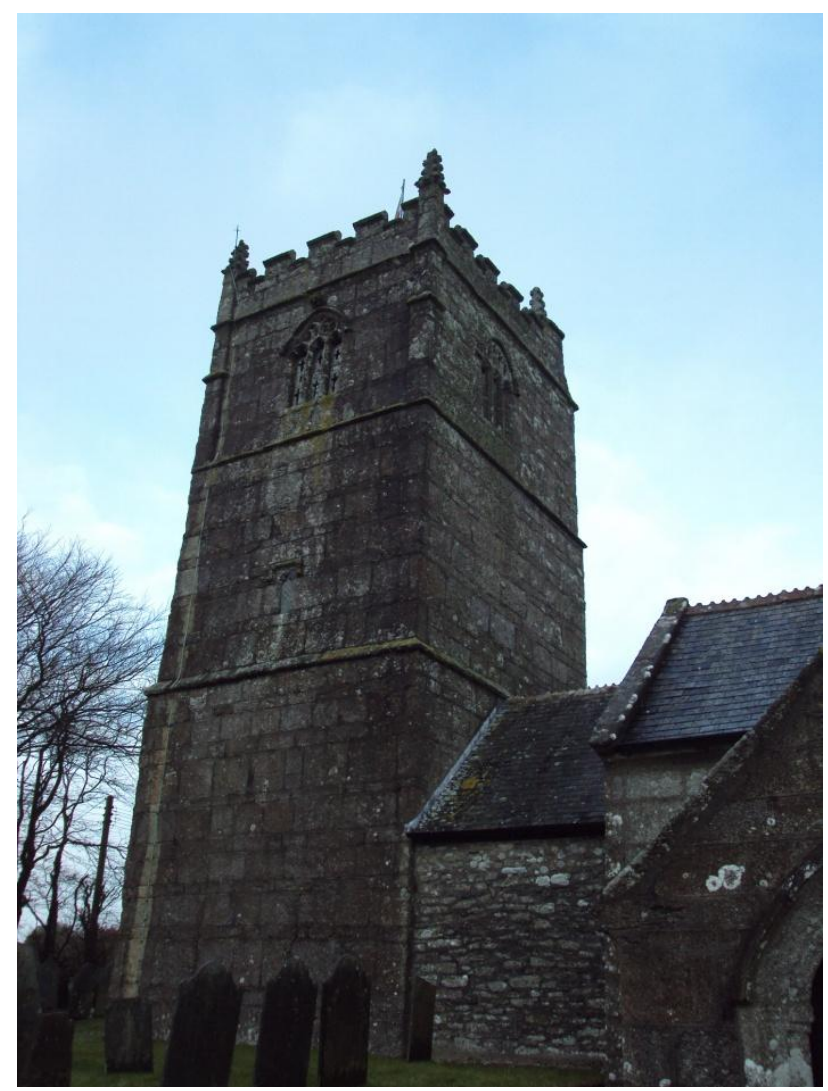




\section{Date: 09/02/2011}

\section{Record \# 010}

Site/Artefact type: Well (Holy)

GPS coordinates: $\mathrm{N}: 50^{\circ} 33.643 \mathrm{~W}: 004^{\circ} 41.820$

\#76

Position related to route: Off road through St Breward, down track towards valley floor.

Photo/Sketch record number(s): $51-54 \quad$ (1137-1139)

Date of site/artefact (if identifiable): First mentioned in 1442, in Oliver's Montasticon

Dedication: St Breward/Seynt Bruard/St Michael/St James

Description of site/artefact (including interior decoration if applicable): Square solid structure, small arch, overgrown, roughly $5 \mathrm{ft}$ high and well is $1 \mathrm{ft}$ deep. Reputed to have healing qualities for eye ailments, and ribbons are tied onto nearby trees as offerings.

Surrounding landscape/natural features: Farmland, the river valley floor, wooded sections around the Camel banks.

Visible relation to neighbouring sites/landscape: Virtually invisible until at site itself. Hidden by flora and slope of valley side.

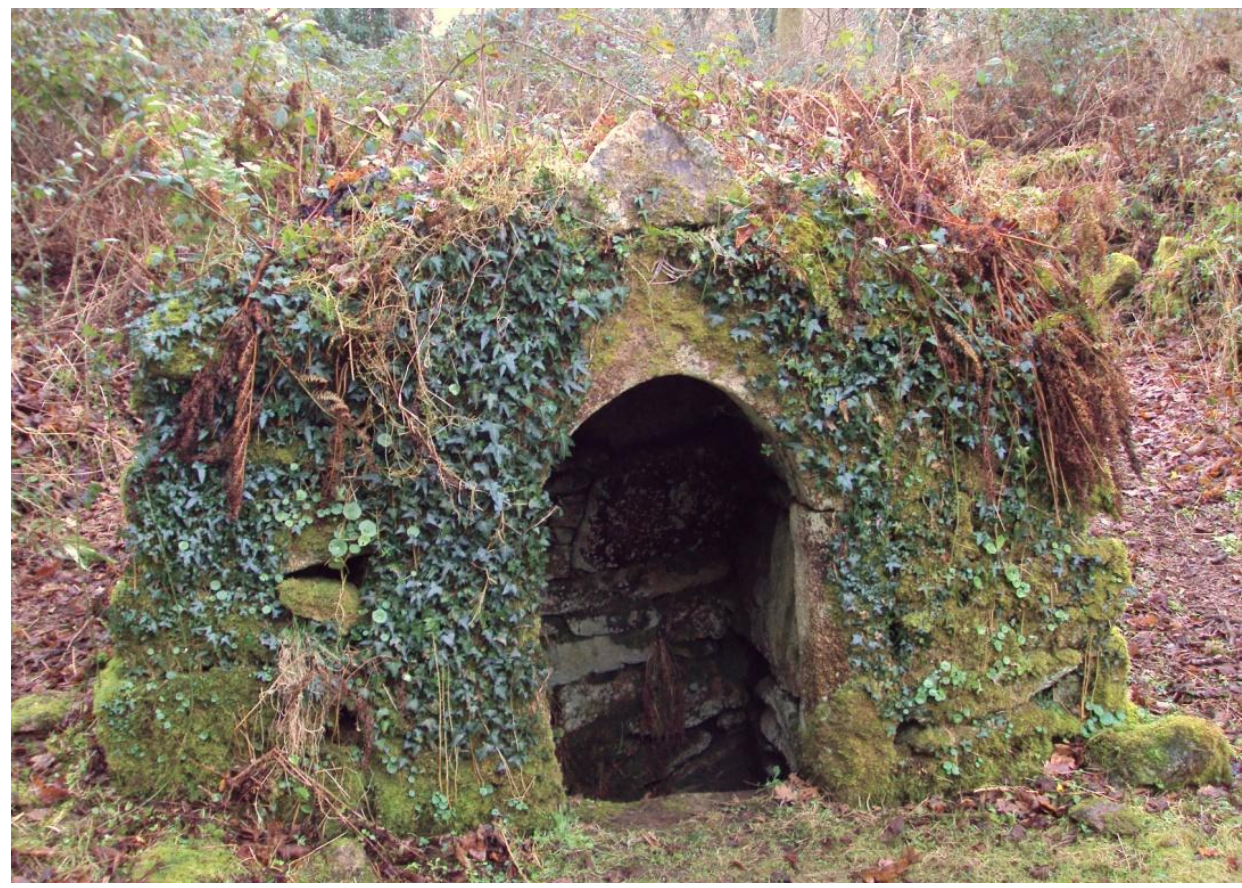


Date: 09/02/2011

\section{Record \# 011}

Feature: River Camel

GPS coordinates: N: $50^{\circ} 32.073$ W: $004^{\circ} 42.398$

Photo/Sketch record number(s): 62

Position related to route: Alongside route (Camel Trail)

Point at which visible from the route (GPS): N: $50^{\circ} 32.073 \quad$ W: $004^{\circ} 42.398$

Surrounding features: Farmland, grazing fields, tree lined river bank, hills/valley tops.

Interaction between feature \& pilgrim (slope, shelter, dominance of view etc): Having come downhill from walking along the valley top, it is much more sheltered here and calm (especially in the rain), feeling of being led towards sanctuary via the river. River also links one to the origin of the pilgrimage (Camelford).

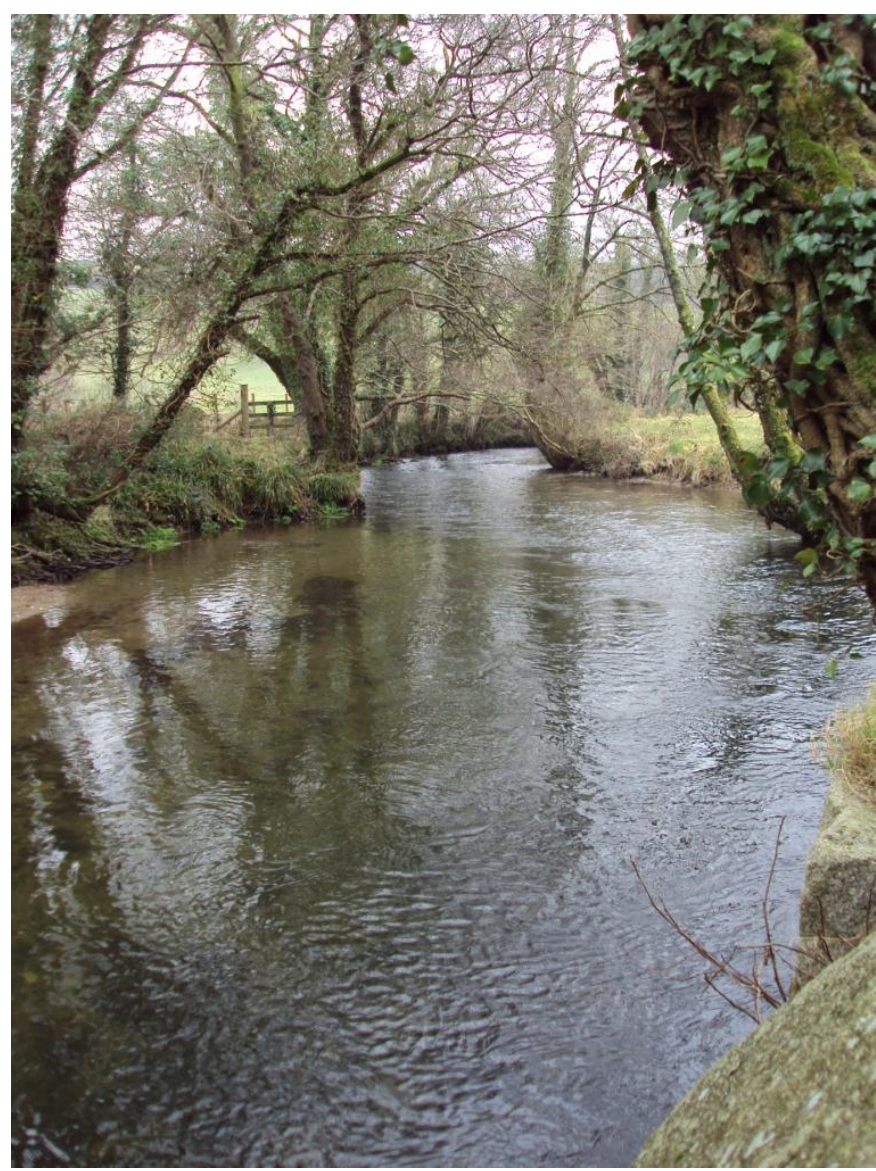




\section{Date: 09/02/2011}

\section{Record \# 012}

Site/Artefact type: Church at St Hellands

GPS coordinates: $N$ : $50^{\circ} 30.431$ W: $004^{\circ} 42.971$

Position related to route: On road through village, leaving Camel trail and river.

Photo/Sketch record number(s): $68-70 \quad(1156-1158)$

Date of site/artefact (if identifiable): Norman

Dedication: St Julietta

Description of site/artefact (including interior decoration if applicable):

Typical square Norman tower, basic cruciform shape, encircled by graveyard, no exterior decoration of note, locked.

Surrounding landscape/natural features:

Wells nearby (not holy), at elevation above Camel trail/valley but obscured by trees. Mainly surrounded by fields/farmland. Some woodland visible on the other valley side.

Visible relation to neighbouring sites/landscape: Tower although tall and elevated not visible from other points due to trees and approach.
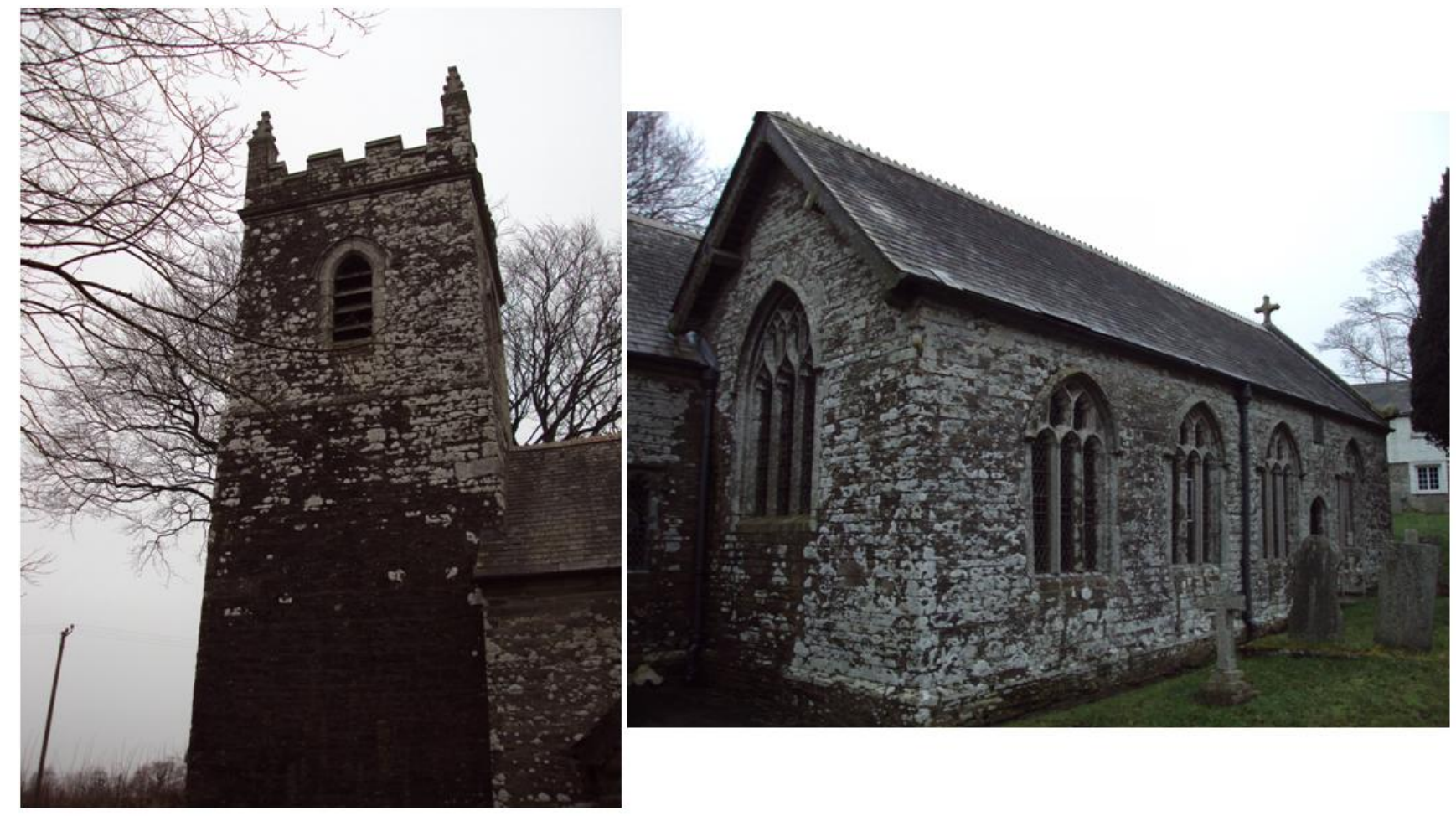


\section{Date: 09/02/2011}

\section{Record \# 013}

Feature: First sight of Bodmin \& Church tower from Northern approach.

GPS coordinates: N: $50^{\circ} 28.721$ W: $004^{\circ} 43.099$

\#79

Photo/Sketch record number(s): $71 \quad$ (1161)

Position related to route: On northern road entering Bodmin outskirts

Point at which visible from the route (GPS): N: $50^{\circ} 28.721 \quad$ W: $004^{\circ} 43.099$

Surrounding features: Rolling fields/grazing land/paddocks. River Camel not visible but audible.

Interaction between feature \& pilgrim (slope, shelter, dominance of view etc): This is the first sight of Bodmin church/priory \& the sacred site of St Petroc's cult centre. After a long day's walking the pilgrim is rewarded with his first glimpse of Bodmin, accompanied by the sound of the Camel river, which has accompanied the pilgrim intermittently throughout his journey. By this point he is also very close to the Berry Tower, recorded nest. A clear transition point from wilderness to sanctuary.

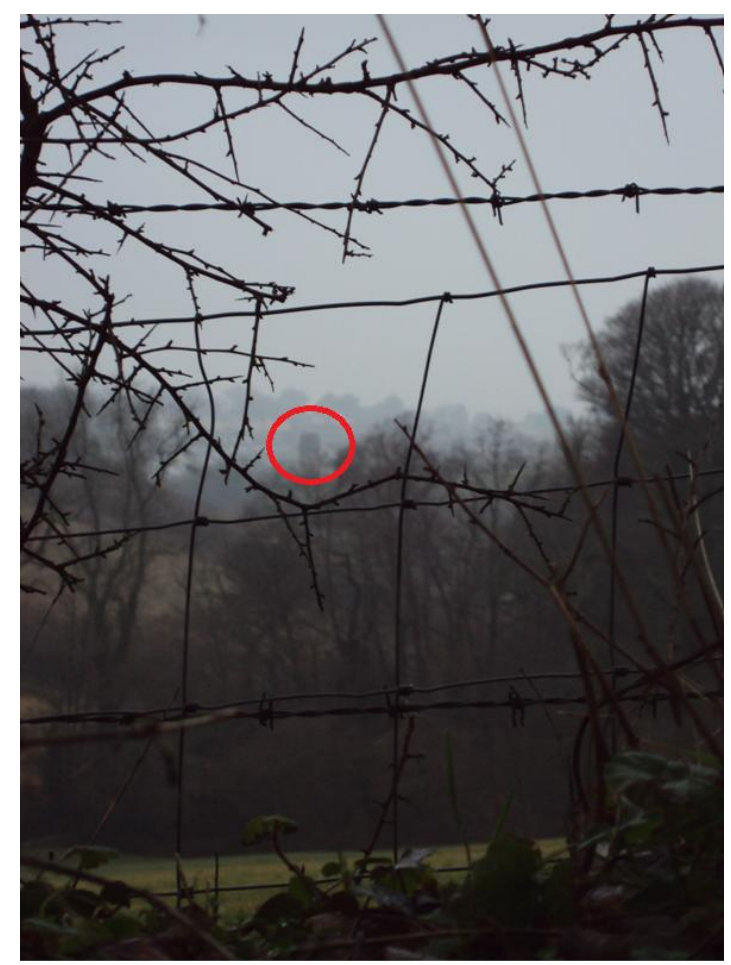




\section{Date: 09/02/2011}

\section{Record \# 014}

Site/Artefact type: Berry Tower \& Chapel of the Rood

GPS coordinates: N: $50^{\circ} 28.518$ W: $004^{\circ} 43.076$

\#80

Position related to route: On $\mathrm{N}$ road entering Bodmin, now in cemetery.

Photo/Sketch record number(s): $74-80 \quad(1162-1168)$

Date of site/artefact (if identifiable): 1501

Dedication: Holy Rood

Description of site/artefact (including interior decoration if applicable): Ruined free standing tower, roughly $40 \mathrm{ft}$ high. Was centre for the Holy Rood cult, included a chapel.

Surrounding landscape/natural features: Overlooks Bodmin.

Visible relation to neighbouring sites/landscape: Priory would have been visible from this point, and potentially some of the 13 chapels, hospitals, guild houses and Friary which existed in Bodmin prior to the Reformation.

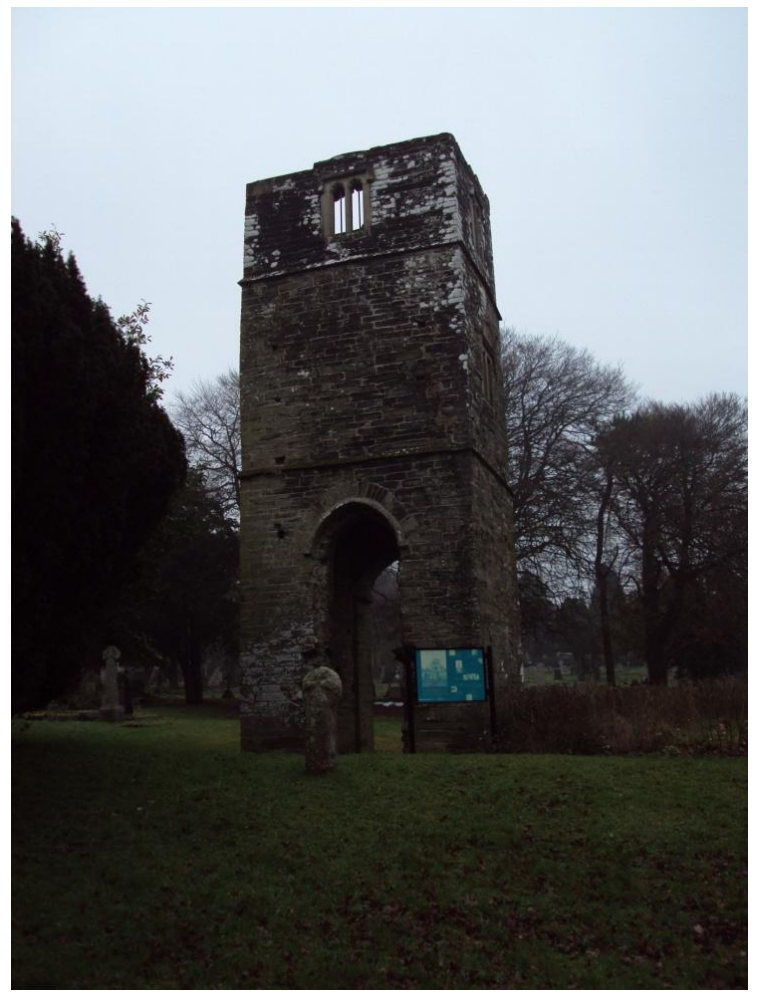


Date: $10 / 02 / 2011$

\section{Record \# 015}

Site/Artefact type: St Gurun's Well \& Well House

GPS coordinates: $\mathrm{N}: 50^{\circ} 28.282 \mathrm{~W}: 004^{\circ} 43.022$

Position related to route: Next to Church of St Petroc, nr Priory site.

Photo/Sketch record number(s): $87-90 \quad(1182-1185)$

Date of site/artefact (if identifiable): Well is $12^{\text {th }} \mathrm{c}$. Well house is 1545.

Dedication: St Gurun

Description of site/artefact (including interior decoration if applicable): Water emerges from gulley in wall, and 2 spouts shaped like heads. Inscribed stone above one head. Water falls onto shallow square trough. Roughly 10 metres from church. Is no incorporated into the slope leaving the church grounds.

Surrounding landscape/natural features: Town of Bodmin \& church.

Visible relation to neighbouring sites/landscape: Next to church of St Petroc. Historical and hagiographical link between Gurun \& Petroc, as Gurun was a mentor figure for this young son of a Welsh king.

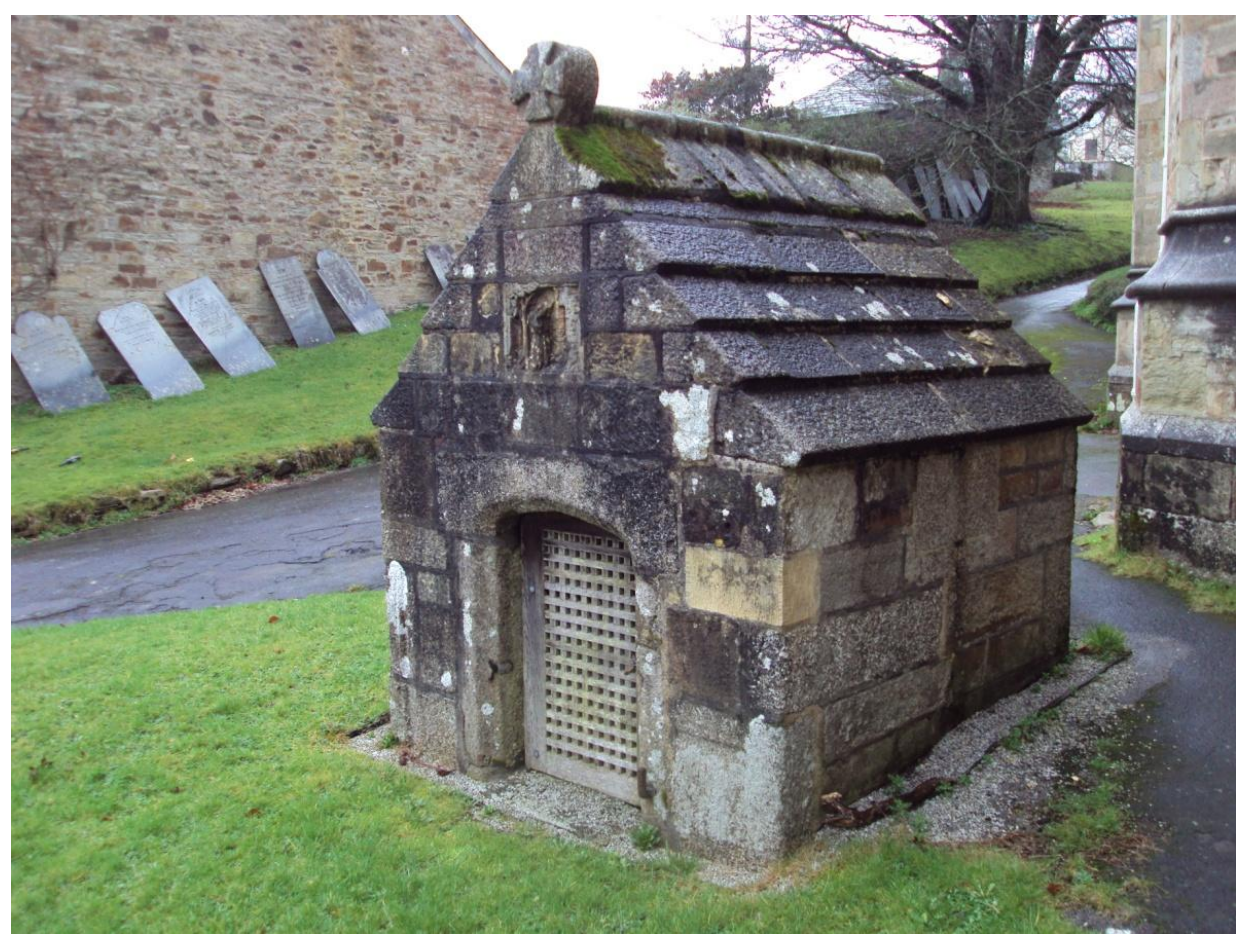


Date: $10 / 02 / 2011$

\section{Record \# 016}

Site/Artefact type: Church of St Petroc

GPS coordinates: $\mathrm{N}: 50^{\circ} 28.283 \mathrm{~W}: 004^{\circ} 43.020$

Position related to route: In centre of Bodmin

Photo/Sketch record number(s): $79-86 \& 93-101$

Date of site/artefact (if identifiable): $\quad 1470$

Dedication: St Petroc

Description of site/artefact (including interior decoration if applicable): Built on the site of earlier unrecorded churches. The tower contains Norman masonry, and is the largest Parish church in Cornwall. There is a $12^{\text {th }}$ century font with beast scenes, and $15^{\text {th }}$ century German painted panels. At the North of the church is the Vyvian Tomb, housing the remains of the penultimate Prior of Bodmin (died 1533) and formally stood in front of the High Altar. In the Lady chapel are remnents of the original carved and painted beams (1472). There is also a reliquary for St Petroc (now minus the relics), whose casket was stolen in1176 and returned from Mont St Michel in 1177, then lost after the Dissolution (returned in 1957). There is a ruined chapel of St Thomas Becket to the east of the church, licensed in 1377 which was used as a schoolhouse for 300 years. Underneath is a vaulted crypt which may have been a charnel house (inaccessible).

Surrounding landscape/natural features:

Surrounded by Bodmin settlement. Opposite is the site of the Bodmin Priory.

Visible relation to neighbouring sites/landscape:

The tower is visible from many aspects of the town and the prior recorded spot on the Northern road entering the town's outskirts. 


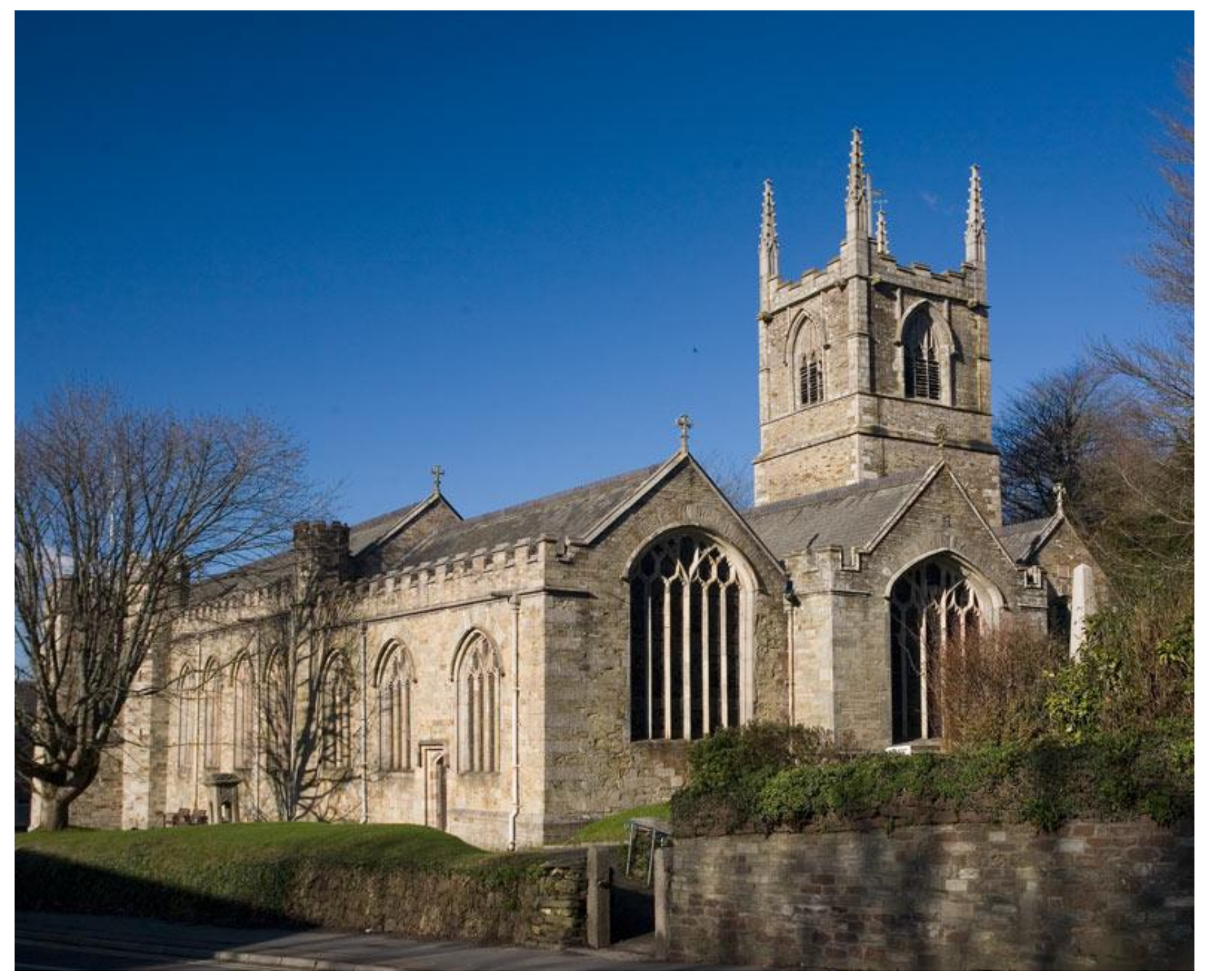

Reproduced from http://www.cornwalls.co.uk/photos/data/media/2/bodmin_church.jpg 
Date: $11 / 02 / 2011$

\section{Record \# 017}

Site/Artefact type: Former site of Bodmin Priory

GPS coordinates: N: $50^{\circ} 28.162$ W: $004^{\circ} 42.986$

\#84

Position related to route: Opposite St Petroc's Church

Photo/Sketch record number(s): $102-105 \quad(1201-1204)$

Date of site/artefact (if identifiable): 1138 - 1539

Dedication: Mary \& St Petroc

Description of site/artefact (including interior decoration if applicable): Now nothing remains, site has been except the monk's fishpond (known as Priory Pond). Some remnants of broken carved masonry are stacked along the border hedges, but essentially the site has been lost. There are no records of the architecture or design of the Priory, however in street names there are many references to monastic activity around the area.

Surrounding landscape/natural features: Situated at the heart of Bodmin in a depression within the landscape.

Visible relation to neighbouring sites/landscape: Being located at a low topographical point in the centre of the town, the site essentially forms a hub of ecclesiastical activity, with other (now disappeared) chapels, churches and the Friary radiating out from this centre. There are few/no records showing locations of these churches etc so this is not strictly geographically the case, but in terms of influence and status it stood as the centre for religious power the St Petroc cult within the region, certainly within Bodmin itself. 


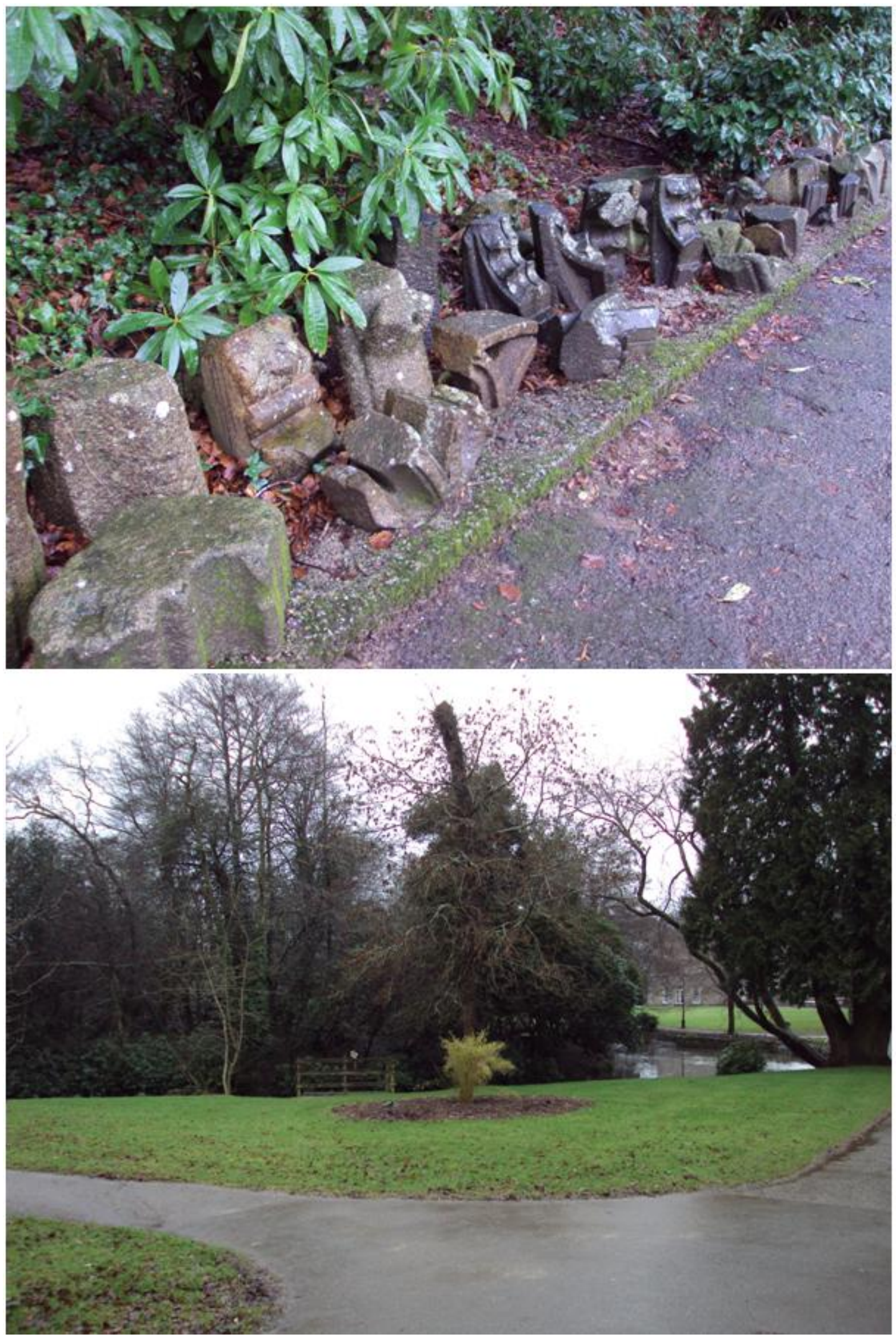


Date: $11 / 02 / 2011$

\section{Record \# 016}

Site/Artefact type: Scarlett's Well (Holy)

GPS coordinates: N: $50^{\circ} 28.507$ W: $004^{\circ} 44.43$

\#85

Position related to route: On Camel trail as it enters Bodmin from the West.

Photo/Sketch record number(s): $107-109$

$(1206-1208)$

Date of site/artefact (if identifiable): $14^{\text {th }}$ century

Dedication: linked to 'Priory of Bodiniel' (Bodmin? If so then St Petroc?)

Description of site/artefact (including interior decoration if applicable): A small rectangular stone structure built into a stone wall bordering fields. Reputed to have healing properties Carew (c. 1600) mentions people visiting in 'large numbers'. The information panel states that this was the most renowned well in Bodmin, and was named after the Scarlett family who lived locally and provided 3 MPs for parliament in 19 years $(1312-1341)$.

Surrounding landscape/natural features: Set at the Western edge of the town, and is located very near the River Camel and backs onto fields and some wooded river paths.

Visible relation to neighbouring sites/landscape: This is the first 'spiritual' site encountered when entering Bodmin from the West (i.e. when following the river down to the settlement from Camelford).

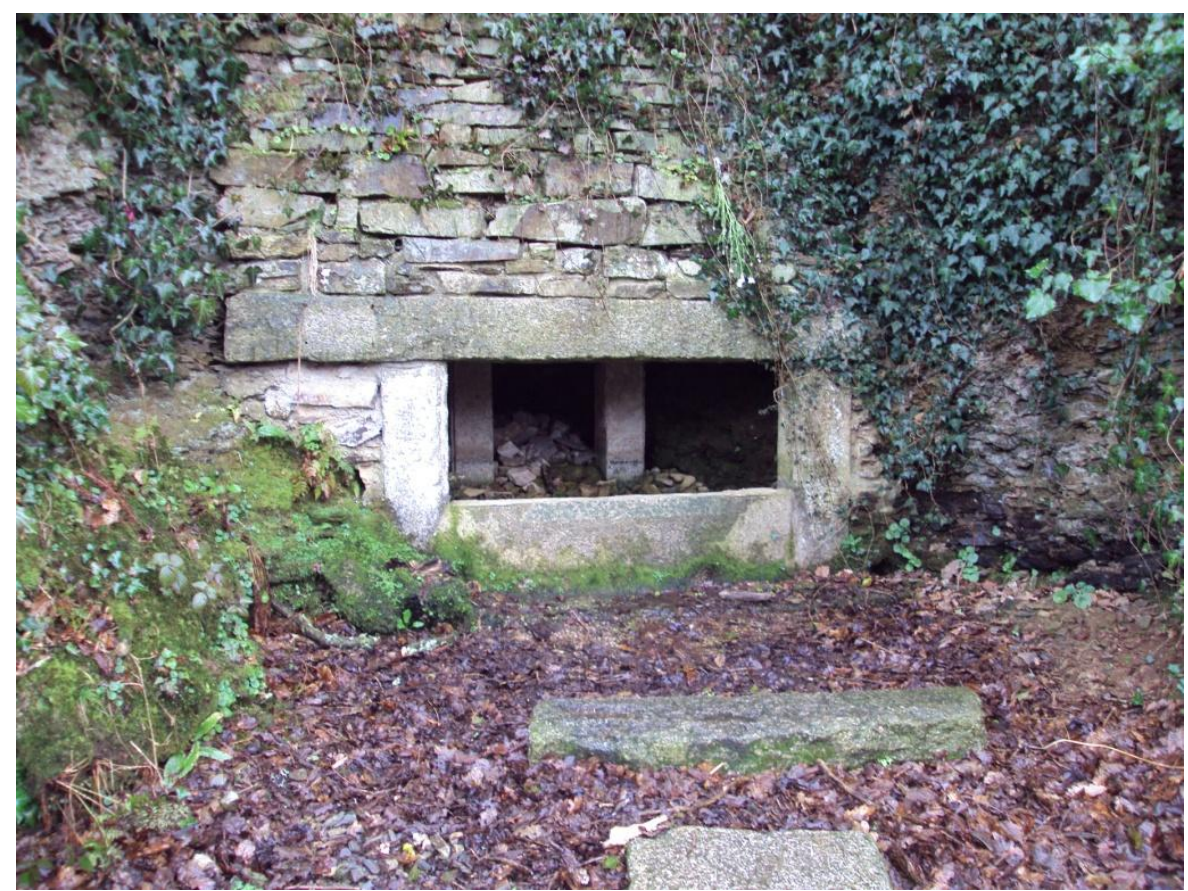




\section{Appendix D}

Individual Surviving Pre-Reformation Church Dedications:

Norfolk (Highlighted are on the Palmer's Way)

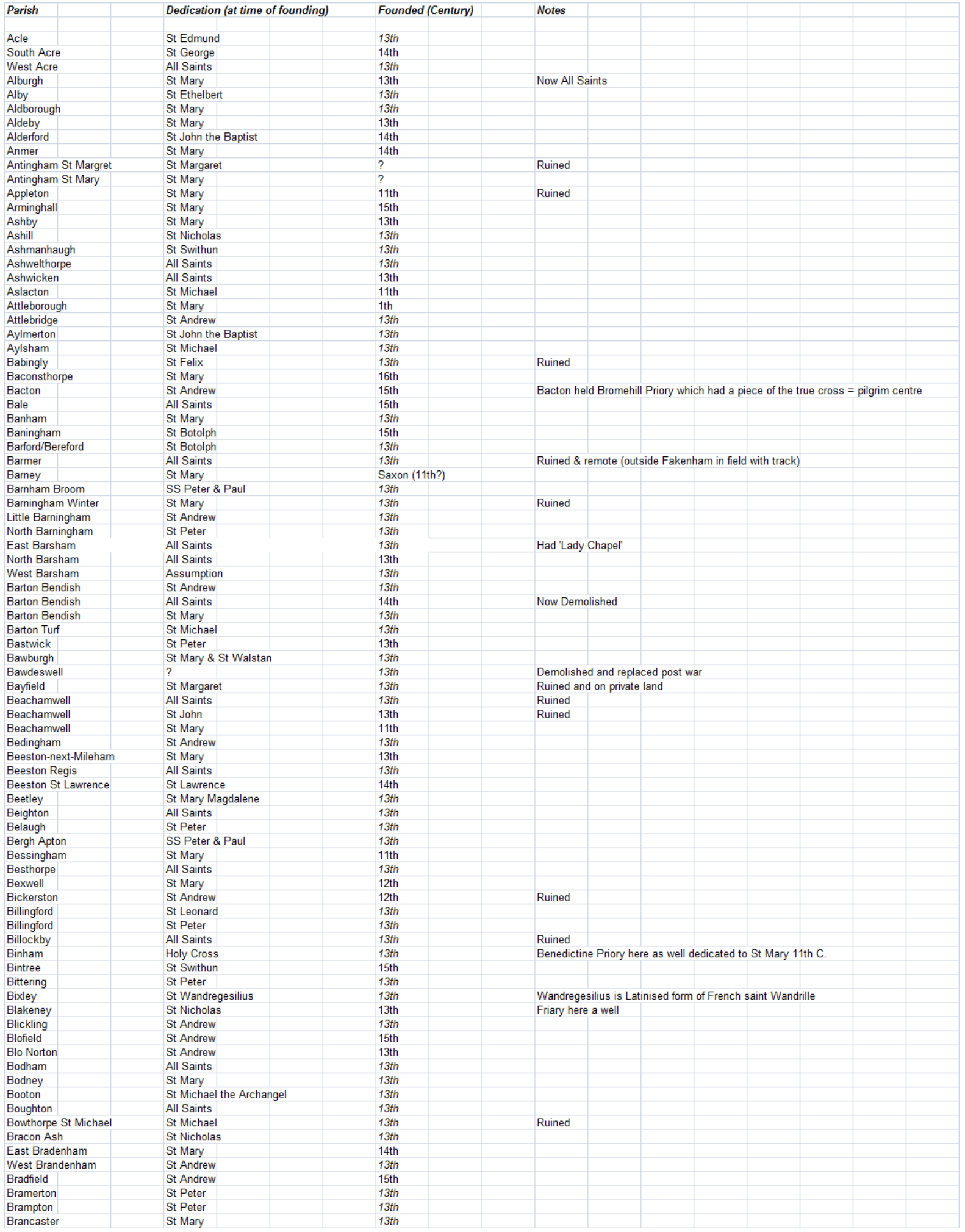




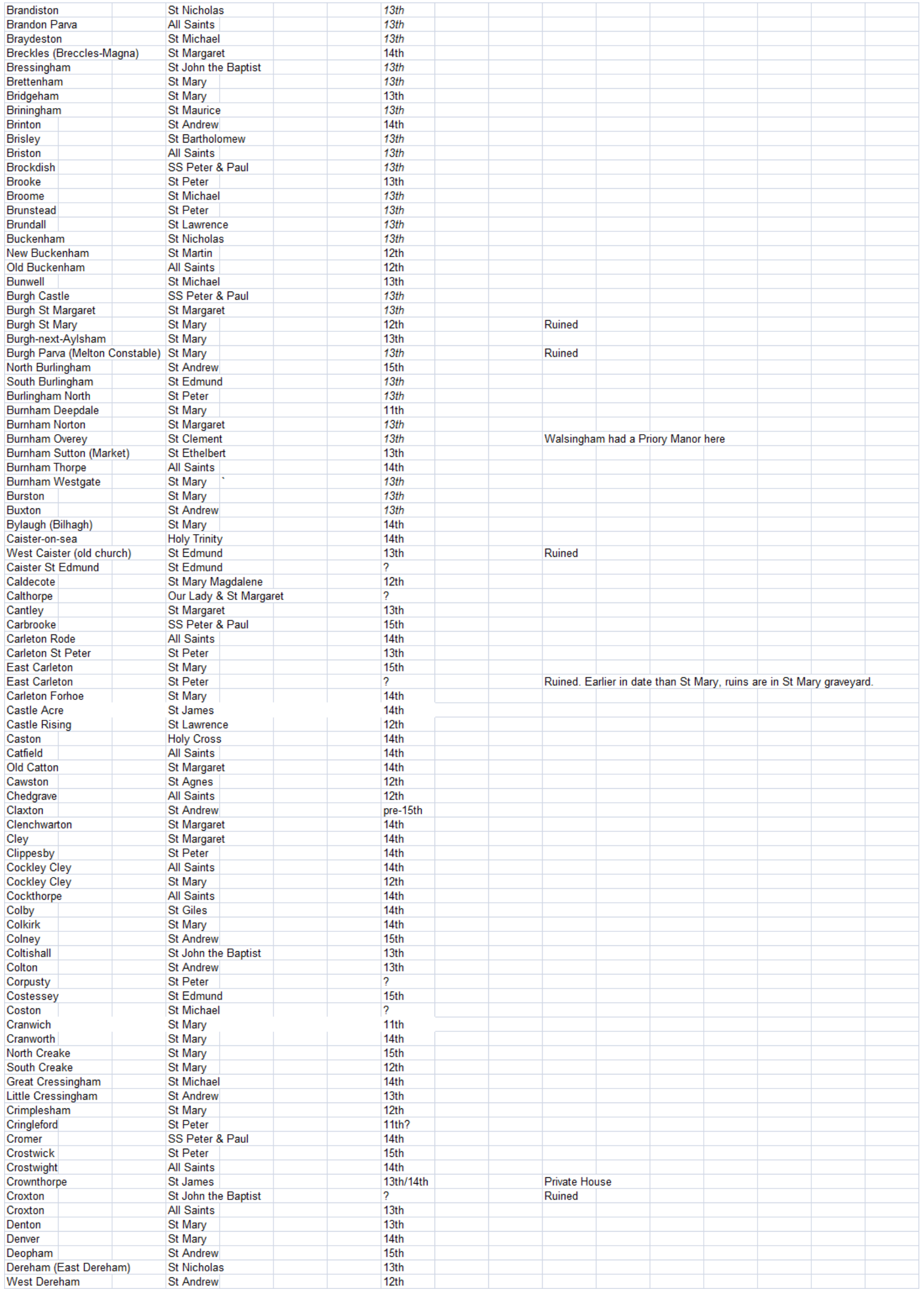




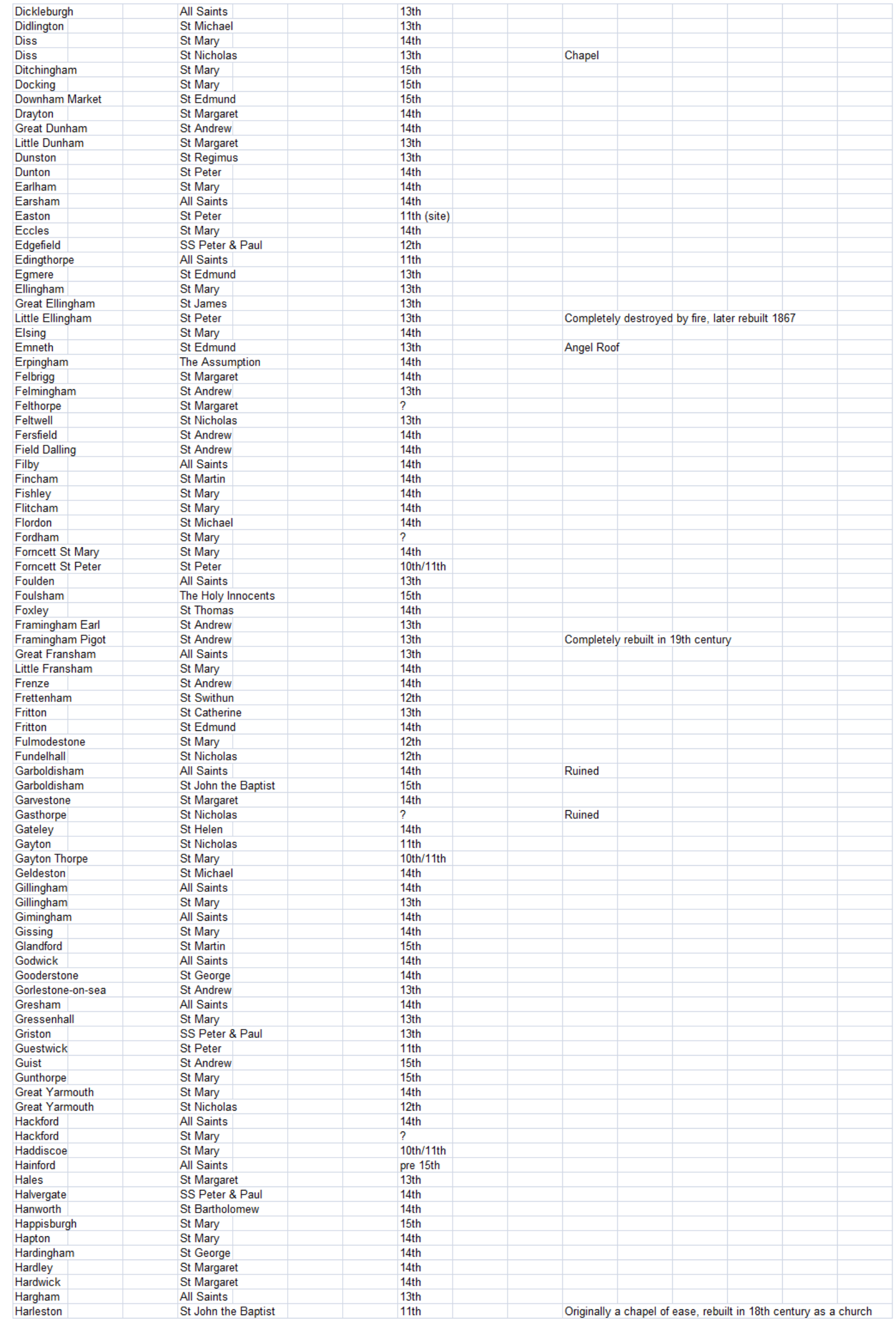




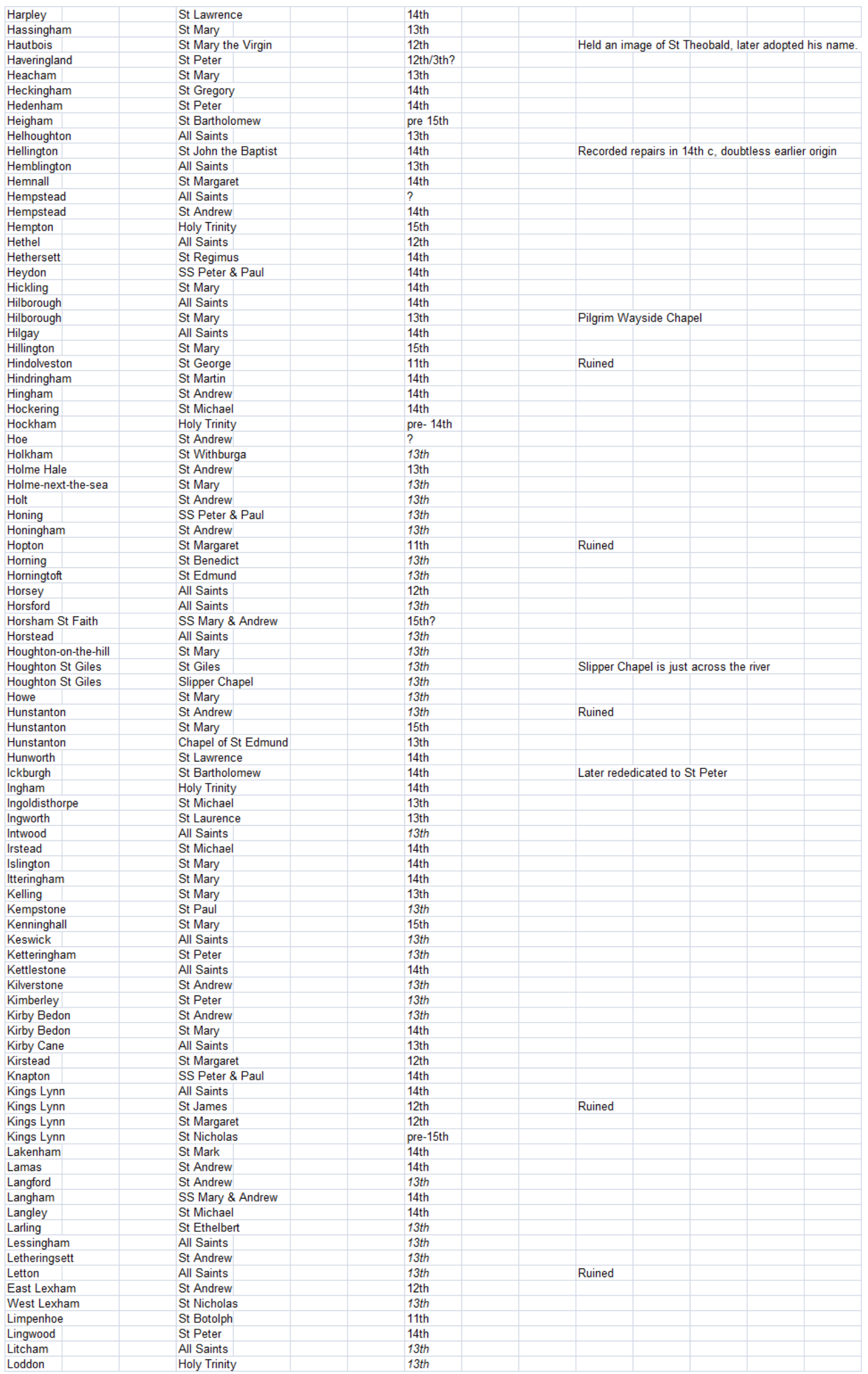




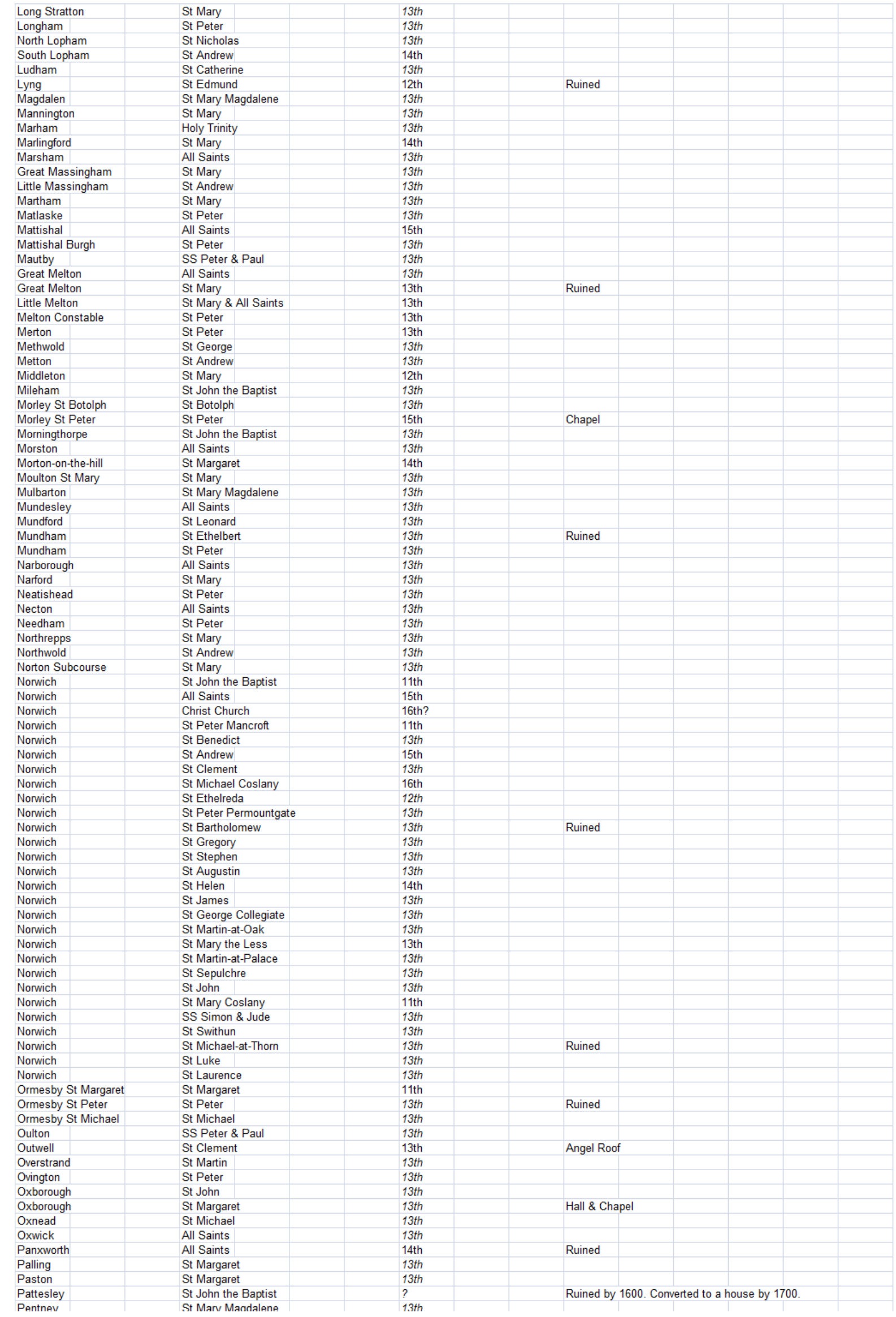




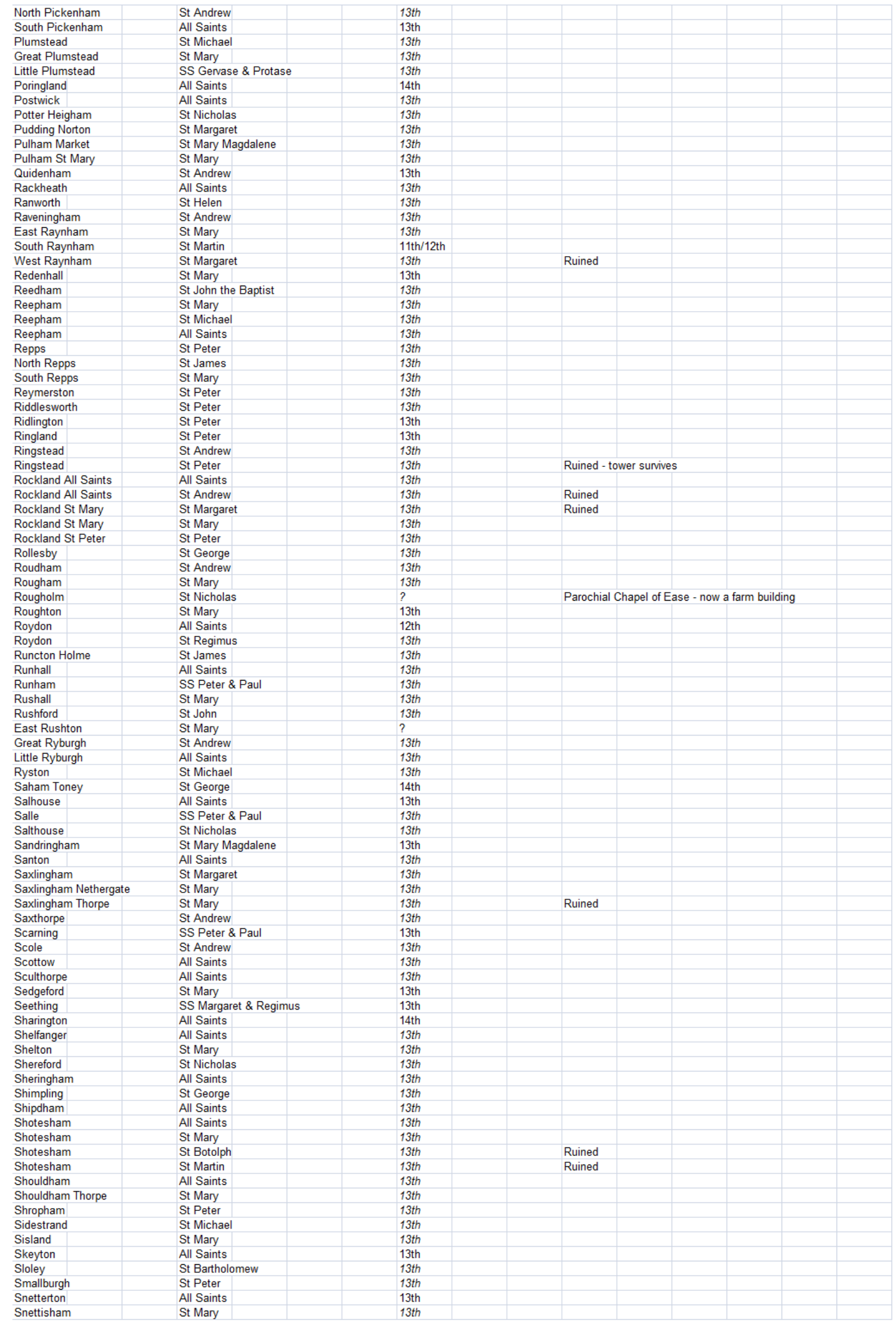




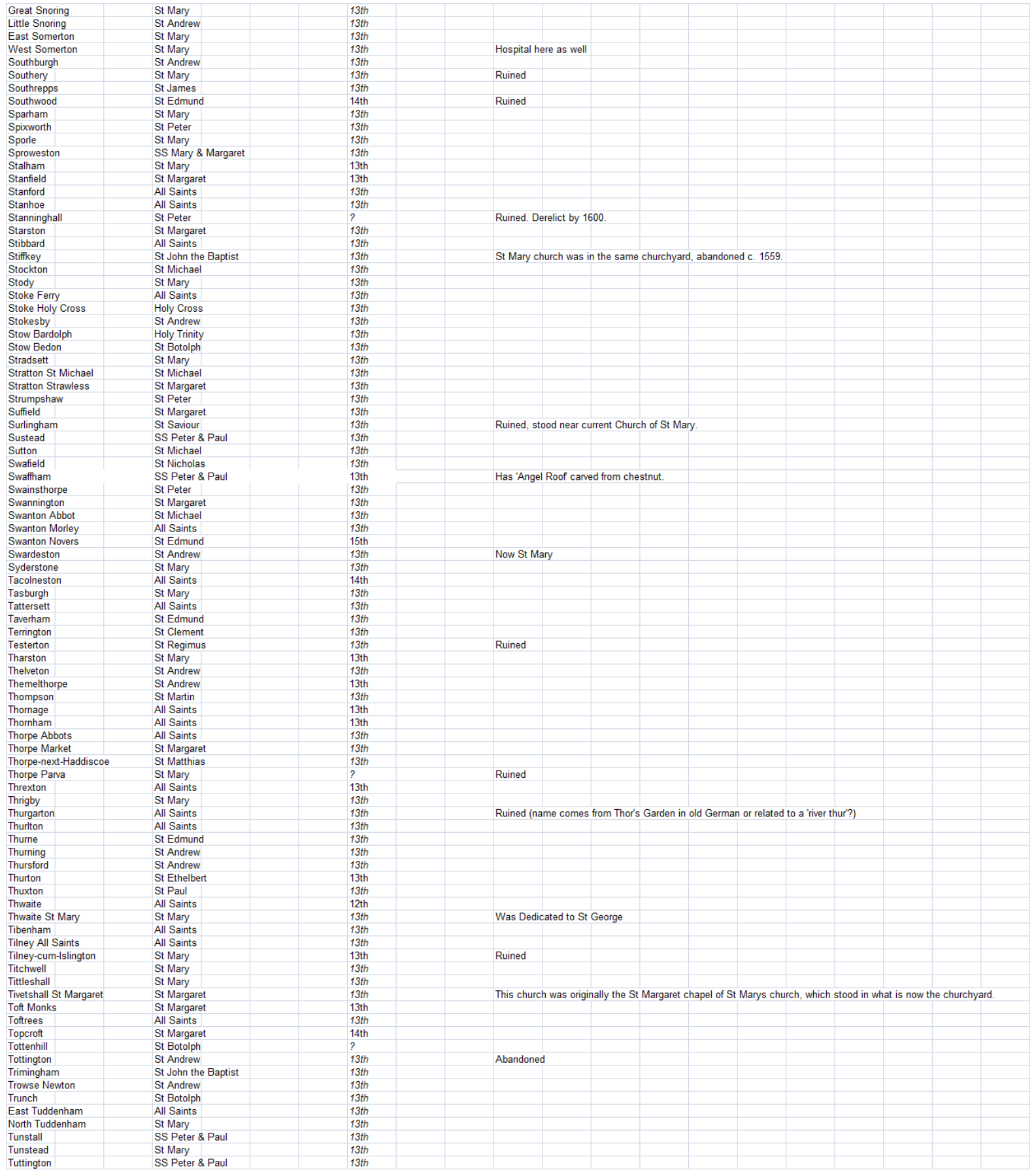




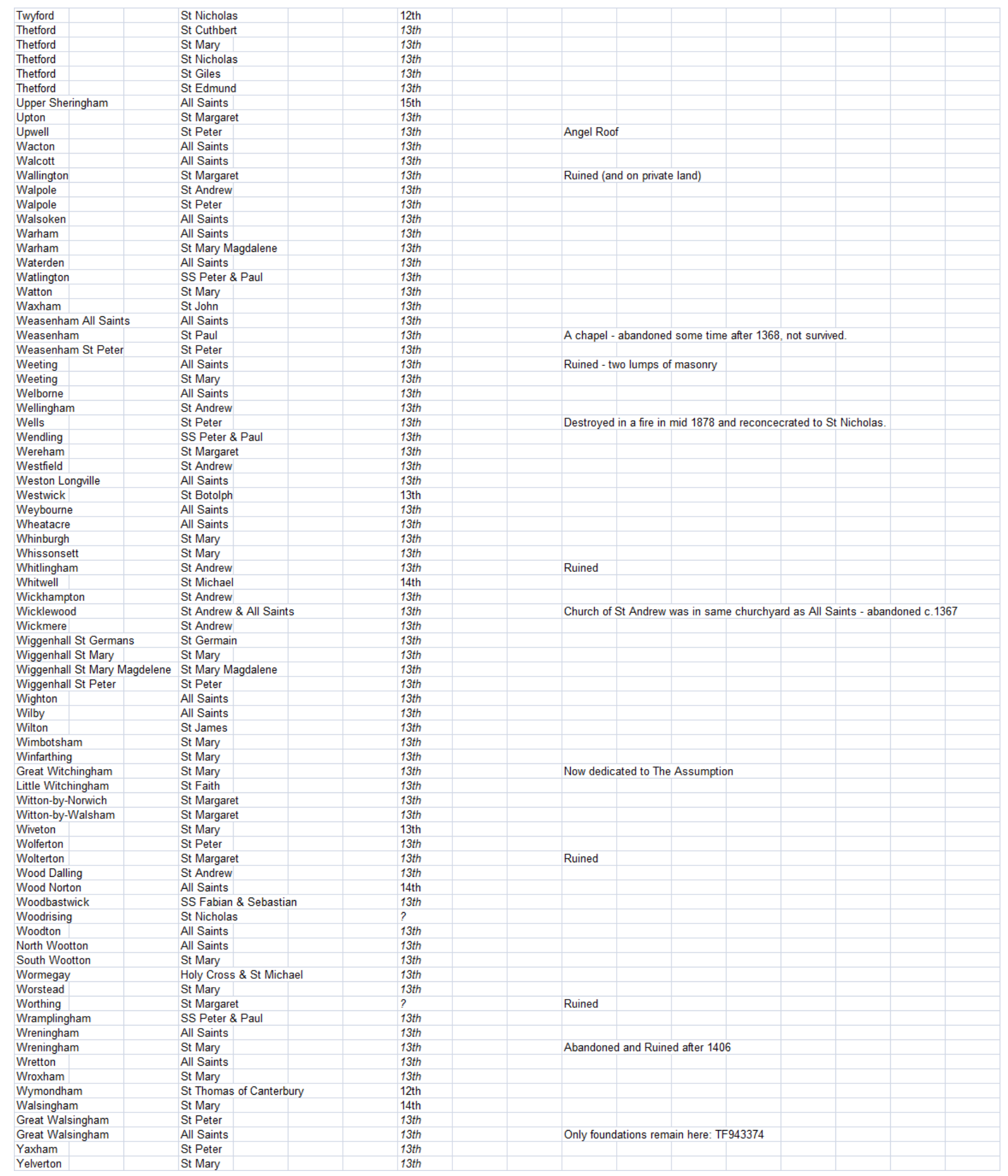


Hampshire \& Wiltshire:

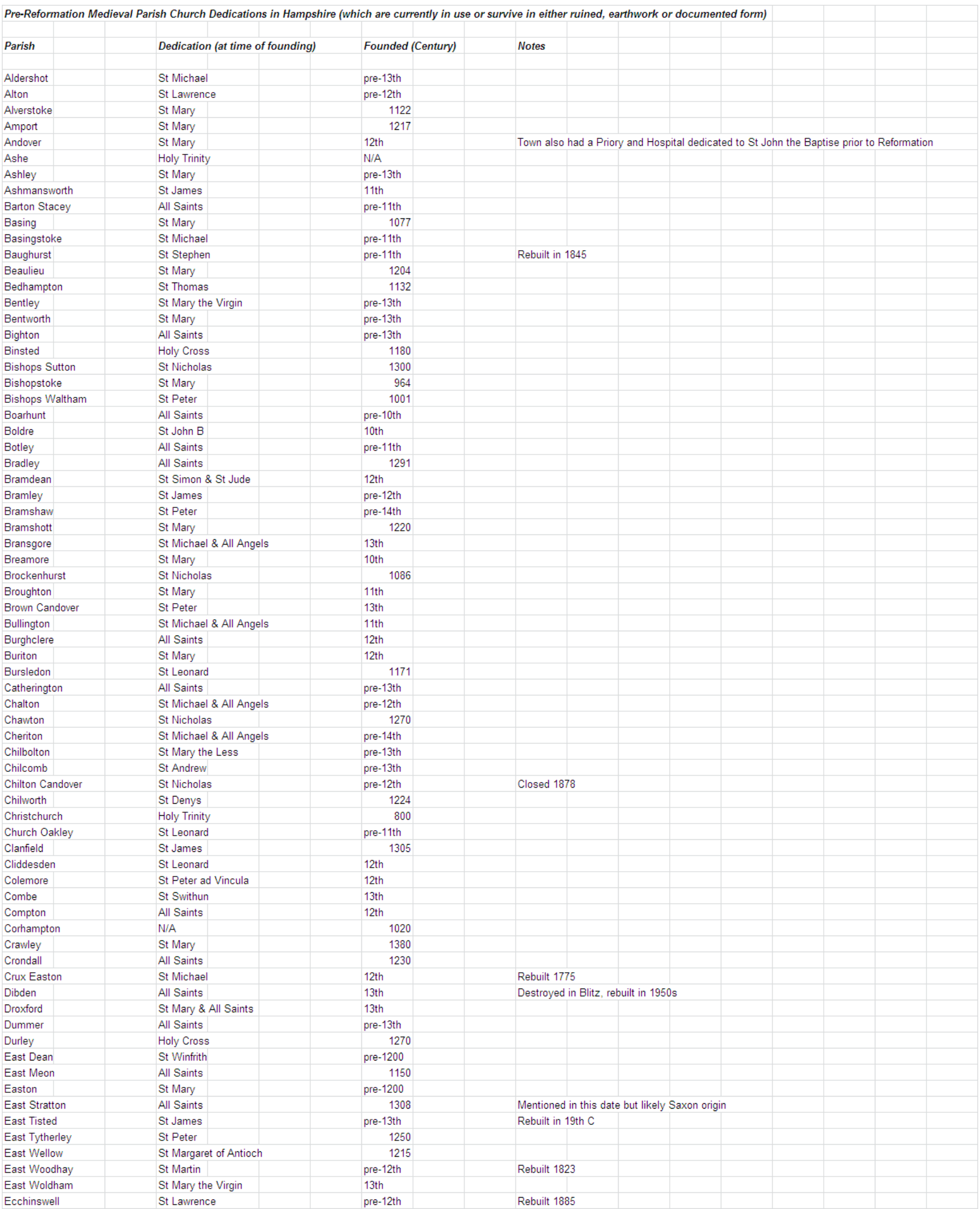




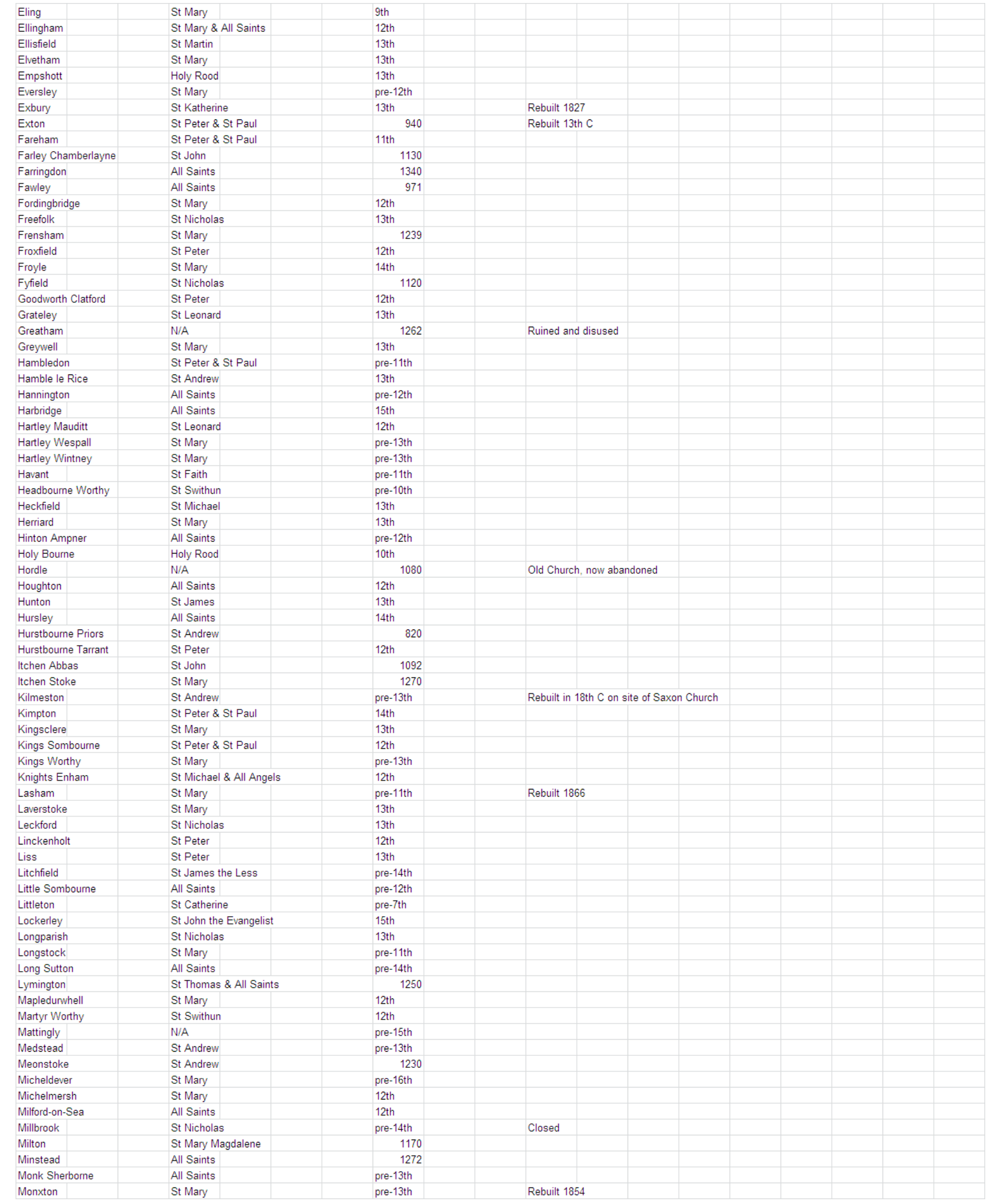




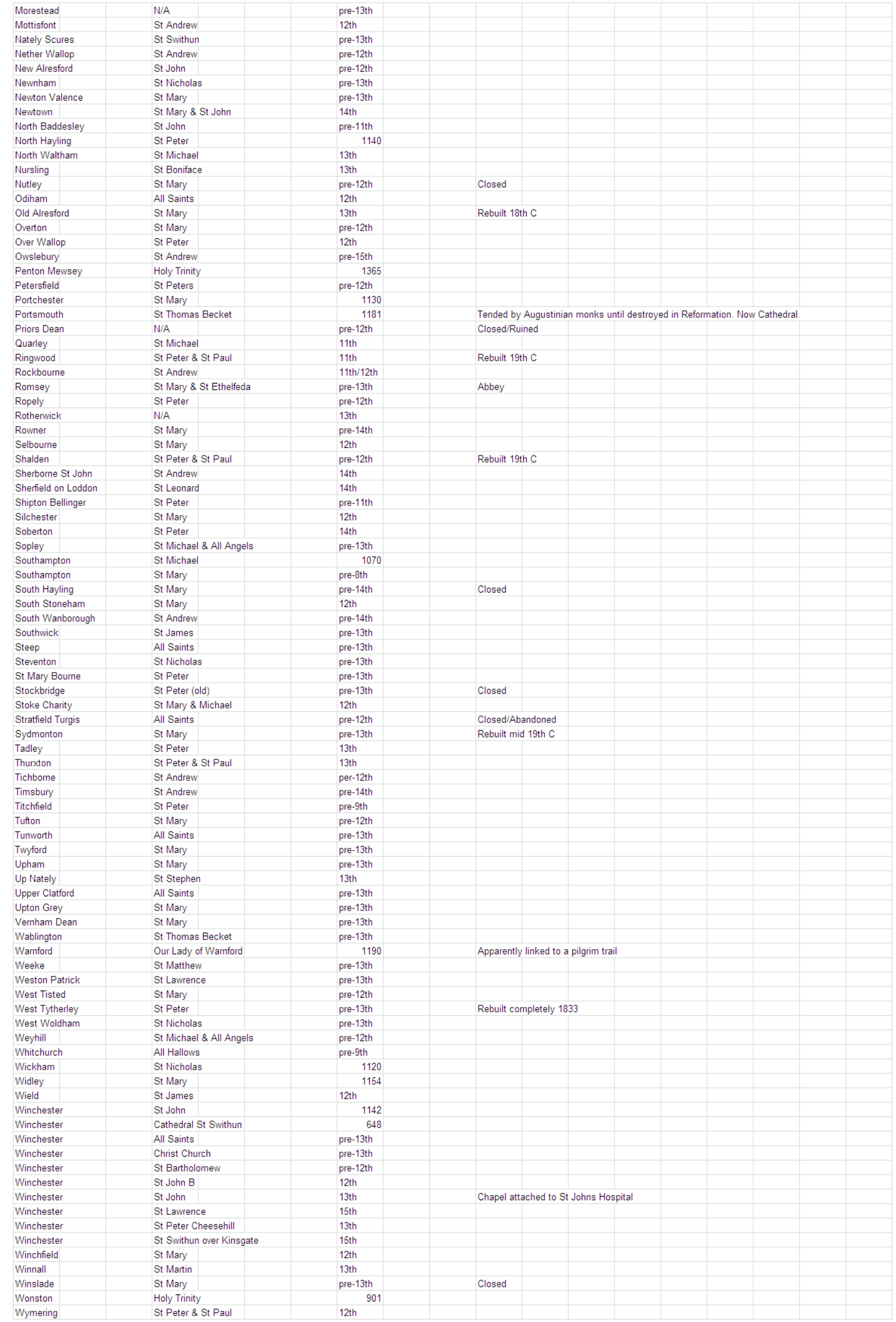


Pre-Reformation Medieval Parish Church Dedications in Wiltshire (which are currently in use or survive in either ruined, earthwork or documented form)

\begin{tabular}{|c|}
\hline \\
\hline Parish \\
\hline Aldbourne \\
\hline Aldebury \\
\hline Alderton \\
\hline Allington \\
\hline Allington \\
\hline Alton \\
\hline Alvediston \\
\hline Amesbury \\
\hline Ansty \\
\hline Ashton Key \\
\hline Atworth \\
\hline Atworth \\
\hline Avebury \\
\hline Barford St I \\
\hline Baydon \\
\hline Beechingst \\
\hline Berwick Ba \\
\hline Berwick St \\
\hline Berwick St \\
\hline Biddestone \\
\hline Biddestone \\
\hline Bishops Ca \\
\hline Bishopston \\
\hline Bishopstow \\
\hline Bowerchalk \\
\hline Box \\
\hline Box \\
\hline Box (Hazell \\
\hline Boyton \\
\hline Bradford-up \\
\hline Bradford-up \\
\hline Bratton \\
\hline Bremhill \\
\hline Bremhill \\
\hline Brinkworth \\
\hline Britford \\
\hline Brixton Dev \\
\hline Broad Chall \\
\hline Broad Hinto \\
\hline Brokenboro \\
\hline Bromham \\
\hline Broughton \\
\hline Bulford \\
\hline Bulkington \\
\hline Burbage \\
\hline Burcombe \\
\hline Calne \\
\hline Calne With \\
\hline Calne With \\
\hline Castle Com \\
\hline Charlton \\
\hline Cherhill \\
\hline Cherhill \\
\hline Chilmark \\
\hline Chippenhan \\
\hline Christian M \\
\hline Codford \\
\hline Codford \\
\hline Colerne \\
\hline Collingbour \\
\hline Compton B \\
\hline Compton C \\
\hline Coombe Bi \\
\hline Corsham \\
\hline Coulston \\
\hline Cricklade \\
\hline Crudwell \\
\hline Dauntsey \\
\hline Devizes \\
\hline Devizes \\
\hline Devizes \\
\hline Dilton \\
\hline Dinton \\
\hline Donhead St \\
\hline Donhead St \\
\hline Downton \\
\hline Downton \\
\hline Downton \\
\hline Durnford \\
\hline Durrington \\
\hline East Kenne \\
\hline East Knoyl \\
\hline Easton Roy \\
\hline Ebbesbourr \\
\hline Edington \\
\hline Enford \\
\hline Erlestoke \\
\hline Etchilhamp \\
\hline Figheldean \\
\hline Fonthill Bis \\
\hline Froxfield \\
\hline Flyfield \\
\hline Great Bedw \\
\hline Great Chev \\
\hline Great Some \\
\hline Grittleton \\
\hline
\end{tabular}




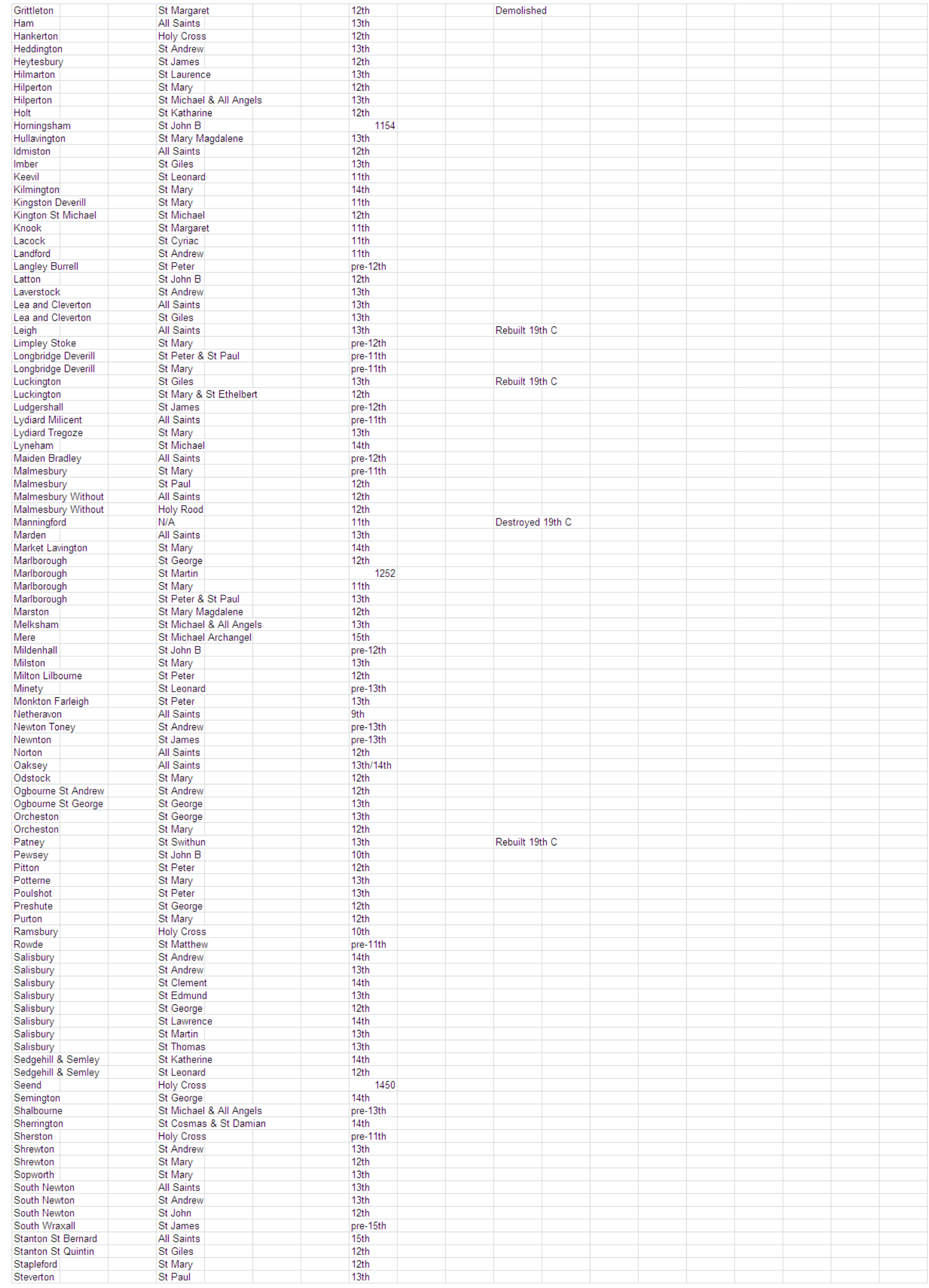




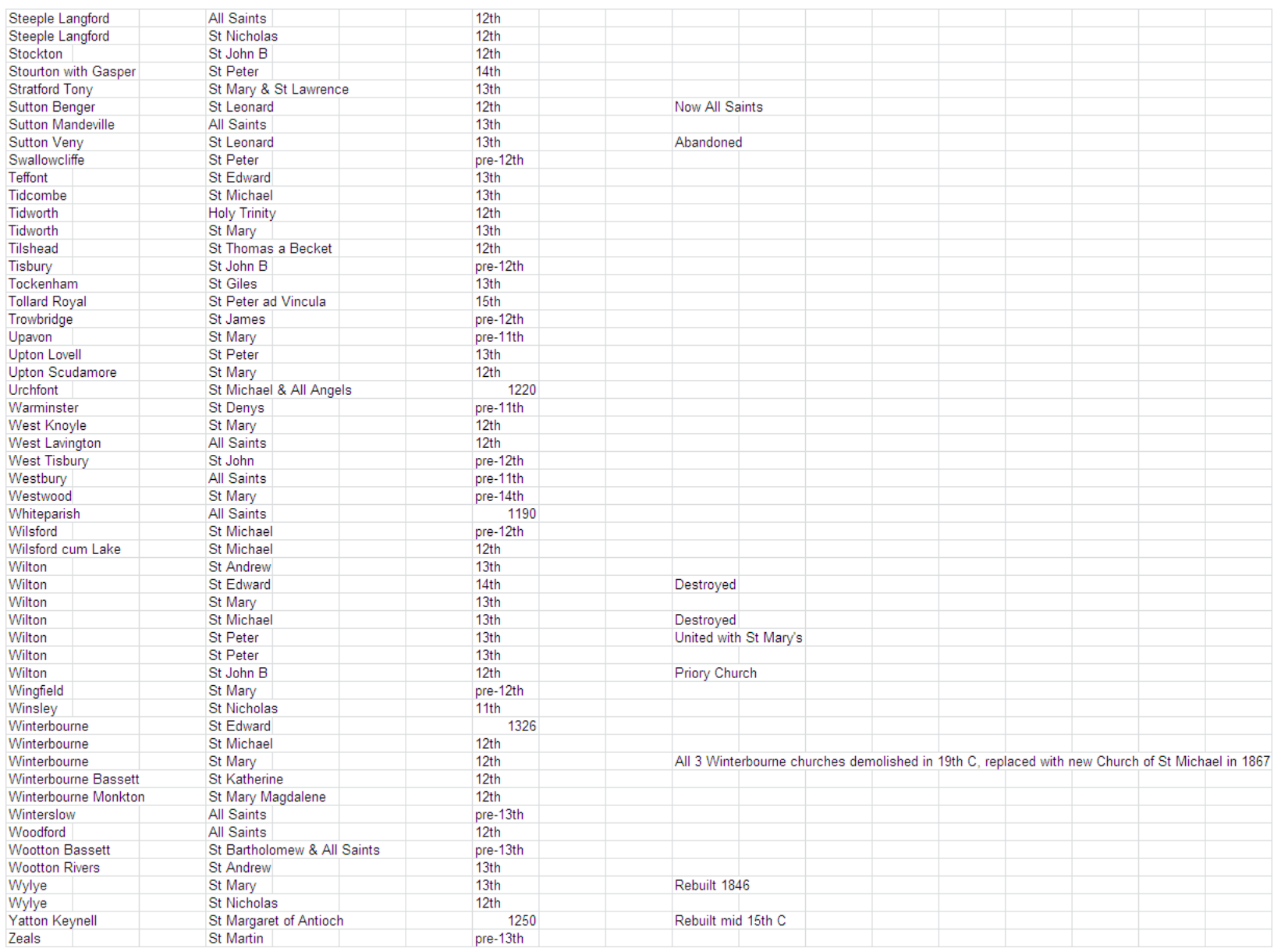


Denbighshire \& Flintshire:

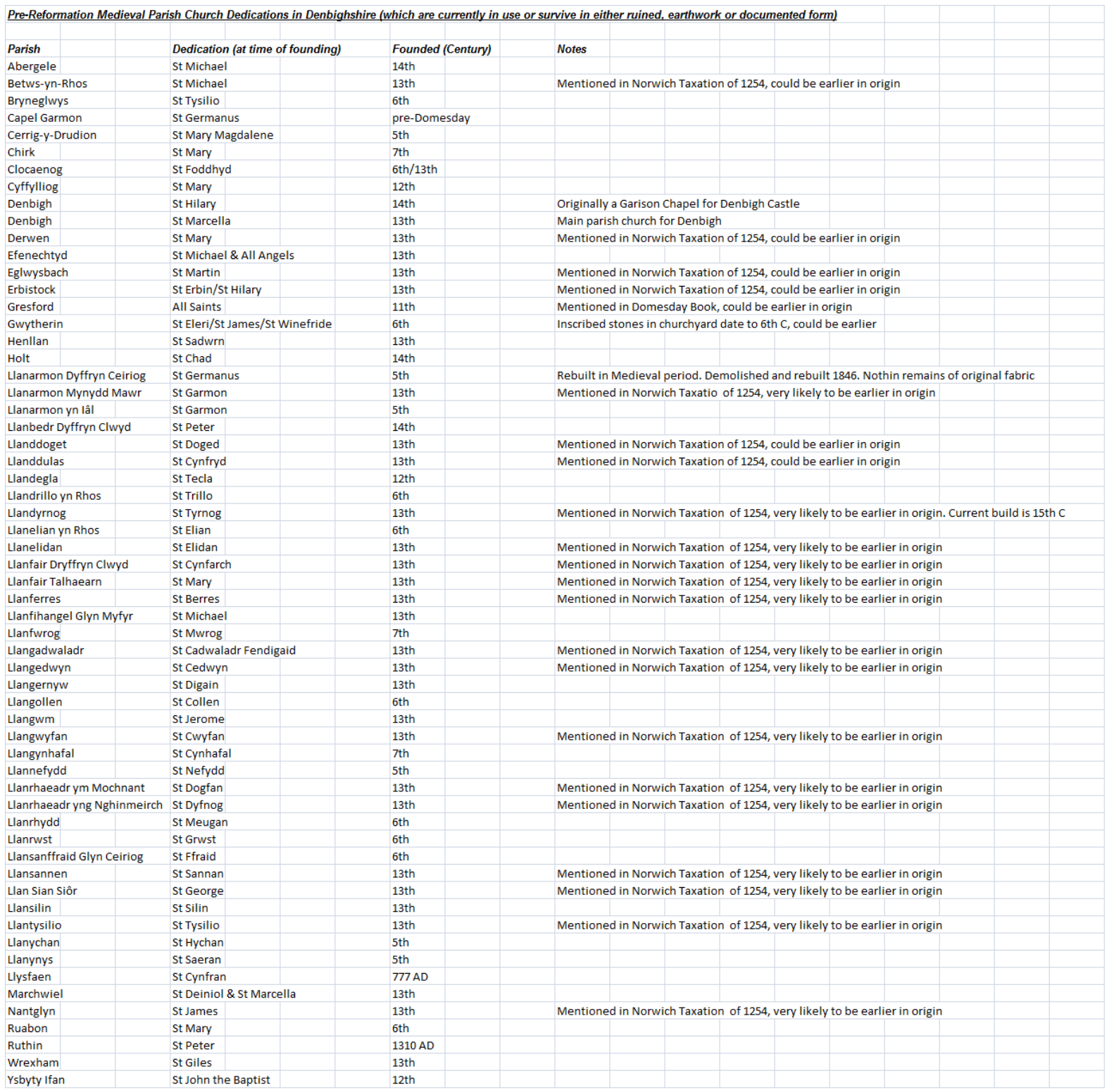




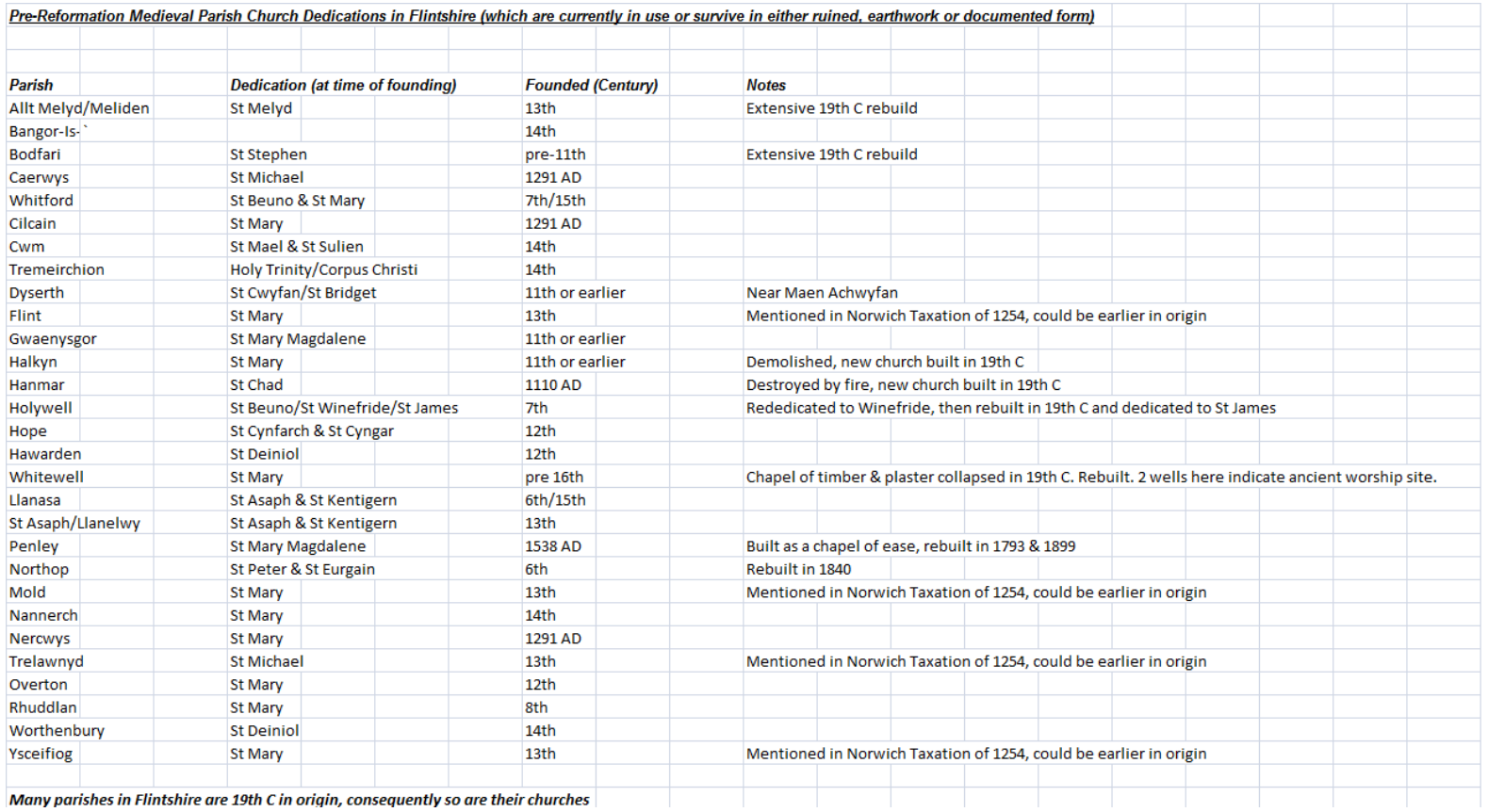


Cornwall

Pre-Reformation Medieval Parish Church Dedications in Cornwall (which are currently in use or survive in either ruined, earthwork or documented form) Excluding the Isles of Scilly

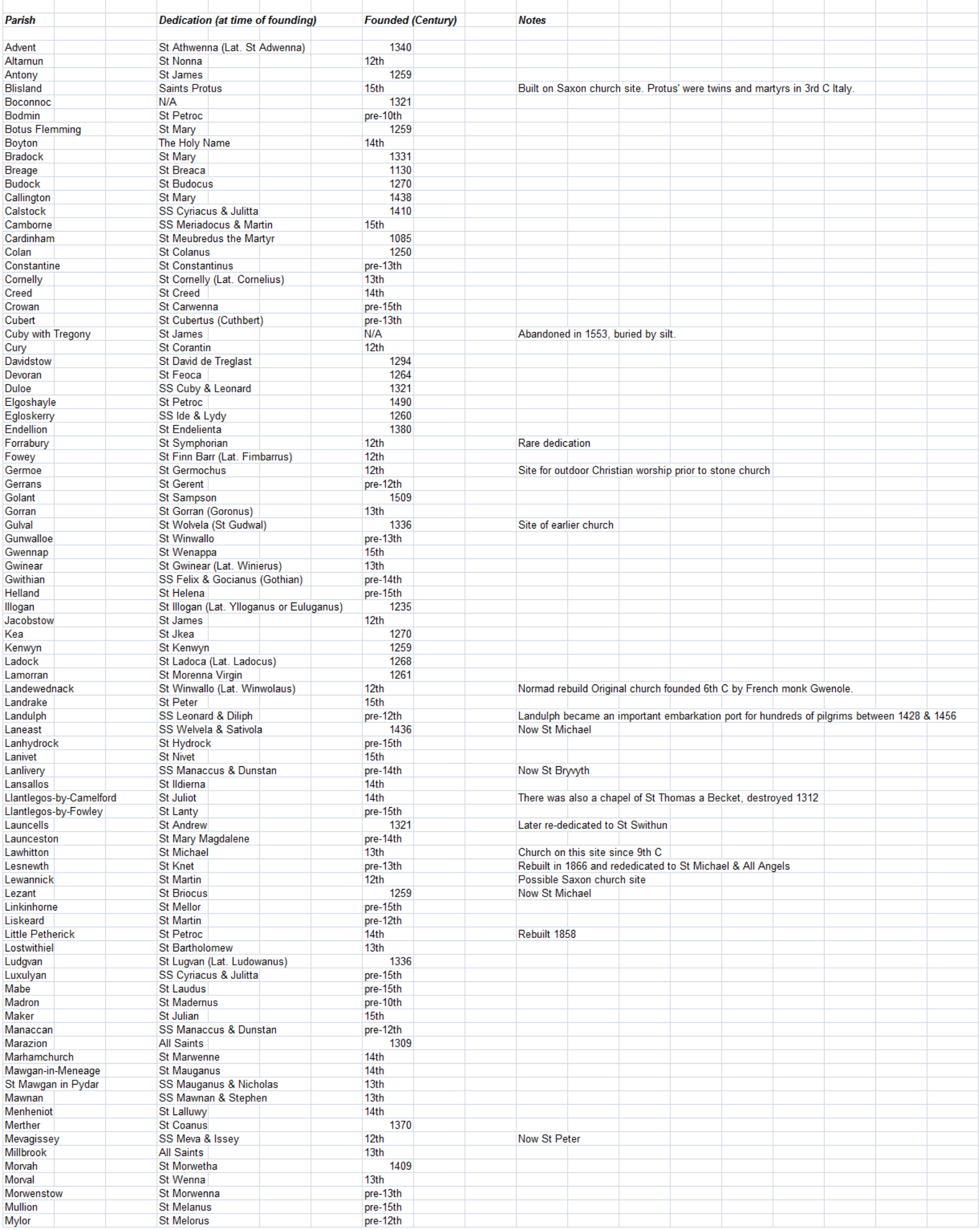




\begin{tabular}{|c|c|c|}
\hline Newlyn Eas & & St Newlyn the Virgin \\
\hline North Tame & erton & St Denis \\
\hline Otterham & & St Denis \\
\hline Padstow & & St Petroc \\
\hline Paul & & St Paulinus \\
\hline Pelynt & & St Nonna \\
\hline Perranarwo & orthal & St Piran \\
\hline Perranuthnc & & SS Piran \& Nicholas \\
\hline Phillack & & St Felicitas \\
\hline Philleigh & & St Felicitas \\
\hline Pillaton & & St Odulph \\
\hline Poughill & & St Olaf \\
\hline Poundstock & & St Neot/St Winwaloe \\
\hline Probus & & SS Probus \& Grace \\
\hline Quethiock & & St Hugo (Hugh) \\
\hline Rame & & St Germanus \\
\hline Roche & & St Goemandus \\
\hline Ruan Lanio & & St Rumon \\
\hline Saltash & & SS Nicholas \& Faith \\
\hline Sancreed & & St Credan \\
\hline Sennen & & St Sinnius \\
\hline Sheviock & & SS Peter \& Paul \\
\hline Sithney & & St Sidinius \\
\hline South Hill & & St Sampson \\
\hline South Peth & erwin & St Paternus \\
\hline St Agnes & & St Agnes \\
\hline St Allen & & St Alnus \\
\hline St Anthony & in Meneag & St Anthony \\
\hline St Anthony & in Roselan & St Anthony \\
\hline St Austel & & St Austolus \\
\hline St Blazey & & St Blaise \\
\hline St Breock & & St Briocus \\
\hline St Breward & & St Brueredus (St Brar \\
\hline St Buryan & & St Berian \\
\hline St Cleer & & St Clarus \\
\hline St Clement & & St Clement \\
\hline St Clether & & St Cleder \\
\hline St Columb & Major & St Columba \\
\hline St Columb & Minor & St Columba \\
\hline St Dennis & & St Dionisius (Dennis) \\
\hline St Dominic & & St Dominicia \\
\hline St Endellior & & St Endelienta \\
\hline St Enoder & & St Enodorus \\
\hline St Erme & & St Hermes \\
\hline St Erth & & St Ercius \\
\hline St Ervand & & St Hermes \\
\hline St Eval & & St Uvelus \\
\hline St Ewe & & St Ewe \\
\hline St Germans & & St Germanus \\
\hline St Gluvius & & St Gluvius the Martyr \\
\hline Ist Issey & & St Issey \\
\hline St lve & & St lve \\
\hline St John & & St John B \\
\hline St Juiliot & & St Juliot \\
\hline St Just in $P$ & Penwith & St Just \\
\hline St Just in $\mathrm{R}$ & Roseland & St Just \\
\hline St Keverne & & St Keverne \\
\hline St Kew & & St Kew \\
\hline St Keyne & & St Keyne \\
\hline St Levan & & St Selevan \\
\hline St Mabyn & & St Mabyn \\
\hline St Martin-b & by-Looe & SS Martin \& Keyne \\
\hline Stt Mellion & & St Melanus \\
\hline St Merryn & & SS Marina \& Thomas \\
\hline St Mewan & & St Mewan \\
\hline St Michael & Caerhays & St Michael \\
\hline St Michael & I Penkival & St Michael \\
\hline St Michaels & Is Mount & St Michael \\
\hline St Minver & & St Minver \\
\hline St Neot & & St Neot \\
\hline Stokeclims & sland & All Saints \\
\hline St Pinnock & & St Pinnock \\
\hline St Stratton & & St Andrew \\
\hline St Stephen & by Launce & St Stephen \\
\hline St Stephen & $\mathrm{n}$ in Brannel & St Stephen \\
\hline St Stephen & is by Saltas & St Stephen \\
\hline St Teath & & St Tetha \\
\hline St Thomas & by Launces & St Thomas \\
\hline St Tudy & & St Tudius \\
\hline St Veep & & St Vepus \\
\hline St Wenn & & St Wenna \\
\hline St Winnow & & St Wiinnocus \\
\hline Talland & & St Tallanus \\
\hline Tintagel & & St Merteraine \\
\hline Treneglos & & St Gregory \\
\hline Tresmere & & St Winwolus \\
\hline Trevalga & & St Petroc \\
\hline Tywardreatl & & St Andrew \\
\hline Veryan & & St Symphorian \\
\hline Warbstow & & St Werburgh \\
\hline Warleggan & & St Bartholomew \\
\hline Wendron & & St Wendron \\
\hline Whitstone & & St Anne \\
\hline Withiel & & St Clement \\
\hline Zennor & & St Senara (Sinar) \\
\hline
\end{tabular}




\section{Appendix E}

Religious houses in Norfolk, Wiltshire, Hampshire, Denbighshire, Flintshire and Cornwall, as recorded by Knowles \& Hadock in 'Religious Houses of England \& Wales' (1953).

Norfolk:

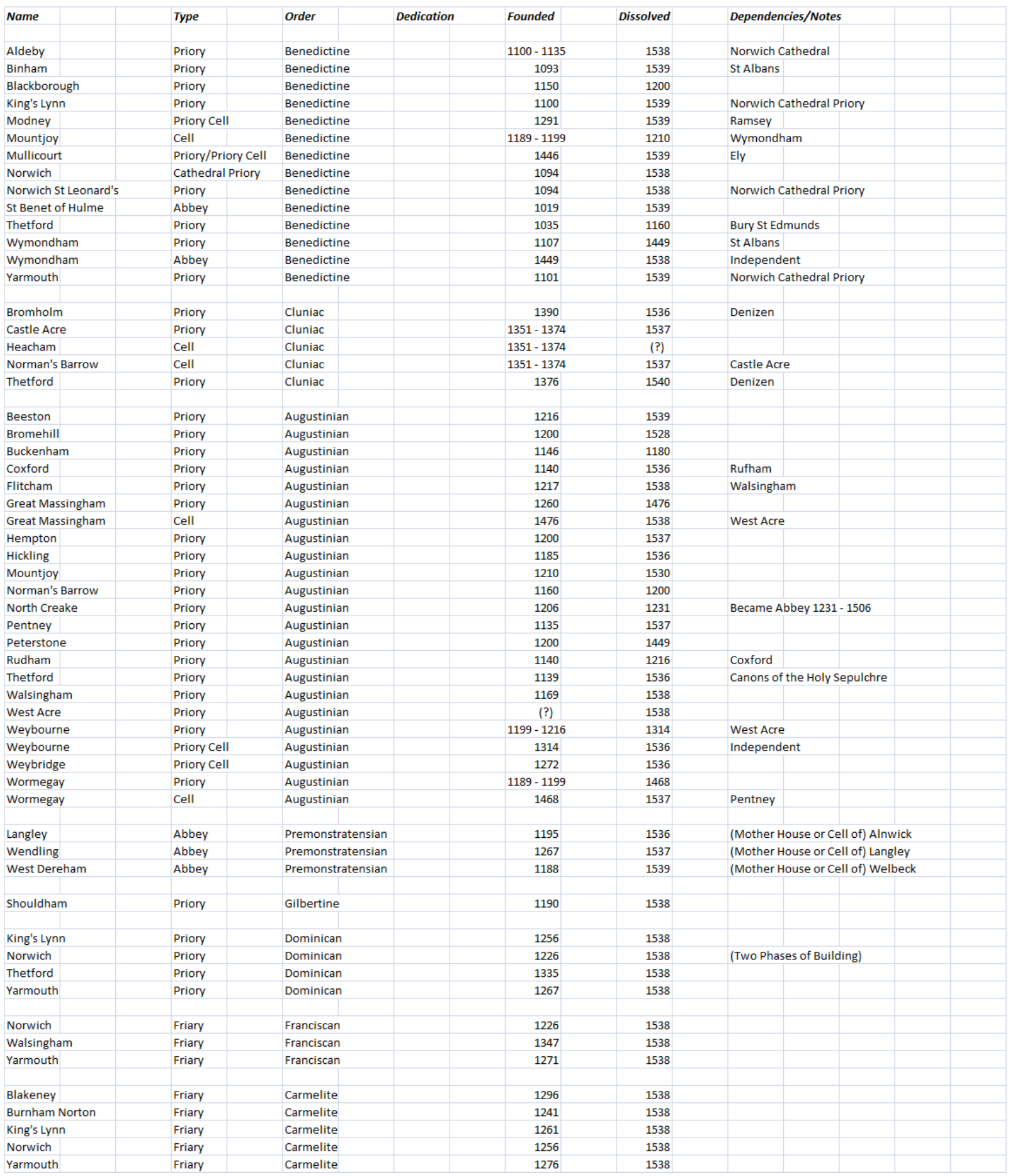




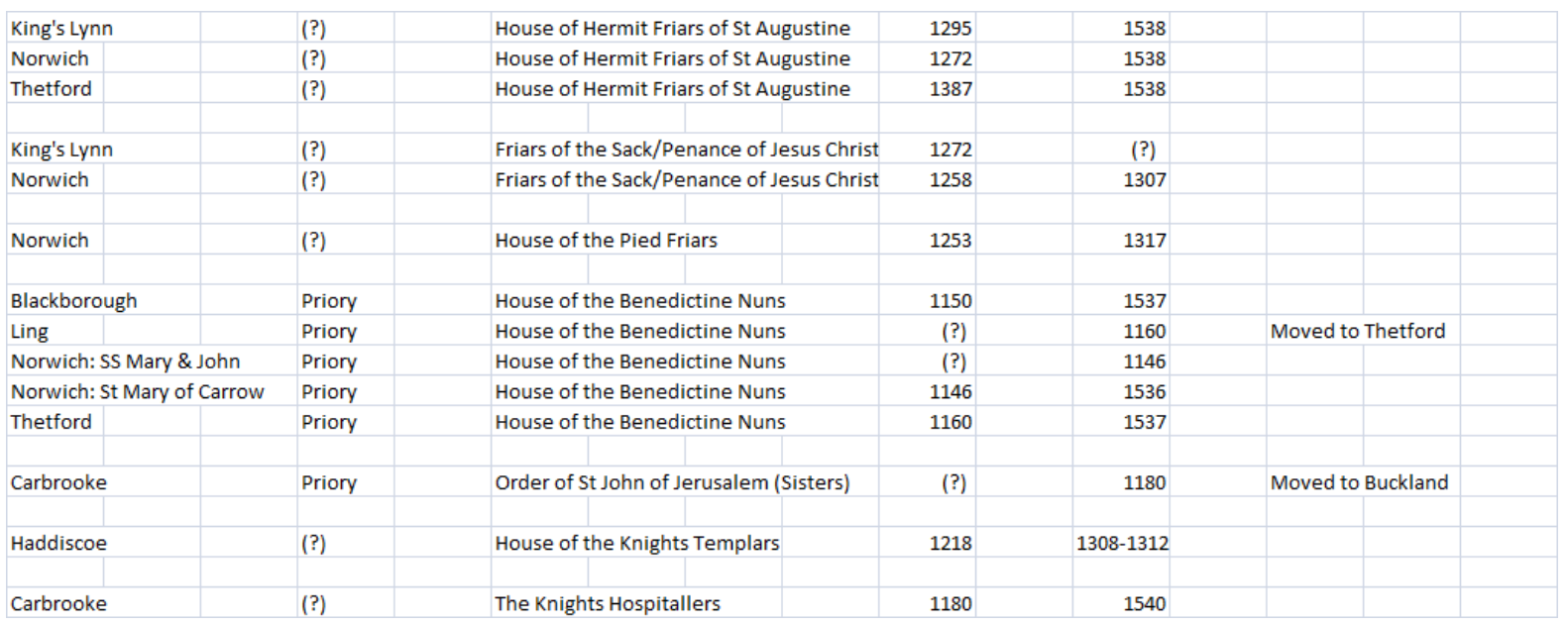

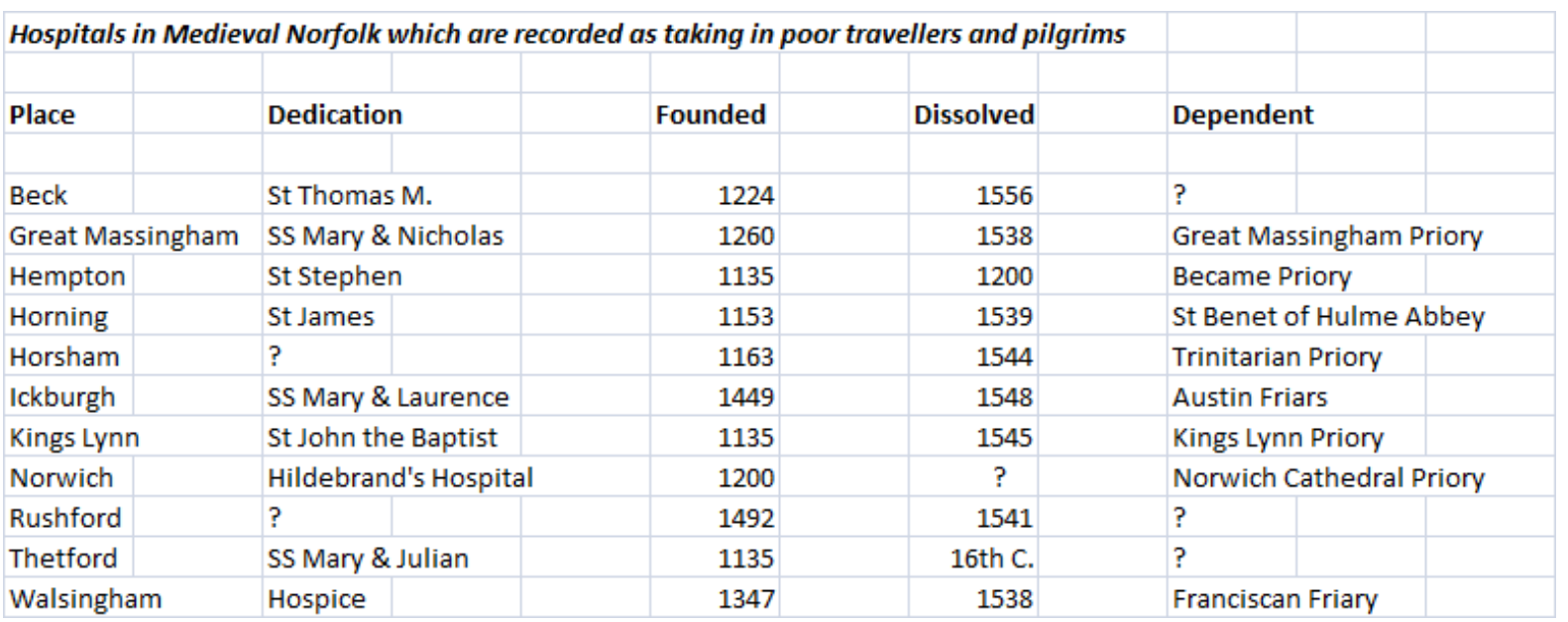


Wiltshire \& Hampshire:

\begin{tabular}{|c|c|c|c|c|c|c|c|c|c|c|}
\hline \multicolumn{11}{|l|}{ Wiltshire } \\
\hline & & & & & & & & & & \\
\hline \multicolumn{2}{|l|}{ Name } & Type & \multirow{2}{*}{\begin{tabular}{|l} 
Order \\
Benedictine
\end{tabular}} & Dedication & Founded & Dissolved & \multicolumn{3}{|c|}{ Dependencies/Notes } & \\
\hline \multicolumn{2}{|c|}{ Malmesbury } & Abbey & & & c.965 & 1539 & & & & \\
\hline \multicolumn{2}{|c|}{ Kington St Michael } & Abbey (N & Benedictine & & 1155 & 1536 & & & & \\
\hline \multirow[t]{2}{*}{ Wilton } & & Abbey & Benedictine & & 963 & 1539 & & & & \\
\hline & & & & & & & & & & \\
\hline \multirow[t]{2}{*}{ Monkton } & & Abbey \& & Cluniac & & $1351-74$ & 1536 & Dependen & it on Lewes & & \\
\hline & & & & & & & & & & \\
\hline \multirow[t]{2}{*}{ Loxwell } & & Abbey & Cistercian & & 1151 & 1154 & Dependen & it on Quarr & (moved to Stanley) & \\
\hline & & & & & & & & & & \\
\hline \multicolumn{2}{|c|}{ Bradenstoke } & Priory & Augustinian & & 1142 & 1539 & & & & \\
\hline \multicolumn{2}{|c|}{ Briontune } & Priory & Augustinian & & ? & ? & \multicolumn{4}{|c|}{ Must be a name for another recorded house } \\
\hline \multicolumn{2}{|c|}{ Ivy Church } & Priory & Augustinian & & In reign of & 1536 & & & & \\
\hline Longleat & & Priory & Augustinian & & c.1272 & $1529-30$ & & & & \\
\hline Maiden $\mathrm{Br}$ & & Priory & Augustinian & & c.1154 & 1536 & & & & \\
\hline Lacock & & Abbey & Augustinian & & 1232 & 1538 & Canonesse & & & \\
\hline & & & & & & & & & & \\
\hline Charlton & & Priory & Premonstratensian & & 1187 & 1380 & & & & \\
\hline & & & & & & & & & & \\
\hline Edington & & House & House of Bonshomm & & 1283 & 1539 & & & & \\
\hline & & & & & & & & & & \\
\hline Easton & & House & House of Trinitarians & & 1245 & 1538 & & & & \\
\hline & & & & & & & & & & \\
\hline Salisbury & & House & Dominican & & 1281 & 1538 & Dependen & it on Londo & & \\
\hline Wilton & & House & Dominican & & 1245 & 1280 & & & & \\
\hline & & & & & & & & & & \\
\hline Salisbury & & House & Franciscan & & 1230 & 1538 & & & & \\
\hline & & & & & & & & & & \\
\hline Marlborou & & House & Carmelite & & 1318 & 1538 & & & & \\
\hline & & & & & & & & & & \\
\hline Rockley & & House & Knights Templars & & $1155-6$ & $1308-12$ & & & & \\
\hline & & & & & & & & & & \\
\hline Bedwyn & & Hospital & St John B. & & 1264 & ? & & & & \\
\hline Bradford $\mathrm{C}$ & & Hospital & St Margaret & & 1235 & 1539 & Lepers & & & \\
\hline Chippenh & & Hospital & St Laurence & & 1338 & ? & & & & \\
\hline Devizes & & Hospital & St John B. & & 1207 & 1695 & Poor/sick & & & \\
\hline Devizes & & Hospital & St James & & 1207 & 1340 & Leppers an & id Alms & & \\
\hline Easton & & Hospital & Holy Trinity & & 1246 & 1538 & Poor/aged & 1/sick & & \\
\hline Heytesbur & & Hospital & SS John \& Katherine & & 1449 & NS (not sup & Male alms & house & & \\
\hline Malmesbc & & Hospital & St John B. & & ? & ? & Poor/aged & 1/sick & & \\
\hline Malmesbu & & Hospital & St Anthony & & 1224 & ? & ? & & & \\
\hline Malmesbu & & Hospital & St Mary M & & 1222 & ? & Lepers & & & \\
\hline Marlborou & & Hospital & St John B. & & 1215 & 1540 & Poor/aged & 1/sick & & \\
\hline Marlborou & & Hospital & St Thomas M & & 1246 & 1394 & Lepers & & & \\
\hline Old Sarum & & Hospital & Leper Hospital & & 1195 & ? & Lepers & & & \\
\hline Old Sarum & & Hospital & St John B. & & 1231 & 1535 & Poor/aged & 1/sick & & \\
\hline Salisbury & & Hospital & St Nicholas & & 1214 & NS & Served ma & iny incl. Tra & vellers \& pilgrims & \\
\hline Salisbury & & Hospital & Holy Trinity & & 1379 & NS & Sick & & & \\
\hline Salisbury & & Hospital & East Harnham & & 1361 & ? & Lepers & & & \\
\hline Wootton E & & Hospital & St John B. & & 1266 & 15th $c$. & Poor/sick & & & \\
\hline Wraxall & & Hospital & ? & & 14th $\mathrm{c}$. & ? & Travellers/ & /pilgrims & & \\
\hline
\end{tabular}




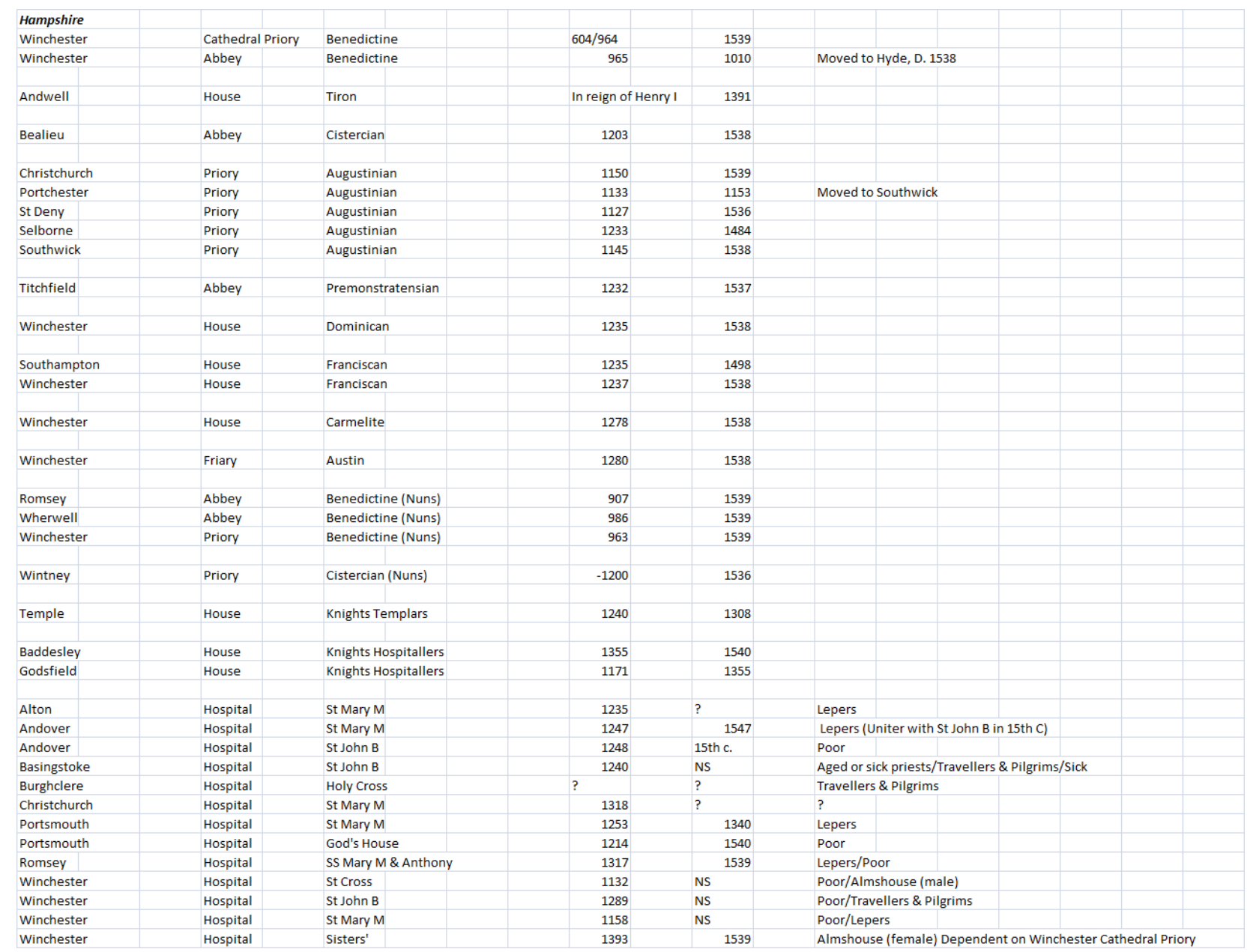


Denbighshire \& Flintshire:

None recorded.

\section{Cornwall:}

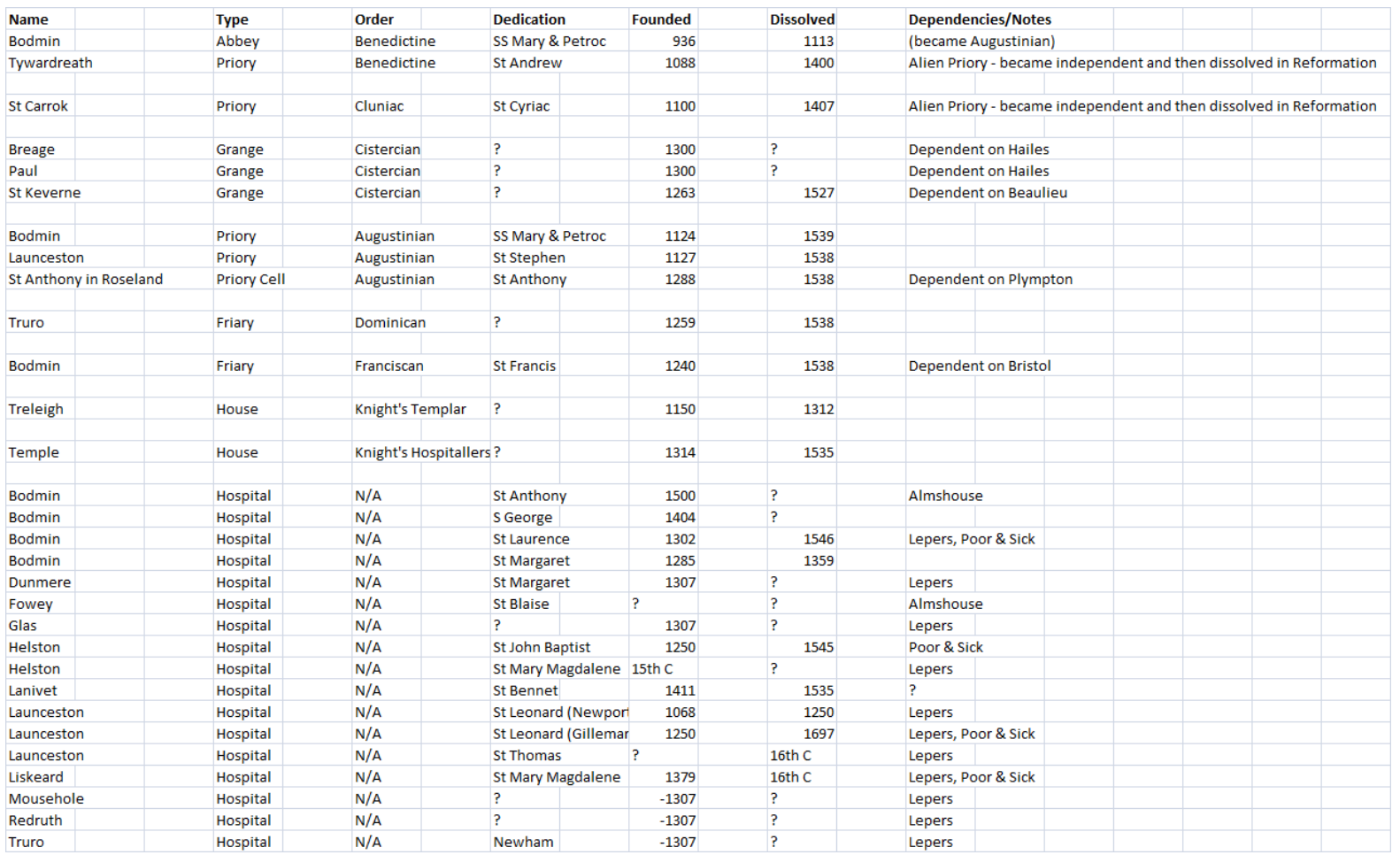




\section{Appendix F}

Catalogue of Ampullae from Portable Antiquities Scheme Database with Motifs Relating to Walsingham

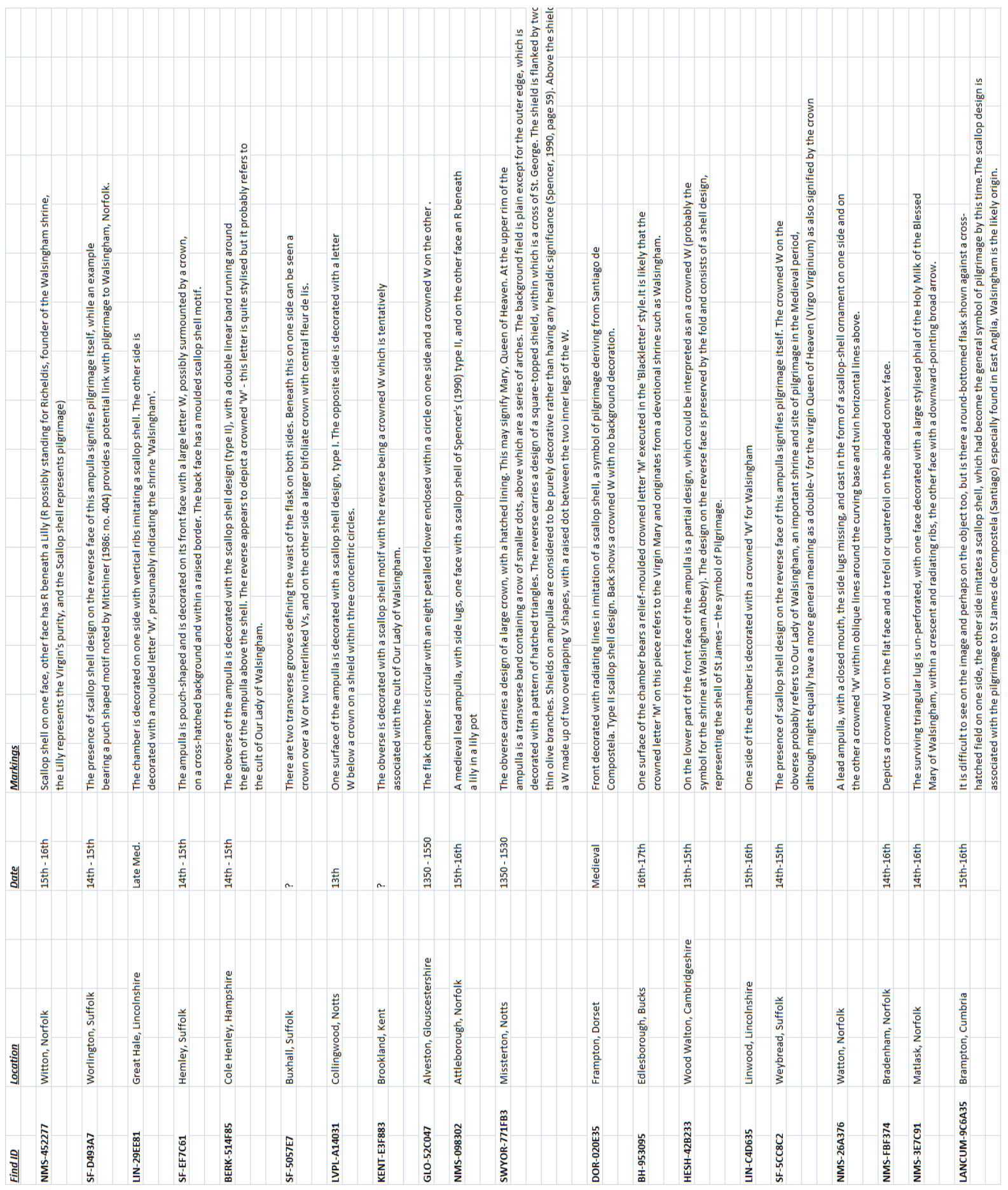




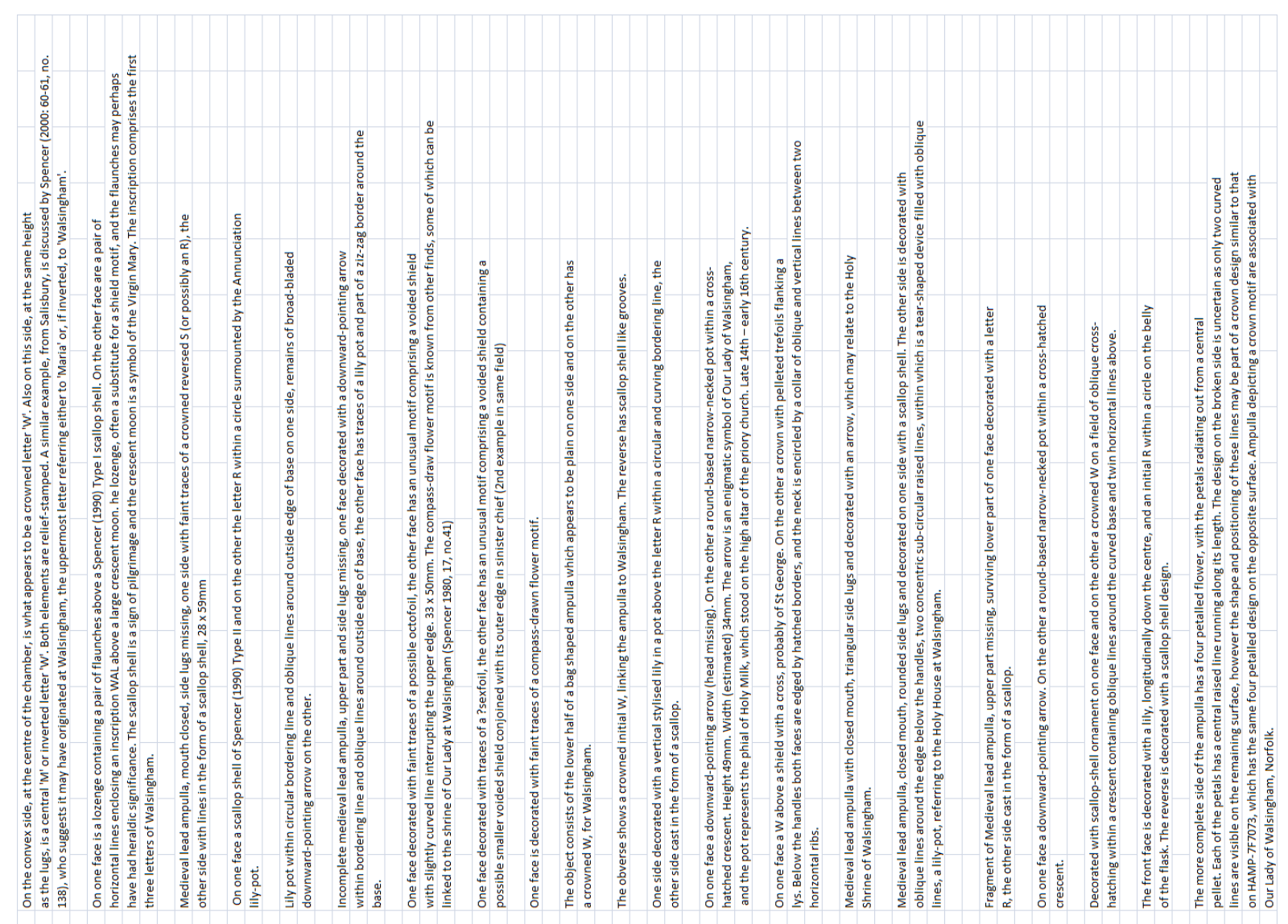

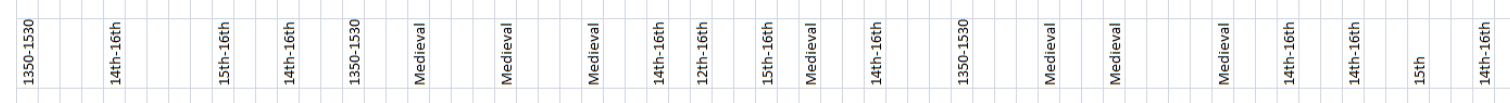
HHHHHHHHHHHH

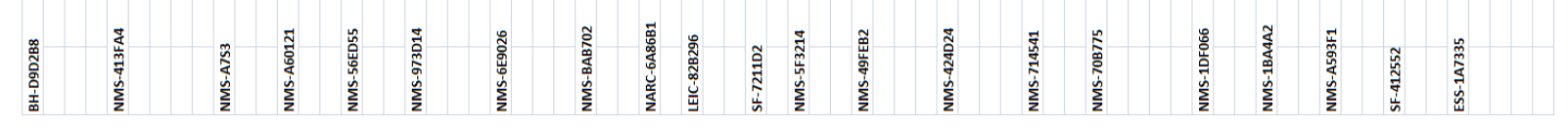




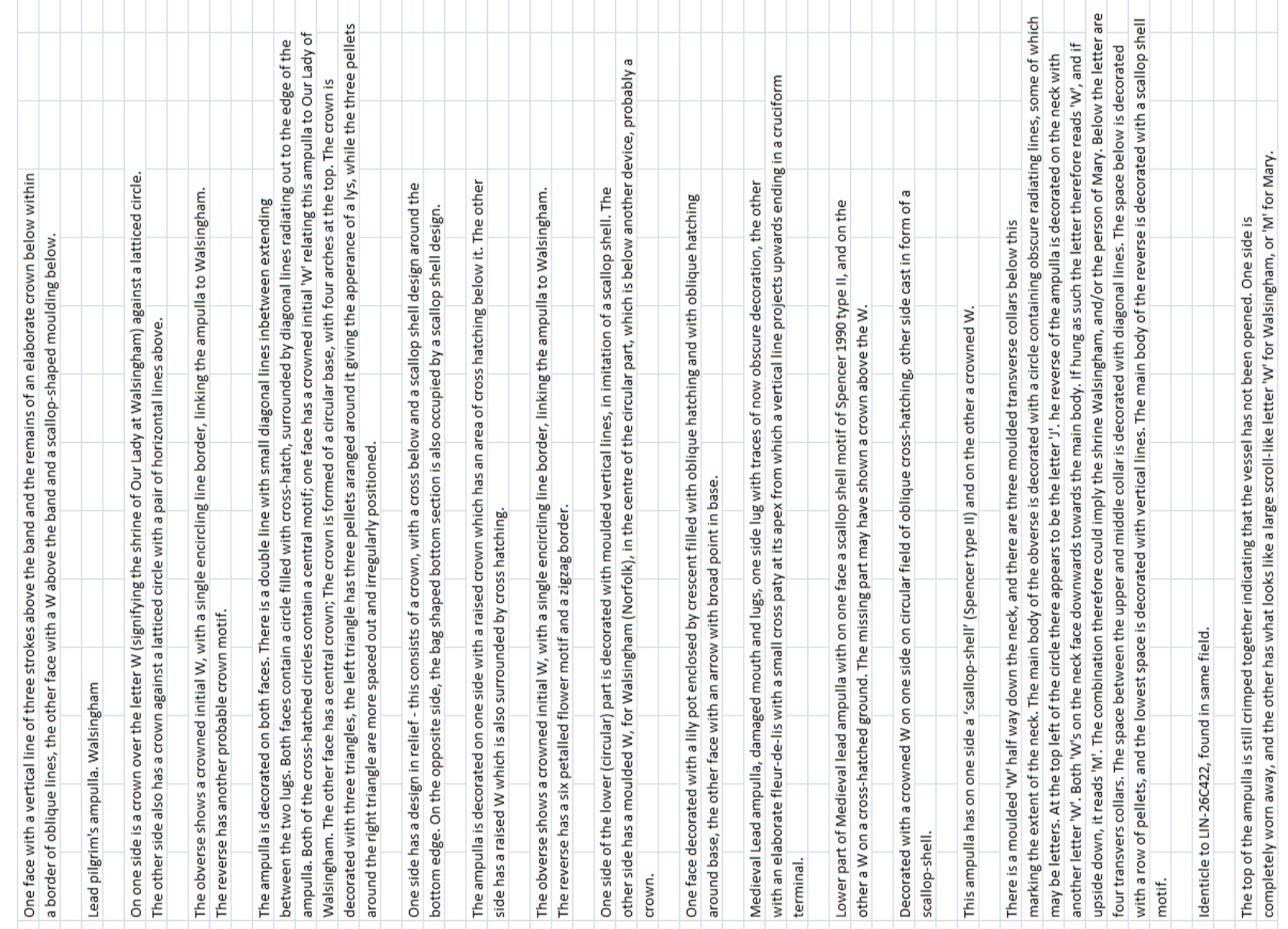

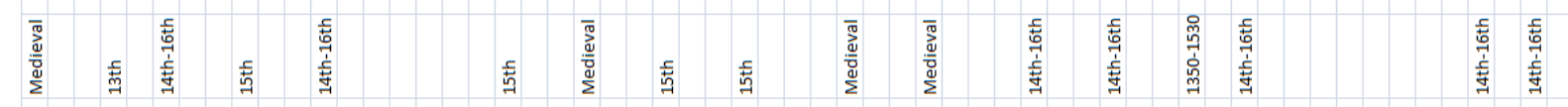

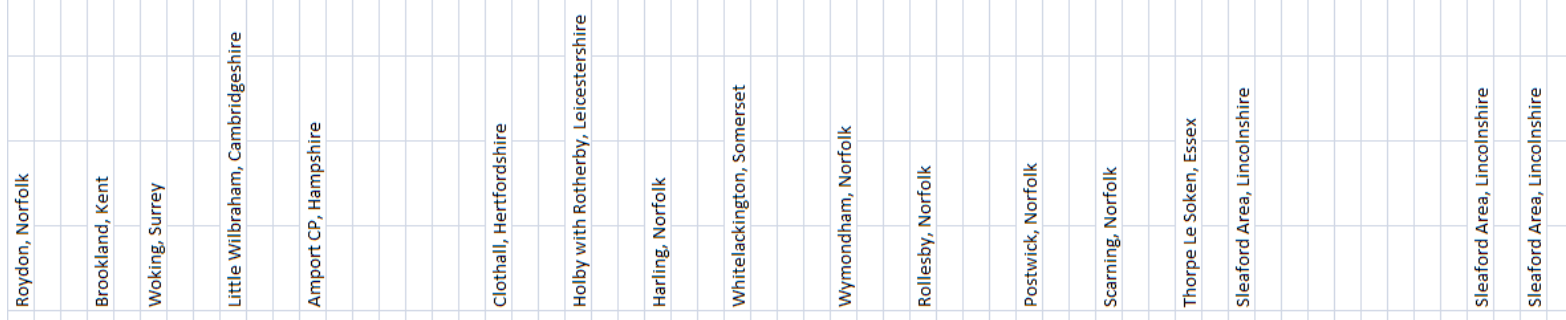

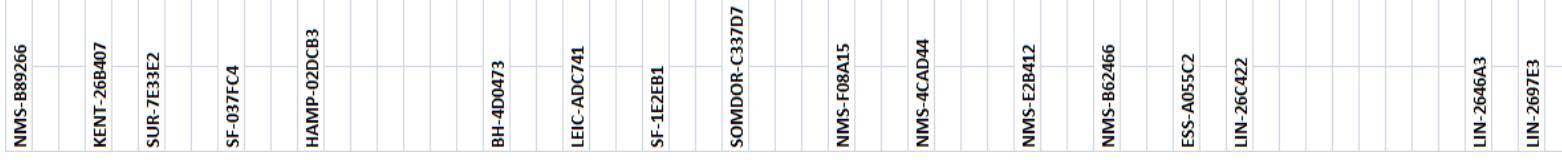




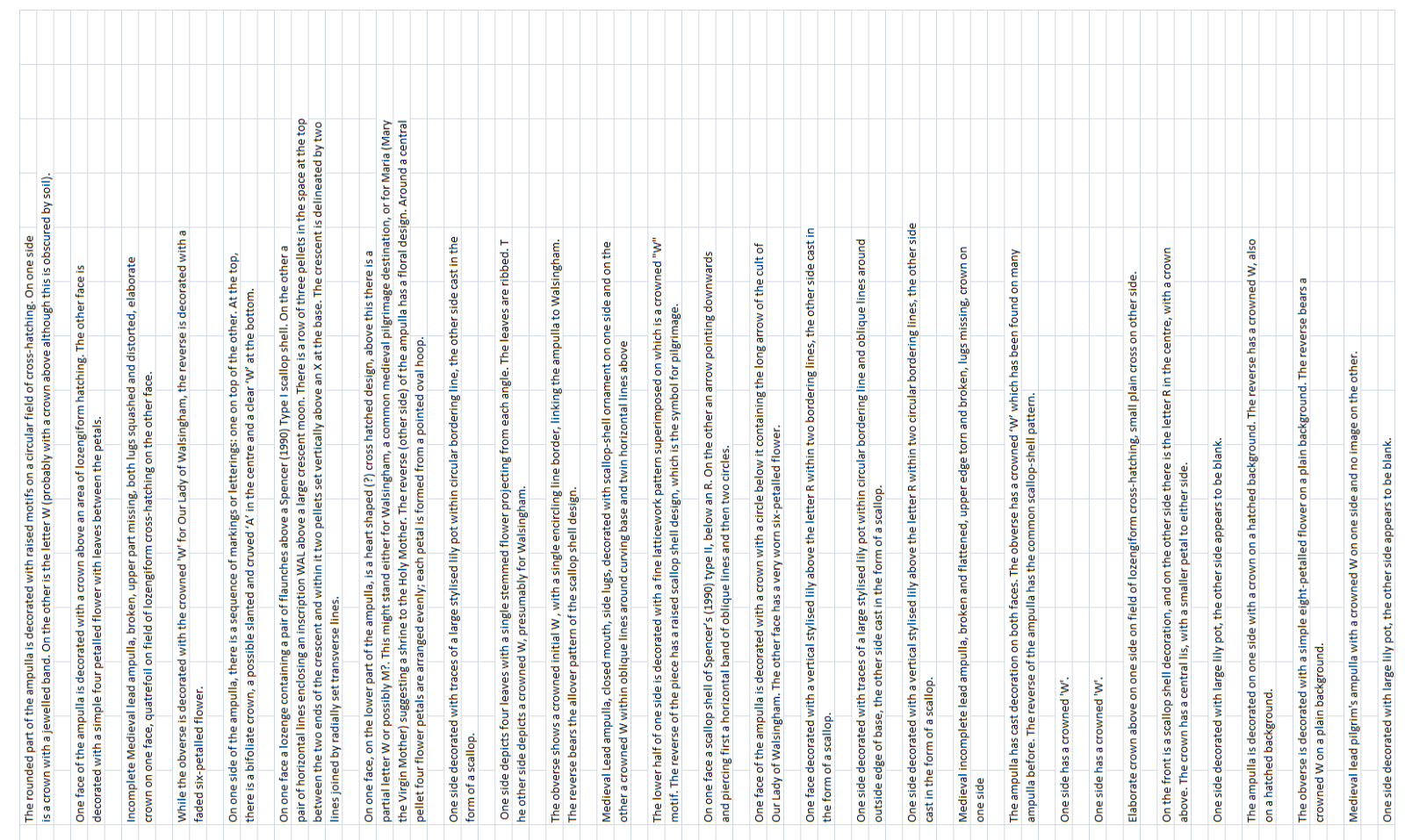

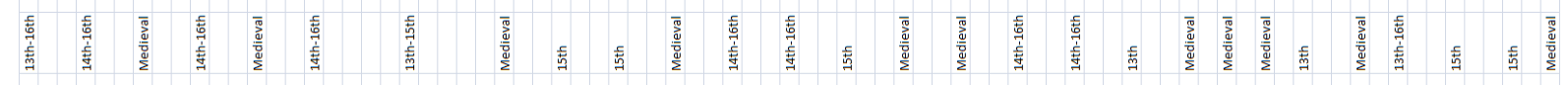

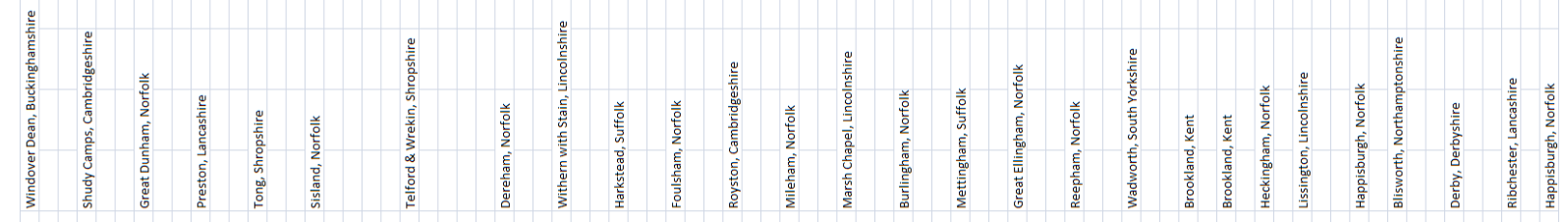

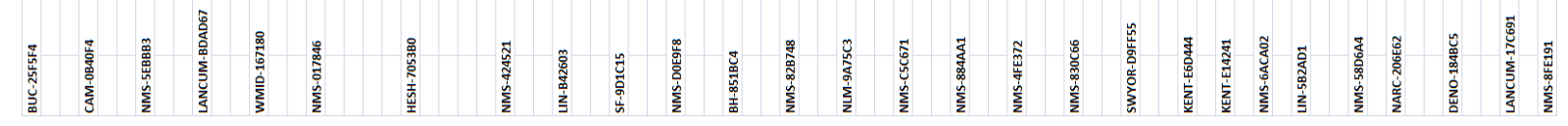




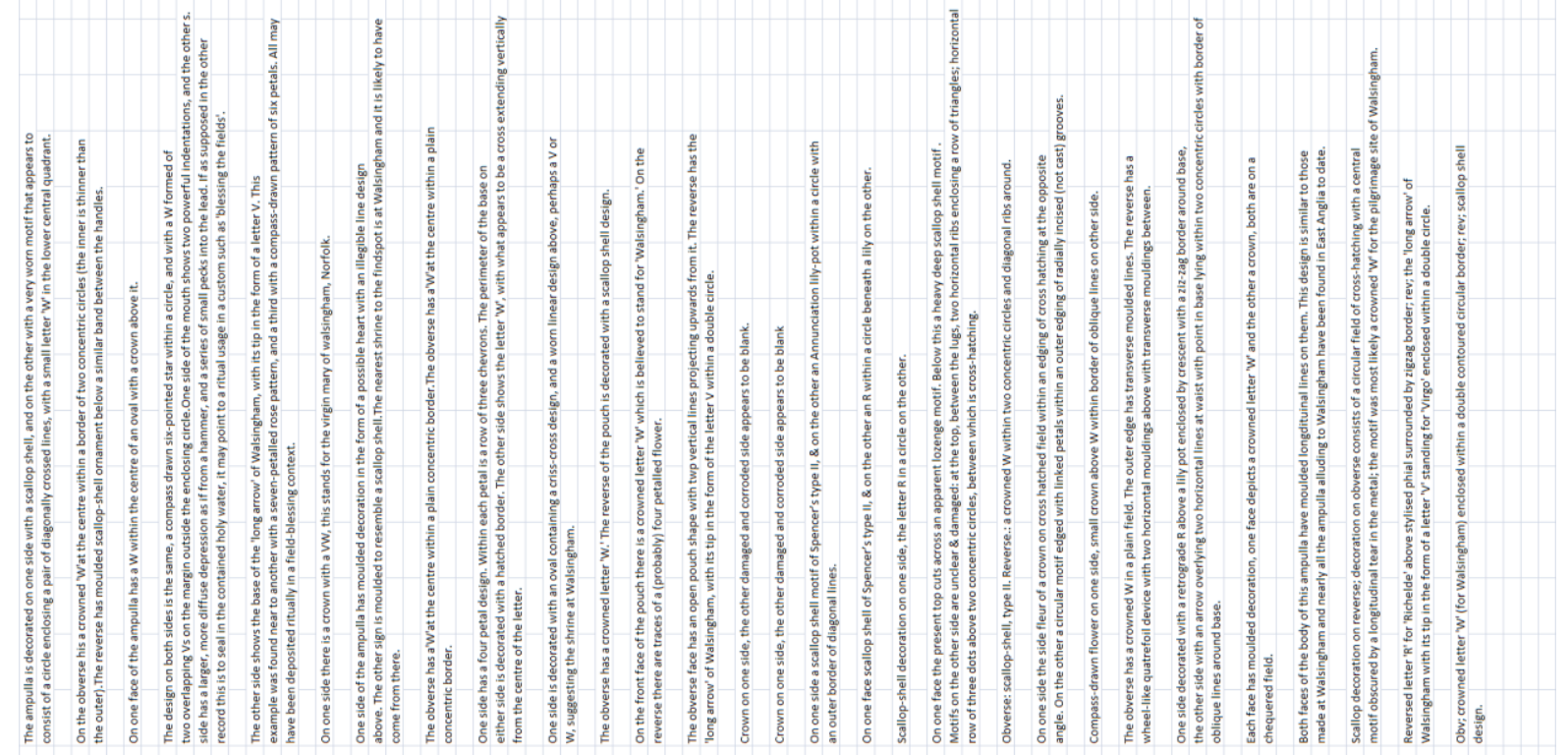

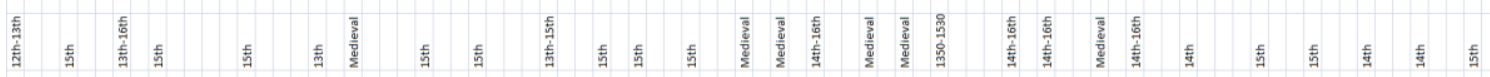

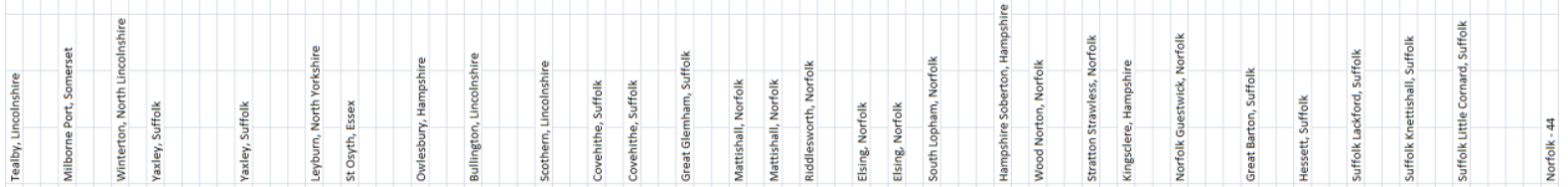
\|\|\|\|\|\|\|\|\|\|\|\|\|\|\|\|$\| 1$ 


\section{Appendix G}

Catalogue of Pilgrim Badges from Portable Antiquities Scheme Database with Motifs Definitely Relating to Walsingham (Excluding the London Waterfront Cluster)

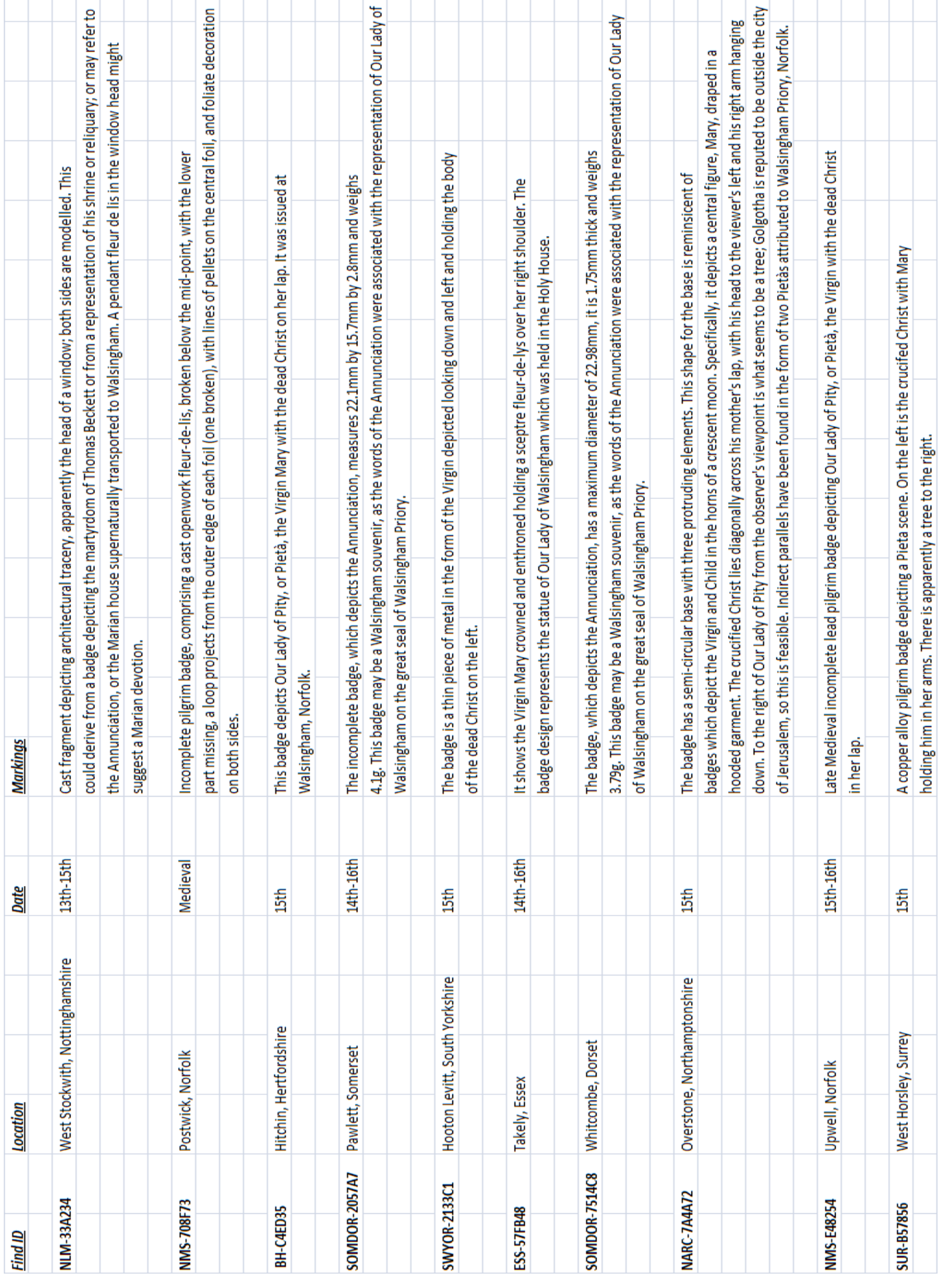

